NYPL RESEARCH LIBRARIES

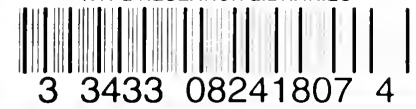


Digitized by the Internet Archive in 2008 with funding from Microsoft Corporation 


$$
\begin{aligned}
& \text { AN } \\
& (\text { Youmans) } \\
& \text { Fiske }
\end{aligned}
$$





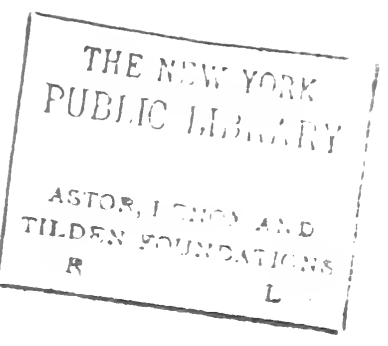




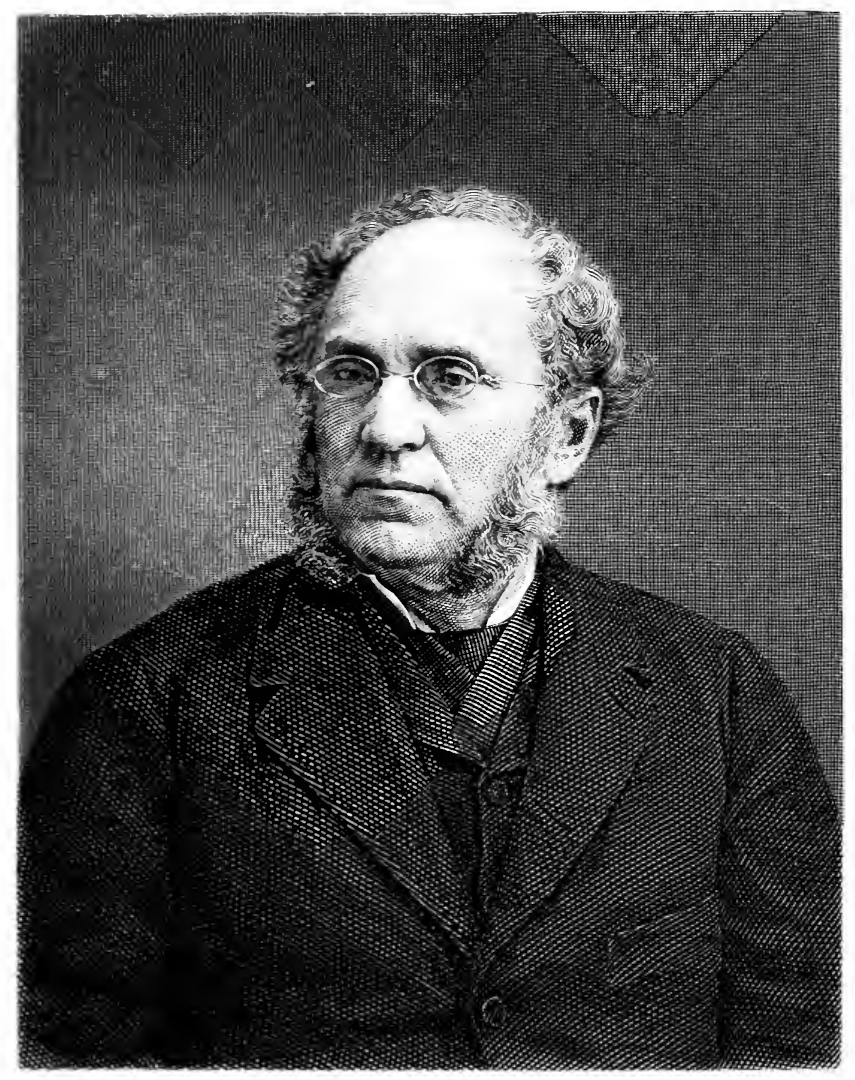

$$
\begin{aligned}
& \text { Siriencly zams } \\
& \text { E. Lyasunasus }
\end{aligned}
$$




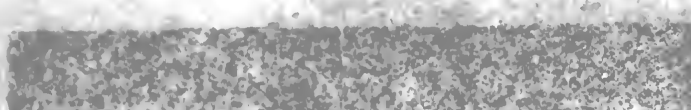

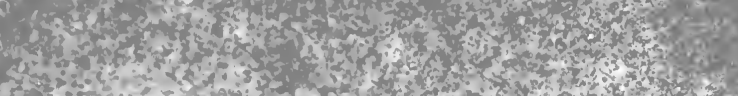

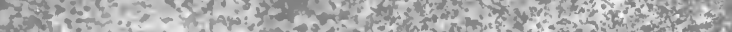
(1) th.

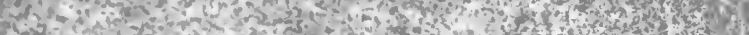

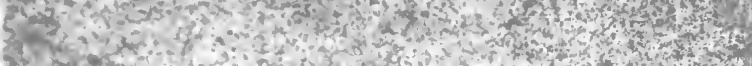

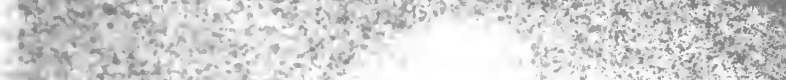

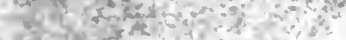

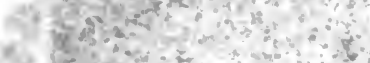

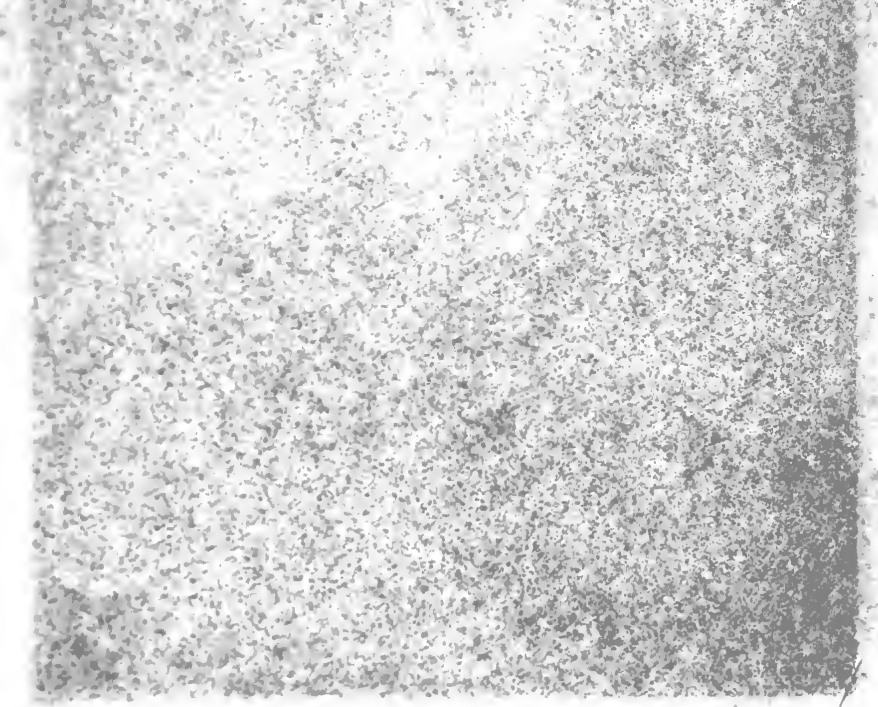

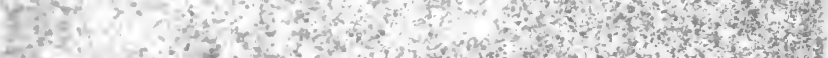

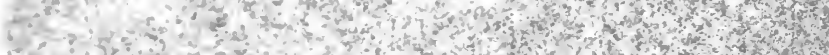
10. A.

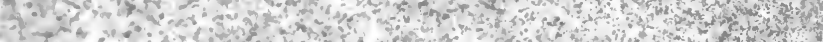

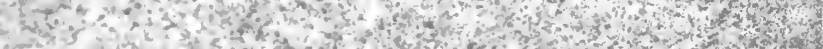
-

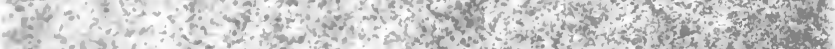

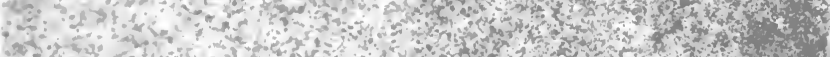

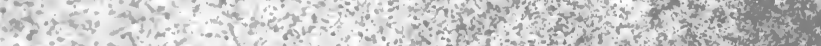

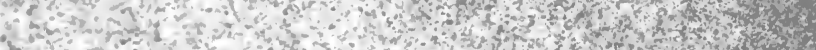

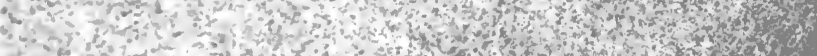

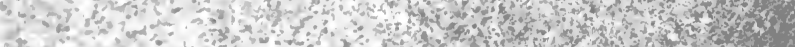

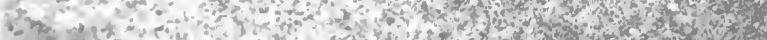

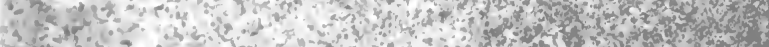

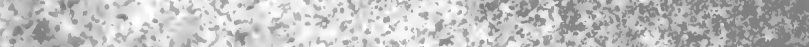

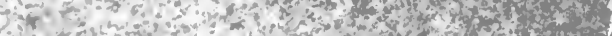

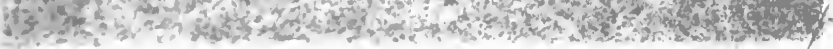
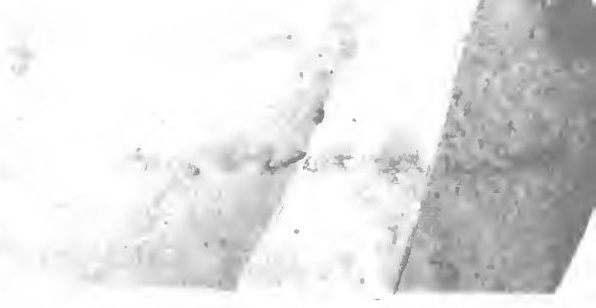


\title{
EDWARD LIVINGSTON YOUMANS
}

Interpreter of Fcience for the Ineople

\author{
A SKETCH OF HIS LIFE
}

WITH SELECTIONS FROM HIS PUBLISHED WRITINGS AND EXTRACTS FROM HIS CORRESPONDENCE WITH SPENCER, HUXLEY, TYNDALL

AND OTHERS

JOHN FISKE

NEW YORK

D. APPLETON AND COMPANY

1894 


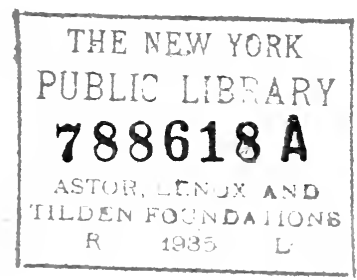

- Copyright, 1894,

BY D. APPLETON AND COMPANY.

Electrotyped and Printed

at the A preleton Press, U.S. A. 


\section{HERBERT SPENCER.}

\section{My dear Spencer :}

It was thirty years ago this month that our personal acquaintance began, in so far as the exchange of letters could make such a beginning. It wal as at the time of my first zisit to Youmans, in this very street and within a stone's throw from where I now sit writing; and as the last of this memorial volume goes hence to the press, recollections of day's that can never come again crowd thickly upon me. Our friend expressed a wish that, if his biography were to be wirtten, I should be the one to do it; no sign from him is necded to assure me that he would have been glad to have me dedicate it to you. Pray accept the book, my dear Spencer, with all its imperfections, in token of the long friendship we have shared with each other and with him who has gone from us; and belicie me, as always,

Faithfully yours,

JOHN FISKE.

Irving Place, New York, February 12, 1894. 


\section{CONTENTS.}

CHAPTER

PACE

I.-Birth AND ChildhoOd . . . . . . . I

II.-Youtil and Education . . . . . . . . . 19

III.-YeARs OF Blindness . . . . . . . . . 35

IV.-Years of Blindness (continued).-The Class-Book of

Chemistry . . . . . . . . . . 56

V.-The Scientific Lecturer . . . . . . . $7 \mathrm{I}$

VI.-Houseifold Science . . . . . . . . . . 92

ViI.-First Acquaintance witil Herbert Spencer · . IO2

VIII.-MARriage AND First Visit to ENGland . . . II6

IX.-Tiie Apostle of Evolution . • . . . . . . IfI

X.-Second and Third Visits to England . . . . 185

XI.-Popular Education, ANd other Matters . . . 22 I

XII.-APpletons' Journal • • • • • • • . . 255

XIII.-The International Scientific Series . . . . . 266

XIV.-The Popular Science Monthly . . . . . 295

XV.-VARIOUS AfFairs . . . . . . . . . . 317

XVI.-Winter in The Riviera . . . . . . . . 345

XVII.-LAST YEARS . . . . . . . . . . . . . 366

\section{SELECT WRITINGS.}

I.-Mental Discipline in Education . . . . . 399

II.-ON the Scientific Study of Human Nature - . 45 I

III.-What We MeAN by Science . . . . . . 456

IV.-The Religious WORK of Science . . . . . 49l

V.-Herbert Spencer and the Doctrine of Evolution · 502 
vi

Contents.

PAGE

VI. -The Charges against the Popular Science Monthly . 552 Vil.-Concerning the Suppressed Book .

. 562

Appendix A. Ancestry .

B. List of Writings

INDEX

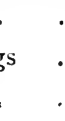

. . . . .585

.590

. 593 


\section{LIST OF ILLUSTRATIONS.}

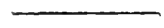

FACING

PAGE

Portrait at the age of sixty . . . . . Frontispiece

Portrait at the age of thirty . . . . . . 56

Facsimile of handwriting . . . . . . . . . $9^{\mathrm{I}}$ 


\section{MEMOIR OF}

\section{EDWARD LIVINGSTON YOUMANS.}

CHAPTER I.

BIRTH AND CHILDHOOD.

$$
\text { 1821-I83I. Age I-IO. }
$$

FORTY years ago scientific education had made but little progress in the United States. There is certainly room enough for improvement to-day; but to those of us who still remember vividly the decade that went before the civil war, the contrast between now and then is very striking. In the first place, there are the wonderful strides that have been made in discovery. A retrospect of forty years takes us back to the days before The Origin of Species was published, the days when the triumphs of spectrum analysis were still hidden in futurity, when teachers of physics looked askance at the "correlation of forces," and students of medicine went through their whole "curriculum " in blissful ignorance of bacteria. So with applied science. Those were the days of wooden war-ships, while railroad and telegraph were in their callow infancy, and antiseptic surgery had never been heard of. As for getting motive power out of electricity so as to move heavy cars or wagons, I heard it conclusively proved in 1862, by our Professor of Physics at Harvard, that no such thing could ever be done. 
This swift advance in scientific discovery has become a commonplace fact; there are few cultivated people who have not felt it and remarked upon it. But among the American people, in the days before the war, scientific education was far from following so briskly in the wake of discovery as it does to-day. Information was more slowly diffused, and new ideas were received with more distrust. People's minds were less flexible and less cosmopolitan. A country clergyman in Connecticut once said to me, in I857, "There is a great intellectual movement going on in Europe of which scarcely anything is known or even suspected in this country." There was much truth in this remark. What the worthy minister had chiefly in mind (for he used to read German books) was the ludicrous ignorance of biblical criticism displayed in American theological magazines and journals; but what he said was true of many departments of study. Lyell's great work on geology was published in 1830 ; a quarter of a century later I do not believe there were five men in our town who had ever heard of "uniformitarianism"; it was only a very bold spirit that ventured to allude to the earth as more than six thousand years old. Science in general was regarded as a miscellaneous collection of facts and rules, some useful, some curious or even pretty; as for looking upon it as a vast coherent body of truths concerning the universe and its interdependent provinces, few minds, indeed, had grappled with such a staggering conception. The sciences were studied in fragments, and how crude were the methods is well shown by the fact that Harvard students were set to learn physics and chemistry by reading in books about magnets and alkalis. 
Few things at that time were more generally needed in America than the kind of stimulus that no one can impart but a public teacher enthusiastic and eloquent, broad and tolerant, trained in the methods of modern science, and brimful of its blithe and aggressive but self-restrained and sober spirit. Such teachers are not too common at any time. To produce one requires a rare combination of qualities. One may mect with a hundred men learned in science, a thousand men who can skim over its surface in entertaining talk, sooner than one will find this rare combination. In our days it has been realized in no one so completely as in the man to whose memory it is the purpose of this volume to pay a brief word of tribute. It is but a little while since that noble face was here among us, and the tones of that kindly voice were fraught with good cheer for us. No one who knew Edward Livingston Youmans is likely ever to forget him. But for those who knew the man it will not be superfluous to recount the main incidents of his life and work. For those who knew him not it is desirable that the story should be set forth, for the work was like the man, unselfish and unobtrusive, and in the hurry of modern life such work is liable to be lost from sight, so that people profit by it without knowing that it was ever done. So genuinely modest, so destitute of self-regarding impulses was my friend, that I am sure it would be quite like him to chide me for thus setting forth, with what he would deem too much emphasis, his claims to public remembrance. But such mild reproof it is right that we should disregard; for the memory of a life so beautiful and useful is a precious possession of which mankind ought not to be deprived. We shall see how Edward Youmans, in spite of scanty 
schooling and long years of blindness, developed into a teacher of science. I have called his work unobtrusive; we shall see how multifarious and potent it came to be, and what rare qualities of intellect and of character it required and displayed. We shall witness his profound conviction of the value of scientific knowledge in promoting the welfare of the people. He found that most needful knowledge monopolized by a few specially trained persons; his warm, popular sympathies urged him to do what he could to make the multitude sharers in the priceless possession. By tongue and pen, on the platform and through the press, he worked with devoted energy in this noble cause, until he had done more than any other American of his time to diffuse a knowledge of science and an appreciation of scientific methods among the American people. He did more than any one else to prepare the way in America for the great scientific awakening which first became visible after the publication of The Origin of Species. In Youmans the approaching better era found its John the Baptist.

Edward Livingston Youmans was born in the town of Coeymans, Albany County, N. Y., on the $3 \mathrm{~d}$ of June, 1821. From his father and mother, both of whom survived him, he inherited strong traits of character as well as an immense fund of vital energy. His father, Vincent Youmans, was a man of independent character, strong convictions, and perfect moral courage, with a quick and ready tongue, in the use of which earnestness and frankness perhaps sometimes prevailed over prudence. The mother, Catherine Scofield, was notable for balance of judgment, prudence, and tact. Her maternal grandfather was Irish; and, 
while I very much doubt the soundness of the generalizations we are so prone to make about race characteristics, I can not but feel that for the impulsive-one had almost said explosive-warmth of sympathy, the enchanting grace and vivacity of manner, in Edward Youmans, this strain of Irish blood may have been to some extent accountable. Both father and mother belonged to the old Puritan stock of New England, and, excepting a Dutch great-grandmother, the father's ancestry was purely English.* Nothing could be more honourably or characteristically English than the name. In the old feudal society the yeoman, like the franklin, was the small freeholder, owning a modest estate yet holding it by no servile tenure, a man of the common people yet no churl, a member of the state who "knew his rights, and knowing dared maintain." Few, indeed, were the nooks and corners outside of merry England where such men flourished as the yeomen and franklins who founded democratic New England. It has often been remarked how the most illustrious of Franklins exemplified the typical virtues of his class. There was much that was similar in the temperament and disposition of Edward Youmans-the sagacity and penetration, the broad common sense, the earnest purpose veiled but not hidden by the blithe humour, the devotion to ends of wide practical value, the habit of making in the best sense the most out of life.

Into the mother's skein of heredity there had entered a silken thread of romance. Her grandmother, Catherine Moore, when a child of three or four years, had landed at New Haven, after a stormy voyage across the Atlantic. Family tradition has it that the

* See Appendix A. 
little waif had embarked in charge of a woman who seemed to be her nurse, and who died during the voyage. On his arrival in port, the captain, following an ordinary custom under such circumstances, put little Catherine up at auction for her passage money. She was bought by a physician of New Haven. Her clothing, her delicate features and graceful manners, all betokened refined parentage-but who could her parents be? Her purchaser, who became fondly attached to her, endeavoured time and again to ascertain. But in days of slow and infrequent ocean voyages, of inland travel slower still, his efforts proved fruitless. As Catherine Moore grew to womanhood her graces of mind and person increased the interest felt in her origin, but the mystery was never cleared up. At the age of sixteen she was wooed and won by Philip Kennedy, a native of Ireland. Their eldest daughter became the mother of Catherine Moore Scofield, who married Vincent Youmans.

At the time of this marriage Miss Scofield's family were living at Westerlo, in Albany County. Vincent Youmans was brought up on a farm in the neighbouring town of Coeymans. The market for the Coeymans farmers was at Albany, some fifteen miles distant, and hence there was urgent need of "lumber wagons," as they were called, for carrying farm products. One Jabez Burrill, a shrewd and energetic wagon maker of Sheffield, in the Berkshire Hills, was foremost in supplying this demand, and not unfrequently visited Coeymans to deliver wagons and get fresh orders. He was in the habit of stopping at the house of Jeremiah Youmans, and made a great impression on the minds of that farmer's sons, John and Vincent. Both were eager to accept his offer to take 
one of them as an apprentice. After due deliberation it was decided that Vincent should go with Mr. Burrill, and that after his return home he should set up a wagon shop and communicate the mysteries of this handicraft to his brother. Accordingly, in the autumn of 1808 , having nearly completed his fifteenth year, Vincent Youmans went to Sheffield. His art was learned with conscientious thoroughness. Upon his return to Coeymans he opened a wagon shop and worked early and late, from daybreak until nightfall, and then by candlelight. He took great pains in gathering his materials, and his work was done with most scrupulous care. No detail was neglected, and it used to be said that Youmans's wagons lasted forever. But his profits were small; and besides the three or four wagons which he could make by hand in the course of a year, it was necessary to eke out the scanty income by more or less repairing and tinkering, and by shoeing horses.

While he was engaged in these avocations Miss Scofield was teaching school in the neighbourhood. A favourite sister of Vincent Youmans was about to be married; and while he was speaking one day of the loneliness that would come upon the household when she left it, one of his sisters told him he had better get married himself, and added, that if he could only get "the school-teacher at Uncle Levi's" it would be the luckiest thing that could ever happen to him. This remark made a strange impression upon the young man. Though he had never seen Miss Scofield, he had "a feeling at his heart which he could not mistake," and which he interpreted as a sign by which God gave him to know that she would one day be his 
wife. Soon afterward, at a Sunday afternoon meeting, she was pointed out to him, but some months elapsed before he sought her acquaintance. From the first he seems to have had no misgivings as to her becoming his wife, but it was left to Providence to determine the manner of meeting. One day, having hurt his hand in the shop so that he could not go on with his work, the spirit moved young Vincent to pay a visit at Uncle Levi's. There he found a quilting party and met Miss Scofield, in whose good graces he made rapid progress. In 1820 they were married. Vincent was twenty-six years of age, and his bride twenty-two. Their long union was broken by the death of Mrs. Youmans in February, I888; her husband survived her nearly a year. At this great age both remained in full possession of their mental faculties, and some of these incidents were related by Vincent Youmans after his wife's death.

About a month before the wedding day the wagon shop caught fire and was burned to the ground, and about four hundred dollars worth of finished work, just ready for delivery, was destroyed. But this bitter calamity did not postpone the marriage, for Miss Scofield had saved two hundred dollars from her earnings, and with this sum the young husband's business was again set going. He rebuilt his shop, and the first housekeeping of the newly married pair was in a little old $\log$ house that stood near by. It was here that my friend Edward was born in the following June. (On the day of his birth his maternal grandmother came to see the happy parents, and was permitted to name the child. She wished to give him the name of her revered pastor, Robert Living- 
ston, of Coxsackie, but as the father objected to double names it was agreed to call him Livingston simply: In after years he himself assumed the forename Edward, by which most of his friends soon came to know him, though his mother always called him Livingston till the end of his days.

As the good grandmother Scofield was taking leave of the newcomer that day she tenderly breathed over him the prayer that he might become as good and as useful a man as the minister whose name he was to bear; which in her mind, of course, was equivalent to praying that he might become a minister. In later years, when hopes that had been encouraged by his rare gifts of mind and heart were seemingly thwarted by the unforeseen line of development which he began to follow, his mother sometimes reproachfully reminded him of this early consecration to the work of saving souls. Edward always met this mood seriously, assuring her that he felt his responsibility, and should certainly employ such powers as he had in the way his loving and beloved grandmother had pointed out. But in order to clear his own path, and to widen the scope of his mother's perceptions, he never failed to insist that in order to take part in the work of saving souls it was not necessary to be a clergyman. It was difficult for Calvinists and Puritans, like Vincent Youmans and his wife, to understand any other classification of pursuits than that of sacred and secular, and what they regarded as Edward's religious defection was a source of keen disappointment and worry. But after he had reached middle life it was an unspeakable comfort to him that they came to recognize their error, and to see that his career was a true answer to the grandmother's prayer. Even if they did not 
quite admit his claim concerning the sacredness of his chosen work, and if they were unable fully to appreciate its extent and importance, they could well understand the singleness of purpose with which it was pursued, and the lofty moral qualities which it revealed from day to day.

To the religious experiences of the family we shall have occasion to return. At present we are concerned with the circumstances of Edward's childhood. When he was a babe of six months his parents removed from Coeymans to the town of Greenfield, in Saratoga County, finding a home three miles west of Saratoga Springs, at the Four Corners, where for half a century there had stood a Congregationalist meeting-house, a district schoolhouse, a store, and two or three dwellings. On one of the corners was a little estate of three acres, with its comfortable house, where Vincent Youmans set up his wagon shop and smithy, and for a short time kept a tavern. The situation was favourable for thirsty customers at election times and when lawsuits were in progress, but this source of income was soon abandoned. The first temperance society established in the United States whose members were required to sign a pledge to abstain from intoxicating liquors was organized by the pastor of the neighbouring Congregational church, and within its walls the society still holds its regular meetings. One Sunday his pastor preached so moving a sermon on the evils of intemperance, that next morning Vincent Youmans pulled down his tavern sign, spilled the contents of his kegs and bottles on the ground, and never dealt in liquor again.

His neighbours, mainly farmers, were chiefly of Connecticut stock. On soil none too generous, many 
of these men were obliged to eke out a livelihood as carpenters, masons, shoemakers, and blacksmiths. A Yankee versatility had been developed in their race by sheer necessity. It was not only common, for example, to weave cloth at home, but also to build the loom for it at home. Adaptability and ingenuity had an earning power denied to routine work of any kind. "Handiness" was universal; machinery had as yet made but small encroachment on handicraft skill. Capital was then the junior partner of labour, and these men were more independent, more individualized, than men of similar grade to-day. Special aptitudes were not seldom discovered in the wide variety of work set before every man as a farmer, builder, machinist, repairer. Yet while intelligence was undoubtedly quickened by this almost total absence of division of labour, the financial results then and there were not encouraging. Times were very bad in rural New York when Vincent Youmans came to settle in Greenfield. His house and lot had cost him four hundred dollars, of which he had had to borrow two hundred and forty dollars. His trade of wagon making did not prove particularly profitable. Money was not to be had for wagons, so as opportunity offered they had to be traded for supplies, or for articles which on occasion could be exchanged for supplies. Making ends meet involved much planning, incessant toil, ceaseless anxieties. At the end of ten years four sons and a daughter had been born to the parents,* who in the meantime had united with the Congregational Church. The easily satisfied personal wants, the pref-

* Then, after an interval of nine years, the sixth child. William Jav Youmans, the present editor of the Popular Science Monthly, was born in 1839. The seventh and last child, Eliot, was born in I8千I. 
erence for simplicity of living to cumbrous luxury, which marked Edward Youmans through life, had their origin, no doubt, in his natural good sense, but they were fostered by his early circumstances and early discipline. As the firstborn, he was soon impressed into helping to bring up his sister and brothers; there was to the end something paternal in his solicitude for them and all their concerns. When absent on his European journeys his remembrances to family and friends were as manifold as those at the close of a Pauline epistle. His mother, in the last year of her long life, the year following his death, used to tell what a good boy Edward was-he would never go to play without first asking if there was anything he could do for her, and he would often leave play to come in and repeat the question. When company was entertained it was his pride to set the table and serve the guests. The schoolhouse was close by, and at three years of age Edward was tempted by his playmates to take a place beside them there. Sixty years ago infant classes in country schools ran little risk of undue brain excitement, and no very severe strain was put upon Edward's dawning mind. He quickly learned to read, write, spell, and cipher, but beyond these acquirements there was little else gained than the useful discipline a child gets by coming into contact and collision with other children. It was less in the formal lessons of this primitive district school than in home influences that his real education proceeded. His mind and heart were drawn out by the example of God-fearing parents, who lived industriously, soberly, and kindly. He had all the recreation his buoyant nature demanded, and with access to books soon showed a passion for reading. His home 
life, if it had its hardships, had also much genuine pleasure.

Narrow means gave every member of the househóld a score of opportunities for helpfulness where wealth would have begrudged one. If the strain to earn and save was never relaxed, it was largely because the parents persisted in giving to their children educational privileges better than were enjoyed by neighbouring families in much easier circumstances. Small as the store of ready cash might be, there was always enough for the purchase of books and newspapers, as well as for some aid to religious and social reforms.

Vincent Youmans was a man who liked to talk and hear others talk; his home was a centre where neighbours were wont to gather and exchange views. Gossip was, perhaps, the staple of conversation; but topics of moment and dignity were often discussed. Labour-saving appliances, improved farm implements, the best manner of utilizing manure, and kindred matters, were duly canvassed. In a community where mechanical ingenuity was general, there was much to stir the deepest interest when the first steamboats were plying the Hudson, and when experimental locomotives were being built by Trevithick and Stephenson. At times, instead of dwelling on these inventions and picturing the wonders they were likely to usher into the world, questions of politics, theology, and reform were briskly and keenly argued. Whatever might be the topic, Vincent Youmans used to bear his part as pithily as anybody, and was wont to speak with the tone and emphasis of a pulpit exhorter. To listen to his father and the visitors was Edward's delight. Sometimes his interest in the subject overcame 
his timidity, and he would nervously contribute a remark. On such occasions his mother, who was a reticent woman, was apt to restrain him; she did not like forwardness in little boys. It is evident that Vincent Youmans was one of those men who supply an intellectual stimulus to the whole community in which they live. For a lad of bright and inquisitive mind listening to such talk is no mean education. It often goes much further than the reading of books. From an early age Edward Youmans appropriated all such means of instruction. He had that ravening, insatiable thirst for knowledge which is one of God's best gifts to man; for he who is born with this appetite must needs be grievously ill-made in other respects if it does not constrain him to lead a happy and useful life.

When Edward was about nine years old an event took place which greatly agitated the district. A new schoolhouse had been built, and part of its cost was assessed on a family named Wheeler, which refused to pay. It was then the custom for the cost of maintaining district schools to be levied on the families who sent children to them. Families who sent four children paid twice as much as those who sent two ; childless families paid nothing. With regard to the manner in which the contributions necessary for building the schoolhouse should be gathered, the law was not clearly understood. The Wheelers pleaded that, as they had no children to send to school, it was as unjust to make them pay toward building a schoolhouse as it would be to oblige them to help maintain a school. Through two years litigation dragged on, when these sturdy "village Hampdens," much out of pocket and quite out of temper, lost their case. In 
its progress the suit furnished the neighbourhood with topics of comment and denunciation for months and years. The resulting feuds affected every family in the district, and friendships were broken, never to be healed. Every debate was spiced with general and hearty dislike of the Wheelers. Greenfield was a thorough democracy, in which, by some side wind of fortune, that family of aristocratic tastes and manners had been stranded. Their demeanour toward neighbours quite their equals in intelligence and refinement was pervaded by a condescension that was more than Greenfield human nature could bear. These Wheelers lived much like a squire's family in Yorkshire; they called their "help" "servants"; and they kept fox hounds of English breed, whose depredations so aggrieved Mrs. Youmans (who lived in the next house) that to the end of her life she detested dogs, classing them all as "hounds," in remembrance of Greenfield days.

In the general ill-will felt toward this family, Edward, child as he was, did not join. His sunny face and lively ways had given him the free range of their demesnes. He was sorry to see people who had been kind to him contemned and humiliated. Their lawsuit about the school, with all the discussion it aroused, made a deep impression on his mind, and served as a nucleus for observation and thought. As years went on, this early implanted interest in the rights and wrongs of State education deepened and widened.

In the Wheeler household there was a humble inmate to whom Edward became strongly attached. This was a negro boy about five years his senior, Joe Gundy by name. Joe did chores for the family; but his duties were so light that he had a good deal of 
leisure on his hands. He was the local organizer of boys into bands bent on fun and mischief, so that his popularity among his playmates was equaled only by his unpopularity with their mothers. He formed a company of boy soldiers, Edward among the number, and much pomp and flourish attended their stated drill. Joe was an imaginative and superstitious African, whose chosen reading book at school was the New Testament; and his juvenile hearers would listen with bated breath when he read favourite chapters from the book of Revelation. Joe was so daring, amusing, and resourceful that his influence over Edward almost amounted to fascination. Although mischievous, Joe was in the main a good boy. Nobody followed his leadership or gave him readier obedience in all schemes and excursions than Edward, and no harm came of it. Thus as a child did he manifest his trait of generous admiration for superior gifts, for natural ability of any kind-a trait which in mature years much extended his usefulness by making him the loyal second and supporter of men whom he justly deemed worthy of leadership. No one can be a friend, a trusted lieutenant and apostle, unless he is first a man-honest, honourable, capable of disinterested attachment. Such a man in the making was the little fellow who saw and acknowledged more talent and goodness in a negro servant than in any boy of white race he then knew. His memory in after years often reverted to Joe, and with sorrow, for there came a report that in early manhood that humble friend had been sold into slavery.

Another trait of character-individuality and the love of individuality-found a favouring nursery in Greenfield. Just becausc it was a sparsely settled 
community did every man in it have a clear perception of his rights and responsibilities as a man and a citizen. No man's vote or influerice was indistinguishably merged with those of thousands of other men. A unit was not so petty a fraction of the social or political total as to be in danger of regarding himself as practically a cipher. There was no local magnate who, by wealth, office, or superior education, could keep any of his neighbours in eclipse, or subduc any of them to be echoes of his mind and will. As appointers of school trustees, of town and county officers, as voters in the State, every man had a "say," which he said, and which he acted upon with clearly perceived effect. Greenfield was a fair sample of thousands of such communities then extant-substantially American in population, homogeneous, democratic; communities fast disappearing (alas!) before immigration of low type, before the disparities of fortune created by steam, electricity, and modern methods of trade and manufacture,-most of all, doubtless, by the iniquitous tariff laws of the last thirty years. Wholesome as much of the life in Greenfield was, it had its inevitable little battles between progress and tradition. Of this, let one example suffice. At a certain State election party feeling ran high, and for the first time on record the Congregationalist minister dared to vote. His political opponents, especially those in his own church, were furious, and years passed before the act was forgiven. Edward much admired this plucky clergyman-Rev. Mr. Redfield-first, because he liked and drove a fast horse; secondly, because he had the courage of his convictions.

Small as Greenfield was, it nevertheless contained a freethinker or two, who stayed away from church 
and read Voltaire and Paine. Between these men and divers champions of orthodoxy was waged constant war, to Edward's great instruction. He was early made familiar with the stock criticisms directed against organized Christianity, yet his essentially religious nature forbade his ever joining in an attack on institutions which, however faulty, he held to contain a core supremely true. 
CHAP'TER II.

YOUTH AND EDUCATION.

$$
\text { 1831-1837. Age 10-16. }
$$

AfTER living in Greenfield ten years, Vincent Youmans determined to leave it and buy a farm, where he could add to the very limited gains of wagon making. At Milton, two miles away, he was offered at a low price a farm of eighty acres. He bought it and removed there in the fall of $183 \mathrm{I}$. The place had been owned by a widow, and worked at much disadvan. tage ; the soil, originally thin, had been pretty well exhausted; the fences were dilapidated, and of timber little was left. The house was much smaller than the one in Greenfield. It had been erected the previous winter by a "bee," to replace a house destroyed by fire, and its hasty workmanship and makeshift materials afforded much incidental ventilation through walls and roof. However, the removal to Milton was advantageous in many ways. Farming gave the father employment when wagons were not in demand; the boys, as they grew up, were helpful; a dairy and poultry yard, managed by the mother, yielded a small but certain cash income, which was carefully hoarded to pay the debts. Food and shelter, so costly in cities, were supplied by the farm, and gave no concern; but there were the doctor's bills, school bills, church subscriptions, and so forth, to be 
met, so that the question of ways and means was ever urgent. The children were early taken into the family counsels, as each one for himself, through individual needs, had a living interest in the issue of these deliberations. The educational effect of this, though unthought of at the time, was manifold. Keeping their minds active about practical matters and their wits at work to achieve desired ends, supplied to these children a needed supplement to the abstract and unapplied teaching of the school. They were vitally interested in promoting domestic and farm operations, and in intervals when work at home was not pressing the boys gladly " hired out" to the neighbouring farmers. The situation had also its moral reactions. The painful consciousness of defective dress or other appointments led to reflection, and to the feeling of the relative unimportance of such things. Nor did this discipline diminish self-respect, for it led to an early classification of the interests of life in which good character and intelligence were most honoured. And so, by common consent, although the family income was larger at Milton than at Greenfield, if any increase in expenditure was afforded, it was for the purchase of more books, in subscriptions to church and reform funds, rather than in any outlay for matters of mere fashion or appearance. There was no relaxation of toil or economy. Constant improvements demanded outlay, interest had to be met, the mortgage gradually paid off. Careful tillage and good management brought their reward. When Vincent Youmans had worked his farm eight years he was able to sell it for three thousand dollars; it had cost him originally but a third of that sum.

Until his sixteenth year Edward helped his father 
at work in summer, attending the district school in winter, where he learned quite as much from intercourse with his fellow-scholars as from either teacher or book. Fifty years ago such schools enjoyed more of the interest and attention of parents than now. Each voter's school tax was larger, proportionatcly to his means. Keen interest was taken in the autumn election of school trustees, whose selection of teachers was justly regarded as a matter of weight, worthy of careful discussion. Sometimes the majority of trustees-and voters, for that matter-would be content to take a mediocre teacher at a small salary. Under such circumstances it was not uncommon for a few dissatisfied heads of families to secure better talent by supplementing the voted salary from their own pockets.

These engagements of teachers were usually short; men taught in winter, women in summer. A teacher who found favour in the sight of trustees and pupils was sometimes engaged for a second season. If the pupils failed to get excellence of tuition, they did not lack variety of it, and were not permitted to subside into any sluggish habit of respect for those set in temporary authority over them. Rarely did one teacher succeed another without fully and freely criticising the predecessor's methods; and such criticisms, heard on the benches, were sure to be carried home and to keep alive the parental interest in school matters. No uniformity of text-books was required; all sorts of grammars, geographies, and arithmetics, new and old, met together on friendly terms. Not seldom one book economically served two pupils. At the advent of a new teacher proficiency was measured and position in the classes defined. A free-and-easy mutual criticism 
abated any pretense of knowledge where knowledge did not exist. If a boy dishonestly claimed to be "away up" in any subject, he was sure to be searchingly examined by his comrades, and merciless ridicule greeted the pretender's silence or his blundering answer. Public opinion among the scholars was strong, and a stringent standard of honour was enforced. Fewness of rules and scantiness of machinery favoured the individuality that could render a reason. It was a school of democracy quite as much as a place for learning arithmetic and grammar. The most wholesome feature in the district school of those days was this absence of over-regulation. It was a feature that Edward learned early to appreciate, and he always cherished a distrust of excessive organization, and a dislike to machine methods without elasticity of adaptation to pupils with special gifts or tastes.

It was then common for boys to visit schools in districts adjoining their own, and the practice tended to the advancement of learning in two ways: abroad, the boys were ready enough to tell wherein their own schools might excel, and if they could bring home any new light wherewith to criticise their teacher, they did so cheerfully. On visits of this kind Edward went to a school at Greenfield Centre attended by his cousins. There he saw a teacher who had a decided "call" to his office, and who retained his charge for many years. Jeremiah Goodrich, or Uncle Good, as he was always called, had originally studied law, but, disliking the contests of the courts, had, early in his practice, abandoned the bar for the schoolroom. He had all the elaborate courtesy of a gentleman of the last century. Because he loved children they loved him, and 
so the exercise of his uncommon gifts as a teacher was easy. Uncle Grood held that the mind needed rather to be provoked than informed. He cared little for rote learning; his aim was to develop the thinking faculty in his pupils by well-considered questions and suggestions. Grammar was his strong point and a parsing lesson his delight. He would start a question of syntax, stimulate the expression of independent opinion, and then show that the right answer proved good grammar to be nothing else than good sense. Of order, as commonly observed, there was little in Uncle Good's school; the pupils sat where they liked, moved about freely, talked aloud if they chose, but seldom lost sight of the work for which they had come together. The utmost familiarity subsisted between pupils and teacher, but respect for him was never forgotten. He had his well-understood rules of conduct, any breach of which drew down not the ferule but something more dreadful still, his displeasure. $\mathrm{He}$ gave pet names to the pupils, many of which, from their aptness, stuck to them through life. From a cross-beam above his chair-he had no desk-after a lesson he would shake raisins and candy to the floor, to be scrambled for by the children in the abandonment of delight.

For all their unconventionality, Uncle Good's methods proved sound, his pupils learned quickly and thoroughly, and illustrated the value of his great principle - the right guidance of spontaneity. His fame not only brought him all the children in the district, but many candidates for the teaching office sought his instruction. Edward plainly saw that it was Uncle Good's rare personal qualities that enabled him to dispense with the rigid rules needed by ordinary 
teachers. In after years he used to say that it was Uncle Good who first taught him what his mind was for.

Through intercourse and training of this sort he learned to doubt, to test the soundness of opinions, to make original inquiries, and to find and follow clews. After the schooldays were over Edward used often to visit this admirable preceptor, and their friendship ripened into warmth. When he gave Edward the range of his little library he freely expressed his own preferences, but drew out those of the lad, and courteously suggested that they were probably the lines on which he could read and study with most profit. This deference to even a boy's individuality made a deep impression on Edward's mind; it confirmed his own high valuation of a quality which he was to express in later years in suggestive words. When Darwin showed that organic evolution proceeds upon the spontaneous variation of individual plants and animals, Youmans declared individuality among men to be in the realm of mind the same precious manifestation, to respect and foster which was to give the race its best opportunity of advancement.

Would that every community of school-children might find its "Uncle Good!" But even the best of teachers can effect but little unless he finds a mind ready of itself to take the initiative. It is doubtful if men of eminent ability are ever made so by schooling. The school offers opportunities, but in such men the tendency to the initiative is so strong that if opportunities are not offered they will somehow contrive to create them. When Edward was about thirteen years old he persuaded his father to buy him a copy of Comstock's Natural Philosophy, and studied it at home in 
his leisure hours. He repeated many of the experiments with crude appliances of his own making, for Vincent Youmans always encouraged the use of tools by his sons. Edward's most striking experiment was with a centrifugal water wheel. He first made one with arms not more than three inches long, and poured the water into the vertical shaft from a teakettle. When the wheel began to revolve in a direction opposite to that of the stream he was exultant, and at once entered upon the building of a larger and better model, moved by raising a small dam in a spring-fed stream near the house. This machine was a source of interest to all the boys and not a few of the men in the neighbourhood, and Edward was happy in explaining to them the principle of its motion. It was his earliest attempt at giving scientific lectures. It was natural that one who had become interested in physics should wish to study chemistry. The teacher (who was not Uncle Good) had never so much as laid eyes on a text-book of chemistry ; but Edward was not to be daunted by such trifles. A copy of Comstock's manual was procured, another pupil was found willing to join in the study, and this class of two proceeded to learn what they could from reading the book, while the teacher asked them the printed questions-those questions the mere existence of which in text-books is apt to show what a low view publishers take of the average intelligence of teachers! It was not a very hopeful way of studying such a subject as chemistry; but the time was not wasted, and the foundations for a future knowledge of chemistry were laid. The experience of farm work which accompanied these studies awakened an especial interest in agricultural chemistry, and explains the charm which that subject had for Youmans in later 
years. He came to realize how crude and primitive are our methods of making the earth yield its produce, and it was his opinion-I believe most profound and farsighted-that, when men have once learned how to conduct agriculture upon sound scientific principles, farming will become one of the most wholesome and attractive forms of human industry.

It was chiefly during the summer intervals, when he did not attend school, that Edward helped his father on the farm. His younger brother Warren, an untiring worker, used sometimes to find him in a shady corner with a book in his hand instead of a hoe, and was known to utter candid criticisms upon such kind of farming. The offending book was apt to relate to subjects widely remote from agriculture. Edward read quite as much for pleasure as for profit. One of the Wheeler boys lent him, when nine years old, a copy of the Iliad containing an English translation, and this interested him so deeply that after a while his father bought it for him, along with the Odyssey, the Eneid, and Ovid's Metamorphoses. The minister, the doctor, and the whole neighbourhood were brought under contribution to satisfy this thirst for knowledge. Edward was from his earliest childhood a borrower of books. In later years, after I had come to know him, I thought I had never seen a man so generous with books; it was his delight not so much to lend as to give them outright wherever he saw that they could do good. His mother used to allude to his supreme disgust, at the age of ten, when an old woman in the neighbourhood refused him the loan of Pilgrim's Progress on the ground that he could not understand it. To his persistent researches things often turned up in queer places. His sister, Miss Eliza Youmans, says the 
first book she ever read through was the old-fashioned popular romance of Alonso and Melissa, which Edward had borrowed of "a coloured farm labourer at Deacon Thomas's." He found Don Quixote in possession of a half-witted man who had never thought of reading it, but was very willing to lend and ultimately to barter it for a trifle. It was in four small, closely printed volumes bound in sheepskin, and in the years of blindness that were to come, at times when all other means of diversion failed to relieve the gloom that settled so deep and thick over poor Edward, his sister found that she had only to open one of these volumes and read from it to call forth a smile or a laugh. In the never-failing interest in Sancho and his master his own miseries were forgotten.

When a small circulating library was organized at Milton he became a subscriber, paying the subscription from a potato patch his father allotted him in the corner of a field. The only scientific book on the shelves of this library was Buffon's "Natural History," and this he read again and again.

This constant reading not only informed Edward's mind, but developed his natural powers of expression. In the family circle he would often repeat the substance of a chapter or book he had been reading, and could not fail to find how much the effective worth of a thought is multiplied when it is told clearly and forcibly, and with adaptation to the hearers.

As a youth Edward was very strong and athletic, a capital sportsman. His sight was the keenest and his aim the surest. He would often, in a shooting party, bring down a bird before any one else had so much as descried it. His enjoyments afield were, however, to be cut short just as he was entering upon manhood. 
In the fall of 1835 and the succeeding winter he was attacked by inflammation of the eyes. This was the prelude to those long painful years of blindness that were to defeat all his plans of study and largely determine his career. His persistence in reading and writing when his eyes needed rest did much to aggravate their malady. He had always a newspaper, pamphlet, or book in his pocket to read at every spare moment. At the noon dinner hour he would hurry through his meal so as to have the more time to write in his chamber. Imprudence and neglect prevented his recovery. About this time, in his sixteenth year, his father's house was extended and substantially rebuilt. Edward mixed mortar, and fetched and carried generally. The master mason, Ephraim Child, liked the bright, willing lad, and in the evenings taught him to play the fife. Years afterward, when blind, he became proficient on the violin also, and his musical capacity brought him both recreation and solace.

In those days, as always, Edward pursued his ends with puritanical energy. He was as uneasy as his father at "neglect of work" and "loss of time." In later years, while he sympathized with modern opinions concerning the value of amusements, and could give good advice to other people on the importance of "intermittent activity" and of sometimes taking a rest, nevertheless his inborn disposition was apt to overpower his judgment in such matters, and the result for him was too much like "all work and no play." Not dullness, but blindness, was the catastrophe partly brought on, or at all events seriously aggravated, by the unremittent application of his youthful days. From his fourteenth year until his eighteenth his life was a conflict between bad eyesight on the one 
hand and the passion for reading on the other. When warned by friends, he did not seem to realize his danger, and would either reply carelessly, or perhaps exclaim, with the rash warmth of youthful blood, that he would rather be a blind man than an ignoramus. Nor did the parents understand the seriousness of the situation. In the minds of people in Saratoga County, or any other rural neighbourhood sixty years ago, there was little or no idea of inflexible laws of nature ruling our lives and bringing upon us the consequences of our actions. A summary reference to the dispensations of Providence was apt to dispose of such matters.

We are thus brought once more to the religious experiences of the family, to which I have briefly alluded. The father and mother.were very unlike in their way of looking at things. Vincent Youmans seems to have been a born doubter and rationalist, with clear ideas and a ready flow of language. His wife was a marvel of common sense, along with a deep religious tendency. Outside of her daily duties and the practical questions involved in the maintenance of the family her religion explained all the problems of life; and she exerted a powerful influence over her husband, who otherwise might perhaps never have become a member of the church. There was much that was interesting in the reaction of those two strong natures upon each other. They were in the habit of discussing all sorts of questions in the presence of the children; and in regard to political and social matters much freedom of speech was indulged, for in that little rural world the leaven of great moral reforms was working. Between husband and wife there was complete harmony on the "temperance question," and they belonged to the dominant and most respectable 
party in the community - a circumstance which counted for much with Mrs. Youmans, but for little or nothing with her husband, who cared not if he stood alone, so long as he satisfied himself that he was right. For a long time questions of religious belief were not discussed in the family; for in that one field the father had abdicated his reason, while the mother had no temptation to exercise her reason. But as the children grew up the case was altered. All seemed to have inherited the father's mental tendency, and thus there was awakened in the mother a painful solicitude. for their religious welfare, which kept the subject alive and ready at any moment to be brought forward.

A political situation, here as in many an American family at that time, came in to complicate matters. In the eastern counties of New York the antislavery agitation was just beginning. Vincent Youmans was the first man in his town to declare himself an abolitionist, and he gave hearty support to any friend of that cause who came in his way. Antislavery speeches, pamphlets, and books-of many of which the acrid and violent tone was an index of the intensity of ill-nature that opposition to great reforms is sure to evokesoon formed the staple of his reading and added fresh pungency to his talk. This marked and isolated attitude of the father at once put the family on the defensive everywhere. They were obliged to sustain themselves against ridicule and abuse by their own inward sense of what was right. For a while Mrs. Youmans had little to say on the subject of the antislavery crusade, but presently it assumed a shape that aroused her antagonism. The Church was assailed by the abolitionists-and not without much reason-as afraid to oppose slavery and indifferent to the fate of the negro. 
Vincent Youmans could see that the clergy as a body were culpable in this respect, but his wife could not see it. To admit any faults or shortcomings in the Church seemed to her to be undermining the foundations of religion. As the children grew up the urgency of friends and relatives concerning the condition of their souls was constant. Edward especially was "laboured with," but apparently to little purpose. At one time, when eleven or twelve years old, he was sufficiently excited with the goings on at a Baptist protracted meeting to go forward to the "anxious seat." But there was evidently nothing in this act beyond momentary excitement, for a few days afterward, as Edward caught a glimpse of the Baptist minister in the unwonted act of coming in at the Youmans farmstead, he guessed his errand and carefully kept out of sight. It is clear that from early youth Edward's mind was inhospitably disposed, not indeed to religion or to Christianity, but to the form of it that was offered him for acceptance. He was wont to bring forward Quaker arguments with regard to Sunday observances and Calvinistic symbolism generally. Upon doctrinal questions he was familiar with the positions of many different sects, and had a way of setting off one against another that was sometimes comical. Even at that early time he had learned something about the attitude of scientific thought with reference to the origin of the earth, and used to urge geological objections to the so-called Mosaic account of the creation. He also expressed skepticism about miracles, as infractions of the order of nature requiring much more evidence to make them credible than has ever been produced. Such ideas seemed to the mother unspeakably dreadful, and, womanlike, she was disposed to attribute 
them partly to some subtle influence emanating from the eccentric Uncle Good, partly to the antislavery agitation, which seemed to be fast destroying all reverence for the Church. Scarcely a Sunday passed but the sermon just heard or the book last read gave rise to animated discussion, which on her part often ended in tears. Since among the evidences of Christianity miracles were most relied on and most discussed, it was almost inevitable that as time went on the trouble deepened and the skepticism of the doubters was strengthened. On the part of the young people there was a painful urgency to make a clear defense of their position to their own minds at least, even if they could not convince their parents. This was no doubt a powerful motive toward inquiry into the origin of things and the causes of the natural processes going on around us. For example, the mother's arguments confounded the events of the gospel miracles with the mysterious natural processes of birth and death, of growth and decay, and the children were challenged to explain any of these mysteries. Science studied under such circumstances would not remain in their eager minds in the fragmentary state in which it is apt to be presented in text-books. Its elements tended toward coordination and organization into a coherent unity that might help one's conceptions of how the world is made and governed.

In such discussions the rationalistic freethinking side was always represented by Edward, and he had to bear the full responsibility of it. He was often told that he was fast tending to "infidelity," and leading the other children along with him; and "infidelity " was of course the worst imaginable form of wickedness. The age has fortunately gone by (whatever 
English clergymen may feel it necessary to declare when hard pushed by Professor Huxley) when belief in the historical character of the "Gadarene pigbedevilment," or any other miracle in the four gospels, was regarded by intelligent people as an important part of 'one's Christian faith. It is fast becoming difficult to comprehend the state of mind which attached the highest value to the most barren parts of the Scriptures, and visited with condemnation all attempts to use one's reason and common sense about that literature as about any other subject. One thing, however, is clear-the struggle involved in gaining one's intellectual freedom in those days afforded a most valuable discipline for the mind and character.

Edward's freethinking did not make him unpopular. Unlike his father, whose plain speaking often gave offense, Edward could maintain any opinion without irritating his antagonists. Without being disputatious, he was fond of argument, but there was such disinterested search for truth in what he said, such readiness to admit facts that told against him, such utter absence of selfish desire to make a point, such genuine respect for the individuality of other persons, that he was the most genial controversialist I ever knew. His powers of persuasion were of the rarest order. Not long ago a younger brother, now a man of sixty, remarked: "Edward always had his way with me. I could not withstand him. If I knew beforehand what he would be at, and were never so certain that I could not agree with him, it was sure to turn out in the end that I gave in with perfect concurrence of sentiment." With such qualities Edward was always the leader among his comrades, and was a favourite with all. 
This chapter may fitly end with a pleasant reminiscence in his sister's words :

Edward's habit of helping his mother resulted in great handiness in domestic matters. When leaving home for a day, his parents left the care of affairs with him. He prepared the meals, and took responsible charge of things. A sufficient comment upon his management is the fact that his parents were satisfied with it, and the children always greatly enjoyed such occasions. He was an amusing and entertaining companion-full of interesting explanations, kindly warnings, merry stories, and lively songs. I think he kept us in tolerable order, but we certainly led a happier life than when our parents were with us. I do not recall any instance of rebellion against his authority. $\mathrm{He}$ did not coddle us, nor was he assuming or authoritative. He was simply faithful to the needs of the hour, and from morning till night kept up our interest in whatever occupied his mind at the time. 


\section{CHAP'TER III.}

\section{YEARS OF BLINDNESS.}

1838-1844. Age, I7-23.

IN 1838 Edivard's long-cherished ambition to become an educated man was in a fair way to be realized. His talents, his parents felt sure, were such as to fit him for a professional career, and law was thought of as the profession which he might in due season adopt. The way to the bar seemed clear enough. Other young men in the vicinity no better off than he were taking college courses of study, and helping to meet the expense by school-teaching in winter. But one obstacle to his ambition existed, which unfortunately was not recognized in its full seriousness. His eyes were still weak, and their condition should have forbidden the protracted studies which he undertook. He entered the academy at Galway, Saratoga County, New York, in May, is 38. The term until the summer vacation was to be fourteen weeks, and twice during that time he had to go home with inflamed eyes for rest.

His appearance at this time is described in the following letter from one of his fellow-students:

AnN ARbor, December $13,18 S_{7}$.

Miss Eliza A. Youmans: In complying with your kind request to give my recollections of your late brother, I can 
only wish that they possessed some real value in proportion to the usefulness that the faithful record of such a life must have for all who find themselves compelled to struggle with obstacles seemingly insurmountable; but such as they are I most willingly place at your disposal in the following sketch:

In the year 1838 a new academy was opened under the presidency of Professor Morgan, at the small village of Galway, Saratoga County, New York, and it was there, during the summer months of that year, your brother and myself became schoolmates together. As I remember it, there was nothing in the peculiar advantages of the school or in the character of its teaching specially fitted to call forth or develop any talent not already struggling for spontaneous manifestation; but to some minds only opportunity is needed; all other help is but adventitious, and not essential. Of such was your brother. Although fifty years have come and gone since that time, I recall with great distinctness the impressions then made upon me by our brief association as fellow-students, for from the very first there was some genial attraction that drew us together and speedily ripened our intimacy into a warm-hearted friendship. Though we were born in the same year, there was in his appearance a maturity of demeanour and expression which made him seem my senior. He was less boyish and more grave than myself and others of about the same age. Yet was there nothing austere or repellent in his manner; on the contrary, he was ever cordial and affable, and entered with zest into our academic sports and jests. His perceptions of the ridiculous were keen and appreciative. When the matron's cockney English son-in-law requested us one day to "haliow those birds to henter the gate," this appellation of birds to some very common barnyard fowls seemed to him such a sudden promotion that its funny aspect fairly overcame his gravity, and ever after the sight of those birds brought a twinkle into his eyes. In sportive- 
ness he and I once thought to make a fellow-student the innocent subject of a practical joke suggested by our finding an old Independence ball invitation. This invitation, with its date properly corrected, was by due course of mail transmitted to one of the lady teachers, purporting to have been sent by our intended victim, and, as we thought, was sure to be returned at once with a dignified if not indignant refusal. Alas! the lady's logic had not arrived at the same conclusion, as we learned to our consternation the next day, when the student showed us a polite acceptance of the invitation and vainly wondered what it all meant. Of course we lost our intended joke; but the contretemps put the whole thing, as well as ourselves, into such a ridiculous attitude that we had many a good laugh over the affair, though not at the other student's expense. The teacher's tears of chagrin were a cause of deep regret to us both; but our share in the transaction prevented any overt expression of sympathy.

At that time your brother was slight rather than frail of figure, with a somewhat pallid, colourless complexion, and a perceptible stoop in the shoulders. A weakness of the eyes caused a partial closing of the lids in order to shield them from the light, and his manly, symmetrical features from this cause lost in part their naturally frank and attractive expression. I believe his habits and speech were exceptionally free from youthful improprieties and vulgarity, and his intercourse with all showed the governing influence of a pure and generous nature. If I were asked what peculiarity was most noticeable in him, I should say it was his ready and apt use of words, both in composition and speech, which were not quite the ordinary and commonplace forms of expression among students and young men of his age. This did not take the appearance of pedantry or of any conscious effort at display, but rather of an intuitive love for nicety of expression and a resulting habit of selecting and treasuring up in memory 
all such strong words as appealed to this peculiar taste. And does not this, I may ask, seem almost prophetic of that high place he subsequently attained as a writer, in spite of the small aid derived from the schoolroom and of obstacles that would have dismayed a soul less strong? Scarcely less noticeable also was the ample storehouse of facts and observations he had accumulated upon almost every conceivable subject, indicating a woracious hunger for information and a natural ability to gratify it even outside the traditional means furnished by our systems of education.

Having different studies and classes, I am not able to speak of his standing or proficiency, except to state that he seemed a diligent scholar and deeply interested in the discharge of every duty. Between recitations it was our wont to seek the shelter and shade of an open shed near by, and in the comfortable seat of a cutter * standing there in summer quarters we passed many an hour with our books and in the abandon of school-fellow talk. He spoke often of his desire to fit himself for active life with the best educational training in his power, but expressed the fear that his eyes would not permit him to accomplish all he wished. As I was about to enter college, he frequently referred to the advantages of such an opportunity, though I do not remember that he ever expressed any intention to enter upon the acquisition of what is generally termed a "liberal education." Its chief attraction to him seemed to be in the vast storehouse of science, literature, and general knowledge to which a college life was supposed to give access, and in which his insatiate thirst for information could be fully gratified. With the close of the first term our personal intercourse was interrupted, never again to be renewed; but

* For my British readers this word needs defining. A cutter is " a small, light sleigh, with a single seat for one or two persons, usually drawn by one horse."-Cintury Dictionary, s. v. 
considering the brief duration of our intimacy, the impressions it made upon me have remained singularly indelible. Following the usual practice of schoolmates who cherish some mutual regard, we subsequently kept up a brief correspondence. I regret to say that among the relics of that far-off epistolary period I can only find two of your brother's letters.

That of September, 1839 , gives a sad picture of his profound despondency, arising from ill health, disappointed hopes, and blindness. To one of his intensely active mind, longing for the contest upon the great arena of real life, what a marvel had it been otherwise! Yet did he not utterly despair, but all the days of his appointed time would he wait.

In the letter of June $2 \mathrm{I}, \mathrm{I} 840$, he draws a vivid contrast between his fortune and that which had fallen to my own lot, and in it we discover the glorious vision a collegiate career spread out before him while he was left "standing upon the strand of earthly enjoyment, in sight of an eternity of tripled, yea, quadrupled misery." Manifestly, depression of spirits and mental suffering could no further go, and it is a most pleasant reflection for me now, as it was a profound satisfaction at the time, that amid all this gloom any words of mine could enable him to say that the time spent in their perusal had been among the happiest moments of his life.

I must here close this imperfect sketch of my recollections of your brother. If anything here recorded can aid you in a faithful presentation of his strangely diversified life, making it an example and encouragement to any whom misfortune or disappointment may be likely to overcome, I shall feel amply rewarded; and it is with grateful satisfaction I can now turn from the sad impression his letters would otherwise leave, to the many subsequent years of his active and eventful life in a field so congenial and so near to the ideal of his young ambition. 
Very sincerely, and with earnest wishes for the success of the Memoir,

I am yours,

JOHN M. WhEELFR.

Edward contrived to get through the fall term of I 838 without any break, and in November he began teaching in a district school in North Greenfield. The schoolhouse could not be properly warmed in the fierce winter weather. The redhot stove in the middle of the room and the cold currents everywhere made the daytime a time of exposure, which the vicissitudes of food and shelter attendant upon "boarding around" among the farmers of the district did not tend to counteract. After six weeks Edward was obliged to relinquish his school and go to Ballston Spa for treatment by a physician who had some reputation as an oculist. Sharp caustics were applied to the eyelids, and calomel was administered in large doses; and as the patient was not warned against exposure while using this drug, he took a severe cold which settled in his eyes, ulcerating one eyeball severely. Sight never returned to this eye except to reveal a vague difference between darkness and light, and the other eye became almost useless. After suffering cruelly at the hands of the Ballston oculist, hope of relief through him was abandoned, and in the spring of I 839 Edward was brought home. His case was serious, and for the first time he felt its full seriousness. He had not yet been aware that the peril of blindness hung over him, and the shock now depressed him profoundly. It meant that it might be his hard fate to be shut out from the chief joys of life, never to be able to study, or even to earn a scanty livelihood without painful dependence upon others. The blindness continued 
for months, but there was no cessation of mental work. Much was done to relieve his tedium by reading to him, and the reading took a wide range in newspapers and books-news, fiction, verse. In agricultural journals he took special interest, and he already began to apply his smattering of chemistry to the topics discussed in them. Having spent his youth among farmers who could think clearly and independently on moral, political, and religious questions, he was not inclined to ascribe to any real lack of mental capacity the fact that they were unintelligent and unbusinesslike in their methods of agriculture. This shortcoming he rightly attributed to their lack of elementary training in science, and in his youthful ardour, with his large sense of the importance of agriculture, his perception of what chemistry might do for it, and his genuine faith in the power of education, he was already beginning to think it possible that, in spite of the failure of his regular studies, he might succeed in making himself useful in this direction.

Newspapers then were apt to contain articles such as are now more likely to appear in magazines-long, closely reasoned, and comparatively well written. In the Youmans family such articles, supplemented by new pamphlets and books lent from hand to hand, furnished themes for earnest discussion. One of the most intelligent friends of the family was Mr. Ransom Cook, of Saratoga, well known as a manufacturer and inventor, and pleasantly remembered by many beside myself for his gracious cordiality of manner and the suggestiveness of his racy conversation. His library, which he placed quite at Edward's disposal, contained the standard treatises on science and the mechanical arts. As a freethinker, Mr. Cook had collected many 
books of a sort that Edward, when he had borrowed them, did not think it quite prudent to leave "lying about the house." From him was obtained the "Vestiges of Creation," which was read to Edward in the early days of his blindness, and was much talked of in the family. His sister, being always at hand, spent much of her time reading for him. She thus soon became his constant companion and helper, and the relation then established lasted until the end of his life. It was, no doubt, his eager interest in all current questions that served to occupy his mind and save him from utter despondency.

With settled summer weather his health was mended, and his remaining eye grew so much better that he could walk about without being led. In July he was able to attend the famous Albany convention in which the Liberty party was formed, and after it was over, instead of returning directly home with his father ancbrother, he undertook to make a visit to New YorkHe went down the river on one of the day steamers;, and the shimmer of sunlight on the water put out what little sight he had, so that on arriving at the city he could not go ashore. He returned to Albany on the same boat, and contrived somehow to make his way home.

This was only one of the first of many relapses that were to tantalize the eager young man and sicken his heart with hope deferred. As the autumn of 1840 arrived without bringing the desired improvement, and one of the neighbours happened to be going to New York, Edward was placed in his care and escorted to the eye infirmary, where Dr. Delafield took charge of his case. After several weeks, although the doctor always spoke cheerfully and gave hopes of 
recovery, he found his eyes growing worse; and one day, in his impatience, he asked the doctor's assistant very pointedly if there was really any chance of his getting well or not. With injunction of strict sccrecy about such a breach of confidence, the young physi. cian replied that Dr. Delafield's encouraging tone was sinply "a way of his," and that he really considered the case incurable. This opinion the kind but plainspeaking young oculist shared, and proceeded to fortify with reasons of his own, but Youmans was not yet ready thus to abandon hope. If he had any strength of character or fertility of resource in a dire emergency, the time had now come for its exercise. Alone in a large city, amid surroundings of which he had not the slightest experience, friendless, stone-blind, baffled in his hopes of the infirmary, how should he make a furur attempt to get efficient medical aid? Among his low-patients were half a dozen other young men in inilar plight, all hopeless of benefit from a further stay in that place, all poor, one or two actually penniiess and dependent on charity. One of them, however, could see well enough to serve as pilot for the others, and so the whole party sallied forth into the treets and went about from one oculist's office to inother in quest of advice. Youmans, the youngest of the company, was relied upon as spokesman for all. Whether it was he that organized the movement or ot, one sees in it the boldness of purpose and vigour of xecution that always characterized his way of doing hings. We can imagine the anxiety with which he stened, in one office after another, to the various pinions offered as to whether he was likely ever again see the light of day. Some of the physicians prounced cure impossible; one promised recovery on 
the sole condition of faith; others contented themselves with severely criticising the treatment he had received. Among them all, Dr. Samuel M. Elliott gave him most encouragement, and something in his manner inspired a confidence that turned out to be well grounded; for through the coming twelve years of difficult treatment the doctor's skill was never at fault, nor his sympathy wanting.

When their circuit among the oculists thus came to an end, Youmans and his fellow-patients turned their steps toward a boarding-house. They were directed to one kept by a Mrs. Cook, at the corner of Pearl and Hague Streets. She was a humane and kindly woman, but the struggle to keep up her boarding-house and support her family kept business considerations, of course, in the foreground. These blind men could not be brought to her table; so she found for them in hr, basement some quarters, which they hailed with and light as a change from the infirmary. Since the intik. view with Dr. Elliott the party were in high spirits, and Youmans created much merriment with his droll quips and sallies. In a few weeks all the rest had left Mrs. Cook's; Youmans remained, but not in the basement. Charmed with his modest dignity, his sparks ling conversation, and his witchery of manner, the landlady at once became his friend. He was accommodated with a large and comfortable room, and when her daughters could find leisure for it th $n^{3}$ would read to him. Among the boarders were sc ei, bright young printers, and soon they too became in: $\mathrm{t}^{\mathrm{P}}$ ested in the newcomer. They brought him bo li $^{\text {- }}$ and papers, they came to his room and read for ' $\mathrm{o}^{\mathrm{rk}}$ and always felt more than rewarded by his shre to comments and telling illustrations. It was here trof 
Youmans first met Horace Greeley-the beginning of a warm friendship.

Dr. Elliott had expressed a belief that the cure could be effected in six months. In saying this he probably stretched a point, for it was evident that a less hopeful view might prevent Edward from undertaking the treatment. Edward felt that the doctor's fee of one hundred and sixty dollars, besides the cost of board in the city for six months, would be a heavy burden for his father. A longer stay would at that moment have seemed impracticable.

At first the progress toward recovery seemed rapid, but painful and vexatious relapses kept occurring. Sometimes the patient would be able to read the signs over shop doors, then for a long time he would be totally blind. It thus gradually became theident that years rather than months might be fel:eded for the cure. After the first installment of sirxty dollars had been paid the doctor would not raccept any further payment until the cure should be complete; and so many years passed before this result was reached, and so many occasions had there been for mutual good offices, that further payment was Snever thought of.

? Edward's home was with Mrs. Cook throughout the year 184I, except now and then in the summer, 'when he was able to superintend the workmen upon Dr. Elliott's estate on Staten Island, which he was always glad to do, for when there, besides the welcome opportunity of earning his support, he had healthful outdoor life, sea bathing, and even some horseback riding, and was much improved thereby. Nevertheless the relapses would come. If he happened to catch cold, however slightly, the congestion always seized 
upon that eye. From a state of comparative comfort and self-helpfulness on going to bed he would often in the morning arise quite blind again; and when this happened at the island, he had to go back to the city and take the treatment at the doctor's office.

Early in 1842 he left Mrs. Cook's and boarded for a time at Mrs. Chipman's, on Chambers Street. It was here that he made the acquaintance of Walt Whitman, when he was plain Mr. Whitman, wearing a coat - and necktie like other people, and editing a newspaper called the Aurora, for which Edward wrote occasional "Saratoga correspondence." In later years Youmans always maintained that Walt was an arrant humbug, and that his "barbaric yawp" and obtrusive filthiness were assumed purely for pelf, after he had found that polite writing would not pay his bills. Among the friends made at this time, and who for many long, weary years proved most sympathetic and helpful, was Mr. Benjamin Flanders, whom he met at Dr. Elliott's office undergoing treatment for a minor malady of the eyes.* Mr. Flanders was a sailmaker do-

* The sight of any one in trouble always moved Mr. Flanders to help him in some way if he could. Hence he sought Edward's acquaintance, and at once took a personal liking to him. He was much pleased by Edward's manner, in which at that time, along with the embarrassment due to blindness, there was unusual modesty and deference to others, associated with peculiar energy of speech and confidence of statement. No doubt the liberal opinions of the youth and his ability to state and defend them also -pleased Mr. Flanders, so that when his eyes were cured and the two friends ceased to meet at the doctor's office he sought Edward out in his boarding-house and in the most delicate way did much to alleviate his circumstances. His persistent kindness throughout the long years of helpless dependence that were to follow had much to do in bringing about the final recovery. In the early years of his stay in New York Edward was much alone, and suffered a great deal from low spirits. Often when Mr. Flanders found him downhearted he would take him to his home in 
ing a large business, for that was before the time when American shipping was destroyed by idiotic navigation laws and robber tariffs. He was interested in Fourierism, and as a member of the North American Phalanx was associated with Horace Greeley, William H. Channing, Freeman Hunt, Edgar Hicks, Richard H. Manning, and other prominent reformers of the time. Mr. Flanders took Edward with him to social gatherings in Brooklyn where these gentlemen were present and where the subject of the reorganization of society was a leading topic of conversation. At these gatherings questions of reform were presented in a broader light and involved more fundamental changes than the antislavery and temperance discussions to which Edward was accustomed, and we may be sure that he made the most of these opportunities. He was too heavily weighted by the consciousness of his infirmity to make acquaintances readily in such mixed gatherings, but he came to know some of Mr. Flanders's more intimate associates, and we shall see how lasting were the friendships commenced in those enthusiastic days when the immediate and indefinite educability of everybody, mentally and morally, was believed in without reserve-when generous zeal believed that a new heaven and a new earth were at hand.

Necessity had wrought in Edward that development of touch and hearing which comes to all who lose sight, and his memory, naturally very retentive, became still stronger. He was able to find his way

Brooklyn for a time and cheer him in many ways, not the least of which was the confident tone he always kept up about Edward's ultimate recovery of vision. Mr. Flanders lived to see him a successful author, and in wide repute as a popular scientific teacher. 
through the less crowded streets, and sometimes took great risks in venturing about alone.* He was often driven to exposures which a little money might have enabled him to avoid, and thus poverty hindered and jeopardized his recovery. One of his worst exposures, however, was connected with an incident of which I never heard until after his death, when I came to put together this memoir. In 1842 , as he was picking his way along one of the riverside streets near the edge of a wharf, he heard a sudden splash in the water and cries for help close by. Instantly seizing a large chain that happened to be within reach, fastened at one end to a post on the wharf, he let himself down into the water, got hold of the drowning man, and kept him up until help came, thus saving his life. It was midwinter, and this stay of several minutes in the freezing water brought on a violent fever, which detained Edward for nearly three months in a hospital, while his anxious family had no news of him. It was eighteen months before his sight could be brought back even to the dim twilight condition it was in at the time of the accident. This brave act was just like Youmans, and it was also like him never to speak of it.

A pleasant incident of his first year in New York led shortly to results of much consequence. Some time during his stay at Mrs. Cook's his watch needed mending, and he was told to take it to Mr. James

* Once a man who was carrying a plank on his shoulder on the sidewalk hit him with it so violently that his fall injured him seriously. His narrowest escape was one evening when, in going from Mr. Flanders's to his home in New York, he found himself at the very brink of the water wall below Fulton Ferry, where one step more would have precipitated him into the East River. It was not built up then for a considerable distance below the present upper entrance to the ferry. 
Ketcham, a watchmaker living hard by. Mr. Ketcham was a Quaker, and a genial old bachelor withal. That he felt drawn toward the blind young man was no more than natural-everybody felt drawn toward him; there never was such a magnetic creature as Edward Youmans. This circumstance was the beginning of a pleasant acquaintance which soon ripened into friendship, so that when Edward left the neighborhood to go to Mrs. Chipman's boardinghouse he frequently spent a pleasant hour at the watchmaker's shop. He was invited and urged to visit Mr. Ketcham's household, over which a maiden sister presided. This he for a long time declined to do, because of the embarrassment of his blindness; but his hesitation was at length overcome and the invitation was accepted. The interest he had awakened in the brother was at once shared by the other members of the family. This was soon after his escape from the hospital. He was in delicate health, and so helpless that the Ketchams insisted upon his making his home with them, where he might have care and attention impossible in a boarding-house. He was very glad to accept the proposal, and for many years thereafter his New York home was in the Ketcham family. Thus, within three years after coming to New York, blind and helpless as he was most of the time, he had won friends on every side, friends whose sympathy and kindness he gratefully remembered to the close of his life. Seventeen years afterward, in 1859 , he visited Detroit on a lecturing tour; Mrs. Cook was then living in that city, and he called upon her. During their conversation many reminiscences of his years of blindness and privation were recalled, and he thus alludes to it in a letter written at the time: "I yearn for those 
old friends who assisted and cheered me in days of affliction, and I was most glad to see her. Yet our talk revived so much that was painful that I was sad all day afterward."

Late in the summer of 1843 , with his scanty vision somewhat improved, he went home to Milton and spent some pleasant weeks while his sister read to him. In these days, along with the reading of current literature, the subjects which engaged his attention were chemistry, pure and applied, the geology of soils, mineralogy, botany, physiology, and astronomy. "Our reading," says Miss Youmans, "constantly outran our knowledge and kept us on the strain for explanations."

At this time Mr. Youmans had begun to support himself by miscellaneous literary work-precarious, difficult to get, and difficult to do. He early began writing for the press, which gave him practice in composition' and brought him into journalistic relations which grew in extent and in after years were of the utmost importance. In writing reviews, popularized citations from technical works, etc., his blindness proved an almost insuperable obstacle. Aid from friendly eyes and hands could of course be only occasional. He had to resign himself to spending weary weeks over tasks that with sound eyesight could have been dispatched in as many days. He invented some kind of writing machine, which held his paper firmly and enabled his pen to follow straight lines at proper distances apart. Long practice of this sort gave his handwriting a peculiar character, which it retained in later years. When I first saw it, in 1863, it seemed almost undecipherable; but that was far from being the case, and after I had grown used to it I found it 
but little less legible than the most beautiful chirography. The strokes, gnarled and jagged as they were, had a method in their madness, and every pithy sentence went straight as an arrow to its mark.

I have already mentioned Youmans's strong sympathy with the little party of abolitionists, then held in such scornful disfavour by all other parties. He was also interested in the party of temperance, which, as he and others were afterward to learn, compounded for its essential uprightness of purpose by indulging in very gross intemperance of speech and action. The disinterestedness which always characterized him was illustrated by his writing many articles for a temperance paper which could not afford to pay its contributors, although he was struggling with such disadvantages in earning his own livelihood and carrying on his scientific studies. It was not often, however, that he was called upon to work for nothing.

Among the friends whom he made at the home of the Ketchams was William Baner, a stereotyper, and in a small way a publisher. Through him Mr. Youmans had occasional employment on liberal terms. One day, for example, Baner sent to him an old sea captain who had an original system of the universe wrapped up in a bandanna handkerchief ; this comprehensive effort received grammatical and other revision for a very satisfactory honorarium. Mr. Baner published on his own account a history of the life and times of Madame de Pompadour, revised and edited by his literary coadjutor.

The rare conversational powers which from the first had interested so many people in Mr. Youmans were constantly ripening and expanding. Especial development was observed in his power of explaining 
problems abstruse in themselves or unfamiliar to his hearers. Naturally great, this power of exposition was developed until it came to be marvelous. His deprivation of sight contributed to this. When sitting silent and alone in his room for hours together, his mind was always busy; its activity was spurred by his necessities and definitely directed by such opportunities of work as came to him. When he had heard a scientific article or a chapter in a scientific book read, whether he intended to use it or not, he would go over the entire statement or train of reasoning, searching out defects and fallacies, pushing the arguments to new conclusions. Such links as he laboriously thought out between the familiar and the unfamiliar he would repeat in talking over his favourite themes to his friends, and Mr. Ketcham was a great help to him in this respect. He was intelligent, interested in everything, and fond of argument. He had no greater pleasure than in talking over with Edward whatever subject was uppermost at the time. This laborious mastery of what he learned gave Youmans the key to masterly exposition when that became his task. Blindness and solitude had some compensations, though sadly inadequate. With his impulsive and somewhat impetuous temperament they enforced a depth and steadiness of reflection he might not otherwise have known, although at the expense of pain unspeakably bitter.

In the winter of 1844 there was some excitement in New York, in educational circles, over the system of artificial memory brought out in a course of lectures by a Frenchman, one F. F. Goureaud. For a time this system of phreno-mnemotechny, as it was called, was very popular, and its author reaped large pecuniary rewards. Youmans incidentally made Gou- 
reaud's acquaintance, and found a class of young men preparing themselves under his guidance to become teachers of his system. Having sight enough at the time to get about alone, he enlisted with these pupils, simply with the hope of gain. Goureaud had applicd his system to all the important dates of secular and ecclesiastical history, and these had to be learned by the young teachers as illustrations to their audiences of the power of the mnemonic system. Youmans presently went home to Milton, where he could have the help of others' eyes, and began memorizing long lists of biblical and political dates. This labour was soon accomplished, and he taught his first class in Saratoga. He could not read the text-book, but fortunately his sight was sufficient to enable him to read a few notes printed in large characters upon slips of paper concealed within it. He had no pleasure in the work for its own sake, but he was happy to be able to earn something, and for several months he taught these classes at intervals in neighbouring towns. The topics to which Goureaud applied the system had for him little importance. From the first he began a list of his own, made up of the dates of inventions and discoveries. This was congenial work, and he spent all his leisure in collecting and memorizing facts of this sort. As his list grew, and was marked off into centuries and classified according to subjects, he became more and more interested in the growth of knowledge, and especially in the progress of the sciences and their successive dependence one upon another. He was fairly successful in teaching, but in this itinerant life he often took severe colds, with consequent relapses into blindness, and so he had to abandon the work. But he kept up the study of scientific progress with 
increasing interest, using this mnemonic system to fix dates in memory, and throughout life he found it of service in remembering facts expressed in figures.

Amid all the earning of daily bread and butter and all the visits to Dr. Elliott's office, Youmans kept constantly in mind the theme of agricultural chemistry. Railroad development had not then made it easy to forsake old land for new; at Milton, as elsewhere throughout the older settlements of the country, the main question was how to get the most out of longtilled soil. His visits at home always brought this problem sharply before him. His reading was discursive, but his interest always came back to the science which could ease his father's toil and increase the small gains of his industry. In the spring of I 844 Liebig's Agricultural Chemistry was read to him. It opened up a new world to his mind. During the previous year his sister had been trying to fit herself to give him aid by attending a course of chemical lectures delivered by Prof. Mather in Fairfield, N. Y. The knowledge thus acquired was to be brought to a severe test. She was plied with questions regarding obscure or ambiguous statements met in the textbooks. Edward would never pass a definition or term he did not understand, and so there were perpetual interruptions for consultation of dictionaries and works of reference. He was full of comment and suggestion as the reading went on, and when it was ended he would sit quietly for hours absorbed in thought.

Sometimes there were days-and rarely, perhaps, a week or so-when he could see well enough to go about and superintend work. He was eager to put his scientific knowledge into effect, and such success as attended experiments in drainage, fertilizing, or 
new crops, undertaken at his instance, made him jubilant. During one visit at home he had muck spread with excellent effect on the farm's thin, sandy soil. At another time he introduced a hydraulic ram, the first ever known in that neighborhood. Among other household improvements of his were a bathhouse and an ice-house, well planned and well built. 
CHAPTER IV.

YEARS OF BLINDNESS (Continued); THE CLASS-BOOK OF CHEMISTRY.

$$
\text { I845-IS5I. Age, 24-30. }
$$

In the summer of $1846 \mathrm{Mr}$. Youmans had a long period of total blindness, and two members of the Ketcham household, who rendered him much service in reading and in leading him through the streets, were obliged in the autumn to leave New York. He now wrote to his sister, asking her if she could come to New York to set free his friends from their care of him, and to aid him in some projected literary work. She went to him at once, and was pleased to find, notwithstanding the despondent tone of his letters, that his personal charm had drawn about him so many helpful friends.

He had several literary projects to lay before his sister, the chief of which was a history of progress in discovery and invention, and upon this book work was forthwith begun. Despite all obstacles, he had year by year contrived to pick up a good deal of information regarding scientific progress all along the line; and the themes which he now discussed with most animation were those suggested by modern geology and the nebular theory. Are Nature's laws uniform? Is the universe vastly older than has been supposed? These were grave questions to a man 


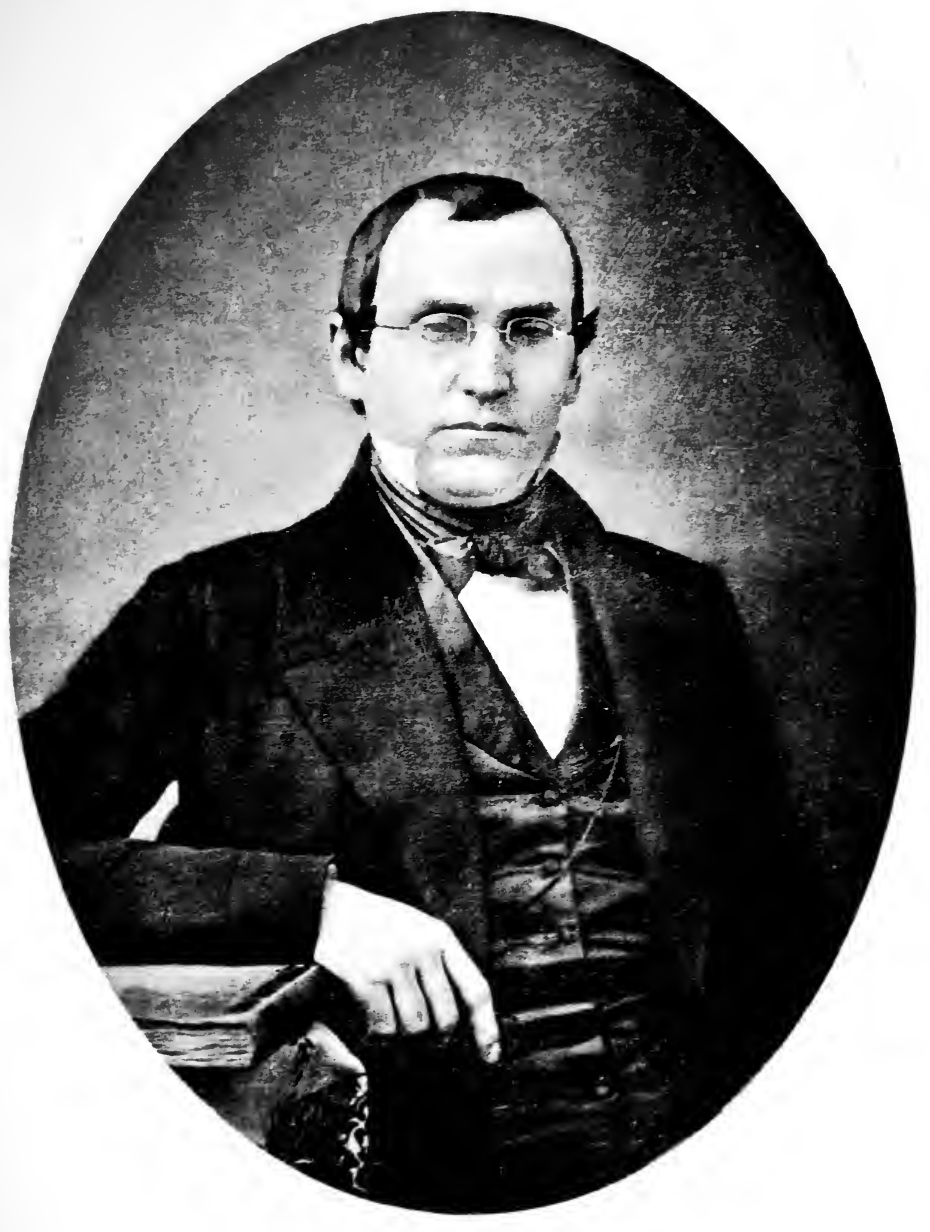

EDWARD L. YOUMANS

AT THE AGE OF THIRTY

From! a photograph taken in 1951 


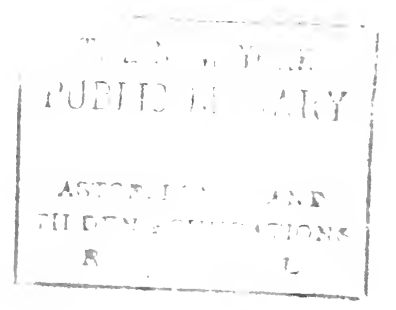


brought up to regard the Bible not only as the authoritative basis of religion, but also as absolutely correct in its science. His thought upon these subjects was greatly stimulated by the first lectures delivered in New York by Professor Agassiz. To these lectures, introductory to the study of natural history, Miss Youmans escorted her brother soon after her arrival in the city. They were delivered to crowded audiences in the hall of the College of Physicians and Surgeons, in Crosby Street. Every fitting occasion in the course of the lectures was used by Agassiz to illustrate his favourite conception of the truths of science as the thoughts of God. People were so eager to hear him express an opinion on the development theory, that in his sixth lecture he felt constrained to turn aside from his systematic exposition, and say:

But with the progress. of species, as we find them in different geological strata, the question is, Can we find in Nature external causes which will produce these changes? And, again, Can we refer these successive appearances of different types to the influences of external causes? I say No; because, since man has studied Nature, he has never seen any species modified under external influences.

\section{And again :}

These views-to which I shall recur when I come to speak of the position of man in Nature, and of his relations to the animal kingdom-disagree entirely with the views, and have not the slightest alliance with the views, of a work which is very much spoken of [The Vestiges of Creation], but which I consider entirely unworthy of notice by any serious scientific man, because it is made up of oldfashioned views which have been brought before the notice 
of the public for half a century by the French school, and are supported only by antiquated assertions, and by no means by facts scientifically ascertained. It must be owing to some particular circumstance that this work has been so much noticed, because really it is not worthy of critical examination by a serious scientific man.

This criticism of The Vestiges is in the main correct and well deserved; yet I suspect that Youmans already felt that somewhere in all that heap of chaff there was a sound and sturdy kernel of truth. Sir Charles Lyell had in I830 shown how enormous geologic effects are wrought by the cumulative action of slight and unobtrusive causes; and this, which had so much to do with turning men's minds toward some conception of evolution, was not without its effect upon Youmans. Full illustrated reports of Agassiz's lectures were published in the Tribune, and were read and re-read to him and carefully pondered; and from this time the tendency of his thinking was more and more toward the development theory.*

The project for a history of progress in discovery and invention had been suggested by the dates in Goureaud's mnemotechnical system. Eschewing the deeds of popes, kings, and emperors, the dates of sieges, battles, and massacres, Youmans was intent on weaving into a connected story the triumphs of observers, explorers, experimenters, and philosophers. At once brother and sister began the work of gather-

* In this connection I can not refrain from adding that in my own case the immediate cause which drove me to the development theory was the mental reaction experienced in reading Agassiz's arguments against that theory in his Essay on Classification, in I 859, shortly before Darwin's book was published. 
ing and arranging materials. Every day they paid long visits to the public libraries to consult authoritics and make extracts. In those days New York was no larger than Buffalo is now, and its public libraries were near together. The Mercantile Library was on Nassau Street, the Library of the American Institute on Chambers Street, the Society Library on the corner of Broadway and Franklin Street. Sometimes the needed book was not to be found in any of these places, and recourse would be had to the book-stores. Sometimes those who had books to sell were unwilling to lend them, even in a good cause; but this was not always the case. One morning, on their round of calls, Miss Youmans led her brother into D. Appleton \& Co.'s store, then on Broadway below the City Hall, in quest of a volume. Mr. William H. Appleton at once offered him the loan of it, and of any other book he might want. He frequently availed himself of the privilege so kindly extended, with welcome saving to his slender purse. That chance visit, as we shall see, was a capital incident in Youmans's life, and the Appletons now look back upon it as one of the most auspicious events in the annals of their firm.

After several months of hard work, when the history was well on its way to completion, Youmans learned to his deep chagrin that Mr. George Putnam, the publisher, had just brought out a similar bookThe World's Progress. After recovering from this bitter disappointment, he resumed his usual round of literary work and scientific study. Somewhat more than two years ran uneventfully on. Then, at the close of 1849 , a combination of untoward circumstances plunged him into the deepest despondency of his life. His relapses into total blindness became 
longer, without apparent cause either in exposure or in lack of medical care. Events at home were such as to make a man of his strong family affections most anxious. His father had suffered serious loss by fire, and three of his brothers had gone to the far West, seeking opportunities denied them in rural New York. To his young imagination the remote and untried West had perhaps more of evil than good in it for such adventurous spirits as might brave its perils. Troubled and perplexed, what wonder that the blind man's courage should for a moment desert him?

"I must give up this struggle; it's no use going on in this way ; my case is hopeless," he would say, bidding his sister return home and leave him to his fate. For days and weeks his despair continued, and he would make no effort to go on with work of any kind.*

* When it is remembered that before he had been with Dr. Elliott a year he had advanced as far toward recovery as ever he had done in the ten years following, it does not seem strange that he should at last lose heart. Long before this time many of his friends had become quite hopeless of his recovery, and even his mother, one of the last to give up the case, at length undertook to reconcile him to a life of blindness. "Nothing can be worse," she would say to him, "than these endless alternations of hope and despair. If, in all the fifteen years you have been struggling with disease, the only gain has been brief intervals of partial seeing-intervals that continually become rarer and shorter, while the subsequent lapse into blindness grows harder and harder to bear-how much happier you would be to give it up and adapt yourself to the circumstances." She instanced blind men who were leading happy, useful lives, and assured her son that he could always depend upon the affection and devotion of his family and friends.

In after years, when the subject was referred to, he always said that he never quite ceased to expect recovery. But there were periods when it seemed to his friends that he had lost all hope. At these times he shunned society, even that of his nearest companions. He would sometimes lock the door of his chamber and remain for hours, and even days, in solitude. It seemed as if he shrank even from sympathy. Worry always 
At last a reaction came, and he slowly lifted himsclf out of the slough of despond. To this one or two favouring circumstances contributed. His sister secured what for those times was a well-paid engagement as teacher, with quite enough incidental leisure to act as his amanuensis and reader. His brother Earle sent good news of his prosperity in California, and as an earnest thereof inclosed a generous remittance. Dr. Elliott, who had never wavered in his sincere assurances that his patient would ultimately recover, offered him a lodging at his office, where he could practice sundry economies. The office contained chemical apparatus available for Miss Youmans's experiments. In the district school at Milton, three years before, she had gained a slight experience in chemical work, using the water pail as a trough, and collecting gases in bottles, but she had little knowledge and less skill in handling apparatus. Her brother had long wished that her chemical education should proceed further, but where was the opportunity? lt came at last through Dr. Antisell, an Irish refugee of '48, who had come to New York and established a laboratory as a teacher of chemistry at the corner of Elm and Grand Streets. He had enough of the spirit of revolution and reform to open the first laboratory in the city that admitted women. Every Saturday Miss Youmans spent several hours at work under the doctor's eye. In the evening she described and ex-

made his eyes worse. When at last he did in a measure recover sight, the medical treatment was just the same that it had been from the first. The exhilaration attendant upon the success of his literary work was the beginning of the amendment. He believed, and the doctor was sure, that the same might have happened years before if an evil fate had not waited upon his first efforts at self-support, 
plained to her brother what she had been doing. These studies were intended to be preliminary to the analysis of soils, but by the time she was able to make such analysis Mr. Youmans had become convinced that they were of no value in practical agriculture. In the course of his pondering over chemical facts which he was obliged to take at second hand, it occurred to him that most of the pupils in common schools who studied chemistry were practically no better off. It was easy enough for schools to buy text-books, but difficult for them to provide laboratories and apparatus; and it was much easier withal to find teachers who could ask questions out of a book than those who could use apparatus if provided. It was customary, therefore, to learn chemistry by rote; or, in other words, pupils' heads were crammed with unintelligible statements about things with queer names-such as manganese or tellurium-which they had never seen, and would not know if they were to see them. It occurred to Youmans that, if visible processes could not be brought before pupils, at any rate the fundamental conceptions of chemistry might be made clear by means of diagrams. He began devising diagrams in different colours, to illustrate the diversity in the atomic weights of the principal elements, and the composition of the more familiar compounds. At length, by uniting his diagrams, he obtained a comprehensive coloured chart exhibiting the outlines of the whole scheme of chemical combination according to the binary or dualist theory then in vogue.

These diagrams elicited much interest among his friends. One of them (Mr. J. R. Burdsall) was a druggist and dealer in patent medicines, whose advertise- 
ments Youmans had often written for a liberal honorarium. When the diagrams had been united in a chart Mr. Burdsall became enthusiastic. He declared that it made clear to his mind chemical facts and laws which he had never before understood. It was certain, he said, that a chart so instructive to him would be equally so to others, and that it would have a large sale if published. He urged Youmans to seek a publisher at once, and offered him five hundred dollars for an interest of one fifth in the enterprise. The advice and offer were promptly accepted, and the cash was applied in getting the chart engraved. Before the engraving was finished the chart was put on exhibition at the American Institute Fair, then held in Castle Garden. Its author prepared a brief primer of explanation and tied it to the chart roller, placing his exhibit on a halfway landing of one of the main staircases. This chart, when published, was a great success. It not only facilitated the acquirement of clear conceptions, but it was suggestive of new ideas. It proved very popular, and kept the field until the binary theory was overthrown by the modern doctrine of substitution, which does not lend itself so readily to graphic treatment.

The success of the chemical chart led to the writing of a text-book of chemistry. Friends urged that such a book was needed to accompany the chart, and letters began to come in from different parts of the country with a similar request. The idea took root in Youmans's mind, but, as usual, he had more than one task in hand. He devoted part of every day to writing a text-book of arithmetic, wherein the examples were to introduce the constants of science instead of the usual commercial terms. When his work was 
nearly ready for the press he learned, from a review in one of the morning papers, that Horace Mann had just published an arithmetic on precisely the same plan. His disappointment at being thus a second time forestalled was very keen. But there was much consolation in the remarkable popularity of the chemical chart, and he made up his mind to write the desired chemical text-book. He attended Dr. J. W. Draper's lectures on chemistry and physiology, and always cordially acknowledged his indebtedness, for method as well as for facts, to that eminent teacher. Of reference books he gathered all that he could find that were of real authority. These, after they had been read to him, he would ponder over and digest for hours together. At length, filled with his subject, he began to dictate his book.

Miss Ketcham, at this time, chiefly at his instance, had taken a large five-story boarding-house at 49 Cliff Street. Here, on the fourth floor, he occupied a back bedroom, about eight feet by twelve. Opposite the door was a large west window, and under this was a hinged shelf, which could be let down when not in use. Little space was left for moving about, although bedstead, washstand, bureau, and chairs were of the severely simple type of furniture. During working hours books of reference and manuscript covered every inch of shelf and bed. At night all had to be neatly gathered up and put away. Practice had made our author, naturally a tidy man, very expert in stowage and in finding things exactly where he had placed them.

His idea of the kind of book he wished to write was distinct; he felt an enthusiasm for natural knowledge, and meant to arouse that enthusiasm in others. 
With a vivid recollection of his Milton school, he desired to make a book acceptable to just such boy's and girls as had in years gone by sat on benches at his side. They and thousands like them-farmers' sons and daughters-were surrounded every day of their lives by chemical phenomena which would interest them deeply if understood. Current text-books were, he knew, unfit for their purpose ; they were dry, technical, destitute of sympathy with young minds, and oblivious of their ways of looking at things. As a rule their authors made a perfunctory circuit of all the sciences, and turned out a series of class books in the true style of a mechanic of the pen-work little better than cataloguing or almanac-making. Youmans felt that chemistry ought to be made as popular as physics, or natural philosophy, as it was then called; for this he found his chart prepared the way by its easily understood pictures. His plan of work was, first of all to make himself familiar with what each authority had written upon the topic in hand. He would then slowly elaborate such a statement as he thought best suited to his purpose. The chemical elements were described briefly and plainly, omitting the tedious accounts of apparatus and complex reactions which filled the current books. Instead of these bare details, every fact was presented in its relation to law, every step in the progress of his chapters was systematically linked to the next. Chemistry had not then acquired its present wealth and diversity of specialization. In a volume of three hundred and forty pages he was able not only to give the substance of the current inorganic chemistry, but to include chapters which summarized the chemistry of plant and animal life. In carrying out his method of approach- 
ing the unfamiliar through the familiar, he drew his illustrations from everyday toil and common processes-from farming, cooking, washing, the manufacture of sugar, starch, vinegar, and soap. He sought to open the eyes of young people to the scientific significance of surroundings usually too near to be noticed; he wished to awaken their interest in nature, that they might not only learn how to economize drudgery, but also get more wholesome enjoyment out of life.

In composition Youmans's methods were laborious. He never had so fault-finding a critic as himself. Revision followed revision, and emendations and corrections covered every page of his copy. When at length several chapters were finished they were sent to the Appletons for the judgment of their "reader," Mr. E. P. Tenney, and the decision was awaited with much anxiety. It was very favourable.

These pages give promise of an excellent work on chemistry. The author evidently understands the science, and possesses a clear, logical mind. His manner of presenting the various subjects is quite full, and his thoughts are practical and such as can not fail to make a striking impression on the youthful mind. The "atomic theory" and the subject of chemical combination are not more clearly handled in the works of either Silliman, father or son. More attention should be paid to punctuation.

Thus encouraged, the young author went on and finished his book in high spirits. His introduction, as in all his books, was written with especial care, for he understood the importance of making a favourable impression at the start. If we consider the date when this first edition of the Chemistry was written, and the 


\section{The Class-Book of Chemistry.}

author's experience up to that time, the following passage from the introduction is very interesting:

Among the various occupations which require a knowledge of chemistry to be successfully carried on, that most noble, useful, and universal of all human pursuits, agriculture, stands prominent. The farm is a great laboratory, and all those changes in matter which it is the farmer's chief business to produce are of a chemical nature. He breaks up and pulverizes his soil with plough, harrow, and hoe for the same reason that the practical chemist powders his minerals with pestle and mortar-namely, to expose the materials more perfectly to the action of chemical agents. The field can only be looked upon as a chemical manufactory; the air, soil, and manures are the farmer's raw materials, and the various forms of vegetation are the products of his manufacture. The farmer who raises a bushel of wheat or a hundredweight of flax does not fabricate them out of nothing; he performs no miraculous work of creation, but it is by taking up a certain definite portion of his raw material and converting it into new substances through the action of natural agents; just as those substances are again manufactured in the one case into bread and in the other into cloth. When a crop is removed from the field certain substances are taken away from the ground which differ with different kinds of plants; and if the farmer would know exactly what and how much his field loses by each harvest, and how in the cheapest manner that loss may be restored, chemistry alone is capable of giving him the desired information. To determine the nature and properties of his soil, and its adaptation to various plants, and the best methods of improving it; to economize his natural resources of fertility; to test the purity and value of commercial manures and of beds of marl and muck; to mingle composts and adapt them to special crops; to improve the quality of grains and fruits; to rear and feed 
stock and conduct the dairy in the best manner-farmers require a knowledge of this science. Nor can they as a class afford to be much longer without it; for it has always been found that the application of scientific principles to any branch of industry puts power into the hands of the intelligent to drive ignorance from the field of competition; so that, as discoveries multiply and information is diffused, those farmers who decline to inquire into the principles which govern their vocation, or who prefer the study of politics to that of agriculture, will have occasion to groan more deeply than ever over the unprofitableness of their business.

'The superiority of natural sciences over all other objects of study, to engage the attention and awaken the interest of pupils, is conceded as a fact of experience by the ablest teachers. This can not be otherwise; for the infinite wisdom of the Creator is nowhere so perfectly displayed as in the wonderful adaptation which exists between the young mind and the natural world with which it is encompassed. On one hand, there is the realm of Nature, endless in the variety of its objects, indescribable in its beauty, immutable in its order, boundless in its beneficence, and ever admirable in the simplicity and harmony of its laws; on the other, there is the young intellect, whose earliest trait is curiosity, which asks numberless questions, pries into the reasons of things, and seeks to find out their causes as if by the spontaneous promptings of instinct. The study of Nature is, therefore, the most congenial employment of the opening mind, and one of its purest sources of pleasure. Every fact that is learned becomes a key to others; every progressive step discloses wonders previously unimagined.

When the introduction was finished, in the autumn of $185 \mathrm{I}$, the manuscript was at once placed in the hands of D. Appleton \& Co. for publication. The 
author's brave and patient toil was at length to be rewarded. The book had an immediate and signal success; and to this day, having been twice rewritten in conformity to the advancement of the science, it remains one of our best text-books of chemistry. The sale has reached one hundred and fifty thousand copies. In every State of the Union teachers and pupils welcomed the book. The subject was presented with beautiful clearness, in a most attractive style. There was a firm grasp of the philosophical principles underlying chemical phenomena, and the meaning and functions of the science were set forth in such a way as to charm the student and make him wish for more. At that time a spark of enthusiasm was no more expected in a text-book of chemistry than in a treatise on contingent remainders. But in Youmans's pages the chemical elements were alive. To him oxygen was not merely an element of certain specified weight and affinities; it was alternately the sustainer and destroyer of life, the master builder of organic form and the chief agent of its decay, the purifier of air and sea.

The Class-book of Chemistry was Youmans's germinal book; all his subsequent work was foreshadowed in it-his Correlation, Household Science, Culture, and his articles innumerable. Its reception showed him his strength and his true field. Thenceforth his career was that of breaking the bread of science to the multitude.

The present chapter and its predecessor have their lesson, full of consolation and encouragement as of pathos. When the Chemistry was finished, in the autumn of $185 \mathrm{I}$, its author had been for eleven years under the care of an oculist. Under such circum. 
stances, if a man of eager energy and boundless intellectual craving were to be overwhelmed with despondency, we could not call it strange. If he were to become dependent upon friends for the means of support, it would be ungracious, if not unjust, to blame him. But Edward Youmans was not made of the stuff that acquiesces in defeat. He rose superior to calamity; he won the means of livelihood, and in darkness entered upon the path to an enviable fame; or, as he would doubtless prefer to have it said, he made for himself an opportunity to be helpful to his fellowmen. 


\section{CHAP'TER V.}

THE SCIENTIFIC LECTURER.

$$
\text { I85I-I868. Age, 30-77. }
$$

THE success of the Chemistry was supplemented by increased demand for the chart which illustrated it. Brightened fortunes told favourably and at once on the health and spirits of our author. He had justified his friends' faith that there was "something in him." He had proved that he had more than an empty ambition to bring a knowledge of science to the people. Mind and body soon told the story of cares banished and a fight well won. The long, distressing period of darkness now came to an end. Sight was so far recovered in one eye that it became possible to go about freely, to read, to recognize friends, to travel, and make much of life. I am told that his face had acquired an expression characteristic of the blind, but that expression was afterward completely lost. When I knew him it would never have occurred to me that his sight was imperfect, except as regards length of range. There could be no doubt on that point. He never could recognize any but his most familiar friends at a distance of more than a couple of yards, and this fact was apt to give him a slight air of timidity and reserve, which instantly vanished, however, as soon as he knew to whom he was speaking. When sight was first recovered, it must be confessed that he ran scri- 
ous risks by overtasking the eye, and in after years he was known to repeat this imprudence, but he never again had to put himself urider an oculist's care. When his malady threatened to recur he knew how to arrest its progress, and with firmer general health he became much less liable to attack.

Mr. Youmans's career as a scientific lecturer now began. His first lecture was the beginning of a series on the relations of organic life to the atmosphere. It was illustrated with chemical apparatus, and was given in Dr. Elliott's commodious office to an audience which filled the room, including a number of young ladies from fashionable uptown schools. Probably no lecturer ever faced his first audience without some trepidation, and Youmans had not the mainstay and refuge afforded by a manuscript, for his sight was never good enough to make such an aid available for his lectures. At first the right words were slow in finding their way to those ready lips, and his friends were beginning to grow anxious, when all at once a happy accident broke the spell. He was remarking upon the characteristic instability of nitrogen, and pointing to a jar of that gas on the table before him, when some fidgety movement of his knocked the jar off the table. He improved the occasion with one of his quaint bons mots; and, as there is nothing that greases the wheels of life like a laugh, the lecture went on to a successful close. At the end of the series a general wish was expressed that the lectures should be repeated in a larger audience-room. Among his first topics were the chemistry of organized bodies, of vegetable growth, of food and digestion. He subsequently discussed the sources and nature of alcohol, and its effect on the human system. Then came a series on 
the sunbeam, explaining the varied influences of the solar ray, with an analysis of its forces; the relation of the sun to life on our planet; the chemistry of the sun and the stars; the links uniting the realms of matter and mind. In two lectures on Ancient Philosophy and Modern Science he set forth the debt due by chemist and astronomer to alchemist and astrologer; and here he took occasion to point out how the guesses of Democritus and Lucretius had been barren, notwithstanding their shrewdness, from their not having married experiment to speculation. In his Masquerade of the Elements he presented in glowing outline the phenomena of protean chemical transformation. His New Philosophy of Forces was the first popular exposition of the correlation of forces given in America. In every discourse it was his custom to give ample graphic and experimental illustration; the seen proof riveted the spoken thought. His lectures, moreover, had in them the salt of persuasion; the interest he enjoyed he was anxious others should share. He was a sower desirous that a harvest should spring up so abundant as to make his handfuls of seed corn seem paltry enough. Sympathy, not less than enthusiasm for science, made him one of the most impressive lecturers of his time. One other characteristic never failed to broaden every discourse he delivereda philosophic spirit which passẹd from detail to generalization, from a fact to the law of universal sweep whose manifestation and proof it was. To his mind a part always suggested the whole; he never looked through a window of science so small that it did not show the sky. When he came to the outlook from a new and lofty standpoint his delight would burst forth in poetic fervour. 
The lectures in Dr. Elliott's office were the beginning of a busy career of seventeen years of lecturing, ending in I868; and I believe it is safe to say that few things were done in all those years of more vital and lasting benefit to the American people than this broadcast sowing of the seeds of scientific thought in the lectures of Edward Youmans. They came just at the time when the world was ripe for the doctrine of evolution, when all the wondrous significance of the trend of scientific discovery since Newton's time was beginning to burst upon men's minds. The work of Lyell in geology, followed at length in 1859 by the Darwinian theory; the doctrine of the correlation of forces and the consequent unity of nature; the extension and reformation of chemical theory; the simultaneous advance made in sociological inquiry, and in the conception of the true aims and proper methods of education -all this made the period a most fruitful one for the peculiar work of such a teacher as Youmans.

In his early manhood there was in the community a very inadequate appreciation of natural law. An indolent reverence contented itself with a theological cosmogony little modified by the results of observation and experiment. Physical science had been like an archipelago, with each island distinct and separate from its neighbours. Even while he looked they rose, and the retiring waters showed a continent soon to be parcelled out among sturdy bands of explorers. That the wave circling out from the paddle, the musical note pulsating the air, the throb of electricity, the pull of magnetism, the vibrations of heat and light shot forth from fuel, sun, and star, were in all their diversity fundamentally one, was a conception to fascinate such a mind as his and give charm to his discourses. 
The newness and freshness of a great truth add much to the effect of its intrinsic importance. Fortunate are the men who live in times when ideas of the first magnitude mount above the horizon; who are young enough to be adequately impressed by them, suffi. ciently mature to see their significance and think out their implications.

Such an idea of the first magnitude was the doctrine of evolution, the grandest thought of science. By showing Nature to be a family it gave to classification genetic relationship as its true basis. To education it indicated a new way and the best. It made it possible to write Nature's history backward to the primitive chaos-as wonderful in all its dormant possibilities as the cosmos it contained. It made the universe one in a new sense, for it bound together, in a single web of causation worlds, continents, life, mind. To have lived when this prodigious truth was advanced, debated, established, was a privilese rare in the centuries. The inspiration of seeing the old isolating mists dissolve and reveal the convergence of all branches of knowledge is something that can hardly be known to the men of a later generation, inheritors of what this age has won.

During the course of Youmans's career as a lecturer the atmosphere became charged with conceptions of evolution. Youmans had arrived at such conceptions in the course of his study of the separate lines of scientific speculation which were now about to be summed up and organized by Herbert Spencer. In the field of scientific generalization upon this great scale Youmans was not an originator, but his broadly sympathetic and luminous mind moved on a plane so near to that of the originators that he seized at once 
upon the grand scheme of thought as it was developed, made it his own, and brought to its interpretation and diffusion such a happy combination of qualities as one seldom meets with. The ordinary popularizer of great and novel truths is a man who comprehends them but partially and illustrates them in a lame and fragmentary way. But it was the peculiarity of Youmans that, while on the one hand he could grasp the newest scientific thought so surely and firmly that he seemed to have entered into the innermost mind of its author, on the other hand he could speak to the general public in a convincing and stimulating way that had no parallel. This was the secret of his power, and there can be no question that his influence in educating the American people to receive the doctrine of evolution was great and widespread.

The years when Youmans was travelling and lecturing were the years when the old lyceum system of popular lectures was still in its vigour. The kind of life led by the energetic lecturer in those days was not that of a sybarite, as may be seen from a passage in one of his letters: "I lectured in Sandusky, and had to get up at five o'clock to reach Elyria; I had had but very little sleep. To get from Elyria to Pittsburg I must take the five o'clock morning train, and the hotel darky said he would try to awaken me. I knew what that meant, and so did not get a single wink of sleep that night. Rode all day to Pittsburg, and had to lecture in the great Academy of Music over footlights. ... The train that left for Zanesville departed at two in the morning. I had been assured a hundred times (for I asked everybody I met) that I would get a sleeping car to Zanesville, and when I was all ready to start I was informed that this morn- 
ing there was no sleeping car. By the time I reached here I was pretty completely used up."

Such a fatiguing life, however, has its compensations. It brings the lecturer into friendly contact with the brightest minds among his fellow-countrymen in many places, and enlarges his sphere of influence in a way that is not easy to estimate. Clearly, an earnest lecturer, of commanding intelligence and charming manner, with a great subject to teach, must have an opportunity for sowing seeds that will presently ripen in a change of opinion or sentiment, in an altered way of looking at things on the part of whole communities. No lecturer has ever had a better opportunity of this sort than Edward Youmans, and none ever made a better use of his opportunity. His gifts as a talker were of the highest order. The commonest and plainest story, as told by Edward Youmans, had all the breathless interest of the most thrilling romance. Absolutely unconscious of himself, simple, straightforward, and vehement, wrapped up in his subject, the very embodiment of faith and enthusiasm, of heartiness and good cheer, it was delightful to hear him. And when we join with all this his unfailing common sense, his broad and kindly view of men and things, and the delicious humour that kept flashing out in quaint, pithy phrases such as no other man would have thought of, and such as are the despair of any one trying to remember and quote them, we can seem to imagine what a power he must have been with his lectures.

When such a man goes about for seventeen years, teaching scientific truths for which the world is ripe, we may be sure that his work is great, albeit we have no standard whereby we can exactly measure it. In 
hundreds of little towns with queer names did this strong personality appear and make its way and leave its effects in the shape of new thoughts, new questions, and enlarged hospitality of mind, among the inhabitants. The results of all this are surely visible to-day. In no part of the English world has Herbert Spencer's philosophy met with such a general and cordial reception as in the United States. This may no doubt be largely explained by a reference to general causes; but as it is almost always necessary, along with our general causes, to take into the account some personal influence, so it is in this case. It is safe to say that among the agencies which during the past fifty years have so remarkably broadened the mind of the American people, very few have been more potent than the gentle and subtle but pervasive work done by Edward Youmans with his lectures, and to this has been largely due the hospitable reception of Herbert Spencer's ideas.

Nany a young man in many a town could trace to Youmans and his lectures the first impulse that led him to seek and obtain a university education. In quarters innumerable his advice gave direction to family reading in the best treatises on astronomy, physics, chemistry, geology, and physiology. Nothing in all his experience pleased him more than the genuine interest in science which he used to find in the smallest and unlikeliest places. After a lecture it was always his habit in free and easy talk to draw out the opinion of his hearers, and thus he often got useful hints. It helped him in learning what modes of presentation were most effective, and at what points of the borderland between the known and the unknown his audiences could most readily follow him. He also 
learned how often the stupidity of the average mind will misapprehend and pervert the clearest statements.

His lectures were never committed to memory, but each time delivered with such variation of argument and illustration as to bring to the second or third delivery in a city many of the auditors present at the first. Of his absorption in his subject when he had fairly warmed to his work some amusing stories are told. At Faribault, Minnesota, one evening, such was the amplitude of his excited gyrations that they $\mathrm{ex}$ ceeded the rather narrow bounds of the platform. Twice he slipped off to the floor. Fortunately the platform was a low one, and after each fall he resumed the thread of his exposition without the slightest discomposure. On another occasion, in Brooklyn, his emphasis came out in gesticulation so fierce as almost to bring a heavy screen down on his head. To the relief of his audience, and especially of his committee, the screen stood proof against his thumping.

Miss Youmans tells me that Edward's loud voice and emphatic manner were family traits. When any topic of moment came up in the family circle a stranger might have supposed the talkers were quarrelling, so vehement were their tones. Edward's most conspicuous quality was the amount and intensity of energy displayed in speech and action on all occasions. It should be added, at the same time, that a man of more perfect refinement never lived. WV are apt to associate loud tones with a certain kind of roughness; sometimes, too, with brusqueness. About Youmans there was not the faintest trace of anything of the sort. The combination of explosive animal spirits and intense eagerness with perfect grace and gentleness was such as I have never witnessed in any other man. 
Words cannot describe it. In all that emphasis of tone and gesture there was nothing harsh. The effect was magnetic. I never heard him give a lecture, but I have often been told that his audiences sat as if spellbound, and could not turn their eyes from him while he was speaking. He must have made a fine appearance on the platform, for he did everywhere. He was about five feet and ten inches in height, and in middle life weighed not far from one hundred and ninety pounds. He was well proportioned, and easy in his movements; a man of fine fibre, with clear complexion and soft brown hair, somewhat curly; always plainly dressed, but with daintiest neatness. Quite compatible with perfect manly dignity, and adding to its charm, was a slight touch of modest deference, the natural outgrowth of unselfish interest in his fellow-men and constant readiness to learn something from the person with whom he was talking. In this particular there was something about his manner that used to remind me of $\mathrm{Mr}$. Darwin.

Prosecuted, as these lecture tours were, chiefly in winter, through circuits of thousands of miles, when trains were as yet uncomfortable and slow and their connections uncertain, it was often impossible for the lecturer to avoid exposure that injured his health. Sometimes his vigour was seriously impaired, and the effects could be seen in the lessened animation of his lectures. At last, warned by attacks of rheumatism and increased liability to catch cold, he withdrew from the field where he had been so useful, from the work he had so thoroughly enjoyed.

The following characteristic extracts from his correspondence may serve to illustrate some of the mis- 
haps of a lecturer, and his inevitable ups and downs of fortune and of spirits :

Great Western Railway, CaNain, H'clnesday, Novemlier 30,1850 .

DeAR Sister: "The Lord reigneth, let the earth rejoice." I have great satisfaction in the sentiment, and return thanks. It is so agreeable to think that the devil is superfluous and impotent, and has nothing to do but "loaf and invite his soul," and have a good time generally down below. . . I I discover that I lost my ring. It may be somewhere in the room "knockin' round," and may turn up, unless it came off while washing and went down the pipe, or slipped into the crevice when I lay down upon the sofa or on the bed; but I do not understand, for I did not sleep a wink all night. I don't see how it could have got off without my knowing it. However, it's all right. The auriferous particles are not abolished; matter is never annihilated -it changes place, as the ring illustrates, but the totality is ever undisturbed. What vicissitudes may befall the plain little annulus are beyond the reach of rational speculation; but the Lord has it in his keeping. Let the earth rejoice, and the solitudes of the isle, etc.

Editor Thomas, who professes to reign righteously in the little world of Appletons' Guide, said, "Go by Erie Railroad." I trusted also to Lord Thomas-with the usual result. It is the worst route-miserable; failed to make its connections yesterday. I am consequently behind time, and shall not arrive at Detroit till ten o'clock to-night_-an hour after my audience have dispersed. The Lord reigneth, let the people of Detroit rejoice. It was philosophical fate. If I had taken another line along the planet it would have altered the centre of gravity of the physical universe. If I had stopped at the Hudson River Railroad depot, which I scornfully passed by, I should have arrived in ample time, lectured, and thus altered the centre of gravity of the intel- 
lectual universe. I am so glad to contribute sometining to the harmony of the universe!... We stopped an hour since with the alarm that the baggage car was on fire. Horrifying intelligence for the haves; indifferent, though a little exciting, for the have nots. Let us see: one bag is with me here. The diagrams, too, stick closer than a brother-either of my brothers, at any rate. They are safe, thank the Lord! The large bag with the books, clothing, etc., is in the travelling refrigerator of Shadrach, Mand $\mathrm{A} \longrightarrow$. Let us proceed to ascertain if our bag has had the same experiences as those incombustible old Jews who could have snapped their fingers in the face of all insurance companies in the world. Piles of wet and damaged goods upon the platform, scattered around. Let us see. Books. The late lamented Nicoll, now doubly lamented-an illustrated edition of igneous and aqueous agencies. The illustrated Correlation of Forces-succumbed at last to its own convertibility. Bain in a decidedly baneful way. Carpet bag (except the faithful handles) reverted to the inorganic state-just saves the equilibrium of the organic world. I pray that the Lord will continue to shower down his richest golden blessings with increasing profusion while I am "in." More anon. With much affection, E. L. Y.

The following letters and extracts will have a further interest :

JACKson, Mich., December 7, 1859 .

DeAR Sister: It is painful to be separated from you all, but fifty dollars per night, with the cash in the morning, is so compensating and so mitigating and so assuaging and mollifying and healing! They have just this moment paid me for last night's work. My lecture at Ann Arbor was most satisfactory, and gave general pleasure, although the recollection of the Sunbeam is too recent and the treatment of that topic was too peculiar to permit the advan- 
tageous exhibition of the new subject. But in Jackson it is different. I had never been here before-all strangers. I had the best light yet, and the affair went off satisfactorily. I spoke in the Presbyterian church. The clergyman said it was by far the ablest and most masterly lecture to which he had ever listened, and expressed great wonder at the possibility of cramming so much clear thought into a single performance. The practical, testing effect was that the committee desired to engage me in February for the four on the Chemistry of the Sunbeam, at two hundred dollars. I declined to engage positively. . . . I am stopping with the pleasantest private family in the world. Good folks are everywhere.

Make rough, large skeleton drawings of your own of the brain, its parts and dynamic connections, so as to help me when I return. Can't you draw a rough colossal spinal column, with the thirty-one pairs starting out-two colours, and the entrances sufficiently far apart so that you could print appended to each nerve the part to which it goes, so that the whole could be learned in the quickest way and without reference to text, which loses time? Our studies should be, first, the fullest normal anatomy and physiology of the nervous system; then we shall be prepared to consider fully its pathology and all its morbid phenomena. And then we shall first be prepared to estimate, weigh, and pronounce authoritatively upon the whole domain of mysticism, upon which the public are actually mad, viz., biology, magnetism, spiritism, etc. A large and rich field; and as an offshoot of the first branch of inquiry the Chemistry of the Sunbeam is a mere twig. I write in great haste. Don't forget to drop me a line frequently if you have but a word, and I will do the same.

With love to all, affectionately,

E. L. Y. 
Kalamazoo, Mich., December 11,1859 .

DeAR SIster: I arrived here last night, and found your .letter of Monday, the 5 th. I am in sad plight, and shall write a savage letter. Another fool is in charge of lecturing affairs in Chicago, and I am completely upset by it. Milwaukee fizzles_can't get a hall, and of all the places I have written to I have heard only from Milwaukee and eternal Aurora, who demands the Chemistry of the Sunbeam in one lecture at forty dollars, with the written specification that I shall pay all my own expenses. And so I have now two engagements to play-here to-morrow evening, and at Chicago on Thursday evening-and then I am out for the month, except such chance events as may happen to fall out. I am wanted to lecture in all directions, but there is no chance to arrange, and so I will let it slide. The only difficulty is this-and here I stopped and took up Bain-the charred remains of poor Bain, full of interest. I have been trying to get out of this Western world into Plato's world of pure thought. It has helped. . . . My Ancient Philosophy here last night was perfectly splendid. A fine room, a fine house of intelligent, sympathizing people; the thing went off admirably. I am beyond doubt a better, a rather better speaker than last year. I have profited somewhat; gestures are certainly better, although, Heaven be my witness, they are bad enough yet. . . . Our old landlord is the very lord of that kind of lords. I'd sell out my stock in the universe for one twentieth of his suavity. What wonders I might do then! Oily Gammon was a polar bear beside him. As I descended from the omnibus, tied to that immortal trail of baggage, half a dozen nigs seized upon the plunder, and old Chesterfield took one of my hands, and, passing his other arm so gracefully, so gently, so lovingly around my waist, led, conducted, escorted-took me into his castle, the Burdick House. You remember Burdick! I think I'll lie down. 
Well, I have had a nap and a dream-a smash-up on the railroad; fourteen killed, several wounded. I tried to get admission to the place where the surgeons were operating. Dr. Blake would not admit me. I persisted, and was at length graciously permitted to enter the hospital room after the operating was all done. The first object or "case" I saw was the upper end of a negro, like a blackened bust of Webster standing on a barrel. He was not dead, for he had a pipe in his mouth, which he kept steady with one hand. He was puffing away most leisurely, and seemed entirely happified. How do you think his other hand was occupied? Why, his heart had been taken out by the accident, and the surgeons had replaced it by a pair of small wooden boxes containing valves and pistons, which the acardiac wretch was working alternately and most satisfactorily. Whatever may be said of innate ideas or the creative power of mind, the probability is that I could never have dreamed this dream until after Harvey and the railroad system.

I approach the end of my sheet, but to what purpose have I scribbled? I have had nothing to say, and have stuck to the formula. The Sunday is superb. I stay within, and am blessedly let alone. Do you know, I have a strange sort of feeling concerning this thing of whereabouts. I have never before been so satisfied with drifting, and I have a kind of vague dread of coming back to New York. I have never before been in this sort of mood of mind. I tolerate, I almost enjoy, I almost solicit absence. I have been solidly busy; that may perhaps partially account for it. What mood the coming fortnight will induce remains for determination. You say you don't know if you are managing just right. It makes no difference. Only sleep it out; all the time you spend in sleep is clear gain. If there is any surplus life, draw it off in the direction of letters-sent to Chicago the rest of the time, I guess. Your brother, loving and discouraged,

E. L. Y. 
Eleven at night-I have had a blessed, refreshing season this evening with the first part of Bain, where he opens the nervous system. There is no subject like it in all the world under the sun. Let us rip it up from the bottom. You can't learn too much about it, nor think too much about it. Every step of simplification gained in this region is a mighty stride in a grand direction. So, press on gently with the brain and nervous system...

My position is secured. If health lasts, it only remains now to reap. It is well worth while to battle this thing out. Every little point gained has a great value. I am out of the horrible pit and miry clay of my to-day's letter. Give yourself no trouble; I am not to be unhorsed nou', you understand.

Truly,

E. L. Y.

DeAR Sister:

Lafayette, Ind., December 21,1859 .

I have had a lesson.

"Only one?" you say.

Yes, I have had many,

But the last to-day,

From that costly teacher

Whom we all employ,

In that thorough manner

Which we don't enjoy.

But I can't get on in this way-it's too slow-and so I must dismount from Pegasus and take Foot-Walker line. I have further to report of the Lord's dealings (read the inclosed long extract). Lafayette turns out an audience of a thousand. Think of the Masquerade after the publication of that passage! Wasn't that a fix? But I have been providentially saved from mortification. Yesterday morning, while in the cars, He who watches the ground birds and counts hairs sent a cinder out of the popgun of fate and struck the bird's eye in the white-the left one. It was a 
dead shot. Then my eye swelled and inflamed furiously, and when I arrived here I was done for-helpless. The committee crowded round, condoling, consoling, disappointed, etc. Some one was aware of the state of my eyes heretofore, and enlightened them on the subject. I thought I should have to leave at once for home. After getting all ready to go-packing baggage done, bill paid, waiting for the stage-the lamentations of the committee were so vehement, their protestations of regret at not hearing me so vociferous, that I said: "Gentlemen, if you want to hear me lecture, you can do it. I'll go in blindfold rather than you should suffer. If you say another word, I'll take the risk myself and lecture to-night." "Oh, it's too late now," said they, referring to the evening paper containing extract No. 2, which I inclose. "Very well," said I, "to-morrow night, then." "Agreed," said they. I started out for laudanum, concentrated ammonia, and pills; put myself through, and am round straight again to-day. But this (bless the I.ord!) affords excuse for not reading the Masquerade.* I am going to give them the Sunbeam to-night and to-morrow night. I am now trying to fix up the other places by telegraph where I am unhinged. It will probably bring me home not till the 3 rst-Saturday night. If 1 can get to Schenectady Friday morning I will run up for the day. And now, from the receipt of this till I come home you won't have much to do. They want to see you at Saratoga. Suppose you slip up till the 3 Ist-next week Saturday. I will call, if possible; if not, you can come down alone.

I lectured at $\mathrm{X}$ — last Thursday. My treatment there

* He wrote out a lecture on the Masquerade of the Elements, which his sister printed in large letters with pen and ink, that he might try the experiment of reading, as most lecturers did and do. He succeeded very well with it in places where he had never been before; but people who had heard his extempore Sunbeam lectures did not conceal their disappointment. 
was the shabbiest I have yet received. The committee met me-three of them-and a carriage was ordered. Weall rode to the hotel, five minutes' walk, and I had the pleasure of paying for the party-one dollar. Accommodations at the hotel were fair, charge perfectly exorbitant. After the lecture the secretary came up to me and handed me a roll of bills, muttering indistinctly the word "seventy-five." His manner was that of a sneak who was doing something he was ashamed of. I said nothing, of course. There is not a shadow of doubt that they had stipulated to pay a hundred dollars, but chose to make twenty-five dollars by this process. Well, if they can stand it I certainly can. They will want me again, but will fail to get me.

I lectured in Ashtabula the other night in a howling snowstorm; had a crowd, and, although it was a small place, they paid me seventy-five dollars, and earnestly begged me to promise to come again next year. A teacher drove over in his gig ten miles in the cold gale to attend the lecture. He came to the tavern afterward and introduced himself. He was a very fine, bright young fellow. I commiserated his folly in coming out such an inclement night. " I would not take five hundred dollars," he replied, "for what I have learned this night, and I must hear that lecture again." Next day I got a dispatch to come to Geneva the first vacant night. He said the lecture gave him the first "view" he had ever had in science, and would be the turning point of his studies.

I go from place to place, getting into good quarters and into all sorts of diabolical holes. At Mansfield I was to be called for by the omnibus at five and a half A. M., to get the train at three-quarters and off at six. At a quarter to six it had not come. At ten minutes of six I started, with a negro boy to carry my valise, ran all the way, and jumped on to 
the train after it had started. Omnibus did not come at all. At Youngstown I stayed in the most dismal and dolorous den of a tavern I ever encountered. I was put to bed in at compartment six feet by five, the bed a heap of ragrs, a partition a little higher than my head, and a man dying of consumption on the other side of it, coughing and expectorating all night. Couldn't sleep. Got up at two, went downstairs, and sat in the dingy, filthy, tobaccoed-andsanded bar-room till I left at six for Warren. Crot a good hotel there and a capital room, and enjoyed it. Went to bed at eleven P. M. ; awakened at twelve by a glare of light in my room. Sprang out of bed, and saw that the next house was on fire. Six or eight buildings were burned, but the brick hotel was saved. No sleep that night, of course. Took the train at five o'clock for Cleveland. Got into the cars; overshoes pinched my feet-took them off; fell asleep, and slept an hour and a half, into Cleveland; awoke; overshoes gone-hooked. Such is life, or rather a portion of it, for it has another side and a pleasanter.

At Grand Rapids I finished the Sunbeam with fine success, but certain envious persons started the story that I was a materialist, and there was much excitement. A deputation of my warmest friends, who had been thrown into spasms, waited upon me to get a formal authoritative contradiction of the rumour. I denied their right to get excited, and demanded to know if I had given any occasion for the rumour, and asked them if they were prepared to assume that the naked tendency of science is, or involves, materialism. Could they expect me to preach in addition to lecturing? Had they no confidence that their clergyman could take care of all applications, etc.? They agreed, and so on Sunday afternoon out came Dominie Smith with a sermon on the lectures-conceding everything, praising and puffing them extravagantly. I had ex- 
pected the attendance would fall off at the next lecture, but it did not.

The following is taken from a Buffalo newspaper of 1873 :

The seventh lecture in the Young Men's Association course will be delivered at St. James's Hall this evening by Prof. E. L. Youmans, of New York, editor of The Popular Science Monthly. The subject upon which the professor was originally announced to lecture was What is Social Science? A change became necessary, however, and the subject of the lecture to-night is The Modern Doctrine of Forces. A lecture upon any subject by Prof. Youmans is sure to be both interesting and instructive. The hall should be filled.

But, notwithstanding the eminence which Prof. Youmans has attained as a scientist, those who know him most intimately candidly admit that as a penman he is anything but a success. Some time since Mr. F. D. Locke, chairman of the Lecture Committee of the Young Men's Association, wrote to the professor, reminding him of his engagement here this evening. In due time the chairman received a letter postmarked New York, and having for a signature a combination of hieroglyphics which was supposed to be meant for the name of Prof. Youmans. This letter was evidently intended as a reply to that of Mr. Locke, though it was utterly impossible to master the contents. It was studied and pondered over, and submitted to experts, but "no fellow could find out" what the deuce it was about. Finally it was returned to the writer, with the regrets of the committee that their early educational advantages had been so limited that they were unable to decipher the epistle, and requesting a copy done in a style more easily legible. In reply to this the following was received: 
Mr. FrankLiN D. LOCKE:

My DEAR SIR: I deeply sympathize with you in your lack of early educational opportunities, but thank Heaven that I was not thus neglected. My opening intellect was most sedulously and skilfully cultivated, as is shown by the fact that, when Alonzo Green came around winters in Saratoga County to teach writing school, I took a tallow candle and some paper and quills and waded through the snow for two miles that I might develop my precocious genius for chirography. Such was my proficiency that I resolved to pursue the destiny of a writing master, and if my eyes had not failed me I should probably have ornamented that itinerant vocation to this day.

Yours with commiseration, E. L. Youmaxs.

Here followed an "interpretation" of the letter which had been "too many" for the chairman and members of the lecture committee.

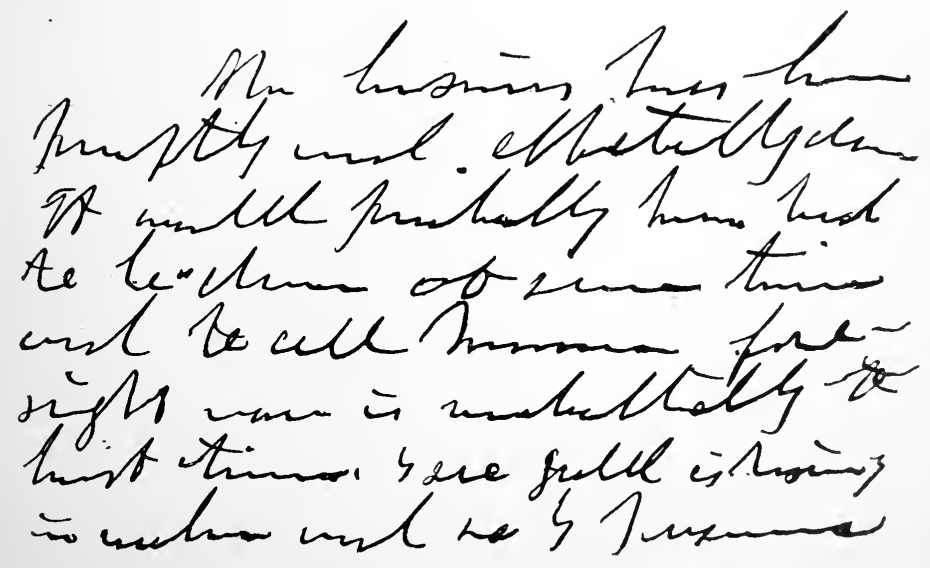

Specimen of Youmans's HaNdwitiNg. 
CHAPTER VI.

HOUSEHOLD SCIENCE.

1853-1860. Age, 32-39.

While writing his Class-Book of Chemistry Mr. Youmans had made a study of the physiological action of alcohol. Following the best authorities of that time-Liebig, Percy, Prout, Carpenter, and othershe regarded alcohol as a disturber of functions and disorganizer of structure, and therefore a poison; and because of its special action on cerebral tissue, a brain poison. In 1853 the question of prohibitory legislation was strongly agitating the public mind, and Youmans prepared a carefully reasoned argument in favour of State action, on the ground that alcohol incited its victims to so much heinous crime as to justify society in legislating against the traffic in it. Mr. Greeley cordially adopted these views, and the article was given an entire page of the Tribune. It so pleased the teetotal party that they urged its writer to make a book of it, which he did, under the title of Alcohol and the Constitution of Man. Further reflection on the subject, and change of conviction as to the legitimacy and efficiency of legislation in the circumstances of the case, led him to abandon the ground he had taken, so he let his book pass out of print.

In the course of 1853 his brother Earle returned from California, and Edward was very anxious to have 
him engage in scientific farming. He proposed that Earle should establish an experimental farm at Saratoga, where all that was new in agricultural chemistry should be practically applied. However, before matters had taken definite shape it became clear that the task would not be congenial, and the enterprise was abandoned. Feeling this disappointment to be due to Earle's lack of scientific training, Edward determined that a younger brother-William-should be better equipped. William was thercfore given a thorough scientific education, and afterward graduated in medicine. All this was designed with distinct reference to the probability of future co-operation; for not only had blindness debarred Youmans from the systematic scientific training he had sought in early life, but impaired vision and incapacity for enduring protracted desk work made a coadjutor necessary to him. Without the co-operation of his brother William he could not some years later have established the Popular Science Monthly. On this brother its editorial duties gradually devolved, until, at the last, they were wholly transferred to his charge.

The success of the Chemical Chart suggested its amplification in book form. A volume was accord. ingly prepared, and published in 1854 , entitled The Chemical Atlas. The scale of illustration was much smaller than that of the Chart; its diagrams portrayed elementary chemistry, the chemistry of rocks and strata, series of homologous compounds, nitrogenized and non-nitrogenized principles of food, and illustrated isomerism and compound radicals. Combustion, respiration, fermentation, and the chemistry of light were also made the subjects of pictures. All the qualities which had recommended the Chemistry equally 
marked this Atlas. Both publications were based on the theory of binary combination; when this was superseded by the current chemical philosophy the Chemistry was rewritten. As the new theories did not lend themselves to graphic illustration, the Chart and Atlas were not revised, and gradually fell out of use.

Ever since the preparation of the Class-Book of Chemistry Mr. Youmans had cherished the purpose of preparing a handbook for the household. His studies no less than his sympathies and tastes had led him to regard the home as a field which perhaps even more imperatively than the farm demanded science for the relief and economy of its toil; while the circumstance that so much of his time throughout the years of blindness was spent indoors made him still more keenly alive to the bearings of scientific studies upon the processes of the household. No work of his life better expresses his character than the Handbook of Household Science, which after several years of preparation was published in 1857 . He had carefully studied the practical applications of science to the heating, lighting, ventilation, and purification of $d$ wellings, and had given especial attention to the subject of foods in relation to health and economy. At this time he was much aided and encouraged by his excellent friend Mr. R. H. Manning, a gentleman of wide knowledge and sound judgment, who was building for himself a house in Brooklyn, and was naturally interested in whatever might tend to make it wholesome and easy to manage. Many were the brisk discussions over points in the Handbook between these two keen men, each with his marked gifts of expression. But on one point they were heartily agreed - that the highest use of knowledge is in minis- 
tering to the everyday welfare of mankind. Some extracts from the Introduction to the Handbook ably summarize some of the author's favourite views on this point:

It deserves to be better understood that the highest value of science is derived from its power of advancing the public good. It is more and more to be consecrated to human improvement as a sublime regenerative agency. Working jointly and harmoniously with the great moral forces of Christian civilization, we believe it is destined to effect extensive social ameliorations. That it is not yet fully accepted in this relation is hardly surprising. The work of presenting scientific truth in those forms which may best engage the popular mind is not to be fairly expected of those who give their lives to its original development. ... Conscious that the effects of his labours are finally and always beneficial in society, the enthusiast of research may be excused his indifference to therr immediate reception and uses. But the formal denial that the allegiance of mind is supremely due to the good of society is quite another affair. The sentiment, too widely entertained in learned and educational circles, that knowledge is to be firstly and chiefly prized for its own sake and the mental gratification it produces, we cannot accept. The view seems narrow and illiberal, and is not inspired of human sympathy. It took origin in the times when the improvement of man's condition, his general education and elevation, were not dreamed of. It came from the ancient philosophy, which was not a dispensation of popular beneficence, an all-diffusive, ennobling agency in society, but confessed its highest aim to be a personal advantage, shut up in the individual soul. It was not radiant and outflowing like the sun, but drew all things inward, engulfing them in a maelstrom of selfishness.

The baneful ethics of this philosophy have given place 
to the higher and more generous inculcations of Christianity, which lays upon human nature its broad and eternal requirement, "to do good." From this authoritative moral demand science cannot be exempted. The power it confers is to be held and used as power is exercised by God himself, for purposes of universal blessing. . . .

We place a high estimate upon the advantages which society may reap from a better acquaintance with material phenomena, for life is a stern realm of cause and effect, fact and law. As such we would deal with it in education, giving prominence to those forms of knowledge which will work the largest practical alleviations and most substantial improvement throughout the community. It is wisely designed that those studies which may become in the highest degree useful are also first in intellectual interest. . . . So far from being unfriendly to the imagination, as is sometimes intimated, science is its noblest precursor and ally. Can that be unfavourable to this faculty which infinitely multiplies its materials and boundlessly multiplies its scope? In unsealing the mysteries of being-in turning the commonest spot into a museum of wonders-who can doubt that science has opened a new and splendid career for the play of the diviner faculties, and that its pursuit affords the most exhilarating as well as the healthiest and purest of intellectual enjoyments?

\section{Of the method of science he says:}

It educates the attention by establishing habits of accurate observation, strengthens the judgment, teaches the supremacy of facts, cultivates order in their classification, and develops the reason through the establishment of general principles. It is claimed, as an advantage of mathematics, that it deals with certainties, and, raising the mind above the confusions and insecurities of imperfect knowledge, habituates it to the demand of absolute truth. That 
benefits may arise from this exalted state of intellectual requirement we are far from doubting, and are conscious of the danger of resting satisfied with anything short of perfect certitude, where that can be attained. But here again there is possibility of error. Mathematical standards and processes are totally inapplicable in the thousandfold contingencies of common experience, and the mind which is deeply imbued with their spirit is little attracted to those departments of thought where, after the utmost labour, there still remain doubt, dimness, uncertainty, and entanglement. And yet such is precisely the practical field in which our minds must daily work. The mental discipline we need, therefore, is not merely a narrow deductive training of the faculties of calculation, with their inflexible demand for exactitude, but such a systematic and symmetric cxercise of its several powers as shall render it pliant and adaptive, and train it in that class of intellectual operations which shall best prepare it for varied and serviceable intellectual duty in the practical affairs of life.

He continues the argument by considering education in its broad relations to liberty and progress:

Education, from the earliest time, has been under the patronage of civil and ecclesiastical despotisms, whose necessary policy has been the repression of free thought. The state of mind forever insisted on has been that of submissive acceptance of authority. Instead of laying open the limitations, uncertainties, and conflicts of knowledge which arise from its progressive nature, the spirit of the general teaching has been that all things are settled, and that wisdom has reached its last fulfilment. Instead of encouraging bold inquiry and inciting to noble conquest, the effect has rather been to reduce the student to a mere tame, unquestioning recipient of established formulas and time-honoured dogmas. It is obvious on all sides that this 
state of things has been deeply disturbed. The introduction of republicanism, with political freedom of speech and action; the advent of Protestantism, with religious liberty of thought; and the splendid march of science, which has enlarged the circle of knowledge, multiplied the elements of power, and scattered social and industrial revolution right and left for the last hundred years-these new dispensations have invaded the old repose and fired the minds of multitudes with a new consciousness of power. Yet we cannot forget that our education still retains much of its ancient spirit, is yet largely scholastic and arbitrarily authoritative. We believe that this evil may be to a considerable degree corrected by a frank admission of the incompleteness of much of our knowledge; by showing that it is necessarily imperfect, and that the only just and honest course often involves reservation of opinion and suspension of judgment. This may be consonant neither with the teacher's pride nor the pupil's ambition, nevertheless it is imperatively demanded. We need to acquire more humility of mind and a sincerer reverence for truth; to understand that much which passes for knowledge is unsettled, and that we should be constant learners through life. The active influences of society, as well as the schoolroom, teach far other lessons. We are committed in early childhood to blind partisanships-political and religious-and drive on through life in the unquestioning and unscrupulous advocacy of doctrines which are quite as likely to be false as true, and are perhaps utterly incapable of honest definitive adjustment. Science inculcates a different spirit, which is most forcibly illustrated in those branches where absolute certainty of conclusion is difficult of attainment.

Coming to the details of his volume, after pointing out that while the principal statements in the chapters on heat, light, and air were comparatively well estab- 
lished, on the other hand our knowledge of the physiological effects of foods was in a much less advanced condition, he closed as follows:

An important result of the more earnest and general pursuit of science by the young will be to find out and develop a larger number of minds having natural aptitudes for research and investigation. As there are born poets and born musicians, so also there are born inventors and born experimenters-minds originally fitted to combine and mould the plastic materials of Nature into numberless forms of usefulness and value. It is a vulgar error that the work of discovery and improvement is already mainly accomplished.- The thoughtful well understand that man has hardly yet entered upon that magnificent career of conquest in the peaceful domain of Nature to which he is destined, and which will be hastened by nothing so much as a more general kindling of the minds of the young with enthusiasm for science. The harvest awaits the reapers. How strange that man should have neglected it so long! Fuel, air, water, and the metals, as we see them acting together now in the living, labouring steam engine, have been waiting from the foundation of the world for a chance to relieve man of the worst drudgeries of toil. Long and fruitlessly did the sunbeam court the opportunity of leaving upon the earth permanent impressions of the things he revealed; while the lightning, though seemingly a rollicking spirit of the skies, was yet impatient to be pressed into the quiet and useful service of man. Can there be a doubt that other powers and forces, equally potent and marvellous, await the discipline of human genius? Not in vain was man called upon, at the very morning of creation, to "subdue the earth." Already has he justified the bestowment of the viceroyal honour. Who shall speak of the possibilities that are awaiting him in the future?

$788618 \mathrm{~A}$ 
The Handbook of Household Science was not the ordinary collection of scrappy comment, recipe, and apothegm, but a thoroughly scientific treatise on air, water, fuel, food, and cleansing materials, written in a simple and lucid style, and it is still a sound and authoritative book. Mr. Youmans had much in mind the need of such a book in girls' schools, and was disappointed at the comparatively small demand for it in that quarter. Teachers complained that it was too full, that its study consumed too large a portion of the time allotted to " the course," and to meet this objection he sometimes spoke of condensing the volume. But the general demand for the book was so satisfactory that he was led to amplify rather than to reduce it. In this mood he planned a comprehensive Household Cyclopædia, and after working at it from time to time, as opportunity offered, for the rest of his life, he bequeathed to his brother William the task of completing it.

In connection with the popularization of science, the following letter to Mr. W. T. Henderson, of Cincinnati, who had charge of the common-school libraries of Ohio, is an illustration of the zeal with which Youmans was sure to extend a helping hand to any fellow-worker :

New YoRK, October 8, 1860.

MY DEAR SIR: I send you this day a copy of a book, What may be Learned from a Tree, which possibly may not have fallen under your notice. I do it though I am assured that the matter of books for the Ohio libraries is closed hermetically; yet, in the hope that there may be somewhere some possible slip or gap or surplus, I nevertheless write. My object in soliciting your attention to the book is, first, I am persuaded you have not a better book 
on your list, and few equal to it in interest, instructiveness, and adaptation to popular want. It is a capital book, clearly written, reliable, thoroughly posted in its science, suggestive, and abounds in lessons of wisdom for the conduct of life which have a high value, as they are linked on so directly to the order of creation-to the life of so familiar and beautiful an object as the living tree. Secondly, I am moved to write and strike for any forlorn chance there may be by the fact that the author is a poor, struggling man of Philadelphia, without practical tact, who can't find the handles of this world, and deserves that others should help him. His book has been out a year, and six hundred copies have been sold, almost entirely by himself. I)r. Draper, of this city, called my attention to the book and the man. I went on to Philadelphia and dug him up-a splendid botanist, a fine thinker, yet in all that appertains to this world a poor creature. The house of Appleton have kindly promised me to do what they can to push the book into better notice. I have done what I could for the author and his work gratuitously. I neither expect nor want anything for my trouble, time, or expense. The publishers say they would be glad to help without expecting to make much in the matter, and, all this being the case, I venture to write you as I have done. If the book pleases you and. it lies in your power, pray give us a little assistance.
Very truly yours,
E. L. Youmans. 


\section{CHAPTER VII.}

FIRST ACQUAINTANCE WITH HERBERT SPENCER.

$$
\text { I860. Age, } 39 .
$$

Ix one of the most beautiful of all the shining pages of his History of the Spanish Conquest in America Sir Arthur Helps describes the way in which, through "some fitness of the season, whether in great scientific discoveries or in the breaking into light of some great moral cause, the same processes are going on in many minds, and it seems as if they communicated with each other invisibly. We may imagine that all good powers aid the 'new light,' and brave and wise thoughts about it float aloft in the atmosphere of thought as downy seeds are borne over the fruitful face of the earth" (rol. iii, page II3). The thinker who elaborates a new system of philosophy deeper and more comprehensive than any yet known to mankind, though he may work in solitude, nevertheless does not work alone. The very fact which makes his great scheme of thought a success and not a failure is the fact that it puts into definite and coherent shape the ideas which many people are more or less vaguely and loosely entertaining, and that it carries to a grand and triumphant conclusion processes of reasoning in which many persons have already begun taking the earlier steps. This community in mental trend between the immortal discoverer and many of the brightest contempo- 
rary minds, far from diminishing the originality of his work, constitutes the feature of it which makes it a permanent acquisition for mankind, and distinguishes it from the eccentric philosophies which now and then come up to startle the world for a while, but are presently discarded and forgotten. The history of modern physics-as in the case of the correlation of forces and the undulatory theory of light-furnishes us with many instances of wise thoughts floating like downy seeds in the atmosphere until the moment has come for them to take root. And so it has been with the greatest achievement of modern thinking-the doctrine of evolution. Students and investigators in all departments, alike in the physical and in the historical sciences, were fairly driven by the nature of the phenomena before them into some hypothesis, more or less vague, of gradual and orderly change or development. The world was ready and waiting for Herbert Spencer's mighty work when it came, and it was for that reason that it was so quickly triumphant over the old order of thought. The victory has been so thorough, swift, and decisive that it will take another generation to narrate the story of it so as to do it full justice. Meanwhile, people's minds are apt to be somewhat dazed with the rapidity and wholesale character of the change; and nothing is more common than to see them adopting Mr. Spencer's ideas without recognizing them as his or knowing whence they got them. As fast as Mr. Spencer could set forth his generalizations they were taken hold of here and there by special workers, each in his own department, and utilized therein. His general system was at once seized, assimilated, and set forth with new illustrations by serious thinkers who were already groping in the regions of abstruse thought 
which the master's vision pierced so clearly. And thus the doctrine of evolution has come to be inseparably interfused with the whole mass of thinking in our day and generation. I do not mean to imply that people commonly entertain very clear ideas about it, for clear ideas on any subject are not altogether common. I suspect that a good many people would hesitate if asked to state exactly what Newton's law of gravitation is; a good many, doubtless, would stop before arriving at that statement about inverse squares which comprises the pith of the whole matter.

Among the very few men in America forty years ago who were feeling their way toward some such unified conception of Nature as Spencer was about to set forth in all its glory-among the very feaw who were thus prepared to grasp the doctrine of evolution at once and expound it with fresh illustrations Edward Youmans was the first in the field. It was in the course of the year 1856 , while he was at work upon the Household Science, that he fell in with an article upon Spencer's Principles of Psychology in the London Medico-Chirurgical Review, written by Dr. J. D. Morell, author of some books on philosophy more read then than now. Youmans was so deeply impressed by the article that he at once sent to London for a copy of the book, which had been published in the preceding year. It will be observed that this was four years before the Darwinian theory was announced in the first edition of the Origin of Species. Toward the end of that book Mr. Darwin looked forward to a "distant future "when the conception of gradual development might be applied to the phenomena of conscious intelligence. He had not then learned of the existence of such a book as the Principles of Psychology. In later 
editions he was obliged to modify his statement, and confess that, instead of looking so far forward, he had better have looked about him. I have more than once heard Mr. Darwin laugh merrily over this, at his own expense.

When the book arrived from London it found Youmans deeply engrossed in his own work. As he cut the leaves and glanced over the pages, they seemed immensely difficult. His sister had more leisure; so he gave the formidable volume to her, to see what she could make of it. Finding in the preface a suggestion that readers unfamiliar with such abstruse studies might perhaps find it for their advantage to read the third and fourth divisions of the work before attempting the first and second, she profited by the hint and soon became deeply interested.

After struggling for a while with the weighty problems of this book-the most profound treatise upon mental phenomena that any human mind has yet produced-Youmans saw that the theory expounded in it was a long stride in the direction of a general theory of evolution. His interest in this subject received a new and fresh stimulus. He read Social Statics, and began to recognize Spencer's hand in the anonymous articles in the quarterlies, in which he was then announcing and illustrating various portions or segments of his newly discovered law of evolution. One evening in February, 1860, as Youmans was calling at Mr. Manning's house, in Brooklyn, the Rev. Samuel Johnson, of Salem, showed him the famous prospectus of the great series of philosophical works which Spencer proposed to issue by subscription. Mr. Johnson had obtained this from Edward Silsbee, of Salem, who was one of the very first Ameri- 
cans to become interested in Spencer. The very next day Youmans wrote the following letter to Spencer, offering his aid in procuring American subscriptions, and otherwise :

New YORK, February 23, 1860.

Dear Sir: My friend, Samuel Johnson, Unitarian clergyman, of Salem, Mass., yesterday called my attention to a letter and circular from yourself, proposing a reissue of your writings. I was not only greatly pleased with the idea, but the circumstance was especially fortunate for me, as it gave me a clue to your whereabouts, which I had for some time sought. I was on the point of writing to Dr. Chapman* for your address. My purpose was this: I meditate the compilation of a volume designed to present the increasing claims of science upon teachers and the directors of education, to contain the addresses of Faraday, Whewell, Tyndall, Paget, and Daubeny before the Royal Institution, on the popular claims of their respective branches of science, together with the address of Agassiz on kindred points, and your own article in the North British (I think), which was omitted from the edition of your essays. There is still another article, the opening one in the Westminster for last July-What Knowledge is of most Worth-which I wish also to include, and my solicitation was to find its authorship. I concluded before I read a page of it that you wrote it; the full perusal strengthened my conviction; yet, of course, as I may be mistaken, I wish to find out about it. I might have applied to the editor of the Westminster, but Scott, the republisher, tells me the conductors are often shy and delicate about giving this kind of information. I should therefore be glad of an assurance from yourself; and if I

* John Chapman, M. D., at that time editor of the Westminster Review. 
happen to have been mistaken, would you not probably be able without trouble to inform me who the author is?

Respecting the plan of your publication I had no opportunity to learn anything, as I had not time to read the circular. But whatever you propose in the matter I fully accept, and will most gladly do anything in my power to forward the enterprise. I have published several elementary books by which I have been somewhat mixed up with book men and the book business, and this circumstance may afford me some opportunity to aid the object. I am more or less connected with the lyceum system throughout the country, and, dealing with scientific topics, I fall in with the class of men who would take most interest in your current thought. Lecturing, however, is now about closed for the season.

I got the impression that the push was first to be made here, and that the project might be somewhat contingent upon the result. How many subscribers will you need here to justify the undertaking? I wish you would forward me a circular, or, if possible, several, with any accompanying statement that may be desirable. If you should send several, you might leave them at 16 Little Britain, which is the London depot of the house I publish with (D. Appleton $\&$ Co.). They will forward with goods. If I succeed in shortly bringing out the volume I spoke of, it will furnish additional means of advancing the object.

I have to thank you most earnestly for the pleasure and advantage I have derived from the yet too hasty and fragmentary perusal of your books; and I am justified in doing the same thing in behalf of quite a number of friends for whom I have had the great gratification of importing several of your volumes. And now I pray you excuse this informal Yankee short cut to business. If it be your pleasure to write me, please direct to the care of D. Appleton $\mathbb{E}$ Co., New York city.

Very respectfully,

E. L. Youmans. 
P. S.-Again: a friend of mine, an admirer of your writings, has expressed a frequent and earnest desire to get your portrait. I share the sentiment. Have you a spare engraving or photograph to send over the sea? You see, we take the utmost advantage of our Yankee reputation.

E. L. Y.

Mr. Spencer's cordial reply was as follows:

24 Oakley Square, London, 26 March, 1860.

DEAR SIR: I am greatly obliged by your letter of 23 February, and must apologize for having so long delayed answering it, partly on the ground that $I$ have been overdone with correspondence in the furtherance of my project here, and partly on the ground that my plans were scarcely mature.

Referring to the points of your letter in the order in which they stand, let me first undeceive you as to the nature of the series of works to be published. I fear that I must have used some misleading expression, for I by no means intend a "reissue of my writings." Four fifths will be wholly new, the parts written will be in most cases greatly developed, and the whole will assume an organization not even indicated in anything I have as yet published. The new organization will absorb, digest, and reorganize the fragments already written, along with a far larger mass that is unwritten.

I very gladly accept the assistance you so kindly offer in furthering my scheme by obtaining subscribers to my series in the United States. I have just written to my friend Mr. E. A. Silsbee, of Salem, Mass. (to whom I sent the circular you saw), inclosing him a revised circular containing, with alterations, a list of the first subscribers in England, including a number of the chief names in science and literature. This revised circular, with its appended names, I have suggested to Mr. Silsbee to reprint (at my 
expense) for distribution in the United States. I have suggested that, in addition to the leading English names, there be added to the American edition of the circular as many American names of note as can be readily obtained. My friend Prof. Huxley has suggested Prof. Dana, Irof. Asa Gray, Prof. Leidy, and Dr. Draper as likely men, and I have hinted to Mr. Silsbee that possibly you would allow your name to be included. If you could, from your knowledge of men of note throughout the States, suggest to Mr. Silsbee any other names of weight which might be got, it would be a service.

By the time that the American edition of the circular is fully printed I propose writing again to Mr. Silsbee with respect to its distribution. Possibly through your connection with the lyceum system, which you are so good as to name in relation to the matter, you would be able to facilitate this. If you could furnish Mr. Silsbee with the names of any who would act as local distributors, it would be an important aid. You see, I am taking you at your word, and am, I fear, imposing on you considerable trouble. The fact, however, that I am unable to do anything myself on the other side of the Atlantic, and have therefore to trust to those who feel an interest in the matter, must be my excuse.

Your question, "How many American subscribers will suffice?" I am not able to answer. My hope is, that the circulation in England and America together will suffice; and until the result is known here (the final issue of the circular not having yet taken place) I cannot say what number from the United States will be needed to make up an adequate list.

Referring to your question concerning the article, What Knowledge is of most Worth? you are right in ascribing it to me. I should, however, regret to see it and the one from the North British included in the volume you con- 
template, because I am myself hoping, in the course of a year, to republish these articles, along with an equal bulk of matter on the same topic, in the shape of a volume on education, and I was thinking of exporting part of the edition to the United States, or else agreeing with an American house to reprint it.

With many thanks for your expressions of sympathy and offers of aid, believe me, dear sir, faithfully yours,

Herbert SPENCER.

With this correspondence began the friendship which was one of the warmest in Youmans's life, and which gave added zest to all his subsequent labours. As the friendship began long before there was any adequate recognition of Spencer's genius by the public, Youmans was able to render him great service. His aid was from the outset important in a material sense, and of still higher value was his intelligent and enthusiastic sympathy.

Mr. Spencer's first idea was to have his projected series of books published in Boston; and there was some talk of Messrs. Ticknor \& Fields-then at the Old Corner Bookstore-undertaking to conduct the series in case subscriptions enough should be received. But when, in the course of I860, Mr. Spencer's book on Education, above referred to, was offered to Ticknor \& Fields, they declined to publish it, which was, of course, a grave mistake from the business point of view. Youmans, however, was not sorry for this, for it gave him the opportunity to place Spencer's books where he could do most to forward their success.

Allusion has already been made to his chance visit to the house of D. Appleton \& Co. in the days of his blindness. It was an auspicious event for all con- 
cerned. In the first place, the Appletons became the publishers of Youmans's books. His sagacity and his magnetic personality prevailed with them as with almost everybody. By degrees he became an adviser as regarded matters of publication, and it was largely through his far-sighted advice that the Appletons entered upon the publication of such books as those of Buckle, Darwin, Huxley, Tyndall, Haeckel, and others of like character, always paying a royalty to the authors, the same as to American authors, in spite of the absence of an international copyright law. As publishers of books of this sort the Appletons have come to be pre-eminent. It is obvious enough nowadays that such books are profitable from a business point of view; but thirty years and more ago this was by no means obvious, and I doubt if there was any other house in the United States that would not have been at least very likely to view the matter in the same light as Messrs. Ticknor \& Fields. The Americans were at that time excessively prorincial. There was much intellectual eagerness, along with very meagre knowledge, and few persons had access to authoritative sources of information. Reprints of English books, translations from French and German, were sadly behind the times. In the Connecticut town where I lived people would begin to wake up to the existence of some great European book or system of thought after it had been before the world anywhere from a dozen to fifty years. In those days, therefore, it required some boldness to undertake the reprinting of new scientific books, and none have recognized more freely than the Appletons the importance of the part played by Youmans in this matter. His work as adviser to a great publishing house and 
his work as lecturer re-enforced each other, and thus his capacity for usefulness was much increased.

When Mr. Spencer's book on Education failed to find favour in Boston, the Appletons took it, and thus presently secured the management of the philosophical series. This brought Youmans into permanent relations with Spencer and his work, as begins to appear in the following letter:

NEW YORK, October 5, 1860.

MY DEAR SiR: I received your kind letter of September IIth, and was grieved to hear of your unusually disturbed health. I trust it is not to continue. My apology for intruding upon you now is, that after the arrangement had been effected Mr. Silsbee had not time to send a letter by the steamer to-day, and I therefore write in his place. Mr. Silsbee probably informed you that Ticknor \& Fields declined to publish the book on Education. He furthermore said there was no chance in Boston, and delegated me to arrange, if possible, in New York. He did not restrict me to specific terms, but as the work had been generously offered to Ticknor \& Fields upon their own conditions, he committed it to me in the same liberal spirit. From mixed considerations I was anxious that the Appletons should publish the book. There is more import in their imprint than in that of any other house on this side of the Atlantic. They have been established nearly half a century, and have won a pre-eminent reputation for sterling and valuable books. I therefore thought it would be wellindeed, best-for the book itself, and also as an introduction of its author to our people; and, besides, the firm have treated me with great personal kindness, and I was anxious they should have the good fortune to publish the book. Furthermore, I have myself put forth some trifles in the way of science for the multitude, and I was ambitious that they might go in company with your masterly exposition 
of the educational claims of science. I thought also that if our house had the management of the work I might possibly in various small ways contribute to urge it forward; for we have found on this side that the straight and narrow way that leads right up to the heaven of success is traversable by but one motor-namely, push. And although in a house of great business, with numerous departments in rigorous discipline, the general movement is steady and automatic, and all things thrown into the hopper are ground out at the usual rate, still the machinery is not without reducing and multiplying gear and some chance for crowding. So I asked the gentlemen to drive on with the book and do the best they could for the author. They promised, and when Mr. W. H. Appleton arrived from Europe, the day before yesterday morning, one hundred pages of the work had been stereotyped. I was anxious to get the volume on Education out at the earliest moment and before the first part of the Series arrives. We do not exactly know about that "Unknowable"; we have great faith in it undoubtedly, but we are sure of the weapon in hand and would prefer to open the campaign with it. I therefore by no means regret the delay of the first part, nor need you trouble yourself to hasten it.

After explaining that the chance for the series at Ticknor \& Fields's was very discouraging, and that it was better that Mr. Spencer should transact business with but one house, he says:

Mr. W. H. Appleton told me yesterday that the firm would take the series and do the best it can with them. I hope this change will be satisfactory to you, and that you may not have placed the names of Ticknor \& Fields upon the first part, nor have sent the volumes yet. If you should have printed their names on the title-page and cover, and not have forwarded them, I would earnestly ask if it will 
not be desirable to change the covers and print "D. Appleton \& Co., New York," thereon instead? The copies of your other work will be brought from Ticknor \& Fields to New York, as they have declared they cannot sell them. Allow me to suggest that the terms Mr. Appleton proposes for the Education-ten per cent of the sales to the author after preliminary expenses are paid-is all that $I$ receive, and the usual rate here, except where a popular author can dictate terms.

And now, dear sir, I pray you do not think of me as having officiously thrust myself into your business. Matters seemed to have "opened," as the Friends say, and I "felt required" to take hold. If in the slightest manner I can contribute to advance your interests it will be an unspeakable pleasure, more especially when I remember that in so doing $I$ am serving the public in the most efficient manner in my power. I hope the course things have taken will not be unsatisfactory to you nor prove a hindrance to your valuable projects.

With best wishes for the restoration of your health, I am, yours most truly,

E. L. Youmans.

As a result of these negotiations the Appletons presently undertook to issue the philosophical series in parts, concurrently with the publication in London. They also published a reprint of Social Statics, with a portrait of Mr. Spencer furnished by Mr. Manning. A selection from the Essays, Scientific, Political, and Speculative, was afterward published, under the title, - Illustrations of Universal Progress. This was a happy thought; for the general reader has a mind of very limited capacity, and usually likes to take his philosophy in morsels, so that doubtless many persons were able to obtain some notion of evolution in this way who would have been simply wearied by the mag- 
nificent long-sustained argument of First Principles. A second selection, under the title, Essays, Political, Moral, and Esthetic, soon followed, and the diversity of themes served to widen the circle of Mr. Spencer's readers. The publication of these books was an experiment entirely due to Youmans's urgency. As soon as they were ready for the market he wrote reviews of them, and by no means in the usual perfunctory way. His reviews and notices were turned out by the score, and scattered about in the magazines and newspapers where they would do the most good. Not content with this, he made numerous pithy and representative extracts for the reading columns of various daily and weekly papers. Whenever he found another writer who could be pressed into the service, he would give him Spencer's books, kindle him with a spark from his own blazing enthusiasm, and set him to writing for the press. The effects of this work were multifarious and far-reaching, and-year in and year out-it was never for a moment allowed to flag. The most indefatigable vender of wares was never more ruthlessly persistent in advertising for lucre's sake than Edward Youmans in preaching in a spirit of the purest disinterestedness the gospel of evolution. As long as he lived Mr. Spencer had upon this side of the Atlantic an alter ego ever on the alert, with vision like that of a hawk for the slightest chance to promote his interests and those of his system of thought. 


\section{CHAPTER VIII.}

\section{MARRIAGE AND FIRST VISIT TO ENGLAND.}

$$
\text { I86I-I862. Age, 40-4I. }
$$

Mr. Youmans was married in I86I to Mrs. William L. Lee, the widow of a distinguished jurist, and a lady of culture, refinement, and much critical literary ability. That a wife of such nice perceptions and intellectual gifts should earnestly sympathize with the literary and scientific work of her husband was to be expected. As his amanuensis, and as an assistant and companion in the occupations, correspondence, and travel, by means of which he was brought into intimate relations with the leading thinkers of England and America, she rendered him valuable aid which he highly appreciated.

Accompanied by his wife, in the year following their marriage he made his first visit to England and to the Continent of Europe, sailing from New York in the Great Eastern, July 26, 1862. There were a good many secessionists on board, and the voyage was enlivened by a characteristic incident:

One evening there was a ball, and the saloon was decorated with English and American flags. Secesh wouldn't dance under the Stars and Stripes, and went raging out of the room. Captain made a very good speech; said that this was a neutral vessel, and so long as he was in command the American flag should remain. But Secesh was 
not pacified; ordered liquor, and drank to George Washington, the first rebel, then to Jeff Davis, etc.

Youmans went directly to Derby, where he was expecting to find Herbert Spencer, but was disappointed. Mr. Spencer was taking his customary vacation in Scotland, but his father and mother were at home, and the following extract from a letter dated London, August IO, I862, gives an account of Youmans's call at their house:

I sat a few moments in the dark, when a tall, dignifiedlooking gentleman of very quiet deportment entered, and, approaching in a very measured and pleasant way, said, "Mr. Youmans?" I said, "Mr. Spencer, father of Herbert Spencer?" and he said, "Yes; take a seat." Thus was I fairly ensconced in the unpretentious home of the Spencers. They have but one child-Herbert; they have had others, but they are dead. Mr. Spencer does not teach a school [though he did until his health broke down, many years before], but he receives pupils in mathematics and other things, who come and get lessons at his house [or receive them at their own]. He is an unusually fine-looking person -indeed, I think, handsome. He has a fine, profuse head of grey hair, which he wears in a spirited standing way; must be sixty-five or sixty-eight years of age [he was then seventy-two], but looks younger in the face, although his shrivelled hands proclaim him older. Herbert has not his face, but his brain. $\dagger$ His lips are quite thick, but his mouth is handsome and expressive, with fine curves. A narrow band of close-cut grey whiskers surrounds his face. His expression of mouth reminded me of Joe Wood's mouth; indeed, there is considerable resemblance in their thought-

* The remarks within brackets are Mr. Herbert Spencer's comments.

+ Youmans, of course, when writing this letter, knew Herbert Spencer's face only by a photograph. 
ful and reserved manner. Fancy Joe Wood handsome, a little taller, a little slenderer, like Newbury Loomis, and with the old-school style of Uncle Good, and all these characteristics will, of course, mislead you. The English are reserved. Mr. Spencer was reserved. He remarked that Herbert talks but little of his friends. With his constitutional quietude and lack of enthusiasm, I could not expect he would take me in his arms, or scream or faint at my momentous arrival. Don't mistake. I am not apologizing for a cool reception, but for not having a hot one. It was as warm as the correlation of forces would permit, and was eminently agreeable and satisfactory. We became quickly well acquainted. He brought wine, which I tasted, and then Mrs. Spencer came in. She is about Ma's size; Herbert's mouth exactly, but I guess handsomer; wears spectacles; was blind of cataracts, and was operated on successfully; is pleasant, communicative; has read the Education and Essays, but can't understand the other books. They appreciate their wonderful son, and of course love him and worry about him. His father says he is apt to overdo himself in exercise. He is now on an expedition in the north of Scotland, fishing, rambling, botanizing, to be absent till mid-October. I saw a very fine morocco-bound copy of First Principles, to be presented to the person whom Herbert frequently visits in Scotland. Conversation was free and rambling, but I brought it back to Herbert as often as possible, and there was no difficulty about it. $\mathrm{He}$ did not like his business of civil engineering [this is a mistake; he did like it], but was very successful in it. His father showed us his herbarium, twenty years old, and a beautiful coloured drawing of a locomotive, which he had been begging his son to allow him to frame, but could not get his consent. They brought me a little shred of a photograph, faint and yellow; the father told me it was taken just before the Psychology was finished, when he was in 
wretched health and very sleepless. He is not a great reader. His father and mother see very little of him. He spends but little time in Derby, and, when there, but little at home. Takes long rambles in the country.

Herbert learned to sing by note after he was a grown man, liked it, and complained of his father for not letting him learn earlier. I stayed an hour and a half, and then invited old Mr. Spencer to call next forenoon on Kitty.* He courteously replied that if it would be agreeable he would accompany me then. So he walked with me a twenty-five minutes' distance to the Queen's Hotel. It was later than I had supposed, and Kitty was in bed, and we separated with the arrangement that he was to meet us at the station next morning, ten minutes to nine, to accompany us to Elvaston Castle, the estate of Lord Harrington.

The following extracts from letters of August 17 th and 19th, give some first impressions of London:

We have been in this great city a week, and seen a great many sights and heard a great many sounds, the general effect of which has been to put each other out and to produce a meagre impression of confusion. I don't know where to begin or in what direction to write. I am in the same state of mind that I am when I go out of doors to start for some place. We are now established in the city, miles further from the Exhibition than you are from Saratoga, so we have given but little attention to that yet, intending to be located nearer it when we return. We move in omnibuses and cabs. The omnibuses are like our own, save that there is a man on the steps to collect fares when you come out. The currency is very simple. I learned it the first day. Everything is silver and gold. One half the cabs are on four wheels, the other on two. "Hansom's

* The reference is to Mrs. Youmans. 
Patent Safety Cab" is the most unhandsome thing I ever looked upon. It is a top on two wheels, and, as it rains nearly all the timé, it has two doors in front, which lie down like a pair of outside cellar doors, only a little steeper. A seat for the driver is carried behind, supported by long iron rods; and when "cabby" gets mounted, with two or three trunks on top before him, and his basket of oats swinging under his seat, the whole thing is altogether the most outlandish exhibition to be seen anywhere but in London. On the whole they drive much faster than in New York, but the loaded horses take much larger loads, go tandem, and very slow. The place resembles a half dozen New Yorks, with any number of Broadways, crooked and straight, running in every direction. I am beginning to have a dim idea of the place, but it will take a very long time to get a clear one of it, unless one's entire time could be given to its study. There is no use in my describing particulars; that is done elsewhere much better than I can do it. Eating is much like eating everywhere, but they never have butter at dinner; their water is always brought in bottles, and never iced. They have no pies-or, rather, they call them tarts, and make them in small dishes like sauce dishes, two inches deep, with no under crust, and an upper crust of triple thickness, served with a spoon. But we live well enough. ...

I yesterday got track of Silsbee, and went to his registered place. He was not there; it was the family he was with before and spoke of to us. The people were quite interesting. An elderly lady sat in her large armchair, highly dressed, with white kid gloves on, reading the Prayer Book (it was Sunday afternoon). A youngish woman (married) was with her, and at once opened conversation concerning Mr. Silsbee and Mr. Spencer, "her friends." She had some personal acquaintance with Mr. Spencer, but seemed to understand little of his works; and although 
an intelligent woman, she had a vague, horrified sense of the awfulness of anybody thinking for himself.

I had also a letter from Mr. Spencer; he had received one from his father announcing our arrival in Derby, and turned his course at once southward. He wrote he would be in Glasgow to-night to await a letter from me, or my coming there, and so we have concluded to drop the Continent for the present and go to Scotland. We have not much time, as we have decided to return home in October, and therefore shall stay in Scotland but a day or two perhaps. . . . There is so much to see of surpassing interest on this side that a flying trip is almost ridiculous, and the Exhibition a very small affair comparatively. Were I at home with all the knowledge I have now, I would not make my stay less than six months, and I would come over in February. I would stay in London till May, while its people are at home and it isn't crowded, and expenses are reasonable. After that I would take the English country and the Continent.

The meeting with Mr. Spencer in Glasgow is thus described in a letter of August 24th, to Miss You. mans :

We returned this morning from Scotland after riding all night from Edinburgh-four hundred miles, and with but little sleep the night before. I think I never was so nearly used up, and have slept painfully and heavily nearly all day till four o'clock. I should have commenced writing as soon as I returned, but had not power to get the materials together. However, I now feel refreshed and bright, and, that nothing may intervene to weaken the impression of the last three days, I sit down to write at once. Spencer has come forth from his realm of abstraction, and is a living, breathing, and in many respects very human specimen of human nature. He wrote me he would be in Glasgow Tuesday 
night. We received the letter on Tuesday, and thought to go on that night, and hence did not write him. But we could not get away till Wednesday morning, arriving at Glasgow at one that night. Spencer had telegraphed Tuesday evening to r6 Little Britain, but it was shut up, and if it had not been so they did not know where we were. The purport of the telegram was, that Spencer would come to London to see me if we were not coming to Scotland. His father had written him that we would meet him at any point in Scotland which he would indicate. I had emphatically stated that I did not want him to turn a step out of his way to meet us. I found him at eight in the morning at his hotel. Ascending two flights of stairs, I was ushered into the dining room. I inquired for Mr. Spencer; the waiter said he was there at the other end of the room. I went forward and made myself known to him. He received me very quietly and cordially, and asked me first if I had received his telegram; said he had been waiting in suspense, and should have left for London at four that afternoon; would be round to see us after breakfast and arrange how to dispose of our time. He was ready for an expedition of any length we might desire. We had but little time. He urged us to take more. We decided to stay in Scotland from Thursday morning till Saturday night. He arranged the route so that we should go from Glasgow to Edinburgh at once, see the city on Thursday, start for the mountains and lakes on Friday morning, and get back to Edinburgh to take the Saturday afternoon train at four o'clock, he accompanying us about four hours, and then diverging to go and visit J. D. Morell, who lives near Manchester.

I cannot give you a progressive account of the journey, for it is all a confused thing in my memory, and much, I fear, has already escaped, we hurried through so rapidly and changed so often. I went on account of Spencer. The 
scenery was fine, but I cared nothing for it and paid no attention to it. We went from Edinburgh to Stirling; beyond that a few miles, took the old-fashioned stage-coach, riding on top for eight miles to Loch Katrine, five miles long, which we crossed in a packet steamer; staged four miles again, then crossed Loch Lomond, walked a mile and a half, and stayed all night. Saturday morning, at six, took the boat again on Loch Lomond and went to Glasgow, and then to Edinburgh by rail. Spencer, of course, wished to help us all he could, on various occasions expressing his warmest obligations, indebtedness, etc.; but, aside from all this, he is the most prompt, ready, adaptive, and useful man on such an expedition I have ever known. $\mathrm{He}$ is wonderfully practical, and handles circumstances as they arise with all the energy and readiness of an experienced business man. A hundred vagabonds were demanding stipends. I was confused, and would have given them all I had. He knew just what to do, and did it decisively, allowing no nonsense, and dealing sharply with importunate or outrageous claimants.

His health is bad. The difficulty is with his brainsleeplessness. He has not had a night's rest since he wrote the Psychology. He can't sleep, and if he does he wakes ten or twenty times during the night. He is very excitable, and when excited cannot sleep at all, gets alarmed at the state of his brain, and flies from the scene of danger. He undertook to attend to some Derby ladies at the exposition, and had to fly from the city before his time.

As respects his business the poor man has had a troubled time indeed. His books have never paid him anything, but, on the contrary, have weighed him down like a millstone.*

* In reading this passage the reader must not forget that it was written thirty years ago. Many years have now elapsed since Mr. Spencer's books began to return a considerable and steadily increasing income to the author and his publishers. 
Five hundred copies of the Psychology were published; three hundred remain on his hands. The Social Statics has done better. Seven hundred and fifty were published eleven years ago, and the edition is nearly exhausted. None of them are stereotyped, and so the several editions will very shortly be out of print, and he says he shall not try it again. Five hundred Education were printed, and two hundred are sold. He was desirous of doing something to circulate them, so he bound up some cheaper, to be sent by mail to teachers if they desired. Twelve copies were thus disposed of, with the result of giving mortal offence to the book trade, who are down upon the work in consequence of this informality. To crown his experience, his publisher, George Manwaring, has failed within three months, whereby he loses everything from the Education, and enough more on his other publications to make his loss five hundred dollars. As respects the First Principles, notwithstanding all the efforts, the whole thing would have been exploded and abandoned this summer but for some means which he obtained from the death of an uncle. By using that little capital he has been enabled to maintain the project and live. He did not say much to me about his experience, but alluded to it two or three times in a very simple and touching way in connection with the assistance he had received from America. That is all the profit he has ever yet had from his work, and he said it was as grateful and opportune as it was unexpected, for he had but little hope from that quarter; and he said his father thought that when he sent a circular to Mr. Silsbee and expressed some hope from that, he was very foolish; "but," said he to me, "you have quite extinguished the old gentleman."

And when I looked upon the man, with his health broken and nerves shattered, and remembered that his is the foremost intellect of our civilization, and that he is a man be- 
yond all other men of his age to control the thought of the future; when I thought of him hampered and harassed for want of means to publish his great thoughts-as having to think for the world and then having to pay the expense of instruction, setting up other men in intellectual business with a paragraph, I confess I thank God that I had had a little opportunity to do him service. Dear sister, let us respect ourselves more that we saw through the obscurity of distance the genuine and exalted claims of this unheralded man, and were led to help him in a way that he most needed help.

Mr. Spencer is a man who lives his philosophy. He applies his principles in the proper phraseology to the criticism and consideration of all questions which arise. $\mathrm{He}$ has not the slightest doubt or hesitation, nor is he at a loss. He did not talk much upon these topics, to be sure, while I was with him, nor did I desire to lead him into it, but the evidence of the complete mastery of his themes, that they are part of his mind's nature, crops out constantly. Again, he is equally ready in the application of his convictions of right and justice. "You see," said he, after two or three days' acquaintance with me, "that I have a very disagreeable habit of speaking my mind." For instance, he pounced upon every man in the cars who smoked, and several attempted it, as they have no smoking cars. Individuals would try to smoke out of the window. He always attacked them. "Is it disagreeable to you ?" they would say. "Not at all," he would reply; "but it is against the law, and the law is a wholesome and proper one. You have no right to break it, and you shall not do it; and if you do not desist I will call the guard." Again, when we were in Edinburgh Castle, in the bedroom of Mary, Queen of Scots, where her son was born, and let down outside through the window, an old Scotchman was trying to rally his recollections about some details, and appealed to Spencer. "I am 
happy to say I don't know," he replied. The old man was thunderstruck, and said he wished he knew all about history. "I should hate to have my head filled up with it, for it would exclude better things." With porter, cabby, or steamboat captain he was ever ready to do battle for the cause of justice; but he deprecates the tendency to faultfinding. "I used to visit Carlyle, but he has got so cross and misanthropic, and raves so constantly about the hor-r-rible state of things (imitating the Scotch accent) that I couldn't stand it. I do not want to argue with him and I will not listen to his nonsense, and so I stay away. $\mathrm{He}$ is a prodigious talker. His tongue rattles incessantly; even his wife can't get a chance to say a word till he goes out to smoke a pipe, when she starts up and proves that nothing but her husband is able to extinguish her." Carlyle's conversation, he said, was "one long damn."

When we stopped at the inn on Friday night, as the boat left at six, and we could breakfast on board, we left word to be awakened at half past five. Spencer hoped to sleep a little, as he had not done so the night before in Edinburgh in consequence of the noise; but we were all called a quarter before five. I lay abed. Kitty dressed and went down. There was a register on a side table in the diningroom, where travellers offer any sentiment about the scenery after their names, and often record praises of the hotel; and so the book is an object of display. When Kitty went down she found written, as nearly as I can recollect, as follows: "Prof. and Mrs. Youmans, of America, and Herbert Spencer, of London, taking lodgings for the night, left orders to be called at half past five o'clock, but were called three quarters of an hour earlier. This is part of a system pursued in this region to induce travellers to take breakfast before starting. I was imposed upon in the same way a few nights ago at Oban." Kitty says Mr. Spencer was very an- 
gry at the imposition.* 'The book was quickly whipped out of sight.

He thinks Mrs. Lewes the greatest woman living, if not the greatest female intellect that has ever appeared in the world. Lewes and wife live much by themselves, receive a few friends on Sunday, and he is the only person who has admission to them at all times. He called there one lay as she was finishing The Mill on the Floss, and Mr. Lewes, who was just leaving the house for an errand, met him on the steps. "Oh, Spencer," he exclaimed, "do go in and comfort Polly; she is crying her eyes out over the death of her children" (i. e. Tom and Maggie Tulliver). 'To obtain emotional relaxation after writing Adam Bede she read through his Psychology the second time. She is masculine in features, but soft and feminine in manners. He says he first proposed her writing fiction and pressed her into it. She was full of self-distrust, but at last she told him she had commenced Scenes in Clerical Life. He and Huxley think Silas Marner one of her very best things-a perfect prose poem. $\dagger$

He says Huxley has a new work on the relation of the

* Youmans's recollection was not quite accurate, for later in the letter he adds that Mrs. Youmans copied the writing in the album above referred to, and the latter part runs thus: "A similar course has been pursued at Oban to induce travellers to breakfast at the hotel, which reason may have operated also in this case." It was friends who had been treated that way, not himself.

† Another anecdote of Lewes and George Eliot may find a place here. Lewes had arranged to take a ramble in the country with Spencer and Youmans, but was prevented at the last minute, as the following note explained: "My dear philosopher: Polly is ill, and as husbands are inclivisible (and for that reason probably no matter), I am sorry to say that I shall not have a leg or a cerebellum at your service. Faithfully yours, G. H. Lewes." The quip on the divisibility of matter is a fair specimen of the atrocious puns and jokes with which Lewes was always bubbling over. There was something tonic and refreshing in that irrepressible flow of animal spirits. 
human brain to those of inferior tribes; Lyell, a new work on The Antiquity of Man; and Tyndall, a new work on the mechanical theory of heat. He reads nothing but what bears on the immediate thing he is writing, and but little of that. He expects to be reviewed by Mansel, whom he has thrust into an embarrassing position. Goldwin Smith and Mansel, at the same university, are at loggerheads over the doctrine of Mansel's Limits to Religious Thought. Smith charges him with atheism, and quotes Spencer's use of the doctrine as proof of it. Yet, when one of Spencer's parts is delayed, Goldwin Smith writes him a very kind letter of solicitude for his health, and is thus liberal and gentlemanly though thoroughly antagonistic. He says there is obviously a growing liberality of thought and speech toward the United States.

I broke off abruptly this morning, as I was forced away. I tried to put down everything material about Spencer. If I remember anything further $I$ will record it. He knows nothing about the state of practical education, never heard of the Home Colonial Training School, and thinks there is nothing here to be imitated. Viewed through English lenses, things look gloomy enough at the North. Everybody regards the independence of the South as a fixed and foregone and irreversible fact, and they look upon the movements of the North as the blind, infatuated, impotent struggling of political pride. Every success of the South is hailed with pleasure, and only the gloomy side of Northern affairs is presented. Even Mr. Spencer regards dissolution as determined, and deludes himself with the weakest sophistry to explain the present confused attitude of England. Your "conscription" and the frantic efforts to evade it are made everything of. . . . We leave to-morrow morning for Dover, Ostend, Brussels, Cologne, Basel, and where else Heaven only knows, to be gone a fortnight or three weeks. We shall not hear from you in all that time, but 
shall expect letters on our return. I shall see nobody that you are interested in, or I either, and as for a description of the places, you will find it far better in Cornell's geography. We write to-night to secure berths on the Great Eastern for October Ist. Give my tenderest love to Ma, and say to her that as she is a Christian and has faith that all things are ordered well, she should not vex herself about the course of worldly affairs. Remember me kindly to all, and write often.

Upon Youmans's return to London Mr. Spencer introduced him to Huxley and several other friends eminent in science and philosophy. From more than one of these men I have heard the warmest expressions of personal affection for Youmans, and of keen appreciation of the aid that they have obtained in innumerable ways from his intelligent and enthusiastic sympathy.

These beginnings of valued friendships were extremely pleasant, but there was much to mar the enjoyment of this first journey abroad. It was war time, and depressing news came by every mail. There was much to perturb a man of patriotic spirit in the general sympathy with the Southern cause expressed by Englishmen. From much pleasure in sight-seeing Youmans was debarred by his imperfect vision, while his irritable nerves suffered amid the worries and fatigues of constant travel. He visited the great Exhibition at the Crystal Palace, but cared little for it. However, when he attended the British Association's meeting at Cambridge, he felt amply repaid for having crossed the Atlantic. The addresses and papers pleased him greatly; and there was endless delight in observing men of his own race and language, who seemed to him foreign in so many ways. Their 
starchiness on the platform, their kittenish flow of animal spirits before and after business, the odd way in which men of advanced views were surrounded and "supported" by their friends, were all to him new and most amusing.

The following extracts contain some interesting details of the last days of this first visit to England:

\section{London, September 25, 1862.}

My Dear Sister: . . . I intended not to have called on Spencer, desiring not to trouble him until just before leaving London. But on Tuesday (I think it was) I met him on the street. He had heard, through Silsbee, that we had returned, and seemed quite surprised that we had not called on him or notified him of our return. I think he had been at some pains to find a place for us. He had on the everlasting stovepipe, which everybody-yes, everybody-wears. I was walking with him and let drop the word "residua," when he suddenly said: "By-the-by, Morell is in town, and dines with me to-night. Come and have dinner with us, and get acquainted with him. The only difficulty is, we are somewhat crowded at table." I protested I did not wish to intrude, but he said, "Walk home with me, and I will find out if there will be room." $\mathrm{He}$ insisted, and so we started. It was a mighty long way to Gloster Square across Hyde Park almost to the Exhibition. Gloster Square is about the size of Westcott's dooryard, and the house is about two blocks away from it, so that the green patch is just remotely in sight. Yet the neighbourhood is tiptop, and that is a very great deal here in England.

The mistress of the house, a doctor's widow, is a tall, conceited, pompous, spoony-looking creature. Mr. Spencer, somewhat embarrassed, unfolded the business: "Oh, yes, certainly-most happy. If there is not room we will make 
room." Then, turning to me with a smike, "Mr. Herbert is a great favourite in the house." "Mr. Herbert" curtly remarked that he "wasn't aware of it." As soon as we were out of doors he burst out: "The shallow hypocrite! I have done nothing to make myself popular in the house, least of all with her." I may dismiss the woman with an incident Silsbee mentioned. Sitting on the sofa, sewing, one day, she suddenly exclaimed: "Mr. Spencer, you are fond of books; here is Scott's Marmion!" pulling the volume out of her basket and tendering it to him. The dinner hour was half past six. I went home, and was back ten minutes before the time. Was taken upstairs to the sittingroom, where Spencer received me and introduced me to Dr. Morell. Oh, my! my! my! A youngish, jolly, jaunty, sandy-haired, thin-bearded, gold-spectacled, small-headed, little-nosed, undersized individual, the total reverse of all I had supposed.* We got acquainted the first moment. He had never heard of me before; did not understand and could not remember my name; but I knew him, and that was enough for both. He is a laughing, joking, smart conversationalist, who makes indifferent puns. We went to the dinner table. Morell talks German, and Spencer unfortunately seated him beside the most diabolical bore of a German that ever happened in the wrong place. He monopolized the conversation, to my great torment. I tried to turn it in some other direction, but the Dutchman would argue.

I learned that Morell wrote his History of Philosophy at the age of twenty-six; that he is ashamed of it every time he looks at it; and that it continues to sell. Moreil got Boase's work on The Duality of Forces, read five pages, could get no further, and shelved it. Can't read Bain-" "he is all very well, but I have no patience to read him; he is so

* Youmans was still apparently in that period of inexperience when one takes it for granted that distinguished authors must look distinguished. 
tedious." I tried to remember all the things that were said, but could not. It did not amount to much. The two men are different and opposite. Morell is a "national school" inspector, and has been in the receipt of a large salary for fifteen years, visiting schools. Has a place of his own, with cellar stored with choice wines; has made money on every one of his books; is the author of a grammar that sells twenty thousand a year; is in capital English health, etc., and consequently boils over with satisfaction. Spencer, on the other hand, is burdened and embarrassed-no sale for his books, in bad health, sleepless, and with the weight of his mighty subjects pressing upon his soul. It is natural that the bearing of the two men should be very different. I don't know how much they have previously seen of each other, but suspect but little. They made frequent reference to meeting at Dr. Carpenter's. For a little mischief I got them by the ears on the subject of state education. Spencer was intensely earnest; Morell cavalier, grandly indifferent_- had been through all that long since"; "all very well for reasoning, but it was a different thing to have the responsibility of acting in reference to the matter." I had to divert the discussion, for Mr. Spencer was getting excited, which is the worst thing in the world for him.

I don't know how it came out, but it did come out, that Morell had been into and through the socialistic craze. He had even had the Fourier fever, and fraternized with Doherty, etc., who represented the thing in England, as Brisbane did in America. He was a little semi-shy in speaking of it; half commended it, half acknowledged the sell; referred to his interviews with W. H. Channing, who sympathized, and is on the whole somewhat in the condition of Ripley on the subject. This is the rendering I put on what was hastily said. Another thing I was surprised to learn in regard to Mill. While intellectually there is accorded to 
him the same supremacy here as with us, yet personally he is regarded as a fanatic. He was so carried away with Malthusianism that he personally distributed tracts through London, like Bill Green-went round throwing them into the cellars. On the subject of women all his friends regard him as a monomaniac. If the intellectual equality of men and women is questioned in his presence he flies into a passion and raves and rages at an awful rate. Furthermore, his view of his late wife is recognized as part of the monomania. He married very late-lived with his wife but three or four years. She was a widow, and followed him over the Continent a good while before they were married. How she could have been "the inspirer and in part the author of all that is best" in his writings seems singular. She is buried at Avignon. He has built a splendid monument to her, and takes charge of the English portion of the cemetery, going there every year and spending a good deal of his time. These are quite curious personal details.

Morell knew Sir William Hamilton well. It was mentioned in illustration of Sir William's irascibility that, being once at a meeting of the Philosophical Society where Glacier Forbes, who was something of a dandy, attacked him, he exclaimed that he "was not going to be put down by a d-d puppy!" Great commotion. "Why, why, Sir William," cried the president, "such language as that before this learned body!" "I don't call this a learned body!" sputtered the angry Hamilton.

Morell thinks he shall rewrite his history, bringing it down to the present day; thinks he is better fitted for a historian than an analytic psychologist. The article he published in the Medico-Chirurgical in 1855 , which first introduced us to Spencer, was written at the request of the National Review, Martineau's Unitarian organ. As they had called for it, they sent him the money for it, but refused to publish it-it was too materialistic. Morell says they 
were just then introducing the phase of transcendental mysticism. (By-the-by, Garth Wilkinson was one of Morell's intimates in the Fourieristic time.) Spencer, in Part I, gives Martineau a rub, and now there is to be a review of Spencer in that magazine, entitled Science, Nescience, and Faith. Mill has an article in the forthcoming Westminster Review on the Slave Power.

When we broke up, Morell reproached Spencer for the brevity of his recent visit to him. He then unceremoniously took my arm and we walked homeward, his place being in Pall Mall (pronounced Pell Mell), near to mine. He gave me a cordial invitation to come up and spend a day or two with him. His business in London now is to inspect a training school-the Normal Training College, which stands upon the ground where Joseph Lancaster first established the monitorial system in the beginning of the present century. Morell says that it is the best training school in England, has the least theology about it, and nothing of the "routine" of the Home Colonial. So I made immediate arrangements to go over to the school and see some of the examinations. In all that, I was as much disappointed as in Morell himself at first. I had no reason, perhaps, for being so, but could not help it. Officials take things easy -as Spencer says, it is the nature of officialism. I saw the plan of working the machine, and was interested, of course, but there was not much inspection. The principal, Prof. Fitch, also examiner in English literature in the University of London, is an accomplished lecturer and a close thinker. I was delighted with him. I went to the school again yesterday. Morell got into the same stage, and we rode over the Thames (Waterloo Bridge) together, to the Borough Road, where the school is situated. . . . I lunched with Morell and Prof. Wilkes, who lives in the building. Lunch, as usual everywhere-hashed veal, boiled potatoes, cold meat, bread, and ale, with an apple or plum tart for dessert, all 
fresh and insipid. The American war was up. Morell favoured the view of Mill, and recognized slavery as at the bottom of the whole business. Wilkes stoutly denied it: slavery had nothing to do with it! He is a student of the Times, and quoted all the proslavery action of the North, with the recent demonstration of Lincoln to the black committee.* Morell gave me a copy of his Grammar, and Fitch of his Arithmetic. It is now Friday morning. Morell, Spencer, and Silsbee are to dine with us Sunday night at seven. The Scientific Association meets at Cambridge, October rst. Morell does not go. We shall go, though whether we remain till the close is uncertain. . . .

I went with Spencer at his request to see Tyndall respecting the republishing of his forthcoming book. He was at the Royal Institution, where their researches are carried on in a dingy hole dow'n cellar, which Tyndall denominated the "den." $\mathrm{He}$ is a single man of forty, with a scanty" strip of forehead, and big, straight, prominent nose-the most restless, nerrous creature I ever set eyes on. We stayed but a few minutes, and nothing was said of anything but the book and the publication of books.

Saturday, September 27th.-Was in the Exhibition yesterday, $\nmid$ and never had such a realizing sense of the humbug of art criticism. "Breadth, depth, simplicity, truthfulness"; "Truthfulness, simplicity, life, beauty - a splendid little piece of Nature," etc., ad infinitum.

We have nothing from home since September $2 \mathrm{~d}$, though we watch daily and with extreme aridity. The war plot thickens with you. Heaven only knows how the knot is to be cut; but by the present outlook it must be soon. The sympathy with the courage and spirit of the South is universal here. Our last newspapers are the inth September,

* The news of the emancipation proclamation had not yet reached England to confute Prof. Wilkes.

$\dagger$ He was in the picture gallery in company with a couple of art critics. 
dispatches by telegraph to the $\mathrm{r} 2 \mathrm{th}$. We wait most anxiously for later news.

London, September $30,1862$.

At the close of my last I mentioned that we had invited Spencer, Morell, and Silsbee to dine with us on Sunday evening at seven. Spencer invited us (Silsbee and ourselves) to go to Kew Gardens in the afternoon, or rather to go first to Richmond, which is three or four miles beyond Kew, and see the scenery, which is said to be very fine, and then return by a small boat to the Garden. We did so, taking rail at ten o'clock. It was muddy, foggy, and semi-rainy, the nastiest sort of a morning. As we left the city it cleared up, but upon our arrival at Richmond-eleven or twelve miles-it had again clouded up densely; a fog covered everything, and we could see nothing. Stopping at an inn, we took a little lunch and proceeded to the Gardens. Dr. Joseph Hooker, the most philosophical botanist of England, is in charge of the Gardens. Spencer knows him, and intimated that he should call upon him, and he would perhaps accompany us. He called. We went on, but he overtuok us alone; the doctor did not accompany him. Spencer said he did not offer to come out, "as showing the Gardens is no doubt a great bore to him." We wandered round till five o'clock, when there suddenly came a heavy rain. We waited under a large horse-chestnut tree till it began to rain through, and then started amid shower and mud for the depot. We were getting drenched, so Spencer got a cab, and we got into the place with an immense crowd, all driven in by the shower, which made it doubtful whether we could all be accommodated by the train. I had wished to take the half past four train, but Spencer overruled it quite abruptlysaid there would not be time at the Gardens-that we could get to the city station at five minutes past six, and be at home at half past six, in abundant time for dinner at seven. The great crowd caused delay of the train, and when we 
reached the station, three and a half miles from our place, not a vehicle was to be had, so we had to foot it through the mud a long distance. Got a cab at length, and got home one minute before seven, bedraggled with wet and mud. Morell was waiting, and we dined. ...

I have been over to the Training School this afternoon to see a specimen of the way they do things. It was very interesting, and shows great progress. Principal Fitch is a very able man-I think the best adapted for his position that they have in this country. Spencer called to-day while I was out, and left us an introductory note to Huxley, who is president of the zoölogical section. It was very kind and quite unexpected. I called on Prof. Miller, at King's College. He received me pleasantly, and showed me the laboratory, which is down cellar, but more roomy than the Royal Institution. He was disposed to discuss the war, but couldn't understand what we were fighting about. We go to Cambridge to-morrow.

Cambridge, October 2, I862.

We arrived yesterday on the bank of the Cam. All were notified to proceed to the Town Hall at once to secure places. We inquired of a fellow-passenger the distance from the station to the hall, and were told "five minutes' walk"; so we started and found it nearer an hour's walk. There was a great crowd of applicants for places. The hotels were all filled; lodgings only were to be had, and there was a book with registered places, prices varying with proximity to the place of meeting. We took quarters at 34 Jesus Lane, five minutes' walk from the centre of attraction, and opposite Jesus College. I went back with the porter, who showed us how to procure our baggage; then went to the hall again to get some information, and shortly started for our new quarters in Christ's Lane. The town is a confused network of little crooked lanes. I inquired for Christ's Lane, and was di- 
rected, and wandered and wandered till I found it. I then went the whole length of it and couldn't find the house. I then counted the numbers, and there was not a 34 in it. I think I was mad at the town. There was Christ's College and there was Christ's Lane, but no place to enter. So I attacked every person I met on the general subject of the theo-topography of Cambridge. At length somebody asked if it might not be "Jesus" Lane that I wanted. I told him "Certainly." Then said he, "You will find it near Jesus College, at the other end of the town." So I found it, and a quite comfortable place it is. Opposite is a low stone building used as a store, and over the door the name of the keeper-G. Death.

The first meeting was last night, at eight. We got in at 7.30 , and went up near the platform. It is a fine lecture room in appearance and decoration, but without the slightest ventilation. Only those were admitted who had tickets, but it was full-nine hundred or a thousand. The hall was early crowded, and such a hum and bustle of joyous recognition I never before witnessed. The English on such an occasion are far more hearty and social than the Americans. Everybody was busy shaking hands and chatting with everybody, and at the same time watching and inquiring who were present. The president-elect was Rev. Robert Willis, Professor of Natural Philosophy at Cambridge, and he gave as an opening address of an hour and a half the History of the Association. It appeared in full in next morning's Times. Prof. Owen moved a vote of thanks with a little speech, the first part of which was glib, but the last part fizzled amazingly. The Dean of Ely, a high ecclesiastical functionary, seconded the motion, with a little speech which, although good, tapered to a vanishing point like the other. A large, florid, very fine-looking man, with the port and semblance of old Ike Rowland, and something of the aspect of a Methodist parson, appeared before us. He 
had a lady with him, evidently his wife, and they took the second seat in front of us. At the first glance I whispered to Kitty, "I think that is Dr. Whewell!" Presently I asked a man near us who it was, and he replied, "The Master of Trinity!"

On Thursday, business opened at eleven by addresses by the chairmen of the several sections. There is no general session. We selected Huxley's, in the department of zoology and botany, and we were fortunate, for it was a most admirable address-explanatory of the scope and purposes of biology. I meant to have got his classification, and shall yet; it is very lucid. Spencer says that, of all the scientific men he knows, Huxley is the only one who understands the importance of biology and sympathizes with his work in this direction. . . I In the geological section there was yesterday some fun. Owen came down on Huxley about man and monkeys in his papers, one after another. The two men hate and despise each other. Huxley is much more of a man, and is more like Spencer, outspoken and independent. Owen is an old grandmother, whose business is to nurse her reputation-jealous of newcomers and exasperated at opposition. He was not present at the reading of Huxley's address. . . . Last night there was an address by Tyndall before the association in the lecture room; subject, Water in its Several Conditions. It was altogether the most brilliant affair of the kind I have ever seen. . . . The new philosophy of forces permeates everything. All science seems worked with reference to it. Tyndall not only assumed it, but it was the foundation of his philosophy. While I was with him the other day Spencer started the point of using the term "persistence of force" rather than "conservation." They had quite a spurt over it, Tyndall declining to meddle with the words he found. But to-day Huxley used the term "persistence of force." The experiments last night were, first, testing oxygen and hydrogen separately ; second, 
exploding them together; third, bursting iron bottles by freezing; fourth, exhibiting the formations of crystals by the electric light in a vacuum; fifth, formation of an immense spectrum on a screen-absorption of its different parts by coloured glasses; and, sixth, regelation of iron. He had splendid diagrams of the glaciers, but hardly referred to them ; was chiefly occupied with the watery vapour of the air and its relations to obscure radiant heat. Tyndall has sufficient Irish blood and temperament-not brogue-to remind me constantly of Plunkett. He was not still a moment, but bending and twisting in all possible shapes, as if he had the St. Vitus's dance-twisting his legs together, bending down to the desk, and working and jerking himself in all possible directions. Everybody was kept wide awake, entertained, and instructed. It was a work of enthusiasm.

At Cambridge and elsewhere Youmans learned much, and picked up many hints for future work, but on the whole he was not sorry to return home after an absence of four months. 


\section{CHAPTER IX.}

THE APOSTLE OF EVOLUTION.

$$
\text { 1863-1864. Age 42-43. }
$$

THE next year (1863) was the mid-year of the war, the year of the great victories at Gettysburg, Vicksburg, and Chattanooga, but none the less a time of sore anxiety, for no one could as yet see how near the end was. The publishing business, in which Mr. Youmans had already so many broad and generous interests bound up, suffered severely. Telegrams from the battlefield withdrew people's attention from science and philosophy; and the violent fluctuations of an ill-advised currency of inconvertible paper added to the losses of a curtailed publishing trade. "As things are," said Mr. W. H. Appleton one day, "it is no object to publish any book; we would rather stop business if it were possible." The plates of Social Statics were offered, by way of experiment, to "three of our best publishers. They liked the book, and were aware of the favourable position of the author in this country, but they did not want to publish anything. They were compelled to issue a book now and then to keep their names before the public, but would far rather sell the works of other houses than manufacture themselves."

I cannot expect to give you a satisfactory account of the state of things here [wrote Youmans to Spencer a little 
later], but I will attempt it; the fact is, you ought to come here and spend six months and then you could judge for yourself. The difficulties are, first, that the labour and materials are enormously advanced in price; composition and stereotyping are doubled, and paper is trebled. Government has levied a tax of five per cent directly upon all sales, while all business transactions and advertising are also heavily taxed. In your letter you comment on this state of things, and observe, "If the cost of labour and materials has risen, I do not see why the cost of manufactured articles does not rise in something like the same proportion." Well, such is the case generally, and the price of books in some instances is doubled. Your Essays, which five years ago would have been a dollar, now sell for two dollars.

But there is this trouble-books are luxuries, to be bought only after other wants are supplied, or not bought at all if there is not plenty of money. People finding themselves pressed on all sides by exorbitant prices retrench when they can.

Butter has gone up from ten to fifty cents per pound, and a considerable portion of the community are now abstaining from its use.

Moreover, it is the chief book-buying class-people formerly in easy circumstances, with fixed incomes-that now suffer. The rate of interest is the same, and their former income of gold is now an income of greenbacks only nominally equal. The consequence is, that as the price of books rises the sales diminish in a greater ratio than in any other business. But though sales diminish, the publisher must still keep up his stock.

Mr. Appleton remarked: "Should materials fall to their former prices, I should lose a hundred thousand dollars on paper alone-printed stock." Again, if a house is wealthy, like Appletons' or Harper's, it matters little how things go; 
they can stand it. They can put up prices stiffly, and let things take their course. But not so with the trade generally. The mass of booksellers are far from rich; they must sell. if at the smallest profit; accordingly they yield to the pressure and sell low. The book business at the present time must therefore be looked upon as an anomaly in respect to the relation between the price of materials and manufactured products.

Throughout that dreadful summer of $1863 \mathrm{Mr}$. Youmans found in hard work the best specific for nervous depression. He was busily engaged in rewriting his Chemistry, so as to take account of the remarkable discoveries which had overthrown the old binary theory and given a new aspect to the whole science. Amid the beating of drums and the bugle notes of regiments starting for the seat of war, his work was most thoroughly and conscientiously done. While this was going on, a moment of acute terror visited the city of New York. The following letters give some account of the "draft riots":

Wednesday, July 15, 1863.

Dear Father and Mother: We are in the midst of very exciting times, and as you are probably informed of it by the newspapers and may be anxious about us, I drop you a line. The city has been proclaimed by the Governor to be in a state of insurrection, and he is certainly right. The mob rules the city. By actual violence and by fear and terror they control everything. They commanded the city railroad and omnibus establishments to stop running or they would set fire to their stables. They are therefore all stopped. They have cut the telegraphs, and torn up the tracks of the railroads which go out of the city, to prevent the transmission of intelligence and the entrance 
of troops. Having broken up the places of drafting and burned them without resistance, they then went to burning negro dwellings, and from that to general burning, pillage, plunder, theft, robbery, and murder. A man last evening was seized and choked, in front of our house, until he gave up his purse. Men are knocked down and robbed everywhere with perfect impunity, for the police are gathered in companies to fight the rioters en masse, and thus the streets are left unprotected. Nor dare men resist, for worse may befall them. The effect of intimidation is tremendous, and the mob work it skilfully. I ventured out this forenoon to the printer's-half a mile or so away. While I was there, up in the fifth story, where they are doing my work, two bullies entered the office below and ordered the establishment instantly closed, and all the hands (three hundred) turned out, or else they would burn the building. The risk was real; the order was at once complied with and business stopped. The two bullies went right on doing the same thing to other estabiishments with equal success, and the consequence is that the streets are deluged with working people out of business. A portion of this crowd is of course sucked into the vortex of strife, and the rest so clog the thoroughfares as to make it dreadful for the military to fire. The innocent are far more liable to suffer than the guilty. And as there is no other way under heaven but to fire, great numbers of women, children, and innocent men are injured. The mob is nearly all composed of Irish, and they are raging for the blood of the negroes. We hear nothing but "damned nigger" and "damned abolitionists" in all directions. But when the blood is up, nothing comes amiss. They cleaned out a whole row of stores on Grand Street yesterday. A hatter thought he was going to escape by damning niggers too, but they took every hat out of his shop. The draft is no doubt unpopular, but those news- 
papers that have made its unpopularity their capital, and raved about the despotism of Lincoln, have got more than they bargained for. We are very comfortable, and hope the storm will soon pass by, so that in ten days or so we may be able to leave the town. But there is no knowing how long it will last.

With dear love to all, very affectionately,

$$
\text { E. L. Youmans. }
$$

NEW YORK, Friday evening, July 17, 1863.

DeAR Sister: I received your two letters to-day, and was every way relieved, and pleased that you were at home. I take but a moment to write; it is seven o'clock, and dangerous to be out later-if, indeed, it is safe to venture out one block to the lamp-post. The fury of the riot, I think, is passed, but we were kept awake till midnight last night by the firing on Second Avenue. We are well, and oppressively busy; the printers are pushing on, and we shall be done soon, and can come home, which I greatly desire. You will have time to write, so don't forget us.

\section{Friday morning, July 24, 1863 .}

Dear Sister : Coming in at D. Appleton \& Co.'s I find your letter. . . I first heard yesterday of the alarm at Saratoga, and heard it had been very serious. I am drudging with desperation to get things along as fast as possible. I did have hopes of getting the text done this week. Proof reached 380 last night. It will probably make 450 , and they will get to 4 ro or 420 to-morrow night. I am now straining everything to finish next week, and shall come up the minute the last line is corrected. When the text is made there will then be the contents and preface. Kitty can do the former and I the latter. I calculate to have the text done by Sunday night.

In the course of the next twelvemonth the sale of the New Chemistry attained large dimensions, and 
not the least gratifying recognition of its value came in an order from Harvard University for two hundred copies. Youmans was much gratified at receiving the following letter from Dr. Oliver Wendell Holmes :

2i Charles Street, Boston, March ro, 1864.

MY DEAR SIR: You may remember-what I certainly have not forgotten-that you called on me some months since and left me a copy of your Class-Book of Chemistry. I placed it upon my shelves, thinking that at some future time I might do something more than glance over it, which was all I pretended to do at that time.

Some days ago I had occasion to look at it for some accidental reason, and while it was in my hands I was drawn to a more particular examination of it. I read the dedication, and liked it particularly. I read the preface, and was pleased with that. I read the introduction, and was struck with its philosophical breadth and the simple clearness of its style. I looked over all the illustrations, which seemed to me particularly well contrived or selected. I had become interested in the book, and read various chapters relating to matters of which I knew something but wished to know more. In every instance I was very much gratified with the neatness of statement, the freshness of the views brought forward, showing that you kept up with the vanguard of science instead of lingering in the rear. I was also pleased with the unpretentious way in which the true essentials of each special branch of the science were laid down, without any unnecessary amplifications for the sake of making a book, as is too commonly done. I was furthermore glad to see that the proportions of the various parts were preserved, so that no subject was overdone and none neglected.

In mentioning your book to Prof. Bacon, of the Harvard Medical School, I was glad to find that he agreed with me in the very favourable opinion I had formed of it, 
and that it was on the list of books recommended by him to the students. For myself, I consider it a real accession to my library, and renew my thanks for it with thrice their first cordiality. And so, my dear sir, I have the pleasure of signing myself, Your truly obliged friend,

O. W. Holmes.

Soon after rewriting the Chemistry, Youmans published, under the title of The Correlation and Conservation of Forces, a collection of monographs by Faraday, Grove, Liebig, Carpenter, and Mayer, with an introduction by himself. This introduction is an able condensed statement of the modern doctrine of forces, with its pregnant implications for the guidance of life. The book was just what people needed, and it had a very large sale.

As a consequence of his visit to England, Youmans had been instrumental in having the Appletons reprint the principal works of Bain, Huxley, Tyndall, and other men of mark. It became part of his daily task to do what he could to bring these volumes suitably before the public. In this he was much helped by his wide acquaintance throughout the country among teachers and others interested in the spread of science. Wherever he knew a competent reviewer he sought his aid in connection with the local press. In New York his journalistic relations were such as to insure the widest circulation for the reviews he himself wrote. These were usually analyses clearly bringing out the positions of an author, adducing the arguments in support of his conclusions. This was exactly the kind of work he liked and excelled in. The results attending the faithful work of himself and his allies, performed as it was in the midst 
of the turmoil of war, were satisfactory. His faith that new science had but to be known to be appreciated was justified.

While enthusiastic in propagating modern views in physics, chemistry, geology, and the organic sciences, contained in the works of Tyndall, Huxley, Darwin, and their allies, Youmans felt their work to be tributary to that of disseminating the philosophy of evolution. As presenting the supreme organizing idea of modern thought, his chief effort at all times lay in directing inquirers to Mr. Spencer's works, in explaining their doctrines, defending them from misquotation and misunderstanding-in being, in short, the American apostle of evolution, fervid, instant in season and out of season, making opportunities where he did not find them. A series of extracts from the correspondence of 1863 and I864 will illustrate the zeal and efficiency with which this work was carried on.

New YoRk, March 28, 1863.

My dear Mr. Spencer: I ought to have written you before, but have been delayed partly from being very busy and partly to get some information concerning the state of your account. But so great is the pressure in the department which has your subscription in charge that I have as yet quite failed. The new Cyclopædia is just finished, and is having an enormous sale! The presses are driven day and night upon it, and they are far behind their orders. The clerks are overworked, and I have not pressed them for the information I wanted... The subject of an American edition of the Essays is still in my mind. I suspect it will come to that at last, and perhaps soon. The book trade is recruiting. I feel a sort of embarrassment at soliciting anything further from you under present commercial circumstances, and I must take the liberty of very strongly 
urging you not to draw money from this side at the present ruinous condition of exchange.

I know you view the state of affairs here with great apprehension, and it is not surprising that you should; but we are NO'r going to the devil. "My word for it," if you want a guarantee! I believe that any amount you may leave in the hands of $\mathrm{D}$. Appleton \& Co. will be just as safe as if in the hands of the best London publishing house you could name. It would be far better to let it lie idle in their hands a considerable time than to draw it before exchange finds its equilibrium; or, better yet, you can have it deposited in a savings bank, where it will draw six per cent interest. I believe those institutions are entirely trustworthy. I trust them myself without hesitation. I hope you will trust us for the present, and when the amount of indebtedness becomes considerable, if exchange is still high, it would be better to invest it in some form of produce consigned to a London or Liverpool commission house. Excuse me for interfering with this element of your business. I have done it in pure friendliness, and I shall be grieved and disheartened were you again to lose as you sacrificed last fall.

I received the advance sheets of Prof. Tyndall's book on Heat, and I beg of you to express to him my sincere thanks for the kindness. The Appletons will issue it at the earliest moment, the cuts being already nearly all re-engraved. It is a very fascinating and altogether remarkable book, and it will be a pure pleasure for me to work for its circulation. It cannot fail, I think, to have a good sale.

Prof. Huxley's Lectures to Workingmen we have issued,* and the Evidence of Man's Place in Nature is in the

* In a letter to his sister, dated February I3, I863, Youmans thus speaks of Huxley's little book: "There came at the same time from England a book of Huxley's of which I had not heard-six lectures to workingmen on-what do you think?-Darwinism. The most perfect 
printers' hands. There was competition for the latter volume. The Appletons advertised it as soon as I returned, and have continued to do so; the Philadelphia publisher of Lyell's new work wanted it badly, and ventured upon the ruse of announcing it from advance sheets; but when he began to realize that if he persisted the Appletons might possibly reprint Lyell upon him, he prudently withdrew from the contest. The work is now in the best hands that could have it.

So you see we are getting used to the war, and there begins to be liberty again to think of something else. And speaking of "liberty" reminds me of Mill's Liberty, and the growth of liberality here, of which it is an illustration. When it first appeared I tried to get the Appletons to publish it, but they were afraid of its radical doctrines, and other houses also refused it. I revived it again recently, and they consented to issue it. But on advertising, it turned out that five houses had simultaneously announced it, while Ticknor \& Fields, of Boston, having the start of all the others, will publish it. I am glad we are to have it for general circulation. I have read Part I of the Biology with great interest. I think more can be done with this than with its predecessors in the way of business. I have firm faith that as your philosophy is unfolded it will be better and better appreciated, and may ultimately prove compensating and indeed very profitable to you. My wife, who happens just now to be busy directing some circulars to those of your subscribers who have not renewed their sub-

little gem of a book I have met with! George Appleton sat up till midnight the first day of its reception to read it, and is crazy to have it republished. My first impulse was to send you my copy, but I decided not to, for two reasons: It would distract your attention, and you have not strength for so much now ; and, besides, there is a lecture in it on Method that is so inimitable-Spencer's idea of the growth of science, etc.-that I am ashamed of my introduction and shall reconstruct it. Huxley beats Hugh Miller out of sight in lucidity." 
scriptions, asks to be very kindly remembered to you. I thought it best not to send away Parts V and VI any faster than they were paid for. Remember me with kind regards to Mr. Silsbee, if he is still with you; and believe me, Faithfully yours, E. L. Youmans.

29 Bloomsbury Square, London, W. C., May 12, 1863.

My Dear Younans: Let me once more thank you for your continued attention to my affairs, which is the more to be valued by me as being given under your present great pressure of work. Your unflagging enthusiasm for the propagation of advanced ideas is something quite remarkable, and the spectacle of it serves one as a kind of moral tonic.

I read to Huxley and Tyndall the passages in your letter concerning them. They were pleased at finding their respective reprints so rapidly pushed forward. . . . I am much obliged to you for your advice respecting the disposal of the amount due to me from Appletons. I asked the opinions of several mercantile men here (one an American), and they advise me to draw at whatever sacrifice. I feel somewhat inclined to follow this advice, notwithstanding your protest. I cannot but think that the comparative prosperity you describe is an illusive indication of your social state, and results from the spending of capital rather than revenue. There was a like condition of things during the French Revolution, and in England during the war with France. But in both cases there came a fearful prostration and a discontent of the lower classes, which would probably have produced social convulsion had not the repressive power of political organization been so great. With you there is nothing like so great a repressive political organization, and under the same intensity of popular distress a crash would be much more likely to result.* I doubt not

* Mr. Spencer was probably wrong here. I doubt if any other government in existence would be so hard to overturn by a social convulsion as that of the United States. 
that you would afterward recover your equilibrium, but I suspect that terrible commercial catastrophes and an immense sacrifice of property would have to be gone through. On the whole, I prefer to lose by the state of the exchange than to run the risk of much greater loss. Please, therefore, when the account has been made out let the balance be transmitted. I was greatly obliged to Mrs. Youmans for her interesting letter of April IIth. I was glad of her information and opinion respecting the war and its prospects. The view she takes of the past and future of this terrible struggle is one in which I perfectly coincide.

Ever yours, very truly, Herbert Spencer.

29 Bloomsbury Square, W. C., October 28, 1863.

My DEAR Youmans: . . Thank you for the copy of the New Englander which you have been so good as to forward. The review it contains is a fair representation of the first part of First Principles, especially considering that it is written by a minister.* The objections made are such as must, of course, be looked for from such a quarter. One point in it, however, annoys me--viz., the assertion that I belong to the school of Comte. This is a misunderstanding which I am anxious to rectify; for, though I am quite ready to encounter the prejudices raised by opinions which I hold, I do not like to bear the odium of opinions which I do not hold. Dissenting from Comte as I do on all those points that are distinctive of his philosophy, I object to being classed as in any degree his disciple. I am therefore thinking of writing a letter to the New Englander, setting myself right with its readers on this point. Should this letter appear, I should be glad if you could get it republished in the Tribune; for I fear

* This review was written by Rev. Jonathan Ebenezer Barnes, of Middletown, Conn., a scholarly and thoughtful clergyman, whom I knew well and highly respected. He died at an early age in I 866 . 
that this erroneous notion is widely spread, and may do me much harm if not rectified.

In the last number of the North American Review I see an interesting article on the Evolution of Language, partly based on First Principles. ${ }^{*}$ If there have appeared, or should appear hereafter, any noteworthy criticism, I should be glad if you would let me know, so that I can get copies of them through Williams \& Norgate, who have now become American agents. . . .

Faithfully yours,

Herbert Spencer.

The foregoing extract is inserted in advance of some of earlier date, which are now to follow, and which present a continuous story. It must be borne in mind that up to this time none of Mr. Spencer's books had been reprinted in America except the Education, though First Principles and part of the Biology had been issued to subscribers in numbers, as published in London.

New YoRk, Wednesciay, September 16, 1863.

My DEAR Sister: I want very much to go up [to Saratoga] to-night, and have hitherto hoped to do so, but I shall not be able. Things to do-important things-thicken, and must be attended to. I find myself in such a position of influence with the New York men that I must avail myself of my opportunity. ... Ripley is doing the splendid thing by me in the Tribune, and the more I know him the better I like him. He is broader than I supposed, and

* I was the author of this article, published in the North American Review, October, 1863 ; and it was followed by another, entitled The Genesis of Language, in the same Review, October, I869. Neither of these have been republished among my collected writings, because the rapid progress of linguistic science has rendered them somewhat antiquated. 
much of his apparent narrowness and intolerance I have found out to be mere bluster. He dined with us the other day.

Saratoga, November 4, $186_{3}$.

My DEAR Spencer: When last I wrote you I promised and expected to write again very soon, but the plans I had formed, depending as they did upon seeing many persons, were not so readily executed as I had hoped, and I thought best to delay troubling you with a letter until I could communicate something definite and satisfactory. My purpose has been, from the beginning, twofold-to circulate your writings as extensively as possible, and to do it in such a manner that you might share the pecuniary results.

It had been comparatively easy to accomplish the first object unembarrassed by the second. That (which would have been also much easier under usual circumstances) has been made difficult by the state of the times, and so refractory have been the elements with which I have had to work that I could not urge the business as I would like to have done. I find satisfaction, however, in the thought that the course which has been taken is perhaps on the whole the best.

There has been in many minds a helpful progress and ripening of opinion respecting your philosophical views, which makes the present a fitter time for action than would have been any period earlier. As respects writing to you, what I have lost in time I shall now make up in quantity, and must trespass upon your patience, to lay before you with some fullness the present aspect of affairs.

Some weeks since I urged Mr. William Appleton to republish the present volume of the Essays upon the same terms as the Education. He read it and spoke highly of it, but said that by printing it you would gain nothing and he would lose. I replied that the writings of Mr. Spencer had many admirers throughout the country, and that I thought their relations to the author had in them so much of sym- 
pathy and personal interest that they might be counted upon to assist the circulation of the work. He replied: "We have a great deal of that kind of talk in the course of business, but it will not do as a basis of action. Yet, if $\mathrm{Mr}$. Spencer has friends who are so much interested in his thought that they are willing to divide with me the risk of publication, I will meet them with an equal liberality. Whatever their action produces shall result in an increased dividend to Mr. Spencer." This was certainly fair, and all I could desire; I have therefore taken action accordingly.

But let me here state that Mr. Appleton's refusal to publish the book is by no means to be taken as an index to the universal publishing mind. This house is proverbially slow and cautious; other establishments are more venturesome and ready, and would be unhindered by any consideration of copyright. I have reason to know that there has been, and is now, much danger of your books being seized upon by other houses. The long and, I think, exceedingly favourable review (considering its orthodoxy) of First Principles in the October New Englander (a copy of which I have ordered sent you at Derby), the recent article in the North American Review, which the author * will send you, and other indications, show a growing appreciation of your works, and I am sure that the danger is imminent of their seizure by other houses. The effect of this would be that you would get nothing from the new publisher, while the competition immediately arising would make it impossible that any other house should pay you anything. Should Blanchard $\uparrow$ publish First Principles-and it is far

* I had just met Youmans for the first time three days before this letter was written, as will appear below.

† Calvin Blanchard, a disreputable publisher who kept a shop on Nassau Street, where you could buy any kind of book that your minister would frown upon-whether for free thought or for obscenity made little difference to this unsavoury Calvin. It is odd to find him wanting to pub- 
from impossible (I prevented him from publishing Social Statics)-it would not only ruin the entire subscription project, but, by mingling your name with the gang of obscene, prurient, and scoffing authors whom he patronizes and advertises, would make it very embarrassing for others.

Perceiving, then, as I thought, all the bearings of the case-the hope of advantage and the danger of loss-I determined to proceed from Mr. Appleton's proposition as a base, and see what might be done. I have accordingly spent the last three weeks in a tour of observation and inquiry through New England, to make the acquaintance of some of those who have taken interest in your writings, and $I$ have had a most gratifying experience. I found with most of them a hearty and earnest appreciation for your labours and a deep solicitude for their continuance.

There was a uniform and strong desire that your books should be issued here in a form suited to the American market, and, I need not add, a cordial and unanimous wish that you should reap every practicable pecuniary advantage. The plan I proposed met with general concurrence, and it was resolved to issue one of your volumes at once upon the terms offered by Mr. Appleton.

I have not seen that gentleman lately, but expect to talk with him soon, and arrange the precise terms of the undertaking. There was some diversity of sentiment as to which of your works should be selected for publication, but it was generally thought your Essays would be most successful. Others considered it more desirable to issue First Principles, and in behalf of this opinion it was said that this being your latest work, and coming forward into notice as the opening of a new system of philosophy, it will be more in demand. In this stage of the matter I should be glad to learn what you think upon this point, and also

lish Social Statics. Probably somebody had told him that the author was an "infidel" or a "positivist." That would have been enough. 
to get a statement concerning the forthcoming volume of Essays. Will you not send me its table of contents, and tell me how much it will make, what will be its price, whether you have begun to print, whether it is now too late to negotiate for a large edition, and, if not too late, on what terms it could be procured? Should we publish the present Essays, could we not procure editions of First Principles and of the new series, by taking a considerable number, so near to cost price that we could afford to throw them into the American market as high-priced American books, and thus secure a supply and forestall competition? I fear that the rate of exchange will make this utterly impracticable, and at any rate it is only a suggestion of my own, and amounts to nothing until I see Mr. Appleton. My chief anxiety now is to learn concerning the new volume of Essays. We may choose to print a volume selected from the two, particularly if it is impossible to arrange for an American edition of the second series. How does that notion strike you? It would be every way desirable to make the book we issue now as complete a business success as possible. Such a result would be highly salutary in all directions. If desirable, another volume could follow with the remaining essays. I wish, however, to begin in such a way that step by step we shall get all your works; for a very common experience with us is, that when a person has procured one he subsequently wants the rest, and it is most desirable also that they should all be procurable in one place. Again, I want a popular introductory statement of your scheme of philosophy to prefix to the volume we publish-something continuous, readable, and attractive. Your synopsis is of course invaluable, and should be published at the close of the volume, but it is not the thing to win strangers. I am not competent to do that any sort of justice; I will do the best I can with such assistance as I can get, but I should be glad of any hints from you; or, if 
there has been any sketch of the kind in newspaper or review, will you not send it to me, if convenient?

It has been suggested that the term Essays is the worst title by which a book can be known, and that this class of works is generally least successful of all. There may be something in the suggestion, but I should not like to interfere with an author's preferences. Would you object to a change, or, if we should compose a volume out of the two, could you not suggest something fresh, sharply defined, and "taking"? You have a remarkable facility in this; it struck me long since, and I have heard many remark it. I will not protract this letter, as I have communicated all that is of special importance. I will write you again soon, and speak of some persons I met and their relations to your writings.

I look forward to the time, and I believe it is not very distant, when all your books will be republished here, and you will have an extensive and appreciative American audience. In view of this, if there were any articles or parts of articles in the Essays which have reappeared or are to reappear in the early parts of your serial you might perhaps choose to omit them. We have decided to publish one book now, and it will probably be the Essays.

The action I have taken is to me a great source of pleasure. I have enjoyed it every way, and have a deep gratification in its promise of future results. You very kindly allowed me to take the thing into my own hands, and I have adopted the course which all approve and think wisest. I trust your health continues as good as you last reported it. I am afraid you will have trouble to read what I have written, but my wife (who begs to be kindly remembered to you) thinks it may be readable. Please remember us both with very kind regards to your father and mother, who are, we hope, still in good health.

Yours very truly and sincerely,

E. L. Younans. 
The unconsciousness of the opening paragraph of Mr. Spencer's next letter is charming:

6 Hinde Street, Manchester Square, November $18,1863$.

My DEAR Youmans: I have been hoping for some time past to hear from you. I suppose, however, that the getting out of your Chemistry has absorbed all your attention; and also, perhaps, that you have nothing special to report.

I fear that the present disastrous state of things with you will have an injurious effect on your literary enterprise, as well as on the enterprises of others. It is reported here that the New York publishers have agreed to bring out no more new books for the present. Is this true? and, if so, how will it affect you?...

November 21.--Had it not been that I had lost my copy of the Reader which contained the accompanying extract, and that I have been delayed in getting another copy, I should have posted the enclosed sheet to you three days ago-that is, before the arrival of your welcome letter, which reached me last night.

The energy and self-sacrifice you continue to show in the advancement of my scheme quite astonishes me; and while in one respect it is very gratifying to me, yet in another it gives me a certain uncomfortable sense of obligation more weighty than I like to be under. If it were not that this sense of obligation is in some degree qualified by the consciousness that you are in great part prompted to what you do by your love of truth and your philanthropic desire to aid the spread of it, my feeling on the matter would be really oppressive. Similarly, though in a smaller degree, the results of the tour you describe give me a pleasure which, though great, is not unmixed. While I am rejoiced to find so much interest felt by many of your countrymen in the diffusion of my writings, yet the consciousness that they run any risk in aiding this diffusion is 
a somewhat painful one to me. However, I hope that what steps are taken will be taken with such caution that those who stand in the position of guarantors will suffer no loss. ...

The first part of this letter answers several of the questions contained in yours. The new volume of Essays is now issued here, and the two hundred and fifty copies for America are on their way to you. In printing these two hundred and fifty only for your market I acted on the opinion which you sent me, and, not anticipating any such step as that which you are proposing to take, did not stereotype. Unfortunately, therefore, we cannot supply you with a cheap edition of this book from the English type. Of First Principles you can, as I think you know, have an unlimited supply at a cheap rate. .. I I am by no means sure, however, that First Principles would be the best book to start with. I agree in the impression that the Essays are more likely to be popular. I agree also in the belief that the title Essays is a bad one; and $I$ agree also in the notion that a selection from the two series of Essays would be the most likely to succeed. The contents of the new volume are as follows: The Nebular Hypothesis, Illogical Geology, The Physiology of Laughter, Bain on the Emotions and the Will, The Social Organism, Representative Government-What is it good for? Parliamentary Reform; the Dangers and the Safeguards, Prison Ethics, State Tamperings with Money and Banks, The Morals of Trade. Now, bearing in mind all that you tell me, the proposal I make is this: $r$. That you sell off the two hundred and fifty copies of the new series of Essays as soon as you get them at the ordinary American prices; and similarly with what you have remaining of the first series, so that the highpriced stock may be at once got rid of. 2. That out of the two series you then select all the essays bearing directly on the doctrine of evolution, viz., Progress-Its Law and 
Cause, The Nebular Hypothesis, Illogical Geology, Transcendental Physiology, Bain on the Emotions and the Will, The Social Organism, The Genesis of Science, Manners and Fashion, The Origin and Function of Music; and that this group of essays be republished under some such title as, How all Things Progress. 3. That if this succeeds, I then supply you with a thousand First Principles, at such price as to be sold at American rates. 'The further steps would, of course, be decided by the results of these. Such a volume of essays as that which I have described would, I think, be popular; and would be a good introduction to the System of Philosophy. Moreover, the popular sketch of the System of Philosophy would form a good prefix to such a volume of essays; since the essays would be so many illustrations of it.

When you see Mr. Appleton, thank him for the very liberal course he has taken on this matter, as on all preceding matters. He has done much more than was to be expected from one in his position. I will see whether I can find any appropriate materials for such a sketch as you propose, and, if so, will send them to you.

Mrs. Youmans was quite right in not copying your letter for you. I made it out, save one or two words, with but little difficulty. I am glad to hear of your settled intentions for the spring, when I hope to see much more of you both than I did before. Meanwhile I am again,
Very truly yours,
Herbert Spencer.

Saratoga Springs, November 23,1863 .

My dear Mr. Spencer: In my last letter sent to Derby I mentioned the measures I had recently been taking to bring about an American reprint of your books. We want them for general circulation.

Sooner or later they will be republished. This will end the sale of English copies, and if not attended to will cut you off from any pecuniary advantage. Conscious of the 
injustice of our copyright law, your friends have resolved that you shall not be the loser. They accept Mr. Appleton's proposal and will furnish him the stereotype plates, while he pledges himself to pay you double the usual copyright, or twenty per cent upon the sales. This arrangement, as I wrote you, refers to the Essays, and we are now ready and anxious to go forward with the book, and only wait to hear from you respecting revision. . .

I promised in my former letter to give you some further particulars of my recent visit East. It was undertaken, as I mentioned before, with a view to concerting measures with those who are interested in your works, for bringing them before the public, and the result was in a high degree encouraging to your prospects. I found everywhere a deep interest in your writings (though in some cases but a partial mastery of them), and a desire to learn of your personal welfare as if they had been old friends. I was heartily thanked for offering them an opportunity of doing something to promote the circulation of your writings, and I think an important effect of the course taken will be to secure additional attention and more prominent notice of future publications.

At Bangor, Me., I made the acquaintance of the Rev. Charles Carroll Everett, a Unitarian clergyman of large liberality and with a fine reputation for ability and scholarly attainments, who was the author of the review of First Principles in the Christian Examiner. He is a thorough student of your various writings, and much in sympathy with their spirit and aims. A brother parson was rallying him a while since on his endorsing a philosophy which began without God and ended without freedom. He replied "that these first generalizations of Spencer's are only the emerging peaks of the rising continent."

At Portland, Me., I met the Rev. Horatio Stebbins, who had been with great reluctance induced by Mr. Alger, of 
Boston, to subscribe for the serial. His interest in the work had led him to procure your other writings, and he was extremely desirous that they should be republished in this country. The Rev. Mr. Alger is not only an appreciative student of your works, but a confessed and ultra-enthusiastic disciple. He is a gentleman of much culture and refinement, but his training has been rather scholastic than scientific. Charles Sumner was an admiring reader of your Social Statics, and boasts that he had the first copy in this country. He acknowledges large indebtedness to it, but his former bad health and the pressure of public duties, he regretted to say, had prevented him from following up your subsequent publications. Wendell Phillips, the "goldentongued," was happy to be ranked as a reader and admirer of Mr. Spencer's writings. He had read Social Statics early, often quoted its author in his discussions, and asked me when I wrote you to convey to you his cordial respects, with an acknowledgment of his deep indebtedness to your labours. He was delighted with the project of reissuing your books, and begged to be used in any way that would forward the undertaking. Mr. G. B. Emerson, an eminent and influential educator of Boston, expressed.great pleasure in the hope of having all your works in American form, and asked me to say to you that if your readers in this country are not numerous, they are at least appreciative and multiplying.

Upon approaching the University of Cambridge, the brain of Boston, the interest deepened. Prof. Asa Gray expressed astonishment that the serial had not succeeded eminently, both in this country and in Europe, and could hardly credit the statement that it had not paid its own expenses. He did not seem to be much interested in the republication of the old books, but thought something ought to be done immediately to advance the circulation of the work now being issued. The first six numbers he had not 
read, for Dr. Walker (formerly president of the college) had borrowed them. He was, however, much interested in the Biology; thought it promised to be more taking than its predecessors, and might be made popular.

Dr. Thomas Hill, present president of the college, told me that he was not a subscriber to the serial and had not read First Principles; but he had prepared a sermon directed against its doctrines (no names being mentioned), which he considered but a reproduction of the French atheism of the last century.

There is a literary club in Cambridge, embracing the president and some of the professors, at the monthly meetings of which an essay from one of the members is read and discussed. I gathered from various remarks that the philosophy of Herbert Spencer was brought up at the last meeting by an essay of Dr. Walker, the borrower of Gray's - numbers. The college is in the midst of a ferocious fight between the scientists and the classicists, the latter having become alarmed at the inroads of the former. The new president is regarded as a triumph of science, and I suspect that his newly prepared sermon may be intended to conciliate the adverse party.

I tracked out the author of the article on the Evolution of Language, in the last North American, who proved to be a very able young fellow, only twenty-one, named Fiske-a resident graduate of Cambridge and a student of the law school. You may remember I mentioned to you an article in the National Quarterly on Buckle, which had a reference to you. That article was also by Fiske.* He has an intimate companion named Roberts, and they have read, pondered, and discussed together every line of yours they could obtain, in volume or review. First Principles they have read through twice together, and they have not only

* Mr. Buckle's Fallacies, National Quarterly Review, December, r86r ; republished in my Darwinism, and Other Essays. 
adopted your philosophy but assimilated it, employing your terminology habitually in conversation. While Fiske is busy with the principle of evolution in its application to language, Roberts is applying it to the history of jurisprudence. Their three favourite authors are Spencer, Mill, and G. C. Lewis, although they did not consider the last two comparable with the first. They are brimful of fire and enthusiasm, and may be relied on for important assistance.

The editor of the North American Review* erased the passages from Fiske's article which were most complimentary to you, but the periodical has now passed into other hands, $\nmid$ which we trust are more liberal. Mr. Fiske has been solicited to become a regular contributor, and says he will never again submit to the mutilation of his articles. The young men had been debating for a year whether it would do to write to you, and as I took the liberty of encouraging them to do so I presume you have heard from them before this time. Prof. Wm. B. Rogers, who has constant fights with Agassiz about the development hypothesis, was another of those appreciative friends who acknowledged the value of your labours and expressed a desire to be of assistance to our project.

While in Boston I met Mr. S1lsbee, who was in remarkably fine health, his northern expedition having evidently been of immense benefit to him. He heartily approved of my plans, and was of considerable assistance to me. To resume business, I may add that several of our leading and most important organs of public opinion (newspapers and periodicals-Silliman's Journal, Atlantic Monthly, Boston Journal and Transcript, the New York Tribune, Times, and Evening Post) are pledged to full notices of anything from your pen. As I should like to bring these influences

* Rev. Andrew Preston Peabody.

† James Russell Lowell and Charles Eliot Norton. 
to bear upon your philosophy, I am especially anxious to get the First Principles in hand as soon as possible. With earnest wishes for your health and general well-being, I remain,
Very cordially yours,
E. L. Youmans.

In reading this letter for the first time, almost thirty years since it was written, and five years since all that was mortal of my noble friend was laid in the grave, many bright and tender reminiscences are awakened. Subtle links of causation had begun to join our lives together before we ever met. It was owing to Youmans that the first volume of Buckle's History of Civilization was reprinted by the Appletons in 1858 . A copy was not long in finding its way to Middletown, Conn., where I soon got hold of it and devoured it. Many years would probably have passed before a copy of the London edition would have reached that little town. I thus owed to Youmans the most powerful intellectual stimulus of those early years and the occasion of my first published essay. The study of Buckle led directly to Mill's System of Logic and to Comte's Philosophie Positive, which interested me as suggesting that the special doctrines of the several sciences might be organized into a general body of doctrine of universal significance. Comte's work was crude and often wildly absurd, but there was much in it that was very suggestive. I have already mentioned how, early in I860, Youmans first saw the prospectus of Spencer's proposed series of works setting forth the doctrine of evolution, and how he wrote his first letter to Spencer the very next day. It was at about the same time that I first became aware of Spencer's existence, through a single paragraph quoted from 
him by Lewes, ${ }^{*}$ and in that paragraph there was immense fascination. On my first visit to Massachusetts, in May, I860, I fell upon a copy of that same prospectus of Spencer's series, in the Old Corner Bookstore, in Boston, and read it with exulting delight, for clearly there was to be such an organization of scientific doctrine as the world was waiting for. When I published the essay on the Evolution of Language, in I863, there were so few people who had any conception of what Spencer's work meant that they could have been counted on one's fingers. At that time I knew of only four-the Rev. John Langdon Dudley, of Middletown, a preacher of extraordinary wisdom and power: my old comrade and fellow-student Mr. George Litch Roberts, of Boston, now one of the most eminent patent lawyers in the United States; Mr. John Spencer Clark, now of the Prang Educational Company; and the late Professor Gurney, of Harvard. Of course there were others, besides Youmans himself, whose names occur in the foregoing letter and elsewhere in this book. Some of us entertained pretty decided opinions about Mr. Spencer's work. When we sometimes ventured to observe that it was as great as Newton's, and that his theory of evolution was going to remodel human thinking upon all subjects whatever, people used to stare at us and take us for idiots. Any one member of such a small community was easy to find; and I have always dated a new era in my life from the Sunday afternoon when Youmans, escorted by Roberts, came to my room in Cambridge. It was the beginning of a

* Lewes, Comte's Philosophy of the Sciences, London, 1853, pp. I68-I 7I. 
friendship such as hardly comes but once to a man. At that first meeting I knew nothing of him except that he was the author of a text-book of chemistry which I had found interesting in spite of its having been crammed down my throat by an old-fashioned memorizing teacher who, I am convinced, never really knew so much as the difference between oxygen and antimony. At first it was a matter of breathless interest to talk with a man who had seen Herbert Spencer; but one of the immediate results of this interview was the beginning of my own correspondence and life-long friendship with Mr. Spencer. And from that time forth it always seemed as if, whenever any of the good or lovely things of life came to my lot, somehow or other Edward Youmans was either the cause of it, or, at any rate, intimately concerned with it. The sphere of his unselfish goodness was so wide and its quality so potent that one could not come into near relations with him without becoming in all manner of unsuspected ways strengthened and enriched.

His next letter, in which his scheme has taken on still more definite shape as to the volume of essays, is highly characteristic:

New York, December 14, 1863.

My dear Mr. Spencer: Your favour of November i 8 th reached me about a week since. I was very glad to get it, as it put an end to my suspense and settled at once what was to be done. . . I like the prospect of the volume of selected essays, and am glad that you agree to the notion of a new title. Either of the titles you suggest might answer, but I have thought that with more time you might perhaps improve them. I think it important that the term "progress" should be incorporated in the title, but should 
it be Illustrations of Progress, or Phases of Progress, or the like? I think there should be a further explanatory clause. But I am no adept at these things, and you are. There is also no hurry about it. You do not name the article on The Philosophy of Style, yet I think it should be by all means included, as it has great value and is much admired. Bancroft was to-day eulogizing it to me in very high terms.

Respecting your protest to the New Englander, I think it all-important. Theologians, of all men, love to throw mud-to use Tyndall's phrase-and the Comtean puddle is now the favourite. In looking over the American press notices of your works I find the dominant idea is that you belong to the positive school; and although not one in a hundred knows what Positivism is, all are agreed that it is positively dreadful. It is desirable to stop this authoritatively, and I should be glad to have a pointed disclaimer to append to the popular sketch of your philosophy for our new volume. Excuse the suggestion; you know, of course, far better what needs to be done than I do. Respecting First Principles, I had a conversation to-day with Mr. Appleton; he thinks it best to import five hundred copies in sheets and bind them here. I still entertain the hope that we shall be able to get the use of your plates when we can adopt a thoroughly liberal policy toward the press.

As respects what I have done, I pray you give yourself no uneasiness. It is but little at any rate, and it seems to be my kind of work. I greatly like it, and never enjoy myself so well as when occupied in promoting by some measure the diffusion of valuable thought. I am an ultra and thoroughgoing American. I believe there is great work to be done here for civilization. What we want are ideas-large, organizing ideas-and I believe there is no other man whose thoughts are so valuable for our needs as 
yours are. It is pleasant to find myself less and less alone in my estimate of the case and in my efforts. . . .

Yours very truly and sincerely,

E. L. Youmans.

"It seems to be my kind of work." Bless his dear, unselfish, modest heart, how much of Edward Youmans is summed up in that unconscious remark! Never was anybody's kind of work more nobly done.

The next letter from Mr. Spencer answers the letter of November 23d:

29 Bloomsbury Square, W. C., December $17,1863$.

MY DEAR YOUMANS: I suppose you have before this received a letter which $I$ wrote in answer to your last, and which I directed to the care of the Appletons.

The description you give me of the reception which your philanthropic proposals met with during your tour are highly encouraging to me. Evidently the American mind is more plastic than the average English mind, which is so much more restrained by institutions and traditions. The progress that I make here, though tolerably sure, is very slow. But the aspect of matters with you compensates. The list of subscribers here, instead of increasing, has greatly decreased since the completion of the first volume; but the sale of the first volume itself makes some compensation for this. And, taking into account the prospects your generous efforts have opened to me, I feel tolerably safe in pursuing the course I have marked out for myself. ...

I must really protest against the amount of sacrifice so generously proposed to be made by my American friends. The obligations under which you have placed me, and to which you have lately been adding so greatly, it has been beyond my power to avoid, had I wished to avoid them; 
but the obligations foreshadowed in your last letter are in part such as I can and must avoid. If my American friends, moved by your active efforts, agree to take upon themselves the risk of republishing some of my writingsa risk which I dare not run myself-I cannot help it; and while I feel somewhat uneasy at seeing such responsibilities undertaken, I cannot but feel a considerable pleasure in finding so much interest manifested in the success of my aims. But when it is proposed that my friends should supply Messrs. Appleton with the stereotype plates, and that I should begin to reap the profits of the reprint from the outset, as seems to be implied by your statement of the arrangement, I must decline to agree. It is, I think, a quite sufficient generosity on their part if they save me from a contingent risk and give me the contingent profit after their expenses have been paid. The twenty per cent. on the sales, which the Appletons agree to give me, must be set aside for defraying the cost of composition and stereotyping, until that cost has been repaid-supposing this twenty per cent. profit should suffice for the repayment. Only after such repayment has been made must the twenty per cent. on the sales be payable to me-only then will I accept it. . . Perhaps the best title for this proposed volume of selected essays would be Illustrations of Universal Progress. . .

Give my kind regards to Mrs. Youmans, along with my thanks for the trouble she expended in copying your last letter. Once more accept yourself my warm acknowledgments for your untiring and disinterested labours in furtherance of my scheme, and believe me,

Very truly yours,

Herbert Spencer.

New York, January 12, 1864.

My dear Mr. Spencer: Yours of the 17 th of December, $186_{3}$, is received, and I regret exceedingly that you so interpret what we are doing as to be troubled with any 
sense of obligation. Certainly, if the matter is to be viewed in the light of debit and credit, the indebtedness will be mainly on the side of your friends. My chief purpose in this affair was not to raise funds, for, although the publishers would not risk the issue of the essays, I could readily have done so, as there is really no risk to run. There will be no difficulty in this volume at least paying expenses.

But I wanted active co-operation, and therefore took steps to personally commit a few gentleman of wealth and influence-persons who appreciated and acted upon the public bearings of the case-to an interest in the undertaking. I of course did not hesitate to state that your English publications did not prove remunerative, but I explicitly disavowed this consideration as the motive of my efforts. Nevertheless your requirement shall be faithfully complied with, and, with this assurance, pray dismiss all solicitude and leave us to work out our mission, using your tools and paying as fairly as may be for their use. I like the new title very much. The work is in the printers' hands, and will be finished in less than a month.

29 Bloomsbury Square, London, W. C., Jamuary 3, 1864.

My Dear Youmans: I did not include the essay on The Philosophy of Style, because it does not in any manifest way illustrate evolution. A further reason for not including it is, that if there should be a second volume of essays issued in case the first succeeds it is desirable that some of the more interesting articles should be reserved for it. ...

I have not yet heard from the two Cambridge students whom you name. I shall be very glad to do so; your account of them is very encouraging, and they are evidently adherents well worth having. The article on the Evolution of Language interested me much, showing, as it 
does, not only extensive information, but power of independent thought.*

I was pleased to find that you agree with me in thinking it important to disabuse the American public respecting the imputation of Comtism. I had at first thought of embodying in my letter to the New Englander a general disclaimer on behalf of the scientific thinkers of England, but I concluded that, as the matter was essentially a personal one, the editor might object to my entering on the more general question. Now, however, that you suggest the addition of some such remarks to my letters, with a view to general distribution, I willingly make them.

I embody them in a paragraph on the next page; which you may quote as an extract from one of my letters and append to the republished letters to the New Englander. I inclose a copy of the letter to the New Englander, lest it should not have been published.

My father, who is with me, joins me in kind remembrance to Mrs. Youmans and yourself.

Very sincerely yours, Herbert Spexcer.

There appears to have got abroad in the United States a very erroneous impression respecting the influence of Comte's writings in England. I suppose that the currency obtained by the words "positivism" and "positivist" is to blame for this. Comte having designated by the term "positive philosophy" all that body of definitely established knowledge which men of science have been gradually organizing into a coherent body of doctrine, and having habitually placed this in opposition to the in-

* This paragraph, quoted by Youmans in his next letter to me, gave me the courage which had hitherto been lacking to write to Mr. Spencer. I did so in February, I864, and received a very prompt and cordial reply. It was the beginning of my personal acquaintance and friendship with Mr. Spencer. 
coherent body of doctrine defended by theologians, it has become the habit of the theological party to think of the antagonist scientific party under this title of positivists, applied to them by Comte. And then, from the habit of calling them positivists there has grown up the assumption that they call themselves positivists, and that they are disciples of Comte. The truth is, however, that Comte and his doctrines receive here scarcely any attention. I know something of the scientific world in England, and I cannot name a single man of science who acknowledges himself a follower of Comte or accepts the title of positivist. Lest, however, there should be some such who were unknown to me, I have recently made some inquiries into the matter. To Prof. Tyndall I put the question, whether Comte had exercised any appreciable influence on his own course of thought; and he replied, "So far as I know, my course of thought would have been exactly the same had Comte never existed." I then put the further question, "Do you know any man of science whose views have been affected by Comte's writings?" and his answer was, "The influence of Comte on scientific thought in England is absolutely nil." I put the same two questions to Prof. Huxley, and received, in other words, just the same answers. And Prof. Huxley pointed out to me passages in his own writings in which he spoke of Comte in language almost contemptuous. Prof. Huxley and Tyndall, being leaders in their respective departments, and being also men of general culture and philosophic insight, I think that, joining their impressions with my own, I am justified in saying that the scientific world of England is wholly uninfluenced by Comte. Such small influence as Comte has had here has been on some literary men and historians-men who were attracted by the grand achievements of science, who were charmed by the plausible system of scientific generalizations put forth by Comte, with the usual French 
regard for symmetry and disregard for fact, and who were, from their want of scientific training, unable to detect the essential fallaciousness of his system. Of these, the most notable example was the late Mr. Buckle. Besides him, I can name but seven men who have been, in any appreciable degree, influenced by Comte; and of them, four, if not five, are scarcely known to the public.

29 Bloomsbury Square, W. C., March 26, 1864.

My DEAR Youmans: Thanks for the two letters which I have received since I wrote last. Probably you have been somewhat surprised at not receiving an answer before now; but I have been for the last six weeks wholly absorbed in writing a pamphlet on The Classification of the Sciences, with an appendix repudiating the philosophy of Comte. An article on First Principles, in the Revue des Deux Mondes for February I5, which speaks of me as belonging to the "positive" school, has led me to take this step, and I have postponed everything else until this needful work was done. The pamphlet will be published here in a few days. I am having papier-maché impressions taken from the type, which I will send to you by the next steamer, so that you will be able to cast stereotype plates and print at once. I think an extensive distribution of this pamphlet in the United States will be desirable.

New York, April 12, 1864.

My dear Mr. Spencer: After more delay than I anticipated our new book is published and presents a very satisfactory appearance. I have taken the liberty, as you will see, of making some changes, which seemed demanded by circumstances. Besides putting headings over alternate pages, I have broken up some of your larger paragraphs, so as to lighten the pages and render them more attractive to miscellaneous readers. It was not easy to find points of cleavage, so closely runs the thought, but I tried to violate 
the continuities as little as possible. I give the volume the subtitle of A Series of Discussions, in order to avoid the word "essays" on the title-page and thus preserve the individualities of the separate works. I have prefixed to the volume a notice of your philosophical system more creditable, I trust, than the hastily written pages I sent you.

First Principles is nearly ready, and is to be published as soon as the present volume is fairly out of the way.

Your remaining essays are now in press, and will be published as soon as First Principles is off the track. As the original title is now unsuitable, I have made it Essays: Moral, Political, and Esthetic, the latter term being justified by the three papers on Style, Personal Beauty, and Gracefulness. We have concluded, furthermore, to follow the publication of the Essays by that of Social Statics, and thus complete the American series of your works, a large copyright being allowed on the whole.

I think you once remarked to me that certain of your views had been considerably modified since the publication of Social Statics; but as you intimated that the change consisted in a divergence from the democratic views there expressed, the volume may be more acceptable to us in its present form than it would be after your revision. You will hence see the propriety of a republication here, when you might not choose to have it reissued in England. I think it is especially the book we need at the present time, and may do important service.

I have sent you a notice of the Progress I prepared for the Tribune. It is not what it ought to be. I am thoroughly sensible of my incompetency to do you justice, but it is better than I could get done by anybody else. The best thing about it is that it enables you to speak for yourself. I. however, take some little credit to myself for managing its publication. The Tribune is the most influential journal in this country. I long ago saw its importance in regard to 
our enterprise, and acted accordingly. The literary editor, Mr. Ripley, is a fine scholar, but a Unitarian clergyman to begin with, and classical to the core, and infected with German metaphysics-an unpromising subject certainly, and, most of all, pointedly and publicly committed against the new views of Herbert Spencer. The notice of the Education, I must confess, was fairly battled into the 'Tribune through friend Greeley's influence, Mr. Ripley vehemently protesting against this new evangel of education. He had not read it, and would not look at it. But an old copy of your Essays (found in Beecher's library, when he went to Europe, with the margins of the pages written full of notes) fell into his hands, arrested his attention, and changed the current of his opinion. Since that time his views have been gradually modifying,* and the upshot of the matter is, that I have been able to get the long notice in all the editions of the Tribune (a copy of each of which I send you), the daily having a circulation of 400,000 , the scmiweekly of 30,000 , and the weekly of 160,000 . Advertising in the latter is one dollar per line, the market value of the space allowed me being \$96o. Considering that the Tribune circulates mainly among that class which it is important to reach, and is moreover of great influence with other newspapers, this gain is a telling one. I published the notice in the daily the very day the work was advertised.

I send you the New York Observer, the most bigoted of our religious journals. The criticism is surprisingly mild, the editor having evidently read only the introductory notice, which I aimed to make a sort of religious breakwater to protect First Principles from the rush of the pious flood. The Independent is the most largely circulated and influential religious journal in the country, having six or eight thousand clergymen on its subscription lists. I have

* In course of time Mr. Ripley became an unqualified adherent of Mr. Spencer's philosophy. 
written a notice for it, which will appear next week. Prof. Gibbs has promised me a notice in Silliman's Journal and Mr. Quincy in the Atlantic Monthly. I am making interest also in several other quarters, so you see things are slowly moving along.

As for myself, I am not at all well. I had a week or two ago an attack of neuralgia of the chest, accompanied with high fever and other distressing symptoms, and since that time have been troubled with dizziness and loss of ordinary strength. As my work in town is nearly done, I shall leave for Saratoga in a few days, hoping to recover my wonted tone by exercise in the bracing country air. The prospect of getting to England soon is not very encouraging, as the rate of exchange is frightfully high.

The last number of Biology delights me, as did all its predecessors. We must issue it as soon as our volume is completed, and you had better keep duplicate plates of the remainder. ...

As regards the obstacles in the way of our going to England, I am rather glad of it, for though I should like greatly to avail myself of the intellectual advantages of the London season, yet I am well content to forego them if I can accomplish the important work with which I am occupied. I am certain that I can in no way so effectively promote the true interests of the American people as by bringing these works before them and urging public opinion to them at the present time. The effects of the war are far more profound than is generally realized. Whatever be the political results, there is a mental emancipation to which this generation has been a stranger. The great slave system, intrenched in conservatism, and the natural ally of everything old, superstitious, arbitrary, and barbarous-the sworn foe of all liberty of thought and expression, all reform and progress, and ruling us first through the Government, and then, by a thousand pressures, commercially, for 
the South was our great customer-this system had wellnigh paralyzed the mind of the nation. But the war has broken the spell. I have never before known such boldness of inquiry and demand for first principles. If the slave system is broken up in this convulsion, the mind of the country will be far freer than ever before; if not, I see no escape from utter mental re-enslavement. If the slave power has the vitality to maintain itself through the shocks of this war and achieve its aim, it will be regnant in the future; it will be dominant over the continent, and make fight with the course of civilization, Heaven only knows how long! But be that as it may, now is the time for action, and I have striven my utmost to make it available. I shall strongly hope that events will so shape themselves that I may be in London next winter.

29 Bloomsbury Square, W. C., May $18,1867$.

My Dear Youmans: Accept my thanks both for the Progress and for the copy of your own Chemistry, which you have been so kind as to send me. I have as yet had little time to dip into it, but I am struck with the immense amount of matter you have contrived to put into a small space, and also with the very great clearness of statement. It seems to me admirably adapted to serve its purpose as a class-book. I expect to find it useful for ready reference; and have, indeed, already done so on one point I had forgotten.

As to the Progress, it looks very well, and is evidently more fitted to be popular than it was in its original form. You must have bestowed an immensity of trouble upon it, in putting the headings to the pages and dividing the paragraphs, as well as in correcting the press. Indeed, in this, as all along, you amaze me by the amount of labour you expend in furthering my undertaking. I cannot but feel somewhat oppressed by the consciousness of it, since the disturbance uf health which you describe can hardly fail to 
have been either produced by overapplication or made worse by it. Pray be a little more economical of yourself. Even with a riew to the most efficient propagation of the ideas in which you are interested, it is needful that you should be more moderate in your exertions. A breakdown in health entails more loss of time than all those minor losses that may result from taking work somewhat more easily. My own case may serve you as a demonstration.

You say, "So you see things are slowly moving along." It seems to me rather that they are moving along with great rapidity. If I could describe them as moving with an equal "slowness" on this side the water I should be quite satisfied. The rapidity with which you are proposing to bring out the successive reprints is indeed rather startling to me, since I had understood that the results of the publication of this first volume were to determine the steps to be taken with respect to the others. I hope I may rationally infer that the promptitude with which the others are to be brought out is an indication that the prospects are good. It may indeed be not a bad policy to bring out the volumes in rapid succession. The result will no doubt be to keep up and deepen the interest more decidedly than a slow succession would do.

I was amused and pleased with your skilful generalship with respect to the criticism in the Tribune, especially as the diminished antagonism of the literary editor has been one of its accompaniments.

Respecting Social Statics, I gave you a somewhat wrong impression if you gathered from me that I had receded from any of its main principles. The parts which $I$ had in view when I spoke of having modified my opinions on some points were chiefly the chapters on the rights of women and children. I should probably also somewhat qualify the theological form of expression used in some of the earlier chapters. But the essentials of the book would remain as 
they are. When you come to the reprinting of Social Statics, should that project be persevered in, I should like to put a brief prefatory note stating my present attitude toward it.

In the essay on Classification of the Sciences which I sent you there is a new generalization respecting the ultimate conditions to evolution and dissolution. The arrival at this has led me to see that the second part of First Principles is by no means complete in its organization, and the result is that $I$ have some thought of reorganizing it. If my intention does not change I may probably set about doing this as soon as I have completed the first volume of the Biology. Part XI will be out in the course of next week, and Part XII, completing the volumes, I shall probably get finished early in the autumn. If this should be so, and if I should then commence remodelling the second part of First Principles, it may be that by the end of the year I shall want the stereotype plates back. This, however, is problematical; for if I take this step, I shall not take it until the existing stock of First Principles is sold off, which it may not be at that time.

I greatly regret that you have had to abandon your project of coming to England for the present. The ruinous rate of exchange is a very sufficient reason. Let us hope that this obstacle may very soon disappear. With wishes that you are by this time quite well again, and with kind regards and thanks to Mrs. Youmans,

Believe me, very sincerely yours,

Herbert Spencer.

29 Blgomsbury Square, London, June 8, 1864.

My DEAR Youmans: When I wrote to you last I believe I had not read the new introductory notice you have written for the volume of the Essays on Progress. Had I done so, I should have expressed to you my indebtedness for the very admirable and judicious way in which you 
have presented the leading points of the system. The theological aspect especially you have presented in such a way as is very well calculated to serve the purpose you had in view-to act as a breakwater against the sectarian storm. No doubt the favourable reception given to the book by some of the theological journals has been in great part due to this. . . .

I have quite decided on making the reorganization of the second part of First Principles. The further development which will be given to the doctrine is too important to let it stand over. . . .

I find good reason to be glad that I have published a distinct repudiation of Comtism, for the impression that I am a Comtist was far more widely spread than I had supposed. One of the reviewers of the pamphlet says: "By this publication Mr. Spencer has completely removed the impression that he was a mere slavish adherent of Comte!" My estimate of the average intelligence has never been very high, but really the degree of stupidity implied by such a remark exceeds even my anticipation.* The prevalence of such perverse interpretations makes me feel, even more than before, how desirable it is that the pamphlet should be extensively circulated in the United States.

I am inclined hereafter to follow your advice respecting the amounts due from the Appletons, and, instead of having them remitted here, invest them in America-perhaps in railway stock, of which I already hold a little. I name this now not with a view of making any immediate decision, but lest I should forget to name it before the next account becomes due.

* For it was really very much as if one had said: "Mr. Theodore Parker has completely removed the impression that he was a mere slavish adherent of Jonathan Edwards!" It would be difficult to find in all the history of philosophy a more intense and radical antagonism than that between Spencer and Comte. 
88 Kensington Gardens Squark, London, W., Octuber 14, $156 . \%$.

... The batch of opinions of the press which Mrs. Youmans was so kind as to collect for me, and the accompanying letter, in which she was at so much trouble in giving me accounts of their writers, \&c., reached me while in Scotland. The receipt of them formed a very pleasant little episode in my Highland life-calling me back to things which were for the time wholly out of my thoughts; for when with my friends at Ardtonish, occupied with various sports and amusements, I get wholly absorbed in surrounding things-forgetting all about philosophy and the writing of books. I have to thank Mrs. Youmans for reminding me of them in so agreeable a way.

I have but little to report respecting the progress of things here. Your American style of doing things makes me somewhat dissatisfied with the very small results achieved in England. The most hopeful fact is that I gain the suffrages of all the most highly cultivated men; and I suppose that the suffrages of a wider public will follow in due time. I am very glad that I published when I did the essay on the Classification of the Sciences, for I was surprised to find how widely there was spread the erroneous impression that $I$ was an adherent of Comte. I hope the pamphlet has been well circulated with you.

Thanks for the photograph of Mr. Fiske which you sent me. Do you know who is the author of the article on $A$ Physical Theory of the Universe (or some such title) in the July number of the North American Review? I suppose it is one of your astronomers.

The article in question was by Chauncey IVright, containing a discussion of the nebular and meteoric theories of stellar evolution. It betrayed a misunderstanding of the general principles of evolution, which 
called forth a very able criticism by George Roberts, to which Spencer thus refers:

Thanks for the further press notices which you sent me along with the Boston Evening Transcript. I presume from the initials that the letter is by Mr. Roberts. I read it with much pleasure, and thought it extremely well done. The replies are very much the same as I should have made myself, the only further way in which I might have enforced the reply being by referring to the chapter on The Rhythm of Motion as being an elaborate statement of that "principle of countermovements" on which the reviewer insists. When you write to Mr. Roberts pray convey to him my thanks for his very efficient defence.

The following sentence, coming soon after, in an acknowledgment of the publishers' accounts, illustrates one of Youmans's inveterate habits. I believe one of his chief delights in buying books was to have them to give away:

I see in the account the item, "seven copies of the Essays sold to Professor Youmans." Surely you have not been throwing away your money on my books to give away! If there are any presentation copies which you think it well to give, pray always order the Appletons to send them, and debit me with them.

I cannot close this chapter more appropriately than with an incident clipped from a letter of Christmas, I 864: "Henry Carey called in to blow up the Appletons for publishing Spencer's British free-trade doctrines. Spencer was an upstart; his system would soon die, like Comte's and Mill's. Said W. H. Appleton, 'I can tell you one thing-Spencer won't die as long as Youmans lives!'” 


\section{CHAPTER X.}

SECOND AND THIRD VISITS TO ENGLAND.

$$
\text { I865-I866. Age, 44-45. }
$$

Mr. Youmans sailed from Portland, with his wife and sister, on April 15, I865, the day when strong men were crying on the streets and utter strangers wrung one another's hands in grief over the dreadful news of the murder of President Lincoln. The voyage was dismal enough. There were no other Americans on board, and nobody had a good word or a good wish for the United States. The captain, in the hope of being the first to reach England with the news, made all haste. From Liverpool the party proceeded without delay to London, where Youmans at once entered upon the work entrusted to him by the Appletons, of arranging with divers authors for the republication of their works in America. Incidentally he took note of British progress in scientific education, and projected a book which should have value as a criticism of tendencies much stronger then than now in American educational policy. He intended to show that university education in England had been developed as the natural concomitant of an aristocratic Government, swayed by adherence to old traditions and by respect for social rank quite as much as for merit. He held that this system of education, as brought over to America and long established here, 
was unsuited to the needs of our people; and that in so far as our universities gave direction to general education, the influence of "classicism " was extremely injurious. His design, pretty fully sketched, was never completed, but he afterward made much editorial use of facts and arguments gathered with reference to it.

In the course of the summer the party made a journey to Switzerland. I give a few extracts from the correspondence of the spring and summer. Miss Youmans was at that time in rather poor health.

LoNDON, May 20, 1865 .

DEAR FRIENDS: I yesterday morning breakfasted with Mr. Forster, M. P., the great champion of America. I had a note to him from Minister Adams. I am having the opportunity I have so long desired of informing myself upon educational facts, points, and questions, and I think I shall profit by it. I was yesterday present in a committee room of the House of Commons, or rather Westminster Hall, in which both Commons and Peers came to witness the examination of Archdeacon Dickinson, who appeared in behalf of the High Church to oppose the new "conscience clause," as it is termed, which it is proposed to introduce into the school management. The national schools are in charge of the Church, superintended by the clergy, and no child is permitted to enter them unless he has been first baptized by a Church clergyman, and attends the Church and Church Sunday-school. The "conscience clause" proposes to abolish this, and let dissenters' children in without requiring this of them. The archdeacon opposed this to the bitter end: it was dangerous and wicked; there was only one Church, the Episcopal, and therefore but one religion, and the business of all education is to teach religion. It was curious and highly interesting. 
London, June 7, 1865 .

Dear Brother: We continue in our place still, but with no immediate prospect of change. The weather is exceedingly cool and refreshing. We went to the Borough Road Training School this morning directly after breakfast, which occurs at $9 \mathrm{~A}$. $\mathrm{m}$. It is almost three miles. The omnibus took us from door to door. Staying there two or three hours, we came back to the Jermyn Street School of Mines and heard Tyndall's lecture on Spectrum Analysis, which closed at half-past three. Having had tickets presented us to the gardens of the Royal Botanical Society, in Regent's Park, we took a cab from the lecture directly to that place. ...

We made an excursion to Kew three or four days ago. Kew is about eight miles by rail from Charing Cross. It is an old royal park converted into extensive gardens, and is the great botanical establishment of Europe. We left home at ten and a half, accompanied by Mr. Spencer, took a cab for the Hungerford Bridge over the Thames, and a boat from there to Chelsea for "tuppence." (Tuppence and tuppence ha'penny are great institutions here.) At Chelsea we changed boats and navigated the crooked river up to Kew. The boats are abominable little black things with no covers, close crowded, and most disagreeable. We lunched at Kew, under a shed, on cold ham, cold beef, bread and butter, with salad. Eliza had to travel slowly over the extensive grounds, but there were frequent seats. The immense park is filled with venerable and magnificent trees, and is traversed by broad gravelly walks, straight, crossed, and curving around. Numberless plants and shrubs and countless groups, beds, banks, and borders of flowers are everywhere. And then through the grounds are distributed plant houses, heated for the reception of tropical plants, aquatics, and various collections too numerous to mention and far too numerous to see. We returned by 
rail at exactly dinner time, half past six. Kew Gardens were founded and have grown up under the care and control of Sir William Hooker. His son, Dr. Joseph Hooker, is now the active man and lives on the spot. He married the daughter of Rev. John Henslow, Professor of Botany in Cambridge. Prof. Henslow was a very able man, and his hobby was popularizing botany and introducing it into the very lowest schools. He devised a method for this, and tried it in the parish schools with great success. He prepared a plan, a regular philosophic system, but did not publish it before his premature death. His son, Rev. George Henslow, made over the manuscripts to Prof. Oliver, of the London University, who has lately published them in the shape of a small volume, which Eliza got yesterday. George Henslow has inherited his father's reputation as a botanist, with his system and all appurtenances. He teaches a grammar school in South Crescent, about ten minutes' walk from here, and also takes private pupils in botany. Eliza is going to take some lessons of him. $\mathrm{He}$ has explained to her his method, which pleases her. She will begin day after to-morrow. If her strength holds out she will probably Americanize Henslow's method and reproduce his text-book. It has certain very important elements for educational purposes.

Lucerne, Switzerland, August i6, 1865 .

Dear Father and Mother: Presuming that before this reaches you Jay will have left the United States, I address this to you, and will try to make it so legible that you can easily read it. We left London a week ago yesterday, and have travelled through France, Belgium, Prussia, and Bavaria, and are now in Switzerland-a pretty good week's work for invalids. We crossed the Channel without difficulty. Eliza expected to be horribly seasick and dreaded the trip, but went to sleep and was there before she knew it. We stopped the first night in Brussels, 
the next at Aix-la-Chapelle, the next at Cologne, Friday night at Heidelberg, Saturday night at Strasburg, Sunday night at Basel, and Monday and 'Tuesday nights at Zurich, from which place we came this morning. We have visited the chief objects of interest and curiosity in each of these places, and Eliza has stood it remarkably well-much better than I should have thought she could. Of course she gets tired, and when tired, like her mother, myself, and the human family generally, frets a little, but that is nothing. I think she is enjoying her Continental experience, and that it will prove extremely profitable to her. We found her old teacher and my old friend Prof. Wislicenus, and had a very delightful visit with him and his family. We are now fairly among the Alps, and are experiencing the uncertain and changeable weather which belongs to this region. An hour ago we were admiring the magnificent ranges of mountains, which raised their numberless peaks all around in front of us, the beautiful lake intervening between; now all is hidden from view by enveloping clouds, and there is a drenching rain. We expect to leave here tomorrow morning, having, with a party of three English people, engaged a private carriage to take us to Meiringen. There we shall take mules and cross a mountain which abounds in fine views, and, after passing through the most interesting portion of the country, return to England perhaps early in September. Kitty is very well-looking extremely well, and in excellent spirits. Eliza is picking the coloured spots or little figures out of one of her silk dresses, and is actually getting up a little bit of a sing. I am to have our letters sent to Geneva, where I expect to meet them next Monday or Tuesday. The boat is just returning, bringing the excursionists from their trip over Lake Lucerne, with a band of music in full blast-a jolly lot altogether. I cannot go into any particulars of our journeyings and experiences, but will reserve that till our re- 
turn, in October. I hope this will find you well. Don't overwork; old people generally kill themselves by exposure. Not that you are very old, but ought to be old enough to take care of yourselves.

London, August 30, 1865 .

Dear Father and Mother: We returned yesterday from the Continent. In the whirl and haste of our tour I have quite forgotten from what point I wrote you last. I have, however, sent but one letter from the other side of the Channel. I think we were just entering Switzerland. Well, we went through that remarkably hilly country and saw a great deal of it. The peculiarity of Switzerland is this: you thread your way through long narrow valleys at a rapid rate on the finest roads that are found in the world, with the mountains rising on each side of you all along, from 5,000 to 14,000 feet high. Many of them are snowclad-the highest-but the more common ranges are not. The Swiss live in these valleys in their little cottages, some of them part way up the sides of the mountains, and in consequence of the stagnation of air they are often very unhealthy. Sometimes it is desirable to go from one valley into another without going round. We then either ride in vehicles (in a few cases they have made roads zigzagging up the steep slopes), but most commonly we have to go over on mules or horses, as the paths are so steep and crooked and narrow that no vehicle can be got up. The places where we cross are called "passes" and are of various heights. They are interesting as commanding distant views of the lofty, snow-clad summits. We all went over one very fine pass in a private carriage and enjoyed it exceedingly.

In October Youmans returned to America with his wife, leaving his sister and brother in London. $\mathrm{He}$ had scarcely reached home, at Saratoga, when the 
shocking news arrived that his brother Warren had been murdered on his own farm in Minnesota.

\section{Saratoga, October 23, 1865 .}

Dear Brother and Sister: The letter I wrote you last week is probably in mid-ocean, yet when it was written our dear brother Warren was already quietly resting in his grave. His life has been full of manly activity and earnest struggle, but he is now released, and the vicissitudes of earth will trouble him no more. The manner of his death was shocking, but his suffering could hardly have been protracted. It may perhaps matter little to the subject of it what are the accompaniments of his exit, but the reflection must always be most painful to the survivors that it involved a crime and was a consequence of human brutality. Yes, as Earle says, the family circle, so long happily preserved, is broken at last. The tragic elements of life come into sharper relief, and we have a stern and startling admonition that whatever we do must be done promptly, for the time will swiftly come when we must take our place beside our fallen brother. I have a very deep satisfaction in my remembrance of the visit we had with Warren last winter. I enjoyed it inexpressibly at the time, and I think it was a very pleasant experience to him. He was so unaffected and natural, satisfied to be simply himself-as had always been one of his marked traits of character. . . .

I brought Earle's letter home last Friday, and did not open it till I found $\mathrm{Pa}$ in the barn husking, as it was directed to him. Of course, it was a terrible blow to us both, but $\mathrm{Pa}$ bore it very calmly. We went in and took Ma upstairs into your room. I told her we had dreadful news, and she was hardly able to make her way. "Is Ann Eliza dead?" said she. I told her "No," it was Warren, and explained how he died. She was deeply affected, but bore it far better than I feared she would. Of course, the first thought was about his dying "unprepared." I 
replied at once and decisively to that, and I think it greatly composed her. Indeed, I am well persuaded that this first practical trial of her theology shows it to have utterly lost its power. She quickly recovered her entire self-possession, and, although deeply saddened by the affliction, she is quite herself again. Zella, * of course, felt very badly, but, poor child, she could not realize the event. The destroying angel has passed over our house, and one of our family has disappeared from the scene; the rest remain as before, preserving the courses that each must follow for himself. I am again at work preparing my lectures, which I think of illustrating somewhat, and hope to get Millicent to make my diagrams. The work is much advanced outside-corn husked, potatoes safe-only the turnips to secure. The weather is quite cold and blustering; to-day is pleasanter, but the time of bleak and rasping winds has come. I had almost forgotten to say that we received your long, welcome, and satisfactory letter of .October $2 \mathrm{~d}$ last Thursday. I have no time to comment on it now, nor is it needful. I am very glad that events so shaped themselves that you can continue in your place, as it has many advantages. Your opportunity is a golden one, and I know you will improve it. Let nothing disturb you. Ma's chief trouble in our late affliction is fearing its effect upon you, for you are more constantly in her thoughts than any other. It was a sore disappointment that you did not return; but as soon as she understood the circumstances she cheerfully acquiesced in the course adopted. I am most happy that we are at home now.

Very affectionately,

EDWARD.

The brother (William Jay Youmans) and the sister were busily occupied in London, he studying physi-

* Warren's daughter by his first wife. She had lived with her grand. parents since her babyhood. 
ology with Huxley and she botany with Henslow, and each preparing to make a text-book available for American purposes.* Delightful place as London is for persons engaged in such sort of work, there is nothing strange or unusual in one's having a fit of the blues when the broad ocean is between one's self and one's home. The following fragments of a most kindly and cosy letter tell their own story :

Sara'toga, November 12, 1865.

Dear Brother and Sister: Your letter of superabounding misery came yesterday. It seems to me it must explode soon; I do not think the boilers can stand another inch of pressure. I think we have discomfort enough on this raw, bleak, windy hill, with our extraordinary environment. I have Millicent here, drawing part of the time; Kitty has a seamstress part of the time; Kitty, Carrie, and Zella are housekeepers. Last Thursday Mrs. Rowland sent word that she and Mrs. Carr were coming a-visiting Friday. At the same time Carrie received a letter that her folks were to have a surprise party Friday night, and she must come home. And so $\mathrm{Pa}$ had to quit the securing of his cabbage and go up on to the mountain to carry his help, and Zella has been after her to-day. I can't get a thing done to the ice-house; the turnips and the cabbages have occupied the last three weeks. Our father's cabbage crop comes out as usual-he can't get anything for it. Three fourths of the teams we meet coming from Saratoga are laden with cabbages which they can't give away. Cabbages, rye, and rye-straw are the minima of the market. Why do I talk about such things? Because the universe from this standpoint is composed entirely of cabbages and carrots and kindred objects and interests. They have hired

\footnotetext{
* Miss Youmans's Botany was published in I869, and has been a very successful text-book.
} 
a school teacher of very remarkable claims at a great price. Mrs. Rowland says "she writes an excellent hand, and closes the school with singing"-or will close it after she begins. It is inspiring to see $H$. R. pressing up the educational mountain with superhuman afflatus, disappearing among the clouds and shouting "Excelsior!" There is no news-that is, nobody's dead that I have heard of. I am beginning my lecture to-day; have two weeks to prepare it in. As I approach it I begin to have hope of it again. Millicent has finished one diagram and has another advanced. The third and largest will occupy her a good while. I hope she will have it done by the time I am ready. I am going to try it on up at the meeting-house for the benefit of the society, at ten cents a head. The prospect is I shall have a good deal of lecturing to do, but how much is still undetermined. I have many applications, but they are scattered. I shall get from fifty to one hundred dollars-mostly, I think, seventy-five dollars. Buffalo, Cleveland, Akron, Detroit, will pay a hundred; others less. Many new places are applying in Ohio, Michigan, Wisconsin, Illinois, Iowa. I shall work chiefly in the West and be there most of the winter. Your letter of October 22 , filled with rain, fog, smoke, and universal misery, has caused a very considerable amount of misery here also. Ma is certain that Eliza will either go crazy or die this winter.

The Botany may be all very well, but it may cost too much. I have no doubt the weather is crushing and killing to the spirits. Whenever you feel that you can't stand it any longer, or that there is no further object or use in your staying, come back. Take a Cunarder-the China for Boston, or the Scotia for New York, it's immaterial which; and if on the China, get a berth, if possible (and I presume there will be no difficulty in winter), near the staircase. It will have air and be away from noise. Twelve 
or thirteen days in winter will probably fetch you across; but I would not return till I had tried changing quarters, and get good quarters if you change at all. Respecting Spencer's affairs, I cannot write more till I have something to write, and I shall have nothing to write till I do something myself. That I shall do as soon as I can.

I wish Eliza would go to the British Museum, find the transactions of the Royal Society, look over the list of contributors from its foundation to 1860 , and see how many noblemen are among them. This is important, and has not been done. I shall go into this field-this English education field-next winter. It will be very popular and very important. I wish she would also call on Miss Margaret Jones, whose whereabouts can be learned at the "Home Colonial," St. Chadd's Row. I think it is not far from your place, and I would go there and hunt the woman out and see her school. I would take a little whiskey and stir around. It is Sunday night; our folks are writing.

$$
\text { Affectionately, } \quad \text { E. L. Y. }
$$

Sunday Evening, November $12,1865$.

Dear Children: To-morrow morning, Edward says, a letter must start for Europe, and I thought I would drop a few lines to you, so that you might not have it to say that $\mathrm{Pa}$ never wrote to us while in Europe. And what shall I say? The first thing I have to say is that we are alive and well, and I think Eliza will say that is a great blessing. It is indeed, especially if we rightly improve it; and who does rightly improve it? Those only who glorify God, that they may enjoy him forever. Think of it! We have recently had fresh proof of the uncertainty of life. We received a letter last night from you, dated the latter part of October, and were very glad to hear from you, and especially of your resolution to write every week. It may stimulate us to write oftener. We were sorry to hear that Eliza was so miserable. No doubt you are homesick. If that be the 
case you can cure yourself of it by just saying, Well, I cannot go home until next April, and I will take things easy. Do not expose yourself by overdoing or underdoing. Take no more exercise than is necessary; it has been the bane of our family-overdoing. You might all stop overdoing but myself; I cannot. However, my time is so near out, it makes but little difference with me. Another idea is, time is on the wing; days and weeks and months fly apace. April will soon be here; then we shall all be glad to see you and bid you a hearty welcome.

\section{Youmans.}

Mr very dear Eliza and Jay: When we heard the sad tidings of your brother's death my first reflection was my unfaithfulness to my dear ones when they were young. This was a cutting reflection, and I thought if I could once more meet you all I would entreat and endeavour to persuade you to make that preparation which is all-important. Everything earthly seems to vanish, and eternity with all its vast realities looms up before my mind. One immortal spirit committed to my charge has gone to the judgment. Feeling and knowing that the Judge of all the earth will do right, we leave him there. But the living-where are they? Will not they now listen to the voice that speaks from the tomb, saying, Be ye also ready, for in such an hour as ye think not death may come and cut short all your prospects? Feeling that no words of mine will reach your case, I go to the Mercy seat and lay your case before the Saviour, pleading that he will grant the Holy Spirit so to impress truth upon your hearts that you may be led to inquire, What shall I do to be saved? Only look up to the Light, ask to be guided aright, and you will soon be safe within the inclosure. If you come with penitence, the Saviour will meet you with open arms and bid you a ... 
Monday, Nowember $13^{\text {th }}$.

Ma broke down at half past ten last night at the point where I now commence in Mr. Cook's shop.*

I have little to add, except to say I will send you all the money you can use. Go to the theatre every night-to Christy's-everywhere where there is any fun going on. Spend at least fifty cents to a dollar every day in cab riding; anything to stir up and get out of the clumps. If Eliza sews any, she had better do it on dresses, silk or what not. Jay can buy shirts already made, but dresses you can't get so. Nor can you pass through the customhouse goods merely cut into breadths. They must be finished and worn. There is no prospect of goods being lower in a long tıme. It is the infernal tariff, and not the exchange, which makes them so high. . . . In December Kitty will probably be in New York. You had better direct to New York, care of Appletons. If we are here, they will send up. If we are in New York, we can send up home. Don't write anything for our folks that is discouraging. Write anything to me.
Affectionately,
EDWARD.

Century Club, New York, December 4, 1865.

My DEAR Sister: I left home Thursday-it is now Monday night-lectured yesterday before the Normal School, on Friday at Cooperstown; spent Sunday here; go to-night to Albany; speak on Wednesday at Utica, on Thursday at Jersey City, and then rest a little. Your letter about the Botany came the very hour of my leaving; I had to leave it for our folks. It mortifies me that I have made myself so little understood that you suppose I am especially anxious for you to work at either the Botany or any other task. If you can enjoy it better to do otherwise, by all means do that which will be most agreeable; that is

* Edward's mother had trouble with her eyes, and in this instance they failed her so that she could rot finish the sentence. 
the very first condition of health, and I did not dream of your touching the Botany except when you felt like it, and would rather, from intrinsic pleasure, work at it than not. It would, no doubt, be very well, but I care little for itnothing, absolutely nothing, for it in comparison with your comfort. I think there is a great deal in Spencer's suggestion, that if you make a business of amusement you can get interested in it; and to get thus interested in something would be your salvation. So pray take it up systematically, cost what it will; that is nothing, literally less than nothing, in the scale of benefits. I shall get seventy-five dollars a night this winter, and sometimes one hundred dollars. Am beginning to realize the fruition of long labour and long weary waiting, in all of which you have shared, and in all of which you must continue to share. Take Jay and go to the theatre every night, to the minstrels, the wax figures, the workhouse, and I think that last will be an excellent place to go to for change. Be assiduous in taking it easy. I have thought latterly that the Botany was perhaps a mistake; you had got deeper in and further on with the Psychology - that would have worked itself. Say to Jay to go in for nervous system and brains. If Huxley does as he has a mind to in treating subjects, so may his partner. Brains are the things, and are coming up. I have got some brains in Dynamics of Life, and they tell. Say further to Jay to have as good a time as he can get and while he can get it. . . O Our folks have come out Universalists. They say they don't believe in any literal hell of real genuine fire, and never did! - which is the tallest kind of an orthodox fib.

Shortly after his return from England Youmans received a letter from his friend, the Rev. Dr. Bellows, of New York, urging him to accept a non-resident professorship at the college founded by Horace Mann, at Antioch, Ohio. His duties were limited to giving a 
course of twelve lectures annually, for a salary of five hundred dollars. Some time before he had been offered the presidency of this college, and had declined it. He now accepted Dr. Bellows's proposal, and gave his course of lectures there in 1866 . Then the pressure of other duties obliged him to resign.

In that autumn of 1865 we were all dismayed by the announcement that Mr. Spencer would no longer be able to go on issuing his series of philosophical works setting forth the doctrine of evolution. In London they were published at his own expense and risk, and despite the earnest efforts made in America the state of the accounts was very discouraging. His property was too small to admit of his going on and losing at such a rate. As soon as this was known, John Stuart Mill begged to be allowed to assume the entire pecuniary responsibility of continuing the publication; but this Mr. Spencer, while deeply affected by such noble sympathy, would not hear of. He consented, however, with great reluctance, to the attempt of Huxley and Lubbock and other friends to increase artificially the list of subscribers by inducing people to take the work just in order to help support it. But after several months the sudden death of Mr. Spencer's father added something to his means of support, and he thereupon withdrew his consent to this arrangement, and determined to go on publishing as before, and bearing the loss.

But, as soon as the first evil tidings reached America, Youmans determined to avert the disaster, if possible. As the needful aid was not to be had through any available accession to his list of subscribers to the serial, he made up his mind that a sum of money must 
forthwith be raised by subscription for the express purpose of repairing the loss already incurred, and thus enabling Mr. Spencer to go on with his work. Once let this difficulty of a day be surmounted, and the path of the new philosophy would soon become straight and easy. It is delightful to remember the vigour with which our dear friend took up this task. It was more of "his kind of work," and, as usual, it was successful. The sum of seven thousand dollars was raised and invested in American securities in $\mathrm{Mr}$. Spencer's name. If he did not see fit to accept these securities, they would go without an owner. The best Waltham watch that could be procured was presented to Mr. Spencer by his American friends; a letter, worded with rare delicacy and tact, was written by the late Robert Minturn; and Youmans, who was going to England to publish there his Culture demanded by Modern Life, took the watch to Spencer. It was a charming scene on a summer day in an English garden when the great philosopher was apprised of what had been done. It was so skilfully managed that he could not refuse the tribute without seeming churlish. He therefore accepted it, and applied it to extending his researches in descriptive sociology.

In this connection the following extracts are interesting :

New York, January 2, 1866.

DEAR Sister: Sixty-five is in its grave, and we start fresh with a new year. In my last two letters I have indicated in a vague way what $I$ am about. I made up my mind to make a drive in the direction of a cash testimonial to Mr. Spencer that should cover his loss of $\$ 5,500$ since he commenced publication. Having myself decided upon it, I drew up a circular, a copy of which I send to you (care 
of Layton, for fear some accident might cause it to transpire at 88).* Read it, and then h:de it. Neither let Spencer nor anybody else but Jay have a glimpse of it ; it might be fatal to all future action. I send it for your satisfaction alone, and to show that I have not been idle. I came down to the city last week expressly'on this business. Of course I cannot tell now what will be the result. I had but one day here to try it after I got the circular, but things look fair.... I called on Beecher-I had spoken to him when he lectured in Saratoga that I wanted to see him about some such matter. I called with the proof of the circular. He says, "Well, what's this nonsense?" "I want your distinct opinion of this circular-its suitableness for its work, its redundancy, its diffuseness." He glanced it over: " Mongrel scheme of aristocratical and ecclesiastical government'! That won't do; strike out mongrel. Spencer never calls names or uses an epithet, not even when he is going to cut a thing up root and branch. Well, it's very good. Have you seen $X, Y$, and $Z$ ?" $†$ "No," said I; "I sort of disliked to call on them. I did so before and thought they were a little afraid." "Yes, that's it; nobody so cowardly as your half liberal, who has got to take care of his position. See here! leave those old infidel fellows to me. I'll say, 'Here, you needn't be afraid of this if I ain't.' It's revolutionary, but who cares. Turn which way it will, I'm bound to come out on top, for I go in for the truth. $\downarrow$ Send me some of those circulars as soon as

* He means 88 Kensington Gardens Square, Mr. Spencer's lodging at that time.

† Naming three distinguished liberal preachers. I do not think it necessary to give the names.

$\ddagger$ Nobly said, old Beecher! His head was always sound and clear on such points. In a letter of November, I864, Youmans says: "I saw Beecher yesterday. He says: "Stir them up-subsoil the people with Spencer, Huxley, and Tyndall. I have got them all, and go in for them all. If the trellis of old philosophies is rotten and falling down, take it 
possible. I have a little time now, but I shall soon be off." ... Of course it won't do to let Spencer know what is going on at all. He would spoil it, sure as fate. It is uncertain at best, but to succeed it must be already done and come upon him in a shape he cannot help. . . . Good-by. I leave to-night for the West to be absent at least six weeks. I am sorry to go just now.

Freetort, Ill., February 14, 1866.

DeAr Sister: Welcome back again with all gladness, if you are back and not dead. It was plucky to undertake it, just after Jay's account of sea-sickness, but I suppose you rushed into it with a fatal fascination, as people go and hang themselves when the air is filled with rumours of suicide. I trust you came through with nothing more than indescribable physical discomfort. I know all were delighted to see you at home, as I certainly shall be if I ever get home, and I hope you will take it easy and pick up strength. I am storm-bound here; snow deep; thermometer minus twenty, and railroad obstructed. Went to lecturing hall-only twenty persons present, the weather so horrible. Night before last missed an engagement by failing to connect. Shall try it again to-night, but this week will amount to nothing. I hope to be back to New York by first of March.

I smoke-praise be to God for tobacco!

NEw York, $\operatorname{March}_{3}, 1866$.

MY DEAR FISKE: I have just returned from a long lecturing tour West, in which I had the calamity to get no news from home for nearly two months-everything missed me. Your letter of January 20 th therefore has been left till now unconsidered. I was delighted to see it, to hear from you, and to get a glimpse of such a vision of glory

away and let us have a better. We can train the vines of faith on the new one just as well.'" 
as you there picture. I think you are altogether right; I never thought the practice of law would satisfy you. You are on the right track-a little routine literary work, which will not exhaust the mind, but will keep the pot in a state of brisk ebullition, leaving the surplus of time and force for independent thinking. Business first, of coursethe dear wife and darling baby, food and raiment, before all other things-and beyond doubt the first condition of all other, success. But a non-professional and literary business, if possible, as a profession tends to suck up all the mental juices and leaves only a husk for other things. Your bill of fare is indeed tempting, and makes one's mouth water to glance it over.* I cannot doubt its success, and by this I mean that you will have no difficulty in procuring a first-rate publisher, and your book would be bound to work its way into the libraries of the best thinkers.

But it will be wise not to entertain too sanguine expectations in reference to the profits of a work of this grave character, and a first effort at that. Still, I doubt not it will do well, and, being intrinsically valuable, can be made to do well at any rate.

I opened the ball for Spencer before leaving for the West. I hoped it would be a good thing to get it simmering; and when I return and find nothing, nothing, nothing done by anybody, I am a little alarmed, for there was considerable stir and promise before I left.

There is one thing that is bad-infernally bad just now. Some Eastern Abbot-Time and Space Abbot, I suppose $\nmid$

* The reference is to a projected volume of essays illustrating the doctrine of evolution. I had sent Youmans a list of the subjects which I proposed to treat. Such work as was done in pursuance of this design was afterward absorbed in the larger enterprise of the Outlines of Cosmic Philosophy, begun in I869. The chapter of that work entitled Sociology and Free Will was written in this year (I866).

$\nmid$ Mr. Francis Ellingwood Abbot, of Cambridge (class of 1559), who. 
-has just published the ablest thing yet against Spencer in the March Christian Examiner. There is concession of second-rate ability, but a mean ingenuity in concentrating upon Spencer all the blistering rays of theological odium, and that, too, with a vast pretence for caring only for the truth. It is a panic appeal, a scream, to the entire theological world that their day of judgment is at hand, and that Herbert Spencer, materialist and atheist, is the head devil who is engineering the headlong movement. It is all right enough, and at any other time would be of no account, but just now it embargoes "liberal Christianity," and leaves us to raise money out of the "world, the flesh, and the devil." Well, if these will give the money, I will vote them the true saints and bet on their chances of paradise. I am going to work at this thing at once, and don't mean to be bluffed.

I got a letter from my brother in London yesterday, who stated that Spencer had received one from Mill the day before expressing regret and proposing a remedy, but did it in such a way as, of course, to elicit a prompt and decided refusal. Tact is all-essential in such a matter. I have Mill's letter, and it is noble, though not adroit. Spencer exacted a promise that it should not go out of my hands. If I come to Boston, as I may before long, I will bring it. I an now going to work, and will advise you of the result of the experiment. I will send this to Roberts's care, thinking perhaps it will get more prompt delivery. Write me what you think of Abbot's article, and oblige me by pointing out every flaw you see.

New York, March 5, 1866.

DEAR Sister:... There is nothing in reference to the Spencer enterprise. Nothing whatever has been done,

had published an able essay on the Philosophy of Time and Space in the North American Review. 
as far as 1 can learn, by anybody, and that is not the worst. An article has just appeared in the Christian Examiner, by "Time and Space" Abbot, of a most malignant character concerning Spencer. It is able and ugly. I am afraid of the effect, as it circulates among just the class to whom the appeal is to be made. I received your letter containing Mill's letter to Spencer. I was glad to get it this morning, as its tendency was somewhat to counteract the unpleasant effect of the Examiner paper. That article accords merit to Spencer as an organizer of the sciences, but is savage on his religious doctrines, and his cowardice as evinced in his preface to his Psychology, where he says there was a fifth part withheld from prudence.* At any other time I should not mind it, but now it is bad. I shall, however, go forward with the undertaking to see what will come of it. I have seen nobody yet, and have just drawn up the paper for signature.

New York, March 27th.

I am working away with all my might upon the review for the Tribune. I find I have a considerably shorter time to do it in than I had expected. Ripley leaves Boston April 25th, and New York a week earlier, and he wants this thing attended to before he goes, as also do I. I am getting on very well with it - that is, I have got well at work. I have a little room at the club, warmed and cosy, where I go most of the day and till late at night; it is perfectly still and quiet, and favourable to my work. I

* This absurd charge of " cowardice," brought against Mr. Spencer by Mr. Abbot, would seem to have been made in a spirit of mere captiousness. The fifth part of the Psychology, entitled Physical Synthesis, was withheld from the first edition in 1855 simply because Mr. Spencer rightly believed that without more explanatory context than he could provide for it in that book it would not be correctly understood. After the publication of First Principles and Biology the case was altered, and the second edition of the Psychology contained the portion omitted in the first, with many other additions. 
shall stick right to it till I finish it. I am going to review Spencer's Philosophy generally, First Principles and Biology, making as taking and impressive an article as I can. I want to complete it at the earliest possible moment, to get it through all the Tribune editions. Sam May sends me the names of all the Boston clergy to help. Poor soul!

April 18 th.

DEAR Sister: I have an envelope directed to you. I may as well fill it. As for Philamadelphiana, I have been in that interesting and religious town and have come away no richer but much wiser than I went. They have been Chauncey Wrighted. $\mathrm{He}$ is a relation, I think, of the set into which I fell; and they coolly assured me that I would find it worse in Boston, for Spencer was hated there. I go to Boston to-night to try.

New York, April, 1866.

My Dear Spencer: I send you the daily Tribune containing my article, which will also appear in the larger weekly and semiweekly editions of that journal. There is no other paper in the country whose opinion of books has equal weight with that of the Tribune, and none also which is so widely taken by the editors. We know how utterly indiscriminating and stupid newspaper notices of works like yours usually are, and I felt it to be important that something should be done, however slight, to help these gentlemen of the quill. The notice I have written is, I know, very imperfect and totally inadequate to the subject. I am conscious of my own utter incompetence to do justice to the subject, but if I had been less disturbed, and had had any opportunity for quiet thought, it might have been better. Still, there is evidence that the article is somewhat suited to its purpose. I may add that the closing remarks are not mere empty talk, as I trust time will show. You are doing great work in this country, and have friends who very thoroughly appreciate it. 
And now I have something of a favour to ask. For the success which has attended your reprints in this country we are very largely indebted to the liberal and kindly feeling of Mr. George Ripley, literary editor of the Tribune. At first he was not easy to manage, but, being eminently candid and liberal, he soon came into favourable relation with our movement, and has allowed me the unrestricted use of the Tribune, to act upon public sentiment. While in no sense has he mastered your Philosophy, he is in thorough sympathy with your philosophical aims.

Mr. Ripley was educated for a Unitarian clergyman, and when a young man had charge of the wealthiest congregation in Boston. But he could not endure the clerical relation, and threw up his position to join the socialistic community of Brook Farm. Quickly perceiving that this would not answer, he took to literature systematically. He was the senior and chief editor of the New American Cyclopædia, of which I am told 375,000 volumes have been sold. Well, all this means that Mr. Ripley sals on the $25^{\text {th }}$ of this month for England, and will spend two or three weeks in London. He is desirous of meeting you, and I have given him an introductory note. You will find him intelligent and interesting, and if you can give him some attention while he stays in London I shall appreciate it as a personal favour.

I have told him that you are somewhat at liberty afternoons and evenings, and I presumed would be glad to contribute something to make his visit agreeable. His chief interest is in people, but he is a gentleman, and no gossip. $\mathrm{He}$ has letters to Mill, and I have given him notes to Morell and Bain. I feel so much my indebtedness to Ripley, that if I could be remotely instrumental in making his London visit a pleasant one it would be a real gratification; and if you could bring about the opportunity of his seeing Lewes, Tyndall, and Huxley - though only barely to meet themI should be much obliged. 
88 Kensington Gardens Square, London, W., April $10,1866$.

My DEAR Youmans: Yesterday I received your letter containing the certificate of the shares in which you have invested the amount due to me. This letter and the two preceding ones have greatly encouraged me. Thanks to your skilful superintendence and untiring energy, without which it is clear that nothing would be practicable, it seems to me that I may take a hopeful view of matters. The amount that has come to me is far greater than I had anticipated; and if I may take it as evidence on the strength of which any estimate for the future may be formed, the difficulty becomes greatly lessened. I quite recognize the fact that, after omitting the amounts arising from the Psychology and from Mr. Silsbee's payment, which do not enter into the estimate, the remainder largely consists of the sums arising from the sales of books recently published, which can hereafter be expected to bring in comparatively little. Still, taking the case of the Education as some sort of index (though one evidently much too favourable to apply generally), there seems reasonable ground for anticipating an annual total not to be despised. And if, as you think, the financial condition will improve with tolerable rapidity, the ability to draw the proceeds without much loss would make things much easier.

As to the progress of matters here, though I have been aware from hints dropped for some time that something was doing among those interested in preventing the impending stoppage, I did not learn until two days ago what was the nature of the course taken; and when I did learn it, a misapprehension very nearly led me to put a peremptory stop to it. Indeed, I was on my way to the printers with the draught of an adverse circular, when I learned the true state of the case. It is now probable that, after insisting on certain qualifying conditions, I may agree to the arrangement that has been secretly made, and which I find 
I can hardly resist without quarrelling with my friends who have made it. It seems that the arrangement has resulted under the pressure of a number of persons interested, chiefly wealthy, who were anxious that something should be done to meet the difficulty, and who, under the guidance of Huxley, Tyndall, Busk, Lubbock, and Mill, have arranged to take a large number of copies (250) for distribution; and they say that I cannot prevent them. However, I shall refrain from opposing the arrangement only on condition of a large reduction in the number (down to $15^{\circ}$ ) and the erasure of the names of some of those concerned.

I have received the two periodicals which you have been good enough to send me. As usual, where there is theological antagonism there is plenty of misstatement and garbling of evidence by leaving out passages that give a totally different meaning to the passages quoted. If it were worth while rebutting these statements, a strong case of deliberate untruthfulness might be made out.* But I have no energy to spare in controversies, and must make up my mind to be continually misrepresented. I am glad to hear that the first volume of the Biology is at length printed. I suppose it will be issued before this reaches

* Usually, however, I believe that such misrepresentations admit of a more charitable construction. They are probably oftener due to dulness than to dishonesty. It is hard to make sufficient allowance for the abysmal depth of human stupidity. Such a luminous intelligence as Mr. Spencer's cannot realize the way in which ordinary minds, even of many men who are able enough in some things, grope in darkness and stick fast in the mud. I cannot help feeling some regret that Mr. Spencer has not adhered more closely to the resolution above expressed, not to waste time and strength in controversies. His rejoinders are always delightful to read, but they must often have consumed hours which had been better devoted to the great work. Such arguments as rebutting charges of materialism, etc., are, moreover, apt to be wasted. As long as people feel like making such charges they will do so, but it is less the fashion now than half a century ago, and by and by it will cease entirely. A sufficient number of funerals is sure to bring a change of fashion. 
you. These investigations which I have had to make on the Circulation in Plants have greatly hindered me. I have only quite recently got to work against my next number. I shall not get it out before the end of May or the beginning of June.

Your brother left us ten days ago. I hope he will have had as favourable a voyage as your sister. When next you write you will, I hope, be able to give me some information as to your intended movements. I shall probably remain in London till the middle of July.

With kind regards to your wife and sister, very truly yours, Herbert Spencer.

88 Kensington Gardens Square, London, W., May 7, 1866.

My DEAR Youmans: Before you receive this you will probably have received the Derby paper, which I posted to you on Friday, containing a paragraph which you will read with melancholy interest-a brief tribute of respect to my late father. I was called down to him by telegraph this day fortnight, and found him seriously ill, but not, as I supposed or as any one supposed, in immediate danger. He got gradually worse, however, and died on the Thursday night. As you may imagine, the shock has been great and has unnerved me greatly. Indeed, I found my system running down so rapidly and such serious symptoms showing themselves, that I have been obliged to come up to town for a few days' change of scene, lest I should fall into some nervous condition, out of which it would take me a long time to recover.

I return to Derby probably at the close of this week, and shall most likely be away some time. If Mr. Ripley (your note respecting whom has reached me) should call in the course of the next few days, I shall be happy to show him what little attention is possible under present circumstances; but after Friday it will, I fear, be out of the question for me to do this. 
I duly received the New York Tribune containing your review, which I read with much interest. The general sketch of the aspects of modern thought was very graphic, the antithesis between the aim of ancient philosophy and the philosophy of the moderns being, I thought, particularly happy.

I rejoice to hear that you continue your intention of returning here for the summer. I hope circumstances will permit us to see as much of one another as before. With kind regards to your wife, brother, and sister, very truly yours,

Herbert Spencer.

Antioch College, May 12, 1866 .

DEAR SISTER: It was very kind of you to say that I need not give myself uneasiness about you in my absence or trouble myself to write. I did not at all intend to avail myself of your generosity when I left, but, as Jay has probably informed you, the lectures come thicker than I expected-five a week instead of three. I have therefore been busy every moment of the time. I shall have two days of liberty now-(Saturday and Sunday), and the first thing I do this morning is to drop you a line. The place is pleasanter here than I expected to find it. Indeed, it has some admirable features in its surroundings, of which much might be made if there were the right spirit and plenty of means. The college structures are immense and imposing, but ill adapted to any use. Mr. Mann sent out the plans, but the carpenter threw them under the table, and bought a cheap plan of an architect and built according to his own ignorant notions. I have been glancing over the history of the institution, as shadowed forth in the lately published life of Horace Mann, and it is exceedingly instructive. It has been cursed from the beginning by two things: first, Western jealousy of the East, and second, "religion." Out of debt, with $\$$ r 25,000 endowment, and with a gift of $\$ 4,000$ or $\$ 5,000$ from the Unitarian organization this year, and with 
a full corps of professors, they have less than a hundred students. If the money continues to pour in, of course, all the motions can be kept up. But my opinion is that all the hope of the institution lies in its reorganization upon a scientific basis, and I can conceive few things more futile than such a hope. The listeners to the lectures are from I 00 to 200 insiders and outsiders. The history of $\mathrm{Mr}$. Mann's career is exceedingly impressive. There never was a clearer case of suicide from ignorance of natural laws. His lectures, his letters, his talk, were full of the preaching of natural law. George Combe was his intimate correspondent and his model. The clatter of "natural laws" runs through his entire life, and yet he died twenty years before his time from ignorance of the dynamic law that exercise must be followed by rest. He was offered up to the same Moloch as Hugh Miller, and I have a suspicion that George Combe went in the same way.

New York, June 23d.

Dear Sister: The accompanying note to Marble* will explain itself. A box of two hundred twenty-five-cent Havana cigars and $\$ 950$, making our sum now $\$ 7,000$ clear. So the Spencer affair is finished, all but the most troubtesome part. I will keep you informed, but have no time to write further now. We sail at twelve to-day.

Minturn's letter was sent by mail, as appears further on.

S. S. City of Paris, Monday, July 2, 1866.

DEAR Sister and all the Rest of you: We have had an excellent passage on a very fine ship. We reached Queenstown this morning at five o'clock, eight and three quarters days' journey from New York-a six-hour longer passage than the one previously. Our weather has been on the whole excellent-only two rough days; the rest of

* Manton Marlile, at that time editor of The World. 
the time the sea has been quiet. I have not been seasick a moment nor missed a single meal. Kitty has had the best voyage she has yet had on the Atlantic, having been up every day, though she has been but little at table. I have read some-indeed, considerably-and somewhat warmed myself up for my work, but at the expense of a reputation of great unsociability, which has made it unpleasant for me. The only men of note on board are two sons of Cambridge, Harvard College-Prof. Torrey, of the chair of History, and Prof. Bowen, of Metaphysics, Ethics, and Political Economy. I have somewhat made their acquaintance, and find it agreeable. They run over for their vacation. We learned by the pilot this morning that the war is precipitated in Germany and reform scuttled in England. You, of course, will have the particulars, and perhaps as soon as we do. We expect to reach Liverpool to-night, perhaps by twelve or one o'clock, and leave for London to-morrow morning-Friday-by the 9.30 train.

\section{Loxdos, Ju?y 7,1866 .}

DEAR SISTER: . . I I inclose a note received last night from Spencer. I shall telegraph him to-day, to learn the place and hour of his arrival, and meet him and invite him here,* as there is plenty of room. I called on Williams [of the firm of Williams \& Norgate, publishers of Mr. Spencer's books] this morning.

London, Friday, July 13, 1866.

My DEAR Sister:... I think I sent you the note in which Spencer announced his coming to town. I telegraphed him to meet him, but he replied that he did not know at what hour he should arrive. Next day he sent

* To the boarding house kept by a Mrs. Langford, from which Youmans was writing. Mr. Spencer had left $8 \delta$ Kensington Gardens Square, and had not yet gone to 37 Queens Gardens, Bayswater, where he lived so many years. 
me a dispatch that he would be at King's Cross Station at six o'clock P. M. I went there (and I may state that my object in telegraphing him was to invite him here); the train was behind time. I stayed twenty minutes, and left rather than lose my dinner. He arrived, went to his hotel, where I had left a note for him, and came directly here; decided to stay, and then went after his baggage, and did not come in till Tuesday night. Wednesday morning, after breakfast, it being very hot, I proposed to go out into Mrs. Langford's garden, where there are seats (before that, however, I had presented him with the box of cigars, which he received very cordially). When in the garden we proposed a smoke, and as the cigars are enormously large he cut one into three pieces and began on one third. I then referred to what I had written him in reference to what I had said at the close of the Tribune article, and that I was able to report that we had not been idle. I then handed him Minturn's letter, which had come in good time, and of which I enclos 2 a copy. He read it, and with some excitement and surprise exclaimed: "Why! What is this? Good gracious! Why! I thought perhaps you were going to get me a list of subscribers. Well, really, this is wonderful! So much beyond all that I had expected! It's magnificent! Well, I ought to have a list of the donors." He made reference in language I cannot recollect to the idea of its being all done past recall; and so the thing was neatly accomplished-a perfect success. Of course it was very natural there should be some embarrassment, as well on my part as his, and I certainly had nothing particular to say; so I interrupted the somewhat awkward situation by handing him the blue-velvet box containing the watch and called his attention to the inscription. This, of course, was a descending climax, inflection, or whatever you call it, and served as a relief. He was much pleased with it, and thoroughly delighted 
with the whole thing. I walked with him afterward in the afternoon. He was in excellent spirits, and made frequent reference to the "splendid present," and I could see was revolving plans at once on the basis of it. He once broke out: "I wish my poor father was alive to know of this! Do you know that your Tribune notice only arrived the day after his death?" . . . I called on Huxley this afternoon. He asked very cordially after you and Jay, and complimented Jay as a faithful, industrious student, and asked if he was ready for him. I shall begin to have proofs in a few days, and revise during the vacation and publish during the autumn. I can send them over as fast as they go through the press, so that our brother can be at work on them. So he is clearly calculating on the bargain, and Jay can edit the volume and gain all the advantages I originally proposed. . . . Huxley will expect to have our agreement carried out, so it will only remain for Jay to take right hold of his sheets as fast as they come and add as editor what they need. It need not be a finality, but it will be a capital step forward, giving Jay standing at once, and it will also pay him well for all he does at it.

Herbert Spencer, Esq., London.

NEW YORK, June 25, 1866.

DEAR SIR: The republication in this country of your various writings has awakened profound interest and exerted a powerful influence for good. Many among us believe that few men in the whole history of our race have had the privilege of rendering such important services to society. There is a still larger class here who, while differing radically from some of your conclusions, recognize with the utmost sympathy and admiration the noble and humane spirit which penetrates your works, and own with gratitude their intellectual obligations to you.

The announcement, therefore, that the completion of your philosophical system had been arrested from want of 
proper support has apprised your American friends of a possible loss to themselves and the world too serious to be borne without an effort to avert it, and it has seemed to some of them an opportunity for repaying in such form as they may a portion of the indebtedness to you, which can never be entirely cancelled. They have not permitted themselves to doubt your friendly acceptance of such cooperation as they can offer to insure the continuance of your valuable labours, and they have charged me with the pleasant duty of informing you that the sum of seven thousand dollars has been invested in your name in American securities (a list of which is inclosed, and which you may either retain or convert at your pleasure), and that they have done this not merely as an expression of sincere respect and gratitude toward you personally, but also in the highest interest of liberal thought and civilization.

With great regard, very truly yours,

Robert B. Minturn.

Derby, August 2, 1866.

My DEAR SiR: Though my friend Mr. Youmans, by expressions in his letters, led me to suppose that something was to be done in the United States with a view to preventing the suspension of my work, yet I was wholly unprepared for anything so generous as that which I learn from your letter of June 25 th. In ignorance of the steps which were being taken, I had thought that a revival and possibly an extension of the list of subscribers to my works would be attempted, and, my thought having taken this direction, the unexpected munificence of my American friends quite astonished me, as it astonished all to whom I have named it. Not simply the act itself, but also the manner in which the act has been done, is extremely gratifying to me. Possibly you are aware that, while on the one hand I had decided that I ought not to continue sacrificing what little property I possess, I had on the other 
hand resolved not to place myself in any questionable position, and in pursuance of this resolve I had negatived sundry proposals made here in furtherance of my undertaking. But the course adopted by my American friends is one which appears to give me no alternative, save that of yielding. Already in the case of the profits accruing from republished works, which I declined to receive unless the cost of the stereotype plates had been repaid to those who furnished the funds, they defeated me by saying that if I did not draw the proceeds they would remain in Messrs. Appletons' hands; and I foresee that were I now to be restive under their kindness they would probably take an analogous step. I therefore submit, and feel less hesitation in doing this because the strong sympathy with my aims which from the beginning has been manifested in the United States makes me feel that impersonal rather than personal considerations move those who have acted in the matter, and should also guide me. Will you therefore be so good as to say to all who have joined in raising this magnificent gift, which more than replaces what I have lost during the last sixteen years, that I accept it as a trust to be used for public ends, and that at the same time feelings of another kind compel me to express my gratitude as well as my admiration. Let me add that while the material result of their act will be that of greatly facilitating my labours, the approval conveyed by it in so unparalleled a way from readers of another nation cannot fail to be a moral stimulus and support of great value to me. Believe me, my dear sir, very sincerely yours, Herbert Spencer.

Robert B. Minturn, Esq., New York.

The effect of the subscription gathered by Youmans was rather to extend Spencer's work than to prevent the suspension which a few months before had seemed unavoidable. It enabled him to employ as an amanuensis and assistant a gentleman of univer- 
sity education; and, enjoying the increased demand for his works which Youmans had confidently predicted, Mr. Spencer next year began to collect and organize the data since published in his Descriptive Sociology, engaging three assistants for that purpose.

\section{Aberdovey, Wales, August 8, 1866.}

My DEAR Sister: When I asked Mr. Spencer where to go in the country, he replied, "To get sea bathing, some fishing, some social excitement, and moderate prices, Scarborough." I replied, "I think we will go there," and so intended, but lingered in London until I received a letter from him in Derby, saying that he had not yet heard from his friends in Scotland, and might have some days to spare, so he proposed to come to Scarborough and spend the interval. I replied that I had not gone, and next day sent him another note, proposing to meet him anywhere he chose for a few days. He named Chester as the meeting place, and last Tuesday, a week since, as the time, and some place in north Wales as the destination. We met and started. I undertook to travel with him, and broke down the first day. Thursday I was down sick, Friday miserable and unable to write; hence, I sent nothing last Saturday. Seeing that I could not stand much, he proposed that we pitch for some place and stop. We agreed upon Aberdovey, a Welsh watering place of stone houses in the water under a high bank without a tree, a thousand degrees below Perth Amboy. The cholera report in London had risen from three hundred to one thousand the previous week, and I thought Kitty had better come into the country. So I wrote to her to join us at this place, which she did last Saturday, and it is now Tuesday. 'There's not a decent hotel in town, and so I found a lodging house, a stone affair, sort of like a blacksmith shop, where we have three smail rooms, and are as comfortable 
as we can make ourselves, with but little to get to eat in the town. My breaking down was due to excessive fatigue -going into Greenland-cold sea water to bathe, finding myself with a little fever, and travelling back a long distance to-Heaven knows the name of the place where we were stopping.

The wind was blowing a perfect tornado when we came here last Saturday, and it has kept it up ever since, so that I have not been able to go out at all, except that Mr. Spencer and myself emerged Saturday night in the howling wind to get eatables for Sunday. Went to what they call the market house and called for a piece of beef; the only butcher said that all the beef he had was a little lamb, of which we bought a fore quarter, and one half pound of bacon, also a peck of peas and two pounds of potatoes, also a pound of butter, three pints of gooseberries, a pound of brown sugar, one half pound of coffee, and six candles. We have eaten all except the candles, and Kitty has just gone out into the gale to buy something more. The old Welsh mother of the house we can't understand; the daughter is quite an interesting girl, and waits on us. Spencer had in his pocket the Pall Mall Gazette of July $3^{\mathrm{d}}$, with the following paragraph: "It is stated in American papers that Prof. Youmans recently left that country in order to present to Mr. Herbert Spencer $\$ 5,000$ and a valuable gold watch as a testimonial from his American admirers." He told me that his friends had been dogging him to publish the whole thing as an act of simple justice to the Americans. He thought that the false figures ought to be corrected, but is very fearful that there will be too much of a story made about it. I shall write a corrective note to the Pall Mall fellows. As you may imagine, things have not been favourable for my work. Still, it has been profitable. I have got glimpses of light on many things, which will be helpful in the future. The present 
occasion, moreover, has turned out proximately suitable for doing that little job for brother Abbot. Spencer has his article with him, and we are taking it up point by point. Spencer talks, and I am amanuensis. I have written eight pages of foolscap at his dictation this morning, and have not only had the pleasure of seeing Spencer give it to Abbot much as Artemus Ward says the mob caved in the head of his wax figure of Judas, but I have myself learned some matters and things worth knowing. Spencer doesn't recede or budge a hair, but he interprets.

We shall only remain here this week. There seems to be about as much cholera around here as in London, and I want a little time there before going to the Association at Nottingham. Spencer will be there, if he doesn't get an invitation to Scotland. 


\section{CHAPTER XI.}

POPUlAR EDUCATION, AND OTHER MATTERS.

$$
\text { 1866-1868. Age, 45-47. }
$$

AfTER disposing of the Spencer affair, Youmans devoted all his energies to the work of completing and publishing the collection of essays entitled The Culture demanded by Nodern Life. His chief object in this third visit to England was to bring out this long-projected book* under peculiarly favourable conditions in London. From time to time he had read able essays and addresses bearing on this topic, but they had been published in ephemeral journals or shelved in volumes of Transactions. He now proceeded to carry out his plan of publishing a selection of such essays by the most eminent writers of the day, with an introduction by himself, setting forth the subject in its widest relations. While engaged in this work he came into personal contact with a good many members of the College of Preceptors, and was invited to give them a lecture upon some topic in which they were all directly interested. He chose for his subject The Scientific Study of Human Nature, and after delivering the lecture he inserted it among the essays in his book. $\nmid$ A pleasant account of

* It is mentioned in his first letter to Mr. Spencer, Feb. 23, I 56 ; see above, p. ro6.

† See below, pp. $45^{\mathrm{I}-485}$. 
this, together with some other matters of interest, is given in the following letters to his sister:

London, July' $21,1866$.

There are but few boarders here at Mrs. Langford's, which makes it pleasant, and I have a separate room with all my books and papers, which is very convenient for study. The situation is high, and up near Regent's Park and very eligible, so I shall be contented here a while. I have been thus far reading and making references, and am just now beginning to write. The subject opens finely before me, and I hope I shall have grace to do it justice. Spencer has promised to look over my argument when I get it ready. ... I had almost forgotten to say that Wislicenus and Fick (the latter a physiologist of Zurich) have given the last annihilating blow to Liebig. Their joint paper has been translated, and published in the Philosophical Journal, a copy of which, with Spencer's last number, I have left at Layton's to be sent to New York and forwarded to you by post. It will leave here the last of next week. I am going to write to Wislicenus, asking him the privilege of making a sketch of his American experience preliminary to his statement of his researches, for publication at home. He has proved that animal power is due to the combustion of the hydrocarbons in the muscles, the heat produced being converted into mechanical force!

London, September $1,1866$.

We got here yesterday afternoon, and your letter of August $4^{\text {th }}$ came in the evening. I was greatly rejoiced to learn that you had all gone a-fishing; I hope you will follow it up. The only way to strengthen any tendency, faculty, or habit, is through its own exercise. You can't infer its propriety and then enter upon it. It is a great "victory over the inane" to learn to fish. Pray go often. I shall when I return. I am hard at work, pushed and 
racked with thinking, and have a world to do by midOctober, but I beliez'e in my book. I see Hedge is out in the September Atlantic (which I shall get), on University Reform. This is the subject of the age. England is full of it, and if it were not for the infernal clangour of politics America would be, and it certainly will. Our politics are now intense because we have nothing else to think of. England has politics and religion, and that diminishes the intensity.

September 8th.-I have arranged with Macinillan to publish my book, and he will begin stereotyping next week. There is a sharp attack in this morning's Times on the Classical Dogma. The time is ripe for the work I am preparing. Huxley has sent me rough proofs of the Physiology up to the 206th page, which I will forward in small quantities. Ask Jay to advise me of what he receives, that I may know if any are lost. I am proposing to leave about the middle of October, or the moment I get through writing.

September 28th.-We dined at Huxley's last night. Spencer and a Mr. and Mrs. Young were there, and Frances Power Cobbe; and Frances is a power, or, at all events, a bulk in the land! Huxley is in a bad way; he is undoubtedly failing from overwork. He is now, at the close of his holiday, just as at its beginning, and Spencer is worried about him. . . . After the party I finished my lecture at three this morning, and was so excited that I did not get a wink of sleep till five o'clock. Spencer leaves town to-day at two for a fortnight's absence, and I arranged to call to-day at eleven to read my production to him. With my tail feathers spread and in a state of infinite complacency I went, and returned trailing my glories in the infernal London mud.

Poor man! What could he do? There was but one thing to do, and he did it, you had better believe. Faithful indeed are the cruelties of a friend. My lecture was 
fairly slaughtered. I had such nice authorities for everything. What are "authorities" to Herbert Spencer? The pigs went to the wrong market this time.

"A little too much effort at fine writing"-forty-five pages. "You have lost your point at the fifth page and not recovered it. Why, I thought you wished to make a sharp presentation of science in its bearings upon the study of human nature, and you seem to have entered upon a systematic treatise on physiology interlarded with bad psychology." The unfeeling wretch! "Strike out half, put the rest in type and work it up," was the final injunction. Well, striking out will be better than building up. Easier, at all events. The fact is, I had overworked the details-that was the only real difficulty. I had not read it over, but had passed it over to Kitty to copy, batch by batch. I read it first to-day, and hardly needed telling that it was too long and needed compressing. I shall reshape it and read it the roth, before you get this. But there is one thing: I shall not work as I have done-another month would lay me out. I will not work nights when I can't sleep daytimes. I am very well, but jaded. I fear justice to my enterprise will require me to appropriate the rest of October to it. The book will hardly fail to prove valuable. I see nobody, but drudge on day by day, thinking ever of home, and longing for the moment of return. The fogs have begun to come, and I have lighted candles to read by in the daytime.

The next letter is dated from Mr. Spencer's new apartments, at 37 and 38 Queen's Gardens, Bayswater, October i 3 th :

The lecture on the Scientific Study of Human Nature came off as per appointment at the room in Queen's Square, where you heard Hodgson. I had got hurried proofs of it, and it would take an hour and a half to read it, but as only 
an hour or less was all that could be allowed, I was compelled hastily to scratch it, and I overcut it. Kitty went with me. Just before I began, in came 'Tyndall. I thought I saw through that dodge in a moment. Spencer is out of town, has been away for a fortnight, expected to return, I am told, to-night, and as he was evidently solicitous about the result he got 'Tyndall to go. Whichever way it be, it was fortunate, and I am certainly much obliged to him for his consideration, for the meat was too strong for the babes. They were restless, and as I said thing after thing, a dozen pens sprang convulsively to paper, to note them down and blow them up. There was the closest attention, and at all events $I$ had them in hand. At the close there was cordial applause-as usual, I suppose. A gentleman then arose, and said he was attracted to the meeting by the announcement of my name, having read a very remarkable argument in the shape of an introduction to a work on chemistry lent him by his friend Dr. Farr (to whom I had given a copy), and he said, "I was, therefore, less taken by surprise at the paper we have just heard than most of you have evidently been." After a very pleasant and excellent address, in which he said Locke had laid down the true view of the basis of education two centuries since, which, if followed out, would have produced the most beneficent results, he sat down and Tyndail arose. He made an exceedingly neat and happy address, into the very notch of the case. He put the plaster on large and thick and close, as he best of all men knows how to do, and the consequence was that all subsequent remarks were but adding lesser patches. One good old gentleman of the old school did not really seem to see that there were yet the materials of a new science of human nature, but hoped there would be. The president wound up with a little speech, demurring somewhat to the strictures on the present spirit of teachers, but saying frankly that the address 
was beyond doubt the ablest, and solidest, and most important that had ever been delivered before the College of Preceptors. Tyndall escaped before I could speak to him, but I dropped a note to him next morning, thanking him for his kind consideration in coming, for his too partial remarks, and for his shielding me from the little hailstorm which I should have undoubtedly experienced otherwise. He replied, saying: "I quite expected the little hailstorm, and was astonished to find what you said (for the view was very strong for such a place) so heartily appreciated. Believe me, when I say from my very heart, the paper surprised me as much as it delighted me."

October 20th.- It turned out to be a mistake about Spencer sending Tyndall to the lecture. Spencer was under a wrong impression about the time, and says he intended to be there himself. Tyndall and Huxley were invited the day before. Huxley said, had it not been for a previous engagement he should have been there.

October 27 th.-I have only to-day at twelve sent the last revise of my lecture to the printer; in making it there has been a large loss of power, owing to my solicitude. I was editing the work and thrusting a discourse of my own among the highest names, and assuming the largest and most difficult topic of all to treat. Besides, I was to submit it to the coldest and keenest critic in the world, who cared not tuppence for anything but the facts. I was to write on his own topic-his special topic, and where he rejects all the physiology of psychology to be gathered in books, and doesn't know what an "authority" is. It has been hard work, but I have at last got the epithet "capital" out of him, and that without asking, as you may well understand. I hoped to send you the sheets to-day, and sat up all night nearly, last night, hoping to get them ready; but Spencer could only finish the reading this morning too late, and I have had to give it up. The Introduction I care less about 
in this country, and am not going to have it stereotyped at any rate, as the American argument must be very different. I shall do what I can with it and let it go.

The "highest names" to which allusion is here made were those of Liebig, Tyndall, Henfrey, Huxley, Herschel, and Paget, whose essays were gathered together in Youmans's volume, published under the general title, The Culture demanded by Modern Life. After his return to America, late in the autumn of I866, he added a contribution from Dr. Draper, and summed up his own views in the Introduction on Mental Discipline in Education, which was perhaps the most finished piece of work that ever came from his pen. It is reprinted entire in the present volume.*

The book, published in the spring of 1867 , was received with favour; and there can be no doubt that its contents, in this connected form, were vastly more influential for good than in the separate and narrow fields of their original issue.

The following extracts from letters have interest in connection with this book, as also with other matters, personal and general:

37 QUeEn's Gardens, Bayswater, W., January 14, 1867.

My DEAR Youmans: I have been looking for a letter for some little time past, telling me how you are going on; but I suppose lecturing has carried you away into the West, and is absorbing all your time.

Macmillan delayed for a long time the issue of your volume of Essays. Why, I don't know, unless business policy dictated the delay. We did not get our respective copies until the beginning of January. The volume looks

* See below, pp. 399-450. 
very well, and is likely, I think, to do a great deal of good. Dr. Hodgson, whom I lately met, expressed great satisfaction with it. He said your essay would have delighted George Combe. I suppose you have already printed off the first American edition.

Saratoga Springs, January 20, 1867.

My dear Spencer: I have been very little in New York since my return, and know nothing of the state of the book trade. General business is active, but prices are enormously inflated. Shrewd men say it will be impossible to get back to stability except through widespread financial ruin. One of the most discouraging symptoms of the times is the insane and universal clamour for exorbitant protection. Protection, even to prohibition, is now the cry with many. There are various causes for this. Some think it is the only defence from the impending financial ruin.

The sentiment of nationality or patriotism, which has become a cant since the war, favours protective measures; and the deep feeling of hostility toward England, which pervades almost the whole mass of the people, which talks continually of British free trade, and refuses to think that anything but selfishness can come from that quarter, has also a powerful influence. The Free-trade League has uphill work of it.

Gold has fallen to $\mathbf{I} 30$, although now rising again. I presume it will return to that point again. As you have dipped considerably into American securities, would it not be well-at all events safer-to convert what may become due to you into an available shape? Please indicate what you would like in the matter. I leave to-morrow for the West on a six-weeks' lecturing absence, and dread it intensely, as the country is submerged in deep snow and the weather extremely cold. My wife is in New York, and will remain there until my return. 
37 Queen's Gardens, Bayswater, W., Fibruary 25, 1567.

MY Dear Youmans: I think you are right in your sug gestion as to the impolicy of further investment in American securities for the present. Any balance that may be due to me from the forthcoming account may as well, therefore, be transmitted to me here.

March IIth.-You were saying when over here that you thought the time was coming when we might recommence the issue of the serial in the United States. I doubt, however, whether it would be worth while. Our subscription list here has just been gone through for the purpose of giving a peremptory reminder to those in arrear. I find there is not far short of two hundred pounds sterling due. Possibly the intimation that has been given, that no further numbers will be sent to those whose last two subscriptions are unpaid, will have its effect. But I foresee that, if things go on as they have been doing, it will be needful to give up the issue in parts by the time the Psychology is completed. The trouble and loss will no longer be compensated by the gain. You will be startled in America, as people are being startled here, by the marvellously sudden change of opinion that is taking place in our political world. The phenomenon reminds one of that which takes place with ice when much below the freezing point. You go on raising its temperature for a long time without any appreciable effect, and then all at once it begins to thaw rapidly. Doubtless in the same way a change has been going on here without producing any sign; and now it is making itself visible all at once.

I shall be glad to hear of your doings, and also of your plans for the summer. I hope we shall be able so to manage as to have a sojourn in Paris together.

Ever yours truly,

Herbert Spencer. 
New YoRk, March 17, 1867.

Dear Sister: I am here at the club, * where I have a warm, pleasant room to work in. It is now four, and I have done an excellent day's work. We have had a diabolical storm, and the snow is two feet deep. I have dashed off a rough scheme of study, a rude curriculum, which I will transcribe. If you can help me on it please do so.

I. Home and Primary Education, in which are to be acquired correct habits of expression, familiarity with the properties of common things by the intelligent employment of the object method, reading, drawing, writing, elementary numbers, elementary form, etc.

2. The Discipline of the Physical and Mathematical Sciences-arithmetic, geometry, natural philosophy, chemistry -establishing systematic habits of continuous attention, of observation, induction, deduction, and verification of truths. Familiarity with the conception of cause, law, necessary truth, and with the history of the growth of physical and mathematical sciences. Thus preparing for

3. The Discipline of the Biological Sciences-botany, zoölogy, physiology, geology. Extension of the idea of law and sensation into the departments of life and familiarizing with the conditions of inquiry and methods of reasoning in this department of thought, with the history of the growth of these departments of knowledge. This is a preparation for

4. The Discipline of the Psychological or Representative Sciences-mental philosophy, logic philosophy. Forming the threetold basis for the systematic study of literature, history, ethnology, social science, government, and morality.

This division is on the basis of discipline, as I shall be

* The Century Club, in its pleasant and ever-to-be-regretted old home on Fifteenth Street. 
able to show that the order of ideas in these four stages gives a progressive training, and completes the circle of mental requirements in this respect. But I am tired, and so good-bye.

NEW YoRK, March 23, 1867.

My Dear Spencer: I send you the Atlantic to-day. Holmes has reached the philosophy of hysterics in No. 4 of the Guardian Angel, and will treat the psychological sequelæ of its paroxysms in the next number. Fiske deals with University Reform in a very quiet but able articleas liberal as could be expected from a devotee of philology. His argument does not touch the case as it stands in my mind, but its suggestions require careful pondering. Fiske is strong, but a little pedantic on the lingual side.* I see that Mill makes an unqualified indorsement of Greek and Latin. I shall pay him my respects and include Fiske. By-the-by, Mill is the champion of the classics here now. He is thrown in everybody's face who questions tradition. There are many excellent things in his address, but what he says about the classics won't hold water.

As for what lies before me this summer, Omniscience alone knows it! I should be glad to come over, but fear it will be impossible.

* He means that I am too fond of Greek and Latin, and attach too high a value to the study of those languages and to philological training generally. On this point I have never been able to agree entircly with Spencer and Youmans, owing perhaps to peculiarities of early training and the bias resulting therefrom. From childhood I was steeped in Greek and Latin, and read ancient authors with a zest which time has done nothing to lessen. Naturally, therefore, as to the educational value of the classics, I was inclined to agree with $\mathrm{Mill}$ in his Inaugural Address at the University of St. Andrews, to which Youmans here refers; and with such views as those of the late Prof. W. F. Allen, of the University of Wisconsin, in his Essays and Monographs, Boston, I89o, pp. I55-I64. The article of mine referred to was Considerations on University Reform, in Atlantic Monthly, April, I867, reprinted in Darwinism and Other Essays, revised edition, Boston, $\mathbf{1} 885$. 
37 Queen's Gardens, Bayswater, W., April 8, 1867.

My DEAR YOUMANS: I issued the closing number of the Biology, or rather double number (it contains ten sheets), on the 3 oth of March, just managing, by a good deal of pressure, to save the date. The bound volume is advertised, and I expect to get some copies to-day.

To-morrow I shall commence the revision of First Principles. I had intended to make one or two replies to criticisms in the first part, but have been dissuaded by the Leweses from doing so. Huxley is just through his Hunterian course, and is much better than was to be expected, for he has been in a very shaky state during the last three months under a great pressure of work. Tyndall, too, has been doing too much, and has to pull up. He is urgent to get out his volume on Sound, and, as usual, has been betrayed into overwork by his eagerness.

April 17 th.-The inclosure contained in your letter* was a considerable surprise to me. I had anticipated something very much less. What a wonderful steward you are! I never dreamt a few years ago of any such results arising, and had it not been for you it is clear that no such results would ever have arisen.

Your remark as to the use that is being made of Mill's name completely fulfils the prophecy I made to him. I told him that I regretted to see the weight of his authority given to a side that is already, to say the least, far too strong, and that the result would be that the classicists would appropriale all he said in their favour, and ignore all he said against them.

I regret that you are not thinking of coming, having counted on our having a "good time" at Paris together. As you hold out no hopes of this, I think of making my trip to Paris pretty soon-probably on the $29^{\text {th }}$ of this

* The reference is to the check for royalty on sales. 
month. I shall take some work with me, and most likely stay about a fortnight.

June 7 th.- It may be that you are wise in not coming to the Paris Exhibition. I went for a fortnight, and came back before the week was out. Perpetual sight-seeing soon became a weariness, and I was heartily glad to get back. Matters were made worse by the extremely hot weather, which set in just as I went there.

I have decided within these few days to use a specific title for the whole series of volumes that I am issuing. Originally, when drawing up the programme, I contemplated doing so, and was very nearly using the title Deductive Philosophy; but I was dissuaded, and finally fell back upon the indefinite title of a System of Philosophy. There are decided evils, however, in the absence of a distinctive name, and I have had these evils just now thrust before me afresh. At the close of his new edition of his History of Philosophy Lewes persists in claiming me as one of his school, saying that "Mr. Spencer is unequivocally a positive philosopher, however he may repudiate being considered a disciple of Comte," and he goes on to close his book in the next paragraph by saying, "Am I claiming too much for the Positive Philosophy in claiming for it whatever the future may produce?" Now as-whether Lewes intends it or not - the Positive Philosophy will continue to be understood as the philosophy of Comte, and as I so distinctly repudiate the philosophy of Comte, it is needful to take some step to prevent the confusion. So long as there is no other title in use to express a philosophy formed of organized scientific knowledge, one cannot expect people to discriminate. Another title, therefore, is evidently extremely desirable, and will, I think, in many respects yield positive as well as negative advantages. I have decided upon the title Synthetic Philosophy, which, on the whole, seems the most descriptive. I am intending to make the issue of 
this second edition of First Principles the occasion for introducing it, and propose that each successive volume shall bear this general title on its back in addition to its special title.

June 26th.-We are about to give a public breakfast here to Garrison. Bright is to be in the chair, and the address is to be moved by the Duke of Argyle and seconded by Earl Russell (probably), and also by John Mill. I am one of the Committee of Arrangement.

The second edition of First Principles is working out very satisfactorily-even more satisfactorily than I had anticipated. In its reorganized form it will be extremely coherent all through; the thread of the argument will be unbroken, and it will, I think, have the obvious character of completeness.

DeRby, July 9, 1867 .

MY DEAR Youmans: Williams and Norgate the other day ordered a supply of Biology, Volume I, of which their bound stock was out. On sending an order to the printers, the answer returned was that they had none. My account with them showed that there remained in their hands thirtythree unbound copies, and they admit that the evidence shows it. They cannot be found, however.

Please without delay send the stereotype plates. Do not delay to print any more copies before sending them, for as fast as the printing of the new supply goes on I will have a duplicate set of plates made and sent to you.

Ever yours truly,

Herbert Spencer.

Saratoga Springs, July 30, 1867.

MY DEAR SPENCER: Upon the reception of your letter I took the next train for New York to do myself what could not be trusted to others. There was reluctance, almost resistance, to sending the plates. The cause was this: after having made two mistakes, first in issuing my own book, and then Maudsley's, in midsummer, I had stopped the 
Biology, which was a little behind them, designing to be all ready with it September ist. Hence, when I gatve the order to return the plates, I was met by the statement that there were but one hundred copies of Volume I remaining, and it would not do to publish Volume II without a full supply of the first; and as it would take a long time to get the plates back, and would be attended with considerable expense of transit, they insisted that the better plan would be to take the duplicates here, which could be done in twenty days for three hundred dollars. I refused to entertain the idea, and by driving up the printer and bullying the box-maker I got the plates ready for the shipper the next day at noon. I intended to have seen them on board the steamer, but was taken ill, and had to leave for home. I know, however, that they started for the ship, and I believe they are now on their way, but I should be easier if I knew.

I need not urge the utmost dispatch, as you see the situation. The change of title is desirable, and the one you have hit upon fortunate. But the reasons you offer for taking the step compel me to suggest that if it can be avoided it will be undesirable to reopen the Comte discussion. I have myself never doubted the wisdom of publishing the Classification, but that is by no means the universal opinion. Your original letter disclaiming Comtism had a wide circulation in this country, and was generally felt to be opportune, appropriate, and satisfactory. But when the pamphlet appeared many of your friends said, "Mr. Spencer's work will vindicate itself and find its true place. We are sorry to see him so apparently sensitive about these early misapprehensions of it." You have an antagonism upon this question with your friends the Leweses, while Mr. Lewes is engaged in the business of weighing and measuring philosophers. May not this circumstance have had a tendency to keep the subject alive, if not to exaggerate 
it in your own mind? I think a third reference to your differences with Comte, especially on the occasion of your adoption of a new title for your system, would afford great facility for misinterpretation; and in the preface to the new edition of First Principles, in explaining the reasons for revision of title, I shall be glad to see a minimum recognition of Comte. I incline to think that there is a good deal in this, but you know best.

I send you two notices of my own book by Fiske, clever but partial.* Mr. Mill has unwittingly done the most atrocious thing for the cause of real improvement in this country that any living man could have done. The whole theological world are in ecstasies over his performance at St. Andrew's as an unanswerable argument for the way things are. All he says for science goes for less than nothing-is never referred to, and all his unqualified claims for the classics are borne on the wings of the newspapers to the remotest part of the land.

The presidents of all the colleges in the land are rehashing his classical arguments in their this year's addresses, and scattering them broadcast and throwing up their hats at a new and unexpected accession to their forces, to which they must know they are not justly entitled. The standard of classical attainment upon which Mill insists (and insists that it shall be general) crowds out everything else, and makes futile all talk about the educational claims of science. The Catholic organ warns its clergy against commending the Culture demanded by Modern Life, and the Protestant theologians recommend the diffusion of Mill's classical argument as an antidote to it.

The worst difficulty about it is that the theological party is skilfully working it as a gain of authority, and Mill's name is so potent that the opposite party has us at

* I. e., too much in favour of Greek and Latin? Or, more likely, in his excessive modesty he meant that I praiserl his work too highly. 
an enormous disadvantage. Right here in Saratoga, for example, they are organizing a free high school to be supported entirely by public taxes; the clergy lead in the movement, and demand that the institution shall be coordinated with our college system and arranged upon a classical basis of Latin and Greek; and if a person opens his mouth in protest he is immediately knocked down with Mill's classical argument, and that, too, by those people who have never read another line of his writings and a year ago would as soon have quoted Voltaire as Mill. Somehow and by somebody that argument must be answered. If anything appears in England that has any value as a criticism of it, I will be greatly obliged if you will send it to me. But I am wearying you. My wife and sister join me in expressions of kind and sympathizing regard.

37 Queen's Gardens, Bayswater, W., July zo, 1867.

My dear Youmans: People's blunders are perpetually entailing on me all kinds of trouble and expense. A considerable percentage of my time is taken up in rectifying them. The last is a serious one. The statement on the part of printer and binder that they had no stock of Biology, Vol. I, has turned out to be a mistake on the part of the binder, who has discovered that he had one hundred and seventy-five copies. Thus my hurried order to send off the stereotype plates at once will prove to be a needless and unfortunate one. If you have a sufficient stock to last two or three months it will not matter, as the duplicate stereotype plates can be at once executed and sent to you. Of course, if the plates have not been dispatched before this reaches you, you will retain them.

I leave town for the season in the course of a few days, and shall be at various places, mainly in Scotland. I shall, however, keep Miss Shickle informed as to my whereabouts, so that you may address to me at 37 Queen's Gardens, which, indeed, will now be my permanent address. 
I received the other day-sent, I suppose, by you, though I did not see the address-a copy of No. I of the Journal of Speculative Philosophy, containing a long criticism on me from a Hegelian point of view. You named it, I fancy, some time ago. It has some sharpness here and there, but I am not conscious of being hurt by it.

Ardtonish Tower, Morven, September 1, 1867.

My Dear Youmans: I regret that you should have been put to so much trouble about the sending off the stereos. of the Biology-the more so as it has turned out, as you have since learned, to be needless.

I gave orders for the restereotyping to be immediately commenced, and it is now in progress. "You will probably have the duplicate set of plates by the time you want them. When those of First Principles are sent-which they will be as soon as ever the second edition is out of my hand-you will be set up and we shall have no further bother.

Thanks for your remarks about the title to the series, and about Comte. You have alarmed yourself needlessly, however. Though I referred to Lewes and his description of me as a positivist as a reason for taking the step, I did not say that I should give this as a reason. It never occurred to me to mention Comte or positivism in the preface to the new edition.

I regret to hear what you tell me about Mill's address, but it completely fulfils the prophecy I made to him about its effect. I wish would write a letter direct to him about it, saying that you did so at my suggestion. It might prompt him to write something in one of your papers to rectify the impression. I should very well like to answer it, but it would add another to the many delays that meet me.

I am staying here with my friends in Scotland, doing a little work, but passing most of the time in sports and amusements. I am getting much better. The relaxation did not come too soon, for I find myself anything but 
strong. However, I expect soon to be right. Kind regards to all, and believe me very truly yours,

Herbert Spencer.

Saratoga Springs, August 29, 1867.

My DEAR Spencer: I wrote you some time since that I sent the plates of Biology, as you requested, "promptly," and, furthermore, that it placed us in something of a predicament-putting back the publication of Volume II, I fear, till late. I hope you did not fail to get the letter, as I explained the necessity of the utmost promptness in returning the duplicates. The blunder of your printers was very unfortunate, and cannot fail to tell seriously upon your dividends this year. But I console myself with the reflection that when this obstruction is tided over we shall have clear sailing.

An American edition of Huxley's Elementary Lessons in Physiology, with added chapters on Hygiene, was to be prepared by William Jay Youmans. The causes of delay are explained in the following eminently characteristic letters :

Saratoga, July 30,1867 .

Dear Brother Jay: I think I left Chapter XIV with Werrey.* He will send proofs to me, and after final revision I will send you a set, chapter by chapter. That I have considerable to do on them, as you will perceive, is one of the causes of delay. But I will now hurry it forward. There is nothing new here; everything jogs along at the old rate; some kitchen perturbations give spiciness to domestic life. I have Gorman's brother-green, and a natural fool into the bargain; also Mike. And between the McIllroys and the Gormans there is feud dating back to Ireland, which makes a precious mess of it.

* Head of Appletons' printing department. 
August 3 d.-I found the inclosed passage imbedded in a paragraph, and there having been no reference to the subject before, the first question of an ignorant pupil would be : What is he talking about? What are cysteria? What are trichinæ? What is encephaloid? One of the things I had expected was to find a complete paragraph, or several paragraphs, with a full account of these parasites. Turning to the last section of the chapter on Foods, I find a recurrence to them, but no explanation. Everything is taken for granted. The passage is a somewhat exaggerated sample of your prevailing fault of writing. You must study the art of putting a case. You must, in the first place, throw yourself into the state of mind of one who knows nothing of the subject, and make the explanation simple and complete without his having to go to the dictionary or glossary. A world of practice will be required upon this one point. As practice, you cannot do better than to make a statement, and then make it over and over again, striving each time to get it more simple and clear. I will omit the included passage from its place, and put what is said upon this subject in the last section of the chapter, and I wish you would immediately write out a full account of the matter: the origin, size, circumstances, propagation of the animals, and their physiological effects, harmless or harmful. It will be expected in the book. It is just what the second part of the book is for.

August 4th.-I am head and ears into your job, as I wrote yesterday. The chapter on clothes is the best of all, as the whole discussion is most pertinent. Yet I miss the specific and most important statement to which you have often referred, of the effect of insufficient clothing in infancy. You despatch the whole question of infancy and old age by a short extract from Parkes. If you can muster some statements with specific evil effects, concrete facts, and send them down, I will incorporate them. A note from 
Werrey says some of the manuscript is missing. I hope it will not be serious. I shall send him in a day or two all the copy up to the last section of the chapter on foods. I must keep that for a better statement about trichinæ, as I wrote you yesterday. And in that section also the reference to the diet of children is very meagre and unsatisfac.. tory. The effect of substituting arrowroot for milk in their diet is not referred to. Can you not make some points on this subject by reference to the handbook? And both in respect of diet and clothing, can't you get some concrete hints from Part IV of Spencer's Education? In the chapter on food the last section is really the only part that bites upon the subject of hygiene, the rest is but remotely applicable. I am retrenching what seem the more indirect parts.

September IIth.-I have been down to New York to see about things, and returned this morning. I send by mail to-day twenty-four pages more. Chapter XIX is in the hands of the printer, and I have commenced Chapter XX, the last; must have it done in a week. Send down the questions at once as far as they go. Werrey will set them up and page and stereotype them as soon as the last chapter is through.

I received yours of September 6th this morning. We are all well, our folks quite smart, and slowly gathering themselves together to leave, which they will probably do in October. We shall commence boxing their things shortly. I am not without serious fears respecting the Physiology. Neither Part I nor Part II are just what they ought to be. If the work proves to have any value or promise, I suspect the only method will be a thorough revision and restereotyping. There is too much irrelevant or very remotely relevant matter in Part II. I shall do what I can to make Chapter XX attractive.

September 24th.-A mess of questions, pages ${ }^{3} 3$ to 25 , 
came yesterday. I have not received those going before. If they have been sent and miscarried, you will have to copy or make them over. Let me know about it. You will have to be patient with this long delay: I am doing the very best I can. You won't require much imagination to understand that in the midst of this breaking up there is little opportunity for quiet and contained thought. I am hourly and semi-hourly disturbed. Have been bothered to death to get a man to make our boxes; have at last found a fool who can put them together, but I shall have to do all the packing myself. The last chapter of the book is to be the most important one. It will be quite a new feature, and I wish to make it the card of the work. It is the most difficult thing I ever attempted, and I have to do it many times over. I guess I have broken up and restated the first section already ten times. I shall hurry it along as fast as possible consistent with doing it right, which is the first thing to be considered, for the success of the book is in question, and it is a matter of ten years' interest with no further trouble when done. I have not touched my lecture, nor shall I till this job is finished.

Early in I 868 the Physiology and Hygiene of Prof. Huxley and Dr. William Jay Youmans was published. The following letter alludes to this and to the textbook of Botany which Miss Youmans was preparing:

Saratoga, March 3,1868 .

My DEar Sister: You will be glad to know that the Physiology has been warmly commended by Dr. Austin Flint, who has written Mr. W. H. Appleton a note about it. The only fault he finds is with the illustrations, which he does not consider up to the times. Earle mentions that you have had a little trial trip with the Botany, which proved satisfactory. I was glad to hear it. There rests no doubt in my mind that it is a very big thing education- 
aily, and that the public is quite ripe for it. I had a talk with Mr. Hewitt at the Century the other night, and was glad to find that he had formed a very high opinion of botany in a disciplinary point of view, saying that it was probably as good as mathematics. I showed him in what respects it was superior, and when I told him that it was the only point in the whole course of education at which æsthetics might be naturally developed, I think he was much struck by the remark. He asked me if I thought it could be systematically included or co-ordinated with the other studies in the School of Design. I said, Undoubtedly. He had looked over the Physiology, and liked it. He was interested in your progress with the Botany when I told him about it. The botanical field, as you mean to take it up, is quite unoccupied; how long it may remain so is uncertain. You ought not to carry the book through alone; you must have somebody help you do the drudgery of it.

I have been overhauling the World to find Fiske's articles, ${ }^{*}$ and have been well rewarded. He remembers Spencer every time. I send them to you. Preserve them and bring them down when you come.

In this winter season of I868 Mr. Youmans made the last of his long lecturing journeys, attended by much weariness and discomfort. In reading the letters of this time, that susceptibility to cold-which afterward ended his life-impresses me as greater than in those days I had fully realized.

WinoNa, January 26, 1868 .

My DARLING KITTY: I was gladdened by two letters when I arrived here yesterday, while a third has come to-

* The reference is to various reviews of historical and scientific books, in the course of which the doctrine of evolution was apt to get mentioned, with some of its bearings upon the particular case in hand. 
day. You are a very dutiful little wife. The train which was due at La Crosse at midnight did not arrive till six in the morning. There was no sleeping coach, and the infernal cars were hotter than ovens. Not a wink of sleep did I get, and my eyes became much irritated. I got here at noon, and ah, how solid and dense was my sleep last night! It has left me rather exhausted. . . .

At Freeport there was a protracted meeting in full blast in every church in town except the Episcopal, and a general feeling of pious rage at my appearance on the scene. The Presbyterian clergyman alone, a cold-blooded but highly intelligent man, who had been reluctantly driven into the revivalist movement by sheer competition, appointed his meetings at half-past six, so that people could come to the lecture at eight. My first audience accordingly consisted of about a hundred stragglers from prayer meeting. In my lecture I of course assumed the antiquity of the earth, and that was enough! It got abroad the next day, and was reverberated through the town that "Prof. Youmans is an avowed and unblushing infidel." There was a deuce of a time. I was called upon and offensively catechised as to what I believed. Questions were written out by a clergyman and sent to me to be promptly answered in public. The next night it was scarcely better; but the gentlemen who had my lectures in charge, seeing how things were going and determined not to be baffled, crowded the house the last two nights with pupils of the schools let in freea capital arrangement, for I would always rather talk to them than to the old folks. At the close of the last lecture I gave them a piece of my mind in a dignified way. I turned the tables on them, and showed that the real infidels are those people who have so little faith in God and in his universe as to be skeptical about the wholesomeness of demonstrated truths. It was a successful hit. After I had finished, a splendid-looking man, ever so much like Uncle 
Good in appearance (he was a Mr. Mitchell, member of the Presbyterian Church and president of the principal bank in Freeport), came up to the platform and gathered the committee together. He then said, "I will myself stand the expense of an immediate repetition of this course of lectures free, if Prof. Youmans will stay and deliver them!!!" My engagements, as you know, made this impossible.

I remain, with much love, your vagrant husband,

E. L. Y.

Winona, February 4, 1868 .

My DEAR Wife: I almost dread to sit down to write to you. I seem fated to send you such a lugubrious set of reports that you must be very much wearied with them. Still, if only for the sake of the unities, I am constrained to continue my grad-grindings. It is now Tuesday morning. I left a week ago yesterday morning for Rochester, gave one lecture there and one in St. Paul, and consumed the entire week, only getting back very late Saturday night. The prairie winds drifted the hard dry snow over the railroads, filling the deep cuts as with ice. To be four or six hours in a single snow-bank was a common experience. I counted myself most fortunate in getting back as I did, as the roads are now almost completely blocked, and the train that started out yesterday morning returned at night after having only reached the first station. I lectured at Coldwater on Saturday night, and while under ordinary circumstances I could arrive there by leaving Friday morning, I cannot now venture to leave here later than to-morrow morning. My visit home,* therefore, although by no means spoiled, has been greatly interrupted and disturbed. The cold has been very intense-from ten to twenty-eight degrees below zero-and for this I was not at all prepared.

* Youman's father and mother had left the Saratoga farm, and were now staying at Winona. 
I therefore took a succession of colds, day by day and night by night, and when I returned to Winona was quite ill-hard cough, great hoarseness, extreme and painful soreness of the chest, and headache. Jay at once took me in hand, and what with going to bed, two days' rest, and mustard plasters on my chest, I came out this morning feeling very much better, headache and lung soreness gone, and cough diminished but tightened. The weather has fortunately relaxed. . . I I have mentioned to you repeatedly how predominant is the religious excitement in the various towns where I have lectured. A note from Mr. Cowles, of Freeport, states that Rev. Mr. Cary (who sent me up that series of questions to be publicly answered) announced that he would preach from Genesis i, I, a sermon entitled Thoughts suggested by the Recent Lectures of Prof. Youmans. The Methodist clergyman of Rochester also advertised that he would preach on the Dynamics of Life. I doubt not that both houses will be jammed. My lecture at St. Paul was very satisfactory on my part, but for exactly the same cause the house was slender. All the churches were aflame with the religious excitement. I met the Methodist bishop coming down on the cars (to dedicate some church), who regretted that I had come to St. Paul just at this time when there was so much religious interest. Several gentlemen attacked him because the clergymen did not attend the lectures. He replied: "We never suspend religious meetings for such reasons." The quick rejoinder was, "You did suspend them for Gough and Anna Dickinson," which of course made him angry. He replied, "If they had not adjourned them they would have been left alone." He said, "It is not science that the world wants, but Christ!"

I hope I may soon see you, and be at home somewhere. I am very, very tired with this life of vagrancy. 


\section{Zanfesville, OHio, February $23,1868$.}

Dear Sister: I have held on steadily, and closed my series of engagements last night without losing a lecture, but it has been harder and harder work. I have had a terrible cough, which has been equally distressing to myself and my audience. I could not give another lecture, and yet I think my cold is in that state that if I can stop to rest it will quietly leave me. The speaking tears it up every night. Last night, when I had begun to speak, I had a spasm of the throat that lasted four or five minutes, embarrassing and alarming me very much, but it soon passed entirely away.

\section{Saratoga, March 3, 1868.}

My dear Mother: Earle will report to you that $I$ got home to New York safely, although pretty well used up. He left me yesterday morning at Mechanicsville in the midst of a furious snowstorm. The cars got to Saratoga, but could go no further. Tommy* was there, but the storm was so blinding and furious that we almost gave up the idea of trying to get over to the farm. We had a tough job, I can assure you, and were two hours getting over. The road was buried out of sight, and the drifts were deep, some of them immense. Tommy said the snow was three feet on a level before, and we have had another foot or fifteen inches. The house this morning is completely buried in. I find the house tight as a drum, every door locked (and the key hid) but the kitchen. The house is as neat as waxwork. The kitchen is kept swept, the stove polished, and Tommy has a harness, which he has been oiling in the back kitchen. One of the cows had a calf the night

* Thomas Welsh was a young Irishman who had been left in charge of the farm. When Vincent Youmans and his wife went out to Winona to live Edward took the farm off their hands. He sold it in the course of the spring, and then secured for the faithful "Tommy" a position in the Appletons' printing establishment. 
before I came, but Tommy found it dead. It lies there stiff, and the poor cow feels awfully. Her dumb supplication to us to do something for the poor dead thing is very touching. She goes to it, and then turns back and looks at it and moans, as much as to say, "Can't something be done?" She is doing well, and Tommy says will be all right by the seventh milking. The horses are looking very well. The colt got so fractious that he was compelled to stop giving grain. He gives them alternate stalks and hay. He says old Roan is very fond of the stalks. The road goes across the hill, between the house and barn, and Slade has just gone over it with a snowplough. It is town meeting, but there will be a very light vote to-day. The hens have not begun to lay yet. I had last night the first solid, sound, unmitigated sleep for the last three months. Tommy rolled the hot water thing all round in the bed before I got into it. $\mathrm{He}$ has raised a hundred bushels of ashes, and drawn five or six cords of wood from the mountain, and several cords down in the new roadway. I am going to try hard to sell the place this March. The weather has been terribly cold here, and however it may be in Minnesota, you may well congratulate yourselves on having escaped from this chilling environment. I must go back to New York to-morrow, if possible. Tommy is "a-bilin"" dinner; the pork, cabbage, and potatoes are walloping * away in the pot while he is shovelling out the house. . . . Study to be quiet, and don't go out while it is cold.

The crowded occupations of the autumn and win-

* An ancient and picturesque word: wallop, "to boil," Skeat; "to bubble up," Wright, Halliwell; " to move quickly and with much agitation," Jamieson's Scottish Dict. The Anglo-Saxon is up-weallan, to well up, like a spring ; "aufuallen," Edward Müller, Etym. Woerterb. d. Englischen Sprache; " represents the sound of liquid in agitation," Wedgwood, Etym. Dict. 
ter had prevented the writing of letters to Mr. Spencer, until he had begun to feel some anxiety about his friend.

37 Queen's Gardens, Bayswater, London, W., January 2, 1868.

MY DEAR Younans: I am beginning to be anxious to hear from you, fearing from your silence that something may have happened. The date of your last letter is August 29th-more than four months ago-so that I begin to fear either that my letters have not reached you, or that you have been doing too much and made yourself ill. Pray, let me hear from you.

I am just now suffering under one of my occasional attacks of greater nervousness than usual, resulting more especially in very bad nights. For the last fortnight I have done very little work, and for the last week none at all. To-morrow I am going off into Gloucestershire, where, if the frost which has now set in lasts, I hope to get some skating, and I count upon this for doing a good deal toward setting me right again. I had hoped to get out the first number of the Psychology by the end of February, but this untoward state, entailing, as it may do, considerable delay beyond what has already occurred renders that achievement impossible.

37 Queen's Gardens, Bayswater, London, W., January 22, 1868.

My DEAR Youmans: Your welcome letter reached me a few hours after I had posted my last to you. I was glad to find that nothing amiss had happened.

I dare say you were surprised to find that I had not adopted the new title for the serial,* as I proposed. I discussed the matter with both Huxley and Tyndall, and though I do not think that the objections raised were such as to outweigh the manifest advantages, still there doubt-

* The reference is to the title Synthetic Philosophy, which was adopted somewhat later. 
less are objections, and in the midst of conflicting considerations I eventually became so far undecided as to let the matter stand as it was.

37 Queex's Gardens, Bayswater, London, W., February 29, 1868.

MY DEAR YOuMANS: After losing a great deal of time during the last two months, hoping to get into working order by using half measures, I have been at length coinpelled to take a more decisive course. I start to-morrow morning for Italy, where I propose to spend some two months, expecting that by the end of April, by the combined effect of desisting from all excitements, intellectual and social, and getting the exhilaration due to so much novelty, I shall regain my ordinary state.

I have postponed writing until to-day, hoping that I might hear from you again before starting, and thinking that I might have something to reply. Any letter that arrives from you shortly I expect will reach me in Italy, as I am leaving directions to have all foreign letters sent on.

NEw York, March 4, 1868 .

MY DEAR SPEACER: I have but recently returned from a protracted absence in the West, where I at last broke down from the exposure of travel in a remarkably inclement winter. I left a number of engagements unfulfilled, and did not think to return again, but I am getting better, and am strongly urged to return. If I go, it will take three or four weeks. . . I shall not be able to give attention to your books till I return from the West (if I go). I am now closely occupied with Huxley's Physiology, which must be attended to at once, as the competition against it is going to be very sharp. I was somewhat disappointed at the non-appearance of your new title, as I had fully made up my mind that it would be a desirable thing. What about your coming to this country? Does the project begin to take definite shape? I shall be very glad to hear about it. 
Mrs. Youmans wishes to be remembered, and expresses the hope that you are attending first of all to your health.

NEW YORK, March 16, 1868 .

DEAR Sister: A short note from Spencer this morning states that he is down,* and packing for Italy to start at once and be absent two months or more. A man named B. Waterhouse Hawkins, of London, naturalist or mythologist, acclimatizologist, and palæontologist (reconstructor of the monsters of a former world in the Crystal Palace grounds), called on me day before yesterday with a card from Huxley. He wants to lecture and to reconstruct the American monsters in the Central Park. He has many letters to many people from Lord Stanley and the inevitable Sir Roderick, but Huxley sent him to me, and told him to put himself in my hands, and so I have him on my hands. I gazetted him in all the morning papers, and arranged for him to speak before the Lyceum of Natural History tonight. I had never heard of B. W. H., but he appears to be well known to all the scientific men. Huxley is out with a new and very strong thing, in the March Macmillan, entitled A Liberal Education and Where to get it. $\dagger$

New York, Widnesday, March 28, 1868 .

Dear Sister: I am up to my eyes in this Hawkins business, the whole work of bringing him out devolving

* I. e., in poor health.

$\uparrow$ The place to get a liberal education was certainly not the American college, of which Prof. E. D. Cope once told Youmans, " a college where the whole classical power was concentrated in the effort to throw derision upon his [Cope's] subjects and to shame the boys out of caring for them. He got them well started at first, when an old horse was given them to prepare the skeleton. They commenced boiling him up to clean the bones, when the classical power actually incited a mob to break up the proceedings, and it proved a deathblow to biological studies!" And yet Fourth-of-July orators persist in calling this a free and enlightened country, and allude to the Dark Ages as to a period remote and elapsed. 
upon me. Something may come of it. He lectures at the Cooper Institute to-morrow night. I will go up home on Friday night, and will then write you about it.

New York, April 10, 1868.

MY DEAR SPENCER: I think when I wrote you before I was purposing to go a third time West. I failed, however, to get away, and before I was aware of it I found myself over head and ears in a new job.

Mr. Waterhouse Hawkins, who brought a card from Huxley, had to be set a-going. His success as a lecturer through the country depended entirely on the reception and success he met with in New York. I devoted myself to the enterprise, and by managing the papers and linking on his work to our educational needs in natural history secured for him a splendid reception, of which I inclose an account.

We immediately started for a course of lectures (four), which would have undoubtedly paid him a thousand dollars profit, when he stepped into a hole in one of our villainous pavements and got such a savage sprain of the ankle that he has been in bed ever since, and it will be, I fear, many days befora he can be about-which is as bad as it can be both for me and for him.

We may yet do something, but we have lost our main chance, and the thing now looks discouraging, especially as the lecture season is now past. When I say that I have been completely engrossed day and night with this thing for a month, and wish I were assured of being out of it in another month, you can understand something how delays arise with me to prevent the accomplishment of other things. But for this I should have perhaps reached your works again, and certainly should have written you before this. .. We have felt much concern at the announcement of your serious ill health, and hope your Italian tour will brace you up. If not, I think you had 
better strike your work and come to this country for a year. Forget philosophy, and dip into American life; J believe it would be the very thing for you. 'Think of it.

37 Queen's Gardens, Bayswater, London, W., May 3, 1868.

My dear Youmans: Your first letter, or rather that of Mrs. Youmans written on your behalf, reached me at Rome, and the second and third I got since my return. I cannot say that my hopes that a journey through Italy would put me into working order were realized. I came back no better than I went-in fact, in some respects not so well. I have, however, been improving very considerably during the last week, especially in sleeping, which is my great difficulty. Indeed, I now feel pretty sanguine that with tolerable care I shall shortly get into my usual state.

Thanks for your reminder about my visit to America. I fear, however, there is no prospect of my soon responding to your wish. My recent experience has given me very conclusive proof that, with my irritable nervous system, I am quite unfit for travelling. I was greatly exhausted by my journey to Marseilles, although I stopped a night at Paris and a night at Lyons. My voyage to Naples did me further damage. Sleep was out of the question. What little I got during three nights I owed to morphine. And during the last three weeks of my stay abroad, a leading subject of thought with me was, how I should get home again with the least amount of injury, which was the shortest route, and how it might best be broken into short stays. After this experience you will see that it is out of the question for me to commit myself to a ten or twelve days' voyage, and to such railway journeys as travelling through the United States would involve. If I should ever again get into a normal state-which does not seem very probable-I may decide differently ; but while I remain as I am I must give up the idea of extensive journeys.

A further reason for thus deciding is that, quite apart 
from fatigue, I find the penalties of travelling greater than the pleasures. In early days I had considerable appetite for sight-seeing ; but nowadays my appetite is soon satiated, especially as not looking at things through the spectacles of authority, I often find but little to admire where the world admires, or professes to admire, a great deal. The chief pleasure I get in travelling I get from fine scenery; and of this there is plenty to be had without leaving Great Britain.

Thank you for the copy of the American edition of Culture, etc. I have read a good part of your preliminary essay on Discipline, and like it very much. The argument is sound and well-sustained, and I wish the English edition had the advantage of it. The only passage to which I should take exception is one on page $\mathrm{I}$, where you have committed yourself to the vertebral theory of the skull. You should modify this in the next edition.

I can quite understand that you were disappointed that I did not use the general title of Synthetic Philosophy, as I had thought of doing. I discussed the matter at considerable length with both Huxley and Tyndall, and though the objections they raised were not, to my thinking, adequate, still they had weight, and though I thought, and continue to think, that on the whole this general title would be desirable, my conviction was not sufficiently decided to lead me to make the change in spite of adverse opinions. I see that you have been speaking of this proposed title, and that Mr. Alger has been making use of it. To this I see no objection; and, indeed, it strikes me that this habitual application of it by those who write reviews in America will be the most desirable way of establishing its use, if no reason to the contrary should hereafter arise. Ever yours,

Herbert Spencer. 
CHAPTER XII.

APPLETONS' JOURNAL.

1868-1870. Age 77-79.

From the beginning of his connection with the Appletons my friend had looked forward to a time when he might enlarge the scope of his labours by publishing a magazine which should deal with scientific subjects in such a way as to educate the people. It was a steady purpose of his, and he never neglected a chance of bringing the subject forward and urging its importance. In 1868 the opportunity seemed to have arrived, but the case was complicated by the fact that the Appletons wished to establish a weekly paper of a literary and artistic character, which might have some such business value for its publishers as Harper's Weekly, or as Every Saturday, then published by Ticknor \& Fields. After long consultation it was decided to combine the two schemes and issue an illustrated weekly paper that should be deroted at once to popular science and to art and letters. It was intended to secure contributions from the most eminent writers in Europe as well as America; and with this end in view Mr. Youmans, as editor, sailed for England. On the eve of sailing he wrote to his mother:

$$
\text { New York, September 15, is68. }
$$

My Dear Mother: I cannot leave without dropping you a line, for although little is made of crossing the At- 
lantic by people hereabout, I know you cannot fail to look upon it very differently and as full of danger. But there are dangers also on land, and the perils of land travel rival the perils of the ocean. I go on an errand of importance, I believe, to the public, and which I trust I am partly qualified to execute. There is great satisfaction in having reached a position in which I command the confidence of the publishing house which has known me for eighteen years, and now tenders me an unqualified commission to use their funds to carry out the most important and considerable project they have yet undertaken. Even should nothing come of it, so much, at all events, will remain, and the consideration I have with them I have earned myself. In my connection with them I have never pursued a selfish end, and am as far from it now as is possible for one to be who cannot utterly lose sight of a duty to himself. Should the enterprise be carried out I shall be glad, and do not dread the responsibility or the work it may entail. It will be steady, and so will be healthier than the fitful and anxious course I have hitherto pursued.

I think of you and father very often, often every day, and never forget how much I owe you that I can never repay. I have much happiness in reflecting that you are still so well, though in feeble health, and that you are so comfortably situated in your declining years. Doubtless you have your trials-all have them-but how many have less cause of thankfulness than falls to your lot. You have done your duty; be contented, and all will be well. Worrying is exhaustive, anti-vital, anti-healthful, injurious, and therefore immoral and irreligious. It cannot be altogether avoided, as I know, but something may be done to escape it. It is our highest obligation to make the best of things.

Your very affectionate son,

E. L. Youmans. 
Mr. Spencer had advised him not to undertake the work of editing a periodical:

For your own comfort, health, and happiness, I would advise you not. You will be committed to a slavery full of weariness and vexation. It is a great blessing to be one's own master-a blessing not to be given up unless some peremptory duty or need demands it. You can do quite good enough in the way of public work without thus binding yourself.

But if he must undertake such work, said Mr. Spencer, let it be upon a monthly magazine rather than a weekly paper:

In deciding on a weekly periodical rather than a monthly, you are, I think, entering upon the much more serious undertaking of the two. To have perpetually hanging over you responsibilities that must be fulfilled by a given date, is bad enough when the date recurs at intervals of a month; and when it recurs weekly, the consequent sense of slavery must be very oppressive, and the wear and tear very serious. Unless the mercantile reasons in favour of a weekly periodical are overwhelming, I think a monthly will be very much preferable. I think this for other reasons than that named. The smallness of a weekly periodical necessitates short articles, whether they are otherwise desirable or not; but in a monthly periodical you may have them short or long, as the subject demands. Moreover, from the exercise of this ability to treat with due fulness topics that cannot be well dealt with in a small space, there arises the incidental advantage of having a mixture of long and short articles, so obtaining an additional kind of variety. I should say, too, that editorship can be more satisfactorily discharged with a periodical of longer intervals. More time for arrangement and more 
time for calm judgment are allowed. Then, too, your intervals of relaxation are sufficiently long to admit of absence.

\section{The following letter explains itself :}

37 Queen's Gardens, Bayswater, London, W., November $18,1868$.

MY DEAR SIR: Let me introduce to you my American friend Dr. Youmans. $\mathrm{He}$ is over here to make certain literary arrangements, which he will explain to you, and in the success of which I feel much interest, as do also Huxley, Tyndall, and many leading men whose names Dr. Youmans can give you.

That his project is an important one, and that there is every likelihood of its being successfully carried out, I am fully convinced. It is from no short or superficial acquaintance with Dr. Youmans that I say this. Ever since 1860 he has been working for me in the United States, and it is to his self-sacrificing efforts that I owe the success which my undertaking has had there. His untiring devotion being joined with extensive scientific knowledge and very sound judgment in matters of business, he seems to me thoroughly fitted to carry out the plan he proposes.

If you can do anything to forward his views, either directly or indirectly, you will greatly oblige me.

$$
\text { Sincerely yours, Herbert SPENCER. }
$$

In December we find Youmans back in New York. The first number of Appletons' Journal of Popular Literature, Science, and Art was published April 3, I869. Its editorial announcement was as follows:

The publishing house by which the present Journal is issued has been extensively engaged for nearly half a century in the work of promoting general education and diffusing information among the people of the United 
States through the medium of valuable books in all the leading departments of knowledge. In further pursuance of this important object, and recognizing the increasing tendency of the public to cultivate the periodical form of literature, the publishers have engaged in the enterprise of a weekly Journal, which they design to make worthy the liberal patronage of the reading community.

Omitting ordinary news and avoiding partisan advocacy, both political and sectarian, the Journal will be devoted to general literature, to science, art, and education, and to the diffusion of valuable information upon subjects of public importance. It is intended to make use of all resources, original and selected, domestic and foreign, which can give interest and variety to its pages; and neither exertion nor expense will be spared to secure the aid of the best talent of the time. We abstain from the large professions and the parade of conspicuous names so common on these occasions, and, trusting to the intelligence of the people, shall be content to let the Journal speak for itself.

The principal "attraction" in the new Journal was the translation of Victor Hugo's L'Homme qui Rit, published simultaneously with the appearance of the original work. The first number contained an excellent article by the editor, What we mean by Science. It is reprinted in full in the present book as an illustration of his clear thought and admirable manner of exposition.* But there was not very much science in the Journal, for comparatively little room was allowed for it. In such a novel enterprise the publishers were haunted by a nervous dread of boring the general reader. As Youmans wrote with grim humour to Spencer, April 27, 1869, after four numbers had been issued : 
The paper is having a curious experience. The bare announcement that it would give attention to science and valuable thought raised an almost universal condemnation of it in advance as a certain failure. And although we have had no science in it, and made it as vacant of ideas as possible, it is voted heavy.

A bolder policy from the start might very likely have proved more successful, and would have saved the enterprise from the danger of falling between two stools. From its editor's point of view Appletons' Journal was neither one thing nor another, and after a somewhat irksome year he resigned his charge. His friend Mr. R. H. Manning, of Brooklyn, then came forward with another editorial scheme. He offered to make a considerable investment for the purpose of founding a daily newspaper which should aid the educational reforms in which Youmans felt so deeply interested. Youmans was to edit and control the paper; but after due consideration he declined the liberal offer, for he felt that his work could best be done in other fields than those of daily journalism.

The following glimpse of the winter season of 1870 shows a renewed attempt to give lectures and renewed failure from ill health :

NEW YORK, March 25, 1870.

My dear Spencer: Yours of February $3 \mathrm{~d}$ came punctually. It found me in Minnesota in rather a bad way. I went West in early January to give some lectures, and at the fourth broke down from a heavy cold. After threatening me with something serious in the lungs, it seemed to shift to my right foot as a kind of rheumatic inflammation. I fortunately got to my brother's, in Winona, where I was confined, with much pain, for two months. I returned to New York a fortnight ago with considerable difficulty, but 
am now able to be about, though still lame. I did not write from Winona because I constantly hoped soon to return and be able to speak of business.

37 Queen's Gardens, Bayswater, W., April 26, 1870.

My DEAR Youmans: I was very sorry to hear of your having been so ill. I have long feared that, like many others who are anxious to diffuse a knowledge of the laws of health, you would yourself have to suffer from continuously disregarding them. As I sometimes say jokingly to Huxley, apropos of his transgressions, we ought to erase the proverb "Experience makes fools wise," and write in place of it "Experience does not even make wise men wise." I hope, at any rate, that henceforth you will not so lavishly expend your energies for the benefit of others, taking no care of yourself. It is bad policy in all respects. A man who gives his work gratis is sure to be undervalued.

The lively interest in Mr. Spencer's philosophy felt by a few Americans and their zealous efforts in his behalf had touched him deeply, and for some time he had been thinking of dedicating his System of Philosophy to his American friends. The following letter inclosed the draft of such a dedication :

37 Queen's Gardens, Bayswater, W., October $19,1870$.

My dear Youmans: The inclosed will show you my reason for writing again before you replied to my last.

I dare say you and other Americans may have wondered why I did not take this step before. The fact is that I did contemplate it at the time when the second edition of First Principles was in the press; but I was eventually deterred by the thought that it might seem unfair to those English friends who had, shortly before that time, shown their sympathy by the steps they took. On thinking the matter over of late, however, I have come to the conclusion 
that the reasons against the step do not counterbalance the reasons in its favour. Certainly if there are any cases in which such expressions of feeling are appropriate this is one.

The step will probably be thought somewhat tardy; and I have myself, from time to time, regretfully put aside the thought of it under the impression that it was too late. Recently, however, it occurred to me that, as the dedication includes the whole series of volumes, only part of which is at present issued, it is by no means too late.

I have forthwith acted upon this conclusion, and I send you proofs before stereotyping for the purpose of asking whether you have any suggestion to make.

You had better say nothing about it until the thing is done; indeed, considering that it is somewhat out of the usual course, it will probably be best to say nothing about it when it is done, but let the knowledge of it become gradually diffused by the insertion of the dedication in all copies of First Principles hereafter issued.

Very sincerely yours,

Herbert Spencer.

Youmans's admirable letter in reply must be given entire :

New York, November, 1870.

My DEAR SPfncer: I have delayed replying to your last from want of time, and take it up at the first available moment. The dedication you sent is admirably drawn and no doubt would please American vanity amazingly, but I am of opinion that its publication would be decidedly unadvisable. You have a few friends in the United States, as you have in England and on the Continent, who appreciate the importance of your undertaking, and for this reason have done something to make it known. It happens that in this country other elements than intelligent appreciation have been made available to promote the diffusion of your writings. Yet if these were subtracted from the 
movement here, nothing would be left to distinguish the American reception of your labours from those of other countries. In specializing the Americans for this honour you therefore compliment the wrong thing. We have no claim to it, and it would be unjust to your sincere friends in other countries. Nothing in the whole history of the case can compare with the nobleness of Mr. Mill's proposal to you. You have a large generosity of feeling toward the Americans; they are a great way off, and you know little of the ins and outs of things here, while many of them undoubtedly deserve your kindly regard. But they well enough understand that they are the indebted parties in this matter. Your sensitiveness, however, is natural, and it found ample expression in your letter to Minturn, which ought to have been published as an act of justice to you. I did not like to ask him for it for the purpose, as I had been meddling so much in the matter. I had some time since resolved to do it, however, and hope soon to give it to the public under suitable circumstances; * and this will make the dedication unnecessary for the purpose you have in view.

Your philosophy, Heaven be praised, has no narrowness or taint of nationality about it. It belongs to the world's civilization; let it not be blemished by any external mark of partiality.

In saying that you have a few friends in this country I only refer to those who have been active in the service of your works. You have a very large and growing constituency of students, who are becoming more or less deeply imbued with your views. You are becoming both widely known and deeply felt in these communities. I yesterday received a letter from a young man in Philadelphia the point of which was: "I have Motley's histories in seven

* It has been given in full above, pp. 217, 218. 
volumes perfect; can I exchange them for Spencer's works, which I have long wanted but am unable to buy ?"

There are many such encouraging symptoms which come to my observation. The sales are slow, but I still have strong hope that they may be quickened. I am almost ashamed to refer to this again. It has been my purpose; I have talked about it so much, and so little has come of it, but I have not been favourably situated to do anything. The baulk of the Journal was a very severe thing for me, but there have been other things worse than that which have helped to break me up-things which cannot be explained-and so I have done but little. I have, however, made a loose semi-arrangement with the Appletons to give attention to some of their books. I have devoted myself for weeks to Huxley's and Lubbock's books, and the result is very satisfactory to the publishers. They were doubtful about the policy of getting Lubbock's book at all, yet the second edition is very nearly gone.

They thought a thousand would answer for Huxley a year. It was not published until late in October, and has gone to the third thousand already. The arrangement is a precarious one, as they want much done for small pay; but before it terminates I mean to get at your books and stir up the public about them.

Recurring to the dedication, you say we may have wondered why the step you propose was not taken before. I certainly think not. I believe there is no feeling that anything of the kind is due, and I hope you will dismiss from your thoughts all shadow of anxiety in the matter. If we have done something, we have sufficiently bragged about it and are immensely satisfied.

Could you have come to this country and judged of things for yourself, I should have nothing to say; but, knowing them as I do, I take the liberty of giving you my opinion that it would be an unwise thing.

Ever and truly yours,

E. L. Youmans. 
37 Queen's Gardens, Bayswater, W., December 28, 1870.

My dear Youmans: Your letter dealing with the question of the dedication took me somewhat by surprise. However, it was in one respect satisfactory, since it relieved me from the feeling which I have long had that an adequate recognition of the sympathy of my American friends had not been made and was due from me. I trust to your judgment in the matter. I had very nearly given orders, before receiving your letter, to stereotype the dedication, wishing to prefix it to a supply that was being bound for the English market. However, I did not do so, and since the receipt of your letter I have caused the type to be distributed.

Your late letters have given but evasive replies to my inquiries respecting your own affairs, and have tended to confirm my suspicion that things were not going well with you. This suspicion I was sorry to have verified lately by Dr. Draper, who is over here, and who quite confirmed me in the belief that your sacrifices in the propagation of ideas had entailed an undue neglect of your own interests. This is a very unsatisfactory consciousness for me, knowing as I do that so much of your time has been occupied in the diffusion of my works. I should be well pleased to hear that you were devoting yourself for a time entirely to personal advancement. Would it not be well to look for a professorship ? You have had offers of the kind. The duties would be congenial, and would leave you a considerable share of freedom.

Ever sincerely yours, Herbert Spencer. 


\section{CHAPTER XIII.}

THE INTERNATIONAL SCIENTIFIC SERIES.

$$
\text { I871. Age, } 50 .
$$

FOR chronological and other reasons it is well enough to begin our chapter with some extracts from letters.

$$
\text { New York, April 2I, } 1871 \text {. }
$$

My dear Spencer: Things are going here furiously. I have never known anything like it. Ten thousand Descent of Man have been printed, and I guess they are nearly all gone. Five or six thousand of Lay Sermons have been printed, while Mivart is reprinted and has fallen stillborn. The progress of liberal thought is remarkable. Everybody is asking for explanations. The clergy are in a flutter. McCosh told them not to worry, as whatever might be discovered he would find design in it and put God behind it.

Twenty-five clergymen of Brooklyn sent for me to meet them of a Saturday night and tell them what they should do to be saved. I told them they would find the way of life in the Biology and in the Descent of Man. They said, "Very good," and asked me to come again at the next meeting of the clerical club, to which I went and was again handsomely resoluted. My warrant for attempting to enlighten these gentlemen is that they know nothing whatever about the subject, while I was in wonderfully sympathetic nearness to them. I send you Every Saturday, with new illustrations of That Heathen Chinee, and inclose 
illustrated cards of another bit of slang poetry, but true to nature in Pike County, Illinois. I quite relished the last illustration.*

37 QueEn's Gardens, Bayswater, London, W., June 3, 1871.

My dear Youmans: I inclose a brief article just out. I wrote it partly as a quiet way of setting opinion right on the matter. Since the publication of Darwin's Descent of Man there has been a great sensation about the theory of the development of mind-essays in the magazines on Darwinism and Religion, Darwinism and Morals, Philosophy and Darwinism, all having reference to the question of mental evolution, and all proceeding on the supposition that it is Darwin's hypothesis. As no one says a word in rectification, and as Darwin himself has not indicated the fact that the Principles of Psychology was published five years before the Origin of Species, $\uparrow$ I am obliged to gently indicate it myself.

I send you the letter, thinking that perhaps the republication of the last paragraph with some preliminary explanation might not be amiss in America, where I doubt not the same erroneous idea is current.

$$
\text { Ever yours truly, Herbert Spencer. }
$$

On the date of this last letter (June 3) Mr. Youmans was in mid-ocean, sailing on one of the most important of his many errands to England. Since his resignation of the editorship of Appletons' Journal his services to the Appletons had consisted chiefly in the examination of foreign scientific books, from which

* The reference is to John Hay's Little Breeches, and to the last stanza, where the angels' deed of kindness is felicitously pronounced

"A derned sight better business

Than loafin' 'round the throne."

$+\mathrm{Mr}$. Darwin mentioned the fact next year in the sixth edition of the Origin of Species, pp. xix, 428 . 
he chose such as could be recommended to the Appletons for republication. His sagacity in this regard was marked; scarcely a volume he selected failed to find a satisfactory demand. Among the authors of note first introduced to the American public through his agency were Bagehot, Bain, Buckle, Carpenter, Darwin, Helmholtz, Huxley, Lecky, Lubbock, Maudsley, Roscoe, Sully, and Tyndall. In this department of their business, as already observed, the Appletons were no less honourable than enterprising. They anticipated the benefits of international copyright by paying foreign authors the same rate that was paid to American authors. It occurred to Youmans that this business was capable of being systematized and developed. He suggested that a series of new works be undertaken, covering the entire field of modern science, to be simultaneously issued on both sides of the Atlantic. This scheme was in pursuance of a favourite and eminently sensible idea of his. He realized that popular scientific books adapted to the general reader are apt to be written by third-rate men who do not well understand their subject; they are apt to be dry or superficial, or both. No one can write so good a popular book as the master of a subject, if he only has a fair gift of expressing himself and keeps in mind the public for which he is writing. The master knows what to tell and what to omit, and can thus tell much in a short compass and still make it interesting ; moreover, he avoids the inaccuracies which are sure to occur in second-hand work. Masters of subjects are apt, however, to be too much occupied with original research to write popular books. It was Youmans's plan to induce the leading men of science in Europe and America to contribute smail volumes on 
their special subjects to a series to be published simultaneously in several countries and languages. Furthermore, by special contract with publishing houses of high reputation, the author was to reccive the ordinary royalty on every copy of his book sold in every one of the countries in question, thus anticipating international copyright upon a very wide scale, and giving the author a much more adequate compensation for his labour. To put this scheme into operation was a task of great difficulty, so many conflicting interests had to be considered. Youmans's brilliant success is attested by that noble series of more than seventy volumes on all sorts of scientific subjects, written by men of real eminence, and published in England, France, Italy, Germany, and Russia, as well as in the United States.

In mid-ocean, bound upon this important errand, he wrote to his mother the following letter, thoroughly characteristic, though more occupied with himself than usual, because, in his own humorous phrase, it was an occasion that would never occur again:

Latitude $4 \mathrm{I}^{\circ} \mathrm{N}$., Longitude $57^{\circ}$ W., June $3,187 \%$.

My dear Mother: It is my fiftieth birthday, and away out here on the Atlantic all alone I celebrate it. The weather is fine; the ocean like a pond, smooth and still as glass, and has been so all the way from New York. The passengers are agreeable, and the living is tolerable. Meals could be enjoyed but for the horribie, sickening ship smells. Yet these things do not occupy me much to-day, for my thoughts go back through the years I have spent, with too little good result-back forty years to Greenfield, which I left after the first ten years. Old Greenfield is still very dear in my memory, for my recollections of early childhood are very vivid and pleasant. There is still nothing that I so much enjoy as seeing the persons and reviving the memo- 
ries of that early time. Then came ten years of boyhood and youth in Milton, which still lives vividly in my recollection. It was a chequered kind of life, with bright lights and dark shadows; but the light predominates in memory, and much of my life is now spent in living over again the years from nine to nineteen. From that time on things are much confused in my memory. There came twenty years of struggle, unrest, hard work and poor pay, privation, discipline, disappointment; and yet the time was far from thrown away. I fought it out pretty well, made some headway, and didn't live for nothing. I had won a place in the public consideration and become of some service to the community, and had done it with pluck and perseverance. I suffered much in this time, but always enjoyed working. I was much away, and one of my permanent and neverfailing pleasures, both of anticipation and realization, was going home.

A square half century, terminated in $57^{\circ}$ west longitude, with the water under me two miles deep, in a steamship with all the modern improvements! Steamships, and railroads, and telegraphs, and a thousand other things have grown up with my growth. It has been a stirring age, and I am glad my mind took the turn it did and that I became interested in the progress of humanity. Much of the intellectual pleasure of my life has been derived from this circumstance-that I have looked upon its more hopeful and promising side. To help it on somewhat, to do what I could in the way of mitigation and amelioration, to contribute a little toward making the world somewhat better than I found it, has been my ambition; and although I have accomplished but little-very little in this great directionyet the purpose was certainly commendable. Perhaps I have not come up to your standard of what was required, and I know that there have been plenty of shortcomings. I am not satisfied with my life, nor am I greatly dissatisfied. 
I have tried to do well-tried hard to do as well as I knew how in my own way, and I commit myself and my future in hope and trust to that Divine Power who is the Author of all things, whose ways and works I have tried faithfully to understand-the duty of every rational being.

You see I am now very much in my own mind. It is a peculiar occasion, and will never occur again. Yet I do not forget the rest, and there can be no fitter time than this to acknowledge my deep indebtedness to you, to my dear father, and to my brothers and sister, for the kindness and self-sacrifice I have experienced from all of you. You have been very good to me in my past times of trouble, and very patient with me in my times of irritation. I can never repay the obligations and never sufficiently express my deep feelings of gratitude. A thousand heartfelt thanks to you all. One of the profoundest satisfactions of my life is that you and father are still spared to us, and in circumstances of pecuniary comfort. May your remaining days be pleasant, and may you be happy in the prosperity of your children and in the prospect of a future life!
Your affectionate son,
E. L. Youmans.

On arriving in London he found the great city terribly crowded.

London, June 15, 1871 .

DeAR Sister: I am here for sure, as witness a painful consciousness. Arrived at Euston Station, I took a cab for the Langham. No rooms. Frightened at the reports, I stipulated with cabby by the hour and started. We visited about a dozen places of all sorts, high and low, but to no purpose. Not a room anywhere, nor a private room or apartment either. I then left my trunk at the Langham and went to 37 Queen's Gardens. There they offered me a room not larger than my stateroom, which of course I took. It is close and suffocating, and I have had a hard time in it. I have not got over the sea yet, my brain be- 
ing stirred up in the swimming way. Between that and the stifling atmosphere of the room I did not get asleep till five this morning, and my eyes began to get hot and uncomfortable. However, two or three hours rest has saved me, and I feel better now, although much used up. Spencer is looking very well; plays billiards a great deal; disciplines himself to amusement. I have not yet smoked on English soil, which I presume has much to do with my nervousness.

I have had a few minutes' interview with old Tyndallvery, very cordial and satisfactory. Nothing of business was touched, however. I am writing in the Royal Institution, as there is nowhere else in London where I can get a yard of space. France being shut up is the reason of all this crowding.

I dine privately at Huxley's Saturday night to talk business. Will report progress as soon as there is any. If I send a Punch, send it on west. Spencer's side projects on the Sociology are amazingly interesting. He has been afraid of their being stolen and has kept them shady, but he will show them to me. The pith of the whole matter is, however, that the speed of the enterprise depends upon funds; and in consequence of the prospective delay he is already thinking of going over to the Ethics after Volume I of the Sociology.

London, June 17,1871 .

It is now Saturday afternoon. Have not found a room yet; not a sign of "apartments" visible in London. I have been a little lame with the "distances," but am getting better of it now.

June 23,1871 .- It is as cold as the very grave itself. I sit down to write with my heavy overcoat on and am shivering. I got lodging rooms day before yesterday near Portland Road Station, and have a parlour and large bedroom. I ought to have kept a fire up, but going in and out con- 
stantly I thought it hardly worth while. The weather is dismal, cold, rainy, and sour. Huxley has grown tremendously in public influence. $\mathrm{He}$ is the man of the School Board, though there are other strong men-forty-sevenand two women.

Tyndall is arranging to come over next year. Two illustrated lectures on the glaciers, two or three on heat, others on light and electricity. "I want you to take entire charge of me so far as the public is concerned; my assistant will take charge of the experiments. I will not enslave myself. I will take it just as easy as I have a mind to. I don't want your money, nor will I bring away one dollar of it. I will help your scientific institutions with it, but it shall never be said I went to America to line my pockets. I have no reflections to cast upon those Englishmen who have chosen to do this. It may have been right for them, but it won't do for me."

I have not got hold of the handle of my enterprise yet, but I gather that it promises well. My intention is to make it go at any rate. Bain is all right, and will be helpful. I have this morning had a very interesting interview with Galton. He thinks well of the scheme, and, strange to say, is now writing upon the very subject I had assigned to him. The British Association meets at Edirburgh August 2d. I shall probably stay over till that time, and go from there to Liverpool. Yet the thing I have in hand is large, and, if it goes, will be the thing, and to make it succeed in the fullest manner will rule my movements and my stay.

\section{The following letters tell their own story:}

LoNDON, July 4, 1871 .

My DEAR Youmans: I am anxious to do all that is possible to extend and establish the arrangement you are making with English authors-arrangements which practically amount to international copyright. 
Having for the last ten years benefited so greatly by the arrangements you have made with the Appletons on my behalf, which have put me on a footing as good as the American authors, I have the best possible reasons for thinking that the interests of English authors will be subserved in a very important degree by the success of the negotiations which you have come over here to carry out. Various of my scientific friends who have reaped pecuniary and other advantages from the contracts you have made for them will, I am sure, coincide in this expression of opinion.

From the conversation I had with Mr. Appleton when he was here recently, it was manifest to me that he was anxious to carry out in his relations with other English authors the same equitable system from which I and some others have gained; and now that he has given you full powers to make engagements in pursuance of this system I think it very desirable that all should co-operate. Standing so high as the Appletons do, alike in respect to the character of the works they publish and in the extent of their business, it appears to me clear that this system which they are adopting needs only to be known and understood by English authors to be at once accepted by them.

Pray make use of this letter in any way that will further your negotiations.

Ever yours sincerely,

Herbert Spencer.

To which Prof. Huxley added:

I have read Mr. Spencer's note, and entirely agree with what he has said.

T. H. Huxley.

Then came this additional indorsement:

Royal Institution, July 5, 1871 .

My DEAR Youmans: I am equally desirous with my friend Mr. Spencer to do all that is possible to extend and 
establish the arrangement you are making with English authors, and which will practically amount to international copyright.

Let me also add the expression of my personal recognition of the excellent service which you have already rendered to English authors in America.
Most faithfully yours,
John Tyndall.

Sir John Lubbock added :

I entirely agree with Prof. Tyndall.

John Lubbock.

Youmans did not find his task an easy one. A good many of the authors he called upon had been engaged as contributors to the Journal, and were disappointed in it as an educational medium. Others were so committed to their publishers that they could not join in the series proposed. Some men, so eminent as specialists as to be well-nigh indispensable, were too busy to write or mistrusted their ability to write acceptably. Not a few bluntly stated their opinion that the series would not "go." But Youmans was not the man to be either discouraged or baffled. He knew his project to be sound, and he advanced it with all the address at his command. Some of the incidents of the summer may be cited from his letters :

Losdon, July 15, 1871 .

Dear Sister: Cunarder day has come around again, and therefore again I write-not that a week makes much difference in things. I have now been here a round month - to what end, you ask? Well, to no end-hardly to a beginning, and still possibly to some purpose. I am pretty sharply at issue with my former failure,* which is just as

* I. e., of Appletons' Journal. 
far from being forgotten as possible. I did my other work too effectually, as I now find. They seem to have believed in me awfully, and there is something proportional in the reaction. They listen now with a kind of rapt incredulity as I expand and expound and "expredge" myself on Occidental possibilities. Yet my case is so strong that it gives me the inside track, and they are precious careful about iluffing me. It turns out when I get here, and get serious hold of my subject, that I have in hand a pretty large thing. Its importance grows upon me, and when I think of the quality and difficulty and delicacy of the enterprise, and of the important consequences that may flow from it, although nothing is completed and all is in the crudest grizzle, I am anything but dissatisfied with the aspect of things. It will take but three weeks more to decide it. The British Association meets in Edinburgh August $2 \mathrm{~d}$. I shall fumble till that occasion, and then act.

Darwin was in town this week and called on Mr. W. H. Appleton, who presented me. I was invited to lunch Wednesday at his brother's, Mr. Erasmus Darwin. There were Mr. D., Mrs. D., Miss D., and Master D. It was altogether juicy and jolly. This was fresh material-no dregs of '68-and it went with a rush. I took Mrs. D. in to lunch. They were all curiosity about America. Mr. D. had just resolved to send two of his boys across the Atlantic, and they leave the last of August. I told him about my lecturing the Brooklyn clergymen on evolution. "What!" said he, "clergymen of different denominations all together? How they would fight if you should get them together here!" They were greatly amused with a spiritualistic paper they had received from Chicago, which stated that if it were known that God were dead Beecher would be unanimously elected by the American people to fill his place.

Well, my point is this: that Mr. Darwin insisted on 
having my project brought up at the British Association and indorsed there. I am going to dine with his boys on Monday night, at the new University Club, to post them up a little before they start for America. Of course I cannot at this stage ask Spencer, Tyndall, Huxley, or Lubbock to go in on the enterprise, but I must make them as available as possible to get other men. Tyndall sees $m y$ position and has gone farthest in the way of promise. He asked me what I thought of Helmholtz. I said, " $\mathrm{He}$ is worth the whole of you." Tyndall said, "I think you can get him." He gave me a note at once, and I wrote the same day to Helmholtz, at Berlin, and to Bancroft.* I got a reply yesterday from the latter, oftering all Germany if I wanted it. He went immediately to see Helmholtz, wiho is to be in Scotland in August. He sent also a capital letter to him. And thus it goes, slowly, but as fast as it can; and, as I said, I shall know by the middle of August where I stand. ...

July 17,187 I. - Having worn out my boots kicking against the pricks, I take no further part nor lot in that sort of work. I go in for this world from this date. As evidence of my sincerity I have bought a swallow-tail, and I wear it. I prayed that this cup might pass from me, but the world's scientific salvation required that I should drink it to the dregs. I found it, if not indispensable, at least important to my enterprise not to be singular, but to conform wherever it is possible. I took Addie's advice-told her just exactly how I was situated, and told her I had the most perfect faith in the infallibility of her judgment, and I would abide by it implicitly. "I am afraid," said she, "if I were in your place I should get a swallow-tail." And it was so.

August II, I87I.-The present budget, if it reaches you, will tell the story of my work. It is a success just as far

* The historian George Bancroft, then minister to Germany. 
as a prospective thing of considerable complication can be. My experience in Edinburgh was disgusting, but it answered its purpose. A bewildering crush excited everybody. It was more than the city was worth to find anybody. When found, no one had a minute, and if they gave you their ears for a moment they did not give their attention. I was miserable and unfit to be out, and yet the thing was most decidedly advanced. I should, however, have had far more trouble but for Spencer. When, therefore, I found his note, ${ }^{*}$ which I send, I cannot say that I was surprised, but I was certainly greatly pleased, for I needed him. I could not see. I could find nobody, and was swamped in the turmoil. He took hold earnestly, and it was splendid to see him work. He got interested, and before I get through I shall have a work from him for the series, and perhaps one jointly with Collier, on the Principles of Evolution. $\mathrm{He}$ said the first day that we should have a meeting, and we fixed the time for Friday, ro.30 A. M. He wrote several notes of invitation; I wrote the rest. Our room was in the university where the sections met. This proved fortunate. We had Huxley, Carpenter, Balfour Stewart, Bain, Spencer, and a Dr. Lindsay, of Perth, with whom I had had correspondence regarding a book on the minds of the lower animals. I went over my plan in detail and answered all sorts of questions. Huxley backed me up grandly, and told how much he had received from the Appletons for reprints. After some discussion about an English editor for the series, it was decided that Huxley, Tyndall, and Spencer be an advisory committee to consult with the London publisher. Michael Foster, who is to write on the Involuntary Movements of Animals, may be added.

The last day Spencer was in Edinburgh I couldn't find

* My dear Youmaxs: Here I am, come to help you. You will find me at the Waterloo Hotel, Room No. 40.

Ever yours,

Herbert Spencer. 
him, but he left a note for me saying that he had seen Clifford and Dyer. I had to get part of my circular on the series printed in London and had the names added in Edinburgh. They are weighty, as you see, and the little document carries everything before it. Hooker suggested Dyer to Spencer as one of the most promising young botanists of the age, and he is really a splendid fellow. Clifford is also immensely strong. Huxley says he is the only man in England who can do the work he is engaged for. Edward Smith is the authority on diet. Tylor is great on primitive man-greater than Lubbock-but he may not be able to leave his present publisher. I have other subjects and other men in anticipation, and shall stay till the thing is quite crystallized. Spencer said: "Be deliberate, and don't go till all is closed up." He enjoys my success. But I must stop, for I am completely used up with this wretched cold.

The circular inclosed with the foregoing letter said :

The attention of English scientific writers is asked to a project of international publication which has both public and personal claims to their consideration. It is in contemplation to prepare a series of monographs or elaborate essays on selected scientific topics, and in a form suited for wide circulation. The general aim of the series will be to give authentic, popular expression to the latest advances of thought on the leading subjects of progressive inquiry. The recent and more important steps of physical investigation will come within its scope, and those interpretations of Nature which have undergone marked revision within a recent period. Yet it is desired to give especial prominence to those branches of biological, psychological, and social science which help to a better understanding of human nature and the economy of human life. 
As these works are designed to address the unscientific public, they will require to be thoroughly explanatory and expository in character. It is hoped to secure in this series the greatest freedom from technicalities and the utmost simplicity of style compatible with clearness and precision of scientific presentation. The form of publication proposed is that of handbooks of from two hundred to three hundred pages, about four hundred words to a page. They will be issued in uniform style, with some suitable title for the series. Illustrations will be employed wherever needful.

The subjects treated being of equal interest to people of different countries, it is proposed to organize the undertaking upon an international basis. The proposition comes from the United States, which will give efficient support to such an enterprise. That country now contains a population of nearly forty millions, eminently a reading and bookbuying people. Education is extending and improving among them, and the interest in science, especially in its progressive aspects, is also becoming more earnest and general. There are good grounds for believing, therefore, that such a scheme of publications as that now contemplated-essentially popular and carrying the weight of authoritative names-would have an extensive American patronage, and would become a powerful agency of public education.

To secure the international advantages of such a series of books to English authors, they will be produced by London publishers who will pay the most liberal rates. Duplicate stereotype plates will then be taken for reprinting in the United States, and the books will be simultaneously issued in the two countries. 'The American publishers will engage to pay the foreign contributors to the series the usual rates that are allowed to American authors. The project, in fact, implies that the English authors are to 
be voluntarily allowed the practical benefits of an inter. national copyright law. The subscriber has devoted himself for several years past to bringing about an arrangement of this kind, and may refer to Profs. Tyndall, Huxley, and Bain, to Sir John Lubbock, Messrs. Darwin, Spencer, Lecky, Galton, and Mill, who have had experience of its benefits. In its business aspects, therefore, the present enterprise is but an extension of a policy already existing, and it is now proposed to enlarge the circle of authors who may reap its advantages. Further information regarding the project can be had by addressing the subscriber,

\section{E. L. Youmans.}

i6 Little Britain, London, August, 1871.

The story goes on with the letters:

LoNDon, August I8, 1877 .

My dear Sister: . . I got a note from Dr. Hooker asking me to come over to Kew and dine with him, as he was quite alone. Spencer had spoken to him of my project, and he had suggested Dyer. I had a very interesting time with him. He mentioned receiving your book, and asked after you. He said: "That was an admirable little effort-it came very near being a great book; it was much better for beginners than any they have in England. By-the-by, why don't Miss Youmans put herself into relation with Dr. Gray? He is the greatest botanist in America, and author of the best series of botanical schoolbooks in the world, but his first book is not sufficiently simple for children." I asked him why they did not take the thing up here, and give us a model child's book on Prof. Henslow's method. He replied: “Oh, don't ask. We can do nothing here. England is convulsed with the effort of trying to teach children to read. The stupid conservatism of England is incalculable. Look at Prof. Henslow's work at Hitcham! He worked there, in that parish, twenty years, and revolutionized it so that 
people came from all over Europe to see what had been done. But not a single thing that he did influenced in the slightest degree a single adjacent parish. And when he died the work stopped, and nothing has been done since. I don't know; perhaps something may be done after a while. Strong men are at work, and they have begun at the right end; perhaps something will be brought about after a while.

London, August I9, I87I.

And now next morning some more Hookerian reminiscence. He speaks unreservedly of Spencer; says "Spencer is the mighty thinker among us. And what a splendid talker! He talks right at you like a book, and his language is so fluent and adaptive! He is all right now. The recognition of his genius is now complete. What a lucky thing it was that he failed in getting a consulate or some other public appointment when he began his Philosophy! Had he succeeded, we never should have heard of the Philosophy. The things are absolutely incompatible. No man can do great original work and be hampered by the cares of a position. 'The thing is impossible. The work must have the whole man. That is why I have tried to get Gray free. You Americans don't know how much of a man Gray is; but he is hampered with students' work, and is not able to keep an assistant. When you were working for Spencer on the other side I was working for Gray here. I thought I had got it arranged all right. I obtained a promise from Peabody to give money enough to relieve Gray and let him go on with original research; but when he got over there they worked at him and defeated all the good of the plan. He gave his money to Harvard College. Gray received no help, and the only effect was to pile on him one more official burden. You did better for Spencer. Your work told just where it should. You have a very honourable share in his success." 
London, September 13, 1871 .

My DeAR Sister: I am astonished to write this datehow the time slips! Of myself what shall I say? I have constantly reported myself better of an infernal cold which has had me in its clutches a month. I have been down sick and confined to my room with it for nearly a week. I am certainly better to-day than for the past several days.

I have been immensely reconciled and comforted mentally by my progress. Mr. Appleton will be here in a few days, and then the business aspect of affairs can be settled.

I have turned up a new thing with regard to Spencer. He has heard that Emerson characterized him as a "stock writer," which means a "job writer." His disgust is unspeakable; he has been for the past week gathering up the proofs that he has had one method from the beginning, that he has never written a single article proposed by anybody else; that he had the law of evolution worked out as the basis of a philosophy before Darwin or Wallace ever published a line about it. You know he applied at first for a Government situation to help him. He yesterday handed me the letters to Government on his behalf from Huxley, Tyndall, Mill, Latham, Fraser, Hooker, Holland, Grote, and Sir G. C. Lewis. It astonished me. They recognized as far back as 1858 that he was the man to make a new organon of philosophy.

I play billiards every night with Spencer after dinner; game fifty, but one red ball, which thins out the chances. Scratches here are flukes. Spencer gives me thirty, and then I get to fifty first about as one to three. But I do a stupendous amount of fluking, sometimes to Spencer's great disgust. We started the other night and I fluked up to fifty before he got one. He stands aghast! I assure him that it is merely my general way. 
London, October $7,1871$.

Things are getting thick and exciting. I can't leave yet, and know no more when I shall return than I did at first. I am here to do a certain work, and do it I shall.

Henry S. King \& Co., a new concern, are to be the London publishers of the series. They will drive it with energy, and are bound to make a success. The only apparent remaining difficulty is to transfer authors to the new house. Several are sure, some doubtful, and there are four hopeless, but their places can be supplied. It is infinitely fortunate that Mr. Appleton has been here to advise with, decide, and close matters on the spot. . .

As to my returning, don't think about it. I am bound to this enterprise, and, much as I want to go, I shall be guided absolutely by its requirements. I'm the man to do the work; nobody else can. If the thing shapes as it now promises I shall go to Berlin. Bancroft knows all about the project, and told Mr. Appleton he wanted me to come by all means. The learned men of Germany are soon to be gathered there, and B. knows them. My hopes are therefore that $I$ shall be detained a month or six weeks longer, so good-bye for the present.

London, October $21,187 I$.

We know the lessons of caution pretty well-that nothing is sure till realized-but caution may become a disease, and then we can realize and still not feel sure. My project is now as certain as any human thing contingent upon human conditions can be. I had a hope in this direction when I left you, but the result immensely transcends it. All the arrangements have been closed with Mr. King, and on the most liberal basis. I am going to Berlin next week-first, to get some new authors for the series; second, to get the series republished; third, to get Spencer republished in German; fourth, to get a German student for Spencer to 
assist in carrying out his great sociological project, which I will explain to you when I return.

It is now in my power to extend the scheme largely, and now is the moment to do it. The series in five years will run up to seventy-five or one hundred volumes. It will be the world's popular cyclopædia of reading science. Spencer is delighted but half bewildered; every once in a while he breaks out, "Who would have thought such a result would arrive from your first beginnings with me?" The letter in the Times, of course, greatly pleases him.* He says this whole movement is going to revolutionize the position of English authors.

London, November 2, 1871 .

King proves to be our man-a wide-awake, wholehearted fellow. The thing is now just as much a success as a prospective thing can be, and I shall be easy, but there has been so much to do which I alone can do that it has worn upon me hard. I mean to take it easier, come what will. I go by Paris to Berlin, and Spencer goes to Paris with me. We expect to go to-morrow, if I can. The days are crowded with incidents relating to the enterprise, but I have neither time nor strength to write of them. I began a letter to the Times on copyright, but have had to postpone it till I come back.

PARIS, November 12,1871 .

Things are still going prosperously with the international scheme. France is committed, and I have just received a French note from the publisher pledging ten books from the ablest men in France. One of them will soon be ready. Prof. Ribot, one of Spencer's translators, who lives at Laval, two hundred miles away, came to Paris to meet us. He has nearly done a book entitled Heredity : A Psychological Study-in first, its facts; second, its laws;

* Mr. W. H. Appleton had just written an excellent letter on international copyright, which was published in the London Times. 
third, its causes; fourth, its consequences. He is able, and will make a first-rate book, which I presume the committee will pass. I was so doubtful of France that I did not think it worth attempting, and should not have come here at all if Spencer hadn't proposed it; but it has been a profitable week, and to have got French co-operation in the undertaking will be a great thing. I leave to-morrow morning for Berlin via Cologne.

Complicated with all my embarrassments here-short time, nobody at home, difficulty of interpretation, torments with cab-drivers, etc.- has been another thing. Spencer wanted to do some work here, and tried to get an amanuensis, vexing his soul for three whole days, and, failing at last, I could do no less than offer to write for him. Huxley pitched into him-gently-recently about his nongovernment theories, and attacked a special point of his Social Organism. Spencer couldn't stand it, so he said, "Huxley has been rampaging round about long enough; he must be pulled up." I wrote twenty pages of manuscript; the article is to be very able and instructive, and Huxley will get more than he bargained for. It will appear in the Fortnightly.

But it is nearly night. I have to go and see if I can find Milne Edwards at the Garden of Plants, to pack, and do several other things, for all business must be dispatched to-night, as we start early to-morrow morning.

Berlin, November $17, I \delta 7 I$.

I am now in the capital of the German Empire, unable to understand a word that anybody says. I got here Tuesday night late, and had a pretty hard fight to find a hotel; but I am well situated at the Hotel d'Angleterre, which, being interpreted, means the English Hotel, though it is quite Dutch enough. I have had to hire a "commissioner." He is a pretty good kind of a Dutchman.

France was dispatched quickly because Paris is France. 
It is otherwise here. The men are scattered, and Mr. Bancroft says that although everybody can read here, and there is great boasting of "universal education," yet there is no place in the world where there is on the part of the learned such contempt for popular education, or such shallow and worthless trash as they write when they attempt to write for "the people." He says this business of mine will be a new thing to them, and it remains to be seen how they will regard it. He has invited Helmholtz, Virchow, and Du Bois-Reymond to meet me at dinner on Sunday, and I shall then probably be able to find out something of the prospect. I had a letter to Haeckel, of Jena (six hours from here), from Huxley, and have sent it to him with a message, but have heard nothing yet. I am not sanguine about results here; everything is so scattered.

... Germany is not going to suit me. They are too cocky. "We don't want your translations; we can make our own books; the talent is here," is the way the publishers talk. On the other hand, I find that scientific men here have a contempt for "popularization" more intense than anywhere else. They ostentatiously despise it and the countries that tolerate it. It looks like a very bad market for my pigs, but I am going to know more about it before I get through. I shall meet Helmholtz, Virchow, and Du Bois-Reymond at Bancroft's on Sunday, and I shall try and find out a few things. But it will not trouble me if they don't want the series. I am bound to have something out of them, which will strengthen us. I have called on Asher, a leading publisher here. He says I hold all the cards so far as authors are concerned, and cannot fail to win, but as for the publishers he don't see it. He talks English, and is wide awake. I am afraid there is no show to get Spencer translated here. They have never heard of him, and there is great contempt for English "philosophy." While they do not jump headforemost into my traps, I 
have nevertheless a great respect for these Dutchmen. They are strong, self-reliant, and honest.

Bancroft is extremely obliging and attentive. I have met Helmholtz, Reymond, and Virchow at his table, and it was pleasant and interesting, of course, but business was interdicted, and nothing was gained. I shall go to Leipsic in a day or two to satisfy myself about some things, and then work my passage back to London. It is a horrid, stupid place here.

Berlin, November 23, 1871 .

And so you wonder that I can care for anything! Well, I don't much-not much; the caring time is past-dregs only remain. Half a hundred years, and to what end? What a confounded sell life turns out to be! The only interest is in studying it. I am afraid there is too much truth in that old philosophic view, that "the interest is in the chase and dies with the capture." And so I think I shall go to bed at ten o'clock, two hours earlier than usual. To bed: and such a bed-not a sheet, not a blanket, but only a kind of narrow feather-bed; they call it down that you have to sleep under, and you can't sleep under it. I woke up a hundred times during the night with divers parts of my body out in the air. One hauls them in, but to what purpose? You reawaken with only a variation of the exposure. I have augmented my cold here, and shall quit the ranch to-morrow. It seems to me that if a social organism were constructed especially to get the least out of life, to thwart it all round and make discomfort a policy, these Dutch would take the premium!

And on that I went to bed, and here I am, November

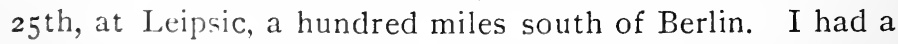
letter to one important man; he is dead. To another, and he is so sick I have been unable to see him. It snows, rains, sleets, and is dark, muddy, and detestable in Leipsic. Not a publisher can speak a word of English in Leipsic. 
I got lost, and could not remember the name of my hotel, and wandered through the mud, and asked the Dutchmen where I lived in Leipsic. I feel that I am at the extremest point of my Quixotic career in Leipsic. I turn round tomorrow, and start for home via Berlin, Brussels, Brunswick, Ostend, Dover, and London. . . . It is the morning of Sunday, 26 th, and I am packed for Berlin. I have this morning seen the sick man-Prof. Charmac, a passionate physiologist, rich, who is going to build a great popular school of physiology-in wretched health; speaks English fluently; had a letter to him from Foster; is in sympathy with my project, and will help the German end of it. I shall be in Berlin to-night; shall try and leave there to-morrow night for Brunswick, if I can get through. My bane and the bane of my enterprise is overhaste. The Dutch are prodigiously slow. They continue as ever to have their doubts, and I find it awful hard work to wait. Still, it will have to be done but once, like gravitation and evolution, and so I contrive to be patient.

But things were moving in deliberate old Germany much faster than our good friend realized, and the tone of the next letter is more cheerful.

London, December 2, 1871 .

Dear Sister: I am back from Germany more dead than alive, but still a good deal vital. It has been a strange experience, that of the last month, but it has been a success as far as such an expedition could be so. I wrote you of France. Germany came into line more readily, and, I think, more effectually. I have arranged for the extension of the series to Germany. Brockhaus, the great house of Leipsic, will probably publish the series, paying foreign authors seven and a half per cent. There is a German committee, of which two members are professors of the University of Berlin-Virchow and Rosenthal-the third 
being Prof. Charmac, of the University of Leipsic. Germany is more ripe for the movement than even England; its best men can be procured. It was Huxley's name which carried the thing there. Spencer will in time reap his greatest conquest in Germany. The whole nation is pervaded with religious skepticism, and they are without any philosophic guidance. Spencer's subject on the list interested them more than any other, and with the publication of his little book, which I bullied him to write, * there will be a prompt demand for the Philosophy. When I wrote this to Spencer the old fellow waked up, went down to King after some circulars, and entered at once upon the work of finding a writer. . . .

I told Spencer what you wrote me about Fiske and sent him Fiske's circular. It did the business at once. $\mathrm{He}$ immediately ordered extra title-pages posted into all his volumes-Synthetic Philosophy-and blew himself up for being such a fool as to listen to the Leweses and others when he proposed it at first. $\nmid$ He cuffs Huxley hand-

* "This work has been written at the instigation of my American friend, Prof. Youmans."-Spencer, Study of Sociology, Preface.

+ For some time it had been felt desirable to have a distinctive name for Mr. Spencer's system of philosophy. Among many reasons for this there was the fact that there was a vague notion afloat that any system of philosophy built up from scientific data by scientific methods must be some form of "positive philosophy" ; and inasmuch as Comte had appropriated that title and made it notorious, there was a fine opportunity for bemuddling things. Writers for the press insisted upon calling Spencer, Huxley, and scientific philosophers generally, "positivists." Considering that Spencer has always repudiated each and every distinctive doctrine held by positivists, this was very absurd and very annoying. There were further reasons why a name for Spencer's philosophy was deemed desirable. Accordingly, in $1867 \mathrm{Mr}$. Spencer decided to adopt the name Synthetic Philosophy, and put it upon the title-pages of his volumes, but after discussing the matter with some of his friends he concluded not to do so. See above, pp. 234, 236, 251, 252, 255.

In the course of my lectures at Harvard University, in the spring of 
somely in the Fortnightly, which I send.* I advertised for a German student of history to undertake a part of his

I87I, I used the name "Cosmic Philosophy" to designate Mr. Spencer's system, and this name grew in favour with me as I used it in various connections. I first made a formal and public use of it in a circular printed in the autumn of I87I. As soon as Spencer saw this circular he adopted the epithet "Synthetic," as Youmans relates above. When I was in London in 1873 , and on the point of publishing my Outlines of Cosmic Philosophy, I had a friendly discussion with Spencer as to the propriety of baptizing his system of philosophy by a title different from the one which he had himself given it. Advice was sought from Lewes and Huxley. Lewes simply fell back upon his old position, that all scientific philosophy ought to be called "positive," and so he condemned both our names. Huxley, on the other hand, suggested that since the name "Synthetic" had been offered to the public, the name "Cosmic" had better be offered also, and let time decide between them-let the fittest survive. Accordingly I adhered to the name "Cosmic," stating at the same time in my preface that Spencer did not approve the name. His objection to "Cosmic" was the same as my objection to "Synthetic," viz., that it was not a distinctive name. It seems to me now that both objections were sound, and fatal! I do not believe that either will survive. The distinctive feature of Spencer's system is that it is "Evolution Philosophy." That would be a somewhat cumbrous name, but I dare say that if in some way or other the word " evolution" could from the start have been wrought into Mr. Spencer's title-pages, it might have prevented a vast amount of popular misapprehension. It would early have helped to associate the doctrine of evolution with the name of its true founder more closely than with Mr. Darwin, whose discoveries were concerned simply with one department of the subject. "Evolutionism" and "Spencerism" are synonymous terms; "evolutionism" and "Darwinism" are not, as is proved by the fact that a man may be an enthusiastic Darwinian and still scout at the doctrine of evolution as a metaphysical chimera; such was the case with the late Chauncey Wright.

As for displacing the ridiculous epithet "positive," I do not believe that either "synthetic" or " cosmic" was ever worth a groat. The stupid old public (begging its pardon, nothing personal intended !) would prob-

* See article “Specialized Administration" in Spencer's Essays, Vol. III, a reply to "Administrative Nihilism," in Huxley's Critiques and Addresses. 
Descriptive Sociology, and think we shall get a suitable man.

\section{Savile Club, December 16,1871 .}

Mr DEAR Sister: I have fixed upon December 3 oth to sail, and shall go in the Russia, the quickest and safest for the winter passage. There is still much to do in the next fortnight, and I shall want the whole of it, yet the body of the work is done. It will go on though I leave. Last Monday night I met Spencer and Tyndall at Huxley's at dinner to consider matters. It was precious different from my first dinner there six months ago. They are fairly in

ably have gone on calling us all "positivists" to this day, had not Huxley, once in a moment of happy inspiration, fired off the term "agnostic." It took so beautifully that people have by this time almost forgotten that there ever was any such thing as "positivism"; and as a missile of theological vituperation the word "agnostic" is so innocent of all definite significance that nobody need mind being pelted with it.

Since writing this footnote, I find among Mr. Spencer's letters the following, which explains my own objection to the name "Synthetic." It was a question of a title for a brief exposition of Spencerian philosophy by Dr. Cazelles :

38 Queen's Gardens, Bayswater, W., April ro, 1874.

My dear Yolmaxs: I send on the annexed leaf a copy of the titlepage as I think it should run. Synthetic Philosophy would be a damper to most, even when it was intelligible-which it would be to but few. Evolution Philosophy will, on the contrary, be attractive, and will convey some idea of the book. I have prefixed the word "Outline" to give further definiteness to the conception. Truly yours,

HERBERT SPENCER.

Outline of the Evolution Philosophy. By Dr. M. E. Cazelles. Translated from the French by the Rev. O. B. Frothingham. With an Appendix by E. L. Youmans.

In using the name "Cosmic" I was actuated by the feeling that it would be less unintelligible and less of a "damper" than the other name. In a certain sense, too, "Cosmic" is a distinctive epithet as applied to a philosophy which excludes miracle and exhibits law as the "harmony of the world." No doubt, however, "Evolution Philosophy" was the title best adapted for leading the "public" into wisdom's narrow path. 
harness and trot quite smoothly. They took hold of work as a matter of course, and are going to make a pretty good committee. It seems to be universally agreed that we have a great thing in prospect and well under way, and which can hardly fail to result in large advantages to many authors and to the public also. I am glad I came now, and glad I stayed it out. It has been rough and tough, and will fitly wind up with a winter passage home. Oh, how I will sleep when I get on that ship!

Before sailing for home Youmans had not only arranged for simultaneous publication in New York, London, Paris, and Leipsic, but also opened negotiations which in the future extended his plan to Milan and St. Petersburg. The International Scientific Series, launched with so much labour, amply justified its projector's anticipations. In it the master hands of science have written the latest word on themes whose special study has won them their distinction. There are many topics of importance for which no single nation provides a sufficiently large circle of readers for remunerative publication. Several such topics have been treated in the series with reward to the authors concerned. And not the least service of the series was its proot that liberal private enterprise could find its account in outrunning the tardy councils of a great nation in doing justice to authorship. When the days of the projector of the series were drawing to a close its fifty-seventh volume had appeared-Mr. Heilprin's Geographical and Geological Distribution of Animals. The first volume was Tyndall's Forms of Water, which drew forth, among other encomiums, one from Thomas Carlyle. The most successful volumes have been Draper's Conflict be- 
tween Religion and Science, Josiah Cooke's New Chemistry, and Spencer's Study of Sociology. This last book was written at Youmans's suggestion, to prepare the public for the Descriptive Sociology which appeared in after years. The Study has passed through eleven English editions, and has proved nearly as popular as its author's Education.

It was unavoidable that in a programme so lengthy some of the co-operators should drop out of the ranks. My dear friend Clifford died before he had more than outlined his proposed work, The Principles of Exact Science explained to the Unmathematical. Prof. Jevons contributed Money and the Mechanism of Exchange, and a second volume was expected from his pen at the time of his drowning. Our editor had to face other difficulties in the execution of his task than those due to mortality. When some of the contributions came in they proved too bulky or too technical for inclusion and had to be rejected. There was not a little grumbling in America at first at the fewness of American contributors, but this died out as the list gradually took up one after another name of authority at home. 


\section{CHAPTER XIV.}

THE POPULAR SCIENCE MONTHLY.

$$
\text { I872. Age, } 51 \text {. }
$$

ON Youmans's return to America after completing arrangements for the International Series, it seemed an opportune time to establish the magazine so long considered which should be a popular medium of communication between men of original thought and research and the general reading public. This, as we have seen, had been for many years one of his most cherished projects. The experiment with Appletons' Journal had failed, through no fault of his; it was time to try again.

Between the International Series-especially the book on The Study of Sociology, which Mr. Spencer was now writing for it -and the starting of the Popular Science Monthly there was a curious causal connection, which is shown in the following extracts:

37 Queen's Gardens, Bayswater, London, W., January 8, 1872.

My DEAR Youmans: I have, as I proposed before you left, arranged with Knowles for publication of the Study of Sociology in the Contemporary in successive installments. $\mathrm{He}$ and the publisher, Strahan, express themselves as rejoicing to make the agreement. No difficulty appears to arise respecting the simultaneous publication in America, so long as it is understood that the publication in some 
American periodical will not interfere with the publication at the same date in that portion of the edition of the Contemporary which circulates in America. I have stipulated for such interval as will allow of your having the sheets in time to make simultaneous publication practicable. Possibly you have by this time taken some steps toward making arrangements for me. I hope you have not made any proposals for its publication in Appletons' Journal. To this I should object. After so long a descending career in respect of quality, I suspect that changing its character would be very difficult, if possible; and until such restoration of character is effected I should not like contributions of mine to appear in it.

Should you start the proposed magazine with the understanding that you are to have full power in the management of it, the case will be quite different. It strikes me that if you had the help of your brother and sister, and if they devoted their whole time to it, the management of such a magazine might not be too much for you along with other things.

NEw YORK, January 26, 1872.

MY DEAR SPEACER: I have yours of the 8 th inst. As respects the sociological articles, I have not for a moment thought of offering them to Appletons' Journal, but I have not made proposals elsewhere, as, if we do start a monthly, I am very anxious to avail myself of them. I shall accept nothing except full control of such a periodical, the only question being whether I will take it at all. My brother is very anxious that I should do so, and my sister inclines to it. I mean to have an opportunity very soon to know just what the publishers are prepared to do and will report promptly; but there will be some little delay, probably, in starting-if we do start-and I hope that you will not begin over there until we are ready here. There would be no harm if you had two or three of the articles done before the first is printed. Indeed, this will be most desirable 
whoever reprints here. You are to remember and provide for this fact, that all our magazines are published two weeks before date. The July magazine is in the market the middle of June. ... There is a furious attack upon you in the Catholic World, under the title The Cosmic Philosophy. The New Englander is also out with an onslaught, so there seems no danger that the Philosophy will be neglected.

NEW YORK, Jamuary 29, 1872 .

My dear Spencer: I have been sorely tried about the periodical. The Appletons are perfectly willing and perfectly indifferent. I have so much to do that I do not like to court responsibility.

To get your articles would be a powerful incentive to immediate action. On the other hand, there ought to be deliberate systematic preparations, and it is also greatly advantageous to start January ist. Other work besides must be done. So unless the wind changes suddenly and soon, we shall have no magazine this year.

What impels me to write to-day is that I have ascertained the time conditions of the issue of your articles on this side. To get a favourable insertion (in place I mean) each article must be here six weeks before the date of its appearance. For May it must be here by the middle of March-must be sent by the rst of March. I have, of course, made no arrangements as yet, but am able to give you the conditions on which depend the market value of your articles, and indeed the only conditions on which they . can appear in any American periodical at all. I am still anxious about the phraseology of your letter. The Contemporary pays you for the English constituency. I know they cannot afford to pay for the lead in America, or what you would lose by leaving your articles with them. You say that they stipulate that you shall not so dispose of the article as to interfere with them. But the thing paid for here is priority. 
London, February 16, 1872.

My dear Youmans: The difficulties you describe respecting the arrangements for publication in an American magazine in such way that the requirements as to date may be duly met, both for such magazine and the Contemporary, seem to me almost insurmountable. Your American custom of issuing a fortnight before date seems to make anything like simultaneous publication out of the question. Either your American magazine must be a fortnight behind the American edition of the Contemporary, or a fortnight before it, and such an arrangement seems to me certain to be negatived by the one or the other, as the case may be. Indeed, I should hardly like to ask Strahan to agree to an arrangement under which the articles should appear in America a fortnight before the Contemporary arrived there.

Under these circumstances I see no other way of meeting the difficulty than that of publication through some other medium than a monthly periodical. I called two days ago on Smalley, to ask him whether it was worth while to make the proposal to the Tribune. He thought it was, saying that from time to time they issue extra sheets, and that it might not improbably be arranged that the successive chapters should appear in them. Under such an arrangement the difficulty as to date would almost disappear. The publication in the Tribune might be almost simultaneous with the American issue of the Contemporary.

I am just about to commence the first chapter for the Contemporary. It will appear on the ist of April. This, of course, negatives my arrangement with an American magazine. If you can arrange with the Tribune, well and good. If not, the scheme of American publication must, I suppose, drop.

Since I wrote to you, one of the chief Berlin publishers 
(Duncker) has written to propose a translation of the Psychology. Probably it will be arranged that some other translator will execute this while Dr. Vetter is executing First Principles and the Biology.

Under the circumstances you name, I think you are quite right in not commencing at present the contemplated magazine. It will be better to wait until all the circumstances are favourable and until you have had leisure for laying out your plans completely, especially as meanwhile you have quite enough to do in preparing for your great literary scheme.

You do not in either letter give me any account of yourself. How is it you have not yet got an amanuensis, as I urged you to do?. You will inevitably break down if you don't economize your energies.

Ever yours,

Herbert Spencer.

NEW York, March \&, 1872 .

My dear Spencer: Your letter regarding the articles came the other day and has much perplexed me. I had arranged for their publication in the Galaxy, which has now a large circulation and is a first-rate medium for such a purpose. Briefly, neither the Atlantic nor Harper's were available for the purpose. The Galaxy has forty thousand circulation, and for the past year has been dipping a good deal into serious discussions. I regret having said anything about simultaneous publication, as I might have known that the Contemporary would not be issued here before it was in England. Our periodicals have to be printed early to transport them to distant places, but they are not published until the 2oth, and therefore cannot reach England before the first of the ensuing month. Besides, it is a common and regular thing to publish articles here in this manner-although, of course, from English magazines that are not reproduced here.

If you make no regular arrangement the articles will be 
at once plundered, and when that thing begins there is no knowing where it will end. I have from the beginning guarded against this result with all care, furnishing everything through Appletons early. But as your name becomes valuable the danger increases, necessitating more vigilance. Another element of apprehension has come into the caseAppleton's course favouring copyright has made him many and ugly enemies lately. As respects the Tribune, I have not yet been able to see Greeley.

It will not be so good as the Galaxy would be, for the newspaper dies in twelve hours, and, besides, it is presidential campaign year, and the papers are already going mad with politics.

New York, March 14, 1872.

My deAR Spencer: I saw Greeley last night with reference to publishing your articles. $\mathrm{He}$ is as ignorant as a Bushman and as prejudiced as a papist, so that conversation on the subject is hardly possible. "As for sociology," said he, "Fourier proclaimed more, thirty years ago, than this generation can appreciate." When your name was mentioned he broke out that he was "dead and forever opposed to that whole laissez-faire school, and if the articles contained any of that, he didn't want them." I urged him as much as I could, and he ended by saying, "When your articles come, let us see them."

But if the Tribune prints the papers, what then? Not being in an accessible monthly, they must be reproduced in pamphlets by somebody. I see no other way but that you get Mr. King to stereotype the chapters in the form of the series and send us the plates. We can strike off a small edition with a large margin, and supply it to those who wish, and thus forestall piracy.

I shall be uneasy until I know what you are going to do about those articles-whether we are to have them early or not. 
New YORK, April 3, 1872.

My DEAr Spencer: A thousand thanks for your favour

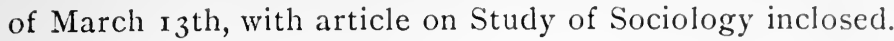
I was beginning to be worried about it, and was on the point of telegraphing you to telegraph me as to what you would do. You did wisely in sending it, and I decided upon our course two minutes after getting it.

I determined to have a monthly at once, and in time to open with this article. It was vital that these articles be not exposed to the temptation to reprint them in pamphlets. Two houses have gone into the business; they are printing series of scientific tracts at a shilling, and have both announced your volume. They will seize upon the first thing offered. We have secured the "Specialized Administration " only by advertising it almost daily ourselves as a pamphlet, to get time to issue it as a book. Remember this: you have become popular here, and are therefore in more peril than before. The courtesies of the trade yielding to priority and recognizing the right of a publisher to the works of his author have a certain value with us, but if once broken through the spell dissolves-that author is not protected. So-and-So has gone in upon his works, and they are now open. This has been done over and over again, and it will not do to leave your things lying around. When I could not get the use of another periodical, and we had to fall back upon the newspapers, it became indispensable to publish as a pamphlet. I have accepted the situation and have done so-with additions.

I received your article less than a week ago. We have started a monthly of 128 pages. The first part of it is now printing; the last pages will be closed up to-morrow, and we will have it out in five days more. Of course, we had to go in on selected articles; but with yours for original and a translation by my sister from the French, a short article by myself, and fragments by my brother, we shall 
make a very fair show, and as we shall print in better style than any other magazine, the thing will do. We shall have a large sale on the first two numbers at any rate. Nothing happens as expected, but often the unexpected is best. I am utterly glad that things have taken the course they have. I have long wanted a medium of speech that I can control, and now I shall have it. It will consolidate plans and facilitate work.

We shall depend on your second article to open also the second number; I hope it will be sent as early as the first. I have not got my amanuensis yet, but soon shall.

\section{April 23, 1872.}

Considering that our gestation was so short, the undertaking has proved very satisfactory. The stroke is unusually applauded, and the incoming support is more than we expected. That which started us and which I was most anxious about-the chance of your articles-is well secured. The first one is attracting a good deal of attention, and is being steadily called for. If we get your second in time we shall be made.

June 2, 1872 .

The unexpected success of the Monthly has increased my anxiety about it, and kept me a good deal on a stretch. We first printed 5,000 each of Nos. I and 2, have printed 2,000 of each since, and they are now both out of print, and have been so half the time for the last several weeks. We shall print 7,000 of No. 3, and it would not surprise me if the first three numbers went up to ro,ooo. The publishers say it is a certain thing, and are greatly pleased, but the American rage for novelty cannot fail to be a large factor, and I indulge in no large hopes. Still, I shall do my best to sustain it. I like the work much, and if it continues to succeed I shall have no further solicitude about remunerative occupation. 
August 21, 1872.

Chapter V has just come, and it is splendid. This series is going to do a grand work; it hits us every time exactly where we live. The papers as they appear will be extensively read, and, although we are in the midst of a presidential convulsion, they are already attracting great attention. The volume cannot fail to do sharp execution. Have you any definite idea of its extent? If so, I shall be glad to know. There is a good deal of inquiry about the Psychology.

As soon as the sociological series breaks I mean to introduce some parts of the Psychology into the Monthly, the sales of which, I am happy to say, steadily continue. I was prepared for a marked falling off during the furious heat and business stagnation of midsummer, but the circulation is well sustained, and there is a constant call for back numbers.

I posted to you a World two days ago, with the alleged report of a European tourist on European philosophers. You will find in it some novel and remarkable statements concerning yourself and your friends. Our newspaper press is simply damnable. "Interviewing" has come to be a regular feature of it, and under its guise are put forth the most preposterous inventions, while the extravagant and the absurd are sure to be caught up and universally circulated. But all this cannot be helped, but must be taken philosophically. Fiske's lecture on the Composition of Mind has been published in Hammond's Psychological Journal, published by the Appletons. John has gone in pretty strong on Psychology. I will send it to you. My sister is very well, and is working steadily at her second book of Botany. The religious press is getting uneasy about the Monthly, and beginning to threaten us. Fver yours,

E. L. Youmans. 
37 Queen's Gardens, Bayswater, W., October 12, 1872.

My DEAR Youmans: I have just finished the second volume of the Psychology, and expect to have it issued in a bound form in less than a fortnight.

I find on looking back that it is just twelve years since I commenced. Having now got half through, it might be inferred that it will take another twelve years to finish. I see reason for hoping, however, that ten will suffice.* Considerably more than two years, I believe, have gone in interruptions-partly due to occasional relapses of health, partly to the second edition of First Principles, partly to various incidental essays and articles, and partly to the arrangement and superintendence of the Descriptive Sociology, which during the earlier stages occupied much time. Indeed, now that I put them down, these interruptions account, I think, for more than two years' loss of time. As I am much better now than I was when I commenced, and as I do not see the likelihood of much incidental writing hereafter, I am inclined to hope that after completing the Study, etc., ten years will suffice to carry me through.

Your last number has reached me, as also the copy of the World, in which I find myself "interviewed" in a somewhat romancing style; for, while I recognize some things in it as having been said to me, there is much in it which I certainly did not say-notably the passages from First Principles which I am represented as repeating.

May I suggest that you are hardly giving the method of dictation a fair trial. Neither the hand of your late amanuensis nor the hand of the one by whom you wrote last implies the ability to write with tolerable rapidity. If you employ a slow writer, you will not only lose valuable

* More than twenty, alas! have since elapsed, and because of unforeseen ill health the series is not yet quite finished. Happily. since 1890 it has been advancing more rapidly, and the end scems almost in sight. 
time, but may get impatient with the system itself, and condemn it as unsatisfactory. By all means get a quick writer. Ever yours,

Herbert Spencer.

The laborious work connected with the magazine did not prevent Youmans from once more trying to give a few lectures; but this time he broke down at the very start, and was soon back in his editorial office again.

Ashland, November 20, 1872.

DEAR Sister: Things are precious bad. I ought not to have undertaken this job. I am sick through and through with the ugliest cold I ever had-headache, sore throat, soreness of chest, and a universal aching to the marrow of the bones. I could not get a fire in a room at Akron, and was freezing all day. I got into a sweat during the lecture, and that clinched the thing. Had to leave at 5.30 in the morning. No vehicles to train, so I got a bed in a nigger hole near the station and shivered in it all night. I had a good deal of fever, and did not get a wink of sleep. It was an awful night, but I got the cars and slept through a fifty-mile ride-or dozed through it. I did not think I should be able to lecture at all, but I went to bed and rested as well as I could, and of course I had to try it. I contrived to talk an hour, and could not stand up any longer. I had a good deal of broken and uncomfortable sleep last night, but am awful stiff and sore this morning; and more-I have to ride back into the country several miles in a cold snowstorm to Lodi. I shall undertake it. So things go, and I will telegraph you. I have long known that I am very shaky, but I did not realize how little remnant of vitality and resistance there is left.

Having thus seen how The Popular Science Monthly came into existence at the time when it was becoming more than ever apparent that our friend's 
career as a lecturer was ended, we may quote his own words in the Editor's Table of the opening number, in which he defined its scope and aim:

The Popular Science Monthly has been started to help on the work of sound public education, by supplying instructive articles on the leading subjects of scientific inquiry. It will contain papers, original and selected, on a wide range of subjects, from the ablest scientific men of different countries, explaining their views to non-scientific people. A magazine is needed here which shall be devoted to this purpose, for, although much is done by the general press in scattering light articles and shreds of information, yet many scientific discussions of merit and moment are passed by. It is therefore thought best to bring this class of contributions together for the benefit of all who are interested in the advance of ideas and the diffusion of valuable knowledge.

The increasing interest in science, in its facts and principles, its practical applications, and its bearings upon opinion, is undeniable; and, with this augmenting interest, there is growing up a new and enlarged meaning of the term which it is important for us to notice. By science is now meant the most accurate knowledge that can be obtained of the order of the universe by which man is surrounded, and of which he is a part. This order was at first perceived in simple physical things, and the tracing of it out in these gave origin to the physical sciences. In its earlier development, therefore, science pertained to certain branches of knowledge, and to many the term science still implies physical science.

But this is an erroneous conception of its real scope. The growth of science involves a widening as well as a progression. The ascertainable order of things proves to be much more extensive than was at first suspected; and the inquiry into it has led to sphere after sphere of new investi- 
gation, until science is now regarded as not applying to this or that class of objects, but to the whole of Natureas being, in fact, a method of the mind, a quality or character of knowledge upon all subjects of which we can think or know.

What some call the progress of science, and others call its encroachments, is undoubtedly the great fact of modern thought, and it implies a more critical method of inquiry applied to subjects not before dealt with in so strict a manner. The effect has been, that many subjects once widely separated from the recognized sciences have been brought nearer to them, and have passed more or less completely under the influence of the scientific method of investigation. Whatever subjects involve accessible and observable phenomena, one causing another, or in any way related to another, belong properly to science for investigation. Intellect, feeling, human action, language, education, history, morals, religion, law, commerce, and all social relations and activities, answer to this condition; each has its basis of fact, which is the legitimate subject-matter of scientific inquiry. Those, therefore, who consider that observatory watching, laboratory work, or the dredging of the sea for specimens to be classified, is all there is to science, make a serious mistake. Science truly means continuous intelligent observation of the characters of men as well as of the characters of insects. It means the analysis of mind as well as that of chemical substances. It means the scrutiny of evidence in regard to political theories as inexorable as that applied to theories of comets. It means the tracing of cause and effect in the sequences of human conduct as well as in the sequences of atmospheric change. It means strict inductive inquiry as to how society has come to be what it is, as well as how the rocky systems have come to be what they are. In short, science is not the mystery of a class, but the common interest of rational 
beings, in whom thinking determines action, and whose highest concern it is that thought shall be brought in to the exactest harmony with things-and this is the supreme purpose of education.

If, in this statement of the scope and work of science, we have not laid stress upon those great achievements by which it has given man power over the material world, it is not because we undervalue them. They are noble results, but they are abundantly eulogized, and their very splendour has operated to dim the view of other conquests less conspicuous but even more important. Telegraphs, steam engines, and the thousand devices to which science has led, are great things; but what, after all, is their value compared with the emancipation of the human spirit from the thralldom of ignorance, which the world owes to this agency? Rightly to appreciate what science has accomplished for humanity, we must remember not only that it has raised men to the understanding and enjoyment of the beautiful order of Nature, but that it has put an end to the baneful superstitions by which for ages men's lives were darkened, to the sufferings of witchcraft, and the terrors of the untaught imagination which filled the world with malignant agencies.

It is this immense extension of the conception of science, in which all the higher subjects of human interest are now included, that gives it an ever-increasing claim on the attention of the public. Besides its indispensable use in all avocations, and its constant application in the sphere of daily life, it is also profoundly affecting the whole circle of questions, speculative and practical, which have agitated the minds of men for generations. Whoever cares to know whither inquiry is tending, or how opinion is changing, what old ideas are perishing, and what new ones are rising into acceptance-briefly, whoever desires to be intelligent as to contemporary movements in the world of thought- 


\section{The Popular Science Monthly.}

must give attention to the course of scientific inquiry. Believing that there are many such in this country, and that they are certain to become more numerous in future, The Popular Science Monthly has been commenced with the intention of meeting their wants more perfectly than any other periodical they can get.

The work of creating science has been organized for centuries. Royal societies and scientific academies are hundreds of years old. Men of science have their journals in all departments, in which they report to each the results of original work, describe their processes, engage in mutual criticism, and cultivate a special literature in the interests of scientific advancement.

The work of diffusing science is, however, as yet but very imperfectly organized, although it is clearly the next great task of civilization. The signs, however, are promising. Schools of science are springing up in all enlightened countries, and old educational establishments are yielding to the reformatory spirit, modifying and modernizing their systems of study. There is, besides, a growing sympathy on the part of men of science of the highest character with the work of popular teaching, and an increasing readiness to co-operate in undertakings that shall promote it. There is, in fact, growing up a valuable literature of popular science-not the trash that caters to public ignorance, wonder, and prejudice, but able and instructive essays and lectures from men who are authorities upon the subjects which they treat. But the task of systematically disseminating these valuable productions is as yet but imperfectly executed, and we propose to contribute what we can to it in the present publication.

The Popular Science Monthly will make its appeal not to the illiterate, but to the generally educated classes. The universities, colleges, academies, and high schools of this country are numbered by hundreds, and their graduates by 
hundreds of thousands. Their culture is generally literary, with but a small portion of elementary science; but they are active-minded, and competent to follow connected thought in untechnical English, even if it be sometimes a little close. Our pages will be adapted to the wants of these, and will enable them to carry on the work of selfinstruction in science.

Thenceforward the editorial duties of the Monthly absorbed the chief energies of Mr. Youmans, and its twenty-eight volumes issued under his care form the principal record of his remaining years. While it was his main intent to give in popular form an account of the progress of the several departments of science, he never lost sight of the aim to show wherein the scientific method was applicable to the larger questions of life-of education, social relations, morals, government, and religion. In enlisting contributors to his pages he did not find it easy to get them to steer between oversimplification on one hand and an undue technicality of expression on the other. The following letter to one of his contributors is eminently characteristic:

My DEAR SIR: Your article is excellent, and will be read by many with appreciation; but when I looked over the proof it occurred to me that it had some faults of presentation, perhaps due to your lack of practice in putting abstract things before common readers. Our scientific readers, of course, will have no trouble in understanding you and will enjoy your argument, but nine tenths of the patrons of the Monthly will get but a partial comprehension of it. Of course so abstract a topic as the Mathematics of Evolution may be expected to require some intellectual force to grasp it, and I am well content with your main exposition. Still I think some serious and systematic attention on your 
part to the artifice of clear and familiar statement, which will give you access to ordinary minds, is very important. I do not mean for a moment that your writing is obscure, but only that your composition would be improved if you had in your mind's eye a person of common intelligence and quite unacquainted with the subject you are seeking to explain. You would then stop and think by what handling or illustration the view so clear to you could be brought into his apprehension. I am speaking from the Popular Science standpoint about a deficiency which marks many of our scientific writers. Generally the deeper and more thorough their science, the poorer is their power of exposition. Excuse me for throwing out these suggestions, a but with your unusual ability of statement and command of appropriate language, if you would study the art of getting at the mind of the multitude, as a dramatist has to study it in elaborating his points with reference to their effect upon theatre goers, you could do very important and increasingly needed work in the field of popular and scientific education.

Have you any leisure to write, and do you care to accomplish anything in that direction? If yes, and you have the necessary works at hand, I should like you to try to make a thoroughly popular and simplified statement of the doctrine of the "dissipation of energy." I want a report in the Monthly of the state of that question, explaining what it is, what we know, and what we don't know about it. What say you?

Ever and truly yours,

E. L. Youmans.

He had very often to perform the common editorial function of returning unsuitable manuscripts, but always with most kindly consideration. Among authors who are to-day prominent might be named several whose first efforts submitted to Youmans were 
found unacceptable, but who were plainly and kindly told wherein lay their deficiencies. Not seldom an article would be offered him unsuitable for the Monthly, but such as some other editor might be glad to publish. In that case the indication would be given, usually accompanied by an introductory card. It was in his treatment of callers that Youmans's good nature was most severely tested. At all hours to his office there would come inventors with models to be "noticed," writers with bulky bundles of book manuscript for examination, and readers to argue down some statement published in the Monthly. He could instinctively discriminate between the callers who had a right to his time and those who had not. A crank or bore would hear something like this: "My good sir, your manuscript is very probably all that you claim, and I should be glad to have the leisure to examine it in detail; but you see how it is. I have ever so much work that I must finish to-day, and so I am obliged to forego the pleasure."

Youmans's extreme kindliness is well illustrated by the effect produced upon the author of a rejected manuscript, who wrote him the following letter:

\section{DR. E. L. Youmans.}

DEAR SIR: Your reasons for not putting my lecture in The Popular Science Monthly are good and sufficient, and perfectly satisfactory to me. You must both have and deserve troops of friends, if the very kind notice you took of my paper marks your habitual manner with new contributors, and I can only thank you, and say you were quite right in rejecting it.

Can you be as correct in some of your remarks? Is Herbert Spencer anything but a "religious destructive"? Does that philosopher exist in any other relation to religion 
than that of destroyer? What is religion? Manifestly a collection of beliefs and emotions founded upon erroneous views of the construction and methods of operation of this and other worlds. Spencer teaches a true cosmos. He must therefore destroy religion wherever he impinges upon it. How could any conclusion be other than a "bald negation"? When it is shown that religion vanishes in the presence of science, what can you do but write finis then and there? The affair is closed. The job is done. To a mind comprehending the facts and theories of science and (I will add) understanding the writings of Spencer, "religion" can no more be entertained than a hobgoblin. It becomes a zero, an excommunicated $x$, a nothing floating in vacuo.

From this mess of crudity one might readily infer that Youmans would have had no use for the writer's article. If he had deemed it necessary to answer this letter, he would probably have gently conveyed some intimation of the fact that the writer was very far from "understanding the writings of Spencer."

After the new magazine had been running about a year and a half Youmans wrote to Spencer:

There can be no doubt that the Monthly is doing an important work in this country. We continue to print I 2,000, although the monthly demand fluctuates around I I,, 00 , and seems to be stationary for the last few months. But the bound volumes sell steadily though moderately, and new subscribers frequently order from the beginning. We have, however, worked up a very deep feeling of hostility, and hear constantly of people who "won't have it in the house." I call your attention to a promised series of articles, of which the first will be in the October number on The Primary Concepts of Modern Physical Science, by a 
Western lawyer.* I send you two Scribners with marked articles that will interest you to glance over, as indicating the depth of the stir among us. Dr. Holland has not got over the drubbing I gave him on evolution, and he has got up this panic with a view "to do the business" for us, and it is unquestionably acting against us. But it is also acting powerfully against him, for the religious world is disgusted at his disclosure of the depth and extent of skepticism, and is pitching into him. As an example, my father and mother refuse to hear the articles read, alleging that "it is the work of some infidel."

Other magazines publish wickeder articles than we do, and nobody objects, but we are under suspicion because we sail under the flag of science.

Early in I 874 we find him writing :

The Popular Science Monthly only holds its own for the last few months, and I think there are some symptoms that we are beginning to lose something with the declining novelty of the enterprise. People bought it from curiosity and a sense of duty, and various motives aside from their desire to read it. The newcomers now only about balance those who fall away. I mean, if possible, to make it more popular.

To this Mr. Spencer characteristically replied :

I think you ought to be satisfied if The Popular Science Monthly "only holds its own" if you have reached a circulation of $\mathrm{i} 2,000$. This is, I think, far beyond what you originally expected to reach, and you can hardly expect to go on increasing without check. I am rather inclined to

* Hon. J. B. Stallo, of Cincinnati, since minister to Italy, a thinker of rare acuteness. The articles now form a volume in the International Scientific Series. 
shake my head when you talk about making it more popular. This is just the tendency which all things set up with a high standard have to guard against-the tendency to make material success the object, to the overlooking of the original object.

Such advice was congenial to Youmans, and he never allowed himself to be diverted from his original purpose. If timid and narrow-minded people were thrown into a flutter by things said now and then in the Monthly, he had the satisfaction of getting little else but praise from the men whose esteem was worth having; as, for example, in the following letter from that embodiment of sound sense and sturdy despiser of sciolism, Dr. Holmes :

Boston, May 3,1874 .

Dear Dr. Youmans: I received, a day or two since, the copy of Dr. Carpenter's Mental Physiology, and thank you for your kindness in transmitting it. I shall write to Dr. Carpenter, to whom I have for so many years been under frequent obligations, and whose works I have known ever since I began teaching anatomy and physiology, and tell him how glad I am to have in a collected form his original and most interesting observations and ideas with reference to the great problems which transcend all others in interest-the mechanism and the springs of this perpetual mental movement which we can no more arrest than we can the beating of our hearts, though we can modify it as we can the acts of respiration.

I must take this opportunity to tell you how much I depend on The Popular Science Monthly. It comes to me like the air they send down to the people in a diving bell. I seem to get a fresh breath with every new number. Believe me, dear Dr. Youmans,

Very truly yours,

O. W. Holmes. 
The Popular Science Monthly has now been with us more than twenty years, its founder's mantle having fallen upon his younger brother, Dr. William Jay Youmans, by whom it is now edited. Its character has always been of the highest, and it has exerted an excellent influence not only as a diffuser of valuable knowledge, but in training its readers to scientific habits of thought in so far as mere reading can ever contribute to such a result. 


\section{CHAP'TER XV.}

\section{VAKIOUS AFFAIRS. 1872-1878. Age 51-57.}

IN the autumn of I872 Mr. Youmans did what he could to make Prof. Tyndall's visit to America pleasant and successful. It will be remembered that the great physicist had said that he would not carry away from this country a penny earned by his lectures here. His net profit of $\$ 13,000$ he very generously placed in the hands of trustees, of whom Youmans was one, the annual income to be devoted to aiding young Americans desirous of prosecuting original research in the laboratories of Europe. In the course of a few years it became advisable to change the application of the income of the trust, which is now divided between Harvard University, Columbia College, and the University of Pennsylvania.

Among the letters received from Prof. Tyndall during the autumn of 1872 was the following:

Boston, October 8,1872 .

My dear Youmans: Thanks many for both your letters, which interested and amused me greatly. This opening of the International Series is very gratifying. I think in founding it you have entered upon a most important enterprise.

I have received a letter from Mr. Winthrop, of Boston, which interests me greatly. $\mathrm{He}$ is descended from John 
Winthrop, who came over in 1630 , and who married Margaret Tyndale, whose great-grandson was the most distinguished professor of natural science in New England of his time. Is not this curious?

The lectures are going on, but they are difficult. The people crowd to hear them, and Mr. Lowell declares that never previously were they held so fast in the lecture room. I give them an hour and a half, though warned that they would not stand more than an hour. Still the lectures by no means please myself, one reason being that I am at sea as regards the intellectual level of my audience.*...

Go on and prosper, my dear Youmans, in the work you have undertaken. I hardly know any man in Europe or America who enjoys your opportunity of doing good, and the best of it is that it is an opportunity created by yourself.

Give my affectionate regards to the Methodists. I will not return railing for railing, but, contrariwise, blessing.

Yours ever,

JOHN TYNDALl.

From Tyndall's numerous letters to Youmans, many of which are concerned with business or else with affairs of strictly private interest, I have culled a few pleasant and characteristic passages:

* An error which has played the mischief with more than one British lecturer in America, notably with the lamented Freeman, who thought it necessary to tell his audiences in Boston and St. Louis simple outlines of English history known to every schoolboy. As I remember Tyndall's lectures, however, he did not go far astray in this direction. Any British lecturer will always be safe in addressing any American audience he is likely to meet in exactly the same way that he addresses his audiences at the Royal Institution in London or at the Philosophical Institution in Edinburgh. 
London, May 26, 1873.

My DEAR Youmans: I was somewhat concerned yesterday to gather from a letter of yours to Spencer that the religious world were bearing hard upon you-seeking to damage Appleton, and in so far damaging you; but your letter of this morning, which is all brightness, dissipates my concern. Surely, surely, a man like you must have labour room in the wide area of the States. The men on this side whom you work with are not scoffers; and if they did not lead the movements of the age, trust me, these movements would fall into more irreverent hands.

Those that have seen 'The Popular Science Monthly here call it "a delightful magazine."

Yours ever,

John Tyndall.

September 15, 1874.

My DEAR Youmans: Thanks, many and hearty, for your cordial letter. I have just time to say that before this week ends a revised copy of the Belfast Address shall be on its way to you.

It has caused tremendous commotion. How foolish they are! Their wisdom would have been shown in letting the thing alone, but they are not Wisdom's children.

Cardinal Cullen has just appointed three days of prayer to keep infidelity out of Ireland!

Yours ever,

John TyNdall.

P.S.-I caught a glimpse of Spencer yesterday, and shall dine with him to-morrow. He is flourishing.

September 28, 1874 .

My dear Mr. Appleton: The Address, separately published, is going off with exceeding rapidity. The third thousand was called for in three days.

Yours ever faithfully,

John TyNdall. 
P. S.-Being busy just now, I have merely glanced at Dr. Youmans's remarks; but I have seen sufficient to assure me of the sagacity, and, indeed, eminent ability which mark his mind in the treatment of great questions. I often think that had he been less hampered by his ailments in youth he would have made a profound mark on his day and generation. Even as it is, he is doing this.

\section{March $17,1876$.}

MY DEAR YOUMANS: I am thoroughly obliged to you for your excellent letter. It gave my wife and myself great joy to read it. In fact, there is a pith and power in your mode of expressing yourself which $\mathrm{I}$ have rarely seen equalled, and which it does one good to read.

I never thanked you for your defence of me in The Popular Science Monthly. Let me do so now. It was quite sufficient-quite as much as I either desired or deserved.

I wish Bastian had permitted me to treat him tenderly. I expressed this wish to himself, but, as Huxley says, tenderness shown to him is sure to be misinterpreted. It is surprising how rapidly he is going to pieces on the first real shock. He had a great number of believers, but their ranks are now wofully thinned. I sometimes feel in a relenting mood toward him, but the matter is too grave to be glossed over.

The Fragments, I expect, will be out in a week or so. I have ordered them to send you stereotype plates.

Ever faithfully yours,

JOHN TYNDALL.

An advance guard or extreme wing of the Unitarians, in 1872, organized themselves into the Free Religious Association, founding the Index as their organ, with Francis Ellingwood Abbot as editor. The association's first president was Rev. O. B. Frothingham, 
and Youmans was upon the list of vice-presidents, which included Ralph Waldo Emerson. In 1873 the association met in New York, when Youmans delivered an address, in Cooper Union, on The Religious Work of Science.* In reference to this address I find, in a letter to his mother a few days later, the following:

I saw Mr. Beecher the other day, and he was very full of his compliments about my sermon at the Cooper Institute, and thought I had mistaken my calling and should have been a preacher. He said my address was like a poultice, and if scientific men generally would soften things in that way, all parties would get along a great deal better. We must remember, however, that Beecher is a foxy fellow, and knows how to say smooth things.

In the summer of 1873 my dear friend's health began to be seriously impaired; his editorial labours were arduous; the International Scientific Series demanded constant care; he was working too hard. Commenting on a long letter from him, wherein his ailments had been described in detail, Mr. Spencer began a series of remonstrances, continued for years afterward. His friend was exhorted in the kindest way to cease from overwork, to husband his strength, to take such timely recreation that he might in the long run be able to do the more. As a first measure of practical reform he was advised to engage an amanuensis. In response to Spencer's appeals, he would promise to amend his methods, to work fewer hours, to take regular exercise, to let subordinates assist him as much as possible. But reform, however earnestly resolved upon, was never systematically carried out.

* It is given in full below, pp. 49I-50I. 
A restless anxiety to push all tasks to completion, a natural buoyancy which for the greater part of the time ignored the evidences of ill-health, united to keep him at the oar when mind and body should have had relaxation and rest. His was the case of the man wise for others, not wise for himself. Next year, i874, no sooner did his health somewhat improve than he began to carry out his project, long entertained, of a Cyclopædia of Household Science, organizing a corps of investigators and writers. His direction and supervision of their work entailed new burdens of responsibility and toil. Yet never was he too busy or too weary to serve the cause of evolution, or to elucidate the true position of its philosopher. On the 5 th of June he delivered a lecture before the New York Liberal (Positivist) Club on Herbert Spencer and the Doctrine of Evolution. This lecture appeared in the Monthly for the following November, and is reprinted as an appendix to Mr. Frothingham's translation of Cazelles's Outlines of Evolution.*

In the autumn of 1874 overwork entailed its accustomed penalty; his health again became poor, and his eyes were so much affected that he had to submit to curtailment in both reading and writing. The next year the interests of the International Scientific Series required his presence in Europe. While abroad he had his cyclopædia constantly in mind, and gathered together many hints and much material for it. $\mathrm{He}$ examined new applications of science in the household; investigated sanitary appliances and the newest methods of heating, lighting, and ventilation. Convinced that among practical arts cooking was only

* This very able and important paper is given in full below, pp. 502-55I. 
second in importance to agriculture, he paid frequent visits to the South Kensington School of Cookery, and here Miss Youmans entered as pupil to gather for him such knowledge as practical training might afford in furtherance of his scheme.

Among the many literary projects which Youmans organized for himself or for others to execute I find one which for some reason or other was not carried out. It is mentioned in a letter to his brother, Mr. Earle Youmans, of Winona, Minn., who, in company with a younger brother, Mr. Addison Youmans, has for years carried on a very large business in lumber, and is, I should judge, eminently qualified to deal successfully with the interesting and important subject mentioned.

New YORK, December 15, 1874 .

Dear Brother Earle: I think you should not give up the lectures. The failure of an audience in Winona amounts to nothing. 'The subject is the next great thing any way, and has got to be considered by this people. I believe political economy, so called, is to take a new shape in the near future and become a branch of scientific sociology. Hitherto it has been treated too much in its abstractions, and its great laws and results when so stated are too complex to be grasped by the mob. A lecture on the evolution of business, that should treat the subject historically and begin with the crudest exchange of the lowest races and trace it through te its largest unfoldings, would make it more concrete and link it on to the diversified workings of human nature in such a way that it could be understood by everybody and could be made attractive as well as instructive. Spencer's Descriptive Sociologies are an unexplored mine of this kind. If you will get up some lectures and work at them regularly, and not be in a hurry about it, you can have the Cooper Institute to deliver them in and 
three thousand people to hear them. I could get them into Hewitt's Saturday night course next year, and then publish them in the Monthly. The lectures are of course free, but that makes no difference. Hewitt has been hunting for something of the sort five years.

Come down, at any rate, as soon after New Year's as you can, and we will get the thing going. We start a new series the first of the year that we think of calling The Popular Science Library. The volumes will be sold at a dollar, will have about one hundred and fifty pages, and Eliza's translation of Quatrefages will be the first. It will be a capital place for a thoroughly elementary book on political economy such as might be worked out by the route of these lectures.

The correspondence is full of remarks and allusions interesting to readers who are interested in Youmans or in Spencer or in the doctrine of evolution, and the judicious reader (to whom the power of skipping when he chooses belongs as an inalienable right) will not find fault with me as I proceed to string together a few extracts covering the seven years from 1873 to I 880 .

37 Queen's Gardens, Bayswater, W., August 26, 1873.

MY DEAR YOUMANS: I greatly regret to hear that you have been out of condition and that things have been going unsatisfactorily in respect of work. I wish I could persuade you to adopt persistently the policy of having an efficient amanuensis. Once establish the habit of dictating, and you would, I am sure, find it a great economy of energy and a great relief; and it is clear to me that.your state of health is such as to make it highly important that you should economize your energies. Instead of postponing the matter of an amanuensis and hoping to get satisfactorily fixed presently, as you have continually said, you 
ought to make that the one thing to be settled before all other things as the means to more easily doing other things. As to the cost, depend upon it you would find it pay.

Will you excuse me if I also suggest that I think you are apt to spread your energies over too many things. It strikes me that in your state of health you will have to learn the art of saying "No" in respect of many undertakings suggested to you or which you suggest to yourself. Lecturing you have, if I understand rightly, given up; and I should advise you to adhere rigorously to this course of abstinence. You had better also abandon all idea of doing anything with the Descriptive Sociology. Let it be issued by the Appletons as other things have been and take its own course. In fact it strikes me that your policy should be to limit yourself exclusively to the International Series and the magazine.

I am just back from Scotland, much earlier than I intended, having met with very bad weather, very little amusement, and unsatisfactory health; for though during this last season I was rejoicing at having been able to bear so much work, I found when I got away that I had overstepped the limits and underwent some collapse. I am still con. siderably below par, but hope to get round presently.

Ever yours,

Herbert Spencer.

The following refers to Youmans's important lecture before the Liberal Club, reprinted below, pages 502-55I:

38 QUeEn's Gardens, Bayswater, June 20, 1874 .

My Dear Youmans: Two days ago I got your letter, and yesterday the copy of The World. Of course I cannot but rejoice at the complete success of your address and exposition. But while it is a source of satisfaction to me to have such able defence and advocacy, I see abundant reason to congratulate you upon the clearness and power of 
that which is wholly your own. Your sketch of the preexisting state of opinion, and of the irrational compromise which had been made by scientific men is admirable, and you bring into a vivid light their failure to recognize the changed position of things that had grown up, and the necessity for a total reorganization of thought. So well have you put the matter that every one who reads must see that such a change was impending, and that the last generation of scientific men, narrowly disciplined by their special studies, were incapable of seeing it. You have put in immense claims for me, and doubtless greatly astonished your audience, and will greatly astonish also the more numerous readers of your address. Now, however, that you have given the facts in their narrative form, referring to the sources and their dates, there will be, one would think, no gainsaying your general assertion-though, indeed, one must expect that with the usual perversity many will go on saying what they did before spite of its demonstrated untruth.

I see you finally decided to have your say about Emerson. It is very pungent, and will, I should think, cause considerable sensation. If, as you say, controversy has been growing hot, we may expect it to grow hotter now that you have added to it these burning criticisms.

The German translation of First Principles is finished and about to go to press. It strikes me that it might not be amiss to prevent the erroneous idea about my relations to Darwin from spreading in Germany, as it has in France and elsewhere, and to this end it would be as well to send a copy of your address in The World to the German translator, Dr. B. Vetter, Seilergasse, Dresden, Germany. Probably he will write a translator's preface, and he might take occasion to warn readers against the error. 
July 12,1874 .

My Dear Youmans: I had quite intended during the week to write and send you the paragraph I named to fill the cut-out space, but I have been so busy preparing to leave for Scotland on Tuesday that I have been unable. I must leave it to you to do it or not, as you see fit.

What I thought desirable was to reindicate, in the briefest way, the growth of the idea* onward from 1842 , its growing comprehensiveness and definiteness, the recognition of the process of selection in the case of human beings, the adoption of the idea of increasing heterogeneity and its gradual extension in various directions, the reappearance of these ideas in the Psychology in a combined form, with the idea of integration as joining differentiation and the entire interpretation of mind on evolution principles; then to indicate that in 1857 the law of evolution, considered inductively as increasing heterogeneity, was enunciated as universal as well as the deductive interpretation of it as due to the instability of the homogeneous and the multiplication of effects; and that the doctrine as it now stands was thus, in its universality and its chief outlines, set forth two years before the Origin of Species appeared. You have clearly enough stated at the end this independent origin of the doctrine; but what strikes me is that this fact would be much more clearly seized if in the narration you briefly indicated the stage it had reached before Darwin published. But I leave this hint for you to act on or not, as you think well.

November 6, 1874 .

My Dear Youmans: On my return to town last night, after a week's absence, I found among various other things your last number of the Monthly. I had no idea you were

* I. e., the growth of the idea of evolution in his own mind. 
going to reproduce your lecture there. I am immensely indebted to you for all the trouble you are taking to rectify current misconceptions; and, what with your lecture, and this republication with its sundry improvements, and the publication of the volume, you will do it very effectually.

\section{NEW YORK, November 24, 1874 .}

My DEAR SPENCER: I have yours of October 8 th, regarding the lecture in the Monthly. I see many indications that it is doing pretty effectual work. It seems to have gone counter to current opinions regarding yourself and Darwin much more strongly than I was prepared for. I have had many letters and messages acknowledging indebtedness for its statements. On the whole, it was an excellent job, though it has taken a prodigious long time. Mr. Emerson is amusing. He protests that he has been quite misunderstood, and never applied the term "stock writer" to Mr. Spencer in any disparaging sense.

38 Queex's Gardens, Bayswater, London, January 29, 1875 .

Mr DEAR YOUMANS: I was glad to get your letter of

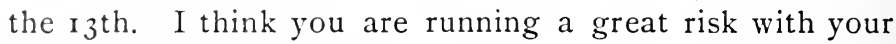
eyes in using them before they are quite strong again. You had much better postpone your Chemistry and take your rest first. It is this endeavour just to finish something in hand before leaving off that is the cause of nearly every breakdown. I have seen it so in myself and in all around me. Pray take warning. Instead of the common attitude, This business must be done even at the cost of health, the attitude should be, My body must be attended to even at the cost of business.

New York, April 3, 1875 .

My deAR Spexcer: You are making very clean work with this matter of Origin of Religion, but in certain respects the cleaner the worse. There is great irritability in 
the theological mind since Tyndall's bombshell,* and I have my foot pretty well into the difficulty. Our concern is very sharply watched.

My Chemistry is still dragging through the press, the Monthly has to be attended to, and I have just had one of my eyes cauterized. From these complications you can infer the difficulty I have in getting away.

Old students of Mr. Spencer's works will recollect the amusing vehemence with which he was attacked in the British Quarterly Review of October, 1873 , and January, I874, by a young Cambridge mathematician named Moulton. The articles contained many ludicrous misconceptions; among other things the writer actually accused Mr. Spencer of identifying persistence of force with conservation of energy! $\dagger$ In two letters from Spencer to Youmans I find allusions to this affair which have some interest, since Cayley and Sylvester are probably the two greatest English mathematicians of the nineteenth century.

\section{April ${ }^{77}, 1874$.}

Last night Hirst gave me the satisfactory information that Cayley entirely agrees with me in the controversy with Moulton, and thought Moulton deserved all he got.

April 14, 1875.

I received a few days ago a piece of information that gratified me extremely. Sylvester came up to me at the club and told me that he had recently been at Cambridge, where he had dined at the fellows' table at the college to which Moulton belongs. Moulton's name came

* I. e., the celebrated Belfast Address.

† The reply to the reviewer may be found in Spencer's Essays, vol. iii, pp. 307-34I. 
up, and it led to a conversation respecting the controversy. He said that there was but one opinion about the matter, namely, that Moulton had committed himself grossly. He said that there was quite a "chorus" of expressions of "wonder" that he should have made such a blunder. Sylvester said that the unanimity of the verdict was just as though Moulton had compromised himself among a number of mathematicians by a serious error in mathematics.

That this should be felt in his own university and in his own college, in spite of the esprit de corps, is remarkable, and more than I should have thought possible. It relieves me greatly.

Youmans's visit to England in the summer of 1875 did not recruit his strength so much as had been hoped; that great fund of vitality had been drawn upon too lavishly. He returned to New York in November.

37 Queen's Gardens, Bayswater, W. London, November 29, 1875.

MY DEAR YOUMANS: I have been often thinking of you since you left, in consequence of the very bad weather we have had, fearing that you must have been dreadfully tossed on the Atlantic, and perhaps so disguisted as to repent of your resolution to repeat your visits.

The new edition of Bain has reached me. I think it greatly improved, and, though he takes to the doctrine of evolution in rather a gingerly way, still he has made a great step for one brought up under the régime of pure empiricism. The book is admirable from a natural history point of view.

Some things of interest have occurred since you left. The Professor of Philosophy at Copenhagen sends me a work on Modern English Philosophy, of which a large part 
is devoted to the synthetic philosophy, and in a letter giving his cordial adhesion he proposes to translate some of the essays into Danish, regretting that there is not a sufficient public for the large works. Dr. Vetter is beginning to translate the Biology, and the French translation of the Biology, Cazelles tells me, is finished-the fifth volume being in Baillère's hands. I heard the other day, too, that the Japanese are beginning to translate!

I hope to get a letter shortly telling me of your safe arrival.

37 Queen's Gardens, December 18, 1875 .

My DEar Youmans: I am very sorry indeed to have an account of your health that is so unsatisfactory alike by what it says and by what it implies. To think that you should have come over here mainly to recruit, and now that you should be apparently no better than when you left, and all because you would go or working and worrying instead of resting! Your intention to be careful now amounts to nothing; you have all along been intending that and doing the contrary. That you will either cut short your life or incapacitate yourself is an inference one cannot avoid drawing, seeing that in your case, as in a host of other cases, experience seems to have not the slightest effect. It is a kind of work-drunkenness, and you seem to be no more able to resist the temptation to work than the dipsomaniac resists alcohol. Excuse my strong expressions. I use them in the hope that they may do some good, though it is a very faint hope. . . As though fulfilment of some passing purpose was necessary, and maintenance of life unnecessary! What is the use of all this propagation of knowledge if it is to end in such results?

38 Queen's Gardens, December 28, 1875.

The other day I received some news from Russia which will interest you. A professor at Kiev proposes, in conjunction with his colleagues and pupils, to translate the 
Descriptive Sociology. He tells me, to my surprise, that all my books have now been translated into Russian with the exception of the Descriptive Sociology, which will thus soon be added to the list. Further he tells me that he has proposed to the Historical Society of Kiev to make a like classification and tabulation of Russian history. The name of this Russian is Lontchitzice.

New YORK, May $19,1876$.

My DEAR SPENCER: Your father's little work on Inventional Geometry is now in the hands of the printers, and we shall bring out a neat edition of it in the form of Macmillan's Science Primers, of which Hooker furnished the last, on Botany. I propose to include the Inventional Geometry in this series, and it will be the best of the lot, although it involves too honest work to suit our teachers and our habits. I trust it will have sale enough at any rate to pay expenses, and in here and there a mind it will bear fruit. I think you told me, when some time ago I spoke of reprinting it, that you would make a little preface for it, recognizing the benefit you had yourself derived from its method. If you can now send me a few lines to that effect, or saying whatever you wish about it, I shall be very glad, as they will be valuable in drawing the attention of teachers to the book and to the method it illustrates.

38 Queen's Gardens, September 13, 1876.

My DEAR Youmans: I returned from Scotland about a week since and am just getting into work again. . . . Since I wrote last I have received a copy of the Italian translation of the Education, and also a copy of the translation of three parts of it into Danish. The first part of the German translation of Biology is, I believe, through the press. The first volume of the Sociology is to be undertaken by Dr. Vetter as soon as the Biology is out of hand, and he 
will commence the Psychology as soon as this first volume of the Sociology is issued.

A curious fact turned up the other day which will interest or, at any rate, amuse you. I think I told you years ago that the name Youmans, differently spelt Yeomans, is not uncommon in Derbyshire. While staying at Derby a few days on my way to the south, I fulfilled an intention I have long entertained of going over to the village whence our family came-Kirk Ireton, in Derbyshire-with the view of tracing ancestry farther back than my great-greatgrandfather, respecting whom I have information in a law deed. While in the village I observed within a stone's throw of the house in which my grandfather was born a sign with the name Geo. Yeomans on it. This is not all. When I returned here, and was examining the law papers, I found among them plans of some cottages that had belonged to our family in Kirk Ireton, with the tenant's name written on the plans. One of the tenants' names was Yeomans. So you see it is within the bounds of possibility that our families came from the same neighbourhood, perhaps from the same village.

I write this letter chiefly to intimate that I am back, and shall be glad to hear from you.

In the course of 1876 it had become clear that the rapid progress of chemical science necessitated a fresh revision of the ever-popular Class-Book of Chemistry ; so Youmans began the work, with Mr. Froebel and Miss Shaw as assistants, and finished it in the course of the next two years.

It was in this summer of 1876 , one of the fiercest seasons even of this land of sweltering heat, that Prof. Huxley and his wife made their visit to the United States. The visit was for recreation, and Huxley gave no formal lectures except in New York, when he point- 
ed out the evidences for Darwinism furnished by sundry newly found American fossils. His journey was carried out according to the plan outlined in the following letter:

\section{EDINBURGH, June 27, 1876 .}

MY DEAR Youmans: Your letter of the fourteenth reached me this evening. My lectures in London begin on October 4 th, so that I must leave New York not later than September 23 d. I suppose a White Star sails on that day. I have laid out my course roughly as follows, on the supposition that we arrive in New York at the end of the first week in August (that gives me just seven weeks clear):

First week, Marsh's fossils, New Haven.

Second week, Agassiz, Newport.

Third week, Fiske, Petersham.

Fourth week, American Association, Buffalo.

Fifth week, tour to Nashville, taking Mammoth Cave on the way.

Sixth week, Baltimore, where I am to give an address, and Philadelphia.

Seventh week, lectures in New York. THREE!

I will take for lecture days September I8th, 2oth, 22d, and be off on the $23 \mathrm{~d}$, ieaving the whole population of New York on the quay in tears at my departure.

Now I think this is behaving very properly. I quite agree with you that I may as well give three lectures as $\mathrm{t} w o$, and the topic shall be the direct evidence of evolution. I cannot bring diagrams, so you must provide me with blackboard space and abundant chalk. That is the only stipulation I have to make; the rest you must arrange at your own sweet will.

As to publication of the lectures, I would rather leave the point open. Instead of getting the leisure I expected, here I am harassed with another confounded commission in the Scottish universities, which wastes half my time and 
throws all my plans out of gear. Pray offer my best thanks to Prof. Marsh for his courtesy; I hope to avail myself of it very largely.

At Buffalo my mouth shall drop nothing but buttered pearls, such as we dispense at the British Association. My wife and I will devote ourselves mainly to Niagara.

Ever, my dear Youmans, faithfully yours,

T. H. HuXley.

New York, September 15, 1876.

My Dear Spencer: I think I told you that a gentleman in Wisconsin had offered to index your work for us. He has sent us the index for the First Principles, which is now in the printers' hands, and is well done. He is at present occupied upon the Sociology, and we shall have that ready so as not to hinder the printing.

This gentleman's rame is Leland. I have had my eye on him for five years as an assistant or co-worker, and have now engaged him on my Cyclopædia for two years. $\mathrm{He}$ is now a cashier in a bank, is a thoroughgoing man of business, a practiced bookkeeper, a writer on currency and social reforms for The Nation and other periodicals, a good practical geologist and botanist, and a man who has your works almost by heart. He is a vigorous and steady worker, and I count on his pulling me through, as I am badly breaking in the power of accomplishment. Although he will be mainly occupied on the Cyclopædia, Mr. Leland will give me assistance on the Monthly, and wherever he can be of best use.

We expect the Huxleys to come to-night. Huxley will give his three lectures in New York next week, and sail next Saturday. His tour has been a laborious ovation rather than a restful vacation, for which he can blame nobody but himself. If he had been less good-natured he would have been more free. 


\section{LoNDon, January 16,1877 .}

My dear Youmans: The chapter which I have just commenced is The Family, and will contain a good deal of interesting matter. In the first place, evidence of the relation between polygamy and the militant state of the race and of monogamy along with the rise of the industrial state; further, a criticism on the doctrines of Sir Henry Maine, showing their inapplicability to all stages of society below the pastoral, and showing why the family as it enters into modern civilizations acquired the traits derived from the pastoral state; and further, an important contrast between the fundamental principles of family ethics and the fundamental principles of social ethics, indicating the evils which arise from confusing the two.

New YORK, March 2, 1877 .

My DEAR SPencer: I have given a note to Mr. E. McClintock, of Milwaukee, for yourself. $\mathrm{He}$ is a very nice fellow, a profound mathematician, and stands very high in the Northwest. His business is that of an insurance actuary, and his head has broken down so that he has had to stop. I think he was anxious to speak to you, but was very modest about it.

A prejudice is growing up against me as a great fighter. I am inclined to stop the controversial policy, and let things shift for themselves, as it is less and less matter how they go.

The outlook is not clear. As an illustration of how flat the book trade has been for the past six months, I may mention that my five per cent on the International Series yields me but three hundred dollars for the lot. But now that we have a usurper foisted into the presidential chair by sheer political trickery we may hope for more prosperity.

ARDTONish Tower, September 9, 1877 .

My dear Youmans: I start south on next Thursday, and expect to be in town next day. The last week has been doing me great good. 
I was amused by the applause of the Comtists. It is droll to see them taking the proof that religions have all arisen from ancestor worship as justification of the "religion of humanity." Hereafter I shall have to point out how odd it is that Comte should have proposed a rehabilitation of ancestor worship at the very time when our emancipation from it is becoming tolerably complete!

I was not sorry either to see them defending Noyes \& Co. against me. It will serve usefully to bring out the contrast.

Ever yours,

Herbert Spencer.

38 QUEEN'S Gardens, London, October $12,1877$.

DeAr Brother: The weather has been fine since my arrival, unusually dry and bracing for London, and I have both enjoyed it and improved by it. I have been out a good deal, walked much, and driven some in the omnibus, and altogether I feel a great deal better for the experience. The stir and action was what I needed, and it comes now in the best shape, as I make all my excursions with some object.

Mr. Spencer, I think, looks extremely well, but he cannot keep steadily at his work. It is probable that slight circumstances derange him now more than formerly. He talks of the possibility of his not being able to get through with his enterprise, and proposes to outline some important feature of his Principles of Morality at odd times, so that this most important portion of his work shall not be left blank in case of a breakdown. $\mathrm{He}$ is going very thoroughly through the Study of Sociology, revising it with a view to style, proposing to make it his most perfect work in this respect. It is funny that a volume which I bullied him into preparing should be chosen for this honour. It is interesting to look over the volume and see what thorough work he is making with it; every page is blackened with erasures and slashings. 
London, October $18,1877$.

MY DEAR WIFE: I have now been here a week and two days. It seems as if it had been two months. As I wrote to Jay, I am very glad I came. It was important for business reasons, and it has afforded the break I needed, or at all events the test of my condition, which it was important I should have. And it turns out that there was a pretty bad state of physical deterioration and lack of vigour. A cold fastened upon me at first, and I have not been able to throw it off. I am better of it, but it hangs about me and almost unfits me for anything.

I have not seen the Tyndalls yet, as they have been out of town and will not return till the last of next week. I went with Mr. Spencer to the Huxleys' last Sunday evening, and we had a very quiet hour and a half, there being nobody there. They asked particularly after you, and Mrs. Huxley referred repeatedly to the lunch you gave her.

Went down to King's, at Epping. I was miserable, and could hardly get through it (and here comes Spencer, who has taken up my case and is heading me off in everything and fights my doing anything; and he says: "What! is not one sheet enough? I never saw anything like it. No wonder you are so pale and miserable! you don't know what rest means.") The Huxley family is all well grown, and they are very cosy. Huxley says he is very well, but he does not look it. I have assigned a fortnight from today on which to sail (in the Germanic), and shall probably do so, but Spencer is strongly opposed to it, and insists very emphatically on my staying.

London, October 29, 1877 .

Dear Sister: Nothing remains but to write, and there is little to write of but personal experiences. These are monotonously varied. On Friday I felt a little aching in my right wrist in writing; on Saturday it became very painful to write. Saturday evening my arm became in- 
tensely painful, and I began to grow anxious. I went to bed, but did not sleep much, as my arm was never free from pain. Sunday morning I was pretty badly off, and was thoroughly scared. It was so much like the old attack of inflammatory rheumatism I had in my forearm at Saratoga that I began to contemplate another siege. I could dress myself only with great difficulty, doing everything with my left hand. My right wrist was much swollen, and it pained me acutely to touch it. Spencer was in a great fume. Lord, how he did give it to me at breakfast! It was Sunday, and the day was splendid. He forbade my going out. We were to dine at Busk's in the evening, and that I had to give up. After preaching till he was tired about my imprudence, etc., he went out to a druggist's and had some liniment made, brought it in, and called "Jeames," the waiter, who came. Then he told me to "take off my coat," which with "Jeames's" help I did, and it nearly killed me. Then the servant was ordered to rub my arm with the liniment. The brute went at it and nearly killed me. It was horribly excruciating, but he kept at it, rubbing around the sore place, and finally I took it up myself, and by very gentle friction at first I was able, after a time, to increase the friction, and in an hour the acute pain was all gone. I repeated the process half a dozen times, and in the evening was nearly all right again. While in the morning I could hardly bend my fingers, at night I could grasp firmly with my hand. I slept well; and, although the wrist is stiff and somewhat sore this morning, I write with only a little aching. The sweliing, however, is not quite all gone yet. It is raining like great guns, and I am again forbidden to go out. It is just as well. This sitting in the house and doing nothing is a great thing, and I think is doing me much good.

Spencer went to Busk's, and put his dressing-gown on me over my coat before he left, and covered my pate with 
his smoking-cap, and so I snoozed by the fire. I shall have to abate my ambition to do things, and take it easier in this wretched November till I can get out of it. . . . Charles Peirce isn't read much on this side. Clifford, however, says he is the greatest living logician, and the second man since Aristotle who has added to the subject something material, the other man being George Boole, author of The Laws of Thought. Clifford is in miserable health.

\section{November 5, 1877.}

My DEAR Sister: Yesterday morning Spencer asked me if I would go over to see the Leweses in the afternoon, as they were recently back from the country. So I went. Coming back, he said he didn't go to Leweses any more on Sunday unless to take a friend, but he lunched there not infrequently, and they had it all to themselves without interruption. There was not only great cordiality, but profound respect and admiration for Spencer on the part of the Leweses. I enjoyed it. I was more at my ease than before, and could study them. They both look immensely older, but are both intellectually strong. She is mortal homely, but very attractive from the brightness of her face when talking. She speaks, however, too deliberately, with too studied an air, and almost a dash of self-consciousness. The conversation was light, and did not run into discussion. Mrs. Lewes asked after you and your work in regard to children, expressing a hearty commendation of it, and saying she had seen your Botany and it interested her-all of which, bear in mind, she certainly never got from me. A sister of Lady Amberley came in with her husband, a Mr. Howard, who will be an earl in a short time, and presently we left. Spencer went to the club and I went to Huxley's last evening.

Soon after his return to America he paid a visit to a newly married niece at her home in Connecticut, 
and upon getting home again to New York he wrote her the following characteristic epistle:

NEW YORK, January 13, 1878 .

My DEAR NiECE: It was both jolly and queer to find you "settled," for it is only the other day that I saw you brought out of the bedroom fresh, ruddy, and squalling, when you at once became official rag baby for the neighbourhood. It seems about six weeks ago, and now you are at the head of a concern yourself, and will be a grandmother long before the century is out. So it did seem funny to see you ruling an establishment on the Naugatuck under an assumed name.

Yet I greatly enjoyed the visit, for, although it was a sort of milestone showing how fast life is spinning away, I did not allow this reflection to trouble me, but rather drew encouragement from it that I am getting pretty nearly through. ...

I was glad to see that you had not gone through the cooking school in vain. Stick to the subject; keep at it. I tell you that cooking and housekeeping make up the one satisfying, happifying, and ever-paying thing for a woman. Study it; practice it; improve it ; and make some one point ahead at least every three days. The range plays a better music than the piano, as time will show.

Few men realized so thoroughly and constantly as Youmans to how vast an extent the physical, intellectual, and moral elevation of mankind is going to be effected by the simple, obscure, and unambitious achievement of making the home comfortable and pleasant. Upon current political matters his judgment was equally sound, and the relations between cause and effect were quite clear to him. 
NEW YoRk, January 8, 1878 .

My dear Spencer: Times are still tight. The promise of revived business which was made in autumn has not been kept. To me things now look worse than ever. The collapse that you feared would come crashing after the war was escaped, but I fear the essential difficulty was only postponed. The people have now leisure to contemplate the stupendous rottenness of the whole greenback war policy, by which they were sold to the speculators of the world and buried under an avalanche of indebtedness.

The spirit of repudiation is rife among the people, and in some places rampant and unchecked. How much soundness remains in American financial feeling will be tested by the result of the present tremendous effort to pay off the national bonds in depreciated silver. Hence the continued depression and prostration of business and the harvest of bankruptcies and defalcations, in which the element of fraud is so frequent and prominent as to cause widespread alarm. There is continued inquiry about your books, and I yesterday sent a letter to the West replying to questions about new editions. People are very ignorant, and there is no end to the work of explanation.

March 8, 1878 .

Our country has entered upon the course of deliberate repudiation. This is what I could not have believed possible, for I have always believed that, whatever else were let go, the Americans would have maintained their trading integrity on the simple ground of self-interest. You will have in the Pall Mall Gazette of to-day the intelligence of the passage of the Silver bill over the President's veto.* When the veto message was read there was not a solitary man in the House or in the Senate to say a good word for

* The reference is to the infamous Bland bill. 
it, which is wholly unprecedented in the history of such transactions, and, moreover, gives the clue to the present wretched situation. The President has not a friend in either party. He was swindled into his place, and everybody knows it - a fact which strips him of all real weight and influence. The consequence has been a sort of demoralization of parties which has made it possible for the wealthy mining interests of the West to enter the field and carry all before them. Had Tilden been inaugurated there would not have been the shadow of a chance of the present scandalous result. He would have wielded his party with its strong majority in the House, so that the question of paying our bonds in depreciated currency would not even have been opened. But with the imbecility of the Administration and the chaotic condition of parties that has come from it the measure was rushed through with as much favour on one side as on the other.

As for myself, I am just now pretty well, but have not been worth much for some time back. I am fortunate in one thing: my brother is very efficient ; and as he acquires experience and confidence, he gives me great relief. $\mathrm{He}$ takes the brunt of the Monthly, and is helping vigorously on the Cyclopædia, which goes slowly, but is still moving.

I have recently taken up my violin $\nmid$ for the first time in a systematic way. I got a teacher-a young GermanAmerican-a trained and skilful player, who knows the thing through and through, and is as stupid as a brute in all that pertains to teaching. So I have the double absorption of mechanical practice and picking explanations out

$\dagger \mathrm{Mr}$. Spencer, in his anxiety for his friend's health some time previous to this, had sought out and presented to Mr. Youmans an excellent old English fiddle, believed to be the work of the famous maker the elder Foster. It did, indeed, afford him some diversion, and revived pleasant early associations. The instrument is greatly prized by a favourite nephew, to whom it was bequeathed, and who has made considerable progress in music, in accordance with his uncle's wish. 
of the teacher. He takes pupils, and follows the business of instruction, and is strong in his blind and absurd rules, so that I have made good proficiency in his hands. Unfortunately, bad habits being worse than no habits, and not being very plastic myself, I get on slowly, but have recovered some of the facility in execution which I had thirty years ago, and am making practice already a source of considerable amusement. My only difficulty is that I cannot get the time needed.

Your papers have been received with general expressions of interest and commendation, but there have been no notices so full as to be worth sending. Peirce (of the Logic, you know) was so pleased with the article on Trophies that he bought the whole set of Descriptive Sociologies. 
CHAPTER XVI.

WINTER IN THE RIVIERA.

1878-1879. Age 57-58.

IT is evident that by $1878 \mathrm{Mr}$. Youmans's vital power had been diminished far more than I realized at the time. He was not wont to complain or to talk much about his ailments, and that glorious vigour of emphasis which was the outcome of his whole-souled enthusiasm never flagged. It was difficult to associate such a voice and such energy with anything short of giant strength. I remember once mentioning to Mr. Spencer that I had lately found Youmans in fine condition; but when Spencer, in his next letter, reported this to Youmans with congratulations, our friend tersely replied, "If Fiske thought I was well it was because he mistook noise for health."

It was in the autumn of I878 that I first noticed in that face, usually so bright and beaming, a weary and haggard look which gave me some anxiety. Too many labours and cares, prolonged with little or no respite, were doing their work. This led Spencer to insist upon Youmans joining him in a vacation journey in the south of France. How they fared will appear in the course of the following correspondence:

38 Queen's Gardens, Bayswater, London, July 22, 1878 .

My DEAR Youmans: I have seen a good deal of Prof. Marsh while he has been over here, and had the opportunity 
of showing him some civility by asking him to join a picnic at Weybridge that I gave this year to some dozen or more friends (as I did also last year). He seemed to enjoy it much, and is, as I gather, enjoying his stay here greatly. $\mathrm{He}$ is evidently doing very careful work in the preparation of his monographs on these fossil types and promises to do good service for us.

How are you bearing the heat? I see from the accounts that in America people have been suffering greatly. You ought to get away to some bracing seaside place, and both escape the heat and take some rest, lolling about on the sands and cultivating idleness. There is one part of culture which it seems to me you have not duly regarded and which I commend to you, namely, the culture of passive receptivity in respect of surrounding impressions-that kind of mood of mind which takes its enjoyment in lying on the grass on a sunny day looking up through the trees.

If you happen to get hold of a newly published work entitled The People of Turkey, by a Consul's Daughter, you will find in Volume II, pages 200-202, a passage that will interest you. It gives an account of a school established and carried on by an intelligent Greek who, educated in Germany, is founding his system of teaching upon my books; and you will find it stated that his methods, having proved successful, "will eventually be adopted in all the educational establishments of the Greeks." It is curious to find that people in Greece, as well as in Russia, both of which places we regard as in so uncivilized a state, are showing themselves so much more receptive than Western people.

You do not say anything about coming over to the meetings of the association. Depend upon it, a sea voyage would, as before, do you a great deal of good, and probably be in the end an economy of time. 
38 Queen's Gardexs, Bayswater, London, W., September 27,1878 .

I wish I could make you more fully realize the fact than you generally do that care for health and the relaxation needed to put yourself in better state are really demanded by regard for your work, and that you will in the long run be able to do much more in discharging your obligations if you do not persist in working when ill than if you do persist. In fact, it seems to me that now you are running considerable risk of failing altogether to do what you have undertaken to do, as well as bringing upon yourself other evils, and that regard for the interests of the Appletons, as well as your own interests, should make you decide upon taking a good holiday. Pray come over here as soon as you can, and after spending a month with me here, which would give you the opportunity of looking after various matters, you might then accompany me for a couple of months to the shores of the Mediterranean.

If you could make up your mind to come with me and do a little idiing in pleasant places, I am convinced that you would find it in the long run a great economy of time. As to not seeing how such things are possible, I hold it to be an instance of the absurd fanaticisms of men like yourself who think that the one thing impossible is to let business go by default, and that the only thing possible is to sacrifice health and life to it.

38 Queen's Gardens, Bayswater, London, W., October $10,1878$.

My DEAR Youmans: I am looking forward with some anxiety to the receipt of a letter from you, which I suppose cannot now be much longer delayed.

Pray yield to my pressure, and to the pressure which I doubt not others also put upon you. You have always on past occasions been glad that you came over, and if you act upon the induction, which you may reasonably do, you may conclude that you will afterward be glad if you come 
over now. My going abroad will very much be determined by your answer. It is quite out of the question for me to go alone, for I am convinced, judging from past experience, that if I did go I should be in a short time so weary of my solitary state, relieved only by my work and walking about, that I should shortly come back again. With you, however, it would be different. I should enjoy the journey much, and, I doubt not, derive great benefit from it.

You will see that the Academy says that I am going to Algiers, but this is a mistake. Algiers has been one of the places I have talked about and which it appears has been remembered by the gossips who circulate and publish these statements; but I have decided in favour of the south of France, moving along the Mediterranean shore from place to place, from Marseilles to Nice and Mentone.

Pray come and join me. For once in your life resolve to take a little pleasure and relaxation. You have not so very great a length of life left that you can with wisdom put it off. You should remember that you have not only got to do your work, but you have got to live; and ever since I have known you you have been thinking only of the work and never of the living.

New YoRk, November 15,1878 .

My DEAR Spencer: I have decided to spare two months to be with you, and this is also the amount of time that you proposed to me to spend in France. When I got your last letter I at first thought I would telegraph you and then take the first ship; but I did not know when you would be prepared to leave, and it might be some time yet. If you wish to leave London before the holidays, telegraph me as soon as this comes. In that case I shall try to take the Germanic, December 7 th.

I must, however, say again, that I am in a miserable condition for such an expedition, and will probably give you as much occupation in dragging me around as you 
will want. It will certainly alleviate your monotony, if that is the main thing. I will try not to bore you with the matters that are occupying my own mind, and which I shall hope to forward somewhat by this break and cutting loose from other things. There is a good deal of such talk over here as Bob Lowe has given utterance to in the last Contemporary about sociology, and it must be met. Moreover, it is the coming subject, and an important one to prepare for. I have not much more work in me, but I would like to direct the remnant that way, and shall want to ask you a lot of questions. Nothing but the desire to be in some way useful to yourself in promoting your work, and at the same time of helping myself in the way proposed, would induce me to encounter another winter passage across the Atlantic. But I will be ready when I hear from you.

New York, December 3, 1878 .

My dear Spencer: I got your peremptory dispatch on Friday, and immediately set about making arrangements to comply with it. No ship at all encouraging for this season was going immediately, and the best I could do was to take passage in the Germanic for Saturday next (December 7 th), which I hinted to you in a telegram yesterday.

The death of Mr. Lewes is announced; was it not unexpected? I know he has not been in very good health, but I supposed he had learned to take care of himself, and being not old, I have been accustomed to think that he would be good for another decade.

In her own low condition of health, the loss of her husband must be very severely felt by Mrs. Lewes.

Steamship Germanic, December 16,1878 .

Dear Brother: . . . Near Liverpool-nobody knows how near-supposed to be about five miles off, at anchor in a dense fog. Should have landed at seven o'clock. The sun shines brightly, and I suppose the fog is perhaps thirty 
or forty feet deep, but it is as thick as pea soup, and we can't see ten feet from the ship. No wind and no prospect of change. The express we calculated on taking leaves at eleven. Everybody was up early, but some have gone back to bed, and some to their cards, and many are profaning on deck. I telegraphed Spencer from Queenstown, "Due Tuesday afternoon in London." Impossible. Vicissitudes of travel.

London, December 18,1878 .

DEAR Sister: I got off at Liverpool at half past one; got through the customhouse at ten minutes of two; got to Lime Street Station at two; got the train with not a second to spare, and got into London at half past eight, the train being an hour behind time. Spencer met me at the door. He is very well, and was ready to start on the instant for the Continent. Everything was ready, tickets taken through, circular notes procured, etc. . . . We shall be off at nine to-morrow morning by Dover and Calais to Paris, where we spend one day, and then take the night train for Marseilles, and that is all I know. I expect it will be two months to a day, and he proposes to spend about a week in a place. Miss Shickle is to send his post to him, so in future you will write to me here, directing 37 Queen's Gardens, and no time will be lost or extra expense in early sending through Layton. ... I shall be put through like anything, but I guess it will do me good. I have no time to write another line. Love to all.

London, December 20, 1878 .

DEAR Sister: We started two hours ago from 37, wrapped and packed as if we were going to Greenland. It was as dark as midnight, the gas being lit in the streets, and even then we could hardly get round. I am now writing in the Charing Cross Station, with one gas burner about seven feet above me, and the room is so dark the people can scarcely be seen. We were to take the train 
for Folkestone and Boulogne at 10.30. Got here, and found it leaves at r.40. Spencer had erred a week in his consultation of the tables. He came all the way over here to get a revised table, and then read it wrong. He has a cold and a little sore throat, and slept last night with a respirator on, by which he breathes through a mass of wire gauze like a regenerator in a caloric engine. He wears it all the time now. He was awfully cut up about the stupidity of his proceeding, which will work in my favour in future. It is quite providential. He was not disposed to leave me alone here for three hours, but I just bullied him to go to the Athenæum Club, which is close by, and toast his shins by a warm fire, get a good hot lunch, and then come here just in time to leave. We get into Paris at I I.20 P. M. Baillière, Alglave, and Ribot are to breakfast with us to-morrow morning, and Ribot has engaged places for to-morrow night's train for Marseilles. I groped my way over to Macmillan's, got the last number of Nature, and a phrase book for French. Then went to Williams \& Norgate, and had a good chat with Williams, who is a very nice man, and has Spencer's books in special charge. He spoke very warmly about my coming, and said it was of great moment to Spencer, whose whole trouble is with his spirits. I have something very interesting to say to you about his forthcoming work, but must postpone it now.

\section{Hyères, France, December 24, 1878.}

Dear Sister: I said I should write a history of our tour, but it will never be written, because such experiences as we have had cannot be written. The Mediterranean was a priori to Spencer, and I hope all his philosophy is not like it, for results do not accord with predictions. We had a great time getting here, our two portmanteaus costing us more trouble than we could get in America out of the movement of ten trunks to Winona; we were chasing and waiting for parties who could not understand us at Bou- 
logne, Paris, Lyons, Toulon, and this place (pronounced He-air!). We have been freezing to death all the way from London, but hoping constantly for the land of warmth, and we haven't found it yet. There are orange trees loaded with uneatable oranges, and there are palms, olives, and numberless tropical fruits, but it is as cold as Greenland still; it don't feel like a tropical country.

It is a poor country supported by English visitors. The hotel is called "Le Grand Hotel des Iles d'Or" (Isles of Gold). That is, you climb a hill behind through a garden, and thence see some islands of the Mediterranean, which are about three miles off. So the hotel takes its name from the isles. ... We are resting, giving the animal a chance. Spencer will let me do nothing but walk and eat. Can't read or write. Have to steal moments to write letters, and hence haven't written much. $\mathrm{He}$ is working like ten horses in quest of what he came for-relaxation! So we walked two hours this afternoon on the piazza, seventeen feet long and ten feet wide, passing each other at every turn. Lord, how the people stared! But Spencer didn't care, and I am sure I shall never see them again.

\section{Friday, December 27th.}

The morning is pleasanter; it has stopped raining; and now we shall have to start through the mud in quest of the "rest" we are after. Spencer is the same and not the same; his qualities abide, but they grow; while not relaxing a jot of his theoretic laissez faire, he is still more irritably denunciatory of people doing as they can and may. $\mathrm{He}$ meddles with me, and interferes with me, and criticises me, and takes care of me, all for my good, of course, in the most assiduous manner. I am beginning to count on momentary escape from his vigilance to do a little writing or reading.-At this point he came for a walk, "a slight ramble of half an hour." It was very wet and muddy, but we rambled through the lanes and alleys, up and around 
the side of the mountain behind us, climbing for an hour, steady pull. Then he struck off into an obscure path that promised more direct descent. We lost the path, and lost our way, and had to plunge down a steep, broken, rocky, muddy side of the great hill full of gorges and deep channels. It was an old olize orchard, old and half dead; the trees are about the size of apple trees, and their tops look as if covered with sage leaves. We got back after a two hours' tramp, and I was quite used up. Then we had "breakfast" at twelve o'clock. Then another tramp of twenty minutes, at the end of which I back out. He has gone on, but will be back for me to get another pull before dinner. This is the history now', with nothing for diversion but to hear these Englishmen quarrel over the comparative merits of the different stopping places along the coast and the different hotels. There is nothing of interest in it all to me, except so far as it may become promotive of hygienic advantage to Spencer and myself. $\mathrm{He}$ professes great benefit already, boasting of eight hours' sleep the three previous nights each, and he falls asleep almost every time he sits down. He slept nearly all the time in the cars, and is evidently making up for his past losses. If nothing happens, it will undoubtedly do him great good.

... I promised to write of his Morals, which is to be a great thing, of course, though I have not seen it. Four chapters are in type, and all is done, or mostly done, but the last three chapters of the Data of Ethics. He will publish it in a volume in April! I judge that it is to be immense, from the titles of his chapters which he has rehearsed to me. He is now revising the first four chapters, but will not let me see them till they are all corrected and all together, which it will take two or three weeks to bring about. It will now begin to be seen what "evolution" is for, and I find the main reason why he has jumped over to ethics is that people had got tired of waiting for some I6 
result, and the ethical writers-mainly Sidgwick, of Cambridge-have said, "After all, morality is found to have nothing to do with evolution." $I$ can begin to see that it does, and how it does. ... Here comes Spencer, bullying me for writing, and I tell him this is the last letter I will write in the next seven weeks.

Hỳ̀res, France, December $3^{I}, 1878$.

It is the last day of the year, our last day in this place. We shall leave to-morrow for Cannes fifty miles distant, and what it will turn out to be I neither know nor care, so we get away from here. One Englishman said last night, "This is a beastly, stinking hole," which is an accurate description of the place. . . . I slept but little last night, owing to the mosquitoes, which are abundant, and fiercer than at home. It is still rainy, cloudy, and muddy, so as to make going out a misery; yet we go out vigorously and regularly and with long pulls. I hope in the coming places we shall have better walking, but come what will, there is to be but seven weeks more of it. And when we shall have had a week's experience each of seven more "beastly, stinking holes," I shall have had enough of this region. "Knowest thou the land?" Certainly I do-all I want to. We go this afternoon three miles to the seaside by rail, and back on foot, to see some Roman antiquities !!!

I have packed, and it is no small job; ready to move to-morrow. And we leave a sad lot at the Hotel of the Golden Isles-all consumptive, or attending upon somebody who has consumption. I have not seen the first case of anybody who came here for pleasure alone.... We have had our last dig through the mud of this miserable region, wandering here and there in search of a dryer place, and always finding a worse one. But $I$ think there is virtue in the exertion. It seems to me $I$ am better for it; and Spencer insists that I am growing stronger, but he is interested in bulling this Mediterranean stock. Spencer 
has received no letters in five days, and he is greatly excited at somebody's derelictions. I have heard nothing yet, but suppose it is not time, and there is probably nothing to hear. When I get to Cannes, if the circumstances allow it, I expect to begin work, in subordination, however, to my picking-up errand. Spencer is very well. This agrees with him. He likes to walk and to talk and to teach, and will sit down in the wet anywhere, and at any time, to give an explanation. $\mathrm{He}$ is a good teacher, but it is late-the last of 1878 -late to be still taking lessons.

\section{Cannes, France, January 2, 1879 .}

Dear Sister: We left Hyères New Year's morning, at 10.45, for this place, stopping at Toulon an hour to wait for the Nice train, and got breakfast at 12.30 at a common, cheap café. It was a new expcrience, and interesting. Everything was clean, and the cooking was excellent. The provision was doubly abundant. First, cold ham, bread and butter; second, free wine; third, fish; fourth, a chop with beans (pods); fifth, beefsteak pudding; sixth, meringue; seventh, Roquefort cheese and fruit. Price, 2 francs.

We got into Cannes a little after four o'clock; it had a different air from."He-air." It is a rich, prosperous watering place-a kind of Saratoga on a side hill. We passed along the Mediterranean coast some distance, shooting through gorges and tunnels as the ridges ran down to the water. The rocks are old red, and the shore is broken, indented with bluff, picturesque rocks.

Spencer had telegraphed for rooms at the Hotel Mont Fleury (Hotel of the Flowery Mountain). We were the sole passengers in its omnibus. We started, and went a mile straight through a narrow street, very narrow, level, and unattractive. This flat part of the town is broken up into patches with chateaus surrounded by trees and low walls. People may look in, but they must be kept out. Then we 
began to rise, and when we had got up twenty feet there was a big hotel (Congress). We went round the end of it and up fifteen or twenty feet higher, and then round the end of another hotel (States), then round that; up another little hitch, back farther to the Hotel of the Flowery Mountain. Altogether there is about as much mountain as Chester Hill. As soon as we had got up Spencer proposed we should go to the poste restante for letters; so we started back on foot, and found the mud worse than at "He-air." It was an awful pull. No letters; and when I got back I was so used up I could hardly get to the room. Table d'hôte at 6.30. A small sally mangy for so large a house. which is full, though there seems to be nobody in it-no piazzas, areas, parlours, or places of parade. We were awfully jammed at table, and nearly suffocated from the closeness of the room.-At this point Spencer comes to start out back of the house up to whatever we may find, ... It grew steeper, and we wandered round for an hour up muddy, long roads and paths to the summit, which gives a fine view of the town beneath and the bay, as well as of some distant mountains. The scenery is fine and clear, and the air mild and very pleasant. . . The place is quiet, and both Spencer and myself slept well last night, having mosquito nets which were effectual-the first time, Spencer says, he ever slept under one.-Back again from another pull. This time it has been through the town, but it is all the same. The mistral to-day has dried the mud, and the walking is better, but I am utterly tired out. It would seem as though this would either kill or cure. I am abundantly conscious of the stupidity of all I have been writing, but there seems nothing else to say or talk about.

Spencer pegs away at his revising an hour or two a day, but is greatly and continuously disgusted at not getting letters, having had but one or two in a week from England. As anything written within ten days after I started 
would be here by this time, I conclude nothing was written, and it is a satisfaction to think there was no occasion for it. Prices here are frightful. I told Spencer his frolic would turn out expensive. He replied, "It would merely make so much less to be left and spent on the Descriptive Sociology "-with which he is evidently getting tired.

\section{Cannes, France, January 7 or 8, 1879 .}

We have now been a week in Cannes, and leave here tomorrow. We have had five beautiful days here that have been both enjoyable and profitable. I am undergoing a sharp discipline; and what between a revolutionized diet, cessation of smoking, and triple my former exercise, I ought to pick up.-At this point I was meddled with by my laissezfaire friend, and now resume at Nice. And it would take a big book to tell it all. It is now Wednesday, and I should think must be the roth. We started yesterday morning from Cannes, and got to Nice in an hour. . . .

I had a fire in my room last night, but could not get warm till toward morning. Routed at eight as usual, but, thank Goodness! it rains so hard we can't go out. So we have fires in our respective rooms, and Spencer has just been in to show me how to bring the table round close to the little fireplace, and then put one side of the rug in the chair and wrap it round my legs, so as not to utterly freeze to death before the fire.

I spoke to you about Spencer's new work, The Data of Ethics. I have not seen it yet, as the corrections of the first four chapters have not come. But I have got the titles of the chapters, and now send them. When they are published the question will cease to be asked, "What has evolution to do with morality?"

This is the first systematic, scientific treatment of ethics, and its effect will be to rank morality with the sciences, to give it the intrinsic authority of science, and to vindicate evolution against the sceptical cui bono. 
Nice, France, January 13, 1879.

Dear Father and Mother:... To-day has been very fine. I had a long walk in the morning, and another this afternoon. Mr. Spencer went off by rail to Mentone to-day to reconnoitre for a place, as we propose not to jump in again so suddenly. I took advantage of his absence to write an editorial, which I mail to Jay to-day. I shall try and squeeze out another in time for the March Monthly....

Mentone, January 27, 1879.

DeAR Sister: ... I have not seen a paper from the United States these three weeks, and am therefore in the dark as to weather there-as well as everything else. But perhaps it is best; as, if there were home news, I should inevitably be reading it, and my eyes are very bad. Spencer doctors them often and vigorously, but the muscular tone is low, and is kept so low by the depressing weather that congestion continues. If the weather should clear up I think it would find me better. I use my eyes the least possible, and read but very little. Nor do I write much, but jot down various things. If we could have bright, exhilarating weather, I should be able to get some things in shape soon to use. Since Spencer has commenced working with my eyes and begins really to find out in how bad a state the left eye is, he is very vehement against my reading at all, or even writing. He says: "I never saw a person subject to such changes of aspect; sometimes your face looks coloured and healthy, and at other times pale, flabby, and haggard; and from what I can see it is reading that makes the change. It is clear to me that you will have to stop writing and go to lecturing." - At this point he came, and we had an hour and a half of digging through the mud.

As for leaving, I am ready and anxious, but Spencer resists it, saying he is not coming down here for nothing. 
We don't talk much about it, but he is determined to have his time out, and thinks it will be best for me to stick to it also, and I should agree with him if the weather were favourable for improvement.

I have now quite given up hearing anything from home, and content myself with the consciousness that no news is good news.

Mentone, January $30,1879$.

My DEAR Mother: It is a magnificent morning, but I am so tired from yesterday's jaunt that I shall not go out with Spencer to tramp ; and although I am writing but little, and not reading at all, I will use the interval to send you a few words.

The weather has changed, the clouds are gone, and now everybody begins to cry out from the heat. And at midday it is tremendous-that is, the sun has, immense power, and in walking one sweats as if mowing. We went on a four hours' tramp yesterday afternoon. The first three hours I suffered much from the heat, but at four o'clock the sun went behind the clouds, and the temperature dropped instanter, so that the cold penetrated and chilled me despite all efforts at brisk walking, and I, moreover, got a cold, which kept me coughing during the night. We have to exercise great care here from the extremes of the weather; not that they are greater than at home, but that we are easier thrown off our guard. We yesterday clambered up a mountain to an old village of stone houses, with narrow, steep streets, and everything tumbling down, so that it looked as if people could not possibly stay in it. The village is probably fifteen hundred years old, if not more, was built by the Romans, and occupied by the Saracens, who ravaged all this coast. There are the remains of an old ruined, tumble-down castle, which many people come up to visit, but it did not interest me. The squalor and wretchedness of the inhabitants, however, was dreadful, and yet in the midst of it there was a Catholic church all gilt 
and decked out in great style. All the ground hereabout is terraced, and in many places the dirt is brought in to make rooting for vines and other plants. Water is their great trouble; it is saved everywhere, in stone tanks of all sizes, and every little trickling rill is led along a stone water course to where it can be made useful for irrigation. The steep hills are all worked up in this way; the necessities of a poor population for probably thousands of years continually having led to the utilization of every foot. But what I meant to say to you and pa, when I sat down, was that you must look out for the cold especially in the mornings, when the pulse is lowest. Be careful of exposure, and take a little stimulus every morning before you get out of bed. February and March are trying months, and people's brains are given them to take care with.

Mentone, February 4, 1879.

DEAR SISTER: Last night there came four of your letters of December I9th, $23 \mathrm{~d}, 27^{\mathrm{th}}$, and 3 Ist, two later ones having been received three or four days ago when I wrote you last. ...

I am getting up an appetite for exercise, and regret that it is raining to-day, so that $I$ have to keep indoors. Yesterday morning we walked an hour and a half, part way up hill; and in the afternoon we took a tramp to a monastery on a distant eminence, with a good deal of steep climbing. It was a two hours' pull, and I kept up and came out of it not at all used up. It is my improvement in this which makes Spencer think if I would follow his directions in all things implicitly I would be born again. . . Spencer will not budge from here till the time is up, and gets angry if I propose going before. He also insists that I should stop a month in London, and have not less than a three months' break. Hearing nothing, and not being stirred up with home difficulties, I have been inclined to listen to his syren song, and hurry nothing. But 
your letter dissipates the illusion, and I must get back to work as promptly as possible. What a year of continuous outdoor life and activity, and total abstinence from books, might do for my eyes I can't say; it would no doubt improve them, at any rate.

\section{London, March 1, 1879 .}

DEAR BRoThER: I wrote and sent out to be posted for Thursday's mail an editorial to go first in the April Monthly. I now send a review of Bain's new book.

You will thus eke out another month. I have not heard whether the Germanic has arrived, but presume she has, and that she will go Thursday, and at all events I expect to leave here Wednesday afternoon for Liverpool. The weather continues simply detestable, and I have been feeling very sharply the effects of it; but it is a little better to-day, and I feel it decidedly. I have been bothered to snatch intervals to get these things done, for Spencer watches me constantly and will listen to nothing. He does not know that I have written anything for the Monthly.

\section{Steamer Germanic, March 7, 1879.}

My dear Spencer: I had a pleasant ride to Liverpool on time, with a lively, fresh companion, a Methodist, who vigorously undertook my conversion. He began thus: "If we smash up, sir, are you insured-I don't mean in the accident company, but in the Grand Salvation Insurance Company? No? Then I have the advantage of you; I took out a policy twenty years ago." I told him there was a great deal of bogus insurance nowadays, and gave him the history of my father's experience in being swindled by a fraudulent fire insurance company, and then put it to him as a necessary business precaution that the validity of the corporation and the soundness of the transaction should be looked into. Being a business man he saw the point, and I had a great deal of fun with him. 
New York, March $18,1879$.

MY DEAR SPENCER: I am back again safe, sound, and satisfied. My return was even finer than my passage over, the sea being like a lake the whole distance.

I find all well here and enjoying the opening of the spring. The sky is clear and the sun bright, although it is still cold. My brother has improved a great deal as a consequence of taking responsibility, and I mean he shall get still further benefit from it. I found the Appletons in a very pleasant mood, but have not yet had time to broach business. There are many things to attend to, some of which have been neglected.

NEw York, June 3, 1879 .

My DEAR Spencer: To-day rounds me up to fiftyeight, and I am making a holiday of it, which gives quite a new sensation. It amounts to little practically, as I am good for nothing to work anyway, being again crippled, confined, and suffering a good deal of pain by a rheumatic relapse of my right foot. I had been better for some days so that I could get about comfortably, though unable to wear an ordinary shoe.

The Chicago Times printed my reply to Van Buren Denslow and I sent you a copy.

You are of course aware before this of the "strike" Fiske has made with his new lectures in Boston, and which has led to a repetition in London. If he succeeds there it will be a great card for him.

38 Queen's Gardens, Bayswater, W., June 20,1879 .

MY DEAR YOUMANS: That was a capital letter of yours in the Chicago paper. The points were all admirably grasped and clearly put. A better expositor I cannot imagine. It is clear to me from this letter, and from all the various things you have from time to time written, that the lectures you have been scheming would be admirably 
adapted to convey general conceptions of the doctrine of evolution to the public mind; and further, that besides putting them so clearly and simply you would make them extremely interesting. It seems to me that you cannot do a better thing than carry out your plans in that direction, and, at any rate for a time, drop other matters. I have no doubt that the better mood of mind that would arise, alike from the different mode of life as well as from the successes that I doubt not would result, would more than anything else conduce to your improved health.

Now that I am not with you and cannot play the bully over you daily, I see you are relapsing into your old malpractices. So far from abiding by the principle of doing all your writing by dictation, you seem to me to be going more in the opposite direction, for the last three letters I have had from you have been in your own hand. However, it is no use saying anything.

LoNDON, July 4, I879.

Fiske's lectures at University College ended satisfactorily, and were greatly applauded at the close. He and Holt and I have had two country excursions, one to Richmond and one to Windsor.

October 1,1879 .

I am glad to find you writing in a more cheerful style, and hope that your more sanguine view of your state will be borne out by the results. I was glad to see in the last number of the Monthly that you are notifying publicly your intention of resuming lecturing. In a certain measure it commits you, and will serve to decide you in favour of that course when otherwise you might hesitate.

I do not see why you should have grown "morbidly timorous about speaking of your [my] views?" So far as I remember, you have always been perfectly correct in your statements, and extremely lucid. Even when it has been a mathematical question you have done extremely well. 
April 19, 1880.

I got this morning the two copies of the New York Times, and read with amusement and satisfaction the account of the row at Yale College that has been produced by the introduction of the Study of Sociology as a textbook. Very probably this local fight will set going a general fight, which will be highly advantageous no doubt.

New YORK, May II, 1880 .

My DEAR SPENCER: Your suggestions regarding the Yale College affair come in the nick of time. I had an editorial in type on the subject which was not very satisfactory, and your hints enabled me to improve it. The Yale College flurry is over, so far as exciting public criticism is concerned, but the antagonism is deep, and will quietly deepen still more.

I am getting sensibly stronger and feeling better, but I am old, sore, and decrepit in my legs and feet. I walk, however, considerably and increasingly, and hope to gain permanently by it. But I suspect an early old age is upon me, and that I must go tottering through my remnant of days.

I am rejoiced to hear that you are not only holding out well but are advancing, so that you can again take hold. Don't you think you can take your vacation next year on the Rocky Mountains? I want to cross the continent very much, but hate to go alone. Meditate upon it. Our claim is at least as good as that of Egypt.

38 Queen's Gardens, Bayswater, London, May 26, 1880.

My dear Youmans: I was glad to have so good an account of you in point of health. By all means keep up your exercise. If you can do that, and increase it little by little, I should think you will gradually get rid of the remnant of mischief arising from your rheumatic affection. 
If, as I suppose, there are deposits and stiffenings, these, providing you do not again bring on an attack, will in course of time, under fit regimen, decrease gradually. Are you thinking of making any lecturing excursion? If you could do it with moderation, and make everything subordinate itself to your physical requirements, it might prove beneficial in all respects; for a little excitement of that kind, being, I have no doubt, to you pleasurable, would benefit your physical state.

Fiske and his wife are coming to lunch with me to-day, and I have asked Masson to meet them. Fiske has given two lectures at the Royal Institution, but I have not heard either. I was out of town when the first was delivered, and yesterday, when the second was delivered, my attendance at an Athenæum committee was imperative. Huxley spoke with praise of the first lecture.

As to coming over to you, I have so much to do, and the three months' absence in Egypt during the winter has retarded me so much, that $I$ cannot think of it at present. I must (after sundry smaller matters are got out of hand) continue the Political Institutions and complete and publish the part before I think of anything in the shape of a long holiday. 


\section{CHAPTER XVII.}

\section{LAST YEARS.}

December, 1880, to January, 1887. Age, 59-65.

DURING the years I880 and I88I Mr. Youmans was working with customary vigour in behalf of international copyright. Questions connected with this subject grew out of his work in Europe ten years before, in establishing the International Scientific Series. In I87 I Mr. W. H. Appleton had taken a decided stand in favour of international copyright, and was powerfully supported and re-enforced by Youmans, who returned to the subject again and again, and did excellent service in arousing and instructing public opinion.

A letter from Tyndall shows that before the end of I 880 the question of Youmans's health was becoming serious :

London, December 29, 1880 .

My dear Youmans: We this day laid the remains of George Eliot in the Highgate Cemetery, and this morning, while I was preparing to join the band of mourners, your letter reached me. A large and reverent crowd surrounded the grave as the coffin, loaded with garlands, was let down into it.

Last night, at Kew, I had a long conversation with Asa Gray regarding the trust, and he, I confess, dissipated a good deal of the fear that I entertained as regards the trouble imposed upon the trustees. Your letter this morn- 
ing comes in the nick of time to confirm my desire to leave the trust in the form originally contemplated. The arrangement you have made is in the highest degree satisfactory.

We did, as you surmise, return from the Alps strong and well. I am glad that you liked the address upon the Sabbath, but I did not know that you would consider it suitable for the pages of The Popular Science Monthly. It is a pleasure to me to see it there, and a still greater pleasure to learn that it is likely to produce a good effect. Longman has published it as a separate pamphlet. An audience of three thousand heard its delivery with marked attention, and, I think I might add, with enthusiasm.

A long letter written with your own hand reached me in Switzerland. One expression in it gave me very deep concern, and that was where you referred to the state of your own health. I trust it is now better, and that for a long time to come you will be able to continue the good work on which you have been hitherto engaged.

Believe me, dear Youmans, yours ever faithfully,

$$
\text { John TYNDall. }
$$

In February, I88 I, in the midst of hard work, there came the sudden blow which after a while was to be attended with fatal results:

\section{New York, April 20, 1881 .}

My dear Spencer: It was ten weeks ago day before yesterday that I was struck with a chill, the result of writing in a cold room, and came down with pneumonia. I was prostrated bodily and mentally from the outset. I grew better, but the stupid nurse washed me with cold water, which brought on a relapse with pleurisy. I got better again and became very smart, so that the doctor began to omit his visits. I was too weak and emaciated to walk or stand, but I could sit up for considerable intervals; but my 
brother, coming down from the West, dropped in, and in the excitement I became exhausted.

The pleuro-pneumonia came on again in an exaggerated form, and I had a hard time with it. I am again much better, but the left lung is in a bad way, and, I fear, threatens long to remain so; but I am free of pain, have a good appetite, am gaining strength, and begin to walk around the room, though with a very tottering step. I was terribly reduced, the first month living chiefly upon brandy. But I am still forbidden to sit up more than half an hour at a time, or to leave the room, or to see anybody, or to talk much, or do anything. But I am hoping that with this abundant experience of the ease of relapse I may be able to guard myself better, and hope to get out of this tiresome place before long. Yet the one mitigating thing is that the weather for the last three months has been terrible, and is still sour cold. Of course, in a business way, the last three months have been a blank.

May 6, 1881 .

I am only now beginning to understand how fast and how far I went down during the first month of my sickness. The recovery is very slow and tedious. I can mark a certain small improvement with each passing week, but I fear it will be a good while yet before I can get out of the house. I am, however, free from pain, have strength to sit up most of the time, and to walk about some, though it seems, whenever I rise, that I weigh a ton. I am able to read considerably and to write some, and this makes life comfortable. I have just helped Jay through his July Monthly, and have quite enjoyed it. I received the proof of your forthcoming article, and Jay wanted me to write something about it; but it is too long and close for me to deal with it now, with but five hours allowed to do it. When I get a little stronger I am going over the whole series carefully, that I may be qualified to say something about it. I re- 
ceived and read with much interest the letters on copyright. Thanks; they will come in play, but I think it would hardly be best to republish them now. I am surprised at the stupid perversity that some of your people display. It is as bad as our open and shameless greed.

37 Queen's Gardens, May zo, 1881 .

My DEAR Youmans: I am glad to get your letter giving me an account of your continued improvement, however slow. I was going to say that I hoped this serious illness will be a warning to you: atways of two things to choose the less dangerous, and not the more dangerous; but I fear that all suggestions of the kind will be futile, for it is not in you to be careful.

I am glad, however, you resisted your brother's suggestion to write some comment upon the last chapter sent. He ought to know better than suggest to you to do anything in the way of work. What you want is some one to suggest the leaving it undone.

New York, May 27 I88I.

My dear Spencer: As regards myself, I am only able to say that, not being worse, I must be better than when I last wrote. My shortness of breath and debility continue, which makes the getting about painful, especially if there is a staircase to be climbed. I, however, go out, and have been to Mount Vernon. The jaunt was exhausting, but I hope it will prove beneficial. While in the country my brother gave me some letters which came during my illness, when I was not in a condition to be disturbed by business.

In one of those letters you explain that your coming chapters will deal with the subject of the Militant and Industrial Types of Government. I consider that the most interesting and the most important part of your series of papers; we cannot get enough of this kind of discussi $n$ for our magazine. There is no salvation for this continent except in the acquirement of some proximately scientific 
conception of the nature of Government. We are without the stability that comes from long habit,* and without àny guidance in the shape of national theory. I am so clear that this is the next subject of supreme public moment that I am glad to devote the Monthly largely to its elucidation.

37 Queen's Gardens, June 13, 1881 .

My DEAR Youmans: I got your last letter some three or four days ago, and regret to hear that you are not gaining strength more rapidly than appears. However, if you are avoiding relapses, that is something; and now that you have, I suppose, favourable weather, we will hope the progress will be more rapid. You ought to stay down in the country and bask in the sun; or, if too hot, then in the shade of a tree. Lounging about in the open air, doing nothing except, if you can, carrying on a lively conversation, is the best thing for you.

* If my old friend were now here at my elbow, he would not merely pardon but would earnestly thank me for pointing out the fallacy in this offhand remark. It is one of those common fallacies into which every thinker and writer is liable to be betrayed, and no one would have acknowledged it more quickly than Youmans. It arises from the prevalent loose fashion of regarding American history as beginning with the Declaration of Independence, or at farthest with the settlement of Jamestown. The fallacy is that a "new people" cannot have old political habits. In point of fact, however, we Americans are not a new people, and we are not "without the stability that comes from long habit." We possess this stability in an extremely high degree, and it is just this ingrained stability of political character, the result of long ages of political habit, that is our chief safeguard against turbulence. What were our forefathers doing at Lewes and Runnymede, or in the days of Henry II and Becket? What were they doing in their open-air assemblies in Friesland and Sleswick before Hengist's keels ploughed the North Sea? They were slowly and surcly building up that stability of political habit by which we, their children, have profited in many a crisis within the memory of living men. Properly to understand the American people and their political acts, one must habitually carry in mind the whole series of ages between Arminius and Cromwell. 
I am glad to see that you take the same view as I do with respect to the supreme importance of true political theory, especially for you in the United States. I do not believe that a true theory will do much good, but one may at any rate say, contrariwise, that an untrue one does a great deal of harm; and at present much mischief is going on among you as a result of untrue theories.

I find myself not adequately acquainted with the state of things in America in respect of some of the traits of industrialism on which I am commenting. When you get the chapter you will probably be able either to give me information bearing on sundry other points, or to indicate some recent books in which I shall get information, so that by the time the volume goes to press I shall be prepared for making the chapter more complete. I presume, from your wishing to have the series continued, that it excites with you some interest, but you have not told me anything about this.

After my experience last year in going to and from Alexandria, on each of which occasions I had a three days' voyage, my fears of sea travelling in respect of entailed sleeplessness are somewhat diminished, and consequently I have of late been entertaining the thought that I may possibly come over to see you. If so, it will be, I think, in the latter half of next year. At present I say this to yourself only, not having come to any positive decision.

Mount Vernon, N. Y., July 8, $188 \pi$.

My Dear Spencer: I believe I wrote you that I was going to try Saratoga. I did so for a week, and although it was a tedious job yet I gained something by it. I endured the exposure without injury.

The bronchitis is disappearing, but the soreness and strain from extensive pleural adhesion continue. I can now be so much out that I expect more marked improvement. I have yours of June $3^{\text {th }}$. Thanks for the important 
hints on lounging, which I will try to follow. In regard to the reception of the articles on Political Institutions, it has of course been far from what we could wish, but has been much as we might have expected. I am not aware that they have elicited intelligent discussion or criticism in any quarter. They have been noticed, with other articles by the newspapers-that is, simply referred to and generally with undiscriminating praise.

There have been a few bursts of impatience, and one unhappy man in Pennsylvania wrote as follows: "I sent you five dollars for the Monthly some months ago; either stop those stupid articles of Spencer or stop my subscription." This afforded me exactly the opportunity I wanted for a discussion, but I had not strength for it. I have, however, been perfectly satisfied to go on with the series, because I know the papers are extensively read. 'They come before the public in a form that cannot fail to secure some attention, and there are many men to whom it is important that they should be furnished. Our circulation is not large, but the magazine is much read. It is the most worn of all in the clubs and libraries. If we depended upon what the press says of the Monthly we should stop it tomorrow. It gets the least critical attention of all the magazines. There is the same commendatory mention of it every month where it is referred to at all. But there is a sort of dread of it, partly from incapacity to understand it, partly from religious prejudice, and very much because of its contrast to the light and lively journals that cater so skilfully to popular ignorance. I think our patronage is quite independent of anything the papers may or may not say. ...

I think we could run the Monthly solely on the contributions that are sent us pro and con in relation to your ideas and works.

So I am delighted that your experiences at length 
make it possible to entertain the idea of coming to the United States. There will be much to interest you, and it is on every account desirable that you should pay this country a visit, if possible. Our fifty million people will soon be a hundred million, and they are developing a continent at a rate which must be seen to be understood. We are loose and getting wild on social matters, and the carpenter theory of government is predominant. Whatever the result may be, the experiment is a grand one, and you should not let it pass without some careful scrutiny. I hope that the project will look increasingly feasible, and as soon as it is fairly settled in your mind I wish you would let me know.

New York, August 30, 1881 .

My deAR SPENCER: The last installment on Industrialism has come. That and the preceding are two mighty chapters. ... I am latterly much better and more in the spirit of work. I hardly mind a single pair of stairs, but a second pair leaves me exhausted. I have still a good deal of soreness connected with the lung constriction, but I think it is gradually diminishing, and I hope that some tolerable soundness may be regained before cold weather is again upon us. My "goings from town" have hitherto been "jobs." I hope to go to Saratoga for a week or two in September to enjoy it. I suppose you will be back in London by the time this gets there, and I trust you will return with the full benefit of your vacation. There are great fishing places on this continent in Canada and elsewhere, and I think you had better plan to give next August to the sport on this side.

38 Queen's Gardens, W., September 21,188 .

MY DEAR Youmans: I arrived back in town the night before last, and found your letter waiting for me. I .m glad to hear that you are gaining strength, not so glad to hear that you are "more in the spirit of work." If instead of this you would write "more in the spirit of play," it 
would be very much better. The worst of you is, the moment you get a little extra strength you use it up too fast. Pray take a good long holiday instead of your short ones. As I have often urged upon you, it is an economy of time in the end.

I am rather amused at your proposing to tempt me over early in August by Canadian salmon fishing. The suggestion has its temptations, but I have a strong impression as to the terrible infliction of mosquitoes and other kinds of flies, of which I am rather intolerant, and of which I remember reading as entailing great irritation on those who are led to Canada by the prospect of sport. I like to take my pleasure neat. If the drawbacks are considerable I would rather not have it at all. My present intention is rather to postpone until the last ten days of August my voyage, so as to arrive in New York about the end of the month. My friend Potter, with whom I have just been staying, and with whom I consulted, has been many times over with you, and he recommends me to go forthwith to the North and to spend the first week or ten days in seeing Niagara and something of Canada, so as to avoid the heat, which is still considerable in the early part of September.

You say respecting your lungs that you "hope some tolerable soundness may be regained before the cold weather is upon us." By all means do not simply hope, but take the most strenuous measures for insuring this result. •

I am glad that you like the two chapters on The Militant Type and The Industrial Type. They are, in fact, the culminating chapters of the part, and, indeed, of the whole work, in point of importance.

The next extract which I take from Spencer, replying to a letter from Youmans giving an account of the progress of the agitation for international copyright, is full of profound wisdom : 
I wish your American public could be made to feel the utter viciousness of the plea commonly put in in defence of your piratical system-that it is essential for your institutions that the people should have access to knowledge, unrestrained by regard for the author's claims. The truth which, instead of this, should be impressed upon them, but which I fear nothing will make them recognize, is, that free institutions can exist and work well only in virtue of an allpervading equity. The coercive form of government, itself implying an over-riding of men's rights, is capable of maintaining a tolerably stable social state among citizens whose. regard for one another's rights is comparatively small: force does what conscience fails to do. But in proportion as a government becomes non-coercive, and is the concomitant of a social system based upon contract, and the working together under voluntary co-operation, things can go well only in proportion as citizens have such natures as prompt them to respect one another's claims. Already the well working of your institutions is perturbed in all kinds of ways by dishonesty. Any increase of dishonesty will eventually in some way or other cause their collapse; their only salvation is increase of honesty. Hence, so far from its being needful, as your people allege, that the necessity is diffusion of knowledge at the expense even of honesty, it is, contrariwise, needful that there should be a diffusion of honesty even should there be some consequent impediment to the spread of knowledge. It is, I suppose, hopeless to try to make them see this.

In the summer of I882 Youmans's long-felt desire to welcome our friend Spencer to America was gratified. Mr..Spencer was accompanied by an old friend, Mr. Edward Lott, of Derby, a traveler of experienc ${ }^{\circ}$, a man of skill in smoothing the difficulties of a rapid tour, blessed with imperturbable good nature, and withal a trusty shield against reporters and intrusive visit- 
ors. One interview, however, with Mr. Spencer was published in the leading newspapers of the Union. - It contained his famous dictum that Americans are gradually losing their liberties, through not insisting on their rights in what they are pleased to consider small matters. The interview provoked much comment and criticism. Followed up as it was by his widely quoted speech at Delmonico's, and within a few months by his papers on Man $v$ s. The State, reprinted in The Popular Science Monthly, he may be credited with having helped forward two important movements: first, that which tends to arouse public conscience with regard to the dangerous encroachments of monopolies and buccaneering corporations of all kinds; second, that which issues in the increasing habit of holiday-making, which disperses every summer a growing percentage of the dwellers in cities along the seashore, among meadows, hills, and forests.

Mr. Spencer's delicate health had rendered him incapable of accepting a tithe of the hospitality proffered him, but the desire that he should be entertained at a public banquet before his embarkation was so warmly expressed that to decline was out of the question. On November gth, therefore, the banquet took place at Delmonico's. The event is memorable in the annals of New York entertainments, not only for the brilliant company it assembled, but for the permanent value of much that was said by the speakers of the evening. Mr. Spencer was so exhilarated by the splendid occasion that its excitements left him better rather than worse.

Among the few letters connected with the period while Spencer was in America I find the following pleasant and characteristic effusion from Mr. Beecher: 
Brooklyn, November 2, 1882 .

My dear Youmans: All of Saturday is free to Mr. Spencer. I will ride with him, talk with him, be silent with him, eat with him, or do anything except commit suicide with him.

We dine at one o'clock. If he will, he shall have oysters or lobsters, beef or mutton, game or fish, or all of them; tea, coffee, or wine-and if the latter, I will give him better port than New York can produce; or he shall have Madeira or sherry or claret or champagne; or if the British blood calls for beer, he shall have that-English ale, brown stout of the finest, German beer, lager beer; and such is my wish to please him that I will even give him cold water. He shall have all these, or, if he prefer, he shall not have any of them. If I had had him in Peekskill yesterday he would have seen such a glory of colour as would have made him exclaim, "This is the gate of heaven!"

I have a complete set of his works, and he may read them if he likes, though I have several bushels of old sermons which might edify him, perhaps, more.

Of course you are expected to come also, and, unless on a doctor's prescription, you will not be expected to take any intoxicating beverage! Faithfully yours,

Henry Ward Beecher.

P. S.-November 3 d, at your office. I learn that Spencer is on his back at Newport. That ends it. All viands and all wines are banished, and strict asceticism resumes its sway.

The winter of 1882-'83 I spent in London and :aw much of Spencer, whose health was then too poor for him to do much work. We were beginning to feel anxious about Youmans's health, as appears in the following letter: 
38 Queen's Gardens, April 12, 1883 .

Dear Youmans: I am glad to hear that though you have had difficulties with the severe winter you have nevertheless got through it thus far without serious mischief. I hope what remains will do you no harm. Next winter pray do not take the risky course of trying to bear it; but take the safe course, and infer that you will not bear it with impunity. It is this running of risks because on previous occasions it has been done with impunity that habitually leads to fatal results.

I am glad to report myself considerably better. The bad weather is pretty well ended; and since the improvement set in I have been gaining ground considerably, so that I am now doing a little work without much inconvenience. However, my sleeping has been considerably worse than usual for the last week; and I am to-day going down to Brighton for a few days to try and get some decent nights. Fiske is going to accompany me as my guest for a day or two. ...

I lately took up a book at the Athenæum entitled Natural Law in the Spiritual World, by Henry Drummond. I found it to be in a considerable measure an endeavour to press me into the support of a qualified theology by showing the harmony between certain views of mine and alleged spiritual laws. It is an interesting example of one of the transitional books which are at present very useful. It occurs to me that while the author proposes to press me into his service, we might advantageously press him into our own service. Just look at the book and see.

Coney Island, September 3, 1883 .

Dear Spencer: The erroneous view of your relation to Darwin is very widespread, and Fiske told me, on his return from England, that he was surprised to find how general it was there. It should not be suffered to extend and 
get confirmed for lack of explicit contradiction and exposure. The truth of the case will no doubt come out sooner or later, but sooner in proportion to the facilities for correcting the false view.* I am very glad of what you say in regard to the article supplementary to that upon music, and I hope you will be able to bring it about in the course of the coming year.

Beecher has been lecturing this summer with great acceptance and to large audiences on the religious bearings of evolution; but his work is very crude, being of the same sort as his address at the dinner. It is no doubt better than that, and Beecher is rapidly improving; but he has taken up the subject very late in life, and has not had the time, as he never had the proper preparation, for mastering the philosophy.

Could I have found a decent excuse for printing in the Monthly the address I prepared for the dinner I should have been satisfied. $\dagger$ I wanted the views there stated to go on record in the line of contributions I have published, and which form a distinctive feature of the periodical. I am not among the fortunate mortals who do work that is to survive. Yet The Popular Science Monthly is bound up in all the American public libraries, and it will hold its place there by sheer force of its bulk-it will hold over at least

* I have set forth the relations of Spencer's work to Darwin's in a way that is entirely satisfactory to Mr. Spencer (as he assures me) in an essay on The Doctrine of Evolution: Its Scope and Influence, published in The Popular Science Monthly, September, I89r, and republished by the Appletons in a volume of essays by various writers, entitled, Evolution in Philosophy, Science, and Art. I may add that the same view of the care, as I set it forth in my Cosmic Philosophy in 1874, was equally satisfactory to Mr. Darwin.

+ It is contained in the little volume, Herbert Spencer in America, published by the Appletons in 1883. It is not reprinted in the present volume, because the same points are given more fully in the essay reprinted below, pp. 502-55 $\mathrm{I}$. 
into the next century; and I am contented that it contains evidence that I knew a good thing when I saw it.

Has Sumner sent you his new little book? It is quite well worth looking over. He presents the anti-philanthropic, anti-meddling side with considerable point and freshness. *

37 Queen's Gardens, October 3, 1883.

MY DEAR YOUmans: By this post I send you a copy (if I can get one) of to-day's Times; if not, by as early a post as I can. It contains a report of the meeting of the Church Congress, which will be interesting and probably useful to you-the address of Prof. Flower, and other papers on the topic of evolution. Theological opposition to the doctrine is rapidly disappearing, and before the end of the century will be forgotten. . . .

I returned two days ago from Gloucestershire, where the fortnight has been very beneficial, especially the first week, during which the weather was fine and I got plenty of outdoor games; lawn tennis, bowls, and quoits, with billiards in the evening, did me a great deal of good.

I have got a copy of Sumner's little book, but have not yet had time to look over it. I am glad he is taking the turn you describe, and wish others who entertain kindred views would devote themselves to active propagation of them, for at present there is a most disastrous movement in the other direction. Indeed, I have almost given up all hope of seeing it checked, for the wave has become too vast. We are on the highway to communism, and I see no likelihood that the movement in that direction will be arrested. Contrariwise, it seems to me that every new step makes more difficult any reversal, since the reactive por-

* What Social Classes owe to each other, by Prof. W. G. Sumner, of Yale University, one of the clearest and strongest of American thinkers. It is a golden little book, and ought to have had a sale of half a million copies, instead of that stupid Looking Backward, the success of which is a sufficient commentary upon Puck's remark, "What fools these mortals be !" 
tion of the public seems likely to become weaker and weaker.*

* I take rather a more hopeful view than is here suggested by $\mathrm{Mr}$. Spencer. The love of private property is strong in men, and those who possess property are the strongest part of society, as they ought to be and always will be. Unjust inroads upon private property are oftenest made either by greedy sharks who lobby for tariff taxes upon articles of prime necessity, or by well-meaning philanthropists who wish to have one enjoyment after another made "free" (which can only be done by taxing the competent people for the benefit of the incompetent), or else by unscrupulous politicians who seek to subsidize a class of voters by granting them pensions or other gratuities. Our country has suffered greatly from such abominations, but the reaction, which has been growing in strength for several years, is already very powerful. It was shown, among other things, in the total defeat of the Blair Education bill, and also in the Democratic victories of 1890 and 1892 , which to a large extent must be interpreted as a rebuke to McKinleyism. A notable symptom is the declaration in the Democratic national platform of 1892 , presaging the revival of the sound doctrine that government has no right to levy taxes for any other purpose than revenue. There are indications that this doctrine will ere long prevail, and that the monstrous edifice of trusts and monopolies, overswollen fortunes, labour unions, walking delegates, boycotts, and general bedevilment which a high-tariff policy has built for us will topple over and disappear. That will involve quite a wholesale destruction of the seeds of communism.

In spite of many appearances to the contrary, the robust political philosophy of Jefferson and Van Buren, which is substantially that of Mr. Spencer, is very strongly rooted in the American mind; and now that we are recovering from the evil effects of our brief but violent spasm of militancy, it is beginning again to assert itself. In view of the comparative freedom of the United States from militancy it seems not improhable that in the next half century we shall advance toward a sound and healthy industrialism more steadily and rapidly than Europe. Excess of militancy, whether exhibited in actual warfare or in the maintenance of vas, armaments, is attended with symptoms of social retrogression, and among these symptoms are the tendencies toward socialistic legislation against which Mr. Spencer has so powerfully protested. They are temporary symptoms, of course. As long as the competents are stronger than the incompetents there is no chance for a general and permanent establishment of socialism or of communism. Possibly such systems may achieve a temporary estab- 
New YoRk, November 28, 1883.

My deAR Spencer: ... Your communications found me in a somewhat uncomfortable condition. I have long anticipated tumbling downstairs and breaking my neck, for only rarely can I see where the top of a staircase begins; so night before last I made the experiment, and fell down a flight of side steps on the street. The glare of gaslights blinded me, and it was a new place and so I tumbled.

The result was a Colles's fracture of my left wrist, the same that my wife had of the right wrist a couple of years ago. It was very painful for the first twenty or thirty hours, but is now tolerably comfortable, and I am able to get the bandaged arm in a sling.

It will be awkward for a month or six weeks, but I expect no very serious inconvenience. Fortunately $\mathrm{I}$ am in pretty good physical case, having taken considerable exercise latterly, so that I think the reparative processes will go on rapidly.

February 26, 1884 .

So, after twenty years of battiing, the sales of your works are larger the last than any preceding year-a little fact which $I$ have not forgotten in dealing with the Edinburgh Review. I got a point on the old quarterly by showing that it is too late to play over again the trick it played on Thomas Young eighty years ago.

The bones of the family continue to break. My sister's carriage was upset ten days ago, breaking her left arm above the elbow, and so badly spraining her shoulder that she has been confined to her bed ever since.

lishment in one or more countries, which will then serve as a melancholy example for the rest of mankind, somewhat as Spain has served in the last three centuries. In Cromwell's time there was more danger of the civilized world succumbing to "divine right of kings" than there is now of its succumbing to communism; yet the danger has been so successfully averted that monarchy has ceased even to be a bugbear. 
38 QUeen's Gardens, May 27, 1884.

My Dear Youmans: I saw Mr. Appleton a week or more ago, and he gave me an unfavourable report of you. I had not gathered from your accounts of yourself that the winter had so much told upon your lungs as to cause such an increased difficulty in breathing that you always in getting up to your office use the lift instead of going up one flight of stairs. This is very sad, and shows how mistaken you were in not deciding early in the winter on going South.

You must do better next time; and to that end the best plan will be for you to come over here and spend the winter with me, either here or abroad. As you see by one of the inclosed extracts, which has in one or other form appeared in many of the newspapers, the public insist that I shall go abroad somewhere. As they have failed in sending me to Australia, they seem to mean that I shall go to the Riviera, and not only that I shall go, but that I shall live there permanently. The decision was quite news to me; but nevertheless it jumps with my intention in so far as that I had contemplated flying south next winter; for though I do not suffer from our own winter in the ordinary way, I suffer from it in the depressing effects of cold. Perhaps Capri and Sicily and the south of Spain may be the places; and if I go, you must come over and go with me, as before.

New York, June 13, 1884 .

My DEAR SPENCER: . . I thank you much and very sincerely for your note after you had seen Mr. Appleton, proposing that I come over for another winter with you in the South. I am certainly in a very bad way, and it would no doubt have been better had I gone somewhere South the past winter.

In fact my satchel was packed in February for such an escape, when my sister broke her arm, and the case proved so bad that I could not leave. I have, however, survived 
the severe winter, and am now getting more strength, but my breathing continues very short, and I have evidently the use of a much diminished portion of my lungs. What the summer may do for me I cannot say, but I hope something. There is, however, hardly enough left of vigour to justify the hope that I could again safely cross the Atlantic; and if I did I fear I should be rather a burden than a helpful companion. But all the same, your invitation is pleasant, and most cordially appreciated.

November 1 I, 1884 .

. . As for myself, I think I can report my health as on the whole considerabiy better. The recent fine autumnal weather has been very favourable, and I have been able to increase my exercise and gain corresponding strength. The state of my lungs puzzles me, as there seems to be some change of symptoms, and I am much inclined to interpret them favourably; but I shall soon consult one of our best authorities on pulmonary matters and get at the present significance of the case. I am every way extremely well except the lung irritability and constant shortness of breath.

I am able to take pretty long walks if at a moderate pace, but the slightest quickening of movement sets the heart to pounding, which I suppose means a demand for more arterialization of the blood than the lungs can give. I still talk of going away, but how to get away and where to go are not easy questions to answer.

No doubt imperfect arterialization of the blood was the most serious feature of the case. From the desperate attack of pneumonia combined with pleurisy, in 1881 , Youmans had never really recovered. The continued and incurable adhesion of the lung to the pleura robbed it of half its efficiency, and under this wretched mechanical difficulty, in spite of the delusive 
moments of exhilaration or encouragement that came from time to time, my gallant old friend's life was steadily ebbing away. The case in many outward respects simulated pulmonary consumption. The approach of winter filled him with dread, but inexorable tasks prevented his retreat southward until February, when, accompanied by his sister, he went to Thomasville, Georgia. Meanwhile in Spencer's letters the note of alarm is very distinctly heard:

38 Queen's Gardens, London, W., January 3, 1885.

My DEAR Youmans: 1 have been looking for a letter from you for some little time, and hope that the rather long interval does not indicate any disturbance in your health from the cold weather, although I decidedly fear it. I regret greatly that you so persistently resist the suggestions to go South, and continually hope that you may run risks without evil, although you have so many times experienced evil from doing this.

\section{January 13, 1885 .}

The long interval since I heard from you leads me to fear that you are ill, or at any rate suffering seriously from the cold weather. Pray go South.

January $14,1885$.

After sending off my note yesterday, in some anxiety about your state, I was glad to get a letter from you this morning which relieved me a little, though not fully, for it appears that the winter is telling upon you, if not in a renewed pulmonary attack, still in other ways.

Why will you, against your better knowledge, yield to this American mania of sacrificing yourself in trying to do more work? You accept in theory the gospel of relaxation; why can you not act upon it? What is the use of both abridging life and making it full of physical miseries, all in the hope of achieving a little more, and eventually 
being baulked of your hope by the very eagerness to achieve? You have done quite enough already in the way of working for the public good. Pay a little regard to yourself, and let things drift. As for trying to brave out again the winter in New York, you have already had amply sufficient lessons of the mischief of taking the risky course, and I should have thought that you would be willing to take the prudent one. Excuse my plain speaking, but it is grievous to me to see you deliberately killing yourself.

\section{February 4, 1885.}

I should like to hear something about you. It is now a month since I gathered that you were in a very shaky state, and that you were feeling obliged to go South. What has happened?

March 23, 1885 .

There has just been published here a book entitled Can the Old Faith live with the New? by the Rev. George Matheson, D. D., evidently a Scotch Presbyterian, for he dates from Annelan, on the Frith of Clyde. It is really a very clever attempt to show that the evolution doctrine is not irreconcilable with the current creed. Accepting evolution in its widest extent as no longer to be gainsaid, and accepting also the metaphysics accompanying it-taking these, indeed, as established-the aim is, as I say, to show that the old faith may live with the new. It will, I think, therefore be an admirable means of introducing evolution doctrines into the ordinary mind. When you get back, pray get hold of it and see whether something cannot be done with it as a reprint. I should think Beecher would rejoice over it and take its doctrines as texts.

I hope you will be getting your breathing apparatus into better order down South. Why have you not let me know something of the results of the change? I dare say you find it difficult to kill time away from your work, but this is better than to let time kill you while at your work. 
Little advantage, however, had come to Youmans from his sojourn in Georgia. Its dreariness went far to outweigh any good results that might have come from the softness of climate, and it is probable that his disease was too far advanced to be arrested by change of scene. Soon after he had returned home Youmans told me that he would far rather die in New York than live in Georgia. There was no Century Club in Thomasville, no thronged and bustling Broadway, no familiar faces of old friends, no daily round of cheerful duties. The balmy breezes from the Gulf were all very well, and the first sight of the negro "in his native jungle" was more or less entertaining; but such things could not reconcile poor Youmans to the pain of lifelong habits brought to a halt. Keenly conscious of all that remained to be done if long-cherished plans were ever to be carried out, there came upon him with overwhelming force a sense of waning powers and numbered days, and he returned to New York rather worse than when he left it.

His attention for the next three months was more or less occupied with the controversy that grew out of the positivist Mr. Frederic Harrison's attack upon the views set forth in Spencer's Religious Retrospect and Prospect. Mr. Harrison's article, in its title, stigmatized Spencer's theory as The Ghost of Religion. Mr. Spencer replied with a paper ex.titled Retrogressive Religion, by which phrase he happily characterized the dismal rubbish inflicted upon an extremely small part of the world by the half-crazed Comte as the "religion of humanity." Whenever a positivist wishes to express withering scorn for anything he does not like he selects as the most 
abusive epithet available the word "metaphysics"; and accordingly the title of Mr. Harrison's next paper proclaimed Spencer's views to be "agnostic metaphysics." Once more Mr. Spencer replied in an article called Last Words about Agnosticism. All these articles, by both antagonists, were published in the Nineteenth Century, and reprinted in The Popular Science Monthly. Mr. Harrison's papers, while characterized by his usual brilliancy of style, were sadly unscrupulous. They abounded in shameless garblings and misrepresentations of Mr. Spencer's views, insomuch that to some unbiassed readers (whose opinions I from time to time solicited) the writer seemed to be sacrificing all other considerations to the single end of parading before his audience with airs of victory. A more charitable, if less probable, construction might excuse him on the ground that perhaps "he didn't know any better." Whether he felt himself to be getting worsted, after all said and done, of course one cannot say; but, curiously enough, after Spencer's last article-which, as Mr. Harrison himself declared, he regarded as a challenge to further discussion-he suddenly changed his audience. Instead of replying to Spencer in the Nineteenth Century he had recourse to the Pall Mall Gazette, and poured forth a fresh volley of misrepresentations before a new set of readers.*

* One of Harrison's remarks in this Pall Mall article reminds me of a little incident in my experience which may be worth preserving. In a preceding article he had alluded to Spencer's Descriptive Sociology as "a pile of clippings made to order." He now went on to say: "I have certainly cast no insinuations whatever on the three conscientious gentlemen who carried out Mr. Spencer's directions to tabulate 'all classes of facts'; but it is too much to ask me to believe either that they knew nothing of 
By this time so much interest had been aroused in the controversy as to make it morally certain that the articles would be collected and issued in book form in America. Such a thing might be done by any of the horde of pirates permitted by the absence of an international copyright law to infest this (quoad hoc) barbarous land; or it might be done by an honourable house like the Appletons, paying to both writers the customary royalty. Under these circumstances Youmans collected the articles and published them in a small volume entitled The Nature and Reality of Religion. To Mr. Harrison's Pall Mall article footnotes were added, pointing out its misrepresentations. Mr. Spencer was consulted as to the republication, and Mr. Harrison, for reasons duly set forth by Youmans, in his article hereto appended, was not. It was natural enough that Mr. Harrison, already somewhat touchy at having the worst of the argument, should have been irritated at this. But the case admitted of ex-

Mr. Spencer's theories, or that they did not tabulate such facts as they judged would be most useful to him. One would as easily believe that when Mr. Gladstone's secretary is directed to tabulate electoral facts he has not the least idea whether the Premier is about to use them in favour of reform or against it." Mr. Harrison seems to think that the mental attitude of a scientific investigator is like that of an ex parte advocate trying to make a point! Naturally enough, for, like the savage, the primitive man, and most of us, he judges the unknown by the known. His remarks recall to me what happened one evening about twenty years agn, when I was dining at 37 Queen's Gardens with Spencer and his assistant, Dr. Richard Scheppig, a pleasant and accomplished German scholar, who compiled some parts of the Descriptive Sociology (among others the Mexican part, in which, by the way, are some grave errors). I happened to ask Dr. Scheppig for his opinion on some point involved in the doctrine of evolution, and I shall never forget his delicious reply, or think of it without laughing: "I do not know anything whatever about evolution; I am a historian!" 
planation, to which he would not listen. For a moment he so far forgot himself as to impute mean pecuniary motives to Spencer and Youmans-an imputation which he soon felt obliged to withdraw. The effect upon Spencer was to make him telegraph at once to the Appletons to stop the sale of the book, destroy the plates, and debit the loss to his account. As matters had taken such a shape, Youmans could hardly do otherwise than suppress the book out of consideration for Spencer's feelings. He published, however, in The Popular Science Monthly for August, 1885 , an article Concerning the Suppressed Book, which is here reprinted in full,* and in which, as every candid reader will admit, his own conduct is amply justified. One cannot wonder that Mr. Harrison objected to a form of publication in which his own articles and Mr. Spencer's appeared side by side!

The last time that I ever saw my best and dearest friend was at his home in New York in March, I886, and for the first time there came over me the chill feeling that I must soon lose him. To accustom myself to the thought of the world without him was not easy-it has not yet become easy ; but I could not deceive myself, like the " everybody " to whom he alludes in the following letter. Dr. Thomas, by direction of the Penn Club, had invited him to Philadelphia as the special guest of the club. His reply was:

247 Fifth Avenue, New York, April 25, 1886.

My DEAR OLD FRIEND: I have to thank you for your very kind letter of April 8th, with its pleasant, not to say

* Sce below, pp. 562-583. 
flattering, invitation to accept at some suitable time the hospitality of your Penn Club.

I thank you most cordially for this offer, which I as sincerely appreciate as if it were in my power to comply with it. But I am physically broken down, emaciated to a skeleton, with strength enough to barely creep around a little. ...

Everybody assures me, loudly and simultaneously, that, though a little thin, I never looked better; that there is nothing much the matter, and that as soon as the weather gets settled I shall pick up and be all right again, and, as Sancho Panza remarks, "according as they say true, so help them God."

At any rate, should it ever become physically possible, I will avail myself of the proffered hospitality of your club. I am a member of the Authors' Club and the Century Club, but have not been able to attend either of them this winter. Ever sincerely yours,

E. L. Youmans.

This is the last of Youmans's letters that I have now at hand; but there are several letters to him from Spencer in this last year, from which I make the following extracts:

Losdon, February 20, 1886 .

My dear Youmans: I often find myself repeating the proposition, which I fancy you have before now heard me express, that each of us, as he gets older, needs a keeper. As internal judgment and will get weaker they reci lire to be supplemented by external judgment and will. But the worst of it is that at the time when this kind of government is most needed it is very commonly most resisted.

I very much fear that you are in a condition in which something approaching to coercion is called for. When I advised that you should submit yourself to the winter requirements and stay indoors altogether, I did not think of 
an evil which ought to have been obvious-namely, that, with your diminished lung capacity, the continued breathing of a more or less vitiated air would be doubly detrimental. Lungs with good capacity must manifestly feel the evil of a bad air much less than lungs of diminished capacity. It seems now highly probable that your depressed and enervated apathetic state is in large measure due to this double diminution of respiratory action and consequent lowered state of vital activity. Purer air and artificially aided circulation (as by massage) will, I am quite sure, brighten the aspect of things to you and make you feel that it is better to fight on even under difficulties than to surrender. I may say, by way of example, that I have myself of late had very discouraging views, my circulation a while since being so bad that I dared not walk from here across to my office or down to the bottom of the Gardens. Indeed, I was so bad that sometimes I could not stand up without producing intermission of the pulse. However, I have persevered, and, on the whole, with considerable improvement; so that now the tendency to intermission has almost disappeared, and my spirits as well as my power of writing have greatly improved. Be encouraged therefore, by my experience, to feel pretty sure that by judicious management the state of things, even when apparently very serious, can be got over.

July $20,1886$.

I was much saddened yesterday to receive a verification of the fears I have been for some weeks entertaining, that your silence was due to illness. Perhaps the condition of things is not so bad as you think; for, as I know from recent personal experience, one is apt to put unduly unfavourable interpretations on the facts. Doubtless it may be said that friends do the reverse; but on the whole the estimates of medical men and friends are perhaps the more to be trusted. 
It is well, however, that you can take so calm a view of the matter as your description and reflections imply; and it may be that, when life has to be carried on under the conditions you describe, the desire for continuance of it may fitly decrease. "What is the use of more to-days?" asks Emerson, referring to days of ordinary life. And if, as one feels in the latter part of life, even under conditions of tolerable health, more days are not particularly to be longed for, it seems reasonable enough that when they bring only suffering and weariness one may feel no great anxiety for prolongation.

... Whatever comes, we may at any rate, both of us, have some satisfaction in the consciousness of having done our work conscientiously, prompted by high motives; and whenever it ends, the friendship between us may be looked back upon by the survivor as one of the valued things of his life.

But more letters may still pass between us, my dear old friend; and in that anticipation I continue yours, with very affectionate regard,

Herbert Spencer.

Brighton, September 17, 1886 .

I should like to have a report of your state. The last account, which came to me through your brother, seemed to imply that he and those around you were almost hopeless of any improvement, and were looking forward with greatly depressed feelings.

Whenever I have thought of you of late I have trought of you as suffering under your sultry August weather-bad enough to bear by one in health, and dreadful to bear by one whose lungs are in large measure incapacitated. It must have been a grievous trial, and I wonder you have borne it. With affectionate regards and sympathies, Ever yours,

Herbert Spencer. 
7 Marine Square, Brighton, November $21,1886$.

I was delighted to have so good a report of you, and hope that the next will show a great deal of improvement.

I was somewhat surprised, however, by the statement that you are going back to New York. Is it because further driving out is now out of the question, and that the being near your medical man is a matter of more moment than being in the country air? One thing I very much fear, namely, that you will be led to live in the stove-heated* air of your American houses in winter; and this cannot fail to be injurious. Cannot you manage to live in rooms heated after the English fashion, by a fire, and without heated air, and make up the needful extra warmth by extra clothing-sitting in your overcoats, wraps, etc.? This would be far better than breathing such air as your American houses have, judging from what sample I had of it.

The next is the last:

7 Marine Square, Brighton, Jamuary $I, 1887$.

MY DEaR Youmans: It is a long time since I heard anything about you, and $I$ am getting anxious to have a report. Pray let me know how you have fared during the cold weather.

I cannot report favourably of myself. It is still the old story-improvement and then relapse. The last relapse was due to a cold, which, of course, in my present state, pulled me back considerably. "The malice of fate" from which I have suffered ever since last May has been almost incredible.

I have great difficulty in killing the time, especially now that I am kept wholly indoors by the weather, being unable

* Of course he does not mean the comparatively innocent old-fashioned stove, but the hot-air furnace and the steam radiator, those twin inventions of the devil. Youmans's house in New York, however, was heated by an improved method, and was admirably ventilated. 
to walk about or to read or talk to any extent, or even to play games. I pass my hours on the sofa wearily enough, as you may imagine. What little work I do is at the Autobiography.

Though the day suggests it, it is absurd for me to wish you, or for you to wish me, a happy New Year. There is not much happiness remaining in store for either of us.

Pray dictate a few lines when you get this.

Ever yours,

Herbert Spencer.

This sad letter found Youmans on his death-bed. On the I 8th of January he passed away without pain, retaining even to the last something of the blithe drollery that was always so charming. His burial place is a beautiful site at Woodlawn.

During Youmans's long illness abundant testimony was borne to his singular capacity for friendship ; constant inquiries, anxious and sympathetic, came not only from within the bounds of the city where he lived and laboured but from distant States and provinces-from beyond the sea. His friendship had a rare quality: not only was it manifested in counsels well considered, and in a generosity lavish in comparison with his means, but in a constant thoughtfulness which deemed no service too slight to be worth rendering. He was always magnanimous, patient, slow to take offence, an ingenious framer of excuses for others. To forfeit his good-will demanded an unusual case of meanness or wickedness. Mere folly or failure in the conventional sense would not do it. If he ascertained anything to the discredit of an acquaintance he merely deducted it from what he knew in his favour-he never let it cancel a good record, as so many people do. 
Himself one of the plain people, as Abraham Lincoln used to call them, he knew what they were and what they wanted. In concluding our survey of his life, what impresses us most, I think, is the broad democratic spirit and the absolute unselfishness which it reveals at every moment and in every act. To-Edward Youmans the imperative need for educating the great mass of the people so as to use their mental powers to the best advantage came home as a living, ever-present fact. He saw all that it meant and means in the raising of mankind to a higher level of thought and action than that upon which they now live. To this end he consecrated himself with unalloyed devotion; and we who mourn his loss look back upon his noble career with a sense of victory, knowing how the good that such a man does lives after him and can never die. 
SELECT WRITINGS. 


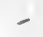




\section{SELECT WRITINGS.}

I.

MENTAL DISCIPLINE IN EDUCATION.

ALL educational inquiries assume that man is individually improvable, and therefore collectively progressive. Through varied experiences he is slowly civilized, and there is a growth of knowledge with the course of ages. But while thought is ever advancing, it is the nature of institutions to fix the mental states of particular times; and there hence arises a tendency to conflict between growing ideas and the external arrangements which are designed to express and embody them. Thought refuses to be stationary; institutions refuse to change, and war is the consequence.

This fact is familiarly illustrated in the case of government. Ideas and character, having outgrown the arbitrary institutions of the remoter past, there has arisen between them an antagonism, of the results of which modern history is full. So, too, religious conceptions having developed beyond the ecclesiastical organizations to which they at first gave rise, a struggle arose in the sixteenth century, which, resulting in the Protestant Reformation, has persisted under various aspects to the present time. And so it is also with the traditional systems of mental culture. Educational institutions which have been bequeathed to us by the past, and which may have been 
suited to their times, have fallen out of harmony with the intellectual necessities of modern life, and a conflict has arisen which is deepening in intensity with the rapid growth of knowledge and the general progress of society.

The friends of educational improvement maintain that the system of culture which prevails in our higher institutions of learning, and which is limited chiefly to the acquisition of the mathematics, and of the ancient languages and literature, was shaped ages ago in a state of things so widely different from the present that it has become inadequate to existing requirements. They urge that since its establishment the human mind has made immense advances; has changed its attitude to nature and entered upon a new career; that realm after realm of new truth has been discovered; that ideas of government, religion, and society have been profoundly modified, and that new revelations of man's powers and possibilities, and nobler expectations of his future, have arisen. As man is a being of action, it is demanded that his education shall be a preparation for action. As the highest use of knowledge is for guidance, it is insisted that our Collegiate establishments shall give a leading place to those subjects of study which will afford a better preparation for the duties and work of the age in which we live.

The adherents of the traditional system reply that all this is but the unreasoning clamour of a restless and innovating age, which wholly misconceives the true aim of a higher culture, and would reduce everything to the standard of a low and sordid utility. They maintain that knowledge is to be acquired not on account of its capability of useful application, but for its own intrinsic interest; that the purpose of a liberal education is not to prepare for a vocation or profession, but to train the intellectual faculties. They, therefore, hold that Mental Discipline is the true object of a higher culture, and that for its attainment 
the study of the ancient classics and mathematics is superior to all other means. From the tone assumed by its defenders, when speaking of its incomparable fitness to develop all the mental faculties, it might be inferred that this scheme of study was formed by the help of a perfected science of the human mind. Nothing, however, could be more erroneous. Not only was that system devised ages anterior to anything like true mental science, but it antedates by centuries the whole body of modern knowledge. There was abundance of vague metaphysics, but hardly a germ of that positive knowledge of the laws of mind which could serve as a valid basis of education. The predominant culture of modern times had its origin, more than eight hundred years ago, in a superstition of the middle ages. A mystical reverence was attached to the sacred number seven, which was supposed to be a key to the order of the universe. That there were seven cardinal virtues, seven deadly sins, seven sacraments, seven days in the week, seven metals, seven planets, and seven apertures in a man's head, was believed to afford sufficient reason for making the course of liberal study consist of seven arts, and occupy seven years. Following another fancy about the relation of three to four, in a certain geometrical figure, these seven arts were divided into two groups. The first three, Grammar, Logic, and Rhetoric, comprised what was called the Trivium; and the remaining four, Arithmetic, Geometry, Astronomy, and Music (the latter as a branch of Arithmetic), formed the Quadrivium. This scheme has been handed down from age to age, and with but slight changes, still predominates in the higher institutions of learning, and still powerfully reacts upon the inferior schools.

Passing by various embarrassing questions suggested by the hypothesis that the one perfect method of bringing the human mind to its highest condition has not only been 
found, but has been actually organized into educational institutions for hundreds of years-a hypothesis which discredits the whole movement of modern intellect in its educational bearings-let us take up this question of mental discipline. The subject is not only intrinsically important, but its importance is greatly heightened when an old and widely established system, challenged by the spirit of the age, yields the point of the usefulness of the knowledge it imparts, and offers as its sole defence its superior merits as a system of mental training; and still more important does it become when the idea is so constantly and vehemently iterated as to acquire all the force and tenacity of a superstition, and breed a regular cant of education, which serves as the stereotyped apology for numberless indefensible projects and crudities of instruction. The writer recently opened a huge volume on Heraldry, and the very first passage which struck his eye in the preface, urged the claims of that subject to more general study on the ground of its excellence as a mental discipline.

I propose, in the present Introduction, first, to point out the defects of the traditional system as a means of disciplining the mind; and, second, to show the superior claims of scientific education for this purpose.

The claims put forth in behalf of the prevailing scheme are as multitudinous and diverse as the tastes and capacities of those who offer them-a natural result, perhaps, in the absence of any considerations so decisive as to command general agreement; but those most commonly urged are, that the grammatical acquisition of the dead languages best disciplines the memory and judgment, and the study of mathematics the reason. Let us briefly notice these points first :

That the acquisition of words exercises the memory is of course true-those of living languages as well as dead 
ones, but their assumed merit for discipline raises the question how they exercise it. Memory is the capability of recalling past mental impressions, and depends chiefly upon the relations subsisting among these impressions in the mind. If they are arbitrary, the power of recall depends upon multiphcity of repetition, and involves a maximum outlay of mental force in acquisition. If, however, ideas are arranged in the mind in a natural order of connection and dependence, this principle becomes the most important element in commanding past acquisitions. The conditions are then reversed; the outlay of effort in acquisition is reduced, and the power of recall increased. Now the memory cultivated in the common acquirement of language, is of this lowest kind. The relation between words and the ideas, or objects, of which they are the signs, is accidental and arbitrary. Although philological science is beginning dimly to trace out certain natural relations between words and the things they signify, it will not be claimed that this is made at all available in the ordinary study of Latin and Greek; indeed, the most thorough-going advocates of these studies claim that their disciplinal value is in the ratio of the naked retentive power which they call into exercise. But the memory cannot be best disciplined by a mental procedure which neglects its highest law. If the power of recovering past states of consciousness depends upon the natural and necessary connections among ideas, then those studies are best suited for a rational discipline of this power which involve these natural rcations among objects. On both grounds the sciences are preferable to dead languages, as instruments of culture. For if it be held desirable merely to task the memory by a dead pull at arbitrary facts (and there are not wanting those who hold to this notion of discipline), then it is only necessary to use the innumerable facts of science, without regard to order; but when we take into account the immense 
importance of methodizing mental acquisition, and utilizing the principle of natural association among the elements of knowledge, the immeasurable superiority of the sciences for this purpose becomes at once apparent. This is happily illustrated by some observations of Dr. Arnold, respecting the memory of geography. He says:

And this deeper knowledge becomes far easier to remember. For my own part I find it extremely difficult to remember the positions of towns, when I have no other association with them than their situations relatively to each other. But let me once understand the real geography of a country-its organic structure, if I may so call it ; the form of its skeleton, that is, of its hills; the magnitude and course of its veins and arteries, that is, of its streams and rivers; let me conceive of it as a whole made up of connected parts; and then the positions of towns viewed in reference to these parts becomes at once easily remembered, and lively and intelligible besides.

If now it be said that it is not mere memory of words that is contended for, but the discipline and judgment afforded by the grammatical study of the structure of language, the crushing answer is that a dead language is unnecessary for this discipline, which is far better secured by the systematic study and thorough logical analysis of the vernacular tongue.* Perhaps there is no point in education in which there is so universal and intense an agreement among independent thinkers, as in condemning the folly of beginning the acquisition of foreign languages, living or dead, by the study of their grammar-the method in general use among those who defend it as a mental discipline. The usual school practice of thrusting the young into the grammar, even of their native tongue, is well known to be one of the most efficient means of the artificial production of stupidity; but the habit of introducing

* See Prof. Jewell's able paper on the Logical Analysis of the English Language, in Proceedings of New York University Convocation. 
them to a foreign language through this gateway, is a still more flagrant outrage. The natural method of acquiring speech is the way we all acquire it; the knowledge of words first, then their combination into sentences, to be followed by the practical use of the language; rules and precepts may then be intelligently applied. But to begin with these is to put the complex before the simple, the abstract before the concrete, generals before particulars, and, in short, to invert the natural order of mental processes, and to work the mind backward, under the plea of disciplining it. An eminent living authority in philology, Prof. Latham, in a lecture before the Royal Institution of Great Britain, observed :

In the ordinary teaching of what is called the grammar of the English language, there are two elements. There is something professed to be taught which is not; and there is something which, from being already learned better than any man can teach it, requires no lessons. The latter is the use and practice of the English tongue. The former is the principles of grammar. The facts, that language is more or less regular; that there is such a thing as grammar ; that certain expressions should be avoided, are all matters worth knowing. And they are all taught even by the worst method of teaching. But are these the proper objects of systematic teaching? Is the importance of their acquisition equivalent to the time, the trouble, and the displacement of more valuable subjects, which are involved in their explanation? I think not. Gross vulgarity of language is a fault to be prevented; but the proper prevention is to be got from habit-not rules. The proprieties of the English language are to be learned, like the proprieties of English manners, by conversa ion and intercourse; and a proper school for both is the best society in which the learner is placed. If this be good, systematic teaching is superfluous; if bad, insufficient. There are unquestionably points where a young person may doubt as to the grammatical propriety of a certain expression. In this case let him ask some one older, and more instructed. Grammar, as an art, is undoubtedly the art of speaking and writing correctly - but then, as an art, it is only required for foreign languages. For our own we have the necessary practice and familiarity. 
The true claim of English grammar, to form part and parcel of an English education, stands or falls with the value of the philological knowledge to which grammatical studies may serve as an introduction, and with the value of scientific grammar, as a disciplinal study. I have no fear of being supposed to undervalue its importance in this respect. Indeed, in assuming that it is very great, I also assume that wherever grammar is studied as grammar, the language which the grammar so studied should represent, must be the mother tongue of the student, whatever that mother tongue may be. This study is the study of a theory; and for this reason it should be complicated as little as possible by points of practice. For this reason a man's mother tongue is the best medium for the elements of scientific philology, simply because it is the one which he knows best in practice.

It thus appears that to secure the disciplinary uses of grammatical study, not even a foreign language is necessary, much less a dead one.

When it is remembered that the Hebrew language had no grammar till a thousand years after Christ; that the masterpieces of Greek literature were produced before Aristotle first laid the grammatical foundations of that language; that the Romans acquired the Greek without grammatical aid, by reading and conversation; that the most eminent scholars of the middle ages and later, Alfred, Abélard, Beauclerc, Roger Bacon, Chaucer, Dante, Petrarch, Lipsius, Buddeus, and the Scaligers-Latin scholars, who have never since been surpassed, learned this language without the assistance of grammar; that Lilly's grammar, in doggerel Latin verse, was thrust upon the English schools by royal edict of Henry VIII, against the vehement protest of men like Ascham, and that the decline of eminent Latinists in that country was coincident with the general establishment of this method of teaching; that Dante, Petrarch, and Boccaccio gave to the world their immortal works two hundred years before the appearance of the first Italian Grammar; that Shakespeare, Mil- 
ton, Dryden, Addison, Pope, Young, Thomson, Johnson, Burns, and others, whose names will live as long as the English language, had not in their childhood learned any English grammar; that Corneille, Molière, La Fontaine, Pascal, Bossuet, Boileau, and Racine, wrote their masterpieces long before the publication of any French grammar; that men like Collet, Wolsey, Erasmus, Milton, Locke, Gibbon, Condillac, Lemare, Abbé Sicard, Basil Hall, Horne Tooke, Adam Smith, and a host of others, have emphatically condemned the method of acquiring language through the study of grammar; that the most eminent masters of language, Demosthenes, Seneca, Malherbe, Clarendon, Montesquieu, Fénelon, Voltaire, Rousseau, Montaigne, Boileau, Dante, Galileo, Franklin, Gibbon, Robertson, Pope, Burns, Byron, and Moore, acknowledge that they attained their excellences of style by the study and imitation of the best models of writing; and finally, that mere grammarians are generally bad writers: when we recall facts like these, we can begin to rate at something like their true value the claims of the grammatical study of defunct forms of speech for mental training. That there is a useful discipline in the critical study of language, as in the critical study of most other things, is not denied; but that it has either the transcendent importance usually assumed, or that it cannot be substantially acquired by the mastery of modern tongues, is what the advocates of the dead languages have failed to prove.*

Let us now notice the discipline of mathematics, the claims of which to an important place in a liberal scheme of education are of course unquestionable. Dealing with conceptions of quantity under various forms of expression,

* For confirmation of the statements in this paragraph see Marcel on Language, in two volumes. London: Chapman \& Hall, I853. It is not creditable to American education that this able work has not been republished here. 
and with a varying application to universal phenomena, they are an indispensable key to universal science, and their basis is, therefore, a broad and solid utility. But the devotees of tradition are not satisfied with this; they make extravagant claims for mathematics, on the ground of the discipline they afford, and then usurp for them an educational predominance to which they are not entitled. In their subordinate place they are invaluable; as a too engrossing subject of study, injurious. Mathematics are suited to form habits of continuous attention by dealing with trains of proof, to help the imagination steadily to grasp abstract relations, and to familiarize the mind with a system of necessary truth. But they do not afford a complete exercise of the reasoning powers. They begin with axioms, self-evident truths, established principles, and proceed to their conclusions along a track each step of which is an intuitive certainty. But it so happens that in our mental dealings with the experiences of life, the first, the most important, and most difficult thing is to get the data or premises from which to reason. The primary question is, What are the facts, the pertinent facts, and all the facts, which bear upon the inquiry? This is the supreme step; for, until this is done, reasoning is futile, and it may be added that, when this is done, the formation of conclusions is a comparatively simple process. Now mathematical training cannot help to this important preliminary work; it leaves its cultivator to the blind acceptance or blind rejection of his premises. Those, therefore, who have exclusively pursued these studies, so as to form mathematical habits of thinking, have no preparation for the practical emergencies of thought, where contingencies are to be taken into account, where probable evidence is to be weighed, and conclusions from imperfect knowledge are to be formed and acted upon. The pure mathematician is therefore liable to a one-sided and erratic judgment of 
affairs. An exclusive mathematical discipline must, therefore, be held as an actual disqualification for the work of life.*

It is important to notice that, so far as the mode of exercising the mind is concerned, mathematical discipline does not correct the defects of lingual discipline, but rather confirms them. We hence see how it was that mathematics so perfectly harmonized with philology as to have been early and naturally incorporated with it in the same scheme of culture. Both begin with the unquestioning acceptance of data-axioms, definitions, rules; both reason deductively from foregone assumptions, and therefore both habituate to the passive acceptance of authority-the highest mental desideratum in the theological ages and establishments which gave origin to the traditional curriculum.

To those familiar with the literature of this discussion, the objections here presented, will, not be new; but there

* Dugald Stewart $\iota_{\text {remarks: "How accurate soever the logical process }}^{\text {rom }}$ may be, if our fir irst principles be rashly assumed, or if our terms be indefinite and ismbiguous, there is no absurdity so great that we may not be brought $t_{s}$ adopt it ; and it unfortunately happens that, while mathematical stud fhes exercise the faculty of reasoning or deduction, they give no employm the other powers of the understanding concerned in the investiga tion of truth. On the contrary, they are apt to produce a facility in the admission of data, and a circumscription of the field of speculation by partial and arbitrary definitions. . . . I think I have observed a peculiar proneness in mathematicians to avail themselves of principles sanctioned by some imposing names, and to avoid all discussion which might tend to an examination of ultimate truths, or involve a rigorous ana' 'sis of their ideas. . . In the course of my own experience $I$ have not met with a mere mathematician, who was not credulous to a fault; credulous not only with respect to human testimony, but credulous also in matters of opinion; and prone, on all subjects which he had not carefully studied, to repose too much faith in illustrations and consecrated names." Pascal also observes: "It is rare that mathematicians are observant, or that observant minds are mathematical, because mathematicians would treat matters of observation by rule of mathematic, and make themselves ridiculous by attempting to commence by definitions, and by principles." 
are certain considerations growing out of the recent progress of thought, which have a powerful bearing upon the question, and which it is desirable now to present. And first, What is the real significance of the phrase "discipline of the mind"?

By mental discipline in education is meant, that systematic and protracted exercise of the mental powers which is suited to raise them to their highest degree of healthful capability, and impart a permanent direction to their activity. The mind takes a set or stamp from the character of the knowledge it acquires, and the mode of activity which these acquisitions involve, and, in this way, mental habits are formed. But, what is the basis of this great fact of mental habits, by which so spiritual an agency as mind becomes fettered? It is a property of the organic constitution, and its consideration brings us down to the firm physiological basis of the whole subject.

There are two methods of studying mind. The old metaphysical method simply takes note of the mental effects which are manifested in consciousness, but modern psychology goes deeper, and takes into account the conditions under which these manifestations arise. It no longer admits of denial or cavil, that the Author of our being has seen fit to connect mind and intelligence with a nervous mechanism: in studying mental phenomena, therefore, in connection with this mechanism, we are studying them in the relation which God has established, and, therefore, in the only true relation. There is still a powerful prejudice against this proceeding. Literature and Theology continue to $r$ jur their contempt upon that " matter" which infinite "sdom has consecrated to the high purpose of manifest.n'g mental effects, while the scientific study of the organ of thought has been, until very recently, outlawed by the state.* Yet nothing is more cer-

* Human dissections having been, until lately, illegal. 
tain than that in future, mind is to be studied in conrection with the organism by which it is conditioned: when we begin to deal with the problem of mental discipline, metaphysics no longer arail: it is the organism whth which we have finally to deal.

When it is said that the brain is the organ of the mind. it is meant that in thinking. remembering. reasoning. th brain aits. It is now admitted that all impressions made upon the brain, and all actions occurting within it, are accompanied by physical changes. Thought usually goes on so quietly, and seems so far remored from bodily actrity. that we are easily betrayed into the notion that it is car. ried on in a region of pure spirit: but this is tat from being the truth. The changes of states of consciousness, the course of thought, and all processes of the understanding. are carried on by a constant succession of nerve excitements and nerve discharges. The brain is not a chaos of parts thrown together at random: it consists of hundreds of millions of cells and tibres. organized into symmetrical order. so as to produce innumerable comnections. crossings. and junctions of exquisite delicacy. The simple elements of mind are built up into complex knowledge by the law of association of ideas: and the mental associations are formed by combinations of currents in the brain, and are made permanent by the growth and modincation of cells at the points of union. When a child associates the sight, weight, and ring of a dollar, with the written word and verbal sound that represent it so firmly togeth.s in its mind that any one of these sensations will instanty bring up the others, it is said to "learn " it. But the real fact of the case is, that the currents formed by visible impressions, vocal movements and sounds, are often repeated together, and are thus combined in the brain, and fixed by speciric growths at their points of union, and in this way the mental associations are cemented by cerebral nutrition. And 
thus the child goes on multiplying its experiences of the properties of objects and of localities, persons, actions, conduct; he observes, compares, contrasts, infers, and judges, and all this growing and complex mass of acquisition is definitely combined in the growing and perfecting organ of the mind.

The basis of educability, and hence of mental discipline, is, therefore, to be sought in the properties of that nerrous substance by which mind is manifested. That basis is the law that cerebral effects are strengthened and made lasting by repetition. When an impression is made upon the brain, a change is produced, and an effect remains in the nerve substance; if it be repeated, the change is deepened, and the effect becomes more lasting. If we have a perception of an object, or if we perform an action only once, the nervous change is so slight that the idea may perhaps never reappear, and the act never be repeated; if experienced twice, the tendency to recur is increased; if many times, this tendency is so deepened, and the links of association become so extended, that the idea will be often obtruded into thought, and the action may take place involuntarily. Intellectual "capacity" is thus at bottom an affair of physical impressibility, or nervous adhesiveness. Regard being had to the law that all nutritive operations involve repose, cohesion or completeness of association depends upon repetition. Of course, constitutions differ widely in this property, some requiring many more repetitions than others, to secure acquirement.* This view leads to important practical conclusions.

* To illustrate the tw modes of viewing mental phenomena, I will quote a couple of cxtracts from eminent authorities, reprobating the pernicious practice of "cramming" for examinations. Dr. Whewell, content with the metaphysical method, observes: "I may add my decided opinion that no system of education which is governed entirely or even mainly by examinations, occupying short times with long intervening intervals, can 
When it is perceived that what we have to deal with in mental acquirement is organic processes, which have a definite time rate of procedure, so that, however vigorously the currents are sustained by keeping at a thing, acquisition is not increased in the same degree; when we see that new attainments are easiest and most rapid during early life-the time of most vigorous growth of the body generally; that thinking exhausts the brain as really as working exhausts the muscles, and that rest and nutrition are as much needed in one case as the other; when we see that rapidity of attainment and tenacity of memory involve the question of cerebral adhesions, and note how widely constitutions differ in these capabilities, how they depend upon blood, stock, and health, and vary with numberless conditions, we become aware how inexorably the problem of mental attainment is hedged round with limitations, and the vague notion that there are no bonds to acquisition except imperfect application disappears forever.*

ever be otherwise than bad mental discipline. Intellectual education requires that the mind should be habitually employed in the acquisition of knowledge, with a certain considerable degree of clear insight and independent activity."

Mr. Bain takes the psychological view, and reaches the vital dynamics of the case. He says: "The system of cramming is a scheme for making temporary acquisitions, regardless of the endurance of them. Excitable brains, that can command a very great concentration of force upon a subject, will be proportionably improved for the time being. By drawing upon the strength of the future, we are able to fix temporarily a great variety of impressions during the exaltation of cerebral power that ' he excitement gives. The occasion past, the brain must lie idle for a corresponding length of time, while a large portion of the excited impressions will gradually perish away. This system is exceedingly unfavorable to permanent acquisitions; for these the brain should be carefully husbanded, and temporarily drawn upon. Every period of undue excitement and feverish susceptibility is a time of great waste for the plastic energy of the mind.

* See page 348 . 
The doctrine of mental limitations, which we thus find grounded in the organic constitution, puts the philosophy of education at once on the basis of the economy of mental power. The student is constantly told that his time is limited, and exhorted not to waste it; but his forces of acquisition are equally limited, and it becomes a question of still higher importance how to economize these, for it is possible sedulously to save the moments while squandering half the energies of the mind in bad application. Obviously if intellectual power has its fixed bounds, the supreme question is, How can the highest results be attained within those bounds?

Nature's method of economizing power is by repetition of actions in constantly varying conditions. The celestial order is maintained by endless repetition of axial and orbital revolutions. The operations of the world are carried on by using over and over again the same stock of resources; matter and force circle round and round through the mineral, vegetable, and animal phases; in the growing plant leaves undergo constant transformation into other organs, while the animal skull is formed of modified vertebral spines. And so in the unfoldings of the mental world, Nature is constantly falling back upon old acquisitions, and using them to produce new effects. In the process of acquirement, ideas and aptitudes once mastered are constantly wrought into higher and more complex combinations. The organ of thought being a vast reduplication of the same simple elements, the growth of thought results from an endless repetition of the same simple operations.

The child, through numberless repetitions of effort, at length gets the aptitude of using its hands for ordinary purposes. But this faculty once secured, serves for life in all the ordinary emergencies of action. The necessity for new and varied movements involves no new acquisitions; within the range of ordinary activity the early aptitudes 
suffice. But if in any case manipulations of special delicacy and precision are required, as in learning to draw, a new acquisition must be made. Yet here the same thing occurs. The new acquirement may be utilized in other similar applications; if the child have first learned to draw, the aptitude will serve also in learning to write.

Again, the instrumental performer, by long drill, acquires a great number of movements, according to the range of his musical sensibility, so that learning new pieces is but little else than new combinations of old sequencesthe new acquisition being, in fact, but a new grouping of old acquisitions. So also in the purely intellectual operations. In learning geometry, the mind having grasped the preliminary definitions, axioms, and postulates, uses them over and over in solving the successive problems; while mathematical genius consists mainly in the ready ability to identify the old elements under the disguises of the new cases. In fixing the conception of a new mineral, plant, or animal, the naturalist recalls the characteristics of known specimens which most nearly resemble them, and superadds to these the new features. The same thing holds in learning languages. The mastery of Latin reduces the labor of acquiring Italian, French, and Spanish, into which it largely enters; and we find new words to be easy in proportion as they consist of old familiar articulations. In historical studies, revolutions, campaigns, negotiations, and political measures, are repeated by the same nation at successive epochs, and by one government after another, so that a new history is but a varied reading of old ones; the really new features bearing but a small proportion to those already fixed in the student's mind. The vast mental economy which would arise throughout civilization by the general adoption of decimal coinage, weights, and measures, is but another illustration of the principle; a few simple arithmetical acquisitions would serve the requirements of all 
who deal with relations of quantity. In short, our reason has been aptly defined as "the power of using old facts in new circumstances," and this is the secret of the production of vast effects with limited resources.*

Now this principle, as it affords the true key to intellectual progress, must become the organizing law of education. We find that extent of mental attainment depends, not alone upon intellectual effort, but upon the order of relations among objects of thought. Of course, mental capacity is the first factor in acquisition, but that being given, the scale of possible attainment depends absolutely upon the order of the course of study. Education cannot make capacity, but it controls the conditions by which the least or the most can be made of it. If the methods of study be such that the mind encounters broad breaks in its course, and is abruptly shifted into new lines of effort, so that past conceptions are not carried on to a progressive unfolding, mental growth is checked and power lost. The extent to which one fact or principle is a repetition or outgrowth of another, in the serial relation of subjects, determines the rate of mental movement, which can only become steady and rapid in continuous ranges of effort. As in the outward world, the past creates the future along unbroken lines of dynamic sequence and causation, so in the mental world, there must be a corresponding continuity of movement by which the past creates the future in intellectual evolution.

We have here the touchstone of educational systems, and the fatal condemnation of the current theory of discipline. How grossly that theory violates the law of mental economy, and, indeed, actually provides for waste of power, will be apparent by glancing briefly at its origin. The

* For a full working out of this doctrine, see Bain's Senses and Intellect. 
notion of mental gymnastics was borrowed from that of bodily gymnastics. In early times, useful labor being regarded as menial and degrading, the superior classes sought the activity needed for health in various artificial exercises. The old Greek gymnastics was a system of athletic exercises cultivated for the attainment of physical development, and had no reference to the preparation of men for the occupations of industry. The ancient philosophers held that it was as degrading to seek useful knowledge as to practice useful arts; hence, subjects of study were chosen as intellectual gymnastics and to acquire mental discipline, and this, not as a preparation for valuable mental labor, but as an end in itself. Not the game, but the excitement of the chase; not the truth, but the exhilaration of its pursuit, were the mottoes of culture. Under these circumstances no vulgar question of economy could arise; mental power was ostentatiously wasted, and with the necessary consequences-truth unsought was not found; the ends of culture being ignored, there was neither conquest of nature nor progress of society.

Not only does the principle of vicarious discipline involve enormous mental waste, but the system of studies employed to secure it grossly violates the great law of acquisition, which should become the basis of education. That system is neither an outgrowth of the proper education of childhood, nor does it flow on into the intellectual life of manhood: it is a foreign body of thought, uncongenial and unaffiliated, thrust into the academic per od, and destroying the unity and continuity of the mental career. The young student is detached from all his early mental connections, expatriated to Greece and Rome for a course of years, becomes charged with antiquated ideas, and then returns to resume his relation with the onflowing current of events in his own age. The radical defect of the traditional system is, that it fails to recognize and grasp the 
controlling ends of culture. Misled by the fallacy that, through a scheme of aimless exercises for discipline, mental power n.ay be accumulated for universal application, it sees no necessity of organizing education with explicit reference to ultimate and definite purposes, and it thus forfeits its right of control over the educational interests of the time. For that there are great and well-defined aims, revealed with more clearness in this age than ever before, to which a higher mental culture should be subservient, does not admit of intelligent question. If the classical system grasps the conception of education, in its ends as well as its beginnings, as a preparation for the activities of life; and of discipline, as the formation of habits to guide a constantly unfolding mental career; and of knowledge, as consisting of a chain of relations, along which the mind is to move in accomplishing that career; if it unfolds the order of the world, and puts the student in command of the ripest and richest results of past thinking; if it qualifies best for the relations of parenthood, citizenship, and the multiform responsibilities of social relation; if it equips for the intelligent and courageous consideration of those vital questions which the progress of knowledge and aspiration are forcing upon society; if it fits most effectually for these supreme ends, then, indeed, it affords a proper discipline for the needs of the time; but if the student, after having faithfully mastered his collegiate tasks, finds, upon entering the world of action, that his acquisitions are not available-that he has to leave them behind him and begin anew, then his preparation has been a bad one; time has been irretrievably lost, power irrecoverably wasted, and the chances are high that he will give the go-by to modern knowledge, and thin down his intellectual life to the languid nursing of his classical memories.

It is well known that, in numerous cases, the success of educated men may be directly traced to neglect of the 
regular college studies, or to their neutralization by the vigorous pursuit of other subjects; and equally notorious that in numberless other cases, where the student has surrenclered himself to college influences and conquered his curriculum, exactly in proportion to his fidelity has been his defeat. He has mastered a disqualifying culture. In hundreds of instances it has been the lot of the writer to listen to expressions of bitter regret on the part of college graduates at the misdirected studies and the misapplied time which their "liberal" education had involved. "O that I had some knowledge of those imminent questions that are urging themselves on public attention, in place of my college lumber!" is a stereotyped exclamation in these cases. And this turn of expression discloses the worst aspect of the matter, for the lumber cannot be got rid of. The mind is not a reservoir to be emptied and refilled at pleasure. The student has not been preparing a soil for future sowing; he has sown it, and to extirpate the roots will consume half a lifetime. In the most plastic period of receptivity he has been making acquisitions and forming habits which, by coercing his attention and engrossing his thoughts, will operate powerfully to obstruct subsequent mental operations ; for if they do not help, they must inevitably hinder.

In the preceding pages, after pointing out some of the special disciplinary defects of the traditional scheme of study, I have endeavored to show that in its very conception of mental training there is involved enormous waste of power, and in its course of study a total nonrecognition of the great law by which alone the highest mental attainment can be reached. I have also shown that this erroneous conception of discipline, by ignoring the great ends of culture, and the adaptation of studies to them, not only wastes power, but gives a false preparation for life. It re- 
mains now to indicate how these errors and defects may be remedied by scientific education.

Let it be remembered that this culture does not deny the importance of mental discipline, but only the wasteful policy of vicarious discipline. The question has three aspects. The ancients employed the useless fact A for disciplinary purposes, and ignored the useful fact $B$. The adherents of the current theory propose to learn first the useless fact A to get the discipline necessary to acquire the useful fact $B$; while a rational system ignores useless $A$ and attacks B at once, making it serve both for knowledge and discipline. The ancient view was more reasonable than that which has grown out of it. It wanted one acquisition, and it made it; the prevailing method wants one, and makes two; and as it costs as much effort to learn a useless fact as a useful one, by this method half the power is wasted.

The moment that the conception of value attaches to power, the idea of its economy inevitably arises, and this is fatal to its vicarious application. Hence gymnastics are never thought of as a preparation for industrial occupation. The employer who should resort to them would quickly come to bankruptcy, for he knows that the laborer has but a limited amount of power, all of which it is necessary to utilize; and he understands that the needed aptness comes in the regular course of occupation, and in that way alone. In the world of business, where results become quickly apparent, and a wrong policy works speedy disaster, the notion of discipline for a special activity, and not through it, could not be entertained, and it only lingers in the world of mind and education because there effects are more remote, complex, and indefinite, and the consequences of a wrong principle are less readily detected. With the growing perception of the relation between human thought and human life, it will be seen that by far 
the most priceless of all things is mental power; while one of the highest offices of education must be strictly to economize and wisely to expend it. Science made the basis of culture, will accomplish this result.

We have affirmed the broad principle of mental limitations, but let none suppose that its necessary corollary is narrow and stinted mental results. It has been explained how this consequence is to be escaped. A limited outlay of energy with results so vast as to seem out of all proportion with it, is exactly the miraculous problem which Nature has solved. It was at first supposed that prodigious quantities of power were required to work the Atlantic cable-an error which probably led to its destruction; but electricians have been recently startled by the discovery that the force generated in a lady's thimble, or even in a percussion cap, is sufficient to operate the ocean telegraph. The lesson of this experience is, that a knowledge of the laws of power is essential to prevent waste of power; and this is no more true in physical dynamics than in mental. Let none indulge apprehensions that this doctrine of limits to acquirement darkens the future of education, or derogates from man's mental dignity. What the human mind has already accomplished is our starting point. Working waywardly, in isolation, by arbitrary methods, upon chaotic materials, and in ignorance of the mighty secret of its power, grand results have nevertheless been achieved, and they are the indices of attainment under the worst conditions. But in the new revelation of a cosmical order, and of the correlation and interdependence of all truth, Science utters a pregnant prophecy of the mind's future destiny, and vindicates her right to take control of its future unfolding.

The ideal of the higher education demanded by the present age, especially in this country, where it is becoming most general, is a scheme of study, which, while it 
represents the present state of knowledge, and affords a varied cultivation and a harmonious discipline, shall at the same time best prepare for the responsible work of life. For this the study of languages and mathematics is necessary, but far from sufficient. Other sciences are to be supplied and a curriculum framed, which, conforming to the true logical order of subjects on the one hand, shall equally conform to the order of unfolding the mental faculties on the other, thus reaching an integral discipline through living and applicable knowledge.

There is great significance in the fact that the prevailing higher culture is without a foundation. Professing to devote itself exclusively to the moulding and evolution of mind-sinking knowledge itself into nothingness in comparison with this effect-its method does not reach back to those beginnings of culture which far outweigh in importance all subsequent action. And this is no trifling criticism of that method. Is it possible for a truly philosophical system of training the mental powers to have been organized for centuries in all the higher institutions, and not have reacted with controlling power upon the processes of primary instruction? Here a true method must begin, and here scientific education does begin. Commencing early, and commencing with Nature, it lays the foundation of culture in the systematic exercise of the observing powers. In childhood there is a vast capability of accumulating simple facts. The higher forms of mental activity not having come into exercise, the whole plastic power of the brain is devoted to the storing up of perceptions, while the vigour of cerebral growth insures the highest intensity of mental adhesiveness. The capability of grasping relations being low, it makes but little difference at first what objects are presented to attention; words or things, with meaning or without, and in the most arbitrary order, stick readily in the memory. Skilful guidance at this period is of the very 
highest importance. When curiosity is freshest, and the perceptions keenest, and memory most impressible, before the maturity of the reflective powers, the opening mind should be led to the art of noticing the aspects, properties, and simple relations of the surrounding objects of Nature. This should be guided into a growing habit, and the young pupil gradually trained to know how to observe, and what to observe among all the objects of its unfolding experience. It should be encouraged to collect many of the little curiosities which awaken its attention, and required carefully to preserve them; but to do all this judiciously is delicate work. The custodian of the child must know something of the objects of Nature, and much of the nature of the young pupil. Above all other things, teachers qualified to do this work are the desperate need of the age. To perfect the object method, and train instructors to its discriminating use, is one of the great functions of Normal Schools, and must become the practical basis of a rational system of education. Let it be remembered that there is nothing forced or artificial here: the scenes of childish pleasure and exuberant activity furnish the objects of thought. In creating an interest in these things a bent is given in the true direction; the valuable habit of observing and seeking is formed, while the numberless disconnected shreds of knowledge are incipient acquisitions, which will grow with time into the ripened forms of science.

With such a preparation, the transition is natural to the regular study of the sciences, in which the observing and reasoning powers are to be systematically cultivated. For this purpose the first to be taken up are mathematics, physics, or natural philosophy, and chemistry, as they deal with the clearest and simplest conceptions, and depend upon the fewest and most definite conditions. The adaptation of mathematics to cultivate deductive reasoning has been noticed. Physics trains equally to accuracy and precision of 
thought; but, beginning with observation, it exercises the reason inducticely. From particulars we pass to generals, from observed facts to principles, by the mental process of induction, which is a powerful instrumentality. When we contemplate the vast extent of the facts which form the body of the various sciences, and the marvellous rapidity with which they are still accumulating, the task of their acquisition seems appalling, and utterly beyond all grasp of the intellect. But there is an order of Nature by which individual facts are connected and bound together, and there is a corresponding capacity in the human mind of seizing upon those relations, of binding the facts into groups, and of dealing with them, as it were, at wholesale or in masses. This is the faculty of generalization, by which wide-reaching principles replace or represent the infinitude of details, which they include. Indeed, the advance of science essentially consists in the successive establishment of such general principles which rise one above another in higher and higher stages, until a few simple laws are found to explain and represent the wide range of phenomena to which they apply. But now mark, that while in this way knowledge is simplified, the mind is called into higher action. The abstraction of a common law from many facts, while it relieves the memory of the burden of a large portion of them, makes a greater demand fpon the understanding. In proportion as knowledge is compressed in bulk, its quality becomes, as it were, more intense; and just to the degree to which this operation is carried, is greater intellectual effort required to master it. Thus, in gaining command of the facts of nature and rising to a comprehension of the order of the universe, we are at the same time securing the highest and most salutary form of mental discipline; and a form of it, it may be added, for which the traditional system of culture makes no provision.

The physical sciences, moreover, afford a discipline in 
deductive reasoning the same as mathematics, but of a still more valuable character. For while mathematics deals with the smallest number of ideas, those of space and num. ber, which may be abstracted entirely from all material existence, physics includes, in addition to these, the conceptions of matter and force, although it deals with them in their universal properties and forms; and it thus comes nearer to the realities of experience. Deduction is the most common and practical form of mental activity. We are constantly reasoning from our general notions or opinions to particular facts and circumstances. Induction lays the mental foundation by showing us how correctly to arrive at these general notions; deduction guides their constant application;-the physical sciences afford the best training-ground for both.

The mental advantages to be derived from a more thorough study of the physical sciences have been very clearly and impressively presented in a late discourse by Mr. John Stuart Mill,* and his view so strongly confirms the present argument as to justify extended quotation:

The most obvious part of the value of scientific instruction, the mere information that it gives, speaks for itself. We are born into a world which we have not made; a world whose phenomena take place according to fixed law's, of which we do not bring any knowledge into the world with us. In such a world we are appointed to live, and in it all our work is to be done. Our whole working power depends on knowing the laws of the world--in other words, the properties of the things which we have to work with, and to work among, and to work upon. We may and do rely, for the greater part of this knowledge, on the few who in each department make its acquisition their main business in life. But unless an elementary knowledge of scientific truths is diffused among the public, they never know what is certain and what is not, or who are entitled to

* Inaugural address delivered to the University of St. Andrew, February I, I867. By John Stuart Mill. 
speak with authority and who are not: and they either have no faith at all in the testimony of science, or are the ready dupes of charlatans and impostors. They alternate between ignorant distrust, and blind, often misplaced, confidence. Besides, who is there who would not wish to understand the meaning of the common physical facts that take place uncler his eye? Who would not wish to know why a pump raises water, why a lever moves heavy weights, why it is hot at the tropics and cold at the poles, why the moon is sometimes dark and sometimes bright, what is the cause of the tides? Do we not feel that he who is totally ignorant of these things, let him be ever so skilled in a special profession, is not an educated man but an ignoramus? It is surely no small part of education to put us in intelligent possession of the most important and most universally interesting facts of the universe, so that the world which surrounds us may not be a sealed book to us, uninteresting because unintelligible. This, however, is but the simplest and most obvious part of the utility of science, and the part which, if neglected in youth, may be the most easily made up for afterward. It is more important to understand the value of scientific instruction as a training and disciplining process, to fit the intellect for the proper work of a human being. Facts are the materials of our knowledge, but the mind itself is the instrument: and it is easier to acquire facts, than to judge what they prove, and how, through the facts which we know, to get to those which we want to know.

The most incessant occupation of the human intellect throughout life is the ascertainment of truth. We are always needing to know what is actually true about something or other. It is not given to us all to discover great general truths that are a light to all men and to future generations; though with a better general education the number of those who could do so would be far greater than it is. But we all require the ability to judge between the conflicting opinions which are offered to us as vital truths; to choose what doctrines we will receive in the matter of religion, for example; to judge whether we ought to be Tories, Whigs, or Radicals, or to what length it is our dluty to go with each; to form a rational conviction on great questions of legislation and internal policy, and on the manner in which our country should behave to dependencies and to foreign nations. And the need we have of knowing how to discriminate truth, is not confined to the larger truths. All through 
life it is our most pressing interest to find out the truth about all the matters we are concerned with. If we are farmers we want to find what will truly improve our soil; if merchants, what will truly influence the markets of our commodities; if judges, or jurymen, or advocates, who it was that truly did an unlawful act, or to whom a disputed right truly belongs. Every time we have to make a new resolution or alter an old one, in any situation in life, we shall go wrong unless we know the truth about the facts on which our resolution depends. Now, however different these searches for truth may look, and however unlike they really are in their subject-matter, the methods of getting at truth, and the tests of truth, are in all cases much the same. There are but two roads by which truth can be discovered : observation and reasoning; observation, of course, including experiment. We all observe, and we all reason, and therefore, more or less successfully, we all ascertain truths: but most of us do it very ill, and could not get on at all were we not able to fall back on others who do it better. If we could not do it in any degree, we should be mere instruments in the hands of those who could: they would be able to reduce us to slavery. Then how shall we best learn to do this? By being shown the way in which it has already been successfully done. The processes by which truth is attained, reasoning and observation, have been carried to their greatest known perfection in the physical sciences. As classical literature furnishes the most perfect types of the art of expression, so do the physical sciences those of the art of thinking. Mathematics, and its application to astronomy and natural philosophy, are the most complete example of the discovery of truths by reasoning ; experimental science, of their discovery by direct observation. In all these cases we know that we can trust the operation, because the conclusions to which it has led have been found true by subsequent trial. It is by the study of these, then, that we may hope to qualify ourselves for distinguishing truth, in cases where there do not exist the same readly means of verification.

In what consists the principal and most characteristic difference between one human intellect and another? In their ability to judge correctly of evidence. Our direct perceptions of truth are so limited; we know so few things by immediate intuition, or, as it used to be called, by simple apprehension-that we depend for almost all our valuable knowledge on evidence external to itself; and most of us 
are very unsafe hands at estimating evidence, where an appeal cannot be made to actual eyesight. The intellectual part of our education has nothing more important to do than to correct or mitigate this almost universal infirmity - this summary and substance of nearly all purely intellectual weakness. To do this with effect needs all the resources which the most perfect system of intellectual training can command. Those resources, as every teacher knows, are but of three kinds: first, models; secondly, rules; thirdly, appropriate practice. The models of the art of estimating evidence are furnished by science; the rules are suggested by science; and the study of science is the most fundamental portion of the practice. . . The logical value of experimental science is comparatively a new subject, yet there is no intellectual discipline more important than that which the experimental sciences afford. Their whole occupation consists in doing well, what all of us, during the whole of life, are engaged in cloing, for the most part badly. All men do not affect to be reasoners, but all profess, and really attempt, to draw inferences from experience : yet hardly any one, who has not been a student of the physical sciences, sets out with any just idea of what the process of interpreting experience really is. If a fact has occurred once or oftener, and another fact has followed it, people think they have got an experiment, and are well on the road toward showing that the one fact is the cause of the other. If they did but know the immense amount of precaution necessary to a scientific experiment ; with what sedulous care the accompanying circumstances are contrived and varied, so as to exclude every agency but that which is the subject of the experiment-or, when disturbing agencies cannot be excluded, the minute accuracy with which their influence is calculated and allowed for, in order that the residue may contain nothing but what is due to the one agency under examination; if these things were attended to people would be much less easily satisfied that their opinions have the evidence of experience; many popular notions and generalizations which are in all mouths, would be thought a great deal less certain than they are supposed to be; but we should begin to lay the foundation of really experimental knowledge, on things which are now the subjects of mere vague discussion, where one side finds as much to say and says it as confidently as another, and each person's opinion is less determined by evidence than by his accidental interest or prepossession. In politics, for instance, it 
is evident to whoever comes to the study from that of the experimental sciences, that no political conclusions of any value for practice can be arrived at by direct experience. Such specific experience as we can have, serves only to verify, and even that insufficiently, the conclusions of reasoning. Take any active force you please in politics, take the liberties of England, or free trade; how should we know that either of these things conduced to prosperity, if we could discern no tendency in the things themselves to produce it? If we had only the evidence of what is called our experience, such prosperity as we enjoy might be owing to a hundred other causes, and might have been obstructed, not promoted, by these. All true political science is, in one sense of the phrase, a priori, being deduced from the tendencies of things, tendencies known either through our general experience of human nature, or as the result of an analysis of the course of history, considered as a progressive evolution. It requires, therefore, the union of induction and deduction, and the mind that is equal to it must have been well disciplined in both. But familiarity with scientific experiment at least does the useful service of inspiring a wholesome scepticism about the conclusions which the mere surface of experience suggests.

The discipline of observation and strict reasoning afforded by the exact sciences, mathematics, physics, and chemistry, pure and applied, being secured, we then pass to the study of the biological sciences, botany, zoölogy, physiology, geology. A new order of truths and new circumstances of knowledge are here encountered, to which the sciences just considered are an indispensable introduction, but for which, the mental habits they form are not an adequate preparation. We are still carefully to observe, still to reason from facts to general principles, but the facts, though equally positive, are now so different-so complex, inaccessible, and indefinite, as to embarrass inference, and call for a higher exercise of the judgment. Experiment or active observation, which plays so prominent a part in physics and chemistry, is here greatly limited; we cannot isolate the phenomena, and turn them round and round, 
and inside out, so as to compel a revelation of their secrets: hence, in proportion as the sources of error become more numerous and fallacies more insidious, a subtler exercise of the reason is demanded-more circumspection in weighing evidence and checking conclusions, and a severer necessity for suspension of judgment. As the biological sciences deal with the laws of life and the phenomena of living beings, man in his animal constitution and relations, is included in their subject-matter, while the problems presented exercise the mind in a manner similar to the formation of judgments upon human affairs. Complete or demonstrative induction being impossible, we are compelled to form conclusions from only a part of the facts involved, and to anticipate the agreement of the rest. This is reasoning from analogy, a powerful but perilous mode of proceeding; one which we are compelled constantly to adopt in our mental treatment of the concerns of life, and for which biological studies are eminently suited to give the requisite discipline.

Another advantage of the study of these subjects is afforded by the comprehensiveness and perfection of their classifications. No other subjects compare with zoölogy and botany in these respects. Not only do they furnish inexhaustible material for the exercise of memory, but by the presentation of facts in their natural relations they exercise it in its highest and most perfect form. It is maintained by Agassiz that classifications in natural history are but reports of the order of Nature-expressions of her profoundest plan; and he even goes so far as to interpret them as a divine ideal programme of constructions, of which the living world is but the execution. However this may be, it is certain that they open to us the broadest view of the relations and harmonies of organic nature, and are best fitted to discipline the mind in dealing with large co-ordinations, and the comprehensive arrangement of 
objects of thought, whether in the arts, the professions, business, or science.

Dr. Whewell, in his defence of the absorbing attention given to mathematics and physics, in the University of Cambridge, has urged the necessity of admitting, as means of education, only those subjects the truths of which are demonstrated and settled forever. But what is the extent of the field of the absolutely unquestionable? Mathematics do indeed present truths upon which rational beings can never disagree; but supposing that the student becomes a little inquisitive, and ventures to ask something about the grounds and origin of these truths, he is instantly launched into the arena of polemical strife, and his teacher, from being a frigid expositor of self-evident principles, is suddenly transformed into an ardent partisan. Dr. Whewell has been the lifelong champion of certain views respecting the nature of mathematical conceptions, which are sharply contested, and have certainly no more than held their own in philosophical conflict. In the field of physics, also, has not the present generation witnessed one of the deepest and most comprehensive revolutions which the history of science records-the acceptance of a totally new view of the nature and relations of forces? What, indeed, is the object of education, the leading out of the mind, if not to arouse thought and provoke inquiry, as well as to direct them? Is the student's mind a tank to be filled, or an organism to be quickened? It may be well pleasing to indolent and arrogant pedagogues never to have their assertions questioned, but it is wholesome neither for themselves nor their students.

Important as may be the mental preparation for dealing with certainties, it is still more important to prepare for dealing with uncertainties : to ignore this, arrests education at an inferior stage, and but ill prepares for the emergencies of practical life. It is matter of notoriety that the so- 
called liberal culture is no adequate protection against numerous fallacies and impostures which are current in society; and to so great an extent is this true that it is common to question whether, after all, for our real needs, education is better than ignorance. But there is an " educated ignorance," which, for the great end of guiding to action and ruling the conduct, is as worthless as blank ignorance. Take the charlatanries of medical treatment; take the question of so-called "spiritual manifestations," and we find persons of reputed culture and good sense venturing opinions, adopting practices, and professing to "investigate," in the completest ignorance of all the conditions of thinking-all the canons of inquiry which have conducted to truth in this high and complex range of subjects.

To meet these and kindred emergencies of our social experience, we require an education not merely in dead languages, mathematics, and physics, with perhaps a superadded smattering of physiology and geology, but such a training in the fundamental organic sciences as shall constitute a thorough biological discipline.

The direct and powerful bearing of biological studies upon an understanding of the nature and relations of man has been so well stated by Mr. Mill, in the address already referred to, in speaking of the educational claims of physiology, that I cannot forbear making another extract:

The first is physiology; the science of the laws of organic and animal life, and especially of the structure and functions of the human body. It would be absurd to pretend that a profound knowledge of this difficult subject can be acquired in youth, or as a part of general education. Yet an acquaintance with its leading truths is one of those acquirements which ought not to be the exclusive property of a particular profession. The value of such knowledge for daily uses has been made familiar to us all by the sanitary discussions of late years. There is hardly one among us who may not, in some position of authority, be required to form an opinion and take part in public 
action on sanitary subjects. And the importance of understancling the true conditions of health and disease-of knowing how to acquire and preserve that healthy habit of body which the most tedious and costly medical treatment so often fails to restore when once lost, should secure a place in general education for the principal maxims of hygiene, and some of those even of practical medicine. For those who aim at high intellectual cultivation, the study of physiology has still greater recommendations, and is, in the present state of advancement of the higher studies, a real necessity. The practice which it gives in the study of Nature is such as no other physical science affords in the same kind, and is the best introduction to the difficult questions of politics and social life. Scientific education, apart from professional objects, is but a preparation for judging rightly of Man, and of his requirements and interests, But to this final pursuit, which has been called par excellence the proper study of mankind, physiology is the most serviceable of the sciences, because it is the nearest. Its subject is already Man : the same complex and manifold being, whose properties are not independent of circumstance, and immovable from age to age, like those of the ellipse and hyperbola, or of sulphur and phosphorus, but are infinitely various, indefinitely modifiable by art or accident, graduating by the nicest shades into one another, and reacting upon one another in a thousand ways, so that they are seldom capable of being isolated and observed separately. With the difficulties of the study of a being so constituted, the physiologist, and he alone among scientific inquirers, is already familiar. Take what view we will of man as a spiritual being, one part of his nature is far more like another than either of them is like anything else. In the organic world $w$ s study Nature under disadvantages very similar to those which affect the study of moral and political phenomena: our means of making experiments are almost as limited, while the extreme complexity of the facts makes the conclusions of general reasoning unusually precarious, on account of the vast number of circumstances that conspire to determine every result. Yet, in spite of these obstacles, it is found possible in physiology to arrive at a considerable number of well-ascertained and important truths. This, therefore, is an excellent school in which to study the means of overcoming similar difficulties elsewhere. It is in physiology, too, that we are first introduced to some of the conceptions which play the greatest part in the moral and social sciences, but 
which do not occur at all in those of inorganic nature. As, for instance, the idea of predisposition, and of predisposing causes, as distinguished from exciting causes. The operation of all moral forces is immensely influenced by predisposition: without that element, it is impossible to explain the commonest facts of history and social life. Physiology is also the first science in which we recognize the influence of habit-the tendency of something to happen again merely because it has happened before. From physiology, too, we get our clearest notion of what is meant by development or evolution. The growth of a plant or animal from the first germ is the typical specimen of a phenomenon which rules through the whole course of the history of man and society-increase of function, through expansion and differentiation of structure by internal forces. I cannot enter into the subject at greater length; it is enough if I throw out hints which may be germs of further thought in yourselves. Those who aim at high intellectual achievements may be assured that no part of their time will be less wasted, than that which they employ in becoming familiar with the methods and with the main conceptions of the science of organization and life.

Physiology, at its upper extremity, touches on Psychology, or the Philosophy of Mind; and without raising any disputed questions about the limits between Matter and Spirit, the nerves and brain are admitted to have so intimate a connection with the mental operations, that the student of the last cannot dispense with a considerable knowledge of the first. The value of psychology itself need hardly be expatiated upon in a Scottish university; for it has always been there studied with brilliant success. Almost everything which has been contributed from these islands toward its advancement since Locke and Berkeley has, until very lately, and much of it even in the present generation, proceeded from Scottish authors and Scottish professors. Psychology, in truth, is simply the knowledge of the laws of human nature. If there is anything that deserves to be studied by man, it is his own nature and that of his fellow-men : and if it is worth studying at all, it is worth studying scientifically, so as to reach the fundamental laws which underlie and govern all the rest. With regard to the suitableness of this subject for general education, a distinction must be made. There are certain observed laws of our thoughts and of our feelings which rest upon experimental evidence, and, once seized, are a clue to the interpretation of much that we are 
conscious of in ourselves, and observe in one another. Such for example, are the laws of association. Psychology, so far as it consists of such laws (I speak of the laws themselves, not of their disputed applications), is as positive and certain a science as chemistry, and fit to be taught as such.

The discipline and the knowledge conferred by study of the preceding group of sciences form the true preparation for that higher class of studies, mental, moral, political, and literary, which completes the course of a true liberal education. Although not themselves ranked as sciences, these extensive and important subjects are constantly becoming more and more scientific in their conceptions and methods, and hence form the natural sequel of a systematic scientific culture. Physiology passes insensibly into psychology, the central science, upon which hinge logic, sociology, political economy, history, ethics, æsthetics, and literature. Mental phenomena are manifestations of life, and their laws are derivatives of the laws of life; only throngh a knowledge of the former, therefore, is it possible to reach a true understanding of the latter. Logic treats of the laws of evidence and proof, by which things and their relations are truly represented in thought.* Sociology considers the relations among human beings and the forces which act upon them in society, and it hence only becomes possible through a prior knowledge of the vital and mental organization of man; political economy, a branch of this subject, treating of industrial and commercial questions, depends upon the same conditions. History is a record of the course of human experience in its multiform phases, and the key to its right interpretation is that knowledge of the character of the Actor and the circumstances of action which it is the prerogative of science alone to give. Ethics, or moral science, determines the principles which should guide the right ruling of conduct, and depends upon every science

* See page 45 . 
which can throw light on the progress of the intellect, the evolution of the emotions, and the limits of moral liberty and responsibility imposed by the conditions of physical organization or social circumstances. Æsthetics, which regards the beautiful in Nature, and gives rise to the fine arts, depends upon the laws of feeling and sensibility. Its principles are founded in the constitution of human nature, and will probably be yet reduced to a scientific system. To work out its great ideas of "unity," "harmony," "proportion," and the laws of beauty, it awaits a better psychology and a deeper penetration into the true spirit of Nature. Literature is that great body of expression of thought upon a vast variety of subjects, the proper judgment of which depends upon the extent and accuracy of our knowledge of the truth of things in reality, conception, and expression.

Thus does scientific culture reach its ultimate and exalted ends. Its course is along a line of connections which are causal and dynamic; its ideas constantly flowing on and widening out until they embrace all the higher subjects of human interest and inquiry. The order of dependence of facts and principles must here imperatively determine the true order of study. To pass directly from languages and mathematics to the complex questions of man and society, is to violate the continuity of Nature's logic; to carry false methods of reasoning and judgment into the highest spheres of thought, and to provide for those errors of theology and vices of practice which are so lamentably conspicuous in the management of social and public affairs. Only by that scientific discipline which confers a steadfast faith in the universality of law, and only as the discipline of mathematical and physical studies is corrected and amplified by familiarity with biological conceptions, will it be possible to secure a class of thinkers who can grapple with the upper grade of questions in 
which the best welfare of society is involved. The culture afforded by these higher subjects is also varied, copious, and quickening. They give breadth, adaptiveness, and enlarged effect to the discipline of the preparatory sciences, and cultivate mental pliancy, readiness of judgment, and practical sagacity.

If it be objected that this scheme is too vast, I reply, first, the student is not expected to grasp the details of the various sciences, but only to master their leading principles. At least one science, however, should be thoroughly acquired by every well-educated person-should be carried into detall, pursued experimentally, and pushed to its boundaries. The student should be brought face to face with the stern problems of Nature, and taught to wrestle with the difficulties she offers; only thus can he truly know how much is meant by the word "truth," and get the discipline that will give value to his other scientific studies. But while the thorough attainment of a single science may serve for training in method, it is highly desirable, and in a mental point of view completely possible, to master two, say inorganic chemistry and botany. They represent separate orders of scientific truths; both are attractive to fascination, and their opportunities of study are universal.

But, secondly, this scheme is not too extended, because its arrangement economizes mental power in the highest degree. Wasting no force for mere discipline, it gives the entire energies of the mind to the direct attainment of knowledge, while the natural sequence of subjects, and the constant reappearance and re-employment of old acquisitions in the track of progress, guarantees a rapidity of mental advancement and a comprehensiveness of attainment without parallel in past experience. With a reverent acquiescence in the finite limitations of mind, science nevertheless gives the clue to reaches of thought and splen- 
dours of achievement which old routinists regard with incredulity. When Nature becomes the subject of study, the love of Nature its stimulus, and the order of Nature its guide, then will results in education rival the achievements of Science in the fields of its noblest triumphs.

What now is the basis of relative valuations among subjects of thought? These subjects fall into three categories-ist, the objects of Nature; $2 \mathrm{~d}$, their mental representations; $3 \mathrm{~d}$, the devices for marking and distinguishing them; and the various terms employed to express these relations may be thus exhibited:

The External World....... Mind.............. Language.

Things............... Ideas...............Words.

Presentation . . . . . . . . Re-presentation ........Re-representation. Physics................. Metaphysics........... Philology.

Objective Realities ........ Subjective Symbols.......Artificial Symbols.

Objects and Relations Nature's Instruments Man's Instruments to be known........ $\}$ for the work....... $\}$ for the work.

In this scheme we build upon the solid foundation of objective nature, and place first that which we find first in the order of the world-the fabric of being into which we are introduced at birth-which was here before we came and will remain when we are gone. Man's first and his lifelong concern is with his environment, the objective universe of God, the theatre of his activity, ownership, ambition, enjoyment, and the multifarious instrumentality of his experience and education. It is a realm of law, and therefore he can understand and control it: a scene of irresistible forces which crush him if he is ignorant, and serve him if he is wise. But in what manner are created intelligences to deal with the organism of nature in which they have such varied and vital interests? By its ideal recreation for the individual. The brain duplicates the universe in miniature; hence, the passage from things to thoughts; 
from objective realities to their ideal symbols. We here, as it were, take one step away from outward nature and enter a world of representation, which is of great importance to us because of the still greater importance of that which it represents. The overlooking of this fact has been the error of ages. Men have been fascinated with the curious phenomenon of mental representation, and have dwelt upon it in utter neglect of that which is represented. Confessedly of high interest, they have forgotten that it is forever subordinate to the original order for which it stands. Losing themselves in the contemplation of this mystery, metaphysicians have often fallen into a kind of sceptical hallucination as to whether, after all, there are any realities back of the ideas; or, granting an external world, they have held it to be of very trifling account, as all its truths are to be excogitated from the realm of pure ideas. Modern psychology inverts this order, and teaches not only that a knowledge of Nature depends upon the direct study of Nature, but that our knowledge of mind itself, of the relations among ideas, depends upon our prior understanding of the relations of phenomena and of the laws of action in the environment. It was this danger of being beguiled with mere symbols that called forth the sagacious adjuration of Newton, "Oh, physics, beware of metaphysics!" Mr. Mill thus points out the mischievous consequences of the error in the case of logic:

The notion that what is of primary importance to the logician in a proposition, is the relation between the two ideas corresponding to the subject and predicate (instead of the relation between the two phenomena which they respectively express), seems to me one of the most fatal errors ever introduced into the philosophy of logic, and the principal cause why the theory of the science has made such inconsiderable progress during the last two centuries. The treatises on logic, and on the branches of mental philosophy connected with logic, which have been produced since the intrusion of this cardinal error, though sometimes written by men of extraordinary abilities and 
attainments, almost always tacitly imply a theory that the investigation of truth consists in contemplating and handling our ideas, or conceptions of things themselves; a doctrine tantamount to the assertion that the only mode of acquiring knowledge of Nature is to study it at second-hand, as represented in our own minds. Meanwhile, inquiries into every kind of natural phenomena were incessantly establishing great and fruitful truths on most important subjects by processes upon which these views of the nature of Judgment and Reasoning threw no light.*

Another step brings us to language-the system of marks and labels for thought-the "signs of ideas." These are the implements furnished by art for dealing with ideas of things. Through the association of ideas with visible symbols, language becomes the embodiment of thought, and there arises a relation among words growing out of the relations among ideas, which again grow out of the relations among things. Both rest upon the order of Nature which science reveals; but that order is twice refracted through distorting media, and although the semblance of science is to be found in both, yet so many imperfections are introduced at each change, that we are only safe by kceping the intellectual eye steadily fixed upon the primal source of truth. The overshadowing error of present edutation is the propensity to accept words in place of the ideas and things for which they stand, and from which they borrow all their value. This false estimate has been well characterized by the observation that "words are the counters of wise men, but the money of fools." Of course, most of the realities of knowledge are inaccessible to us; we know them only through their verbal signs; but all the more necessary is it that we should never forget that we are dealing with thirdhand representations. Words are the tools of the thinker, which he must know how to handle, or they are useless; but the sensible mechanic remembers that his tools are for

* Mill's System of Logic, vol. i, p. 98. 
nothing but use, and hence spends the least possible time in grinding and polishing them. Words are the vehicles of thought; but as the farmer, who, having ten thousand dollars to invest in his business, should put nine thousand of it in wagons to carry his produce to market, reserving only one thousand to buy a farm, would be justly chargeable with stupidity, so the student who invests the principal share of his time and power in variously constructed vehicles of thought, with a corresponding neglect of what they are to carry, is chargeable with an analogous folly. So much of the study of language, and in such forms as are necessary to its intelligent use, is demanded in education; but while this places the study upon explicit grounds of utility, by the principle of utility should it be limited. But the lingual student, captivated by the interest of word studies, loses the end in the means. A plough was sent to a barbarian tribe: they hung it over with ornaments, and fell down and worshipped it. In much the same manner is language treated in education.*

The old scholasticism sported with symbols, ideal and verbal; science makes a serious inquest into the realities for which they stand. The greatest secular event in history was this inversion of values among subjects of thought, and the rise of science and conquest of Nature which followed; and an event of no less moment will be the carrying out of this great intellectual movement in education.

As respects discipline, these considerations present the question thus: Shall it consist in the mere futile flourishing of the instruments of inquiry, or shall it be obtained

* " There is no study that could prove more successful in producing often thorough idleness and vacancy of mind, parrot-like repetition and sing-song knowledge, to the abeyance and destruction of the intellectual powers, as well as to the loss and paralysis of the outward senses, than our traditional study and idolatry of language."-Prof. Halford Vaughan. 
by their employment upon the ends for which they are designed?

In this discussion I use the term Science in its true and largest meaning, which is nothing less than a right interpretation of Nature-a comprehension of the workings of law wherever law prevails. Knowledge grows. Its germs are found in the lowest grades of ignorance, and develop first into the improved form of common information, which then unfolds into the definite and perfected condition of science. It matters nothing whether the subjects are stones or stars, human souls, or the complications of social relation; that most perfect knowledge of each which reveals its uniformities constitutes its special science, and that comprehensive view of the relations which each sustains to all in the cosmical order, realizes the broadest import of the conception. Science, therefore, is the revelation to reason of the policy by which God administers the affairs of the world. But how inadequate is the conception of it generally entertained, even among men of eminent literary cultivation, who seem to think the highest object of understanding the things of Nature is merely to slake a petty curiosity!*

* Mr. Carlyle writes: "For many years it has been one of my constant regrets, that no schoolmaster of mine had a knowledge of natural history, so far at least as to have taught me the grasses that grow by the wayside, and the little winged and wingless neighbours that are continually meeting me, with a salutation which I cannot answer, as things are! Why didn't somebody teach me the constellations, too, and make me at home in the starry heavens, which are always overhead, and which I don't half know to this day? I love to prophesy that there will come a time, when not in Edinburgh only, but in all Scottish and European towns and villages, the schoolmaster will be strictly required to possess these two capabilities (neither Greck nor Latin more strict!), and that no ingenuous little denizen of this universe be thenceforward debarred from his right of liberty in these two departments, and doomed to look on them as if across grated fences all his life!" No hint is here given of that transcendent order of truth to which surrounding objects are but the portals. 
A common form of misapprehension is that which limits science to the consideration of "mere matter," and then reproaches it with being a cold materializing pursuit. But science deals with forces as well as matter; and when those who make this reproach will indicate just how much remains when the actions of power upon matter are exhausted, they will, perhaps, widen their conceptions upon the subject. Not only do the great lines of scientific thought converge to the supreme end of elucidating the regnant subjects of man and society, but its influence is powerfully felt even in the highest regions of philosophical speculation.*

* Prof. Masson, in his lively little work, Recent British Philosophy, remarks: "In no age so conspicuously as in our own has there been a crowding in of new scientific conceptions of all kinds to exercise a perturbing influence on Speculative Philosophy. They have come in almost too fast for Philosophy's powers of reception. She has visibly reeled anid their shocks, and has not yet recovered her equilibrium. Within those years alone which we have been engaged in surveying there have been developments of native British science, not to speak of influxes of scientific ideas, hints, and probabilities from without, in the midst of which British Philosophy has looked about her, scared and bewildered, and has felt that some of her oldest statements about herself, and some of the most important terms in her vocabulary, require re-explication. I think that I can even mark the precise year $18+8$ as a point whence the appearance of an unusual amount of unsteadying thought may be dated-as if, in that year of simultaneous European irritability, not only were the nations agitated politically, as the newspapers saw, but conceptions of an intellectual kind that had long been forming themselves underneath in the depths were shaken up to the surface in scientific journals and books. There are several vital points on which no one can now think, even were he receiving four thousand a year for doing so, as he might very creditably have thought seventeen years ago. There have been during that period, in consequence of revela. tions by scientific research in this direction and in that, some most notable enlargements of our views of physical nature and of history-enlargements even to the breaking down of what had formerly been a wall in the minds of most, and the substitution on that side of a sheer vista of open space. But there is no need of dating from 1848 , or from any other year in particular. In all that we have recently seen of the kind there has been but 
Yet it is by denying this, and insisting that science consists in collecting stones, labelling plants, and dabbling in chemical messes, that the adherents of tradition strive to render it obnoxious to popular prejudice. In defending the policy of the Great English Schools which contemptuously ignore almost the whole body of modern knowledge, the able Head-master of Rugby puts the case on the explicit ground that science deals only with the lower utilities, while classical studies carry us up to the sphere of life and man; that science only instructs, while they humanize. But we have seen that such a view is indefensible. Science being the most perfect form of thought, and man its proper subject, the sharply defined question is, whether he is to be studied by the lower or the higher method. Is the most thorough acquaintance with humanity to be gained by cutting the student off from the life of his own age, and setting him to tunnel through dead languages, to get such imperfect and distorted glimpses as he may of man and society in their antiquated forms; or by equipping him with the best resources of modern thought, and putting him to the direct and systematic study of men and society as they present themselves to observation and experience? In all other departments it is held desirable, as far as possible, to place directly before the student his materials of inquiry: why abandon the principle in the case of its highest application?

Our question thus assumes another aspect: for the best discipline of the human mind, shall we make use of those higher forms and completer methods of knowledge which constitute the science of the present age, or shall we use the lower and looser knowledge and cruder methods of the past?

the prolongation of an action from Science upon Philosophy that had been going on for a considerable time before." 
Science also has great advantage, as a means of mental discipline, in the incentives to which it appeals for arousing mental activity, its motives to effort being such as the pupil can be made most readily to appreciate and feel. The reasons for studying the dead languages are not such as to act with inspiring force upon beginners: hence motives to exertion have largely to be supplied by external authority, which necessitates in the school discipline a decided coercive element, while those who administer it, having little sympathy with "new-light" notions about making study pleasurable, lighten the student's tasks by the enlivening assurance that wearisome toil is evermore the price of great results.

This is the old ascetic misconception of the controlling aims of life-false everywhere, fatal in education. The free and healthy exercise of the faculties and functions is so pleasurable as to be universally spoken of as a "play"; who, then, has the right to turn it into dreary and repulsive task work? The love of enjoyment is the deepest and most powerful impulse of our nature, and the educational system which does not recognize and build upon it violates the highest claim of that nature. The first thing to be done by the teacher is to awaken the pupil's interest, to engage his sympathies and kindle his enthusiasm, for these are the motors of intellectual progress; it is then easy to enchain his attention, to store his mind with knowledge, and carry mental cultivation up to the point of discipline.

This is of the first importance. Flogging has been the accompaniment of education for centuries; and although the humanizing agencies are slowly bringing us out of this barbaric dispensation, yet the penal policy, or that which makes the fear of pain, in one shape or other, the chief incentive to effort, is still prevalent. This not only appeals to the lowest motives, but is self-defeating. Painful feelings are antivital, depressing, fatal to mental spon- 
taneity, and therefore a hindrance to acquisition: agreeable emotions, on the other hand, are stimulating, and favour nervous impressibility and spontaneous impulsion. The instinctive love of pleasurable activity which is so marked in youth becomes therefore a most powerful means of mental improvement. Government appeals to the dread of punishment as a motive to right conduct; but who will compare the influence it thus exerts upon the beneficent activities of society with the general stimulation to this result which springs from the desire of happiness? A scientific system of culture, which deals with the immediate objects and the living agencies of the world, is suited to employ this higher class of motives. The interest of an unperverted mind in the things of twenty centuries ago can never equal its interest in the things of to-day. It cannot for a moment be admitted that an empty and useless shell of a fact has the same relation to the mind that a living and applicable one has. Nothing can arouse, quicken, and mould it like the realities with which it has to deal. It has been well said that "everywhere throughout nature we find faculties developed through the performance of those functions which it is their office to perform, not through artificial exercises devised to fit them for those functions." A system of culture, therefore, which ignores the thousand immediate pressures and solicitations upon feeling and thought, by which human beings are stirred, can neither shape the mind into harmony with its actual circumstances, nor reach the deepest springs of impulse and exertion. The intellect follows the lead of the heart; and with the slow emergence of right ideas respecting the uses of the world, we shall discover that the real scene of human action and enjoyment is also the true source of inspiration and of the noblest incentives to effort. The end of a rational culture being to adjust the student's relations to his own age, it will employ for the purpose all those sub- 
jects which come home to him most directly; and that these are best fitted for rousing and sustaining a pleasurable mental activity is both declared by reason and confirmed by experience.

And this leads me finally to observe that a mental culture, based upon science, and applied to the great questions of the time, will give a type of mental discipline marked by the elements of vigour and courage, and suited to brace the mind for the serious work which comes before it with the advance of society. In this respect the classical cultivation is so faulty as hardly to deserve the name of discipline. Its ideal is European, and is shaped into accordance with the requirements of the European system: it is that of the refined and elegant scholar, fitted for meditative retirement in some cloistered seclusion or "sacred shade," immersed in the past, and disinclined to meddle with the present. But what Sydney Smith calls "the safe and elegant imbecility of classical learning," is not the preparation needed by the cultivated mind of this country. Here all the cumbrous machinery for taking care of people and superseding thought-Monarchy, Nobility, and StateChurch, are gone, and we are thrown back upon first principles, to work out the great problem of a self-governing society, for weal or for woe. The finished classical scholar blinks the issues, and shirks the responsibilities of his time. He is disgusted with the "noise and confusion" of this degenerate utilitarian age, and longs to bury himself in the quietness of the past. "In proportion as the material interests of the present moment become more and more engrossing, more and more tyrannical in their exactions, in the same proportion it becomes more necessary that man should fall back on the common interests of humanity, and free himself from the trammels of the present by living in the past," says the advocate of the English universities, Dr. Donaldson. But this will not do 
here. Not to "fall back," but to press forward should be the motto of American education. Not to escape the present and live in the past, but resolutely to accept the present, thanking God for its opportunities, and to live rather in the future, is the high requirement of mental duty. And herein is the character of the two systems shown, that while the one looks forever backward, the other leads steadfastly forward. Science, therefore, piercing the future, and working toward it through the present, engages naturally with those great subjects of public interest which are no longer to be postponed or evaded.

The classicists are fond of presenting the issue as between liberal culture and money-making, and triumphantiy contrast the refined and generous feelings which cluster around the former, with the vulgar and sordid motives which characterize the latter. But the real issue is far different from this. The mind of our age is confronted with a host of urgent questions, such as the Perils of Misgovernment, the Limits of Legislation, the Management of Criminals, of the Insane, the Congenitally Defective, and the Pauper Class; the operation of Charities, the Philosophy of Philanthropy, the relations of Sex and Race, International Ethics, the Freedom of Trade, the Rights of Industry, Property in Ideas, Public Hygiene, Primary Education, Religious Liberty, the Rights of Invention, Political Representation, and many others, which inosculate and interfuse into the great total of practical inquiry which challenges the intellect of our times; and it is this which the classical scholar evades, when he shrinks from the present and retires into the past. And well he may; for the mastery of the languages and literatures of Greece and Rome, and culture in unprogressive studies, furnish neither suitable ideas nor mental habits for this kind of work. Science, grounding itself in the order and 
truth of Nature, armed with the appropriate knowledge, and inspired with the hope of a better future, to which it sees all things tending, enters the great field as properly its own, and will train its votaries to that breadth of view, that robust boldness of treatment, and that patient and dispassionate temper which the imminent questions of the times so decisively demand.

In his late instructive lecture on the Development of Ideas in Physical Science, Prof. Liebig shows that it has been a slow organic growth, depending upon deeper conditions than the mere favour or opposition of Church or State. He shows that in Greece the progress of science was arrested by its slave system; points out the necessity of abounding wealth to give leisure for thought and culture, and the importance of those social conditions which bring into intimate intercourse all classes of thinkers and workers, upon the mutual co-operation of which the advance of science and of society depends. He says: "Freedom, that is the absence of all restrictions which can prevent men from using to their advantage the powers which God has given them, is the mightiest of all the conditions of progress in civilization and culture"; and he adds that "it can hardly be doubted that among the peoples of the North American Free States, all the conditions exist for their development to the highest point of culture and civilization attainable by man."

These are weighty considerations for the educators of this country. Institutions are but expressions of ideas and habits; and the European policy, governmental and ecclcsiastical, is grounded upon a culture suited to its necessities, and which has grown up with it in the course of -ages. Both idolize the past; both worship precedent and authority, and both dread independent inquiry into first principles: one recoils from Freedom, as the other from Science. Freedom and Science, on the other hand, have 
had a coeval destiny; have suffered together, and grown together. Both break from prescription and throw themselves upon Nature, and the watchword of both is Progress, which consists not in rejecting the past, but in subordinating and outgrowing it, in assimilating and reorganizing its truth, and leaving behind its obsolete forms. In the last century we threw off the trammels of the repressive system, and entered upon the experiment of Free Institutions; but it avails little to shift the external forms if the old ideas are not replaced by new growths of thought and feeling. Our system of Popular Education is the first great constructive measure of National progress, and this has yet to be moulded to its purposes through a system of higher institutions, organized into harmony with the genius of American circumstances and the great requirements of the period.

In the preceding pages I have quoted Mr. J. S. Mill's able presentation of the claims of Scientific Studies; but lest I be accused of partiality in the use of his authority, it is proper to add that in the same address he makes also a strong argument for the Classics. It is not pertinent here to criticise this branch of his argument, as the claims of the classics are put less on the usual ground of "discipline" than on certain high utilities of scholarship. But while, as the reader has seen, Mr. Mill urges the importance of Scientific Studies for all, an examination of his argument for the Classics will show that it is applicable only to those who, like himself, are professional scholars, and devote their lives to Philological, Historical, or Critical Studies. 


\section{II.}

\section{ON THE SCIENTIFIC STUDY OF HUMAN NATURE.}

Perhaps the most correct conception of science that has yet been formed is that which regards it as the highest stage of growing knowledge. Ideas about men, like those about other subjects, undergo development. There is a rude acquaintance with human nature among barbarians: they observe that the young can be trained, and that men are influenced by motives and passions; for without some such knowledge their limited social relations would be impossible. These primitive notions have been gradually unfolded by time into the completer and more accurate ideas which mark the civilized state. Yet the prevailing knowledge of human nature is still imperfect and empirical-that is, it has not expanded into rational principles and general laws. That it will become still more perfect accords with all analogy; and if this process continues, as it undoubtedly must, there seems reasonable hope of the formation of something like a definite Science of Human Nature.

That the scientific method of inquiry is inadequate and inapplicable to the higher study of man, is a widely prevalent notion, and one which seems, to a great extent, to be shared alike by the ignorant and the educated. Holding the crude idea that science pertains only to the material world, they denounce all attempts to make human nature a subject of strict scientific inquiry, as an intrusion into an illegitimate sphere. Maintaining that man's position is 
supreme and exceptional, they insist that he is only to be comprehended, if at all, in some partial, peculiar, and transcendental way. In entire consistence with this hypothesis, is the prevailing practice; for those who by their function as teachers, preachers, and lawgivers, profess to have that knowledge of man which best qualifies for directing him in all relations, are, as a class, confessedly ignorant of science. There are some, however, and happily their number is increasing, who hold that this idea is profoundly erroneous, that the very term "human nature" indicates man's place in that universal order which it is the proper office of science to explore; and they accordingly maintain that it is only as "the servant and interpreter of nature" that he can rise to anything like a true understanding of himself.

The past progress of knowledge, as is well known, has not been a steady and continuous growth: it has advanced by epochs. An interval of apparent rest, perhaps long protracted, is brought to a close by the introduction of some new conception, which revolutionizes a department of thought, and opens new fields of investigation, that lead to uncalculated consequences. Those who have watched the later tendencies of scientific thought can hardly fail to perceive, that we of the present age are entering upon one of those great epochs in our knowledge of man. Standing at the head of the vast system of being of which he forms a part, it is inevitable that the views entertained concerning him at any age will be but a reflex of the knowledge of nature which that age has reached. So long as little was known of the order of the universe, little could be understood of him in whom that order culminates. Those triumphs of science which are embodied in external civilization are well fitted to kindle our admiration; but they are of secondary moment when compared with the consequences which must flow from the full application of the scientific method to the study of man himself. 
The method of regarding man which tradition has transmitted to us from the earliest ages, is, at the outset, to cleave him asunder, and substitute the idea of two beings for the reality of one. Having thus introduced the notion of his double nature-mind and body as separate independent existences-there grew up a series of moral contrasts between the disjointed products. The mind was ranked as the higher, or spiritual nature, the body as the lower, or material nature. The mind was said to be pure, aspiring, immaterial ; the body gross, corrupt, and perishable; and thus the feelings became enlisted to widen the breach and perpetuate the antagonism. Having divided him into two alien entities, and sought all terms of applause to celebrate the one, while exhausting the vocabulary of reproach upon the other, the fragments were given over to two partiesthe body to the doctors of medicine, and the spirit to the doctors of philosophy, who seem to have agreed in but one thing, that the partition shall be eternal, and that neither shall ever intrude into the domain of the other.

As a necessary consequence of this rupture, the living reality, as a subject of study, disappeared from view, and the dignified fraction was substituted in its place. Not man, but mind, became the object of inquiry. With the disappearance of the actual being, went also the conception of individuality, and there remained only mind as an abstraction, to be considered as literally out of all true relations as if the material universe had never existed. The method thus begun has been closely pursued, and for thousands of years the chief occupation of philosophic thought has been to speculate upon the nature and operations of mind as manifested in consciousness. Admitting the legitimacy of the inquiry, and that it has to a certain extent yielded valid results, it is clear that the effect of the divorce was fatally to narrow the course of investigation and to prevent all free and thorough research into the reality of the case; 
thus justifying the charge of emptiness and fruitlessness which is now so extensively made against metaphysical studies. From Plato to Sir William Hamilton, who inscribed upon the walls of his lecture room, "On earth there is nothing great but man; in man there is nothing great but mind," a method has been pursued so confessedly vacant of valuable results, that its partisans have actually denied the attainment of truth to be their object: declaring that the supreme aim of philosophy is nothing more than to serve as a means of intellectual gymnastics.*

In pointed contrast with this view is the method of modern science. In a spirit of reverence for the order and harmony of Nature where all factitious distinctions of great and small disappear; striving to dispossess herself of prejudice, and to aim only at the attainment of truth; rejecting all assumptions which can show no better warrant than that they were made in the infancy of the race, she begins with the simple examination of facts, and rises patiently and cautiously to the knowledge of principles. The study of man is entered upon in the same temper, and by the same methods, that have conducted to truth in other departments of investigation. Finding the notion of his duality, as interpreted in the past, with its resulting double series of independent inquiries, to be erroneous, science proceeds at the outset to reunite the dissevered fragments of humanity, and to reconstitute the individual in thought as he is in life, a concrete unit-the living, thinking, acting being which we encounter in daily experience. It is now established that the dependence of thought upon organic conditions is so intimate and absolute, that they can no longer be considered except as unity. Man, as a problem of study, is simply an organism of varied powers and activities; and the true office of scientific inquiry is to

* See the opening lectures of Hamilton's Metaphysics. 
determine the mechanism, modes, and laws of its action.

My purpose, on the present occasion, is to show that the doctrine which has prevailed in the past, and still prevails, is doomed to complete inversion; that the bodily organism which was so long neglected as of no account, is in reality the first and fundamental thing to be considered; and that, in reaching a knowledge of mind and character through the study of the corporeal system, there has been laid the firm foundation of that Science of Human Nature, the completion of which will constitute the next and highest phase in the progress of man. Of course, so vast a subject can receive but scanty justice in the limits of a lecture: the utmost that I can hope to do will be to present some decisive illustrations of the dependence of mental action upon the bodily system, and to point out certain important results which have been already arrived at by this method of inquiry. A hasty glance, in the first place, at the several steps by which it has been reached, will help to an understanding of the present state of knowledge upon the subject.

The establishment of the modern doctrine, that the brain is the organ of the mind, naturally led to a train of researches into the conditions of the connection. The instrument of thought, being a part of the living system, is, of course, subject to its laws, and our understanding of its action becomes dependent upon the progress of physiological knowledge. Physiology, again, depending upon the various physical sciences, the higher investigation could proceed only with the general advance of inquiry. The discovery of the circulation of the blood laid the foundation for the modern science of physiology; but that discovery did not reach its full significance until chemistry had revealed the constitution of matter, and the reciprocal action of its elements: only then was it possible to arrive 
at the great organic laws of waste and repair, of digestion, nutrition, and respiration. The brain, in its functional exercise, was found to depend, equally with all other living parts, upon these processes. The discovery of the minuter structure of the brain resulted from the application of the perfected microscope. Its grey matter was found to consist of cells, and the white substance of fibres of amazing minuteness-the cells being regarded as the sources of nerve power, while the fibres serve as lines for its discharge.

When a tolerably clear conception of the structure of the nervous system had been reached, physiology immediately propounded the question of its mode of action. The first decisive response was made a number of years ago, by Sir Charles Bell, who found that there are two great systems of nerves, which perform different functions; one conveying impressions from the surface of the body to the centres, and another transmitting impulses from the centres to the muscles, and thus controlling mechanical movement. This discovery was of the gravest importance. It had been contemptuously asked, What has anatomy to do with mind? Bell silenced this cavilling forever by showing that it first revealed a definite mental mechanism, and traced out some of the fundamental conditions of the working of mind.

A few years later, Dr. Marshall Hall made another very important step in determining the organic conditions of mental activity, by the discovery of the independent action of the spinal cord. It had hitherto been held that the brain was the sole seat of nervous power. All impressions were supposed to be conducted directly to it, and all mandates to the muscles to issue from it; and as the brain was the seat of consciousness and volition, these operations were thought to be essentially involved in every bodily action. But Dr. Hall demonstrated that the spinal cord is itself a 
chain of nerve centres, and that impressions reaching it from the surface through the sensory nerves may be immediately reflected back, through the motor nerves, upon the muscles, thus producing bodily movements, without the brain being at all involved. This is termed reflex action. Thus, if the foot of a sleeper be tickled, it will be jerked away-that is, the impression from the skin is conveyed to the spinal centre, and an impulse is immediately reflected back, which contracts the proper muscles of the limbs, and the foot is withdrawn. The most perfect example of it, however, is where stimulus at the surface produces movements of the limbs after division of the cord from the head, and therefore in total unconsciousness. The discovery of reflex action was the first step in the systematic elucidation of the spontaneous movements, or what is known as the automatic system in animal mechanisms.

But reflex action has another aspect. When an impression passes upward along the cord to the nervous masses at the base of the brain, it first flashes into consciousness and becomes a sensation. Reflex effects now take place, in which sensation and consciousness are implicated. Winking, sneezing, coughing, swallowing, are examples: we are conscious of the actions, but they are not the results of volition. The will may, indeed, exert a partial control over them, but they are usually of an automatic character. Thus far, the part of the nerwous mechanism called into action is the spinal system, and the ganglionic masses at the base of the brain known as the sensorium. This apparatus is not peculiar to man; he shares it with the entire vertebrate series, and it is regarded as the source of all purely instinctive actions.

The establishment of these fundamental facts in reference to the working of the mental mechanism of our nature - the definite separation of a large part of its actions from that higher sphere of intellection and volition to which 
they had hitherto been assigned-was a signal event in the progress of physiological inquiry, as it quickly led to the extension of the principle of automatism to the cerebrum itself. This portion of the brain is now regarded as the organ of all the higher mental activities - the seat of.ideas and of the complex intellectual operations, memory, imagination, reason, volition. The most obvious case of reflex cerebral action is where a remembered or suggested idea. produces a spontaneous movement. Thus the recollection of a ludicrous incident may excite an involuntary burst of laughter, the remembrance of a disgusting taste may cause vomiting. When ideas are associated with pleasure or pain, a class of powerful feelings is produced-the emotions, which become the springs of impulsion, or reflex activity. Those bursts of movement which are peculiar to the various emotions, as anger, terror, joy, and which we term their expressions, are examples of cerebral spontaneity.

These facts prepare us to understand the scope and limits of voluntary activity, the function of which is to restrain the impulsive tendencies, and direct the bodily movements to various ends. In voluntary action the will does not replace or dispense with the involuntary system, but rather uses it. Its action is limited by the laws of the vital mechanism with which it works. Of all the numberless movements going on in the organism, volition has control only of the muscular, and of these but partially. It cannot act directly upon the muscles, but liberates nerve force in the brain, which in turn produces muscular contraction. The voluntary powers determine the end to be accomplished, and employ the automatic system to execute the determination. I will a given action, and of the many hundred muscles in my system, a certain, and perhaps a large number, will be called into simultaneous exercise, requiring the most marvellous combinations of separate ac- 
tions to accomplish it: but the will knows nothing of this; it is concerned with the result alone.

In the formation of habits and in the processes of education, voluntary actions are constantly becoming reflex, or, as it is termed, "secondarily automatic." Thus learning to walk at first demands voluntary effort, but at length the act of walking becomes automatic and unconscious. So with all adaptive movements, as the manipulatory exercises of the arts; they at first require an effort of will, and then gradually become "mechanical," or are performed with but slight voluntary exertion. And so it is, also, in the purely intellectual operations, where the cerebral excitement, instead of taking effect upon the motor system, expends itself in the production of new intellectual effects, one state of consciousness passing into another, according to the established laws of thought. Here, also, the agency of the will is but partial, and the mental actions are largely spontaneous. In the case of memory, we all know how little volition can directly effect. We cannot call up an idea by simply willing it. When we try to remember something, which is, of course, out of consciousness, the office of volition is simply to fix the attention upon various ideas which will be most likely to recall, by the law of association, the thing desired. We have all experienced this impotence of the will to recover a forgotten name, or incident, which may subsequently flash into consciousness after the attention has long been withdrawn from the search. The same thing is observed in the exercise of the imagination. It is said of eminent poets, painters, and musicians, that they are born, and not made; that is, their genius is an endowment of nature-a gifted organism which spontaneously utters itself in high achievements, and they often present cases of remarkable automatism. When Mozart was asked how he set to work to compose a symphony, he replied, "If you once think how you are to do it, you will never write 
anything worth hearing; I write because I cannot help it." Jean Paul remarks of the poet's work: "The character must appear living before you, and you must hear it, not merely see it; it must, as takes place in dreams, dictate to you, not you to it. A poet who must reflect whether, in a given case, he will make his character say Yes, or No, to the devil with him!" An author may be as much astonished at the brilliancy of his unwilled inspirations as his most partial reader. "That's splendid!" exclaimed Thackeray, as he struck the table in admiring surprise at the utterance of one of his characters in the story he was writing. Again, the mental actions which constitute reasoning have an undoubted spontaneous element, the office of volition being, as in the former cases, to rivet the attention to the subject of inquiry, while the gradual blending of the like in different ideas into general conceptions is the work of the involuntary faculties. You cannot will a logical conclusion, but only maintain steadily before the mind the problem to be solved. Sir Isaac Newton thus discloses the secret of his immortal discoveries: "I keep the subject constantly before me, and wait till the first dawnings open, by little and little, into a full light."

But corporeal agency in processes of thought has an aspect still more marked; the higher intellectual operations may take place, not only independent of the will, but also independent of consciousness itself. Consciousness and mind are far from being one and the same thing. The former applies only to that which is at any time present in thought; the latter comprehends all psychical activity. Not a thousandth part of our knowledge is at any time in consciousness, but it is all and always in the mind. An idea or feeling passes out of consciousness, but not into annihilation; in what state, then, is it ? We cannot be satisfied with the indefinite statement, that it is stored away in the receptacle or chamber of memory. Science affirms 
an organ of mind, and demands an explanation, in terms of its action. As the thought passes from consciousness, something remains in the cerebral substratum, call it what you will-trace, impression, residue. What the precise character of these residua may be is perhaps questionable, but it is impossible to deny their existence in some form consistent with the nature of the cerebral structure and activity. All thoughts, feelings, and impressions, when disappearing from consciousness, leave behind them in the nerve substance their effects or residua, and in this state they constitute what may be termed latent or statical mind. They are brought into consciousness by the laws of association, and there is much probability that in this unconscious state they are still capable of acting and reacting, and of working out true intellectual results.

There are few who have not had experience of this unconscious working of the mind. It often happens that we pursue a subject until arrested by difficulties which we cannot conquer, when, after dismissing it entirely from the thoughts for a considerable interval, and then taking it up again, the obscurity and confusion are found to have cleared away, the subject is opened in quite new relations, and marked intellectual progress has been made. Nor can we explain this by assuming that the arrest was simply due to weariness, and the clearer insight to ther estoration of vigour by rest, as after a refreshing night's sleep. Time enters largely as an element of the case; weeks and months are often required to produce the result, while the entirely new development which the subject is found to have undergone, seems only explicable by the intermediate and unconscious activity of the cerebral centre. The brain also receives impressions and accumulates residua in partial or total unconsciousness. In reading, for example, we gather the sense of an author most perfectly while almost oblivious of the separate words. And thus, as Dr. Maudsley re- 
marks, "the brain not only receives impressions unconsciously, registers impressions without the co-operation of consciousness, elaborates material unconsciously, calls latent residua again into activity, without consciousness, but it responds also as an organ of organic life to the internal stimuli, which it receives unconsciously from other organs of the body." *

Science now teaches that we know nothing of mental action, except through nervous action, without which there is neither thought, recollection, nor reason. An eminent authority upon this subject, Dr. Bucknill, says: "The activity of the vesicular neurine of the brain is the occasion of all these capabilities. The little cells are the agents of all that is called mind, of all our sensations, thoughts, and desires; and the growth and renovation of these cells are the most ultimate conditions of mind with which we are acquainted." And again; "Not a thrill of sensation can occur, not a flashing thought, or a passing feeling can take place without a change in the living organism, much less can diseased sensation, thought, of feeling occur without such changes."

These facts sufficiently disclose the agency of the bodily system in carrying on mental action; but the view becomes still more impressive when we observe to what an extent corporeal conditions influence and determine intellectual states.

The weight of the human brain ranges from sixty-four ounces to twenty ounces, and, other things being equal, the scale of intellectual power is held to correspond with its mass. Cerebral action has thus an enormous range of limitation, due to the variable volume of the mental organ, but it is also modified in numerous ways and numberless degrees by accompanying physiological conditions. The brain is an

* The Physiology and Pathology of Mind, by Dr. Maudsley, p. 20. 
organ of power; power depends upon change, and change upon circulation; the lungs and heart are therefore immediately involved. To high and sustained mental power, ample lungs and a vigorous heart are essential. And these organs, again, fall back upon the digestive apparatus, which, if feeble, may impair the capacity of a good heart, sound lungs, and a well-constituted brain. Digestion, and even the caprice of appetite, thus stand in direct dynamic relation to intellectual results.

As the brain is more largely dependent than any other organ upon the torrent of blood which pours through it, we find that even a transient variation in the supply disturbs the course of thought. If a portion of the skull is removed and pressure be made upon the brain, consciousness disappears; and the same thing occurs in fainting, from suspension of the circulation. With invigorated action of the heart there is a general exaltation of the mental powers, while an enfeebled circulation depresses mental activity. Apoplectic congestion produces stupor and insensibility; inflammation of the grey substance causes delirium; while inflammation of the fibrous portion produces torpor and diminishes the power of the will over the muscles. In thus saying that the state of the blood influences the mind, we do not use the term mind in any vague or abstract sense; we mean that it affects our views, opinions, feelings, judgments, actions. Change of circulation alters our mental pitch, and with it our relation to the universe. Dr. Laycock observes: "In the earliest stage of general paralysis there is a feeling of energy. Everything, therefore, appears hopeful to the patient; large enterprises, the success of which he never doubts, occupy his mind, and he rushes sometimes into the most extravagant and wasteful speculations. This is the stage of erethism of the capillaries of the part of the brain affected, when it is just sufficient to excite increased cerebral vigour. If, how- 
ever, from any cause, this activity declines, so as to sink below par, a precisely opposite state of consciousness arises, and the patient may fall into a profound melancholy and be insanely hopeless, distrustful, and anxious as to all events, past, present, and to come."* Even the variation in the quantity of blood which enters the brain, by simply taking the recumbent position, may affect mental activity in a marked degree. Persons who, through overexertion of mind, have impaired the contractility of the cerebral vessels, often become intensely wakeful after lying down, although very drowsy before, and sometimes can only sleep in the erect position. Dendy mentions the case of an individual who, when he retired to rest, was constantly haunted by a spectre, which attempted to take his life; though when he raised himself in bed the phantom vanished.

Persons have had their entire character changed by an apparently trifling interference with the circulation of blood in the head. "A person of my acquaintance," says Dr. Hammond, "was naturally of good disposition, amiable and considerate, but after an attack of vertigo, attended with unconsciousness of but a few minutes' duration, his whole mental organization was changed; he became deceitful, morose, and overbearing." Tuke and Bucknill mention the instance of a conscientious lady, who recovered from the brain congestion accompanying smallpox with her disposition greatly changed. The susceptibility of conscience had increased to a state of actual disease, disturbing her happiness, and disqualifying her for the duties of life.

A blow on the head may produce marked mental derangement. The memory may be dislocated, events obliterated, and whole passages from the past life expunged:

* Correlations of Consciousness and Organization, vol. ii, p. 325. 
the faculty of speech may be partially or wholly destroyed, the memory of words confused, or entire parts of speech lost.

Mental perversions are also caused by certain changes in the properties of the blood. A fluid of amazing complexity, holding in exquisite balance the constituents from which the whole being is elaborated, all delicacies of feeling and niceties of thought depend upon its purity. "Polished steel is not quicker dimmed by the slightest breath than is the brain affected by some abnormal conditions of the blood."

If the poisonous products of bodily waste are not constantly swept from the system, the cerebral changes are disturbed and the mind stupefied. Foods, drinks, and drugs affect specifically the appetites, passions vus, and thoughts. To become exhilarated and in are gyous, man charges his blood with wine; to exalt +1 actifer sensations, he takes hashish; to secure a bri11: .111eritant fancy and luxurious imagination, he uses opium sibilit; to abolish consciousness of pain, he breathes var-ull as pour of chloroform. Swedenborg had a peculiar class culso in th visions "after coffee." "A person I know," observes particl Dr. Laycock, "after taking morphine, in a fever, was ha.iverse unted by hideously grotesque and fiendlike spectres; the within ${ }^{*}$ then shortly changed into groups of comical human face ifferen the and finally altered to forms of the human figure of the $e^{c}$ in the most classic beauty, and then disappeared." And this learnischarg of the ir desire sane vary in a definite order, the early stages of exciter ${ }^{3}$ cting - ient enabling the artist to execute beautiful conceptions th forr. of figures and landscapes; then, as the disease advan th forr ces, he passes into comic delineations, and ends with the ${ }_{\text {able }}^{\text {sation }}$ grotesque, or hideous.

$\mathrm{g}$ and Those fluctuations of feeling with which all are more or Ifischar ss familiar, the alternations of hope and despondency, are vitally connected with organic states. In high health, 
the outlook is confident, there is joy in action, and courage in enterprise; but with a low or disturbed circulation, thin, morbid blood, and bodily exhaustion, there is depression of spirits, gloom, inaction, paralysis of will, and weariness of life. That variability of mental state which is so striking and general an experience with the literary and artistic classes, the periods when work is impossible, the moods of sluggish and unsatisfactory effort, the seasons of steady and successful accomplishment, and the moments of rare exaltation, capricious as they may seem, are but the exponents of varying constitutional conditions.

But the part played by the organism becomes still more ucapparent when we consider the mode of action of the stated fus system in producing mental effects. It has been hence the simp this system is composed of fibres and cells; where a cell and fibrt conceivable case of nervous activity is ment and a discharge, the hise active, producing an excitebeing nothing more than a complex $\mathrm{s}$, action of the organ and discharges. In sleep, for example, the face, producing an impression, or char. a fly lights upon a discharge along the nerves to the grey unge, which causes spinal cord. Here force is again liberated, ti matter of the charged along another set of nerves upon the awhich is dismuscles, which, being contracted, bring the "happropriate place where the fly settled. This is the course of a simple reflex action. But when the brain is epti power in conscious exercise in the higher processes of inte just the same thing occurs. A person may be engallection tranquil thinking, when one idea leads on to angas rer natural train of association-that is, where the another ital deof one state of consciousness is dischare excitem ${ }_{S}$ oblitforming a succession of cerebral changed into anoth $n$ ged: course of thought, a ludicrous idea or a witty combination 
may arise, when a large amount of feeling, or nerve excitement, is suddenly awakened. This may be discharged in several directions. One portion may be spent upon the muscles of the face and chest, producing laughter; another portion may pass along the nerves leading to the stomach, perhaps stimulating digestion; and a third may be expended in producing other states of consciousness or new trains of ideas. Mental action is thus manifested as definite and limited nervous action, and when we speak of the unfolding of mind, as in education, the fact signified is the growing adaptation of the brain and nervous apparatus to produce more and more complex effects in accordance with their necessary mode of working.

The child comes into the world a little fountain of spontaneous power. For certain purposes its nervous mechanism is perfected, channels of discharge are open, connections are ready formed, and reflex actions go on from the first. The infant also inherits the capabilities of its type-that is, the possibility of high development which belongs to man as distinguished from inferior creatures; and it also inherits the special tendencies and aptitudes of its particular ancestors. The order of the surrounding universe now begins to take effect upon it, and working within its organic limits, which of course vary widely in different cases, its education begins. Impressions pour in through the senses, and begin to open channels of discharge through the nerve centres. The child sees and desires an object, but has more or less difficulty in connecting the sensation with the movement necessary tions seize it. By numberless efforts a nervous path is at van, th formed, and when a desirable object is see $t_{1}$, the

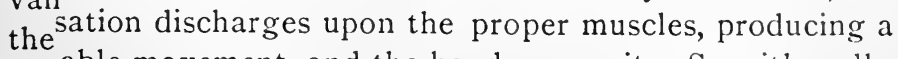
able movement, and the hand grasps it. So with walk${ }_{1 f} g$ and speaking; by repeated exertions lines of nervous lischarge are completed, and the sensations involved are 
co-ordinated with the movements of locomotion and utterance. Repetition strengthens association and facilitates action; that which is difficult at first, requiring a large expenditure of voluntary effort, at last seems "to go of itself." Upon this point Dr. Carpenter remarks: "There can be no doubt that the nerve force is disposed to pass in special tracks, and it seems probable that while some are originally marked out for the automatic movements, others may be gradually worn in by the habitual action of the will, and that thus when a train of sequential actions originally directed by the will has been once set in operation, it may continue without any further influence from that source." *

Thus, in committing to memory a poem, or in learning a piece of music, voluntary effort wears a path of association, so that each word or sound automatically suggests the next, and we can either repeat the words or hum the air in silence, or link on the automatic movements of expression: but by sufficient repetition the words and sounds become so closely associated, that when the first bar of the melody or the first stanza of the poem is awakened, it will cost an effort to prevent running through with them. In this way, as the child grows to maturity, brain connections are established between sensations, ideas, and movements; they become automatic and powerful, and give rise to fixed habits. Peculiarities of gait, attitude, gesture, and speech, and the iteration of set phrases, become partially automatic, their paths of discharge getting so deeply worn that repetition occurs involuntarily. The same thing is seen also in the higher region of ideas and beliefs. Long-established associations and opinions survive their rejection by reason: convince a man of his lifelong errors to-day, and he reasserts them to-morrow, so strong is the tend-

* Principles of Iuman Physiology. Fifth edition, p. 699. 
ency of thought to move in its long-accustomed cerebral tracks.

Now, when we experience a feeling, or think a thought, or determine an act-that is, in every case of excitement and discharge-there is a partial decomposition of the nervous structure in action. In every such act there is loss of energy, or partial exhaustion, the cells and fibres fall below par, and the equilibrium is restored by the nutrition of the weakened part. Brain repair thus takes place in accordance with the modes of mental action, and, as in the blacksmith's arm muscular nutrition is commensurate with its exercise, and augments power, so in every special kind of mental exercise, cerebral nutrition co-operates to raise the standard of nervous power. As waste accompanies exercise, and repair follows waste, the nutrition of the organ is determined by the modes of mental activity-given associations and ideas become patterns, as it were, in conformity to which the brain is moulded. In this way the organic processes re-enforce mental acquisition, and assimilation tends to perpetuate states of feeling and modes of thought and action. Throughout infancy, childhood, and youth, when nutrition is in excess, the brain is thus adapted to its circumstances, and growes to the order of impressions and ideas which it receives.

We have seen that the office of volition is to determine the course of thought and direct bodily actions to specific ends. This capability is the noblest element of our nature, but is greatly variable in different individuals by habit and constitution, and is inexorably limited in all. The will is not an absolute despot, with unbounded authority to do what it lists, but rather a constitutional President, exercising vast power, it may be, but strictly subject to the laws of the organic state. Its regnant prerogative, as we have seen, is that of controlling the attention, by which it is enabled to wield the entire energy of the organism to the 
accomplishment of its purposes. In this way the automatic system becomes a means of exalting the office of volition, and making it in an eminent degree the arbiter of individual destiny. But in the exercise of its prerogative the will is governed by the same great law which rules all the other powers, namely, the acquirement of strength by exercise. Only through that constant exertion by which energy is accumulated can the will gain command of the thoughts and mastery of the impulses. By continual practice the organism grows, as it were, into subordination, and the voluntary powers become habitually predominant. The will is thus, in an eminent degree, capable of education, but when we see how it is enfeebled in bodily debility and utterly extinguished in numerous morbid states of the system, it becomes apparent to what an extent physiological conditions must enter into the policy of its intelligent management. Even its limited freedom, as physicians well understand, is only coincident with healthy bodily action.

Sufficient, I trust, has now been said to show that mental operations are so inextricably interwoven with corporeal actions, that to study them successfully apart is altogether impossible. The mental life and the bodily life are manifestations of the same organism, growing together, fluctuating together, declining together. They depend upon common laws, which must be investigated by a common method; and science, in unravelling the mysteries of the body, has thrown important light upon the workings of the mind. It only remains now to point out, that when subjected to the Baconian test of "fruitfulness "- of practical application to the emergencies of experience-the scientific method of regarding human nature, incomplete as it may be, already stands in marked contrast to the proverbial barrenness of the old metaphysics. I will briefly refer to two or three such applications.

One of the gloomiest chapters of man's social history is 
that which records the treatment of the insane. Those upon whom had fallen the heaviest calamity possible in life, were looked upon with horror, as accursed of God, and treated with a degree of cruelty which seems now incredible. Asylums were dark and dismal jails, where their inmates were left in cold, hunger, and filth, to be chained and lashed at the caprice of savage keepers. And this barbarism continued in countries claiming to be enlightened down to the middle of the present century. Let me mention a solitary instance, of which the literature of the subject is full.

Said Dr. Conolly, in a lecture in 1847: "It was in the Female Infirmary at Hanwell, exactly seven years ago, that I found, among other examples of the forgetfulness of what was due either to the sick or insane, a young woman lying in a crib, bound to the middle of it by a strap around the waist, to the sides of it by the hands, to the foot of it by the ankles, and to the head of it by the neck; she also had her hands in the hard leathern terminations of canvas sleeves. She could not turn, nor lie on her side, nor lift her hand to her face, and her appearance was miserable beyond the power of words to describe. That she was almost always wet and dirty, it is scarcely necessary to say. But the principal point I wish to illustrate by mentioning this case is, that it was a feeble and sick woman who was thus treated. At that very time her whole skin was covered with neglected scabies, and she was suffering all the torture of a large and deep-seated abscess of the breast." "Again," he remarks, "old and young, men and women, the frantic and the melancholy, were treated worse and more neglected than the beasts of the field. The cells of an asylum resembled the dens of a squalid menagerie; the straw was raked out, and the food was thrown in through the bars, and exhibitions of madness were witnessed which are no longer to be found, because they were not the sim- 
ple product of malady, but of malady aggravated by mismanagement."

Now, these statements represent a condition of things as old as history, and we are called upon to account for it. Granting that the insane were dangerous, and required restraint, and granting all that may be urged concerning the barbarity of the times, we have yet to find the cause of the apparently gratuitous ferocity of which they were the victims; and this we do find in the legitimate consequences of the prevailing theory of human nature. The ancient philosophy taught that the body is to be despised, degraded, renounced. 'This view was adopted by theology, and thrown into a concrete and dramatic shape, which made it more capable of vivid realization by the multitude. It pronounced the body to be "a sink of iniquity," the "intrenchment of Satan," a fit residence for demons. The lunatic was one who had incurred Divine displeasure, and was given over to the powers of darkness, by whom he was "possessed." This doctrine, of which witchcraft was one of the developments, abundantly explains the attitude of society toward the victims of mental disorder. What more suitable than dungeons, scourgings, and tortures for the detested wretch, who was thus manifestly forsaken of God and delivered over to the devil? The merciless brute who inflicted untold sufferings upon these unhappy beings deemed himself, like the Inquisitor, but an instrument for executing the will of Heaven.

It availed nothing that, for thousands of years, there had been a broad current of intense and powerful thought in the channels of poetry, polemics, oratory, philosophy, politics, theology, and devotion. All this multifarious culture was powerless to arrest the evil consequences of a radically erroneous view of human nature, for the simple reason that the discovery of truth was not among its objects. It was only when a class of men, participating in 
the new spirit of modern times, and drawn to the investigation by the necessities of their profession, entered earnestly upon the study of the body, that views were reached which have revolutionized and humanized the treatment of the insane. Discovering that the mind is dependent upon the organism, and that its disordered manifestations are the results of organic derangement, they found that insanity is not a devil to be exorcised but a disease to be cured. After a sharp struggle with popular ignorance and traditional prejudice, the better views have triumphed, and society is beginning to reap the beneficent consequences of their labours: the stern and violent measures, that served but to aggravate the malady, have given place to gentle and kindly treatment, which is found to be of itself a most potent means of restoration.

The management of the idiotic, or 'feeble-minded, equally illustrates the argument. Throughout the past no movement was made for the relief of this wretched class, and no one dreamed that anything could be done for them; but the progress of Physiology has made a new revelation in this field also. Dr. Edward Seguin, in his recent able work upon The Treatment of Idiocy by the Physiological Method, observes: "Idiots could not be educated by the methods, nor cured by the treatment, practised prior to 1837 ; but most idiots, and children proximate to them, may be relieved, in a more or less complete measure, of their disabilities by the physiological mode of education."

These facts have a profound significance. They not only show that to be practicable which the world had never suspected to be possible, and that science is true to her beneficent mission in the higher sphere as well as in the lower; they not only show that a change of method in the study of human nature ended some of the grossest barbarisms of the past, but they involve this deeper result-that 
by reaching a knowledge of the true causes of insanity and imbecility, we gain command of the means of their prevention, and arrive at the principles of mental hygiene. And this leads to the consideration of those wider consequences to society at large which the modern method of inquiry is beginning to produce.

This is perhaps best illustrated in the establishment of what may be called the law of mental limitations. The old contrast between matter and mind led to the growth of an all-prevalent error upon this point. To matter belongs extension or limitation in space; but mind is inextended, and therefore it has been inferred to be unlimited: being indefinite, it was supposed to be unbounded in its nature. But force also is inextended, although rigorously limited and measurable; and as mind is nothing more nor less than mental power, it must be subject to the laws of power, and work within quantitative limits, like any other form of force. Power, again, is but the accompaniment of material change, and is hence restricted in quantity by the amount of that change; and as mind is accompanied by cerebral transformation, it must have a necessary limit in the quantity of cerebral transformation. In, therefore, considering man as a being in whom mind is conditioned by a bodily organism, the limitation of mental effects becomes a practical question of the very highest importance.

The doctrine of the conservation of energy and the mutual convertibility of the various forces is now accepted as a fundamental truth of science. Nor is there any ground for regarding the vital forces as an exception to the principle. That the organism cannot create its own force, that its energy is entirely derived from the food ingested, and which, in this point of view, is merely stored force, is beyond question; and the source being thus limited, that its expenditure in one direction makes it impossible to use it in another, is equally evident. This 
principle applies, even in a more marked degree, to the cerebral system. Every one knows that hearty digestion and violent exercise lower the mental activity-that is, the forces are diverted from the brain, and thrown upon the stomach and muscles.

That the purely intellectual powers are also subject to limitation is unquestionable. All minds are fissured with incapacities in one direction or another-clipped away on this side or on that-all are fragmentary. There may be great mathematical ability, but no imagination; fine poetical gifts, without logical faculty; large executive power, coupled with deficient judgment. Dr. Whewell had a powerful memory for books, but a very bad one for persons; Sir William Hamilton cultivated the lore and history of philosophy at the expense of his power of origination and organization; Prescott was so irresolute that he could only spur himself to his literary tasks by the stimulus of betting with his secretary that he would do a certain amount of work in a given time; Theodore Parker was loaded with erudition, but exclaimed on his premature deathbed, "Oh, that I had known the art of life, or found some book, or some man to tell me how to live, to study, to take exercise." The greatest men are all dunces in something: Shakespeare and Newton illustrate the law as absolutely as the veriest weakling of the asylum. The full-orbed intellect is yet to come, and will doubtless bring with it the "perpetual motion" and the Jews" "Messias."

These phenomena find no explanation in the old hypothssis of mind as a vague, spiritual entity; they throw us back immediately on the organism whose acknowledged limitations offer at once a solution of the mystery. These mental inaptitudes may be either organic deficiencies, or a result of concentrating the cerebral energy in certain directions, and its consequent withdrawal from others. 
Thus viewed, every attainment involves the exercise of brain power-each acquisition is a modification of cerebral structure. All sensations of objects and words that we remember, all acquired aptitudes of movement; the associations of the perception of things with visible symbols, vocal actions and sounds, the connection of ideas with feelings and emotions, and the formation of intellectual and moral habits, are all concomitants and consequents of the only kind of action of which the brain is capable-are all the products of organic nutrition; and the rate and limit of acquisition, as well as the capacity for retention, are conditioned upon the completeness of the nutritive processes. As each acquirement involves a growth it is evident that acquisition may reach a point at which the whole organic force is consumed in conserving it, and further attainments can only be made at the expense of the decay and loss of old ones. Hence, if we overburden the brain, as in school "cramming," nutrition is imperfect, adhesion feeble, and acquisition quickly lost.

The one great physiological law upon which bodily and mental health are alike dependent is the alternation of action and repose which results from the limitation of power. 'The eternal equation of vital vigour is, rest equals exercise. That tendency to rhythmic action, which seems to mark all displays of power in the universe, is conspicuously manifested in the organic economy, allowing the muscies of respiration eight hours' repose out of twenty-four, and six hours' rest to those of the heart. The cerebral rhythm is diurnal; except that rest which parts of the brain may obtain when only other parts are in action, the organ finds its appropriate repose in sleep. "Half our days we spend in the shadow of the earth, and the brother of death extracteth a third part of our lives," says the eloquent Sir Thomas Browne; that is, the periodicities of cerebral action are defined by astronomic cycles; 
the brain and the solar system march together. Exercise and repose are equally indispensable to mental vigour; deficiency of exercise produces mental feebleness; deficiency of rest, disease. But there lurks in this statement a deeper and more dangerous meaning than at first appears. The equilibrium once lost is most difficult to restore-there is a fatal persistence in the morbid state. It is a general law of the animal economy, that when the vital powers are from any cause depressed below a certain point, they are not easily, and sometimes are never, repaired. A large loss of blood, or a profound exhaustion, may entail effects upon the constitution which will last for years, perhaps for life. As might be expected, the brain illustrates this principle more impressively than any other portion of the system: if worked beyond its limits, there is produced a rapid exhaustion of power which renders repose impossible. The exhaustion of overwork is accompanied by excitement, which tends to perpetuate the work and accelerate the exhaustion. The will is thus swamped in the uncontrollable mobility of the automatic system, the attention becomes insanely exalted, the brain will not be ordered to rest, and words of warning are wasted. When his physicians admonished Sir Walter Scott of the impending consequences of excessive mental labour, he sadly replied: "As for bidding me not work, you might as well tell Molly to put the kettle on the fire, and then say 'Now don't boil.'"

We live in an age of intense mental activity and everincreasing cerebral strain. Steam and electricity are tasked to bring daily tidings of what is happening all over the world, and impressions pour in upon the brain at a rate with which nothing in the past is comparable. The fierce competitions of business, fashion, study, and political ambition, are at work to sap the vigour and rack the integrity of the mental fabric, and there can be no doubt that there 
is, in consequence, an immense amount of latent brain disease, productive of much secret suffering and slight aberrations of conduct, and which is liable, in sudden stress of circumstances, to break out into permanent mental derangement. The price we pay for our high-pressure civilization is a fearful increase of cerebral exhaustion and disorder, and an augmenting ratio of shattered intellects. We are startled when some conspicuous mind, strained beyond endurance, as in the cases of Hugh Miller, or Admiral Fitzroy, crashes into insanity and suicide, yet these are but symptoms of the prevailing tendencies of modern life.

And here I call attention to the deep defects of that predominant scheme of culture which not only ignores the human brain, and the sciences which illustrate it, as objects of earnest systematic study, but explodes upon it all the traditional contempt which it cherishes for material nature. "This hasty pudding within the skull," said Frederick Robertson, as he epitomized, in a single expression, the stupid prejudice of the prevailing "scholarship." Poor Robertson! smitten down in the midst of a noble career, by the consequences of overtasking, dying of brain disease in the prime of manhood:-how cruelly did Nature avenge the insult !

Men admire the steam-engine of Watt and the calculating engine of Babbage; but how little do they care for the thinking engine of the Infinite Artificer! They venerate days, and dogmas, and ceremonials; but where is the reverence that is due to that most sacred of the things of time, the organism of the soul! We speak of the glories of the stellar universe; but is not the miniature duplicate of that universe in the living brain a more transcendent marvel? We admire the vast fabric of society and government, and that complicated scheme of duties, responsibilities, usages, and laws which constitutes social order; but how few remember that all this has its deep foundation in 
the measured march of cerebral transformations! We point to the inventions, arts, sciences, and literatures, which form the swelling tide of civilization: but were they not all originated in that laboratory of wonders, the human brain? Geological revelations carry us back through durations so boundless, that imagination is bewildered, and reason reels under the grandeur of the demonstration; but through the measureless series of advancing periods, we discover a stupendous plan. Infinite Power, working through infinite time, converges the mighty lines of causality to the fulfilment of an eternal design-the birth of an intellectual and moral era through the development of the brain of man, which thus appears as the final term of an unfolding world.

The ultimate and decisive bearing of the foregoing views upon plans and processes of instruction can hardly fail to have been perceived. The scientific method of studying human nature, important as may be its relation to the management of the insane and feeble-minded, and valuable as is its service in establishing the limits of mental effort, must find its fullest application to the broad subject of education. For, whatever questions of the proper subjects to be taught, their relative claims, or the true method of teaching may arise, there is a prior and fundamental inquiry into the nature, capabilities, and requirements of the being to be taught, upon the elucidation of which all other questions immediately depend. A knowledge of the being to be trained, as it is the basis of all intelligent culture, must be the first necessity of the teacher.

Education is an art, like Locomotion, Mining, or Bleaching, which may be pursued empirically or rationally, as a blind habit, or under intelligent guidance; and the relations of science to it are precisely the same as to all the other arts-to ascertain their conditions and give law 
to their processes. What it has done for Navigation, Telegraphy, and War, it will also do for Culture. The true method of proceeding may be regarded as established, and many important results are already reached, though its systematic application is hardly yet entered upon. Although there is undoubtedly a growing interest in the scientific aspects of the subject, yet what Mr. Wyse wrote twenty-five years ago remains still but too true. He says, "It is unquestionably a singular circumstance, that, of all problems, the problem of Education is that to which by far the smallest share of persevering and vigorous attention has yet been applied. The same empiricism which once reigned supreme in the domains of chemistry, astronomy, and medicine still retains possession, in many instances, of those of education. No journal is kept of the phenomena of infancy and childhood; no parent has yet registered, day after day, with the attention of an astronomer who prepares his ephemerides, the marvellous developments of his child. Until this is done there can be no solid basis for reasoning; we must still deal with conjecture." And why has nothing been done? Because, in the prevailing system of culture, the art of observation, which is the beginning of all true science, the basis of all intellectual discrimination, and the kind of knowledge which is necessary to interpret these observations, are universally neglected. Our teachers mostly belong to the old dispensation. Their preparation is chiefly literary; if they obtain a little scientific knowledge, it is for the purpose of communicating it, and not as a means of tutorial guidance. Their art is a mechanical routine, and hence, very naturally, while admitting the importance of advancing views, they really cannot see what is to be done about it. When we say that education is an affair of the laws of our being, involving a wide range of considerations-an affair of the air respired, its moisture, temperature, density, purity, and 
electrical state; an affair of food, digestion, and nutrition ; of the quantity, quality, and speed of the blood sent to the brain; of clothing and exercise, fatigue and repose, health and disease ; of variable volition, and automatic nerve action; of fluctuating feeling, redundancy and exhaustion of nerve power; an affair of light, colour, sound, resistance; of sensuous impressibility, temperament, family history, constitutional predisposition, and unconscious influence; of material surroundings, and a host of agencies which stamp themselves upon the plastic organism, and reappear in character; in short, that it involves that complete acquaintance with corporeal conditions which science alone can give-when we hint of these things, we seem to be talking in an unknown tongue, or, if intelligible, then very irrelevant and unpractical.

That our general education is in a deplorably chaotic state, presenting a medley of debased ideals, conflicting systems, discordant practices, and unsatisfactory results, no observing person will question; that this state of things is to last forever, we all feel to be impossible; and that its future removal can only come through that powerful instrumentality to which we owe advancement in other departments of social activity, is equally clear to the reflecting. The imminent question is, How may the child and youth be developed healthfully and vigorously, bodily, mentally, and morally? and science alone can answer it by a statement of the laws upon which that development depends. Ignorance of these laws must inevitably involve mismanagement. That there is ? large amount of mental perversion, and absolute stupidity, as well as of bodily disease, produced in school, by measures which operate to the prejudice of the growing brain, is not to be doubted; that dulness, indocility, and viciousness, are frequently aggravated by teachers incapable of discriminating between their mental and bodily causes, is also 
undeniable ; while, that teachers often miserably fail to improve their pupils, and then report the result of their own incompetency as failures of nature, all may have seen, although it is now proved that the lowest imbeciles are no sunk beneath the possibility of elevation.

The purpose of the foregoing remarks has been to bring forward an aspect of man which cannot fail to have an important influence upon processes of instruction. I have endeavoured to illustrate the extent to which Nature works out her own results in the organism of man. The numerous instances of self-made men, who, with no external assistance, have risen to intellectual eminence, and the still more marked instances where students have forced their way to success in spite of the hindrances of an irrational culture, testify to the power of the spontaneous and self-determining tendencies of human character, while the general overlooking of this fact has unquestionably led to an enormous exaggeration of the potency of existing educational methods. In establishing this view, science both limits and modifies the function of the instructor. It limits it by showing that mental operations are corporeally conditioned, that large regions of our nature are beyond direct control, and that mental attainment depends in a great degree upon inherited capacity and organic growth. It limits it by showing that ancestral influences come down upon us as we enter the world, like the hand of Fate; that we are born well, or born badly, and that whoever is ushered into existence at the bottom of the scale, can never rise to the top, because the weight of the universe is upon him. It shows how not to mistake the surface effects of an ostentatious system for a thorough informing of character; how not to mistake the current smattering of languages, the cramming for examinations, the glossing of accomplishments, the showy and superficial pedantries of literature, and the labelling of degrees, for true education. 
The office of the teacher is thus narrowed but not denied. If inherited organization is a factor of destiny never to be cancelled, there is another factor in that culture which rests upon a knowledge of the laws of life and character. Science modifies the tutorial offices by disclosing the direction of its real work, and guarding against waste of effort, and specious and spurious results-by showing that education does not consist in the acquisition of knowledge to be siphoned into the intellectual receivers of the schoolroom, but is rather to direct the working of a mechanism over which neither its owner nor his teacher is omnipotent-a mechanism in which effects follow causes, and which always operates according to law. It shows the instructor that he must take his pupil as he finds him; not a mental abstraction, to be classed with other "minds" and worked by a universal formula, but a personal reality - a part of the order of Nature, which never repeats itself in a single case; a being with individual attributes which are inexorably bound within the limits of his organization. It therefore demands of him to leave the lore which is glorified by tradition until he has thoroughly grounded himself in the elements of that knowledge of human nature -of the springs of action and the conditions and possibilities of real improvement, which alone can confer the highest skill in quickening the intellect and moulding the character.

I have thus attempted to prove that only by inverting the rule of the past, which exalted the mind at the expense of the body, and bringing the resources of modern induction to the study of the corporeal organism, can we arrive at that higher and clearer knowledge of man, which will make possible anything like a true Science of Human Nature. I have pointed out the salutary results which have already flowed from this method in the crucial test of the treatment of the insane, and the vast benefits which 
society cannot fail to reap from that clearer perception of the laws of vital and mental limitations which recent research has so decisively established; and I have also endeavoured to unfold the bearing of this view upon the subject of education; but the results enumerated are far from exhausting the broad applicability of the method. The grand characteristic of science is its universality; what is it, indeed, but the latest report of the human mind on the order of Nature? Its principles are far-reaching and all-inclusive, so that when a knowledge of the true constitution of man is once attained, it confers insight into all the multitudinous phases of human manifestation. The same economy of power which science confers in the material world, and by which we obtain a maximum of effect from a minimum of force, she confers also in the world of mind. When we have mastered the laws of physical education we have the essential data for dealing with questions of mental education, and these steps are the indispensable preparation for an enlightened moral education. And the same knowledge of the organism which shows how it may be best developed, gives also the clue to the understanding of its aberrant phenomena. That mysterious ground which has hitherto been the hot-bed of noxious superstitions and dangerous quackeries, is reclaimed to rational investigation, and the remarkable effects of reverie, ecstasy, hysteria, hallucinations, spectral illusions, dreaming, somnambulism, mesmerism, religious epidemics, and other kindred displays of nervous morbidity, find adequate explanation in the ascertained laws of our being. This kind of knowledge is, furthermore, not only of the highest value to all classes for practical guidance, but the philosophical students of man, whether viewing him in the moral, religious, social, æsthetic, ethnological or historic aspects, must find their equal and indispensable preparation in the mastery of the biological and 
psychological laws which can alone explain the nature of the subject of their research.

After what has been said, it will not be supposed that I entertain any very extravagant expectations of the immediate results to be obtained from improved methods of dealing with human nature. On the contrary, one of the most impressive lessons of science is that permanent growths are slow, and that there are limits which cannot be overpassed. Dealing largely with causes which only work out their results in the fulness of time, it teaches patience, hope, and labour; and not the least of its salutary influences will be, through wholesome discipline of the imagination, and a rational control of the sympathies, to check the waste of power upon impossible projects, and restrain those enthusiasms which are born of the feelings rather than of the judgment. Nor do I believe that the perfectibility of the human race is at hand through the teaching of a little more physiology in schools, or that science is to apply a calculus to human actions, and thus supersede the common sense and practical judgments of mankind. That there is a vast body of valid knowledge concerning the nature of man which is reduced to application, and serves for the management of conduct, is shown in all the multifarious aspects of social activity: I simply hold that this knowledge, valuable as it is, is yet imperfect -in many respects deplorably imperfect-and must grow to a higher state and a more scientific character : and that the organized culture of the present age is bound to help and not to hinder this tendency. The time, I think, has come for demanding that the curriculum of modern liberal education be so reconstructed that its courses of study shall have a more direct and positive bearing upon that most desirable end-a clearer understanding of the Laws of Human Nature. 
III.

\section{WHAT WE MEAN BY SCIENCE.}

In the plan of this journal,* ${ }^{*}$ scientific subjects are to have a prominent share of attention; and as there is not a little confusion in the popular mind as to the ideas conveyed by the term "Science," it is desirable to get a definite understanding of it. At all events, it is necessary to indicate as clearly as possible the signification which will be attached to the word in these pages.

In its prevailing use, the term science suggests a special kind of knowledge which is different from common knowledge, and pertains to a particular class of subjects which are looked upon as foreign to the interests of common life. It is generally regarded as relating to external or physical objects, and calls up ideas of minerals, insects, drug shops, or electrical exhibitions, with a copious literature of forbidding terms. In conformity with this notion, the science department of popular journalism usually consists of a mass of items thrust into an obscure place, where we are briefly informed of the discovery of a new mineral or asteroid, a novel chemical process, a hitherto undescribed zoöphyte, or the latest inventive exploit in the way of churns. Science has its periodicals professedly and properly devoted to the technical details and results of research. These are minced and sorted, and then reproduced for the edification of the public. This information is no

* Appletons' Journal, started in $\mathbf{1} 869$, is the one here alluded to. 
doubt useful, but, to offer it as affording any just idea of science, is little better than a caricature. The time has come when this noble term should be redeemed from these degrading associations, and made to stand for the larger and higher things which it now truly represents. Science is not the peculiar property of a few curious persons, who spend their days in watching bugs, or their nights in watching the stars. It is something, on the contrary, which belongs to the mind itself ; which pertains to our very modes of thinking, and therefore concerns everybody. It is something to be used in reading, conversation, and business, at home and in the street, week days and Sundays, in school, at the lecture, and the political gathering. Let us see how this is.

The iiteral meaning of the term science is to know. But it has been found that there are two kinds of knowing: we may know a subject loosely and vaguely, or with clearness and precision. So important has this distinction now become, that it is necessary to mark it in language, and so the word science has come to be applied to one of those kinds of knowledge; it means, to know accurately. In the course of time and experience, knowledge slowly passes from the indefinite to the definite, from the vague to the precise. This change is of the nature of a growth, and hence, in its quality, science may be defined as the higher or more perfect stage of developing knowledge.

For example, men, in the rudest ages, observed that the days were longer in summer than in winter, and that there was a constancy in the relative position and a reg"larity in the movements of the stars: this was the dim beginning of a knowledge which has grown at length into the splendid science of astronomy. So it was known to everybody that fuel disappears in combustion, and that stones are altered by fire; and these vague notions have been, in time, unfolded into the science of chemistry. In like manner, it 
was understood, even in periods of earliest barbarism, that with scarcity the price of food rises; and that bits of metal may be made serviceable to carry on exchanges: these were the germs which have grown into a body of definite and connected truths, which form the science of political economy. Again, at the earliest dawn of intelligence, men knew that objects seen together are apt to be remembered together: this rudimental fact has been expanded in modern times into the science of psychology.

Such being the essential character of science, the question next arises, How much does the term comprehend? Our knowledge of Nature is all of this growing or progressive kind. In every aspect of the natural world the explanations were at first crude and imperfect, and have gradually ripened into greater distinctness and precision. We are thus brought to the full breadth of meaning of the term science, which is nothing less than the latest and truest interpretation of the order of the world at which the human mind has arrived. It is the perfected mode of thinking in its application to all the phenomena of Nature which can become the subjects of thought.

But it will be asked, What do you mean by Nature? We mean the whole system of appearances-objects and actions-by which we are surrounded in the present state of being. It includes the entire realm of existence and activity, material and mental, with all their interconnections and interactions, which constitute the environment of man. As the material world is but part of the natural order, physical knowledge is but a part of science. Our knowledge of mind and character, of the springs and limits of human action, of the relations of men and the conditions of social welfare, may be either loose and confused, or definite and accurate. This kind of knowledge conforms equally to the conditions of growth, and therefore has its true scientific aspects. But we can only comprehend the 
present attitude of the subject by referring to the relations which subsist among the various departments of thought.

The purely physical sciences, corresponding to the material phases of Nature, are the simplest, and have been developed first. By studying the internal or atomic changes of matter, the science of chemistry has been arrived at. Inquiries concerning the air have led to meteorology, and investigations into the earth's crust have given rise to geology. But the intellectual movement thus exemplified is far from stopping with an exploration of material phenomena. Success here but sharpens the mind for the further research of truth. These departments of physical study have their highest value as a preparation - for something beyond. They are but the training ground of the human intellect for larger spheres of inquiry. The development of the physical sciences has produced grand and beneficent results, as all men know. But the advance of industrial civilization, to which they have led, is far from being their most important effect. Nor is their disclosure of the order of material Nature, by which man has been translated from the darkness of ignorance and superstition into the light and hope of knowledge, by any means their strongest claims to honour. It is in that higher education, and nobler discipline of the human mind, which can alone qualify it to enter upon the more exalted questions of the real nature of man himself, and his true relations to the surrounding world and to his fellow-men; it is here that the nobler function of the physical sciences is to be sought.

That accuracy of thinking, which it is the business of science to enforce, has led to the detection of those uniformities in the course of Nature which we term law. More and more clearly is it perceived that all kinds of action exemplify cause and effect, and therefore conform to law; and more and more apparent is it also becoming that all 
measures of improvement, individual and social, must depend upon our thorough understanding and vivid realization of the conditions and laws upon which all improvement depends. It is not sufficient to know, in a general way, that fresh air is salutary and foul air injurious; the appreciation of the effects must be so clear and intense as to control action like an instinct. To bring about this state of mind, slowly, of course, in the mass of the people, is the duty and destiny of science. Its supreme educational office is to teach men to think more carefully and closely upon whatever subject they are required to think. Its larger use is to habituate them to guard against the disturbing influence of the feelings and the warpings of prejudice, to look beyond the immediate and to forecast distant consequences, to weigh evidence. and avoid those errors of judgment which lead to rash and mistaken practice.

Imperfect knowledge is misleading; the more accurate it is, the better it serves for guidance. But this is no more true in navigation or mining than it is in commercial business or in teaching. The subjects, however, are in some cases simpler than in others, and the simpler must obviously serve as stepping stones to the more complex. It is not that knowledge is to be carried over from one field to another, but the mental training acquired in one field is to be employed in another. Granted that eminent skill in mathematics will not be a suitable preparation for a judge, or expertness in chemistry qualify for the intelligent management of a prison; granted that the knowledge conferred by scientific studies, as at present arranged, is not that demanded in dealing with the practical questions of everyday life; the fact nevertheless remains, that the cultivation of scientific-that is, accurate-habits of thought is the best preparation for action in all circumstances of responsibility. 


\section{IV.}

\section{THE RELIGIOUS WORK OF SCIENCE.}

I HAVE been asked to speak on this occasion upon the important subject of Religion and Science. Much has been said concerning it, and much more will have to be said before the public are duly instructed as to the relation they bear to each other. I have had no time to prepare anything at all worthy the greatness and interest of the topic, and can only offer you some rough suggestions, very hastily drawn up, concerning one of its aspects, viz., The Religious Work of Science. There is deep meaning in the phrase "revolutions of thought," for in the advance of opinion ideas not only diverge, but they go round to opposite positions; they are not only modified, but reversed, and propositions long held as true often turn out to be not only erroneous, but the exact opposite of the truth. The earth, for example, was first supposed to be flat-it is now known to be round; it was long believed to be stationary-it is now known to be in rapid motion; it was long considered as of very recent origin-it is now recognized as having had an incalculable antiquity. Such total inversions of belief are numerous in the past course of thought, and are destined, I suspect, to become still more numerous in the future. I think it will turn out that our present subject furnishes another illustration of it. Science has long been regarded and is still widely believed to be the antagonist of religion; the time is not distant when it will be accepted as its most powerful ally and best friend. 
By science I understand that knowledge which is gained by the intellect of the order of things around us, of which we form a part, and of the laws by which that order is governed. Religion I understand essentially to be the feeling entertained toward that Infinite Being, Power, or Cause, by whatever name called, of which all things are the manifestation, and which is regarded and worshipped as the Creator and Ruler of the Universe. It is the office of science to explore the works of God; of religion to deal with the sentiments and emotions which go out toward the Divine Author of these works. But if praise and adoration are due to the Creator because of the harmony and grandeur displayed in the creation, are not they working to distinctly religious ends who reveal to us these grand characteristics of Divine achievement? To whom are we indebted for a knowledge of the order that God has instituted in the universe? It is to the men whose appreciation of it has been so high that they have given their lives to the discovery of its truths; and if these truths are divine, is not the research in a preeminent sense a religious work? Among the ancients so little was known of the operations of Nature that nothing like a general order or system of laws was suspected. The natural, in fact, was not differentiated in conception from the supernatural. The whole scheme of things was bedded in superstition and mysticism, and the human mind was given over to the conceits and absurdities of an unbridled imagination. It was only with the rise of modern science, in the recent centuries, that the idea of an order of Nature began to dawn upon the world of thought. Copernicus led the way by destroying the geocentric astronomy, and with it the anthropocentric system of ideas that had grown up around it. His theory of the planetary motions opened the door to the conception of their true laws and causes. Kepler and Galileo verified and extended his work, and prepared the way for Newton, who struck out the universal 
law of attraction, which explains the celestial harmonies. This closed the first great scientific epoch by the establishment of the principle of natural order throughout space. But if the order of the universe prevails through space, must it not also prevail through time? Inquiry now took a new direction, the current widened, new sciences arose, and another century of research revealed the grand truth that the system of order and law is as vast and perfect in its time relations as it had been shown to be in the relations of space.

This mighty revelation of the workings of the Infinite Power we owe not to those who devoted themselves professionally to the exposition of the plans and purposes of God, but to men of science who got neither sympathy nor co-operation from that class. In their whole course from the beginning of research, the scientific students of Nature encountered two orders of obstacles. The first pertained to the character of the work. The discovery of new truth is not an easy thing; it is too precious to be had for the mere asking. Under the best methods it is a difficult, painful, and uncertain pursuit, while the methods themselves were only attainable through long experience. Nor is it given to every earnest devotee of science to add to the stock of original truth: while thousands strive, but few secure the prizes. Moreover, the early investigators were embarrassed and constantly defeated by the inherited mass of errors and prejudices by which judgment was warped and the mental vision obscured. The idea that law is inflexible and universal throughout Nature was long unrecognized, and the special students of science went no further than to assume it in their own fields of investigation. Added to these difficulties was the widespread and deeply rooted feeling among the ignorant masses-which in this respect comprehend almost everybody - that existing knowledge was sufficient, and that to pry into the mysteries of Nature was idle, 
if not irreverent and presumptuous. Such were some of the necessary obstacles which scientific men had to overcome in their religious task of unfolding the divine truths which the Creator had embodied in the constitution of the world. But they had difficulties to encounter of another kind. The crude primitive ideas, by which the powers above Nature were supposed to be constantly interfering with its operations, were borne down the current of tradition, and, conforming to the general beliefs, were systematically maintained and defended. The theologians who claimed to be authorized expounders of the divine policy insisted not only that breaks and interruptions of the natural order occurred, but they maintained that it is in these breaches of it that the Creator is to be most conspicuously and impressively seen. Holding that the normal phenomena are of small concern, while their ruptures alone disclose divine intervention, they left it to the men of science to work out the natural order to its completeness, and to vindicate the Almighty, whose wisdom is witnessed not in the violations but in the perfection of his works.

Certainly science has not been the enemy of religion in this, but it is equally certain that theology has been the adversary of science. It has been the business of theology to defend accepted opinions, and it has been the business of science to question them and arrive at new opinions. What the general issue has been would seem obvious, but upon this parties differ. Prof. Hitchcock, at the Tyndall banquet, said: "It seems sometimes as though science and religion had met in a very narrow path on a dizzy ridge, and were interlocking their antlers in a struggle that must be fatal to one or the other of them. If it comes to this, I think history suggests that science, and not religion, must go down the cliff." Prof. Huxley thinks differently. In his Lay Sermons he remarks: "It is true that if philosophers 
have suffered, their cause has been amply avenged. Extinguished theologians lie about the cradle of every science as the strangled snakes beside that of Hercules, and history records that whenever science and orthodoxy have been fairly opposed, the latter has been forced to retire from the lists, bleeding and crushed, if not annihilated." But be this as it may, science has achieved its noble work, as all the world now testifies. It has gained supremacy over the forces of Nature, it has established principles for the guidance of human action, it has liberated the human mind from the paralyzing fear and thralldom of superstition, and opened a new and more hopeful dispensation for humanity. But its grandest achievement is that it has recreated the universe in thought, and, by elevating and expanding man's conceptions of the sphere of harmony and law, has exalted our reverential feelings toward the Infinite Power by which it is ordered and sustained. So profound a revolution as science has accomplished must be felt in every department of thought, theological as well as others, and its influence here is something more than a perturbation; it is seen in a radical modification of views. Less and less do we hear from theologians of what is to be learned from the lapses and suspensions of physical law, and more and more of the teachings of its unbroken order. Theology begins to accord to science the leadership of thought, and avows her readiness to accept whatever science can establish as truth. Take a recent case.

Within the present generation scientific men have promulgated the doctrine that the universe did not come into existence in the way generally believed, but that it has been gradually unfolded, and that the world and all that it contains are but the final terms in an immense series of changes which have been brought about by natural causes in the course of immeasurable time. No theory ever before propounded by science was so all-disturbing as this. It re- 
sets all the problems of Nature and of man. If evolution be a truth, then must we reconsider all the questions of physics and metaphysics that have been settled under the hypothesis that all things came recently and suddenly into existence as we now see them. If evolution be true, the standpoint of all philosophical and scientific inquiry must be changed; old explanations will not answer. The convention of orthodox theologians just held in this city did not shirk this question; they gave it place and time and provided for its consideration. A distinguished divine was appointed to report upon it, which he did in an elaborate paper on "The Religious Aspects of the Doctrine of Development." For science there is but one aspect to the question, Is it true? Theology has other interests to consider, but the inquiry into its bearings presupposed the possible verity of the theory. Dr. McCosh does not deny it, but after surveying the succession of plants and animals in the geological epochs, he said: "In looking at these phenomena, men discover everywhere development or evolution. It appears in inanimate nature, in suns, planets, and moons being evolved out of an original matter in a way which implies that the earth is older than the sun, and must have existed in ages and had light shining upon it before the sun took his solid form. It is a characteristic of organized beings to produce others after their kind. Those who view development in the proper light see in it only a form or manifestation of law. Gravitation is a law of contemporaneous nature, extending over all bodies simultaneously-over sun, moon, and stars the most remote. Development is a law of successive nature, and secures a connection between the past and the present, and, I may add, the future, securing a unity and it may be a progression from age to age. It is merely an exhibition of order running through successive ages, as the other is of order running through coexisting objects." Dr. 
McCosh then points out that there are difficulties with the doctrine, and adds: "I am not sure that religion has any interest in holding absolutely by one side or other of this question which it is for scientific men to settle. I am not sure that religion is entitled to insist that' every species of insect has been created by a special fiat of God, with no secondary agent employed." Dr. McCosh again says: "It is useless to tell the younger naturalists that there is no truth in the doctrine of development, for they know that there is truth which is not to be set aside by denunciation. Religious philosophers might be more profitably employed in showing them the religious aspects of the doctrine of development, and some would be grateful to any who would help them to keep their old faith in God and the Bible with their faith in science."

In the discussion which followed, which was free from bitterness, and which, if evincing some ignorance, evinced also a wholesome desire for knowledge, one of the delegates-the Rev. Dr. Brown, of large opportunities, as he represented St. Petersburg, Cape of Good Hope, and Berwick-upon-Tweed-declared that, as a botanist of twenty years' standing, he accepted the development hypothesis. Indeed, he declared his conviction "that the confirmation or general adoption of the hypothesis of development will ultimately exercise a beneficial influence on religion," which benign influence will be due to the labours of the scientific men who have worked the truth out in the pitiless hailstorm of general execration. Dr. Hodge, of Princeton, the Boanerges of orthodoxy, neither denied the doctrine of evolution nor denounced its believers as unchristian, and was oniy solicitous about its theological relations. He said: "The great question which divides theists from atheists, Christians from unbelievers, is this, Is development an intellectual process guided by God, or is it a blind process of unintelligible, unconscious force, which knows no end and adopts no means?" 
It is worthy of note that the most retrograde position was taken by a distinguished man of science. Dr. Dawson, the geologist, proposed to relegate the question to scriptural decision. Theologians no longer claim for the Bible the character of an infallible scientific text-book; Dr. Dawson avowed it as his authority in biology. He is reported to have said that " as regards varieties Darwin is well enough, but as regards species I don't believe in it, because it comes in conflict with the Bible." President Anderson was willing to admit Darwinism, not as an established fact but as a working hypothesis, which of course implied that it coordinated the facts and expressed the truth more perfectly than any other view. He said: "If a man talks to me about erolution and believes in a God that unrolls the magnificent plan of the universe, I humbly thank God for such a doctrine. When a development is put before me that excludes God, I don't believe a word of it."

We certainly cannot complain that the theologians view the subject in a theological light, but they should be careful that it is not a false light. What would Dr. Anderson think of one who should annex the condition he proposes to the acceptance of the law of gravitation or the atomic theory? The question of evolution is to be first settled by evidence as true or false, and this, as Dr. McCosh admits, it belongs to science alone to determine. If it be rejected by science, there is an end of it for everybody; if it be established, nothing remains for theologians but to adjust it in their system and put it to its proper theological uses. We are here, however, chiefly concerned to note the register of advancing liberality among the evangelicals, as inlicated by the discussion. They defer to science, and do not shrink from the most obnoxious theories, as research shows them to be true. They are to be congratulated on their own development, which is so marked as to lend no small support to the hypothesis. Twenty years ago Dr. 
Brown would have been ejected from such a convention by explosive indignation, as leprous with heresy; and if things proceed at this rate, in twenty years more we shall expect to see the whole Alliance rise to its feet in expression of respect and gratitude when the names of Spencer and Darwin are mentioned. I believe myself that evolution is a grand objective truth of the universe, still much obscured and beset with difficulties, but unmistakably outlined and supported by a mass of evidence that preponderates overwhelmingly. In a religious point of view it has but one significance. Offering a grander conception of the cosmical order and a deeper insight into its wonderful workings than had ever before been attained, it is the sublimest tribute that the human mind has ever made to the glory of the Divine Power to which it must be ascribed. With the acceptance of evolution the unworthy philosophy which has sought to honour God by the derangements of his own work comes to an end, and the argument passes into a new phase. This we owe to science, and there is encouraging evidence that theologians even of the orthodox stamp are beginning to appreciate it and to be powerfully influenced by it. Let me give an example of the large and enlightened views which we now frequently hear from orthodox pulpits.

In a sermon preached before the British Association for the Advancement of Science, in Edinburgh, r871, the Rev. Dr. Caird, now principal of Glasgow University, said: "When God was so conceived as to place him outside of Nature the tendency would be to seek the most significant proof of his presence in interferences with her order, and to regard the assertion of the absolute uniformity of her processes as equivalent to a denial of Providence or the exclusion of God." And there could be no question that a false jealousy had often been entertained by sincere but mistaken religionists with reference to the idea of natural law and the ever-widening domain which science had won 
for it. There was a stage of mental development in which every unexplained fact or phenomenon was translated into the direct expression of a divine will and purpose. But as knowledge advanced the domain of the marvellous was driven further and further back, and innumerable effects, accounted for at first only by immediate supernatural agency, began to be traced to the operation of natural causes. Fixed sequences and relations displaced isolated facts, and law began to take the place of arbitrariness and caprice. And so step by step, as irregularity disappeared and science shed on Nature its all-penetrating light, the darkness in which superstition lived was chased away, and its divinities exorcised from the world. But as the process went on, it had unfortunately sometimes happened that sincere but unenlightened friends of religion had exhibited that jealousy of science which only superstition had just cause to feel. The conflict on this ground between science and theology was, however, a purely imaginary one. In the observation of Nature and the tracing out of her uniform sequences and laws there was, rightly viewed, nothing that led to the suppression of a higher faith, and such an influence could only be ascribed to scientific pursuits by setting up in the mind a false opposition between law and personality. Men wanted to trace a personal thought and agency, the marks of spiritual, supernatural presence in the universe. But the unreflecting mind was apt to associate personality with mere will, and to attach to fixed movement, unbending order and adjustment, the notion of something mechanical, of a blind, material necessity, over which it was the prerogative of a personal intelligence to assert its superiority. This notion was obviousiy one which deeper reflection and higher intellect would tend to remove. For the more men advanced in intelligence, the more clearly did they begin to see that it was only a vulgar necessity of thought which 
identified personality with changefulness, and arbitrariness with sudden paroxysmal acts and special interferences.

What, then, I ask, to a thoughtful observer, would be the kind of phenomena, the aspect of things and events, which would look most like the signs of a personality and a will in Nature? Surely these phenomena and that aspect, from which the indications of anomaly were most completely banished, and throughout which, from beginning to end, reigned calm and changeless order, unbroken sequence and continuity, the majestic presence of power and law. Even if the modern theory of evolution were conclusively established; even if it were proved that as surely as the germ contains virtually the full-grown plant, the whole history of the material universe was potentially contained in the first atom, or "cosmic vapor," and that not a single act of what was erroneously designated supernatural creative power had ever been intercalated into it, so far from excluding, this would only be more profoundly consistent with the agency of an absolutely personal intelligence. For it would be only more fully significant of an intelligence in which the end was ever presupposed in the beginning, and the beginning surely prophetic of the end; and all things were woven together by the grand necessities of thought.

Thus is it confessed that the inflexible order of the universe, as discovered and proclaimed by science, bears the loftiest witness to its Divine Creator, and the revolution of thought is complete. For the view long held as religious, science has substituted a view that is more eminently religious. Shall we deny, then, that those who are deepening and widening our conceptions of the realm of natural truth, are doing an essentially religious work? And may it not be that the constructors of the philosophy of evolution are entitled to a leading place among the evangelists of our time? 
HERBERT SPENCER AND THE DOCTRINE OF EVOLUTION.

THE change that has taken place in the world of thought within our own time, regarding the doctrine of Evolution, is something quite unprecedented in the history of progressive ideas. Twenty years ago that doctrine was almost universally scouted as a groundless and absurd speculation; now, it is admitted as an established principle by many of the ablest men of science, and is almost universally conceded to have a basis of truth, whatever form it may ultimately take. It is, moreover, beginning to exert a powerful influence in the investigation and mode of considering many subjects; while those who avow their belief in it are no longer pointed at as graceless reprobates or incorrigible fools.

With this general reversal of judgment regarding the doctrine, and from the prominence it has assumed as a matter of public criticism and discussion, there is naturally an increasing interest in the question of its origin and authorship; and also, as we might expect, a good deal of misapprehension about it. The name of Herbert Spencer has been long associated in the public mind with the idea of Erolution. And while that idea was passing through what may be called its stage of execration, there was no hesitancy in according to him all the infamy of its paternity; but when the infamy is to be changed to honour, by a kind of perverse consistency of injustice there turns out to be a good deal less alacrity in making the revised award. 
That the system of doctrine put forth by Mr. Spencer would meet with strong opposition was inevitable. Representing the most advanced opinions, and disturbing widely cherished beliefs at many points, it was natural that it should be strenuously resisted and unsparingly criticised. Nor is this to be regretted, as it is by conflict that truth is elicited; and those who, after candid examination, hold his teachings to be erroneous and injurious, are certainly justified in condemning them. With such, at the present time, I have no controversy, but propose to deal with quite another class of critics. There are men of eminence, leaders of opinion, who neither know nor care much for what Mr. Spencer thinks or has done, but are quite ready with their verdicts about him; and, so long as it is not generally known to what an extent we are indebted to him for having originated and elaborated the greatest doctrine of the age, these superficial and careless deliverances from conspicuous men become very misleading and injurious. By many he is regarded as only a clever and versatile essayist, ambitious of writing upon everything, and who has done something to popularize the views of Mr. Darwin and other men of science. For example, M. Taine, in a late Paris journal, says: "Mr. Spencer possesses the rare merit of having extended to the sum of phenomena-to the whole history of Nature and of mind-the two master thoughts which, for the past thirty years, have been giving new form to the positive sciences; the one being Mayer and Joule's Conservation of Energy, the other Darwin's Natural Selection." Colonel Higginson says : * "Mr. Spencer has what Talleyrand calls the weakness of omniscience, and must write not alone on astronomy, metaphysics, and banking, but also on music, on dancing, on style." And again: "It seems rather absurd to attribute to him, as a

* Estimating Spencer, in The Friend of Progress, IS64. 
scientific achievement, any vast enlargement or further generalization of the modern scientific doctrine of evolution." To the same effect, Mr. Emerson, when recently called upon by a newspaper interviewer to furnish his opinions of great men, declared Mr. Spencer to be nothing better than a "stock writer, who writes equally well upon all subjects."

These are not the circumspect and instructive utterances which we should look for from men of authority whose opinions are sought and valued by the public; they are gross and inexcusable misrepresentations, and exemplify a style of criticism that is now so freely indulged in that it requires to be met, in the common interest of justice and truth. By their estimates of Mr. Spencer, the gentlemen quoted have raised the question of his position as a thinker, and the character and claims of his intellectual work. I follow their lead, and propose, on the present occasion, to bring forward some considerations which may help to a more trustworthy judgment upon the subject. Assuming the foregoing statements to be representative, it will be worth while to see what becomes of them under examination. My object will be, less to expound or to defend Mr. Spencer's views, than to trace his mental history, and the quality and extent of his labours as disclosed by an analysis and review of his published writings.

And first, let us glance at the general condition of thought in relation to the origination of things when he began its investigation. Character is tested by emergencies, as well in the world of ideas as in the world of action; and it is by his bearing in one of the great crises of our progressive knowledge of Nature that Mr. Spencer is to be measured.

Down to the early part of the present century it had generally been believed that this world, with all that it contains, was suddenly called into existence but a few 


\section{Herbert Spencer and the Doctrine of Evolution. 505}

thousand years ago in much the same condition as we now see it. Throughout Christendom it was held with the earnestness of religious conviction, that the universe was a Divine manufacture, made out of nothing in a week, and set at once to running in all its present perfection. This doctrine was something more than a mere item of faith; it was a complete theory of the method of origin of natural things, and it gave shape to a whole body of science, philosophy, and common opinion, which was interpreted in accordance with this theory. The problem of origins was thus authoritatively solved, and life, mind, man, and all Nature, were studied under the hypothesis of their late and sudden production.

But it was difficult to inquire into the existing order of Nature without tracing it backward. Modern science was long restrained from this procedure by the power of traditional beliefs, but the force of facts and reasoning at length proved too strong for these beliefs, and it was demonstrated that the prevailing notion concerning the recent origin of the world was not true. Overwhelming evidence was found that the universe did not come into existence in the condition in which we now see it, nor in anything like that condition; but that the present order of things is the outcome of a vast series of changes running back to an indefinite and incalculable antiquity. It was proved that the present forms and distributions of mountains, valleys, continents, and oceans, are but the final terms of a stupendous course of transformations to which the crust of the earth has been subjected. It was also established, that life has stretched back for untold millions of years; that multitudes of its forms arose and perished in a determinate succession, while the last appearing are highest in grade, as if by some principle of order and progression.

It is obvious that one of the great epochs of thought had now been reached; for the point of view from which 
natural things are to be regarded was fundamentally and forever altered. But, as it is impossible to escape at once and completely from the dominion of old ideas, the full import of the position was far from being recognized, and different classes of the thinking world were naturally very differently affected by the new discoveries. To the mass of people who inherit their opinions and rarely inquire into the grounds upon which they rest, the changed view was of no moment; nor had the geological revelations much interest to the literary classes beyond that of bare curiosity about strange and remote speculations. To the theologians, however, the step that had been taken was of grave concern. They were the proprietors of the old view; they claimed for it supernatural authority, and strenuously maintained that its subversion would be the subversion of religion itself. They maintained, moreover, that the controversy involved the very existence of God. The most familiar conception of the Deity was that of a Creator, and crcation was held to mean the grand six-day drama of calling the universe into existence; while this transcendent display of power had always been devoutly held as alike the exemplification and the proof of the Divine attributes. How deep and tenacious was the old error is shown by the fact that, although it has been completely exploded; although the immeasurable antiquity of the earth and the progressive order of its life have been demonstrated and admitted by all intelligent people, yet the pulpit still clings to the old conceptions, and the traditional view is that which generally prevails among the multitude.*

To men of science the new position was, of course, in the highest degree important. It was stated by Prof. Sedgwick, in an anniversary address to the Geological Society of London in 1831 , as follows: "We have a series of 
proofs the most emphatic and convincing that the approach to the present system of things has been gradual, and that there has been a progressive development of organic structure subservient to the purposes of life." The traditional explanation of the origin of the world, and all that belongs to it, being thus discredited, it only remained to seek another explanation: If it has not been done one way, how has it been done? was the inevitable question. One might suppose that the effect of the utter breakdown of the old hypothesis would have been to relegate the whole question to the sphere of science, but this was far from being done. The preternatural solution had failed, but its only logical alternative, a natural solution, or the thorough investigation of the subject on principles of causation, was not adopted or urged. The geologists occupied themselves in extending observations and accumulating facts rather than in working out any comprehensive scientific or philosophical principles from the new point of view. The result was a kind of tacit compromise between the contending parties-the theologians conceding the vast antiquity of the earth, and the geologists conceding preternatural intervention in the regular on-working of the scheme; so that in place of one mighty miracle of creation occurring a few thousand years ago, there was substituted the idea of hundreds of thousands of separate miracles of special creation scattered all along the geological ages, to account for the phenomena of terrestrial life. Two systems of agencies-natural and supernatural-were thus invoked to explain the production of effects. What it now concerns us to note is, that the subject had not yet been brought into the domain of science. One portion of it was still held to be above Nature, and therefore inaccessible to rational inquiry; while that part of the problem which was withheld from science was really the key to the whole situation. Under the new view the question of the origin of 
living forms, or of the action of natural agencies in their production, was as completely barred to science as it had formerly been under the literal Mosaic interpretation; and, as questions of origin were thus virtually interdicted, the old traditional opinions regarding the genesis of the present constitution of things remained in full force.

It is in relation to this great crisis in the course of advancing thought that Herbert Spencer is to be regarded. Like many others, he assumed, at the outset, that the study of the whole phenomenal sphere of Nature belongs to science; but he may claim the honour of being the first to discern the full significance of the new intellectual position. It had been proved that a vast course of orderly changes in the past has led up to the present, and is leading on to the future: Mr. Spencer saw that it was of transcendent moment that the laws of these changes be determined. If natural agencies have been at work in vast periods of time to bring about the present condition of things, he perceived that a new set of problems of immense range and importance is opened to inquiry, the effect of which must be to work an extensive revolution of ideas. It was apparent to him that the hitherto forbidden question as to how things have originated had at length come to be the supreme question. When the conception that the present order had been called into being at once and in all its completeness was found to be no longer defensible, it was claimed that it makes no difference how it originated -that the existing system is the same whatever may have been its source. Mr. Spencer saw, on the contrary, that the question how things have been caused is fundamental; and that we can have no real understanding of what they are, without first knowing how they came to be what they are. Starting from the point of view made probable by the astronomers, and demonstrated by the geologists, that, in the mighty past, Nature has conformed to one system 
of laws; and assuming that the existing order, at any time, is to be regarded as growing out of a pre-existing order, Mr. Spencer saw that nothing remained for science but to consider all the contents of Nature from the same point of view. It was, therefore, apparent that life, mind, man, science, art, language, morality, society, government, and institutions, are things that have undergone a gradual and continuous unfolding, and can be explained in no other way than by a theory of growth and derivation. It is not claimed that Mr. Spencer was the first to adopt this mode of inquiry in relation to special subjects, but that he was the first to grasp it as a general method, the first to see that it must give us a new view of human nature, a new science of mind, a new theory of society-all as parts of one coherent body of thought, and that he was the first to work out a comprehensive philosophical system from this point of inquiry, or on the basis of the principle of Evolution. In a word, I maintain Spencer's position as a thinker to be this: taking a view of $\mathrm{Na}$ ture that was not only generally discredited, but was virtually foreclosed to research, he has done more than any other man to make it the starting point of a new era of knowledge.

For the proof of this I now appeal to his works. Let us trace the rise and development of the conception of Evolution in his own mind, observe how he was led to it and how he pursued it, and see how completely it pervades and unifies his entire intellectual career. Tarious explanatory details that follow I have obtained from conversations with Mr. Spencer himself; but the essential facts of the statement are derived from his works, and may be easily verified by any who choose to take the trouble of doing so.

Mr. Spencer is not a scholar in the current acceptation of the term; that is, he has not mastered the curriculum of any university. Unbiased by the traditions of culture, his 
early studies were in the sciences. Born in a sphere of life which made a vocation necessary, he was educated as a civil engineer, ${ }^{*}$ and up to $\mathbf{1} 84^{2}$, when he was twenty-two years of age, he had written nothing but professional papers published in the Civil Engineer and Architects' Journal. But he had always been keenly interested in political and social questions, which he had almost daily heard discussed by his father and uncles. In the summer of 1842 he began to contribute a series of letters to a weekly newspaper, the Nonconformist, under the title of The Proper Sphere of Government. It was the main object of these letters to show that the functions of government should be limited to the protection of life, property, and social order, leaving all other social ends to be achieved by individual activities. But, beyond this main conception, it was implied throughout that there are such things as laws of social development, natural processes of rectification in society, and an adaptation of man to the conditions of social life. The scientific point of view was thus early assumed, and society was regarded not as a manufacture but as a growth. These letters were revised and published in a pamphlet in $\mathbf{r} 843$.

The argument, however, was unsatisfactory from its want of depth and scientific precision, and Mr. Spencer decided in 1846 to write a work in which the leading doctrine of his pamphlet should be affiliated upon general moral principles. By reading various books upon moral philosophy he had become dissatisfied with the basis of morality which they adopt; and it became clear to him that the question of the proper sphere of government could be dealt with only by tracing ethical principles to their roots. The plan of this work was formed while Mr. Spencer was still a civil engineer; and it was commenced in 1848 , before he abandoned engineering and accepted the position of sub-

* See Note B. 
editor of the Economist. It was issued, under the title of Social Statics, at the close of $185^{\circ}$. In this work various developments of the ideas contained in the pamphlet above named are noticeable. It will be seen that the conception that there is an adaptation going on between human nature and the social state has become dominant. There is the idea that ali social evils result from the want of this adaptation, and are in process of disappearance as the adaptation progresses. There is the notion that all morality consists in conformity to such principles of conduct as allow of the life of each individual being fulfilled, to the uttermost, consistently with the fulfilment of the lives of other individuals; and that the vital activities of the social human being are gradually being moulded into such form that they may be realized to the uttermost without mutual hindrance. Social progress is in fact viewed as a natural evolution, in which human beings are moulded into fitness for the social state, and society adjusted in to fitness for the natures of men-the units and the aggregate perpetually acting and reacting, until equilibrium is reached. There is recognized not only the process of continual direct adaptation of men to their circumstances by the inherited modifications of habit ; but there is also recognized the process of the dying out of the unfit and the survival of the fit. And these changes are regarded as parts of a process of general evolution, tacitly affirmed as running through all animate Nature, tending ever to produce a more complete and self-sufficing individuality, and ending in the highest type of man as the most complete individual.

After finishing Social Statics Mr. Spencer's thoughts were more strongly attracted in the directions of biology and psychology-sciences which he saw were most intimately related with the progress of social questions; and one result reached at this time was significant. As he states in the essay on the Laws of Organic Form, published 
in ${ }_{1} 8_{59}$ in the Medico-Chirurgical Review, it was in the autumn of ${ }_{1} 8_{5} \mathrm{I}$, during a country ramble with Mr. George Henry Lewes, that the germinal idea of that essay was reached. This idea, that the forms of organisms, in respect of the different kinds of their symmetry and asymmetry, are caused by their different relations to surrounding incident forces, implies a general recognition of the doctrine of Evolution, a further extension of the doctrine of adaptation, and a foreshadowing of the theory of life as a correspondence between inner and outer actions.

In $185_{2} \mathrm{Mr}$. Spencer published in the Westminster Review the Theory of Population deduced from the General Law of Animal Fertility, setting forth an important principle which he says that he had entertained as far back as 1847 . Here also the general belief in Evolution was tacitly expressed; the theory being that, in proportion as the power of maintaining individual life is small, the power of multiplication is great; that along with increased evolution of the individual there goes decreased power of reproduction; that the one change is the cause of the other; that in man, as in all other creatures, the advance toward a higher type will be accompanied by a decrease of fertility; and that there will be eventually reached an approximate equilibrium between the rate of mortality and the rate of multiplication. Toward the close of this argument there is a clear recognition of the important fact that excessive multiplication and the consequent struggle for existence cause this advance to a higher type. It is there argued that "only those who do advance under it eventually suriz'," and that these "must be the select of their generation." 'That which, as he subsequently stated in the Principles of Biology, Mr. Spencer failed to recognize at this time $\left(\mathrm{I}_{5} \mathrm{5}_{2}\right)$ was the effect of these influences in producing the diversitics of living forms; that is, he did not then perceive the co-operation of these actions of the struggle 
for existence and the survival of the fittest, with the tendency to variation which organisms exhibit. He saw only the power of these processes to produce a higher form of the same type, and did not recognize how they may give rise to divergencies and consequent differentiations of species, and eventually of genera, orders, and classes.

Early in $185^{2}$ Mr. Spencer also printed a brief essay in the Leader, on The Development Hypothesis, in which some of the new current reasons for believing in the gradual evolution of all organisms, including man, are indicated. To this paper Mr. Darwin refers in the introductory sketch of the previous course of research on the subject of development, which he prefixed to the Origin of Species. In this essay, however, direct adaptation to the conditions of existence is the only process recognized.

In October of the same year $\left(185^{2}\right)$ Mr. Spencer published an essay in the Westminster Review, on the Philosophy of Style, in which, though the subject appears so remote, there are traceable some of the cardinal ideas now indicated, and others that were afterward developed. The subject was treated from a dynamical point of view, and, as Mr. Lewes remarks in his essays on The Principles of Success in Literature, it offers the only scientific exposition of the problem of style that we have. The general theory set forth is, that effectiveness of style depends on a choice of words and forms of sentence offering the least resistance to thought in the mind of the reader or hearer-a foreshadowing of the general law of the "line of least resistance" as applied to the interpretation of psychological phenomena, as well as phenomena in general. Morsover, at the close of the essay there is a reference to the law of Evolution in its application to speech-there is a recognition of the fact that "increasing heterogeneity" has been the characteristic of advance in this as in other things, and that a highly evolved style will "answer to the descrip- 
tion of all highly organized products, both of man and of Nature; it will be, not a series of like parts simply placed in juxtaposition, but one whole made up of unlike parts that are mutally dependent." Here, as early as 1852 , there is recognized in one of the highest spheres both the process of differentiation and the process of integration-the two radical conceptions of Evolution.

In July of the next year (r853) Mr. Spencer's continued interest in the question of the functions of the state led him to write the essay on Over-Legislation in the Westminster Review; and here, as in Social Statics, the conception of society as a growth, under the operation of natural laws, is predominant.

The critical perusal of Mr. Spencer's works shows that this was a very important period in the development of his views. The reading of Mr. Mill's Logic along with some other philosophical works had led him to the elaboration of certain opinions at variance with those of Mr. Mill on the question of our ultimate beliefs, and those he published in the Westminster Review, under the title of The Universal Postulate (1853). The inquiries thus commenced, together with those respecting the nature of the moral feelings, and those concerning life and development, bodily and mental, into which he had been led both by Social Statics and the Theory of Population, prepared the way for the Principles of Psychology. Some of the funclamental conceptions contained in this remarkable work now began to take shape in his mind. Other ideas connected with the subject began also to form in his mind, an example of which is furnished by the essay on Manners and Fashion, published in the Westiminster Review (April, 1854). Various traits of the general doctrine of Evolution are here clearly marked out in their relations to social progress. It is shown that the various forms of restraint exercised over men in society-political, ecclesiastical, and 
ceremonial-are all divergent unfoldings of one original form, and that the development of social structure, in these as in other directions, takes place by gradual and continuous differentiations, "in conformity with the laws of Evolution of all organized bodies."

Mr. Spencer was at the same time engaged in working out his view in a different sphere; the essay on the Genesis of Science being contributed to the British Quarterly Review in July, $\mathbf{1} 854$. This was primarily called forth by Miss Martineau's Abridgment of Comte, then just issued, and was in part devoted to the refutation of the French philosopher's views respecting the classification of the sciences. But it became the occasion for a further development of the doctrine of Evolution in its relation to intellectual progress. The whole genesis of science is there traced out historically under the aspect of a body of truths, which, while they became differentiated into different sciences, became at the same time more and more integrated, or mutually dependent, so as eventuaily to form "an organism of the sciences." There is besides a recognition of the gradual increase in definiteness that accompanies this increase in heterogeneity and in coherence.

It was at this time that Mr. Spencer's views on psychology began to assume the character of a system-the conception of intellectual progress now reached being combined with the ideas of life previously arrived at, in the development of a psychological theory. The essay on the Art of Education,* published in the North British Review (May, r854), assisted in the further development of these ideas. In that essay the conception of the progress of the mind during education is treated in harmony with the con-

* Republished in his little work on Education, under the title of Intellectual Education. 
ception of mental Evolution at large. Methods are considered in relation to the law of development of the faculties as it takes place naturally. Education is regarded as rightly carried on only when it aids the process of selfdevelopment; and it is urged that the course in all cases followed should be from the simple to the complex, from the indefinite to the definite, from the concrete to the abstract, and from the empirical to the rational.

Having reached this stage in the unfolding of his ideas, Mr. Spencer began the writing of the Principles of Psychology in August, 1854 . This is a work of great originality, and is important as marking the advance of $\mathrm{Mr}$. Spencer's philosophical views at the time of its preparation. The whole subject of mind is dealt with from the Evolution point of view. The idea which runs through Social Statics, that there is ever going on an adaptation between living beings and their circumstances, now took on a profounder significance. The relation between the organism and its environing conditions was found to be involved in the very nature of life; and the idea of adaptation was developed into the conception that life itself " is the definite combination of heterogeneous changes both simultaneous and successive in correspondence with internal coexistences and sequences." It is argued that the degree of life varies with the degree of correspondence, and that all mental phenomena ought to be interpreted in terms of this correspondence. Commencing with the lowest types of life, Mr. Spencer, in successive chapters, traces up this relation of correspondence as extending in space and time, as increasing in specialty, in generality, and in complexity. It is also shown that the correspondence progresses from a more homogeneous to a more heterogeneous form, and that it becomes gradually more integrated-the terms here employed in respect to the Evolution of mind being the terms subsequently used in treating of Evolution in general. In 
the fourth part of the work, under the title of Special Synthesis, the Evolution is traced out under its concrete form from reflex action up through instinct, memory, reason, feelings, and the will. Mr. Spencer here distinctly avowed his belief that "life in its multitudinous and infinitely varied embodiments has arisen out of the lowest and simplest beginnings, by steps as gradual as those which evolve a homogeneous microscopic germ into a complex organism " -dissent being at the same time expressed from that version of the doctrine put forth by the author of the Vestiges of the Natural History of Creation. It was, moreover, shown by subjective analysis how intelligence may be resolved, step by step, from its most complex into its simplest elements, and it was also proved that there is "unity of composition" throughout, and that thus mental structure, contemplated internally, harmonizes with the doctrine of Evolution.

It was at this time (1854), as I have been informed by Mr. Spencer, when he had been at work upon the Principles of Psychology not more than two months, that the general conception of Evolution in its causes and extent, as well as its processes, was arrived at. He had somewhat earlier conceived of it as universally a transformation from the homogeneous into the heterogeneous. This kind of change, which Von Baer had shown to take place in every individual organism, as it develops, Mr. Spencer had already traced out as taking place in the progress of social arrangements, in the development of the sciences, and now in the Evolution of mind in general from the lower forms to the higher. And the generalization soon extended itself so as to embrace the transformations undergone by all things inanimate as well as animate. This universal extension of the idea led rapidly to the conception of a universal cause necessitating it. In the autumn of $1854, \mathrm{Mr}$. Spencer proposed to the editor of the Westminster Review to write 
an article upon the subject under the title of The Cause of all Progress, which was objected to as being too assuming. The article was, however, at that time agreed upon, with the understanding that it should be written as soon as the Principles of Psychology was finished. The agreement was doomed to be defeated, however, so far as the date was concerned, for, along with the completion of the Psychology, in July, I855, there came a nervous breakdown, which incapacitated Mr. Spencer for labour during a period of eighteen months-the whole work having been written in less than a year.

We may here note Mr. Spencer's advanced position in dealing with this subject. While yet the notion of Evolution as a process of Nature was as vague and speculative as it had been in the time of Anaximander and Democritus, he had grasped the problem in its universality and its causes, and had successfully applied it to one of the most difficult and important of the sciences. He had traced the operation of the law in the sphere of mind, and placed that study upon a new basis. The conviction is now entertained by many that the Principles of Psychology, by Spencer, in 1855 , is one of the most original and masterly scientific treatises of the present century; if, indeed, it be not the most fruitful contribution to scientific thought that has appeared since the Principia of Newton.* For thousands

* Tlis association of the name of Spencer with Newton, let it be remembered, does not rest upon the authority of the present writer; recent discussions of the subject in the highest quarters are full of it. The Saturlay Kevicw says: "Since Newton there has not in England been a philosopher of more remarkable speculative and systematizing talent than (spite of some errors and some narrowness) Mr. Herbert Spencer." An able writer in the (?uarterly Review, in treating of $\mathrm{Mr}$. Spencer's remarkable power of binding together different and distant subjects of thought by the principle of Evolution, remarks: "The two deepest scientific principles now known of all those relating to material things are the Law of Gravitation and the Law of Evolution." The eminent Professor of Logic in 
of years, from Plato to Hamilton, the world's ablest thinkers had been engaged in the effort to elucidate the phenomena of mind; Herbert Spencer took up the question by a method first rendered possible by modern science, and made a new epoch in its progress. From this time forward, mental philosophy, so called, could not confine itself simply to introspection of the adult human consciousness. The philosophy of mind must deal with the whole range of psychical phenomena, must deal with them as manifestations of organic life, must deal with them genetically, and show how mind is constituted in connection with the experience of the past. In short, as it now begins to be widely recognized, Mr. Spencer has placed the science of mind firmly upon the ground of Evolution. Like all productions that are at the same time new and profound, and go athwart the course of long tradition, there were but few that appreciated his book, a single small edition more than sufficing to meet the wants of the public for a dozen years.* But it began at once to tell upon advanced thinkers, and its influence was soon widely discerned in the best literature of the subject. The man who stood, perhaps, highest in England as a Psychologist, Mr. John Stuart Mill, remarked in one of his books, that it is "one of the finest examples we possess of the psychological method in its full power"; and, as I am aware, after carefully rereading it some years later, he declared that his already high opinion of the work had been raised still morewhich he recognized as due to the progress of his own mind. $\nmid$

Owen's College, Manchester, Mr. W. Stanley Jevons, in his recert treatise entitled The Principles of Science: A Treatise on Logic and Scientific Method, says: "I question whether any scientific works which have appeared since the Principia of Newton are comparable in importance with those of Darwin and Spencer, revolutionizing as they do all our views of the origin of bodily, mental, moral, and social phenomena."

* See Note C.

+ See Note D. 
The article Progress, its Law and Cause, projected, as we have seen, in 1854 , was written early in 1857 . In the first half of it the transformation of the homogeneous into the heterogeneous is traced throughout all orders of phenomena ; in the second half the principle of transformation is deduced from the law of the multiplication of effects. In this essay, moreover, there is indicated the application of the general law of Evolution to the production of species. It is shown that there "would not be a substitution of a thousand more or less modified species, for the thousand original species; but, in place of the thousand modified species, there would arise several thousand species or varieties or changed forms"; and that "each original race of organisms would become the root from which diverged several races differing more or less from it and from each other." It is further argued that the new relations in which animals would be placed toward one another would initiate further differences of habit and consequent modifications, and that " there must arise, not simply a tendency toward the differentiations of each race of organisms into several races, but also a tendency to the occasional production of a somewhat higher organism." The case of the divergent varieties of man, some of them higher than others, caused in this same manner, is given in illustration. Throughout the argument there is a tacit implication that, as a consequence of the cause of Evolution, the production of species will go on, not in ascending linear series but by perpetual divergence and redivergence-branching and again branching. The general conception, however, differs from that of Mr. Darwin in this; that adaptation and readaptation to continually changing conditions is the only process recognized-there is no recognition of "spontaneous variations," and the natural selection of those that are favourable.

During the summer of $1857 \mathrm{Mr}$. Spencer wrote the 
Origin and Function of Music, published in Fraser's Magazine for October. Like nearly all of his other writings, this interesting article is dominated by the idea of Evolution. The general law of nervo-motor action in all animals is shown to furnish an explanation of the tones and cadences of emotional speech; and it is pointed out that from these music is evolved by simple exaltation of all the distinctive traits, and carrying them out into ideal combination. A further step was taken, the same year, in the development of the doctrine of Evolution, which is indicated in the article entitled Transcendental Physiology. It was there explained that the multiplication of effects was not the only cause of the universal change from homogeneity to heterogeneity, but that there was an antecedent principle to be recognized, viz., the Instability of the Homogeneous. The physiological illustrations of the law are mainly dwelt upon, though its other applications are indicated.

In October of the same year, the essay on Representative Government: What is it good for ? appeared in the Westminster Review. The law of progress is here applied to the interpretation of state functions, and it is stated that the specialization of offices, "as exhibited in the Evolution of living creatures, and as exhibited in the Evolution of societies," holds throughout; that "the governmental part of the body politic exemplifies this truth equally with its other parts." In January, 1858 , the essay on State 'Tamperings with Money and Banks appeared in the same periodical. The general doctrine of the limitations of state functions is there reaffirmed, with further illustration of the mischiefs that arise from traversing the normal laws of life ; and it is contended that " the ultimate result of shielding men from the effects of folly is to fill the world with fools "-an indirect way of asserting the beneficial effects of the survival of the fittest.

In April, I858, Mr. Spencer published an essay on 
Moral Education, in the British Quarterly Review, and throughout the argument every thing is again regarded from the Evolution point of view. The general truth insisted upon is, that the natural rewards and restraints of conduct are those which are most appropriate and effectual in modifying character. The principle contended for is, that the moral education of every child should be regarded as an adaptation of its nature to the circumstances of life; and that to become adapted to these circumstances it must be allowed to come in contact with them; must be allowed to suffer the pains and obtain the pleasures which do in the order of Nature follow certain kinds of action. There is here, in fact, applied to actual life the general conception of the nature of life previously inculcated in the Principles of Psychology - a correspondence between the inner and the outer actions that becomes great in proportion as the converse with outer actions through experience becomes extended.

The essay on the Nebular Hypothesis was published in the Westminster Review for July, I858. The opinion was then almost universally held that the nebular hypothesis had been exploded, and the obvious bearing of the question upon the theory of Evolution induced Mr. Spencer to take it up. The conclusions that had been drawn from observations with Lord Rosse's telescope, that the nebular hypothesis had been invalidated, were shown to be erroneous; and the position taken that the nebulæ could not be (as they were then supposed to be) remote sidereal systems, has been since verified. Spectrum analysis has, in fact, proved what Mr. Spencer then maintained, that there are many nebula composed of gaseous matter. To the various indications of the nebular origin of our own solar system commonly given, others were added which had not been previously recognized, while the view that Mr. Spencer took of the constitution of the solar 
atmosphere has since been also verified by spectrum analysis.

In October, 1858 , he published in the Medico-Chirurgical Review a criticism on Prof. Owen's Archetype and Homologies of the Vertebrate Skeleton, which was written in furtherance of the doctrine of Evolution, and to show that the structural peculiarities which are not accounted for on the theory of an archetypal vertebra are accounted for on the hypothesis of development. In January of the next year there appeared in the same review a paper on The Laws of Organic form, already referred to (the germ of which dated back to $185 \mathrm{I}$ ), and which was a further elucidation of the doctrine of Evolution, by showing the direct action of incident forces in modifying the forms of organisms and their parts. In April, 1859 , appeared in the British Quarterly Review an article on Physical Education, in which the bearing of biological principles upon the management of children in respect to their bodily development is considered. It insists upon the normal course of unfolding, versus those hindrances to it which ordinary school regulations impose; it asserts the worth of the bodily appetites and impulses in children, which are commonly so much thwarted; and contends that during this earlier portion of life, in which the main thing to be done is to grow and develop, our educational system is too exacting-"it makes the juvenile life far more like the adult life than it should be." The essay What Knowledge is of most Worth was printed in the Westminster Review for July, i 859 . This argument is familiar to the public, as it has been many times republished; but what is here most worthy of note is that, in criticising the current study of history, it def nes with great distinctness the plan of the Descriptive Sociology (the first divisions of which are now just published), and which will give the comprehensive and systematic data upon which the Principles of Sociology are to be based. 
An argument on Illogical Geology was contributed in Iuly, I 859 , to the Universal Review, which, although nominally a criticism of Hugh Miller, was really an attack upon the prevalent geological doctrine which asserted simultaneity in the systems of strata in different parts of the earth. His view, which was at that time heresy, is now coming into general recognition. In the Medico-Chirurgical Review for January, I860, Mr. Spencer published a criticism on Prof. Bain's Work, The Emotions and the Will, designed to show that the emotions cannot be properly understood and classified without studying them from the point of view of Evolution, and tracing them up through their increasing complications from lower types of animals to higher. The essay on the Social Organism appeared at the same time in the Westminster Review, in which it was maintained that society, consisting of an organized aggregate, follows the same course of Evolution with all other organized aggregates-increasing in mass and showing a higher integration not only in this respect but also in its growing solidarity; becoming more and more heterogeneous in all its structures, and more and more definite in all its differentiations. The Physiology of Laughter, which appeared the same ycar in Macmillan's Magazine, was a contribution to nerrous dynamics from the point of view that had been taken in the Principles of Psychology. Even in Mr. Spencer's discussion of Parliamentary Reforms, their Dangers and Safeguards (Westminster Review, I860), the question is dealt with on scientific grounds ultimately referring to the doctrine of Evolution. It was its general purpose to show that the basis of political power can be safely extended only in proportion as political function is more and more restricted. It was maintained in an earlier essay that representative government is the best possible for that which is the essential office of a government-the maintenance of those social conditions under which every citizen can carry 
on securely and without hindrance the pursuits of life; and that it is the worst possible for other purposes. And in continuation of this argument it was here contended that further extension of popular power should be accompanied by a further restriction of state duty - a further specialization of state function. In the essay on Prison Ethics, contributed to the British Quarterly Review in July, I860, a special question is very ably dealt with in the light of those biological, psychological, and sociological principles which belong to the Evolution philosophy. The principle of moral Evolution is asserted, and the concomitant unfolding of higher and better modes of dealing with criminals.

We have now passed in rapid review the intellectual work of Mr. Spencer for nearly twenty years, and have shown that, though apparently miscellaneous, it was, in reality, of a highly methodical character. Though treating of many subjects, he was steadily engaged with an extensive problem which was resolved, step by step, through the successive discovery of those processes and principles of Nature which constitute the general law of Evolution. Beginning in 1842 with the vague conception of a social progress, he subjected this idea to systematic scientific analysis, gave it gradually a more definite and comprehensive form, propounded the principles of heredity and adaptation in their social applications, recognized the working of the principle of selection in the case of human beings, and affiliated the conception of social progress upon the more general principle of Evolution governing all animate Nature. Seizing the idea of increasing heterogeneity in organic growth, he gradually extended it in various directions. When the great conception thus pursued had grown into a clear, coherent, and well-defined doctrine, he took up the subject of psychology, and, combining the principle of differentiation with that of integration, he placed the 
interpretation of mental phenomena upon the basis of Evolution. We have seen that two years after the publication of the Psychology, or in 1857 , Mr. Spencer had arrived at the law of Evolution as a universal principle of Nature, and worked it out both inductively as a process of increasing heterogeneity, and deductively from the principles of the instability of the homogeneous and the multiplication of effects. How far Mr. Spencer was here in advance of all other workers in this field, will appear when we consider that the doctrine of Evolution, as it now stands, was thus, in its universality, and in its chief outlines, announced by him two years before the appearance of Mr. Darwin's Origin of Species.

A principle of natural changes more universal than any other known, applicable to all orders of phenomena, and so deep as to involve the very origin of things, having thus been established, the final step remained to be taken, which was to give it the same ruling place in the world of thought and of knowledge that it has in the world of fact and of Nature. A principle running through all spheres of phenomena must have the highest value for determining scientific relations; and a genetic law of natural things must necessarily form the deepest root of the philosophy of natural things. It was in $\mathbf{r} 858$, as Mr. Spencer informs me, while writing the article on the Nebular Hypothesis, that the doctrine of Evolution presented itself as the basis of a general system under which all orders of concrete phenomena should be generalized. Already the conception had been traced out in its applications to astronomy, geology, biology, psychology, as well as all the various superorganic products of social activity; and it began to appear both possible and necessary that all these various concrete sciences should be dealt with in detail from the Evolution point of view. By such treatment, and by that only, did it appear practicable to bring them into relation so as to 
form a coherent body of scientific truth-a System of Philosophy.

It is proper to state in this place that, in contemplating the execution of so comprehensive a work, the first difficulty that arose was a pecuniary one. Mr. Spencer had frittered away the greater part of what little he possessed in writing and publishing books that did not pay their expenses, and a period of eighteen months of ill health and enforced idleness consequent on the writing of one of them had further diminished his resources. His state of health was still such that he could work, at the outside, but three hours a day, and very frequently not that, so that what little he could do in the shape of writing for periodicals, even though tolerably paid for it, did not suffice to meet the expenses of a very economical bachelor life. How, then, could he reasonably hope to prosecute a scheme elaborating the doctrine of Evolution throughout all its departments in the way contemplated-a scheme that would involve an enormous amount of thought, labour, and inquiry, and which seemed very unlikely to bring any pecuniary return, even if it paid its expenses? Unable to see any solution of the difficulty, Mr. Spencer wrote, in July, I 858 , to Mr. John Stuart Mill, explaining his project, and asking whether he thought that in the administration for India, in which Mr. Mill held office, there was likely to be any post, rather of trust than of much work, which would leave him leisure enough for the execution of his scheme. Mr. Mill replied sympathetically, but nothing turned out to be available. In despair of any other possibility, Mr. Spencer afterward extended his application to the Govornment, being re-enforced by the influence of various leading scientific men, who expressed themselves strongly respecting the importance of giving him the opportunity he wished.* 
A peculiar difficulty, however, here arose. Mr. Spencer is a very impracticable man-that is, he undertakes to conform his conduct to right principles, and his decided views as to the proper functions of government put an interdict upon the far greater number of posts that might otherwise be fit. Among the few that he could accept, the greater part were not available because they did not offer the requisite leisure. One position became vacant which he might have accepted, that of Inspector of Prisons, I think; but, though effort in his behalf was made by Lord Stanley (now Lord Derby, who was familiar with Mr. Spencer's works and entertained the matter kindly), the claims of party were too strong, and no arrangement was made.

Other plans failing, Mr. Spencer decided to adopt that of subscription, and to issue his System of Philosophy in a serial form. A prospectus of that system was issued in March, I860, which outlined the contents of the successive parts. The first installment of the work was issued in October, I860, and the commencing volume, First Principles, was published in June, I 862 .

In this work the general doctrine of Evolution is presented in a greatly developed form; and the author's former views are not only combined but extended. The law of Von Baer, which formulates organic development as a transformation of the homogeneous into the heterogeneous, Mr. Spencer had previously shown to hold of all aggregates whatever-of the universe as a whole, and of all its component parts. But, in First Principles, it was shown that this universal transformation is a change from indefinite homogeneity to aefinite heterogeneity; and it is pointed out that only when the increasing multiformity is joined with increasing definiteness, does it constitute Evolution as distinguished from other changes that are like it in respect of increasing heterogeneity. There is, however, a much more important development of the principle. 
This change from the indefinite to the definite is shown to be the accompaniment of a more essential change from the incoherent to the coherent. Throughout all aggregates of all orders it is proved that there goes on a process of integration. This process is shown to hold alike in the growth and consolidation of each aggregate as well as in the growth and consolidation of its differentiated parts. The law of the instability of the homogeneous is also more elaborately traced out. Under the head of the principle of segregation it is, moreover, shown that the universal process by which, in aggregates of mixed units, the units of like kinds tend to gather together, and the units of unlike kinds to separate, everywhere co-operates in aiding Evolution. Yet a further universal law is recognized and developed-the law of equilibration. The question is asked, "Can these changes which constitute Evolution continue without limit?" and the answer given is that they cannot; but that they universally tend in each aggregate toward a final state of quiescence, in which all the forces at work have reached a state of balance. Like the other universal process, that of equilibration is traced out in all divisions of phenomena. But the most important development given to the doctrine of Evolution in this volume was its affiliation upon the ultimate principle underlying all sciencethe persistence of force. It was shown that from this ultimate law there result certain universal derivative laws, which are dealt with in chapters on The Correlation and Equivalence of Forces, The Direction of Motion, and The Rhythm of Motion, and it was demonstrated that these derivative laws hold throughout all changes, from the astronomical to the psychical and social. It is then shown that the Instability of the Homogeneous, The Multiplication of Effects, Segregation and Equilibration, are also deducible from this ultimate principle of the persistence of force. So that Evolution, having been first established 
inductively as universal, is further shown to be universal by establishing it deductively as a result of the deepest of all knowable truths.

The first edition of First Principles was published, but another important step in elucidating the philosophy of Evolution required to be taken. In dealing with the classification of the sciences, from the point of view to which his philosophy has brought him, Mr. Spencer had occasion to seek for that aspect of all physical phenomena which forms the most general division of physical science. $\mathrm{He}$ found that what he sought must be some general fact respecting the redistribution of matter and motion. The law was soon arrived at, that integration of matter results from decrease of the contained motion, while disintegration of matter results from increase of the contained motion. It is at once manifest that the law thus reached was deeper than the principle of Evolution, for it is conformed to by mineral bodies, which do not exhibit the phenomena of Evolution as Mr. Spencer had interpreted them. In short, it became clear that a law had been reached, holding of all material things whatever, whether they are those which do or those which do not increase in heterogeneity. It was now first possible to judge of the relative value and importance of the several factors of the evolutionary process. In Von Baer's conception of organic development, it is made to consist essentially and solely in the change of increasing heterogeneity in the evolving body. But Mr. Spencer had shown that evolution is a double process-a tendency to unity as well as to diversity, an integration as well as a differentiation. It was now found that the process of integration, as it applies to all things, whether evolving or not, is a deeper principle, and is, in fact, the primary process in evolution, while the increase of heterogeneity is the secondary process. At the same time, this new view of the matter made it obvious 
that Dissolution is everywhere the correlative of Evolution, and that, before the generalization is complete, I)issolution must be recognized as universally tending to undo what Evolution does.

In a new edition of First Principles this idea was embodied, and the work recast in conformity with it. The doctrine of Evolution thus attained a higher development. The fundamental antagonism between Evolution and Dissolution comes into the foreground as the cardinal conception. It is shown that every aggregate, simple or compound, is, from the beginning to the end of its existence, subject to these opposing processes of change; that, according as its quantity of contained motion is becoming greater or less, it is tending to integrate or disintegrate, evolve or dissolve; that from moment to moment throughout its whole existence it is simultaneously exposed to both these processes, and that the average transformation it is undergoing expresses the predominance of the one process over the other. This being the universal law to which all material things at all times are subject, there come to be recognized certain derivative laws that are not universal although highly general. Evolution is distinguished into simple and compound: simple Evolution being that in which the character of the matter and the rate of its integration are such that this primary process of change from a diffused state to a concentrated state is uncomplicated by secondary changes-compound Evolution being that in which, along with the general integrations, there go on more or less marked differentiations and local integrations. Thus the changes which were originally conceived to constitute Evolution itself came to be recognized as, in order of time and importance, subordinate; integration may go on without differentiation, as in crystals; but differentiation is made possible only by antecedent integration.

The doctrine of Evolution, as a theory of the genesis 
and dissolution of things in the onward course of Nature, was elaborately presented in First Principles, and might have been there left to take its place and its chance among philosophical theories. But it had not been exploited by Mr. Spencer in the way of mental gymnastics, as a piece of novel and ingenious speculation. He believed it to embody a living and applicable principle of the greatest moment. If the law of Evolution be true, it is a truth of transcendent import, no less in the sphere of practical life than in the world of thought, and it was important that it should be carried out in the various fields of its application. Moreover, Mr. Spencer had been drawn to the investigation by his interest in the study of human affairs, and his task was but fairly begun with the establishment of the principle by which they are to be interpreted. In the strict logical order the next step would have been to trace the operation of the law in the inorganic or pre-organic world, but the vastness of the subject forbade this, and Mr. Spencer found it necessary to enter at once upon the organic division of his scheme. In the Principles of Biology the subject of life was accordingly comprehensively dealt with from the Evolution point of view. He then passed to the phenomena of mind, and recast and amplified the Principles of Psychology in accordance with his more matured opinions, placing it upon the ampler basis afforded by First Principles and the Principles of Biology. These three works, forming five volumes of the System of Philosophy, are now published, and they carry him half through the undertaking-the Principles of Sociology, in three volumes, and the Principles of Morality, in two volumes, remaining yet to be written. Mr. Spencer allowed twenty years for the whole enterprise; ill health and unforeseen interruptions have occasioned considerable delay, and it was half accomplished in twelve years.

A further illustration of the comprehensive and thor- 
oughly systematic character of Mr. Spencer's work is afforded by his preparation for the treatment of the subject of Sociology. In dealing with Biology and Psychology, the data for reasoning were readily accessible; but in entering upon the scientific study of so vast and varied a subject as human society a most formidable difficulty appeared at the threshold of the inquiry, in the absence of facts to form the broad basis of sociological reasoning. So deficient and scattered and contradictory were such data that the possibility of any valid social science has been generally regarded with distrust, or unhesitatingly denied. But the phenomena of society are not chaotic; they coexist and succeed each other in an orderly way. The natural laws of the social state are undoubtedly determinable, but such determination is primarily a question of the collection of materials suitable for wide and safe inductions. Mr. Spencer foresaw this several years ago, and began the collection and methodical arrangement of all those numerous classes of facts pertaining to the various forms and states of society which are needed to work out the Principles of Sociology. 'This alone was an immense undertaking. The races of mankind were divided into three groups, illustrating existing civilizations, extinct or decayed civilizations, and the savage state. Three corresponding series of works were projected, a tabular method for the classification and arrangement of facts was devised, and three gentlemen were employed to carry out the work of collection and digestion of materials under Mr. Spencer's supervision. The first installments of each of these divisions are now completed, and published. This important work, wiich is subsidiary to his main enterprise, is the first of the kind ever attempted, and when finished and issued will form a complete Cyclopædia of the multifarious data necessary for the scientific investigation of social questions. Its continued publication will depend upon public support; but the col- 
lection has been made by Mr. Spencer for his own use, and it will form the groundwork of the Principles of Sociology upon which he has now entered, and the first part of which is issued.

Let us now recapitulate his labours in the order of their accomplishment, so as to bring them into one view :

Letters on the Proper Sphere of Government, . . . . . 1842

(Occupied several years as a Railroad Engineer.)

Planned Social Statics,

Social Statics published, . . . . . . . . 1850

Theory of Population,

Philosophy of Style,

Over-Legislation,

The Universal Postulate, $\}$ • • • • • • • 1853

Manners and Fashion,

The Genesis of Science,

The Art of Education,

Eriolution first conceized as Lniviersal,

Principles of Psychology, .

(Breakdown of eighteen months.)

Progress, its Law and Cause, Origin and Function of Music,

Transcendental Plyysiology,

Representative Government,

State Tamperings with Money and Banks, Moral Education,

The Nebular I Iypothesis,

Archetype and Homologies of the Vertebrate Skeleton, Evelution first conceized as the basis of a system of Philosophy,

The Laws of Organic Form,

Physical Education,

What Knowledge is of most Worth,

Illogical Geology,

Prospectus of the Systcm of Philosophy drawn up, 
The Emotions and the Will,

The Social Organism,

The Physiology of Laughter,

Parliamentary Reform,

Prison Ethics,

Prospectus of the I'hilosophical System published,

First Principles,

Classification of the Sciences,

Principles of Biology,

Principles of Psychology, .

The Study of Sociology, ?

Descriptive Sociology, $\zeta$

Principles of Sociology, Part I.,

The facts now presented, I submit, entirely sustain the view with which we set out, in regard to the character of Mr. Spencer's work, and his position in the world of thought. It has been shown that he took up the idea of Progress while it was only a vague speculation, and had not yet become a subject of serious scientific study. We have seen that he verified its reality by gradually tracing its operation step by step, in widely different fields of phenomena; that he analyzed its conditions and causes, and at length formulated it as a universal principle, to which the course of all things conforms. That view of the universe which the science of the world now accepts, it has been shown that Mr. Spencer adopted a generation ago, and entered upon its elucidation as a systematic life-work. We have traced the course of its unfolding, and I appeal to the record of labours here delineated as furnishing an example of original, continuous, and concentrated thinking, which it will be difficult to parallel in the history of intellectual achievement. In newness of conception, unity of purpose, subtilty of analyses, comprehensive grasp, thoroughness of method, and sustained force of execution, this 
series of labours, I believe, may challenge comparison with the highest mental work of any age.

As to the character of the system of thought which Mr. Spencer has elaborated, we have shown that it is such as to form an important epoch in the advance of knowledge. He took up an idea not yet investigated nor entertained by his predecessors or contemporaries, and has made it the corner stone of a philosophy. If by philosophy we understand the deepest explanation of things that is possible to the human mind, the principle of genesis or Evolution certainly answers pre-eminently to this character; for what explanation can go deeper than that which accounts for the origin, continuance, and disappearance of the changing objects around us? It is the newest solution of the oldest problem; a solution based alike upon the most extended knowledge, and upon a reverent recognition that all human investigation, however extensive, must have its inexorable bounds. The philosophy of Evolution is truly a philosophy of creation, carried as far as the human mind can penetrate. If man is finite, the infinite is beyond him; if finite, he is limited, and his knowledge, and all the philosophy that rests upon knowledge, must be also limited. Philosophy is a system of truth pertaining to the order of Nature, and coextensive with it; and, as the various sciences are but the knowledge of the different parts of Nature, Mr. Spencer bases philosophy upon science, and makes it what may be called a science of the sciences. Resting, moreover, upon a universal law, which governs the course and changes of all phenomena, this philosophy becomes powerful to unify and harmonize the hitherto separate and fragmentary systems of truth; and, as this is the predominant trait of Mr. Spencer's system of thought, he very properly denominates it the Synthetic Philosophy.

In estimating the character of Mr. Spencer's Philosoph- 
ical System it is needful to remember that it differs in various fundamental respects from any that has before been offered to the world. It is more logically complete than any other system, because its truths are first derived from facts and phenomena by the method of induction, and then systematically verified by deduction from principles already established. It is more practical than any other, because it bears immediately upon common experience, takes hold of the living questions of the time, throws light upon the course of human affairs, and gives knowledge that may serve both for public and individual guidance. Viewed as an intellectual achievement, his undertaking is neither to be measured by the time consumed in its execution nor by the amount of labour in rolved, but by the nature and quality of the work itself. It was original throughout, was based upon the most comprehensive results of modern science, and was elaborated under the inexorable conditions of logical method. The development of a system of philosophy now is a very different thing from what it was in the earlier times. Plato spun a system of thought before speculation was yet curbed by the knowledge of Nature; Spencer has constructed a philosophy out of the inflexible materials furnished in all the fields of modern investigation. His system is not a digest, but an organon; not merely an analytic dissection, but a grand synthetic construction; not a science, but a co-ordination of the sciences; not a metaphysical elaboration, but a positive body of doctrine conforming to verifiable facts, and based upon the most comprehensive principle of Nature yet arrived at by the human mind.

But no recognition of the greatness of Mr. Spencer's intellectual work will do him justice. There is a moral sublimity in his self-sacrificing career which is not to be neglected in making up the estimate of his character. As remarked by M. Laugel: "If Mr. Spencer, with his talents, 
his fertility of genius, and the almost encyclopædic variety of knowledge, of which his writings furnish the proof, had chosen to follow the beaten path, nothing would have been more easy than for him to secure all those honours of which English Society is so prodigal to those who serve her as she wishes to be served. He preferred, however, with a noble and touching self-denial, to put up with poverty, and, what is still more difficult, with obscurity." In advance of his generation and working against the powerful current of its prejudices, with broken health, without pecuniary resources, and depending upon promises of support that were but very partially redeemed, with an intrepidity that was not wanting in heroism he entered upon the most formidable intellectual project that was ever undertaken by any single mind. One would think that it should have commanded the sympathy of the generous and the cordial approval if not the kindly co-operation of all who appreciate courageous and noble endeavour; but, unhappily, a discriminating appreciation of genuine work is not overabundant in these times; and, in the accomplishment of a task which I believe future generations will regard as the most memorable achievement of this fruitful age, Mr. Spencer has had but stinted encouragement and a very shabby support. In answer to the question, why his contemporaries have been so unappreciative, much might be said, but I will here confine myself to one or two suggestions.

In the first place, Mr. Spencer's work has been done under circumstances peculiarly unfavourable to the recognition of his rights as an original and independent thinker. Of the twenty-five articles prepared in the most active period of his life, and published between $185_{2}$ and 1860 , which, as I have shown, are important contributions toward the development of the doctrine of Evolution in its various phases, most, if not all, appeared anonymously. They were printed in the different leading reviews, and many of them 
attracted marked attention at the time; but their author was unknown, and, of course, lost the advantage of having his ideas accredited to him. $U_{p}$ to the time when he had matured his system of thought, and was ready to enter upon its formal publication, he had been giving it out in fragments, as its several aspects had taken shape in his own mind. His articles, many of which were republished in this country, thus went far toward familiarizing the public mind with the general conception of Evolution, so that he was actually preparing his readers to discredit his subsequent claims to his own views, which, being reproduced and further diff used by others, were regarded as belonging to the common stock of current ideas. So far did this go that he was ultimately exposed to the imputation of plagiarism for the restatement of opinions that he had first put forth, but which other men had appropriated, and sent out as their own. Nor was the case much helped when he began to publish his system of philosophy to subscribers, for so limited was its distribution that it might almost have been said that it was "printed for private circulation." Moreover, being the owner of his own works, the interests of publishers were not enlisted in their diffusion; while the assaults of the press were so malignant, and their representations so false, that for years he was constrained to withhold his series from the periodicals. All this was favourable to misconception, and left Mr. Spencer much at the mercy of dishonest authorship and unscrupulous criticism.

Again, it must be recognized that there were difficulties in appreciating his work which arose from its nature and extent. While a scientific discovery, or a single definite doctrine, is readily apprehended because the impression it makes is narrow and sharp, an extensive system of principles, which it requires power to grasp and time to master, can only be imperfectly received by the general mind. The 
very greatness of Mr. Spencer's work was thus an impediment to its recognition, and this, too, it must be acknowledged, on the part even of men of science. In the scientific world the accumulation of facts has outstripped the work of valid generalization. For, while men of moderate ability can observe, experiment, and multiply details in special departments, it requires men of breadth to arrange them into groups, to educe principles and arrive at comprehensive laws. The great mass of scientific specialists, confined to their departments, and little trained to the work of generalization, are apt to regard lightly the logical processes of science, and to decry mere theorizing and speculation. They forget that facts of themselves are not science, and only become so by being placed in true relations, and that the function of the thinker is therefore supreme; while the work of organizing facts and establishing general truths is, after all, just as much a specialty as that of observation or experiment in any branches of inquiry. The prevalence of these narrow views has been unfavourable to the recognition of Mr. Spencer's work by a large class of the cultivators of science; and the more so, as he has been mainly occupied in the highest spheres of generalization. For this reason it is only by the comparatively small number of scientific men who possess marked philosophic power that his labours have been justly appreciated.

But, while considerations of this kind are not to be overlooked in assigning the responsibilities of criticism, neither are they to be construed into excuses for prejudiced opinions, or crude and hasty judgments. It is the business of critics to inform themselves on important matters of which they speak, or to hold their peace. And, where there is peculiar difficulty or liability to error, they are all the more bound to caution, and to refrain from injurious interpretations. Reverting now to the criticisms cited at the outset of this discussion as typical of a 
class, we are prepared to rate them at what they are worth.

From what has been stated, I think it will be sufficiently evident that Mr. Spencer is no follower of Comte, Darwin, or any other man, and that he has pursued his own independent course in his own way. As to M. 'Taine's statement that "Mr. Spencer has the merit of extending to the phenomena of Nature and of mind "Mr. Darwin's principle of Natural Selection, the facts given show how mistaken was his view of the case. Strange to say, M. Taine, who claims to be a psychologist, puts forth this idea in a review of Mr. Spencer's Principles of Psychology, a work which treated the subject of mind throughout, and for the first time from the point of view of Evolution, and this years before Mr. Darwin had published a word upon the subject.

As this error of $M$. Taine is frequently repeated,* and indicates a total misapprehension of the facts, it is desirable to add a word or two regarding Mr. Darwin's relation to the question. While this illustrious naturalist has contributed immensely toward the extension and establishment of a theory of organic development, he has made no attempt to elucidate the general law of Evolution. His works do not treat of this broad problem; and nothing has tended more to the popular confusion of the subject than the notion that "Darwinism" and Evolution are the same thing. Mr. Darwin's fame rests chiefly upon the skill and perseverance with which he has worked out a single principle in its bearing upon the progressive diversity of organic life. The competitions of Nature leading to a struggle for existence, and that consequent winnowing

* The Saturday Review, for example, in commenting upon Prof. Tyndall's late address, remarks: "What Darwin has done for physiology, Spencer would do for psychology by applying to the nervous system particularly the principles which his teacher (!) has already enunciated for the physical system generally." 
which Mr. Darwin calls "Natural Selection, and Mr. Spencer calls "Survival of the Fittest," were recognized before Mr. Darwin's time: what he did, as I have already explained, was to show how this principle may aid in giving rise to new species from pre-existing species. The principle is a part of the great theory of Evolution, and has a philosophic importance exactly in proportion to the validity of that larger system of doctrine to which it is tributary as an element. Not only has Mr. Darwin never taken up the general question of Evolution, but it was not his aim to explain even the evolution of species in terms of uitimate principles-that is, in terms of the redistribution of matter and motion. Yet it is in this way that all proximate principles, including Natural Selection, have to be expressed before the final interpretation is reached. This mode of dealing with the subject-the analysis of it into those primary principles from which all the proximate principles are derived, and the reduction of the various phases of transformation to a single law, which is the only thoroughly scientific method of its treatment, belongs to Mr. Spencer alone. As to his following Mr. Darwin, we have already seen that, long before the Origin of Species was published, Mr. Spencer had reached the proof of Evolution as a universal law; had traced its dependence upon the principle of the persistence of force; had resolved it into its ultimate dynamical factors; had worked out many of its important applications; had made it the basis of a system of Philosophy; and had shown that it furnishes a new starting-point for the scientific interpretation of human affairs. And for this vast constructive work $\mathrm{Mr}$. Spencer was indebted solely to his own genius. Referring to the subject of Evolution, in a lecture before the Royal Institution, Prof. Huxley said: "The only complete and systematic statement of the doctrine with which I am acquainted is that contained in Mr. Herbert Spencer's System 
of Philosophy;" of this doctrine, I have given the proof "that Mr. Spencer is the chief originator, as well as the only expositor. 'The same ethical canons of research, I therefore maintain, which gave to Copernicus the glory of the heliocentric astronomy; to Newton that of the law of gravitation; to Harvey that of the circulation of the blood; to Priestley that of the discovery of oxygen; to Dr. Young that of the undulatory theory of light; and to Darwin that of natural selection-will also give to Herbert Spencer the honour of having first elucidated and established the law of Universal Evolution.

Colonel Higginson imputes to Mr. Spencer, as a weakness, the propensity to write on a great number of subjects; I have shown, on the contrary, that he has been compelled to write upon many subjects from logical necessity, and has done so in unswerving devotion to the development of one class of ideas. It will be seen that he is now upon the same identical track of thought which he opened in his youth, to which he has consecrated his life, and which he has made his own. Thirty-two years ago he began to study the social condition and relations of men from the scientific point of view, and to treat of human society as a sphere of natural law. After eight years he published a treatise upon the question, which, although in advance of the times, only served to convince its author that the investigation was barely begun, and that, before any adequate social science was possible, the whole subject required to be more deeply grounded in the knowledge of Nature. Upon that deeper study of Nature he then entered, and, after twenty-four years of steady and systematic preparation, the problems of Social Statics are resumed in the Principles of Sociology. If so prolonged and inflexible a course of original inquiry, yielding results which are felt in the highest spheres of thought, are suggestive of "a weakness," we should be glad to be furnished 
with the examples which embody Colonel Higginson's conception of strength in mental character. As to the declaration that it seems absurd to attribute to Mr. Spencer any vast enlargement or further generalization of the modern doctrine of Evolution, we leave its author to reconcile his opinion with the fact that the System of Psychology, which first extended the principle of Evolution to the sphere of mind, had been nine years before the world, the conception of universal Evolution had been formulated and promulgated four years, and First Principles had been for some time published, when this statement was made.

Mr. Emerson's criticism of Spencer is summary and decisive, as becomes a man who has gone to the bottom of a subject. Reticent and mystical no longer, he plumps out his opinion, when interviewed, with all the confidence of one who knows what he is talking about. Into the pantheon of immortals, arranged for the reporter of Frank Leslie's newspaper, none may enter but star-writers, and Mr. Spencer is only a "stock-writer." We may, however, presume that Mr. Emerson has here followed his transcendental lights, as there are many who will insist that he is not for a moment to be suspected of having ever read Mr. Spencer's books-though it will still remain a mystery how he has so skilfully contrived to make his statement as exactly wrong as it could be made. It will, probably, matter little to Mr. Spencer what Mr. Emerson thinks of his position, as it may matter nothing to Mr. Emerson what we think of his judgment; but it should matter a good deal to him that he do not lend the influence of his eminent name to the perpetration of injustice. Speaking in the light of the facts here sketched, we say that Mr. Emerson will search the annals of authorship in vain to find an instance in which his epithet would be more grossly misapplied. And we will do him the justice to say that in 
other days he has taught us a more generous lesson in regard to what is due from the manly and liberal-minded to the heroic endeavours of noble and unrecognized men. Many of his admirers will recall with pleasure the following admirable passage: "What is the scholar, what is the man for, but for hospitality to every new thought of his time? Have you leisure, power, property, friends? you shall be the asylum of every new thought, every unproved opinion, every untried project, which proceeds out of goodwill and honest seeking. All the newspapers, all the tongues of to-day, will, of course, at first defame what is noble; but you, who hold not of to-day, not of the times, but of the everlasting, are to stand for it; and the highest compliment man ever receives from Heaven is the sending to him its disguised and discredited angels." This is a grand exhortation, and has no doubt thrilled many a reader with enthusiasm for the rising thoughts of his time. But the difficulty still remains, how to identify the celestial messengers! Such are the eccentricities of human judgment, that the sympathy which Mr. Emerson invokes is as likely to be given to the worthless as to the worthy. And what shall we say about the duty of common mortals respecting the "disguised and discredited angels," when the Seer himself snubs the author of First Principles as a "stock-writer," and says to the author of that unclean imposture, Leaves of Grass, "I greet you at the beginning of a great career"?

\section{Note A.-Page 506.}

Pulpit exposition, in this case, is to be taken as representing the force of tradition, the persistence of habit, and the adherence to stereotyped ideas and forms of expression, which have been so long used in sacred relations that they have become sacred-rather than the actual and living belief. There has come to be a great discrepancy in this matter between pulpit presentations and the private opinions of clergymen. An example 
of this occurred when Prof. Huxley was invited to address the clerical body of Sion College, and took up, as the subject of his discourse, "The Antiquity of the Earth, of Man, and of Civilization." His address was followed by discussion, in accordance with custom, when several clergymen took occasion to express their surprise that Prof. Huxley should have chosen such a subject for such an audience; that his facts were very elementary, and his views long established and quite commonplace, and that the speaker greatly underrated the intelligence of clergymen if he supposed they needed primary lessons on that subject. To this Prof. Huxley replied: "Why, then, do you not teach these things to your congregations?" But there are plenty of clergymen still who inculcate the old views by no means as a matter of routine. They maintain them with vigour, and still denounce the modern doctrines with fiery vehemence. An illustration of this is afforded by a sermon lately preached in New York by Rev. George B. Cheever, on Evolution, of which the following passages are samples from the Tribune report. Mr. Darwin having referred to the notion of the special creation of man as a miserable hypothesis, Dr. Cheever remarks : "Observe this language, the miserable assumption of a special creation, spoken or written in the full knowledge that, instead of being an assumption at all, it is the very first truth taught in the Bible, as clearly as the being of a God, and no more to be disputed by a Christian than that, but plainly revealed as the foundation of all the obligations and duties of religion, and the corner stone on which the whole scheme of Christianity rests. . . .

"If you demand positive and actual chronology for these postulated, illimitable ages, the archæological and geological scientists have an almanac of Greek scientific terminologies, under the cloak of which both absence and assumption of knowledge without facts they may hide themselves-Eocene, Miocene, Pliocene, and Pleistocene-ingenious compounds of two Greek words; the dawn of recent time, the less recent, the more recent, the most recent. The use of these forms of scientific learning being c-tablished, when you ask the age of any given development or stratum, you are answered, it was Pliocene, or Post-Pliocene, or Eocene, or Miocene. You must be content, for these are but parts of the grammar of endless genealogies, which you must accept for certainties, and any further questioning can only show your ignorance of what be the very first principles of the knowlerlge of earth and time in the processes of evolution. The first postulate of this philosophy is that of countless millions of years to work in, with no creator, and no authority that can bring it to book. Such being the basis of scientific evolution, what can be the God, or the natural principle, at work for such results through illimitable ages? Is it any gain to such a system, or does it obviate, or soften, or neutralize its irreligion, 


\section{Herbert Spencer and the Doctrine of Eiolution. 547}

its atheistic tendency, its monstrosity and cruelty, to suppose a Ciod, or what is called God, hiding himself behind all these millions of ages, and setting all this in motion by inexorable law that evolves its products by natural selection, but gives neither idea, nor knowledge, nor revelation of God, but, on the contrary, makes it impossilble that God should be a father or should ever interpose for the gruidance or benefit of his creatures, or indeed should ever have acted with personal will and purpose, benevolence, and power, as their Crcator?... .

"By their scheme, there never was, and never could have been, a deity interposing to instruct $\Lambda$ dam, to educate $A$ braham, to inspire Joseph, to put down oppressing I'haraoh, to change the rod of Moses into a serpent, to create an additional frog, louse, or mosquito, in Egypt; to call for the waters of a deluge, to spread abroal a rainbow, to speak to the rain to fall on one piece of ground and not on another; to commission a famine, or a pestilence, or a flash of lightning; every drop of rain, and every shower, and every ray of light, and every blade of grass, having been so unalterably woven out of the original supply of force in the web of order, continuous and unbroken forever, as not to admit of a possibility of interference or alteration."

\section{Note B.-Page 510.}

IN regard to Mr. Spencer's education, a few words may be added. As a child he had a delicate constitution, and his father, feeling the danger of exposing him to the usual course of education, kept him from school, and attencled to his early instruction himself. In this respect his case was like that of Mr. Mill, but the plan pursued was very different. For, while young Mill's mind was forced out by a stern coercive discipline, that of Spencer was led out by awakening an interest in knowledge, and guiding and encouraging the spontaneous tendencies of his mind. His father was a professed mathematical teacher, and the son's mathematical studies began early, and were continued systematically with a view to his prospective vocation as a civil engineer. This course was chosen because Herbert early exhibited a marked aptitude for mechanics, mathematics, and scientific studies, and because the occupation of engineering would combine useful employment with outdoor activity, which was favourable to health, and was demanded by his slender constitution. Mr. Mill's early education was purely one of books, and in his autobiography he expresses regret that he never had the discipline of trying experiments in science, or even the advantage of seeing them. Young Spencer, on the other hand, went early into the practical work of science. He cultivated natural history, collected an herbarium, and experimented in physics and 
chemistry. The bent of his mind, moreover, early attracted him to original investigation, and it is known that, before the age of seventeen, he had discovered and worked out the electrotype process independently. He had also solved certain difficult original problems relating to his chosen profession, and devised a new and ingenious theorem in descriptive geometry, which were afterward published in The Civil Engineer and Architect's Journal. He completed his mathematical studies with his uncle, the Rev. Thomas Spencer, a cultivated scholar, who graduated with honours at Cambridge. He was also a man of great liberality, advanced in his political views, and the first clergyman of the Established Church to take a public and prominent part in the movement for the repeal of the Corn Laws, having written and published extensively upon the subject. At seventeen young Spencer commenced life as a civil engineer, being first engaged under Mr. Charles Fox, afterward Sir Charles Fox, who had been a pupil of his father, and afterward built the great Exhibition building of 1850 . Some eight years were spent in this profession, when the reaction from the railway mania of $\mathrm{I} 845$ led to such a depression in the engineering business that he abandoned it, and gave himself up to systematic study and a career of authorship.

\section{Note C.-Page 5 Iq.}

THE following passage is from an able article republished in The Popular Science Monthly, from the Westminster Review, on the Development of Psychology :

"If Mr. Herbert Spencer had no other title to fame, he would still be the greatest of psychologists. The vast construction of his First Principles will ever be a monument of his extraordinary powers of generalization. His designed organization of the Social Science opens up the prospect of intellectual acquisitions in the future, to which the past may furnish few parallels. But the Principles of Psychology will still remain, in its symmetrical completeness and perfect adequacy to the subject, at once the most remarkable of his achievements and the most scientific treatise on the Mind which has yet seen the light. Its publication in 1855 did not make a sensation. The persistent efforts of Mill had not yet succeeded in stemming the muddy tide of the prevailing scholasticism. The bastard Kantism of Hamilton did duty for Metaphysics, and the CommonSense Philosophy of Reid, with the common sense left out, usurped the place of experimental psychology. Experimental Psychology was as usual busy with analysis, and had no eye for an imposing synthetical effort. Mr. Spencer's 'work had, accordingly, a chill reception. Greeted by the aristocratic metaphysicians with only a few words of courtly compliment, but 
treated practically with supercilious disregard, it was received by psychologists of the Association school with hardly more favour than the snarling approval with which a constitutional Whig views the entry into the cabinet of a Birmingham Radical. Mr. Spencer was ahead of his generation, and paid the penalty of his prescience in twenty years of neglect. But now the wheel is coming round. The bovine British public, constitutionally disposed, indeed, to apathy, but drugged into a leaden slumber by its medicine men, is at last awakening to the fact that the peer of Bacon and Newton is here. Writers of all schoels are hastening to define their position with reference to the Synthetic Philosophy. . . . Whatever part of this philosophy may be transitory, Mr. Spencer's present influence is indisputable: and, since the lamented death of Mill, no one can now contest his claims to the philosophic supremacy in these islands. That supremacy rests mainly on his Psychology. . . Mr. Spencer's numerous psychological advances may be grouped in two divisions: the application to mind of the theory of development, and the connection of psychological evolution with evolution in general. The last edition of his work also incorporates Mr. Darwin's law of natural selection in the explanation of the emotions, but this may be regarded as simply an extension of the development theory. In the working out of both principles, Mr. Spencer has fcllowed the lead of the physical sciences. . . . With a prescient insight into the future of science which has probably few parallels, Mr. Spencer founded his Psychology on the hypothesis of development. To all but a few deep-thinking observers there can have seemed few signs in 1855 that that hotly disputed theory was ever likely to be in the ascendant. The exposition of none of the organic sciences, that we know of, had yet been based on it, and its application to mind was undreamt of. But, with a confidence in the intuitions of reason, which is one of the clearest attributes of speculative genius, and which may have its analogue in the statesman, in the nerve to take the vessel of the state over a bar, Mr. Spencer assumed the provisional truth of the theory, and it might be difficult to exaggerate the extent to which his exhibition of it in Psychology has contributed to its establishment."

\section{Note D.-Page 519 .}

High as was Mr. Mill's estimate of the Principles of Psychology, we believe he never grew to a full appreciation of it. He was an ardent partisan of the experiential psychology as opposed to the intuitional, and his bias prevented him from discerning the immense step that Mr. Spencer had taken in harmonizing the fundamental disagreements of the two schools. His position, as defined in the Autobiography, is that "there is 
not any idea, feeling, or power in the human mind, which, in order to account for it, requires that its origin should be referred to any other source than experience," and by this he means the experience of the individual. How strong his feeling was against the a priori view is illustrated by a further passage in the Autobiography. He says: "Whatever may be the practical value of a true philosophy of these matters, it is hardly possible to exaggerate the mischiefs of a false one. The notion that truths external to the mind may be known by intuition or consciousness, independently of observation and experience, is, I am persuaded, in these times the great intellectual support of false doctrines and bad institutions. By the aid of this theory, every inveterate belief and every intense feeling, of which the origin is not remembered, is enabled to dispense with the obligation of justifying itself by reason, and is erected into its own all-sufficient voucher and justification. There never was such an instrument devised for consecrating all deep-seated prejudices." Mr. Spencer, on the contrary, held that the intuitionalists are right in this, that the ideas, feelings, and powers of the mind cannot be explained as originating in the experience of the individual, but that there are intuitions or capacities of knowing born with us. But, instead of merely assuming these with the intuitionalists as ultimate principles beyond explication, he maintains that they originate in the experiences of the race which have been accumulated and transmitted to the individual in his organization. Intuitions are thus affirmed, but their basis is laid in hereditary life, and the law of evolution thus becomes the key to the deepest interpretation of mental phenomena.

In his recent able work, entitled Principles of Mental Physiology, Dr. Carpenter remarks: "No physiologist can deem it improbable that the intuitions which we recognize in our own mental constitution have been acquired by a process of gradual development in the race corresponding to that which we trace by observation in the individual. . . The doctrine that the intellectual and moral intuitions of any one generation are the embodiments in its mental constitution of the experiences of the race was first explicitly put forth by Mr. Herbert Spencer, in whose philosophical treatises it will be found most ably developed." Dr. Carpenter furthermore says that "the great master of the experiential school, Mr. J. S. Mill, was latterly tending toward the acceptance of this view," the evidence of which is given in the following quotation from a letter of Mr. Mill upon the subject to Dr. Carpenter: "There is also considerable evidence that such acquired facilities of passing into certain modes of cerebral action can in many cases be transmitted, more or less completely, by inheritance. The limits of this transmission, and the conditions on which it depends, are a subject now fairly before the scientific world; and we shall, doubt- 


\section{Herbert Spencer and the Doctrine of Evolution. $55 \mathrm{I}$}

less, in time know much more about them than we do now. But, so far as my imperfect knowledge of the subject extends, I take much the same view of it that you do, at least in principle." IVe thus see how profoundly the foremost psychologist of his time was ultimately influenced in his most radical philosophical views by the doctrines of Mr. Spencer; and, when we remember how completely $\mathrm{Mr}$. Spencer had already reconstructed the new psychology upon the basis of the principle thus lately and partially recognized by Mr. Mill, we are enabled to see how far he was in advance of his age in dealing with this great subject.

\section{Note E.-Page 527.}

INTERESTED in all that relates to the history of Mr. Spencer's enterprise, and the conditions under which it was launched, when I learned about his being sustained by eminent men in his application to Government, I sought to know what kind of action they took, and found that their influence was given in the shape of letters to Mr. Spencer, to be used with the Government authorities. They were written by Mr. J. S. Mill, George Grote, and Profs. Huxley, Fraser, Hooker, Tyndall, and Latham, in 1859 , fifteen years ago, and were, of course, responsible estimates of Mr. Spencer as a thinker by some of the most distinguished of his contemporaries. At my request, Mr. Spencer favoured me with the reading of these letters, and the effect of their perusal was to produce a feeling of profound regret that they had never been given to the public ; for this would certainly have made an important difference in the reception accorded to his philosophical project. The writers recognized that Mr. Spencer was eminently the man to do a great and special work for the advancement and organization of knowledge in this age-a work which the British Government would honour itself by promoting; and they predicted the utmost that time has fulfilled in regard to the undertaking. But Mr. Spencer regarded the letters as written for a special purpose, and therefore not to be appropriated to any other. They, however, belonged to the initial stage of his enterprise, were designed to aid it, and should, I think, have been used for that object. I refer to this circumstance because it is an interesting fact; and I have the less concern in speaking about it, as the author of one of the letters assured me that the writers designed them for publication. 
THE CHARGES AGAINST THE POPULAR SCIENCE MONTHLY.

The publishers of this magazine, having declined any longer to issue the North American Review because of its recent articles from the pen of Colonel Ingersoll, have been charged with inconsistency on the ground that, in respect to the matter objected to, the periodical they retain is as bad as the one they have dismissed. A writer in the Evening Post says: "I would like to know how and where Messrs. Appleton \& Co. draw the line which makes the same opinions detestable in the North American Review, which are endured in The Popular Science Monthly. The editorial views of the latter publication are certainly as pronounced in their atheistical tendencies as anything Colonel Ingersoll ever uttered, and for a long period of years this journal has published everything of interest written by pronounced atheists, and excluded everything which has appeared of merit on the other side. The papers of Herbert Spencer, and others of his class, have been presented, but such writers as the Duke of Argyll have never been permitted to offer their views."

This accusation against The Popular Science Monthly, that it is a teacher of atheism, has been made before, and met before; but, as the present circumstances give it point and revive its interest, we propose now to reconsider it, and again see what it amounts to. We shall thereby be enabled to judge whether the two magazines really teach 
the "same opinions" upon this subject, as the writer in the Post affirms.

The paragraph just quoted would have been more satisfactory if it had been more explicit; for here, if anywhere, clear distinctions are demanded. What does the writer mean by "pronounced atheistical tendencies" and "pronounced atheists"? Does he mean that their atheism is avowed, or imputed; that they pronounce themselves atheists, or are so pronounced by others? 'These are not only different things, but the distinction is here very material; so that it becomes necessary, before we can find out who are truly atheists, to have the test by which they are known. Because a man is called an atheist, are we to hold that he is therefore, in fact, an atheist? We were once accosted by an inquisitive Irishman thus: "D'ye b'lieve in the mother o' God?” “No.” “Be gorry, ye're an atheist! I wouldn't be in yer boots for twenty pound." Was that a satisfactory basis of classification? Prof. Huxley had a cook who got on a drunken spree, and made such a row in the house that the police were called. As she was hustled through the yard, she sent back a blast, of which all that could be understood was an emphatic "damn athish!" Is Prof. Huxley, therefore, to be ranked as a "pronounced atheist"? But, if a drunken cook is not an authority on this point, is a sober bigot any better? It is the common and very foolish trick of religious partisans to stigmatize those who differ from them in their views of Deity as atheists. Each one identifies God with his own scheme of belief, and, if that scheme is objected to, the objector is denounced as a denier of God. Particularly where the conception of God is low, gross, and materialistic, is every higher view charged with atheism. There is, however, no honest difficulty here. We have exactly the same means of knowing atheists that we have of knowing Baptists or Buddhiststhat is, by what they profess and teach. We should call 
Bradlaugh a "pronounced atheist," because we have heard him say that he is the only man who ever ran for Parliament distinctly as an atheist. He has, besides, a large following in open agreement with him, and who may, therefore, be properly called atheists. A "pronounced atheist" in short, must simply be one who pronounces himself an atheist.

And now, having found that atheists are those who avow a certain belief, it is desirable to note distinctly what that belief is. "Atheism," says Webster, " is the denial of the existence of a God." But the term God has many significations, and is variously defined. We take the highest definition given by Webster, "the Supreme Being; the Eternal and Infinite Spirit." A pronounced atheist, therefore, is one who professes to deny the existence of "the Supreme Being; the Eternal and Infinite Spirit."

The writer in the Post declares that the Popular Science Monthly "has published everything of interest written by 'pronounced atheists,' and excluded everything that appeared of merit on the other side." The other side of what? Why, the adrocacy of atheism, of course! That is, "for a long period of years" this magazine has been given over to the work of teaching the doctrine of the non-existence of "the Eternal and Infinite Spirit." This statement is not true; it has not a vestige of truth in it; it is wholly and absolutely false. This is one of the charges that calls for proof, and happily the writer has given his proof. It is this, and nothing else-that "the papers of Herbert Spencer and others of his class" have appeared in The Popular Science Monthly. That any such papers really have the character charged, there is not the slightest attempt at proof.

But Herbert Spencer is not an atheist, and never has been. He has never declared his belief in atheism, and he is a man who expresses his opinions very freely and with 
but little regard for their popularity. He has been called an atheist, but that, as we have seen, will not do. If we had space we could fill pages with admissions on the part of all his ablest theological critics that he is not an atheist. We challenge the Post writer to produce a single passage in all his writings, in the Monthly or out, either avowing or defending atheism. On the contrary, he has laboured with all the power of his genius to prove that atheism as a theory of the universe (which it professes to be) is baseless and indefensible. And more than this, no man of the present age has reasoned out the foundations of man's belief in the existence of the "Infinite and Eternal Spirit" with such a depth of analysis and logical force as Herbert Spencer. He has sought to show that the "Infinite and Eternal Spirit," of which all the phenomena of the universe are but the manifestations, is the most absolute of all realities.

And still more than this is true. Mr. Spencer has gone beyond the theologians in their own line, and has rescued them from the consequences of their own logic. Every intelligent person knows that there has been a great progress in the religious ideas of mankind; and in nothing has that progress been so clearly evinced as in the gradual elevation of man's conceptions of the character of the deity he worships. During all the primitive ages religion was idolatry, and still is so, almost all over the world. But with growing intelligence there slowly arises a higher idea of the Divine nature. Polytheism passes into monotheism, and the gross, limited, anthropomorphic idea of God gives place to the loftier ideal of an "Infinite and Eternal Spirit." In this clearing away of limitations how far was the work to go, and what to be finally left? The theologians had been driving destructive criticism to its last extreme, with but little apparent care for the consequences. There grew up a vigorous ecclesiastical agnosticism, asserted even by the fathers of the Church. Clemens Alexandrinus 
(A. D. 200) says of God, "We know not what he is, but only what he is not." Cyril of Jerusalem (A. D. 350) affirms, "To know God is beyond man's power." St. Augustine (A. D. 400) observes, "Rare is the mind that in speaking of God knows what it means." John of Damascus (A. D. 800) declares, "What is the substance of God, or how he exists in all things, we are agnostics, and cannot say a word." Duns Scotus (A. D. 1300) remarks: "Is God accessible to our reason? I hold that he is not." This tendency to remove the Divine nature beyond the grasp of reason, and to hold that "a God understood is no God at all," has grown in strength in modern times, and reached its full expression in the theological philosophy of Hamilton and Mansell, which landed inquiry upon this subject in blank negation. Finding that the "Infinite and Eternal Spirit" transcended and baffled all reason, they assumed that reason brings us to an infinite nothing, so that we have no alternative but to give up the idea of an Infinite Power, or fall back upon faith. Mr. Spencer strenuously resisted this conclusion. He maintained that the most inexorable logic brings us not to an Infinite Nothing, but to an Infinite Something; and, although this "Eternal Spirit" transcends the reach of reason, and is "past finding out," yet that its existence is the profoundest of all verities. Where the case broke down in the hands of the theological analysts, he insists that it is demonstrably the strongest. Whether he proves his case is not here the question; we only declare that such is his position, which is in dead antagonism to atheism. But it is proper to say that many of his able opponents acknowledge that Mr. Spencer has contributed new and powerful arguments for the existence of an "Infinite and Eternal Spirit." In the presence of these facts, well known to all who care to know, what shall we say of the veracity, the honour, or even the decency of those who flippantly reiterate this groundless charge? 
And it is important here still further to observe that $\mathrm{Mr}$. Spencer is not a denier or antagonist of religion. $\mathrm{He}$ holds it to be a reality, a great truth; in short, nothing less than an essential and indestructible element of human nature. The religious institutions of the world, he maintains, represent a genuine and universal feeling in the race just as really as any other institutions. With the accessory superstitions which in all ages of ignorance have overgrown and perverted the religious sentiment, he is, of course, not in agreement; and he maintains that the confounding of these with the religious sentiment itself is a mischievous mistake of religionists and anti-religionists alike. And he furthermore holds that science, in clearing away these superstitions, is bringing us ever nearer to the underlying truth, and is therefore doing the highest religious work. And, besides, in all his discussions of religious subjects, though bold, he is reverent, respectful to sincerity, tolerant of honest prejudice, and never wantonly irritating in the treatment of what he regards as religious errors.

A line is to be here drawn, clear and sharp, separating this mode of regarding religion from that which proclaims it to be a sham, an imposture, and a mere invention of priestcraft to cheat credulous people. Between him who believes that religion is a great and sacred reality, and him who denounces it root and branch as a delusion originating in fraud and knavery, there can be no common ground. These are not the "same opinions," but diametrically opposite opinions. A criticism of religious errors, however trenchant it may be, if it gives the subject sincere and respectful consideration, is as different as any two things can be, from a spiteful, ruthless, and exasperating assault upon the religious sentiment of the community. And when these opinions are published for no other reason than to startle and shock the public by their audacity, and for no other than a sordid purpose, the case is still further aggra- 
vated. The Popular Science Monthly has left others to make what trrey might out of this policy.

The writer in the Post complains that we have not published the views of such men as the Duke of Argyll, to which we reply: r. That we should have been glad to publish the Duke of Argyll's articles, but had no room for them. 2. That we started a supplement to make more room, and did publish the views of the Duke of Argyll. 3 . That the papers of his Grace have been very widely reprinted in other channels, so that the public has experienced no inconvenience from the want of them. The Monthly, we must remember, was established not for the display of polemical pugilism, but for the serious purpose of placing before American readers the most important results of scientific thought as presented by its ablest expositors. So far, indeed, has it been from seeking sensational papers, that its main purpose was to publish a class of valuable scientific articles, which, because they are too heavy or will not pay, or conflict with public prejudices, were systematically excluded from our current magazines. While striving to make our pages as varied and attractive as possible, we have not sacrificed the character of the magazine to promote its pecuniary success. We have maintained a steady course, our last issue is strictly in the line of the first, and all the wide approbation that has been accorded us from the beginning is as applicable now as it ever was.

The New York Observer, in commenting upon this subject, agrees with the writer in the Post that the Monthly is as bad as the Review, if not worse, and it very plainly says: "We with thousands hope sincerely that the commendable course taken by the eminent publishers, in kicking the Review out of their premises, will be followed in regard to the Monthly. Or, what would be better still, let us hope the Monthly will omit its atheistic teachings, and 
The Charges Against the Popular Science Monthly. 559

become such an organ of science as the great body of intelligent people will admit with confidence into their homes."

We have exploded the charge of the Post writer, here repeated, because he gave us his evidence, and we had something tangible to deal with. But the Observer scents atheism in everything scientific, and, if we began to expurgate in accordance with its notions, we should have to expunge the whole Monthly. For does not the Observer hold evolution to be atheistic ? And what would 'The Popular Science Monthly be, mimus evolution? It is the new dispensation of scientific thought, cropping out everywhere, antiquating old views, affording new explanations, reorganizing knowledge, and guiding the researches of scientific men in every field of investigation. Those who do business on old opinions are in a great state of perturbation and distress about it. Some are for "giving in," some are for patching up compromises, and some for "fighting it out." Meanwhile the tide is carrying everything before it, and the confusion of the unready waxes grotesque. The foreign periodicals arrive monthly loaded with evolutionary discussions; and in the last Contemporary Review Calderwood, of Edinburgh, announces that even Hegelianism is but "dialectical evolution."

The Observer suggests that we make such a periodical "as the great body of intelligent people will admit with confidence to their homes." This sounds well, but what is it in a little plainer English? "Divest your Monthly of every feature that can be objectionable to those who care a good deal more for theological than for scientific teachings, and who have a horror of all science as tending to infidelity." We should not be permitted to say a word of the progress of scientific thought, because hardly a step is taken anywhere that somebody with a dogma in that direction does not cry, "Halt, you destroyer of religion!" 
We indulge in no exaggeration. The Observer is authority here, and right above the article in which it recommends that the Monthly be kicked off the premises, we read, "SCIENCE FORGES WEAPONS CONSTANTLY TO DESTROY THE FAITH." What kind of a scientific magazine would that be which should be suited to the state of mind of the dismal creatures who take such a view of science as this? We should rather take the Observer's alternative, and be kicked into the street, than to edit such a periodical.

The Observer accuses science of "forging weapons to destroy the faith"; but need we remind it that science destroys nothing but ignorance and error? Only where faith is the enemy of truth can science be the enemy of faith. Scicnce is the best friend of faith, for only when it has destroyed all it may, can faith have any "abiding foundation." We are afraid that, when the Observer invokes the publishers' boot as a censor of science, it betrays some want of confidence in its own foundation. What shall we say of the security of a religious edifice built upon the basis of literal Old Testament history? But in the very next column to the article we are noticing, it is laid down: "A denial of the literal verity of the Old TestaMENT HISTORY IS THE FIRST STEP IN MODERN INFIDELITY."

No more complete or more mischievous mistake can be committed than to impute to the scientific writers of this age any hostility to religion as the motive of their labours. That the course of inquiry often conflicts with cherished tenets is undoubtedly true, and it is a painful fact; but to charge scientific men with any intention of inflicting this pain, or to make them responsible for it, is wholly unjust. The world has never seen in all its history a class of men more noble in purpose, more fair-minded, more candid, tolerant, or considerate, than the class of men who, in all countries, though with a common spirit, have devoted themselves to the truth-as it is in science. They have done their work 
with a single-mindedness, a freedom from partisan and sectarian passion, and an openness and uprightness of purpose, that find no parallel in any other great group of men engaged in the advancement of a common interest. These men are entitled to stand first in the respect and confidence of the community; and to accuse them of being animated in their study of nature by a desire to destroy religion, or to wound the feelings of religious people, is thoroughly unjustifiable.

The Popular Science Monthly is a record of the scientific activity of the age for the last ten years, and it reflects the breadth, the independence, and the catholicity of thought that distinguish the scientific men of our time. There may have been things said in it which people with a formulated faith find objectionable; but they are the results of honest and earnest thought and the incidents of legitimate discussion, and must, therefore, be tolerated. Science cannot work under the dictation of those interested to restrain it. Are men who make the supreme purpose of their lives the understanding of Nature, to stop research into the laws of life, the genesis of species, the antiquity of man, the functions of the brain, the laws of social growth, or the natural history of superstitions, because there are many who, without ever studying these subjects, have views in relation to them which they do not wish disturbed? It is impossible. The great modern movement of the human mind which we call science is a part of evolving Nature, and we have no liberty to do anything but represent it as faithfully as we are able. 


\section{VII.}

\section{CONCERNING THE SUPPRESSED BOOK.}

IT will be no news to the readers of this Monthly that the volume entitled The Nature and Reality of Religion; A Controversy between Herbert Spencer and Frederic Harrison, published by D. Appleton \& Co. last March, has been suppressed by order of Mr. Spencer. This catastrophe was the result of a public correspondence carried on between these gentlemen in the columns of the London Times. Fragments of the letters were cabled to this country as they appeared, and were widely disseminated by the newspapers, producing some suspense, and giving a confused impression of the affair. At length came the announcement that the disagreeable difference was happily composed; but with it came also a despatch ordering the destruction of the book - copies, plates, and all-the damage to be charged to Mr. Spencer. This seemed a curious way of bringing an unpleasant difference between two authors to a harmonious termination; but without waiting for explanations, the mandate was obeyed and the book suppressed. The letters themselves are now before us, and as they have not all been previously published in this country, they are herewith submitted to the reader in full:

THE SPENCER-HARRISON CORRESPONDENCE.

[London Times, May 29, 1885.]

A NEW FORM OF LITERARY PIRACY.

Mr. Frederic Harrison has forwarded to us for publication the inclosed letter, which he has addressed to Mr. Herbert Spencer : 
"May 28, 1885 .

“DeAr Mr. Spencer: I cannot almit that there is anything to justify you in being a party to the $A$ merican reprint of articles of mine, without my knowledge or consent. I learn accidentally that a volume has appeared in New York, which consists of three recent articles of yours in the Nineteenth Century, printerl alternately with three recent articles of mine, with an introduction, notes, and appendix. This reissue of my articles was made without the knowledgre of myself, or of the proprietor of the Nineteenth Century, and he tells me that it is a case of piracy.

"You now avow (in your letter to me of yesterday) that the volume was issued by your American publishers, and was edited by your friend Prof. Youmans, after consultation with you, with your consent and assistance. You also avow that you furnished the editor with controversial comments on my articles, and requested him to append them in his own way-that is to say, you have abetted a clandestine reprint of three articles of mine, interpolated with notes supplied by yourself. I regard this not only as an act of literary piracy, but as a new and most unworthy form of literary piracy. May I ask if it is proposed to hand you the profits of a book of which I am (in part) the author, or are these to be retained by your American publishers and friend?

"To justify this act you now write that you expected republication in America by my friends. This expectation rests, I can assure you, on a pure invention. No friend of mine, nor any person whatever in America or in England, has ever suggested to me the republication of my articles, nor have I ever heard or thought of such a project. You quote to me, as your authority, a letter from Prof. Youmans, who simply says there is danger of its being done by others, and he adds that I am coming to lecture in America. Again, this is a pure invention. I have never thought of lecturing in America, or of going there, nor has any one on either side of the Atlantic suggested to me to do so. Those who 'convey' my writings will as readily invent my intentions. Inquiry would have shown that neither I nor my friends had any intention of reprinting any articles-much less yours. And I fail to see how an unverified report that they might be reprinted, coupled with an unverified report that I was going to lecture in America, could justify you in promoting and assisting in the unauthorized issue and sale of writings of mine. 
“This is not a simple case of clandestine reprint. Those of us who do not take elaborate precautions are exposed to have what they write appearing in unauthorized American editions. But it does surprise me that an English writer should connive at this treatment of another English writer with whom he had been carrying on an honourable discussion. It is, I think, something new, even in American piracy, to reissue an author's writings behind his back, and sell them interlarded with hostile comment. Reprints, even while they plunder us, spare us the sight of our sentences broken on the same page with such amenities as 'he complacently assumes,' 'loose and misleading statements,' etc. You avow, in your letter of yesterday, that you supplied these comments to my articles; and if internal evidence did not show them to be yours, by your offer to me to republish them now in England, you treat them as yours. I know no instance of such a practice. It is as if I were piratically to reprint your Data of Ethics, freely interspersed with a running commentary on your practice of ethics, and were to justify my act on the ground that I had had a controversy with you, and that I had heard your friends were about to reprint it.

"There is one minor point which serves to show the kind of publication in which you have chosen to take part. My articles in this volume are followed by a cutting from a newspaper account of what the editor calls 'The Little Bethel of the Comtists.' As the volume bears as its subtitle the words, 'A Controversy' between Frederic Harrison and Herbert Spencer,' that newspaper paragraph would only be relevant if it referred to practices in which I had some part, or which I approved. It is well known that I have nothing to do with anything of the kind, and never countenanced it. Nothing of the sort has ever been heard in Newton-hall, where for years past I have presented Positivism as I understand it. The matter is a small bit of polemical mischief; those who are engaged in plunder are not likely to be fair. But $I$ think it is quite unworthy of a place in a volume for which you are responsible, and which you have authorized and adopt.

"You now propose to me to republish this volume in England, where you admit it could not appear without the consent of all concerned. After what you have done I must decline to act with you. I leave your conduct to the judgment of men of sense and of honour. "I am faithfully yours,

\section{“Mr. Herbert Spencer.}

FREDERIC HARRISON." 


\section{[Times, June 1 st.] \\ MR. FREDERIC HARRISON'S CHARGE.}

\section{To the Editor of the Times.}

SIR: Will you oblige me by publishing the following letter, which is a copy of one to Mr. Harrison, referred to by him in his letter contained in The Times of Friday:

Queen's Gardens, Bayswater, W., May 27, 1885.

"DEAR SIR: Here are my replies to the questions put in your note of yesterday.

" Just before the middle of January I received from my American friend, Prof. Youmans, a letter dated January 2, containing, among others, the following paragraphs:

“. And now we have something of a new embarrassment upon which I must consult you. There is a pretty sharp demand for the publication of your controversy with Harrison in a separate form, and the publishers favour it. The question is not simply whether it is desirable, for we cannot control it. There is danger that it will be done by others, and if that should occur it would be construed as a triumph of the Harrison party-the Spencerians having declined to go into it.

“. If I thought no one else would print the correspondence (i. e., the Nineteenth Century articles), I should be in favour of our not doing it. In the first place, for general effect, rhetoric against reason counts as about ten to one. The Comtists are reviving-Harrison is coming over to lecture in this country, and much will be made of his brilliant conduct of the controversy. In the next place, he has this advantage of you: your main work bearing upon the issue is to be sought elsewhere, while Harrison had accumulated all the materials of his assault and gives his whole case, so that the popular effect could not fail to be much in his favour. To the narrower circle of readers who can really appreciate the discussion, the republication would undoubtedly be an excellent thing, and I suppose, after all, it is only these that we should much care for. On the whole it may be politic to reprint. What do you think about it?'

" There was thus raised a quite unexpected problem. I had supposed that the matter had ended with your letter to the Pall Mall Gazette; and having expressed (in the Nineteenth Century) my in- 
tention not to continue the controversy, I hoped it would drop. Here, however, came the prospect of a revival in another shape; and I had to choose between republication by my American friends or republication by your friends, with the implication that I was averse to it. Though I should have preferred passivity, yet, under the circumstances stated, I thought it best to assent to republication. One objection, howerer, became manifest. While in my replies to you I had pointed out sunclry of your many misrepresentations, I passed over others-one reason being that I could not trespass too much on the space of the Nineteenth Century and the attention of its readers. Now, however, when it was proposed that the statements contained in your articles should be rediffused, and take a permanent form instead of a temporary form, I felt that I could not leave unnoticed these other misrepresentations. Appearing in a volume issued by my American publishers, and edited by my American friend, the implication would have been that statements made by you to which no objection was raised were correct statements. If words in quotation marks tacitly ascribed by you to me had not been disowned by me (p. I I2), it would, of course, have been assumed that I had used them, and that I stood convicted of the absurdity which you allege on the assumption that I had used them. If it had not been shown that an opinion you debit me with (p. I29) is wholly at variance with opinions which I have expressed in three different places, it would naturally have been concluded that I held the opinion. Hence it was clear that unless I was to authorize the stereotyping of these and other errors I must take measures to dissipate them. I therefore pointed out to Prof. Youmans the statements which required notice, indicated the needful rectifications, and requested him to append these rectifications in his own way. At the same time I forwarded him a copy of the letter which you published in the Pall Mall Gazette, saying that 'if this reprint of the articles is published without this letter, he (you) will inevitably say that his final reply has been omitted. It is needful, therefore, that it should be included.' And along with your letter I sent indications of the points in it which should be noticed.

"Do you think I was not justified in this course? Do you think I ought to have withheld my consent to the republication by my friends, leaving your friends to republish? Do you think that, having assented to republication, I ought to have let pass without correction 
your misstatements previously uncorrected? If you think either of these things, I imagine that few will agree with you. There is, however, an easy way of bringing the question to issue. All the articles are copyright in England, and cannot be republished here without the consent of all concerned. I do not suppose that Mr. Knowles will raise any difficulty; and if you agree to the reissue of them here, I am quite willing that they should be reissued. If you think that anything said in refutation of your statements should not have been said, we can easily inclucle an appendix in which you can point out this; and then, if you wish it, copies of the volume can be sent round to the press.

" Of course I preserve a copy of this letter with a view to possible future use. Faithfully yours,

"Frederic Harrison, Esq."

"Herbert Spencer.

I will add but two comments. Mr. Harrison had this letter before him when he wrote his statement. Does the reader find that his statement produced an impression anything like that which my letter produces? The other comment is this. Asking whether I have any share in the profits, Mr. Harrison not only by this, but by his title, "A New Form of Literary Piracy," tacitly suggests that I have. Merely stating that the affair is purely the affair of the Messrs. Appleton, and that not even a thought about money ever entered my head concerning it, I draw attention to the readiness with which Mr. Harrison, without a particle of evidence, makes grave insinuations. And I do this because it will enable the reader to judge what need there probably was for taking the measures I did to prevent the wider and more permanent diffusion of Mr. Harrison's misrepresentations.

Concerning the newspaper extract describing a Comtist service I know nothing, and greatly regret that it was appended. I will at once ask to have it withdrawn. If three gentlemen, appointed in the usual way, decide that uncler the circumstances, as stated to me by Prof. Youmans, I was not justified in the course I took, I will, if Mr. Harrison wishes it, request Messrs. Appleton to suppress the book and destroy the stereotype plates, and I will make good their loss to them.

I am, faithfully yours,

HERBERT SPENCER.

May 29. 


\section{[Times, June 2d.]}

MR. SPENCER AND MR. HARRISON.

\section{To the Editor of the Times.}

SIR: I will not pursue this matter further, nor will I insist on Mr. Spencer's fair offer to submit it to arbitration. It satisfies me if he will not claim any absolute and moral right to copyright in America my writings with rectifications of his own. I am accustomed to unauthorized reprints of what I write; and as I hear there is a brisk sale for these essays (quorum pars minima fui) I will only congratulate the Yankee editor on his 'cuteness. As Mr. Spencer, by his offer, now admits it to be possible that he made a mistake, I am ready to regard his share of it as an inadvertence. I know too well his great generosity in money matters to suppose that any question of profit crossed his mind. But it certainly crossed some one's mind; and I referred to it only to convince him that eager partisans had led him into a mistake. It is not easy at any time to get him to see this, and to open his eyes I used for once plain words. Conscious that I had conducted a philosophical debate with an old friend with all the deference and admiration that I really feel for his genius, it did pain me to find myself treated as the proverbial dog whom any stick is good enough to beat. The only arbitration I now desire is that of some common friend who may convince him that I wish nothing more than a return to the position of philosophic friends who agree to differ about their respective systems.

$$
\text { I am, \&c., }
$$

Fune $\mathrm{x}$.

FREDERIC HARRISON.

$$
\text { [Times, June 3d.] }
$$

MR. SPENCER AND MR, HARRISON.

\section{To the Eititor of the Times.}

SIR: Rather than have any further question with Mr. Harrison, and rather than have it supposed that I intentionally ignored his copyright claim, I have telegraphed to Messrs. Appleton to stop the sale, destroy the stock and plates, and debit me with their loss.

I am, faithfully yours,

HERBERT SPENCER.

Clovelly, Fune 2. 


\section{[Times, June $4^{\text {th. }}$ ]}

MR. SPENCER AND MR. HARRISON.

\section{To the Editor of the Times.}

SIR: Allow me to supplement my letter telegraphed yesterday, partly to explain how the thing arose, and partly to correct an impression made by your leader of to-day. I was wrong in assenting to the republication by Messrs. Appleton. I ought to have borne passively the threatened evils of republication by other publishers, and, as my friend has been connected with publishing in New York for thirty years, I supposed his impression that these were coming was correct. But my decision was made in a hurry, without due thought. Believing there was no time to lose, I telegraphed reply, and by the next post indicated corrections to be made in the statements of my views. And here I wish to point out that the notes I indicated were not criticism of Mr. Harrison's opinions, but corrected versions of my own. Any others, if there are any, are Prof. Youmans's. I go on to explain that my mind was so engrossed with the due presentation of the controversy that the question of copyright never occurred to me; and the thought that Mr. Harrison might not like his articles republished was excluded by the impression given me that others would republish them if the Appletons did not. Hence my error. But my error does not, I think, excuse Mr. Harrison's insult. By cancelling the rest of the edition and the plates I have done all that remains possible to rectify the effects of my mistake.

I am, faithfully yours,

ILFRACOMBE, Fune 3 .

Herbert SpeNcer.

[Times, June 6th.]

MR. HARRISON AND MR. SPENCER.

To the Editor of the Times.

SIR: May I once more trespass on your space by asking you to publish the following letter from Mr. Harrison?

I am, faithfully yours. HERBERT SPExCER.

" 38 Westbourne Terrace, W., Fune 4, 1885.

"DEAR Mr. SpenCER: As you still appear to think (in spite of my public disclaimer) that I have brought against you a charge of 
desiring money profit out of this American reprint, I beg to say that I did not intend to make any such charge, and I do not believe that I have. I regret the use of any words which produced that impression on you.

I am, yours faithfully,

"FREDERIC HARRISON.

"P.S.-You can use this letter as you think fit.

"Herbert Spencer, Esq."

[Standard, June roth.]

MR. SPENCER AND MR. HARRISON.

To the Editor of the Standard.

SIR: The fact that the information to which it refers came through The Standard must be my excuse for asking you to publish the following letter, a copy of which I have inclosed to Mr. Harrison, requesting him to post it after reading it.

I am, Sir, your obedient servant,

HERBERT SPENCER.

" 38 Queen's Gardens, Bayswater, London, W., Fune 9.

“MY DEAR YOUmans: I returned home last night, and only this morning learned that in The Standard of Saturday last there was, in a telegram from New York, a statement to the effect that Messrs. Appleton decline to destroy the stock and plates of the reprinted controversy (as I had telegraphed them to do), on the score that the book would be reprinted by some other publisher. In this expectation they are probably right. But a reprint would necessarily be without the notes; since these, as implied in your preface, are your copyright in America. Now, though these notes-or, at least those which I pointed out as needful-are corrections of erroneous statements of my views, yet, rather than have it supposed that I wished to take any advantage of Mr. Harrison in making such corrections, I will submit to the evil of reissue by another publisher without them; and I therefore repeat the request that the stock and stereoplates may be destroyed, and the loss debited to me.

"One word respecting the proposal of the Appletons to share the author's profits between Mr. Harrison and myself. If any have at present accrued, or if, in consequence of refusal to do as I have above requested, any should hereafter accrue, then I wish to say 
that having been, and being now, absolutely indifferent to profit in the matter, I shall decline to accept any portion of the returns.

"Ever sincerely yours,

"Herbert Spencer."

Several points in this correspondence, especially in its opening letter, require some notice in this place; but, before making the critical corrections that seem to be required, I desire to say a few words on the peculiar circumstances of American publication which have an important bearing on the present case.

Mr. Frederic Harrison took offence at the American reprint in a book of some review articles of his, and pronounces it "a case of piracy." The organs of English opinion, in commenting upon these letters, take the same view. The London Times, after referring to the graceful and honourable termination of the disagreeable difference between Mr. Harrison and Mr. Spencer, devotes a leading editorial to the discussion of American piracy on the basis of the fresh and striking illustration of it here afforded. Speaking of the effect of the "tolerably rigid copyright law" of England, the Times says: "But so far as America is concerned it is different. To the English author that country seems to answer very much to Hobbes's idea of a state of nature. Foreign authors are fair prey; for them there is or need be no selling or buying of copyrights, and a good book is to be dealt with as a part of the common elements of Nature. If any laws govern the matter, it is only those which regulate the capture and reduction into possession of wild animals." The case is certainly bad enough, but this is an exaggeration.

At the outset I admit that on the question of international copyright, or the claims of foreign authors to property in their books, the English are right and the Americans wrong-so flagrantly wrong as to justify much of the 
denunciation we receive. The position of our Government upon the subject I regard as wholly indefensible. Its policy is an outrage upon a class of men who are public benefactors, a disgrace to the country, and a scandal to civilization. Grover Cleveland's republic does not recognize that Frederic Harrison and Herbert Spencer have any right of property in the products of their brainwork. Their productions when brought to the United States belong neither to them nor to anybody else. They are not protected by law, and may be appropriated by anybody without violation of law. There are many in this country who realize the vice of this policy quite as vividly as the foreign victims of it and who are labouring hard to put an end to it. But, without offering a word of apology for it, there is still something to be said in behalf of those who are compelled to act under a bad state of things which they reprobate but are for the time powerless to remedy. It is certainiy unjust to involve these in the indiscriminate condemnation of the vicious system. It is a good deal easier to denounce it at a distance than to fight it on the spot. Nor is it possible for authors, living under a government which so stringently protects them that they acquire the habit of regarding literary property as something peculiarly sacred, to fully appreciate the difficulties of publication and the course which business must take under entirely opposite circumstances, where literary property is without any. legal protection. With no international copyright it is certainly impossible to act as if we had one. That the Government does not protect him, and that if protected at all it must be done by himself, is the first and vital fact that has to be taken into account when any publisher makes the venture of reissuing a foreign book in this country. The Government is, in fact, his enemy, and virtually calls upon everybody to make war upon him. However disposed he may be to treat a foreign author well, to bring out his work in 
respectable shape, and pay him for it fairly, he meets this ugly circumstance at the threshold of the transaction, that the money he puts into it may be sunk because anybody can reprint the work in cheaper form and without paying the author anything. Nor is this all; the more honourable he is, the worse it is for him. Any sense of liberality he may indulge works directly against him. If he publishes the book in good form, pays a decent royalty, and makes it properly known by advertising, all this is a temptation to other parties to take advantage of his outlay, and the reputation the book acquires by means of it, to fill the market with mean editions that kill the honest publication. The American publisher is therefore compelled to adopt a policy very different from that in England, where books are vigilantly and effectively protected by law. He has to conform to the necessities of a lawless state of things, and must be left to make the best he can of it.

But the indiscriminate charges of the London Times are not true; all American publishers are not freebooters and pirates. Although it is not possible for them to treat foreign authors with full justice in the absence of international copyright, yet it is false that these authors are preyed upon in the unqualified way asserted by the Times. There are, of course, American publishers, and plenty of them, who are thoroughly unscrupulous; but there are others, and they are not a few, who do the best they can under the present demoralizing system to compensate foreign authors for their work. They pay them by voluntary arrangement, not the rates that they are accustomed to at home, and not always perhaps as much as they might, but often, as I happen to know, to their own loss, when books are reprinted by others and the market supplied by degraded editions on which the author receives nothing. In the absence of an international copyright law, this voluntary action of American publishers is the only thing practicable or possible to 
mitigate the barbarism of the situation. Imperfect as it may be, it is an honest procedure in behalf of the foreign author; and it is now practised to an extent that should materially qualify those wholesale charges of piracy. The present case is to be regarded in the light of these considerations; and I think it will be found that the lesson to be drawn from it is quite different from that which has been drawn by, the English press.

So far as the above correspondence is concerned, the motives that impelled me to take the share I had in bringing out the suppressed book are to be gathered only from a scrap in a hurried private letter to Mr. Spencer; but, as my act is now branded as piratical, I must be excused for stating more fully the reasons by which I was actually influenced in the course taken.

Mr. Harrison had an important controversy with Herbert Spencer on a grave subject, which was published in the Nineteenth Century. In printing their papers $I$ have the right to assume their purpose to be that they should be read as widely as possible. There was much interest in this country to follow this discussion, and we accordingly printed the articles in The Popular Science Monthly.

But, when the controversy was finished, there was a call for its republication in a separate form, more convenient, accessible, and cheaper than in the pages of a magazine. The demand was reasonable, and I was anxious to comply with it, that the discussion might be disseminated as widely as possible. I, moreover, desired the republication for the same reason that I had urged Mr. Spencer to go on with the controversy with Mr. Harrison. Although knowing the low state of his working power, and how important it was that he should not be interrupted by such side issues in the prosecution of the great philosophical work upon which he has been engaged for many years, it seemed to me of 
greater importance that he should seize the opportunity offered by Mr. Harrison's attack to develop more fully his fundamental religious opinions. He had published but little upon that subject for a long time, his views had been much controverted and much misunderstood, and I knew there was a strong lesire on the part of many to read everything he might say in further interpretation and elucidation of them. His distinctive doctrines were now vigorously and formally attacked by a sagacious adversary, long prepared by his special studies to put them to the severest test. For the same reason that I encouraged Mr. Spencer to give time to the discussion, I desired that his readers in this country should be put in ready possession of it when done. I may add that in this I was impelled by the same general motives that had prompted me for many years to do what I could to bring Mr. Spencer's ideas before the American people.

But there were special reasons which made me wish that the publication should be issued by D. Appleton \& Co. This house had printed all of Spencer's works; and as a present statement of his religious views would be an important addition to them, and would naturally be called for in connection with them, it seemed important that his controversy with Harrison should be brought out in a reputable and permanent shape to take its place with his other books. Besides, there was a high degree of certainty that the discussion would be published by somebody. The names of the eminent contestants, and the interest felt by a large number of people in the subject, were evinced by a strong demand for the publication. The discussion in its separate form was called for by the friends of Mr. Harrison and by the friends of Mr. Spencer, and by others who were friends of neither. It was open to anybody to print it, and there was every probability that it would be picked up and issued in a cheap, catchpenny edition, which is now so 
common with publications of every kind. I desired, therefore, that the Appletons should bring it out in a respectable shape and at a moderate price, that the book might be had at any time in a form suitable for preservation.

I protest that these considerations were not vitiated by any covetous desire or purpose whatever. Mr. Harrison says it is a case of "piracy"; but, so far as this involves the taking of his property without compensation, there was no thought of it. In his opening letter he virtually accused Mr. Spencer of collusion in the piracy of his articles, from a sordid intention. Judged by this extraordinary letter, Mr. Harrison's religion of humanity consists chiefly in imputing rile motives to his fellow-men. He said, "May I ask if it is proposed to hand you the profits of a book of which I am (in part) the author, or are these to be retained by your American publishers and friend?" Evidently the pecuniary consideration was uppermost in his own mind. But he had here gone too far. Everybody recognized the outrage. The reader will note the striking difference in tone, amounting to a collapse, between his first and his second letters. He withdrew the offensive insinuation so far as Mr. Spencer was concerned, saying, "I know too well his great generosity in money matters to suppose that any question of profit crossed his mind." But he knew this no better when he wrote his second letter than when he wrote the first. He sent Mr. Spencer a private note asking explanations about the book, and this Mr. Spencer answered, but said nothing respecting the copyright; this did not enter his mind, probably for the reason that the house which issued it had published his books for twentyfive years, paying him regularly on all of them from the first, and he had no care about it, knowing that the equitable thing would of course be done to all concerned. But the inadvertence gave Harrison his opportunity.

But while Mr. Harrison exonerates Mr. Spencer from 
all thought of making profit out of him, he adds, "But it certainly crossed some one's mind," referring, of course, to Mr. Spencer's "American publishers and friend." Yet there was not the slightest wish or design on the part of the publishers of the book to withhold from Mr. Harrison his proper share in its copyright proceeds. They have published the scientific and philosophical works of many English authors, on which they have paid the customary compensation allowed to American authors, and if Mr. Harrison doubts it he can satisfy himself by inquiring of his neighbours, Tyndall, Lecky, Huxley, Bain, Sully, or the Darwins, and there is surely no reason why they should not have compensated Mr. Harrison in the same way; and this was certainly their intention.

But perhaps the party who desired to plunder Mr. Harrison (he uses the significant word twice in his first letter) was Mr. Spencer's American friend, and that he supposed this "friend" capable of sharp practice is inferable from his remark, "I will only congratulate the Yankee editor on his 'cuteness." Yet the 'cute Yankee editor in this case was the only party to get nothing. Among the several stools occupied by authors and publishers, it was his fate to sit on the ground. Neither by stipulation nor expectation was he to have a cent for his labour in editing the volume, or his efforts in promoting its circulation. The reasons which actuated him have been already stated. But as the question is here raised of venal motives in the treatment of foreign authors, and as this transaction has been extensively paraded as a flagitious example of American piracy, the editor of the suppressed book is entitled to say that he has done his full share in a practical way toward promoting international equity in the payment of authors for their books. He gave nearly a year's labour to the organization of the International Scientific Series for the avowed purpose of securing more satisfactory compensa- 
tion to scientific writers. The project was based upon the condition of the payment of copyright to each of the contributors from all the countries in which the books were issued. Nothing of the kind had ever been done or attempted before; and, in regard to its result, Dr. John W. Draper remarked, "Although there are international copyright regulations in Europe, and my various works have been translated into many foreign languages, I have never received anything from them except upon the volume I wrote for the International Series, and on that I have been paid regularly by the English, French, German, and Italian, as well as by the American publishers." Fifty volumes have now appeared in that series, and the American publishers have voluntarily paid all the foreign contributors the same as if they had been citizens of the United States. And this they have done in spite of the fact that this honourable arrangement has been disregarded, and various of the volumes have been reprinted in shabby twenty-cent editions, on which, of course, the authors have received nothing.

This, then, is the way in which Mr. Harrison has been outraged. He had his articles brought out in good shape for such of his friends as desired to possess them in a separate form. He has been "plundered" by being protected against plunder on the part of those who might have issued a trivial and fugitive edition of his controversy, and allowed him nothing for it. He has been "pirated" by having voluntarily secured for him the substantial benefits of an international copyright law.

But Mr. Harrison's articles were used without his consent, and that is what the charge of "piracy" here amounts to. His consent was not asked because it would have implied control of that over which he had no control. If he had refused, that would not have stopped the publication, but would have simply defeated the purposes of those who 
knew better than Mr. Harrison did what required to be done. He was not consulted for the simple reason, now obvious enough, that he would be unlikely to make allowance for a state of things utterly different from that to which he has been accustomed. He was not asked, because, while his assent would have done no good, his dissent would have done injury to himself, to Mr. Spencer, and to the public. And that Mr. Harrison would have witheld his consent is far from improbable. That the book was wanted here by many readers was nothing to him, as is shown by the fact that, when a word would have saved it from destruction, he declined to utter it. Something is of course due to courtesy, but I was not at all certain that courtesy would be met in the same spirit. The feeling of high-toned British authors toward American "pirates" is not usually vented in gracious expression. American experience with such authors is apt to engender diffidence in approaching them. Those gentlemanly and honourable publishers, the Messrs. Putnam, having special reasons recently to make overtures to Mr. Ruskin for the use of one of his articles (to be paid for, of course), were deterred from doing so because that author "absolutely declined to come into any relation with an American publisher." Mr. Harrison is understood to be a particular and punctilious man, and that he can, upon occasion, pretermit the requirements of amiable civility, and take to "plain words," is amply attested by his letter of May zgth to Herbert Spencer.

But, in the matter of "piracy," it is Mr. Spencer who comes in for Harrison's hottest indignation. He accuses him of having invented a new form of it, and aggravated the offence by its clandestine perpetration. Now, let us see what it was that Spencer did. After finishing the controversy in the Nineteenth Century, Mr. Harrison transferred it to the Pall Mall Gazette, in which he printed an additional 
article, addressed to a new audience, and filled with very objectionable misstatements. It would not do, in editing the volume which was intended to be a full presentation of the discussion, to leave this article out. But to print it without corrections would be unjust to Spencer, and to the readers of the book, who wanted and were entitled to the completest statement of the case. There was no call for anything more from Mr. Harrison, who had had his last word, and declared that he should pursue the controversy no further; but there was a need that corrections by Spencer should be supplied. He accordingly sent me the substance of some additions to be appended as notes, and which I inserted in their appropriate places. I deny the wrongfulness of this act, and the ado that has been made over it seems to me perfectly absurd. Mr. Spencer did what it was desirable and entirely proper that he should do. He had not only the right but it was his duty to defend himself against the erroneous representations of $\mathrm{Mr}$. Harrison; and I insist that, if any apology was due either way, it was from Mr. Harrison to Spencer for making the misstatements, rather than from Spencer to Harrison for correcting them.

Mr. Spencer, as will be seen, prints two paragraphs from a private letter of mine giving reasons which induced him to favour the American reprint, and Mr. Harrison characterizes them as chiefly "inventions." I had said, "Harrison is coming over to lecture in this country," and $\mathrm{Mr}$. Harrison says he never thought of it. I wrote carelessly; but my meaning was, that he is expected to come, and in this there was no "invention." It had been talked about, and there was nothing unlikely in it. The coming of eminent Englishmen to this country to lecture is certainly no unusual thing. Mr. Harrison is a lecturer, a man of ideas which he is interested in propagating, and is reputed to have means and leisure. He has many admirers in the 
United States, and a reputation which would be certain to secure him good audiences. As it turns out, "the wish was father to the thought," but the rumour was not improbable. I should have referred to it as a contingency, and I simply meant that it might be worth taking into account, with reference to the publication of the controversy.

Mr. Harrison says the idea that there was any danger of republication in this country by his friends rested also upon pure "invention." But I did not say this. I wrote to Spencer, "There is danger that it will be done by others, and if that should occur it would be construed as a triumph of the Harrison party." Mr. Spencer's interpretation of it was, "I had to choose between republication by my American friends or republication by your friends, with the implication that I was averse to it." And Mr. Spencer was here substantially right. Although there may have been no apprehension that Mr. Harrison's avowed friends would move in reprinting the book, yet if it had been done by anybody but the Appletons, the inevitable inference would have been that their author had been so badly handled that they declined to back him. The book was looked for from Mr. Spencer's publishers, they had printed it in their magazine, they issued all his works, there was a demand for the volume which was certain to make it a safe business venture, and it represented two sides or schools of thought: if, under all these circumstances, D. Appleton \& Co. had left the work for others to publish, the certain construction would have been that the book was abandoned to the party opposed to Mr. Spencer. This is the aspect of the case which he had to meet, and it is not at all affected by Mr. Harrison's statement that his friends had no idea of printing the controversy.

Another explanation seems here called for. Those who will refer to the second paragraph of my letter, quoted by 
Mr. Spencer, will observe both an indecision and a confusion in the statement. This was due not only to hasty writing but to some perplexity in my own mind. I said, "If I thought no one else would print the correspondence" (controversy), "I should be in favour of our not doing it"; and I then go on to give reasons for this conclusion, ending with the remark, "On the whole, it may be politic to reprint." Apparently this indifference to publication is inconsistent with the various reasons I have given for strongly desiring it. But there was a consideration not mentioned in the letter which weighed much with me at the time. I was in very bad health, and was urged by physicians and friends to go South without delay. It seemed therefore to be impracticable, if not impossible, for me to give that attention to the editing and publication of the volume which were prompted by.my interest in it. But it will be noticed that, under this conflict of inclinations, though I gave some trivial reasons for non-publication, the conclusion favours reprinting. This shows the predominant feeling, even in a time of depression; and I must say, as a matter of fact, that, though referring the matter as I did in a hurried note to $\mathrm{Mr}$. Spencer, I had not for a moment really relinquished the purpose of bringing out the book. This explanation is necessary, that the responsibility may rest where it properly belongs. Mr. Harrison lays stress upon Spencer's agency in "promoting and assisting" in the production of "a volume for which you are responsible, and which you have authorized and adopt." But though Mr. Spencer chose to take the responsibility because he had assented to it, and furnished some notes for it, yet it was neither by his suggestion, procurement, nor desire that the book was issued; and truth requires me here to say that, if he had discouraged or even opposed it, the book would probably have been reprinted by D. Appleton \& Co. all the same. Mr. Spencer had, in reality, very little to do with 
the edition. For the Introduction, the bad taste with which the notes were embellished, and the newspaper quotation describing the doings in a branch of the positivist church in London which Mr. Harrison does not like, he is not to be held to account.

For his offence in correcting some injurious misrepresentations in a controversial volume published for the use of a people three thousand miles away, the London Times declares that Mr. Spencer has made the amende honorable by destroying the book: and this is the general English view. The equally general American view is, that this extreme proceeding was ridiculous, that it benefited nobody, and gratuitously deprived many readers in this country of a valuable work on an important subject. It is, at any rate, desirable that the responsibility for this result should be fixed where it justly belongs. Mr. Spencer made two proposals to Harrison looking to the preservation of the work, both of which were absolutely fair, but neither of which was accepted. Mr. Spencer would have been justified in making a stand upon either of these propositions, and refusing further concessions; but Mr. Harrison's rejection of his overtures left the matter in so unsatisfactory a shape that nothing remained for Mr. Spencer but to cut the knot by ordering the book to be suppressed. 



\section{APPENDIX A.}

\section{ANCESTRY.}

Samuel Youmans, the great-great-grandfather of E. L. Youmans, was of English descent, and was born on Long Island about I700. He was a wheelwright. He moved from Long Island to Fishkill-on-the-Hudson, in Dutchess County, about i 720 . He had two sons, John and Anthony, who were farmers, living in Dutchess County till their father was an old man. When, about I770-'75, the cheap land on the west side of the Hudson below Albany was opened to emigrants, these men migrated with their growing families, taking with them their aged father, and settled at Coeymans upon "lease land." The land along the Hudson was mostly owned by a few Dutchmen, who held it by letters patent from the King of Holland. Only in this region did feudalism ever get a foothold in our country, and the last vestige of it disappeared half a century ago in a civil conflict known as the anti-rent war. Each of these Dutch landlords made his own terms with settlers independently of the others, and the business shrewdness of a man was shown as much in the choosing of his landlord as in the choosing of his land. John Youmans took up two hundred acres of heavily timbered land, for which he. agreed to pay what in the end proved a ruinous rent; but five years were given free of rent for clearing the land and getting ready for cropping. 
Jeremiah, the second son of John Youmans, in the year I 791, at the age of twenty-three, married Margaret Vincent, the fifth child of Levi Vincent, a resident of Coeymans, and the young couple began their married life upon a portion of the paternal two hundred acres, to which more were added from adjacent new land belonging to the same landlord. Here Vincent Youmans, their second son and the father of E. L. Youmans, was born in I794. Here his mother, Margaret Vincent Youmans, died in $180 \mathrm{r}$, leaving six little children; here Samuel Youmans died at a great age in 1797 , and John Youmans a few years later. Vincent Youmans distinctly remembered his great-grandfather, whom he saw daily in the early years of his life. At the death of his mother, when he was seven years old, Vincent went to live with his mother's parents-was chosen from the little flock, no doubt, because of his name. He always spoke of their place as "home," but it was only a mile away from his father's house, where he was a daily visitor.

Nothing certain is known of the origin of Samuel Youmans, but it is not improbable that his father or grandfather were among the early colonists of New England. There were Yeamans, Yeomans, and Youmans in and about Boston, Ipswich, and New Haven in I633-'39-'50, and emigration to Long Island from Massachusetts and Connecticut colonies began before $\mathbf{1}_{5} 5^{\circ}$. The various spellings of the name are, of course, not the slightest bar to the supposition that they all descended from the same stock, for everywhere before the nineteenth century there was extreme carelessness about the spelling of names, as, indeed, about spelling in general. The same name will be found spelled in one way in the body of an old local history and will be referred to by another spelling in the index. But, whether four or six generations of Americanization be allowed, Samuel Youmans and his descendants seem to have been perfectly assimilated to the American type of character. 
They were tough, athletic men, of tireless industry, selfreliant, self-asserting, apt to be on the aggressive and unpopular side of public questions both in religion and politics, ultra-democratic, despising people who boasted of their ancestry or claimed distinction on any ground but that of personai merit. To explain the great hardiness of Vincent Youmans, his fervour of conviction, the honour he paid to labour, his contempt of frivolities, and the gloomy severity of his religious experience, seven generations of hardworking pioneer Puritan ancestors are none too many.

The maternal great-grandfather of Vincent Youmans was Leonard Vincent. There is on record at White Plains, Westchester County, a deed of twenty-six acres of land given to Leonard Vincent in $17 \mathrm{r} 3$ by Charles Vincent "with the consent of his parents." This land is now within the limits of New York city. Leonard Vincent married a Dutch girl of the neighbourhood and had four sonsJohn, Levi, Leonard, and Samuel. Levi, the second son, married into a family of Dutchess County Quakers named Hoxie. His wife was the daughter of Zebulon Hoxie, a blacksmith, and one of the first settlers of that county, coming from Stonington and settling in the town of Beekman, where some of his descendants are still living.

Levi Vincent lived for several years after his marriage in Dutchess County, and migrated from there to Coeymans at nearly the same time as the Youmanses. He had a large family, was a skilful blacksmith, and also managed his own farm. He was careful in business, and his family was reared in more comfort than was usual to the time and place. He was a man of sound judgment, much respected by his neighbours, and often chosen by them to settle their disputes and difficulties. He had a cheerful temper and friendly manners, was humorous, and fond of a laugh. It was said by Edward's father and uncles that in character and disposition as well as in certain physical traits he re- 
sembled this ancestor. As Vincent Youmans was reared in his family, we have from him more details of Vincent than of Youmans history. Levi Vincent wore the garb, attended the meetings, and held to the principles of the Quaker society, of which his wife was a member, but he never joined them nor used their form of speech. He had six sons, tall, finely developed men. The Vincents were usually large men, standing six feet in their stockings, and in this respect the Hoxies were like them. There was a double marriage between Zebulon Hoxie's family and that of Leonard Vincent. The Vincents were Tories. And here authentic early history of these Vincent and Hoxie families ends.

But there is a field of conjecture that seems plausible. Vincents and Hoxies are both Cape Cod families. The Hoxies were first heard of in this country at Sandwich about the time the Quakers appeared there, and were themselves Quakers. Their relations with the Vincents in town concerns is matter of history, as follows: There was a family of Vincents living at Plymouth in $\mathbf{r}_{3} 3$, and that very year John Vincent was one of a committee of ten men sent from Plymouth to found the town of Sandwich in Cape Cod. He was also one of the two first representatives of the town of Sandwich in ${ }^{6} 639$ at the Colonial Assembly in New Plymouth. Later he was placed on a committee appointed to lay out the true boundaries of lands in sandwich, and Iudovic and Edward Hoxie were among the owners whose lands the committee adjusted. It seems fair to infer from this that John Vincent was a resident of Sandwich; that these Vincents and Hoxies knew each other and were neighbours. The Vincents were freemen and of the dominant faith. Both the families of Vincents and Hoxics that we know of in later times opposed our revolutionary war with England-the Hoxies on religious grounds, and the Vincents from loyalty to the Crown. 
Now, the first Ludovic Hoxie mentioned above had six sons; four of them bore the names respectively of Joseph, Peleg, Abram, and Ludovic. And the great-grandfather of Vincent Youmans-the Dutchess County Quaker and blacksmith from Stonington-Zebulon Hoxie, had four sonsJoseph, Abram, Peleg, and Ludovic, repetitions of the Cape Cod Hoxie family names. This hardly seems accidental. Zebulon Hoxie might easily have been a grandson of the first Ludovic Hoxie, and Stonington in those days of travel by water was on the route of migration from Cape Cod to Dutchess County. Besides, the double marriage that occurred between the two families from which E. L. Youmans descended, when they were separated many miles by bad roads and primeval forests, indicates family intimacies in earlier times. There are other grounds for this conjecture, but it scarcely seems worth while to present them here. All that is known of the maternal ancestry of Catherine Scofield Youmans is given on page 5. Her father, Gideon Scofield, was born in Connecticut. His mother was a Hoyt, and the Hoyts and Scofields from which he was descended were among the oldest and staunchest families of that famous stronghold of tempered Puritanism. 


\section{APPENDIX B.}

\section{LIST OF WRITINGS.}

A Class-Book of Chemistry. In which the principles of the science are familiarly explained and applied to the arts, agriculture, physiology, dietetics, ventilation, and the most important phenomena of Nature. Designed for the use of academies and schools and for popular reading, by Edward L. Youmans, author of A New Chart of Chemistry.

"To know that which before us lies in daily.life is the prime wisdom."-Milton.

New York: D. Appleton \& Co., 200 Broadway, i85 r. A new edition, entirely rewritten, with over three hundred illustrations, in 1863 . Rewritten and revised, with many new illustrations, in 1875 .

Alcohol and the Constitution of Man. Being a popular scientific account of the chemical properties of alcohol and its leading effects upon the healthy human constitution. Illustrated by a beautifully colored chart. D. Appleton \& Co., 200 Broadway, 1854. Fowler \& Wells, i 3 I Nassau Street, I854.

Chemical Atlas; or, The Chemistry of Familiar Objects. Exhibiting the general principles of the science in a series of beautifully colored diagrams, and accompanied by explanatory essays, embracing the latest views of the subjects illustrated. Designed for the use of students and pupils in all schools where chemistry is taught. By (590) 
Edward L. Youmans. D. Appleton \& Co., 346 and 348 Broadway, 1856 .

The Handbook of Household Science. A popular account of heat, light, air, aliment, and cleansing, in their scientific principles and domestic applications. With numerous illustrative diagrams. Adapted for academies, seminaries, and schools. By Edward L. Youmans. D. Appleton \& Co., 346 and 348 Broadway, I857.

The Correlation and Conservation of Forces. A series of expositions by Prof. Grove, Prof. Helmholtz, Dr. Mayer, Dr. Faraday, Prof. Liebig, and Dr. Carpenter. With an introduction and brief biographical notices of the chief promoters of the new views. By Edward L. Youmans. D. Appleton \& Co., 90, 92, and 94 Grand Street, I 864 .

The Culture demanded by Modern Life. A series of addresses and arguments on the claims of scientific education. By Profs. Tyndall, Henfrey, Huxley, Paget, Whewell, Faraday, Liebig, Draper, De Morgan; Drs. Barnard, Hodgson, Carpenter, Hooker, Acland, Forbes; Herbert Spencer, Sir John Herschel, Sir Charles Lyell, Dr. Seguin, Mr. Mill, etc. With an introduction on Mental Discipline in Education, by E. L. Youmans. D. Appleton \& Co., 549 and 55 I Broadway, I867. 



\section{N D E X.}

Agassiz, Prof., 57.

Agricultural chemistry, 41, 93-94.

Alcohol, writes upon, 92.

Alger, Rev. W. R., I63.

Ancient Philosophy and Modern Science lectures, 73 .

Antioch College, 21 I.

Antisell, Dr., 6r.

Antislavery, 30, $5 \mathrm{I}$.

Appletons, 59, 66, 68, I II, I54 ; Mr.

W. H. Appleton, II3, I4I, I54, I84, 276.

Appletons' Journal, 255, 258-259, 267.

Arithmetical text-book, 63-64.

Beecher, H. W., 201, 321, 377, 379.

Biological science, study of, 429 ; as discipline, 432 .

Blindness, 40-72.

Brain as organ of mind, $4 \mathrm{II}-4 \mathrm{I}_{4}$, $455,462-469$; contempt for, 478 .

Burdsall, J. R., 62.

Cambridge, visit to, 137 .

Carpenter, Dr., $55^{\circ}$.

Charges against P. S. M., 552.

Chemical Atlas, 93.

Chemical Chart, 62.

Chemical studies, beginning of, 25 ; interest in agricultural chemistry,
$4 \mathrm{I}, 50,54$; experiments in, 55 ; attends Draper's lectures, 64 .

Chemical text-book, 63-7o.

Class-Book of Chemistry, 63-70; new edition sale of, 145 .

Comte, I52, I66, I73, I82, 233, 235, 290, 337, 5 I 5 .

Concerning the suppressed book, 562.

Conflict between thought and institutions, 399.

Cook, Mr. Ransom, 4I ; Mrs., 45, 49.

Copyright, 281, 366, 374, 375 ; international, $57 \mathrm{I}$.

Correlation of Forces, publication of, 147.

Cosmic philosophy, 290-29I.

Culture, aims of, 418 ; waste and economy in, 420 ; incentives to, 445.

Culture demanded by Modern Life, publication of, 221 ; introduction to, 399 .

Cyclopædia of Household Science, 322.

Darwin, Charles, 276 ; relation of, to Spencer, I04, 378, $54 \mathrm{r}$.

Darwins, the, 276 .

Dawson, Dr., 498.

Delafield, Dr., 42. 
Discipline, mental, 399 ; of memory, 403 ; of judgment, 404 ; of grammar study, 404-407; of mathematics, 407-409; meaning of, 410 ; vicarious, 417 ; of science studies, 423 ; of language studies, 4.4I.

District school, the, 2I-26.

Education Spencer's essays on, publishers of, IIO.

Eliot, George, 127, 340, 366.

Elliott, Dr., 44.

Essays, Spencer's, I I4, II 5 , I 48 , I54I57, I60, I68, I 76, 5I2-525.

Evolution, teacher of, $74-76$; doctrine of, r04 ; labours for, $\mathrm{I}_{4} 8$; religious aspects of, 496, 497 ; rise of the idea of, 512-5 I 7 .

Eye Infirmary, experience of, 43.

First Principles, 528-533.

Fiske, John, I64, I66, 363, 365, 378 .

Flanders, Benjamin, 46 .

Free Religious Association, address to, $32 \mathrm{I}$.

Good, Uncle, 22.

Grammar, the study of, 404-407.

Greeley, Horace, 45, 300.

Gundy, Joe, 15.

Habit, physiological, meaning of, 459.

Handbook of Household Science, 94.

Handwriting, 50, 9I.

Hawkins, Waterhouse, $25 \mathrm{I}$.

Harrison, Frederic, 387,562 .

Health, 345, 367-369, 383 .

History of progress in arts and invention begun, $5^{8}$.
Holmes, O. W., letters of, $\mathrm{I} 46,315$. Huxley, T. H., I29 ; visits America, 333 ; lectures here, $335,546$.

Human Nature, Scientific Study of, lecture, 223-227, 45 I.

Illogical Geology, essay on, 524 .

Insane, treatment of, $47 \mathrm{I}$.

Instructor, the function of, 482.

International Scientific Series, 266293, 577.

Inventional Geometry, 332.

Judgment, discipline of, 404.

Ketcham, James, 49, 52.

Language, study of, 440 .

Lecturing, 72.

Letters of H. S. to E. L. Y., first, IOS; his view of our national prospects in 1863,151 ; on article in New Englander, 152 ; about his new volume of essays, I 72 ; Comte and positivism, I73; classification of the sciences, 175 ; further explanations of, and of Social Statics, I80 ; reply to Minturn, 216 ; on title of Philosophy, 233 ; dedication to his American friends, 26I ; retrospect and prospects, 304 ; advice to E. L. Y. concerning Monthly, 314; concerning economy of effort, 324; on address of E. L. Y. to Liberal Club, 325 ; growth of the idea of evolution in his own mind, 327 ; on work-drunkenness, 33I ; invites E. L. Y. to go to Riviera, 347 ; speaks of coming to America, 370 ; more about it, 373 ; on international copyright, 375 . 
Letters of E. L. Y. while lecturing, $8 I-9 I, 243-248$; first one to Spencer, I06 ; about publication of Education, II2; of the Spencers at Derby, II7; first impressions of London, II9; visit to Glasgow, I21 ; Lewes, Mrs., 127, 340, 366 ; dines at Gloster Square, meets J. D. Morell, 130 ; of Kew Gardens, 136 ; of Cambridge, 137 ; on state of book business in 1863 , I 42 ; on draft riots, I43-I45; on state of country, 148 : on publication of Essays and other matters, 154 ; account of N. E. trip, I62 ; more about essays, I68; issue of, on Progress, 175 ; letters to family in $1865,186-198$; to Fiske, 202 ; of Ripley and the Tribune, 206; from Antioch College, $2 \mathrm{II}$; visit to Wales, 218 ; of lecture at College of Preceptors, 224; to S. on state of business, 228; Mill's St. Andrew's address, 236 ; about books, 266 ; to his mother on his fiftieth birthday, 269 ; letters of $187 \mathrm{I}, 27 \mathrm{I}-$ 292 ; from Paris, 285 ; from Berlin, 286-289; to a contributor to P. S. M., 310 ; from a contributor to P. S. M., 3II; letters of 1877 , $337-340$; to a niece just settled, $34 \mathrm{I}$; on the state of business in January, $1878,342-344$; decides to go to Riviera with H. S., 348 ; reaching London, 350-35I ; from Riviera, 351-360; of health, 367369 ; articles on political institutions, 372,373 ; fractures his wrist, 382 ; health, 383 ; last letter of, 391.

Liberty, Mill's, I5O.

Lecturer, as a, 78-8r.
Man studied by the scientific method, 452,454 ; by the method of tradition, 453 .

Manning, Mr. R. H., 94, 105, 114 , 260.

Marriage, II 6 .

Masquerade of the Elements, a lecture, 73 .

Mathematics in education, 407-409, 43 I.

McCosh, Dr., 496.

Meeting of British Sci. Ass., I38.

Memory, 403, 459, 468; discipline of, 403 ; meaning of discipline of, 4 IO.

Mental Gymnastics, 4I 7.

Mental limitations, 474 .

Mental states due to states of blood, 465 ; to nervous system, 466.

Mill, John Stuart, I32, 204 ; inaugural address, 236-238, 425-429, $432-435,439,450,547-550$.

Minturn, R. B., letter of, 215.

Morell, Dr. J. D., Iзо.

Moulton's attack on Spencer, 329.

Nature, meaning of, 488.

Philosophical Series, Spencer's, I05I10, II3-II5, I56, I99, 26I-265, 290, 528-537.

Physiology, evolution of, 455-458.

Popular Science Monthly, 205 ; starting of, 296-301 : success of, 302 ; after a year and a half, 313 ; aim of, 306-310: charges against, 552 . Popularization of science, works for, IOI.

Psychology, Spencer's, I05, 5 I6.

Reflex action, 457 .

Repetition, value of, 4I4-416. 
Rest, importance of, 476 .

Ripley, George, I53, 207.

Science, meaning of, 486,492 ; incentives it gives, 445 ; its bracing quality, 447; religious work of, 49I-494.

Science primers, 332.

Science studies, 423 ; order of, 424 ; as information, 425 ; of human nature, $45 \mathrm{I}$.

Scientific lecturing, 72 .

Sister reads for him, $42,50,54$; joins him in N. Y., 56 ; chemical studies, 61 .

Social Statics, republication of, II 4 , I4I, I76.

Sociology, study of, 295.

Specimen of handwriting, 9.2.

Spencer, Herbert, visit to America, 376 ; and the doctrine of evolution, 502 , 5 II ; works of, 504 ; health, 527 ; rights as a thinker, 538 ; religious teachings, 554, 557 ; application to government, $55 \mathrm{I}$; controversy with Harrison, 562.

Staten Island, life at, 45.

Suppressed book, concerning, 562.

Synthetic philosophy, 233, 290, 29 I.

Taine, 503, 505.

Teachers' office, 483.

Tenney, E. P., Appletons' reader, judges of manuscript of ClassBook, 66.

Theology the adversary of science, 494, 500.

Tyndall, Prof., visit to this country, 3I7; letters of, 3I7, 3I9, 320, 366 .

Unconscious mental action, 460.
Vestiges of Creation, 42, 57 .

Vicarious discipline, 4I 7 .

Voluntary activity, limits of, 488.

War times, I16, I35, I4I-I45, I78, I85.

Wheeler, J. M., letter, 35-40.

Wheelers, the, I4-I7.

Whitman, Walt, 46.

Youmans, Catherine Scofield, 4-6.

Youmans, Earle, 6I, 323.

Youmans, E. L., popular sympathies of, 4 ; birth, 4-6 ; childhood, 9-13 ; religious experience, 9, 29-33; freethinkers, 18 ; leaves Greenfield, I9: generosity, 26 ; circulating library, 27 ; inflammation of the eyes, 28 ; powers of persuasion, 33 ; handiness, 34 ; goes to Galway Academy, 35-40; treatment by Ballston oculist, 40 ; blindness, 40 ; reading, 4I, 42, 50 ; relapses, $42,45,59$; goes to N. Y. Eye Infirmary, 42 ; treated by Dr. Elliott, 44; life at Mrs. Cook's, 4445 ; removes to Mrs. Chipman's, 46 ; Mr. Flanders, 46, 47 ; exposures, 48 ; the Ketchams, 49 ; selfsupporting, 50 ; handwriting, 50; literary work, 5I ; conversation, 52 ; power of exposition, 52 ; studies mnemonics, 53 ; sister joins him in N. Y., 56 ; attends Agassiz's lectures, 57 ; historical work undertaken, 58; call at Appletons', 59 ; history forestalled, 59 ; deep discouragement, 60 : Chemical Chart, 62 ; text-book of arithmetic, 63; Class-Book of Chemistry, $63-70$; forestalled, 64 ; begins lecturing, 72 ; as a lecturer, 
78-8I ; letters written when lecturing, $81-92$; studies the physiological action of alcohol, 92 ; first acquaintance with Herbert Spencer, I05 ; writes to him, I06 ; relations with Appletons, II I ; they publish Spencer's Education, and other works, III; E. L. Y.'s labours for their dissemination, II5 ; marriage, II6; voyage in Great Eastern, II6; visits Derby, II7 ; meets H. S., I2I ; visits Cambridge, I37; rewrites Chemistry, I43; publishes Correlation of Forces, 147 ; labours for the diffusion of modern views, 148 ; meets Fiske, I64 ; second visit to England, 185 ; accepts professorship at Antioch, I 99 ; threatened failure of Spencer's serial publicationlabours to prevent, I99; Antioch College, 2 II ; third visit to England, 22I ; fourth visit to England, 255 ; fifth visit to England, 267 ; International Scientific Serics, 267, 273-28I, 284, 293; as an editor, 302 ; health, 321, 322, 367 ; lecture before Liberal Club, 322; rewrites Class-Book of Chemistry, 333 ; visits the Riviera, 345-349; goes to Thomasville, 385 ; trouble with Harrison, 387; last days, 395.

Youmans, Vincent, 4-6, 9-13.

Youmans, William Jay, 93, I92 ; goes to England, I88. 



\section{APPLETON \& CO'S PUBLICATIONS.}

\section{Professor E. L. YOUMANS'S WORKS.}

\section{THE HAND-BOOK OF MOUSEHOLD SCIENCH. A}

Popular Account of Ileat, Light, Air, Aliment, and Cleansing, in their Scientific Principles and Domestic Applications. 12mo. Illustrated. Cloth, $\$ 1.75$.

\section{THE CULTURE DEMANDED BY MODERN LIFE.}

A Series of Addresses and Arguments on the Claims of Seientific Education. Edited, with an Introduction on Mental Discipline in Education. 1 vol., 12 mo. Cloth, $\$ 2.00$.

\section{CORRELATION AND CONSERVATION OF FORCES.}

A Scries of Expositions by Scientific Men. Edited, with an Introduction and Brief Biographical Notices of the Chief Promoters of the New Views, by Edward L. Youmass, M. D. 12mo. Cloth, $\$ 2.00$.

\section{CONTENTS.}

I. By Professor W. R. Grove. The Correlation of Physical Forces.

II. By Professor Hecmholtz. The Interaction of Natural Forces.

III. By Dr. J. R. Mayer. 1. Remarks on the Forces of Inorganic Nature.

2. On Celestial Dynamics.

3. On the Mechanical Equivalent of Heat.

IV. By Dr. Faraday. Some Thoughts on the Conservation of Forces.

V. By Professor Lrebig. The Connection and Equivalence of Forces.

VI. By Dr. Carpenter. The Correlation of the Physical and Vital Forces.

"This work is a very welcome addition to our scientific literature, and will be particularly acceptable to those who rish to obtain a popular but at the same time precise and clear view of what Faraday justly calls the highest law in physical science, the principle of the conservation of force. Sufficient attention has not been paid to the publication of collected monographs or memoirs upon special subjects. Dr. Youmans's work exhibits the value of such collections in a very striking manner, and we earnestly hope his excellent example may be followed in otler branches of science." American Journal of Science.

New York: D. APPLETON \& C0., 1, 3, \& 5 Bond Street. 


\section{JOHN TYNDALL'S WORKS.}

ESSAYS ON THE FLOATING MATTER OF THE AIR, in Relation to Putrefaction and Infection. 12mo. Cloth, $\$ 1.50$.

ON FORHS OF WATER, in Clouds, Rivers, Ice, and Glaciers. With 35 Illustrations. $12 \mathrm{~m}$. Cloth, $\$ 1.50$.

HEAT AS A MODE OF MOTION. New edition. $12 \mathrm{mo.}$ Cloth, \$2.50.

ON SOUND : A Course of Eight Lectures delivered at the Royal Institution of Great Britain. Illustrated. 12mo. New edition. Cloth, \$2.00.

FRAGMENTS OF SCIENCE FOR UNSCIENTIFIC PEOPLE. 12mo. New rerised and enlarged edition. Cloth, $\$ 2.50$.

LIGHT AND ELECTRICITY. 12mo. Cloth, \$1.25.

LESSONS IN ELECTRICITY, 1875-'76. 12mo. Cloth, \$1.60. HOLRS OF EXERCISE IN THE ALPS. With Illustrations. $12 \mathrm{mo}$. Cloth, $\$ 2.00$.

FARADAY AS A DISCOVERER. A Memoir. 12mo. Cloth, $\$ 1.00$.

Contributions To MoLECULAR Physics in the Do. main of Radiant Heat. $\$ 5.00$.

SIX LECTURES ON LIGHT. Delivered in Ameriea in 1872'73. With an Appendis and numerous Illustrations. Cloth, $\$ 1.50$.

FA IREWELL BANQUET given at Delmonico's, New York. Paper, 50 cents.

ADDREsS delivered before the British Association, assembled at Belfast. Revised, with Additions. 12mo. Paper, 50 cents.

RESEARCIES ON DIAMAGNETISM AND MAGNE. CRYSTALIIC ACTION, including the Question of Diamagnetic Polarity. With Ten Plates. 12mo. Cloth, \$1.50.

NEW FRAGMENTS. 12mo. Cloth, $\$ 2.00$.

New York: D. APPLETON \& CO., 1, 3, \& 5 Bond Street. 
SIR JOHN LUBBOCK'S (Bart.) WORKS.

THE ORIGIN OF CIVILIZATION AND THE PRIMI TIVE CONDITION OF MAN, MENTAL AND SOCIAL CONDITION OF SAVAGES. Fourth edition, with numerous $\mathrm{Ad}$. ditions, With Illustrations, 8ro, Cloth, \$5.00.

"This interesting work-for it is intensely so in its aim, scope, and the abil. ity of its antior-treats of what the scientists denominate anthropology, or the natural history of the human species; the complete science of man, bridy, and soul, including sex, temperament, race, civilization, etc."-l'rociderice Press.

\section{PREHISTORIC TIMES, AS ILLUSTRATED BY ANCIENT} REMAINS AND THE MANNERS AND CLSTOHS OF MIODERY SAVAGES. Illustrated, 8vo. Cloth, \$5.00.

"This is, perhaps, the best summary of evidence now in our possession concerning the general character of prehisto ric times. The Bronze Age, The Stone Age, The Tumuli, The Lake Inhabitants of Switzerland, The Shell Mounds, The Cave Man, and The Antiquity of Man, are the title- of the most important chap. ters."-Dr. C. K. Adams's Manual of" Historical Literature.

ANTS, BEES, AND WASPS. A Record of Observations on the Habits of the Social Hymenoptera. With Colored Plates. $12 \mathrm{mo}$. Cloth, $\$ 2.00$ 。

"This volume contains the record of various experiments made with ants, bees, and wasps during the last ten vears, with a view to test their mental condition and powers of sense. The author has earefuliy watched and marked particular insects, and has had their nests under observation for long periods-une of his ants' nests having been ander coustart inspection ever since 18\%4. His observations are made principally upon auts, because they show more power and fiexibility of mind; and the value of his studies is that they belong to the de. partment of original research."

ON THE SENSES, INSTINC'TS, AND INTELLIGENCE OF ANIMALS, WITH SPECIAL REFERENCE TO INSECTS, "International Scientific Scries," With over One Hundred Illustra. tions, $12 \mathrm{mo}$. Cloth, $\$ 1.75$.

The author has here collected some of his recent observations on the senses anr intelligence of animals, and especially of insects, and has attempted to give, very briefly, some idea of the organs of serst, commencing in each case with those of man himself.

THE PLEASURES OF LIFE. 12mo. Cioth, 50 cents; papet, 25 cents.

CONTENTS.-The DUtr of Happiness. The Happiness of Detr. A Song of Books. The Choice of Books. 'The Blessing of Friends. The Valde of Time. The Pleasures of Trajel. The Pleagures of Home. Science. Education.

New York: D. APPLETON \& CO., 1, 3, \& 5 Bond Strent. 
D. APPLETON \& CO.'S FUBLICATIONS.

CHARLES DARWIN'S WORKS.

GRIGIN OF SPECIES BY MEANS OF NATURAL SELECTION, OR THE PRESERVATION OF FAIORED IRLCES IN THE STRUGGLE FOR LIFE. From sixth and last London edition. 2 vols., 12mo. Cloth, $\$ 4.00$.

DESCENT OF MAN, AND SEIECTION IN RELATION TO SEX. With many Illustrations. A new edition. $12 \mathrm{mo.}$ Cloth, $\$ 3.10$.

A NATURALIST'S VOYAGE AROUND THE WOHLD. Journal of Rescarches into the Natural IHistory and Geology of Countries visited during the Toyage of H. M. S. "Beagle." Illustrated with Maps and 100 Views of the places visited and deccribed, chiefly from sketches taken on the spot, by $R$. T. Pritchett. Sro. Cloth, \$5.00.

Also popular edition. $12 \mathrm{mo}$. Cloth, $\$ 2.00$.

THE: STIEUCTURE ANID DISTRIBUTION OF CORAT, IREELS. Based on Observations made during the Voyage of the "Beagle." With Charts and Illustrations. 12mo. Cloth, \$.111).

1: EOECGIC:A 1. OBSERVATIONS on the Voleanie Islands and l'ats of South Anerica visited during the Voyage of the "Iseagle." With Maps and Illustrations. 12mo. Cloth, \$2.50.

EMOTIONAI, EXPIRSIONS OF MAN AND THE LOWVIR A NIMAS. 12mo. Cloth, $\$ 3.50$ 。 
D. APPLETON \& CO.'S PUBLICATIONS.

Charles Darwin's Works.-(Contiuued.)

THE VARIATIONS OF A NIMALSAND ILANTS UNDEIR DOMESTICA'TION. With a Preface, by Professor Asa Gray。 2 vols. Illustrated. Cloth, \$5.00.

INSECTIVOROUS PYAN'TS. 12mo. Cloth, $\$ 2.00$.

MOVEMENTS AND HABITS OF CLIMBING PLANTS.

With Illustrations. $12 \mathrm{mo}$. Cloth, $\$ 1.25$.

THE VARIOUS CONTRIVANCES BY WHICH ORCHIDS ARE FERTILIZED BY INSECTS. Revised eäition, with Illustrations. $12 \mathrm{mo}$. Cloth, $\$ 1.75$.

THE EFFECTS OF CROSS AND SELF FERTILIZATION IN THE VEGETABLE KINGDOM. $12 \mathrm{mo}$ Cloth, $\$ 2.00$.

DIFFERENT FORMS OF FLOWERS ON PLANTS OF THE SAME SPECIES. With Illustrations. 12mo. Cloth, $\$ 1.50$.

THE POWER OF MOVEMENT IN PLANTS. By Charles Darwix, LL. D., F. R. S., assisted by Francis Darmin. With Illustrations. $12 \mathrm{mo}$. Cloth, $\$ 2.00$.

TH E FORMATION OF VEGETABLE MOULD THROUGH THE ACTION OF WORMS. With Observations on their Habits. With I'iustrations. 12mo. Cloth, $\$ 1.50$.

New York: D. APPLETON \& C0., 1, 3, \& 5 Bond Street. 


\section{Appletons'}

\section{Popular Science Monthly.}

Edited by WILLIAM $\mathcal{F} A Y$ YOUMANS.

The Popular Science Monthly is without a competitor.

It is not a technical magazine.

It stands alone as an educator, and is the best periodical for people who think.

All its articles are by writers of long practical acquaintance with their subjects, and are written in such a manner as to be readily understood.

It deals particularly with those general and practical subjects which are of the greatest interest and importance to the people at large.

It keeps its readers fully informed of all that is being done in the broad field of science.

Illustrations, from drawings or photographs, are freely used in all cases in which the text may be thereby elucidated.

Examination of any recent number will more than confirm the foregoing.

$\$ 5.00$ per annuin; single copy, 50 cents.

New York: D. APPLETON \& CO., I, 3, E 5 Bond St. 
. 
$-$ 



\section{.}




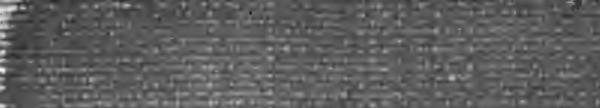

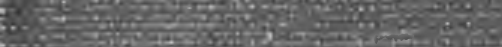

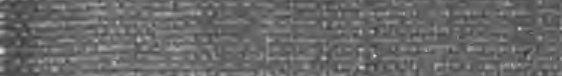

